\title{
Influência de Recalques em Edifícios de Alvenaria Estrutural
}

Osvaldo Gomes de Holanda J únior

Tese apresentada à Escola de Engenharia de São Carlos, da Universidade de São Paulo, como parte dos requisitos para obtenção do título de Doutor em Engenharia de Estruturas.

Orientador: Prof. Assoc. Marcio Antonio Ramalho

São Carlos 2002 
Aos meus pais,

Osvaldo e Lourdinha,

e à minha esposa,

Kristiane. 


\section{AGRADECIMENTOS}

Ao professor Marcio Ramalho, pela excelente orientação, apoio e incentivo durante toda a elaboração deste trabalho.

Aos meus pais, à minha esposa, aos meus sogros, Ângelo e Nida, e à D. Branca pelo constante incentivo e apoio, sem os quais esta tarefa teria sido muito difícil.

À Kristiane, mais uma vez, pelo carinho e pela ajuda nas diversas etapas desta pesquisa, sempre apresentando valiosas contribuições.

À Vanessa, grande amiga e madrinha, por estar sempre presente e disposta a ajudar, distribuindo alegria e sorrisos em todos os lugares.

Aos amigos Joel e Valentim, pelo companheirismo, pela colaboração imensurável em todos os aspectos relacionados a este trabalho e por havermos formado o grupo de estudo da alvenaria estrutural.

À Suzana e à Aline Barboza, que, mesmo com pouco tempo disponível, foram muito solícitas, fornecendo orientações iniciais sobre a utilização do Ansys e a realização dos ensaios.

A todos os amigos da pós-graduação, que tornaram a estada em São Carlos tão prazerosa. Agradeço em especial a Alex, Silvana, Anamaria, Tatiana, Mônica, Juliana, Andréa, Rejane, Renato, Luciana, Julio, Gabriela, Romel e Topó.

Aos funcionários Masaki, Rosi, Marta, Nadir, Toninho, Júnior, Eli, Rui, Sílvia e Felícia, pelo excelente serviço que prestam a todos os pós-graduandos.

Ao corpo técnico do Laboratório de Estruturas, cuja dedicação e capacidade foram imprescindíveis à correta realização do programa experimental. Devo citar: Luiz Vareda, Amauri, Jorge, Valdir, Mário, Mauri, João, Juliano e Fabiano.

À ST Indústria Cerâmica Ltda. e à Jeruel Artefatos Plásticos Ltda., pela doação de material para a pesquisa experimental. Em especial a Guilherme Kaspar, responsável pela moldagem dos blocos em escala reduzida.

A todos que, direta ou indiretamente, contribuíram para a elaboração deste trabalho.

Ao CNPq, pela bolsa de estudos, e à FAPESP, pelo auxílio à pesquisa. 


\section{SUMÁRIO}

Lista de figuras................................................................................................................................................. i

Lista de tabelas................................................................................................................ vii

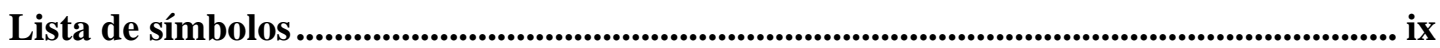

Resumo

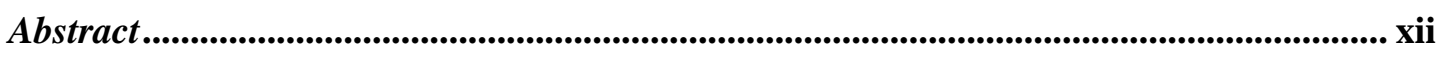

1. Introduçãa

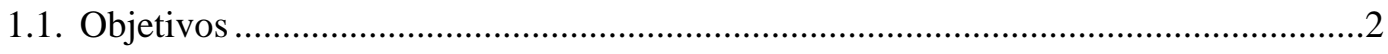

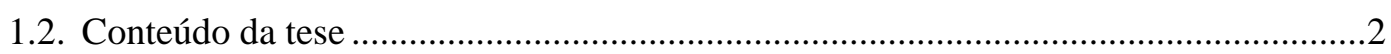

2. Conceitos fundamentais ............................................................................................................4

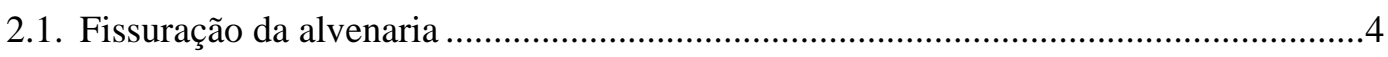

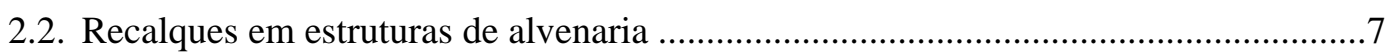

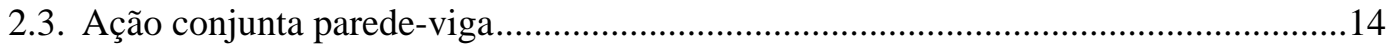

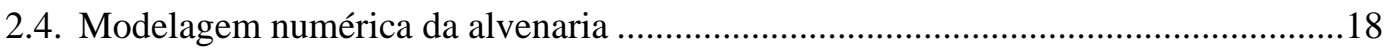

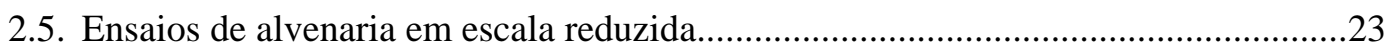

2.6. Resistência ao cisalhamento da junta de argamassa....................................................26

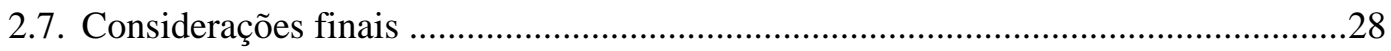

3. Estudo experimental ......................................................................................................................32

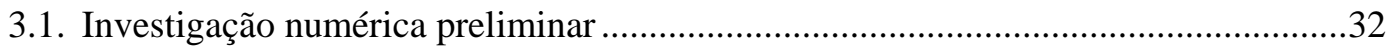

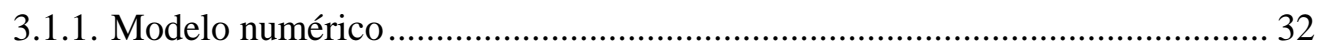

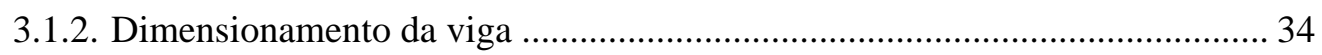

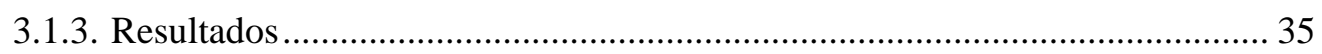

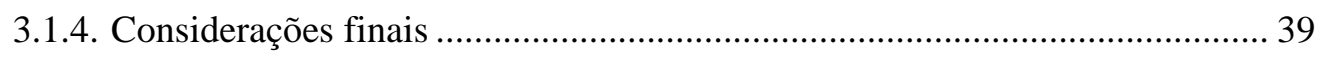

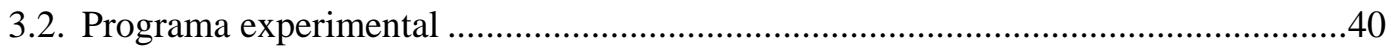

3.2.1. Objetivos específicos do programa experimental ........................................ 41

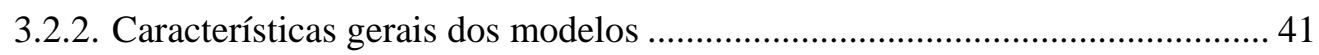

3.2.3. Tipologia e procedimentos gerais dos ensaios ............................................ 42

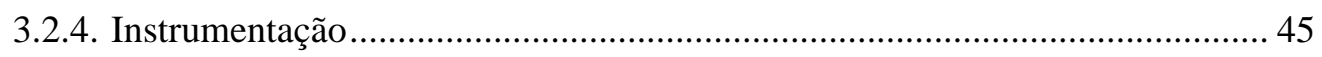

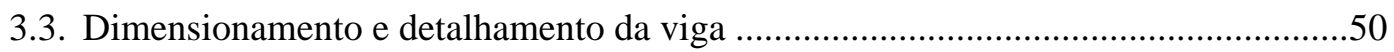




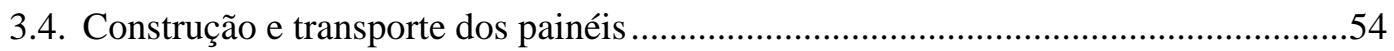

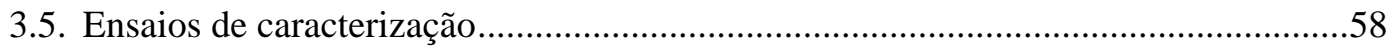

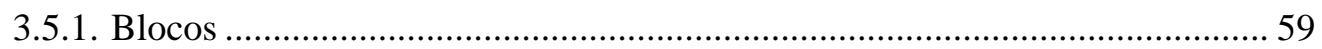

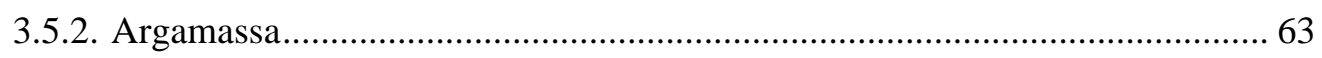

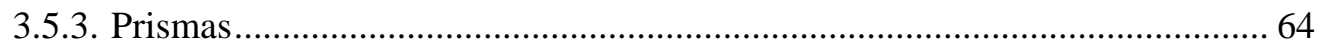

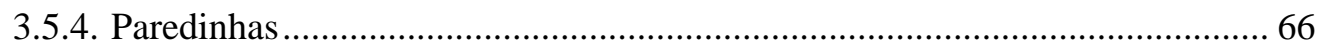

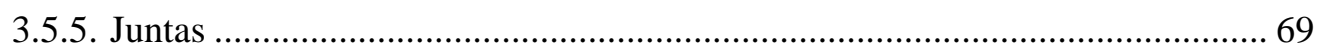

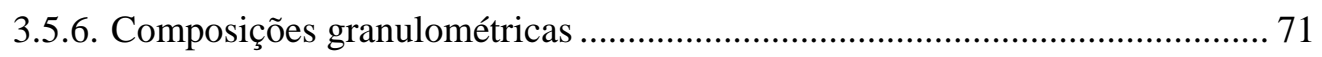

3.5.7. Considerações sobre os ensaios de caracterização........................................... 73

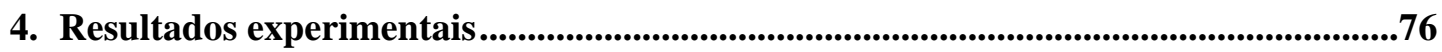

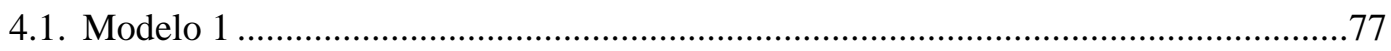

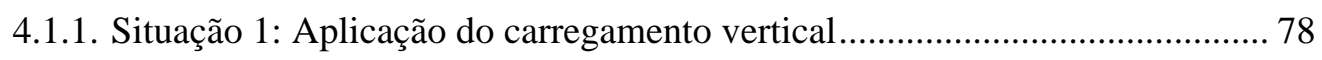

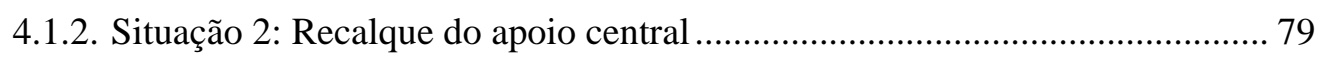

4.1.3. Situação 3: Recalque do apoio de extremidade ................................................ 84

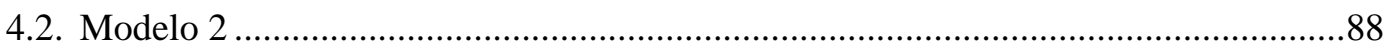

4.2.1. Situação 1: Aplicação do carregamento vertical................................................ 89

4.2.2. Situação 2: Recalque do apoio central ........................................................... 91

4.2.3. Situação 3: Recalque do apoio de extremidade ............................................. 96

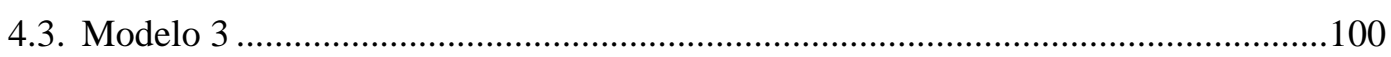

4.3.1. Situação 1: Aplicação do carregamento vertical........................................... 101

4.3.2. Situação 2: Recalque do apoio central ......................................................... 103

4.3.3. Situação 3: Recalque do apoio de extremidade ........................................... 107

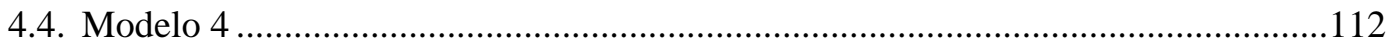

4.4.1. Situação 1: Aplicação do carregamento vertical.......................................... 113

4.4.2. Situação 2: Recalque do apoio central ......................................................... 115

4.4.3. Situação 3: Recalque do apoio de extremidade ........................................... 119

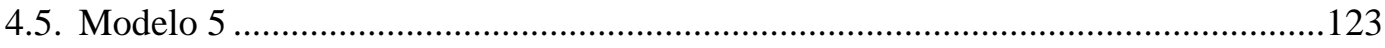

4.5.1. Situação 1: Aplicação do carregamento vertical .......................................... 124

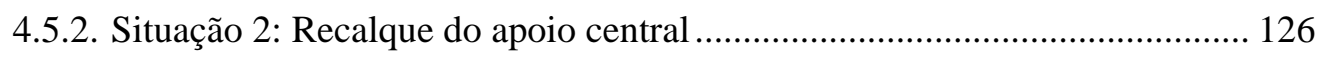

4.5.3. Situação 3: Recalque do apoio de extremidade ............................................ 130

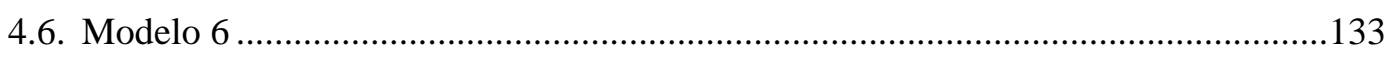

4.6.1. Situação 1: Aplicação do carregamento vertical............................................ 135

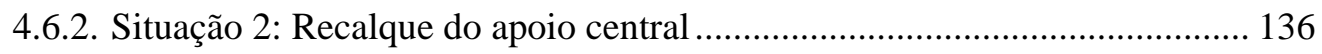

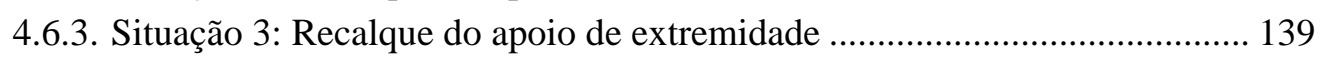

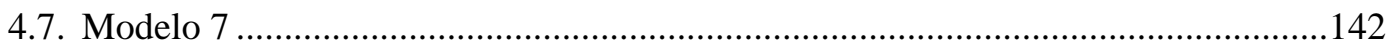

4.7.1. Situação 1: Aplicação do carregamento vertical........................................... 144

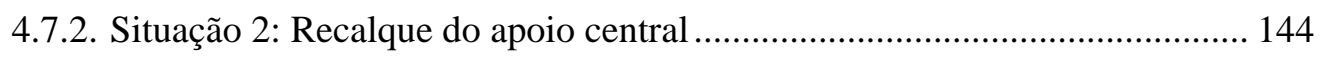

4.7.3. Situação 3: Recalque do apoio de extremidade ............................................ 145

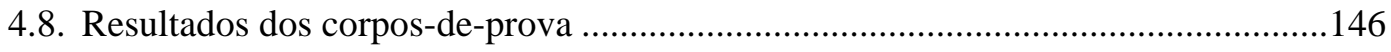

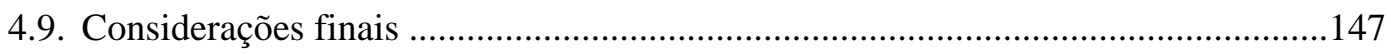

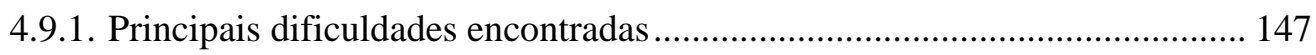

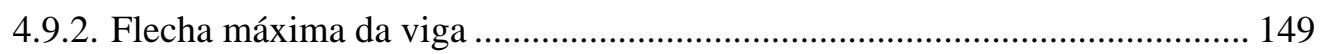


4.9.3. Comprimento de contato.

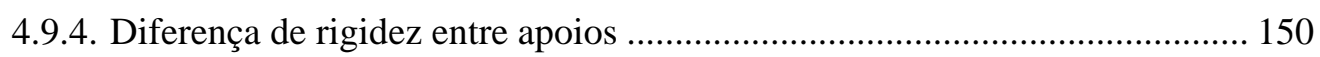

4.9.5. Aspecto provável da fissuração em função do apoio deslocado .................... 151

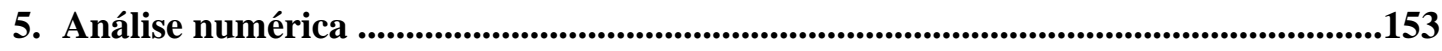

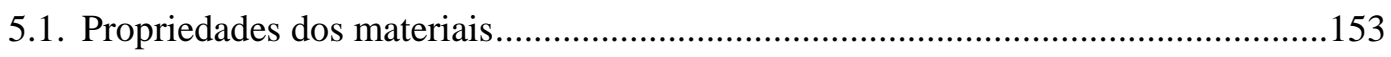

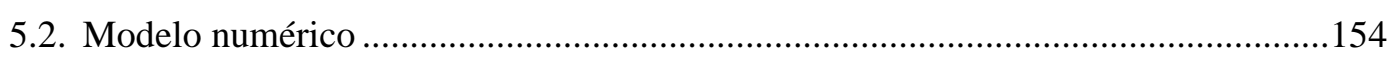

5.2.1. Coeficiente de rigidez normal (FKN) ...................................................... 155

5.2.2. Critério de ruptura ao cisalhamento na junta parede-viga ........................... 156

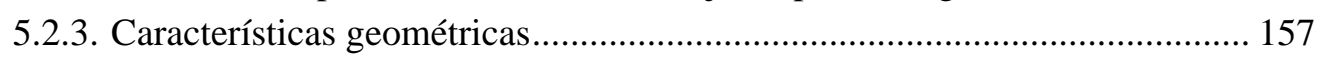

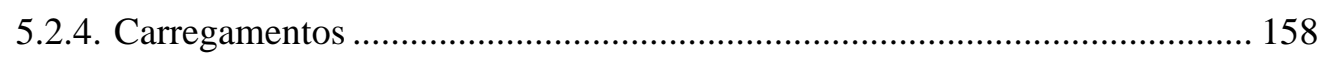

5.3. Análise comparativa entre os resultados numéricos e experimentais .......................159

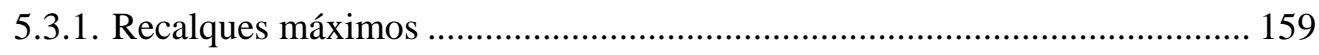

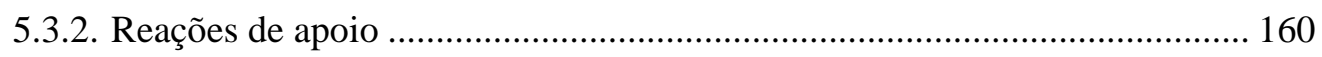

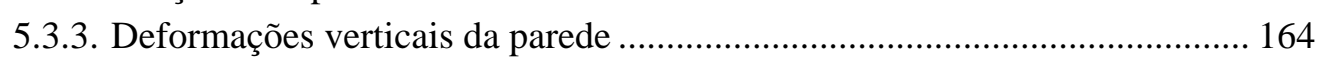

5.3.4. Deformações verticais ao longo da primeira fiada......................................... 168

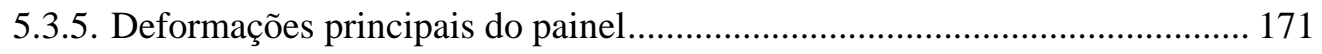

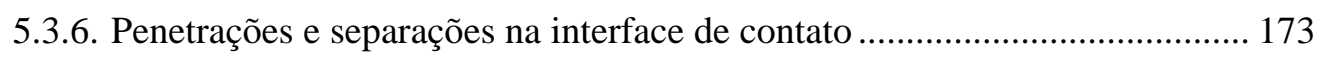

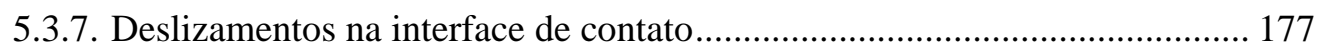

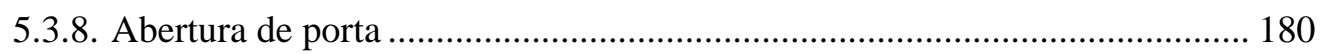

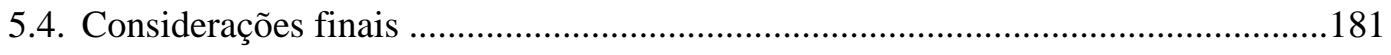

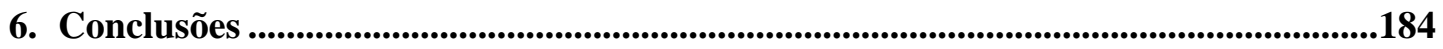

Anexo

Referências bibliográficas ...............................................................................................217

Bibliografia complementar ................................................................................................................223 


\section{LISTA DE FIGURAS}

Figura 2.1 Configurações básicas das fissuras em alvenaria. ................................................

Figura 2.2 Exemplos de fissuras causadas por recalques (GRIMM, 1988) ............................6

Figura 2.3 Definições de movimentos da fundação..............................................................

Figura 2.4 Distribuição de tensões no sistema parede-viga. (a) Concentrações de tensões na base da parede. (b) Tensões horizontais ao longo da linha média do sistema parede-viga. (BARBOSA, 2000) ...................................................16

Figura 2.5 Distribuição das tensões verticais (HENDRY et al., 1981)...................................16

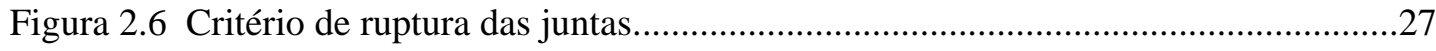

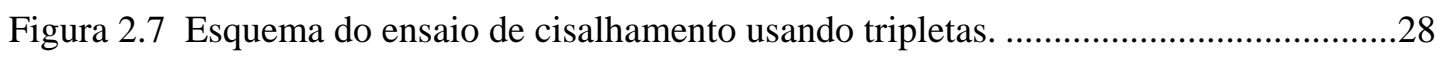

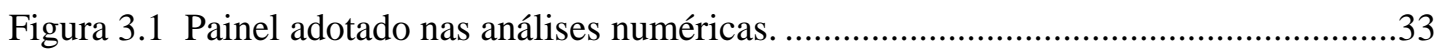

Figura 3.2 Dimensionamento da viga. (a) Carregamento uniformemente distribuído.

(b) Carregamento decorrente do efeito arco.

Figura 3.3 Representação vetorial das tensões principais: apoios fixos. Modelagens (a) com e (b) sem elementos de contato.

Figura 3.4 Representação vetorial das tensões principais: apoio central retirado. Modelagens (a) com e (b) sem elementos de contato

Figura 3.5 Representação vetorial das tensões principais: apoio extremo retirado. Modelagens (a) com e (b) sem elementos de contato.........................................38

Figura 3.6 (a) Separações e (b) deslizamentos na região do contato.....................................39

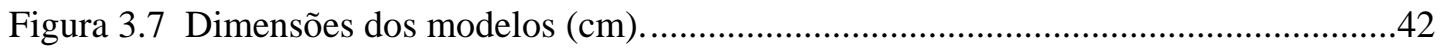

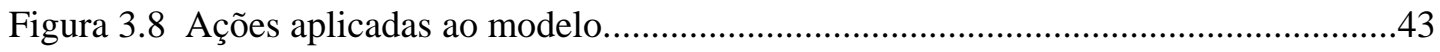

Figura 3.9 Esquema de ensaio (medidas aproximadas em $\mathrm{cm}$ ). ...........................................44

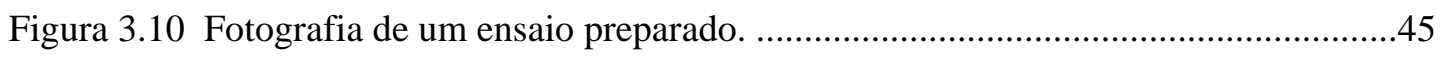

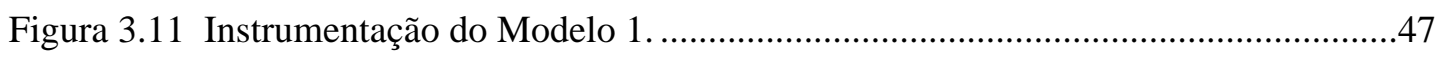

Figura 3.12 Instrumentação do Modelo 2 2 ...........................................................................48

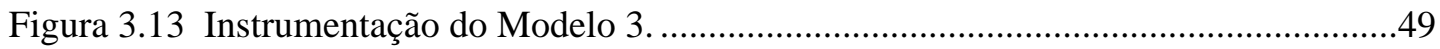

Figura 3.14 Dimensionamento da viga dos modelos 1 a 4,6 e $7 \ldots \ldots \ldots \ldots \ldots \ldots \ldots \ldots \ldots \ldots \ldots \ldots \ldots . . . . .50$

Figura 3.15 Detalhamento da viga dos modelos 1 a 4,6 e $7 \ldots \ldots \ldots \ldots \ldots \ldots \ldots \ldots \ldots \ldots \ldots \ldots \ldots \ldots \ldots \ldots \ldots . . . . .52$

Figura 3.16 Dimensionamento da viga do Modelo 5 ...........................................................53

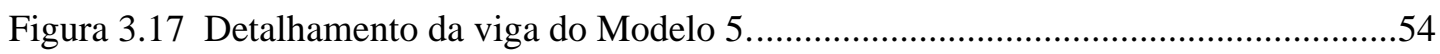




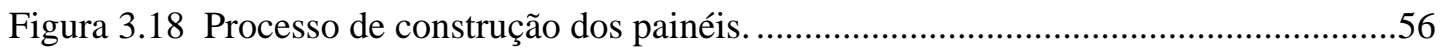

Figura 3.19 Operação de grauteamento do Modelo 6 ...........................................................57

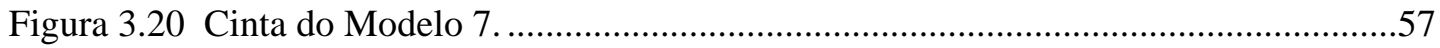

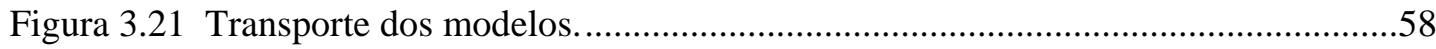

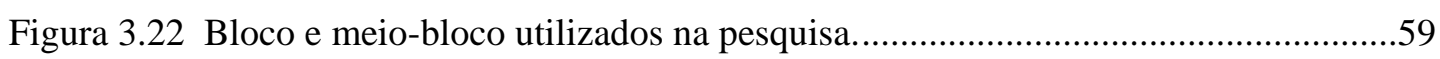

Figura 3.23 Gráficos tensão-deformação dos blocos...........................................................61

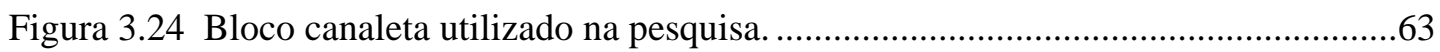

Figura 3.25 Evolução da resistência dos prismas com a idade. .............................................66

Figura 3.26 Esquemas de ensaio. (a) Compressão axial. (b) Compressão diagonal...............67

Figura 3.27 Trechos lineares dos gráficos tensão-deformação das paredinhas A1, A2 e A3

Figura 3.28 Trechos lineares dos gráficos (tensão de cisalhamento)-distorção das paredinhas D1, D2 e D3.

Figura 3.29 (a) Fotografia do ensaio em andamento. (b) Detalhe da tripleta. .70

Figura 3.30 Ruptura ao cisalhamento das juntas bloco-concreto (valores de tensão na área bruta).

Figura 3.31 Curva granulométrica da areia da argamassa. ..................................................72

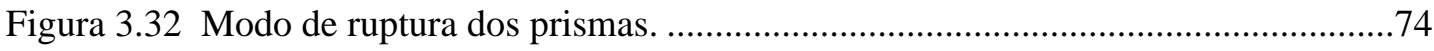

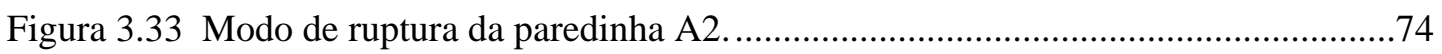

Figura 3.34 Modos de ruptura possíveis no ensaio de compressão diagonal (GALLEGOS, 1989). .75

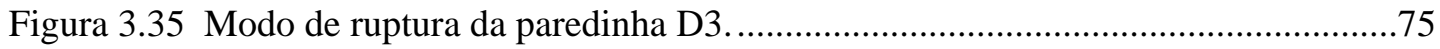

Figura 4.1 Movimentos da viga de fundação........................................................................76

Figura 4.2 Instrumentação do Modelo 1.........................................................................78

Figura 4.3 Configuração deformada da viga - Modelo 1, Situação 1. (F em kN) ..................79

Figura 4.4 (a) Reações de apoio; (b) Deformação na parede - Modelo 1, Situação 1...........79

Figura 4.5 Configuração deformada da viga - Modelo 1, Situação 2. ( $\delta$ em mm) .................80

Figura 4.6 Distribuição de fissuras após ensaio - Modelo 1, Situação 2 ................................82

Figura 4.7 Fotografia do painel após ensaio - Modelo 1, Situação 2 ...................................82

Figura 4.8 (a) Reações de apoio; (b) Deformação na parede; (c) Deformações na primeira fiada - Modelo 1, Situação 2. 83

Figura 4.9 Deformações na base da parede - Modelo 1, Situação 2. $(\delta$ em $\mathrm{mm})$....................84

Figura 4.10 Configuração deformada da viga - Modelo 1, Situação 3. ( $\delta$ em $\mathrm{mm})$................85

Figura 4.11 Distribuição de fissuras após ensaio - Modelo 1, Situação 3...............................86

Figura 4.12 Fotografias de detalhes do painel após ensaio - Modelo 1, Situação 3..............87

Figura 4.13 (a) Reações de apoio; (b) Deformação na parede - Modelo 1, Situação 3.........88

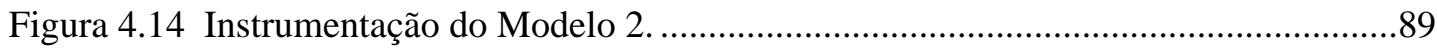


Figura 4.15 Configuração deformada da viga - Modelo 2, Situação 1. (F em kN) .90

Figura 4.16 (a) Reações de apoio; (b) Deformação na parede - Modelo 2, Situação 1.........90

Figura 4.17 Leituras abaixo da janela - Modelo 2, Situação 1 ...............................................91

Figura 4.18 Deformações na base da parede - Modelo 2, Situação 1. (F em kN) .................91

Figura 4.19 Configuração deformada da viga - Modelo 2, Situação 2. ( $\delta$ em mm) ...............93

Figura 4.20 Distribuição de fissuras após ensaio - Modelo 2, Situação 2 (Verso do painel).

Figura 4.21 Fotografia do painel após ensaio - Modelo 2, Situação 2 (Verso do painel). ....94

Figura 4.22 (a) Reações de apoio; (b) Deformação na parede - Modelo 2, Situação 2.........95

Figura 4.23 Leituras abaixo da janela - Modelo 2, Situação 2 ..............................................95

Figura 4.24 Deformações na base da parede - Modelo 2, Situação 2. $(\delta$ em mm) .................96

Figura 4.25 Configuração deformada da viga - Modelo 2, Situação 3. ( $\delta$ em mm) ..............97

Figura 4.26 Distribuição de fissuras após ensaio - Modelo 2, Situação 3...............................98

Figura 4.27 Fotografia do painel após ensaio - Modelo 2, Situação 3 ...................................99

Figura 4.28 (a) Reações de apoio; (b) Deformação na parede - Modelo 2, Situação 3.........99

Figura 4.29 Deformações na base da parede - Modelo 2, Situação 3. ( $\delta$ em mm)..............100

Figura 4.30 Leituras abaixo da janela - Modelo 2, Situação 3 ……………………….........100

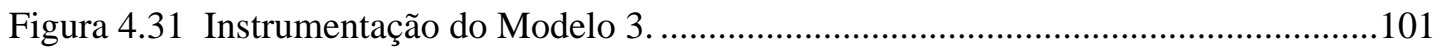

Figura 4.32 Configuração deformada da viga - Modelo 3, Situação 1. (F em kN) ..............102

Figura 4.33 (a) Reações de apoio; (b) Deformação na parede - Modelo 3, Situação 1.......102

Figura 4.34 Leituras ao lado da porta - Modelo 3, Situação 1.............................................103

Figura 4.35 Deformações na base da parede - Modelo 3, Situação 1. (F em kN) .................103

Figura 4.36 Detalhe da fissura no canto da porta - Modelo 3, Situação 2............................104

Figura 4.37 Configuração deformada da viga - Modelo 3, Situação 2. ( $\delta$ em mm) .............105

Figura 4.38 Distribuição de fissuras após ensaio - Modelo 3, Situação 2. (Verso do

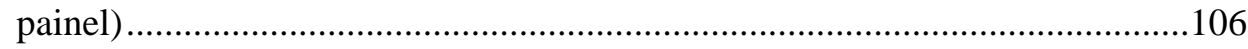

Figura 4.39 Fotografia do painel após ensaio - Modelo 3, Situação 2. (Verso do painel) ..106

Figura 4.40 Deformações na base da parede - Modelo 3, Situação 2. ( $\delta$ em mm)..............107

Figura 4.41 Leituras ao lado da porta - Modelo 3, Situação 2. ..........................................107

Figura 4.42 Detalhe da fissura vertical central - Modelo 3, Situação 3. ...............................108

Figura 4.43 Configuração deformada da viga - Modelo 3, Situação 3. ( $\delta$ em mm) .............109

Figura 4.44 Distribuição de fissuras após ensaio - Modelo 3, Situação 3.............................110

Figura 4.45 Fotografia do painel após ensaio - Modelo 3, Situação 3 ..................................110

Figura 4.46 (a) Reações de apoio; (b) Deformação na parede - Modelo 3, Situação 3.......111

Figura 4.47 Leituras ao lado da porta - Modelo 3, Situação 3..............................................111

Figura 4.48 Deformações na base da parede - Modelo 3, Situação 3. ( $\delta$ em mm) ...............112 
Figura 4.49 Instrumentação do Modelo 4. 113

Figura 4.50 Configuração deformada da viga - Modelo 4, Situação 1. (F em kN) 114

Figura 4.51 (a) Reações de apoio; (b) Deformação na parede - Modelo 4, Situação 1.......114

Figura 4.52 Leituras (a) ao lado da porta e (b) abaixo da janela - Modelo 4, Situação 1....115

Figura 4.53 Deformações na base da parede - Modelo 4, Situação 1. (F em kN) ................115

Figura 4.54 Configuração deformada da viga - Modelo 4, Situação 2. ( $\delta$ em mm) .............116

Figura 4.55 Distribuição de fissuras após ensaio - Modelo 4, Situação 2. (Verso do painel).

Figura 4.56 Fotografia do painel após ensaio - Modelo 4, Situação 2. (Verso do painel) ..118

Figura 4.57 Leituras (a) ao lado da porta e (b) abaixo da janela - Modelo 4, Situação 2....118

Figura 4.58 Deformações na base da parede - Modelo 4, Situação 2. ( $\delta$ em mm) ...............119

Figura 4.59 Configuração deformada da viga - Modelo 4, Situação 3. ( $\delta$ em mm) .............120

Figura 4.60 Distribuição de fissuras após ensaio - Modelo 4, Situação 3............................121

Figura 4.61 Fotografia do painel após ensaio - Modelo 4, Situação 3 .................................121

Figura 4.62 (a) Reações de apoio; (b) Deformação na parede - Modelo 4, Situação 3.......122

Figura 4.63 Leituras (a) ao lado da porta e (b) abaixo da janela - Modelo 4, Situação 3....122

Figura 4.64 Deformações na base da parede - Modelo 4, Situação 3. ( $\delta$ em mm) ...............123

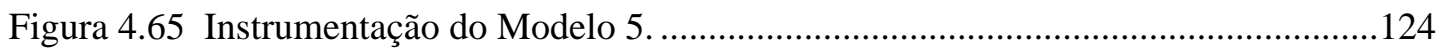

Figura 4.66 Configuração deformada da viga - Modelo 5, Situação 1. (F em kN) ..............125

Figura 4.67 (a) Reações de apoio; (b) Deformação na parede - Modelo 5, Situação 1.......125

Figura 4.68 Deformações na base da parede - Modelo 5, Situação 1. (F em kN) .................126

Figura 4.69 Configuração deformada da viga - Modelo 5, Situação 2. ( $\delta$ em mm) .............127

Figura 4.70 Distribuição de fissuras após ensaio - Modelo 5, Situação 2...........................128

Figura 4.71 Fotografia do painel após ensaio - Modelo 5, Situação 2 ..................................128

Figura 4.72 (a) Reações de apoio; (b) Deformação na parede - Modelo 5, Situação 2.......129

Figura 4.73 Deformações na primeira fiada - Modelo 5, Situação 2....................................129

Figura 4.74 Deformações na base da parede - Modelo 5, Situação 2. ( $\delta$ em mm) ...............130

Figura 4.75 Configuração deformada da viga - Modelo 5, Situação 3. ( $\delta$ em mm) .............131

Figura 4.76 Distribuição de fissuras após ensaio - Modelo 5, Situação 3. (Verso do painel).

Figura 4.77 Fotografia do painel após ensaio - Modelo 5, Situação 3. (Verso do painel) ..132

Figura 4.78 (a) Reações de apoio; (b) Deformação na parede - Modelo 5, Situação 3.......133

Figura 4.79 Deformações na base da parede - Modelo 5, Situação 3. ( $\delta$ em mm) ...............133

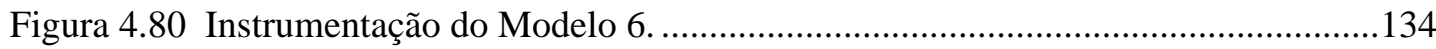

Figura 4.81 Configuração deformada da viga - Modelo 6, Situação 1. (F em kN) ..............135

Figura 4.82 (a) Reações de apoio; (b) Deformação na parede - Modelo 6, Situação 1.......135 
Figura 4.83 Deformações na base da parede - Modelo 6, Situação 1. (F em kN) ................136

Figura 4.84 Configuração deformada da viga - Modelo 6, Situação 2. ( $\delta$ em mm) ............137

Figura 4.85 Distribuição de fissuras após ensaio - Modelo 6, Situação 2.............................138

Figura 4.86 Fotografia do painel após ensaio - Modelo 6, Situação 2. .................................138

Figura 4.87 (a) Reações de apoio; (b) Deformação na parede - Modelo 6, Situação 2.......139

Figura 4.88 Deformações na base da parede - Modelo 6, Situação 2. ( $\delta$ em mm)...............139

Figura 4.89 Configuração deformada da viga - Modelo 6, Situação 3. ( $\delta$ em mm) .............140

Figura 4.90 Distribuição de fissuras após ensaio - Modelo 6, Situação 3. (Verso do painel).

Figura 4.91 Fotografia do painel após ensaio - Modelo 6, Situação 3. (Verso do painel) ..141

Figura 4.92 (a) Reações de apoio; (b) Deformação na parede - Modelo 6, Situação 3.......142

Figura 4.93 Deformações na base da parede - Modelo 6, Situação 3. ( $\delta$ em mm) ...............142

Figura 4.94 Instrumentação do Modelo 7 .........................................................................143

Figura 4.95 Fotografia do painel após ensaio - Modelo 7, Situação 2. ................................145

Figura 4.96 Fotografia do painel após ensaio - Modelo 7, Situação 3. (Verso do painel) ..146

Figura 4.97 Sistema de travamento dos perfis metálicos. 148

Figura 4.98 (a) Anéis de travamento. (b) Cilindro com deslocamento liberado (apenas com anel menor) e cilindro travado.

Figura 4.99 Aspecto provável da fissuração de painéis sem abertura....................................151

Figura 4.100 Aspecto provável da fissuração em porções de parede contendo aberturas. ..152

Figura 5.1 Modelo de atrito no contato do ANSYS..........................................................156

Figura 5.2 Critério adotado nas análises $\times$ valores experimentais. .....................................157

Figura 5.3 Características geométricas dos modelos numéricos $(\mathrm{cm})$................................157

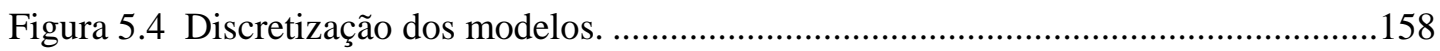

Figura 5.5 Reações de apoio experimentais e numéricas - Situação 1 .................................161

Figura 5.6 Reações de apoio experimentais e numéricas - Situação 2.................................163

Figura 5.7 Reações de apoio experimentais e numéricas - Situação 3..................................164

Figura 5.8 Deformações experimentais e numéricas na parede - Situação 1.......................165

Figura 5.9 Deformações experimentais e numéricas na parede - Situação 2 . ......................166

Figura 5.10 Deformações experimentais e numéricas na parede - Situação 3....................167

Figura 5.11 Deformações verticais na primeira fiada - Situação 1. ....................................169

Figura 5.12 Deformações verticais na primeira fiada - Situação 2 ...................................170

Figura 5.13 Deformações verticais na primeira fiada - Situação 3. ....................................171

Figura 5.14 Deformações principais, Modelos 3 e 4 - Situação 2........................................172

Figura 5.15 Deformações principais, Modelos 1 e 6 - Situação 2.........................................173

Figura 5.16 Penetrações (-) e separações (+) experimentais e numéricas - Situação 1.......175 
Figura 5.17 Penetrações (-) e separações (+) experimentais e numéricas - Situação 2.......176

Figura 5.18 Penetrações (-) e separações (+) experimentais e numéricas - Situação 3.......177

Figura 5.19 Deslizamentos experimentais e numéricos - Situação 1 ...................................178

Figura 5.20 Deslizamentos experimentais e numéricos - Situação 2 ..................................179

Figura 5.21 Deslizamentos experimentais e numéricos - Situação 3.................................180

Figura 5.22 Variação da abertura de porta: valores experimentais e numéricos...................181 


\section{LISTA DE TABELAS}

Tabela 2.1 Rotações relativas limites para a não ocorrência de problemas (THOMAZ, $1998 b)$

Tabela 2.2 Recomendações de valores limites para evitar fissuração...................................29

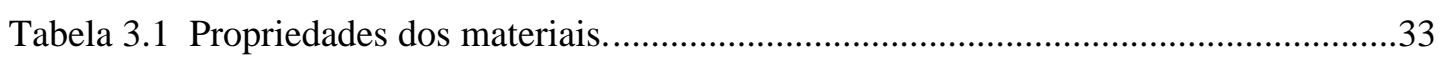

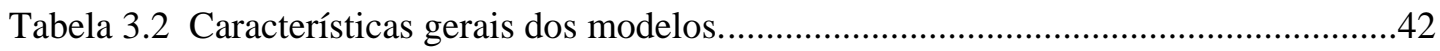

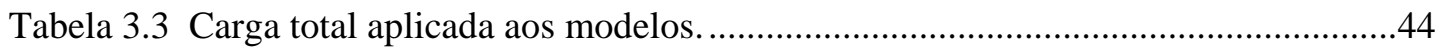

Tabela 3.4 Instrumentos de medição utilizados...................................................................46

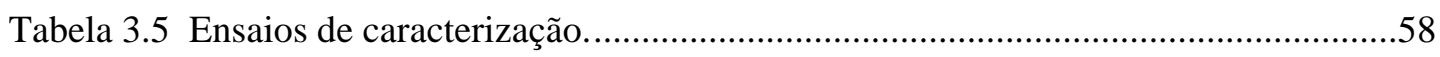

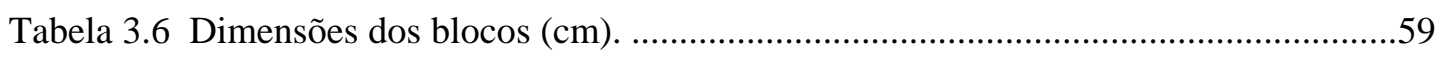

Tabela 3.7 Dimensões dos meio-blocos $(\mathrm{cm})$. ..........................................................60

Tabela 3.8 Resultados dos ensaios de compressão dos blocos. ..............................................61

Tabela 3.9 Teor de umidade, absorção de água e área líquida dos blocos..............................62

Tabela 3.10 Dimensões dos blocos canaleta $(\mathrm{cm})$..............................................................62

Tabela 3.11 Resistência da argamassa à compressão...........................................................64

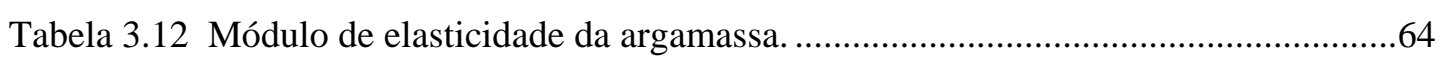

Tabela 3.13 Resistência dos prismas à compressão..........................................................65

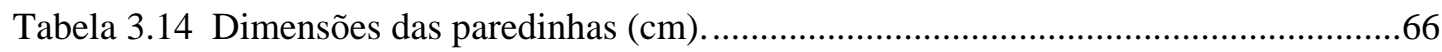

Tabela 3.15 Resultados dos ensaios de compressão axial....................................................68

Tabela 3.16 Resultados dos ensaios de compressão diagonal................................................69

Tabela 3.17 Resultados dos ensaios de cisalhamento nas juntas bloco-concreto. ...................70

Tabela 3.18 Composição granulométrica da areia da argamassa............................................72

Tabela 3.19 Composição granulométrica da areia do concreto. .............................................73

Tabela 3.20 Composição granulométrica do pedrisco. .........................................................73

Tabela 3.21 Eficiências de prismas e paredinhas..................................................................73

Tabela 4.1 Parâmetros de curvatura - Modelo 1, Situação 2.................................................81

Tabela 4.2 Parâmetros de curvatura - Modelo 1, Situação 3..................................................86

Tabela 4.3 Parâmetros de curvatura - Modelo 2, Situação 2 ................................................93

Tabela 4.4 Parâmetros de curvatura - Modelo 2, Situação 3...............................................98 
Tabela 4.5 Reações de apoio e deformações da parede - Modelo 3, Situação 1. ..................101

Tabela 4.6 Parâmetros de curvatura - Modelo 3, Situação 2................................................105

Tabela 4.7 Parâmetros de curvatura - Modelo 3, Situação 3................................................109

Tabela 4.8 Reações de apoio e deformações da parede - Modelo 4, Situação 1..................113

Tabela 4.9 Parâmetros de curvatura - Modelo 4, Situação 2 ...............................................117

Tabela 4.10 Parâmetros de curvatura - Modelo 4, Situação 3..............................................120

Tabela 4.11 Parâmetros de curvatura - Modelo 5, Situação 2 .............................................127

Tabela 4.12 Parâmetros de curvatura - Modelo 5, Situação 3 .............................................131

Tabela 4.13 Parâmetros de curvatura - Modelo 6, Situação 2 ..............................................137

Tabela 4.14 Parâmetros de curvatura - Modelo 6, Situação 3..............................................140

Tabela 4.15 Resistência média à compressão (MPa) e coeficiente de variação.....................146

Tabela 4.16 Resistência média à compressão diametral (MPa) e coeficiente de variação. .147

Tabela 4.17 Módulo de elasticidade secante médio (MPa) e coeficiente de variação. .........147

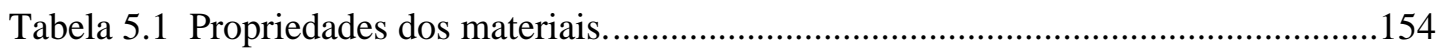

Tabela 5.2 Carregamentos aplicados nas análises numéricas............................................159

Tabela 5.3 Comparação entre recalques totais máximos (mm). .........................................159

Tabela 5.4 Comparação entre recalques diferenciais máximos $(\mathrm{mm})$...............................160 


\section{LISTA DE SÍMBOLOS}

$\mathrm{A}_{\mathrm{s}} \quad$ Área da seção transversal da armadura longitudinal positiva da viga

$\mathrm{A}_{\mathrm{s}}$ ' Área da seção transversal da armadura longitudinal negativa da viga

$\mathrm{A}_{\mathrm{sw}} \quad$ Área da seção transversal da armadura transversal (estribos) da viga

B Constante de calibração do comprimento de contato

d Altura útil da seção transversal da viga

$\mathrm{E}_{\mathrm{a}} \quad$ Módulo de elasticidade da argamassa

$\mathrm{E}_{\text {alv }} \quad$ Módulo de elasticidade da alvenaria

$\mathrm{E}_{\text {alv-g }} \quad$ Módulo de elasticidade da alvenaria grauteada

$\mathrm{E}_{\mathrm{b}} \quad$ Módulo de elasticidade do bloco

$\mathrm{E}_{\mathrm{c}} \quad$ Módulo de elasticidade do concreto

$\mathrm{E}_{\mathrm{c}-\mathrm{vi}} \quad$ Módulo de elasticidade do concreto das vigas (experimental)

$\mathrm{E}_{\mathrm{c}-\mathrm{ve}} \quad$ Módulo de elasticidade do concreto das vergas (experimental)

$\mathrm{E}_{\mathrm{g}} \quad$ Módulo de elasticidade do graute

$\mathrm{E}_{\mathrm{p}} \quad$ Módulo de elasticidade da parede

$\mathrm{E}_{\mathrm{v}} \quad$ Módulo de elasticidade da viga

$\mathrm{f}_{\mathrm{alv}, \mathrm{c}} \quad$ Resistência à compressão da alvenaria

$\mathrm{f}_{\mathrm{alv}, \mathrm{t}} \quad$ Resistência à tração da alvenaria

$\mathrm{f}_{\mathrm{ck}} \quad$ Resistência característica à compressão do concreto

FKN Coeficiente de rigidez normal (modelo de contato)

$\mathrm{G}_{\text {alv }} \quad$ Módulo de elasticidade transversal da alvenaria

$\mathrm{H} \quad$ Altura da parede

$\mathrm{I}_{\mathrm{v}} \quad$ Momento de inércia da viga

K Parâmetro de rigidez relativa parede-viga (Riddington \& Stafford Smith, 1978)

$\ell \quad$ Distância entre pontos de referência na fundação ou vão livre

L Comprimento da parede

$\mathrm{M}_{\mathrm{d}} \quad$ Momento fletor de cálculo

$\mathrm{M}_{\mathrm{k}} \quad$ Momento fletor característico

$\mathrm{P} \quad$ Carga total da parede, incluindo seu peso próprio 
R Parâmetro de rigidez relativa parede-viga (Davies \& Ahmed, 1977) ou reação de apoio

s Espaçamento entre estribos

$t_{p} \quad$ Espessura da parede

$\mathrm{V}_{\mathrm{c}} \quad$ Parcela de força cortante resistida por mecanismos complementares ao modelo em treliça

$\mathrm{V}_{\mathrm{Rd} 2} \quad$ Força cortante resistente de cálculo, relativa à ruína das diagonais comprimidas de concreto

$\mathrm{V}_{\mathrm{Rd} 3} \quad$ Força cortante resistente de cálculo, relativa à ruína por tração diagonal

$\mathrm{V}_{\mathrm{Sd}} \quad$ Força cortante solicitante de cálculo

$\mathrm{V}_{\mathrm{sw}} \quad$ Parcela de força cortante resistida pela armadura transversal

$\alpha \quad$ Comprimento de contato

$\alpha_{\mathrm{f}} \quad$ Fator de multiplicação da flecha imediata para obtenção da flecha adicional diferida

$\beta=\delta / \ell$

$\delta \quad$ Recalque diferencial

$\delta / \ell \quad$ Rotação relativa ou distorção angular

$\Delta / \mathrm{L} \quad$ Parâmetro de curvatura, razão de deflexão

$\Delta \mathrm{M} \quad$ Parcela de redução do momento fletor (NBR 6118, 2001)

$\mu \quad$ Coeficiente de atrito interno

$v_{\text {alv }} \quad$ Coeficiente de Poisson da alvenaria

$v_{\mathrm{c}} \quad$ Coeficiente de Poisson do concreto

$v_{\mathrm{g}} \quad$ Coeficiente de Poisson do graute

$\sigma_{c} \quad$ Tensão de compressão

$\tau_{\mathrm{o}} \quad$ Resistência ao cisalhamento na ausência de pré-compressão

$\tau_{\text {máx }} \quad$ Tensão máxima de cisalhamento (modelo de contato)

$\tau_{\mathrm{u}} \quad$ Resistência ao cisalhamento

$\omega$ Rotação do edifício 


\section{RESUMO}

HOLANDA JR., O. G. (2002). Influência de recalques em edifícios de alvenaria estrutural. São Carlos. 224 p. Tese (Doutorado) - Escola de Engenharia de São Carlos, Universidade de São Paulo.

Nesta pesquisa estudou-se a influência de recalques em edifícios de alvenaria estrutural. Inicialmente os efeitos desses deslocamentos foram avaliados por meio de uma investigação numérica preliminar. A partir das análises realizadas foram definidos alguns casos mais interessantes de painéis constituídos por parede de alvenaria sobre viga de concreto armado para serem submetidos a ensaios em laboratório. Desta forma foi possível observar experimentalmente o comportamento desses painéis, variando-se alguns dos parâmetros mais importantes: existência e tipo de abertura e rigidez da viga. Além disso, foram avaliadas algumas alternativas para a minimização da fissuração. Utilizando os resultados experimentais, foram realizadas novas análises numéricas com o intuito de validar a modelagem adotada. Verificou-se em especial a importância de consideração da nãolinearidade de contato.

Palavras-chave: alvenaria estrutural, interação solo-estrutura, recalques, análise experimental, análise numérica. 


\section{ABSTRACT}

HOLANDA JR., O. G. (2002). Influence of settlements on structural masonry buildings. São Carlos. 224 p. Tese (Doutorado) - Escola de Engenharia de São Carlos, Universidade de São Paulo.

In this research, the influence of settlements on structural masonry buildings has been studied. Initially the effect of these displacements was evaluated by means of a preliminary numerical investigation. From these analyses, some interesting cases of panels made of masonry wall on reinforced concrete beam were defined to be submitted to laboratory tests. Thus, it was possible to experimentally observe the behavior of these panels, varying some of the most important parameters: existence and type of opening and rigidity of the beam. Moreover, some cracking minimization alternatives have been evaluated. Using the experimental results, new numerical analyses have been performed to validate the modeling adopted. The importance of contact non-linearity consideration has been specially verified.

Keywords: structural masonry, soil-structure interaction, settlements, experimental analysis, numerical analysis. 


\section{INTRODUÇÃO}

Nos últimos anos, o interesse pela alvenaria estrutural cresceu de forma notável, especialmente pelas condições nitidamente favoráveis que se obtêm em termos de economia. Por ser um sistema construtivo que permite e até, de certa forma, exige que se empregue uma maior racionalidade no projeto e na execução das obras, o consumo e o desperdício de materiais pode ser minimizado. Além disso, a rapidez que pode ser atingida durante a construção também concorre para gerar economia e, dessa maneira, propiciar uma maior inserção no mercado.

Deve-se considerar entretanto que o projeto de edifícios de alvenaria estrutural necessita ainda de grandes avanços tecnológicos para se aproximar do desenvolvimento que se observa com relação às estruturas convencionais em concreto armado. A própria normatização nacional é pobre e um grande esforço precisa ser feito com o intuito de aprimorá-la para que se possa projetar e executar edifícios cada vez mais econômicos e seguros. Esse esforço traduz-se em pesquisas voltadas para a realidade brasileira, sem o que se tornará praticamente impossível desenvolver de forma satisfatória os procedimentos normativos nessa área.

Assim sendo, é imprescindível e urgente que haja uma concentração de esforços na implementação de um conjunto de pesquisas que possam permitir o desenvolvimento de tecnologias adequadas. Exatamente por se encaixar nesse objetivo geral é que se justifica a importância e a motivação para a elaboração do presente trabalho. Sua finalidade é, principalmente, contribuir para a elucidação de detalhes significativos sobre esse processo construtivo de grande viabilidade econômica e interesse social.

Nesse aspecto, um dos pontos de grande importância que precisam ser mais bem estudados é exatamente a interação da estrutura de alvenaria estrutural com a estrutura de fundação. Por se tratar de um sistema estrutural com pequena ductilidade, a alvenaria sofre de forma notável a influência das estruturas sobre as quais ela se apóia. Assim, quaisquer deslocamentos que porventura possam ocorrer nas fundações podem ocasionar danos significativos às paredes. É necessário, portanto, um melhor conhecimento dos limites que podem ser admitidos para esses deslocamentos e uma previsão para os efeitos que essas 
movimentações da fundação podem causar à superestrutura. $\mathrm{O}$ avanço nessa área do conhecimento tem como conseqüência a concepção de projetos estruturais mais adequados à realidade, oriundos da capacidade de previsão dos danos estruturais e de sua prevenção.

\subsection{OBJETIVOS}

Os principais objetivos da pesquisa podem ser resumidos nos itens a seguir:

- Buscar, na literatura técnica, valores máximos de recalques diferenciais que podem ocasionar danos a edifícios de alvenaria.

- Modelar matematicamente paredes de alvenaria e impor os recalques avaliados no item acima de forma a se verificar a ação desses deslocamentos nas paredes, especialmente junto a cantos, bordas e aberturas.

- Verificar experimentalmente os resultados obtidos com a modelagem numérica de forma a validar os modelos matemáticos utilizados.

- Verificar experimentalmente a eficiência de alternativas para o combate à fissuração provocada por recalques em painéis de alvenaria.

- Avaliar a importância da consideração da não-linearidade de contato nas simulações numéricas.

\subsection{CONTEÚDO DA TESE}

No próximo capítulo são apresentados aspectos da fundamentação teórica desta pesquisa, retirados da literatura técnica. Procurou-se expor um breve panorama dos estudos já realizados sobre os temas envolvidos neste trabalho, priorizando trabalhos mais recentes. Para facilitar a compreensão, os trabalhos foram agrupados em seis seções temáticas: fissuração da alvenaria, recalques em estruturas de alvenaria, ação conjunta parede-viga, modelagem numérica da alvenaria, ensaios de alvenaria em escala reduzida e resistência ao cisalhamento da junta de argamassa.

O Capítulo 3 inicia-se com a discussão da análise numérica de caráter exploratório realizada com base nos conceitos do Capítulo 2. A partir desta análise preliminar foram determinados os modelos físicos a serem ensaiados em laboratório, com suas respectivas instrumentações. Em seguida, o programa experimental desenvolvido é detalhadamente descrito. Neste capítulo também se encontram os procedimentos de construção e transporte dos painéis, bem como os procedimentos de realização e os resultados dos ensaios de caracterização dos materiais utilizados.

No Capítulo 4 apresentam-se e discutem-se os resultados dos ensaios dos modelos de painéis. Procurou-se detalhar os acontecimentos observados durante a realização dos ensaios e apresentar os principais resultados. Os aspectos finais de fissuração de cada 
situação de ensaio podem ser visualizados em fotos e em esquemas, sendo possível observar a evolução da fissuração respectivamente em função dos recalques totais e diferenciais.

Os resultados experimentais são em seguida comparados com resultados numéricos, compondo a discussão de que consiste o Capítulo 5. Inicialmente são reapresentadas de forma concisa as propriedades dos materiais, cuja obtenção foi feita anteriormente nos ensaios de caracterização. Descreve-se, então, a modelagem adotada, indicando os valores de todas as variáveis. Dedica-se especial atenção aos parâmetros do modelo de contato. Em seguida comenta-se sobre as análises, que foram aplicadas a cada modelo ensaiado, respeitando suas particularidades. Foram realizadas simulações numéricas com e sem a consideração da não-linearidade de contato, a fim de avaliar a sua importância no problema em questão.

Finalmente, as principais conclusões do trabalho encontram-se reunidas no Capítulo 6. Nele também são feitas sugestões de temas para pesquisas futuras.

Em anexo são apresentadas, sob a forma de gráficos, as leituras da instrumentação dos painéis ensaiados. As referências bibliográficas citadas estão listadas no final, seguidas de uma bibliografia complementar. 


\section{CONCEITOS FUNDAMENTAIS}

Neste capítulo apresenta-se um resumo dos principais trabalhos obtidos com a pesquisa bibliográfica desenvolvida. Buscou-se, nos assuntos de maior interesse, fazer um apanhado histórico sobre as pesquisas já realizadas para se acompanhar o desenvolvimento atingido até os dias atuais. Para permitir uma melhor compreensão, os trabalhos encontramse a seguir divididos em seções temáticas.

\subsection{FISSURAÇÃO DA ALVENARIA}

A cerâmica, o concreto e as demais matérias-primas utilizadas na fabricação de blocos e tijolos são materiais frágeis e que apresentam baixa resistência à tração. O mesmo pode ser dito com relação à argamassa de assentamento comumente empregada. Logo, a alvenaria, sendo um conjunto de blocos ou tijolos unidos por juntas de argamassa, também apresenta tais características. Além disso, as interfaces entre as unidades e a argamassa constituem superfícies bastante suscetíveis à separação, uma vez que a resistência à tração nesses locais é muito pequena. Esses fatores explicam porque fissuras constituem um estado patológico bastante comum em estruturas de alvenaria

Por esse motivo, a fissuração da alvenaria tem sido tema de diversas pesquisas, quer sejam as fissuras estudadas indicadoras de uma ruptura iminente, quer estejam elas estabilizadas. SHRIVE (1983), por exemplo, com base na teoria da mecânica da fratura para metais, procurou apresentar uma teoria semelhante para a alvenaria, adaptando os conceitos e as aproximações adotadas. Partiu-se do critério de que deve haver tração para que surja uma fissura. Daí foi desenvolvida uma teoria para a iniciação das fissuras, com o objetivo de identificar a tensão causadora do início da fissuração e a direção de propagação inicial. Alertou-se para a necessidade de pesquisas sobre o critério de energia para a propagação das fissuras, possibilitando futuramente determinar se as fissuras se estabilizarão ou levarão a estrutura ao colapso. Assim, segundo o autor, poderá ser estabelecido um conjunto simples e consistente de critérios de ruptura para a alvenaria sob qualquer tipo de carregamento.

Segundo GRIMM (1988 e 1997) a fissuração pode ser considerada como a causa mais freqüente de falha de desempenho da alvenaria. Na maioria das ocasiões, 
entretanto, as fissuras não estão relacionadas com danos estruturais, mas prejudicam a estética, o conforto do usuário e a estanqueidade da construção, ou seja, as condições de serviço deixam de ser atendidas.

Com base nas causas de fissuras em alvenaria apresentadas por GRIMM (1988), PAGE (1993) e THOMAZ (1998a), pode-se classificá-las em basicamente três tipos: efeitos externos, mudanças volumétricas dos materiais, e interação com outros elementos estruturais. Os efeitos externos compreendem principalmente a atuação das cargas variáveis e a movimentação das fundações. O segundo tipo da classificação refere-se às mudanças volumétricas provocadas por retração, mudanças de temperatura e de umidade, etc. A interação da alvenaria com outros elementos estruturais causa fissuras, por exemplo, quando tais elementos retraem-se ou se dilatam, ou quando induzem deformações excessivas na alvenaria.

Neste trabalho será estudada a influência dos recalques em edifícios de alvenaria estrutural. Portanto, o tema da pesquisa envolve a fissuração provocada por um tipo específico de efeito externo.

Em painéis de alvenaria as fissuras podem se apresentar nas direções horizontal, vertical, diagonal ou uma combinação destas. Quando verticais ou diagonais elas podem ser retas, atravessando unidades e juntas, ou podem ter um aspecto escalonado, passando apenas pelas juntas. As configurações possíveis estão esquematizadas na Figura 2.1. A forma da fissura é influenciada por vários fatores, incluindo a rigidez relativa das juntas com relação às unidades, a presença de aberturas ou outros pontos de fragilidade, as restrições da parede e a causa da fissura.

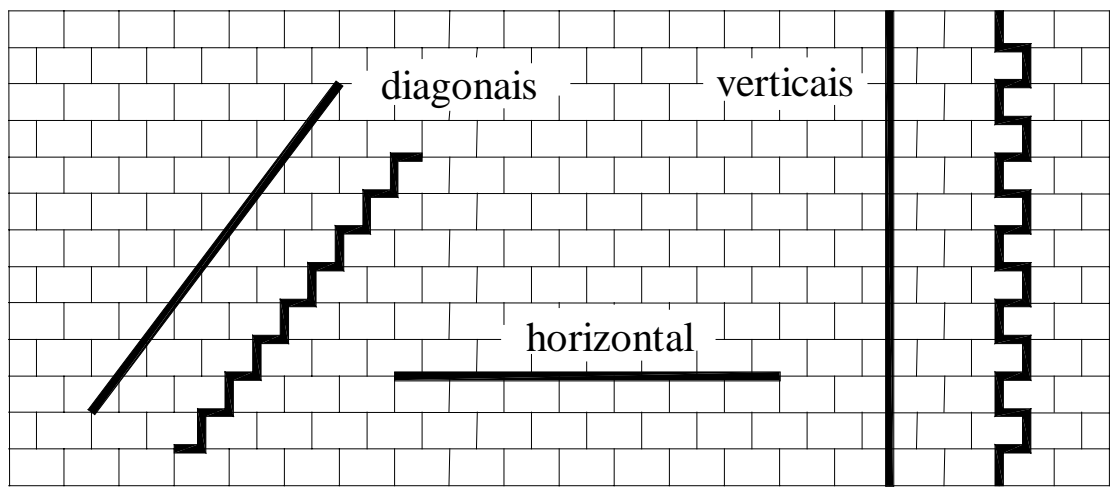

Figura 2.1 Configurações básicas das fissuras em alvenaria.

Especialmente no caso de painéis de alvenaria submetidos a recalques, GRIMM (1988 e 1997), PAGE (1993) e THOMAZ (1998a) ressaltaram que as fissuras decorrentes normalmente são verticais ou diagonais, com variação da abertura ao longo do seu 
comprimento. A Figura 2.2 ilustra as configurações das fissuras em algumas situações de recalques.
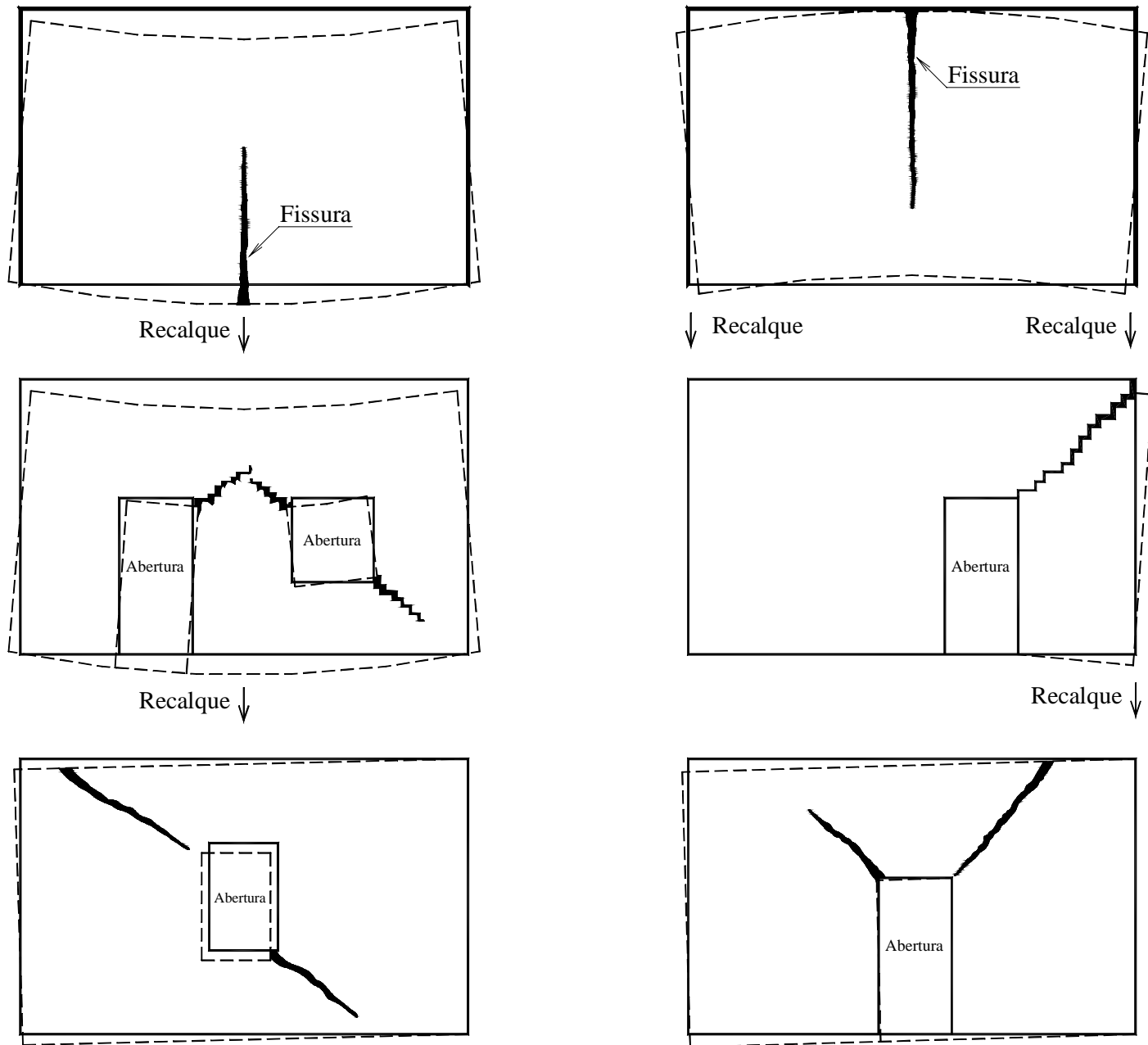

$\downarrow$ Recalque

$\downarrow$ Recalque

Figura 2.2 Exemplos de fissuras causadas por recalques (GRIMM, 1988).

Embora seja difícil impedir completamente o aparecimento de fissuras em edifícios, medidas preventivas adotadas ainda na fase de projeto podem minimizá-las. Se a movimentação da fundação puder ser prevista, PAGE (1993) afirmou que ela deve então ser dimensionada rígida o suficiente para acomodar esses movimentos, evitando assim deformações excessivas na alvenaria. A norma australiana citada no trabalho limita a curvatura de vigas e lajes que suportam paredes de alvenaria a vão/500, quando se tomam providências para minimizar os efeitos da movimentação, ou vão/1000, no caso contrário. Alternativamente, a alvenaria pode ser projetada para atuar como viga-parede, cujo vão seria o da região do recalque. Todavia, se houver fissuração neste caso, ela tende a ser excessiva. Se forem projetadas juntas de controle de fissuração, de forma que a alvenaria possa tolerar algum movimento da fundação, a rigidez desta última pode ser reduzida. 
THOMAZ (1998b) ressaltou a prática da inserção de juntas nas estruturas como forma eficiente de evitar fissuras provocadas por acomodações da fundação. Foram citados alguns casos em que se recomendam juntas: edifícios com forma muito alongada; plantas recortadas; carregamentos muito diferenciados; fundações apoiadas em cotas diferentes; diferentes tipos de fundação; e diferentes etapas de construção.

Ainda sob o tema de fissuras em alvenaria, pode-se citar o trabalho de GRIMM (1982) sobre investigação de fissuras em edifícios já construídos. Foi apresentada uma metodologia desse tipo de trabalho, bastante interessante tanto para a prática de engenheiros construtores, avaliadores, consultores, dentre outros, quanto para a pesquisa envolvendo vistoria em campo.

\subsection{RECALQUES EM ESTRUTURAS DE ALVENARIA}

Apesar de normalmente não ser aplicada na prática cotidiana de projetistas de estruturas, já que seu conhecimento ainda não está suficientemente desenvolvido, a interação solo-estrutura vem sendo objeto de estudo de pesquisadores há pelo menos cinco décadas. MEYERHOF (1953) defendeu em seu artigo que solo, fundação e estrutura devem ser consideradas como um só sistema, posição amplamente divulgada pelos demais estudiosos do fenômeno.

Analisando resultados de ensaios publicados, MEYERHOF (1953) sugeriu um valor máximo para o parâmetro de curvatura $\Delta / \mathrm{L}$ (ver Figura 2.3), também chamado razão de deflexão, de 1/2000 e para a tensão de tração de aproximadamente 0,21 MPa. Tais valores são aplicáveis a paredes estruturais compostas de blocos maciços. Afirmou ainda que em situações reais, a relação $\Delta / L$ para uma dada tensão pode ser maior que a obtida em laboratório, devido à fluência da alvenaria.

Atenção também foi dada para as ações horizontais. Concluiu-se que, embora o recalque seja geralmente o movimento mais importante das fundações, deslocamentos horizontais e rotações exercem considerável influência no comportamento de paredes de alvenaria, de estruturas de apenas um pavimento e na parte inferior de edifícios de muitos andares.

Com base em observações realizadas por diversos pesquisadores em 98 edifícios construídos entre 1860 e 1952, SKEMPTON \& MacDONALD (1956) publicaram um estudo sobre recalques admissíveis em edifícios com estrutura de aço, concreto ou alvenaria. Afirmaram que é provavelmente o raio de curvatura da superfície de recalque o fator determinante da fissuração dos edifícios.

Dada a dificuldade de se medir tal grandeza, sugeriram um outro parâmetro mais prático para aferição in loco, que denominaram distorção angular, mais tarde 
redefinido por BURLAND et al. (1977) como rotação relativa ( $\beta$ ).Esta última denominação será usada ao longo deste trabalho. Tal parâmetro é definido como a razão entre o recalque diferencial $(\delta)$ e a distância $(\ell)$ entre dois pontos de referência na fundação, conforme ilustrado na Figura 2.3. Os pontos de referência correspondem a pontos na fundação do edifício (designados por A, B, C e D). No cálculo tanto de $\delta / \ell$ como de $\Delta / \mathrm{L}$ deve-se retirar a parcela de movimento de corpo rígido, referente ao recalque uniforme e à rotação do edifício $(\omega)$. Estas definições foram também apresentadas, de forma didática, por NOVAISFERREIRA (1977).

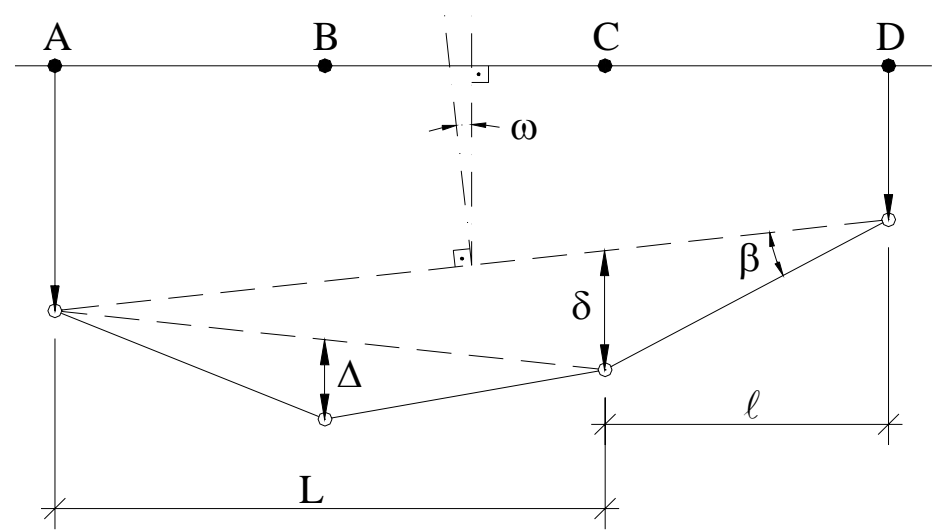

Figura 2.3 Definições de movimentos da fundação.

A partir dos dados referentes aos edifícios analisados, SKEMPTON \& MacDONALD (1956) sugeriram o valor $1 / 300$ como o limite máximo para $\delta / \ell$ de forma a não ocorrerem fissuras nas edificações. Entretanto, em outras ocasiões foi observada a ocorrência de fissuração com valores menores de $\delta / \ell$, provavelmente justificada pelo uso de argamassa muito resistente e pelo fato de terem sido casos de ensaio em laboratório, em que a razão de deformação é bem maior que em estruturas reais.

SKEMPTON \& MacDONALD (1956) concluíram ressaltando que os limites sugeridos são válidos para edifícios com fundação em sapatas, radier ou estacas, diretamente sobre camadas de areia ou argila. Apesar de afirmarem que os limites são conservadores, sugeriram que não se ultrapasse $\delta / \ell=1 / 500$, no qual se aplicou um coeficiente de segurança aproximadamente igual a 1,7 .

POLSHIN \& TOKAR (1957) estudaram, dentre outros, o caso de paredes estruturais de tijolos maciços. Concluíram que para relações comprimento/altura (L/H) menores que 3, o máximo valor do parâmetro de curvatura $\Delta / \mathrm{L}$ deve ser 0,0003 e 0,0004 para areia e argila mole, respectivamente. Para $\mathrm{L} / \mathrm{H}$ maior que 5 , os valores passam a ser correspondentemente 0,0005 e 0,0007. Dois conceitos importantes foram utilizados: a 
relação comprimento/altura do edifício ou da parede, e a deformação por tração limite para que não ocorra fissura. As recomendações apresentadas são para a não ocorrência de fissura na parede.

Quase duas décadas mais tarde, GRANT et al. (1974) atualizaram, ampliaram e examinaram criticamente o trabalho de SKEMPTON \& MacDONALD (1956). Adicionaram 95 edifícios à amostra inicial dos 98 analisados no trabalho mais antigo. Além disso, corrigiram os valores de rotação relativa $(\delta / \ell)$, retirando a parte referente a movimento de corpo rígido da edificação, ou seja, rotação e recalque uniforme.

Observando toda a amostra adicional, composta de edifícios com estruturas em aço, concreto e alvenaria, ratificaram o limite de $1 / 300$ sugerido para $\delta / \ell$ máximo da edificação, de forma a não ocorrerem danos. Ressaltaram ainda que danos não ocorrem necessariamente quando, localmente, $\delta / \ell$ exceder aquele limite.

Além disso, verificaram se seria mais adequado utilizar o parâmetro de curvatura $\Delta / \mathrm{L}$, uma vez que a curvatura é determinante nesse tipo de problema e este parâmetro a caracteriza melhor. Como conclusão, afirmaram que $\Delta / \mathrm{L}$ não apresenta vantagens consideráveis sobre $\delta / \ell$, pois o segundo é de mais fácil obtenção e produz resultados bastante satisfatórios, desde que seja retirada a parcela referente a movimentos de corpo rígido.

Também se tentou verificar a influência da razão de recalque com o tempo na ocorrência de danos. Contudo, a amostra utilizada não permitiu chegar a resultados conclusivos, pois nos edifícios para os quais se considerou recalque "rápido", este aconteceu num prazo de dois anos. As diferenças, portanto, não foram significativas com relação aos edifícios que apresentaram recalque "lento". Apesar disso, afirmaram ser importante a consideração deste parâmetro em casos extremos de velocidade de recalque. Os casos de ensaios de painéis em laboratório são qualificados como de recalque "rápido".

Edifícios com estruturas em pórticos que sofrem a maior parcela de recalque durante a construção podem tolerar maiores recalques, uma vez que os elementos não estruturais, suscetíveis a danos arquitetônicos, normalmente são posicionados somente após a construção da estrutura. Porém, isto não é o que ocorre em estruturas de alvenaria, pois os painéis, sujeitos a danos arquitetônicos, funcionais e estruturais, constituem a própria estrutura do edifício, não havendo intervalo de tempo para os recalques ocorrerem antes da sua colocação.

Com o auxílio de alguns casos reais, CRAWFORD (1976) discutiu sobre as causas e as consequiências dos movimentos de fundações. Mais uma vez foi citada a rotação relativa como parâmetro adequado para o estudo dos danos prováveis causados por recalques 
diferenciais em edifícios. Afirmou-se que o recalque admissível para uma edificação depende do seu tamanho, tipo e uso. Concluiu ressaltando duas formas de se lidar com o problema: projetar uma estrutura para acomodar razoáveis recalques diferenciais, provavelmente com a adoção de juntas, ou projetá-la de forma a tentar evitar que eles ocorram, o que acarreta maior custo financeiro da fundação.

BURLAND et al. (1977) apresentaram um extenso estado-da-arte sobre o comportamento de fundações e estruturas. Preocuparam-se muito com interação soloestrutura e afirmaram que, comparada à literatura sobre previsão de movimentos da fundação, a influência desses movimentos sobre a utilização e o serviço das estruturas e edifícios tem recebido pouca atenção. Apontaram como algumas causas desse pequeno progresso: as condições de serviço de uma edificação são muito subjetivas; as características dos edifícios variam muito, tais como função, forma, material, detalhes e acabamento; e, devido às simplificações adotadas no projeto, os edifícios dificilmente se comportam exatamente como previsto.

Afirmaram que uma certa quantidade de fissuras é praticamente inevitável, dado que a obra deve ser econômica. Daí sua conclusão de que o problema de combate às conseqüências dos recalques freqüentemente pode ser resolvido projetando o edifício para acomodar esses movimentos, e não para resistí-los.

Com a finalidade de se evitar grandes danos à edificação, citaram três critérios a serem satisfeitos para o estabelecimento de recalques limites: aparência, condições de utilização e estabilidade. Todavia, segundo SKEMPTON \& MacDONALD (1956), tais limites normalmente são dados pelos dois primeiros critérios.

Paredes estruturais não-armadas submetidas a uma deformação da sua fundação com concavidade para cima constituem um caso de propagação de fissuras controlada, segundo BURLAND et al. (1977). Ou seja, o confinamento propiciado por essa concavidade impede a propagação indefinida das fissuras enquanto mantidas as demais ações externas. As paredes normalmente atingem uma configuração estável.

Ao contrário, quando a deformação da fundação apresenta concavidade para baixo, a propagação de fissuras pode ser não-controlada. Neste caso, não havendo impedimento para a continuidade da fissuração, pode-se atingir mais facilmente a ruína.

KOMORNIK \& MAZURIK (1977) ressaltaram que os recalques são restringidos pela rigidez dos elementos da superestrutura, causando redistribuição de reações na fundação. A suposição de que os apoios acompanham a deformação do solo como se agissem separadamente, e que as suas reações são invariantes, é muito simplificada, 
principalmente quando a rigidez é tão alta a ponto de afetar radicalmente os recalques e o fluxo das cargas.

No seu estudo, analisaram teoricamente um edifício de concreto armado preenchido com paredes de alvenaria, de apenas um pavimento e forma quadrada, sobre uma fundação composta de nove sapatas. Estimaram os recalques, a partir de um método próprio, variando o dimensionamento da fundação, a configuração da camada de argila abaixo do edifício, e considerando ou não a rigidez da estrutura. Nas análises adotaram um valor máximo para o parâmetro de curvatura $\Delta / \mathrm{L}$ de $1 / 1000$ para que ocorressem danos arquitetônicos e de 1/500 para danos estruturais. A partir dos resultados concluiu-se que os três parâmetros verificados são importantes e influenciam bastante na configuração dos recalques e, por conseqüência, na probabilidade de ocorrência de danos ao edifício.

Dentro de uma linha de pesquisa sobre o comportamento das estruturas em alvenaria, TRIKHA \& BHANDARI (1977) analisaram numericamente cinco painéis submetidos a recalque. A configuração do recalque aplicado foi de uma reta com inclinação de 1/1000 abrangendo parte da base do painel, em que o deslocamento vertical máximo posicionava-se na extremidade.

Buscou-se determinar as tensões de tração na parede, a fim de prever como as fissuras se propagariam, utilizando o valor de 1,5 MPa para a resistência à tração. Foram realizadas análises lineares aplicando o método dos elementos finitos. Os parâmetros elásticos da alvenaria foram estimados a partir dos valores referentes a tijolos e argamassa. Os resultados, todavia, sofreram as conseqüências de muitas simplificações adotadas, além da consideração de uma resistência à tração muito alta para a alvenaria.

BERANEK (1987) publicou um cuidadoso estudo sobre previsão de danos em conjuntos de seis casas conjugadas provocados por recalques. O problema teve origem na extração de gás natural em uma província da Holanda. As casas analisadas são típicas daquela região, construídas em alvenaria e possuindo dois pavimentos. Como principais parâmetros no estudo foram adotados: constituição e propriedades do subsolo, geometria do edifício e das fundações, propriedades mecânicas dos materiais constituintes, e magnitude e variação das mudanças do nível do lençol freático.

Variando os parâmetros acima, fez-se uma análise dos esforços nos painéis de alvenaria que constituíam as casas, por meio do Método dos Elementos Finitos. Procurou-se observar principalmente a probabilidade de ocorrência de fissuras por tração na alvenaria. Relatou-se que a resistência à compressão da alvenaria segundo as direções vertical e horizontal variava entre 8 e $16 \mathrm{MPa}$ para o caso em questão. A resistência à tração na interface entre bloco e argamassa foi considerada compreendida no intervalo de 0,1 a 
0,3 MPa. Um extenso estudo da literatura realizado por BERANEK (1987) indicou a probabilidade de superação dos seguintes valores de resistência à tração de paredes de alvenaria $\left(\mathrm{f}_{\mathrm{alv}, \mathrm{t}}\right)$ :

95\% de probabilidade de superação: $\quad \mathrm{f}_{\mathrm{alv}, \mathrm{t}}=0,250 \mathrm{MPa}$

$50 \%$ de probabilidade de superação: $\mathrm{f}_{\text {alv,t }}=0,375 \mathrm{MPa}$ (valor médio)

$5 \%$ de probabilidade de superação: $\mathrm{f}_{\mathrm{alv}, \mathrm{t}}=0,500 \mathrm{MPa}$

desvio padrão: $s=0,076 \mathrm{MPa}$

Paredes antigas espessas de alvenaria acomodavam os recalques satisfatoriamente, ao contrário das paredes modernas, altamente tensionadas. Esta afirmação foi feita por MacLEOD (1987), que sugeriu o uso de armadura nas juntas horizontais da alvenaria para resistir às deformações por recalque. A justificativa advém da fragilidade da alvenaria, ao passo que para combater os efeitos dos recalques é preciso ductilidade. Partiuse do princípio de que os recalques afetam a capacidade de utilização do edifício, sendo o risco de colapso por essa causa normalmente desprezível.

Em suas análises, aplicadas a uma fachada em alvenaria, definiu como principais modos de deformação a flexão, com concavidade para cima ou para baixo, e o cisalhamento. Para tais casos, apresentou princípios e procedimentos de dimensionamento e detalhamento das armaduras longitudinais, as quais devem ser colocadas em zonas de tração a fim de que a alvenaria possa apresentar um comportamento dúctil.

Ao comentar sobre fissuras em edifícios de alvenaria provocados por recalques das fundações, supôs válida a estimativa dos recalques absolutos utilizando valores aproximados para parâmetros elásticos do solo, quando da falta de indicações mais precisas, já que se procura com maior interesse estimar os recalques diferenciais, que supostamente não seriam muito afetados pela aproximação adotada.

Porém, deve-se questionar a validade desse procedimento simplificado, pois MEYERHOF (1953), a partir de análises com adoção de diferentes valores de rigidez relativa estrutura-solo, verificou-se que o recalque total máximo é pouco afetado por esse índice, apesar de sofrer leve decréscimo com o aumento da rigidez relativa. Em contrapartida, o recalque diferencial máximo diminui rapidamente com esse aumento.

THOMAZ (1998b) também publicou uma tabela, que é reproduzida a seguir, contendo valores limites sugeridos para as rotações relativas, de forma a não ocorrerem fissuras. Os valores seguem basicamente as recomendações de SKEMPTON \& MacDONALD (1956). 
Tabela 2.1 Rotações relativas limites para a não ocorrência de problemas (THOMAZ, 1998b).

\begin{tabular}{c|l}
\hline $\begin{array}{c}\text { ROTAÇÃO } \\
\text { RELATIVA } \\
(\delta / \ell)\end{array}$ & \multicolumn{1}{c}{ OCORRÊNCIAS PREVISTAS } \\
\hline $1 / 600$ & Possibilidade de fissuras em estruturas contraventadas por peças diagonais. \\
\hline $1 / 500$ & Limite de segurança para obras que não podem apresentar fissuras. \\
\hline $1 / 300$ & $\begin{array}{l}\text { Possibilidade de ocorrências das primeiras fissuras em alvenarias e paredes } \\
\text { em geral. Início de problemas com operação de pontes rolantes. }\end{array}$ \\
\hline $1 / 250$ & $\begin{array}{l}\text { Limite a partir do qual a inclinação de prédios altos, por efeito dos recalques, } \\
\text { começa a ser visível. }\end{array}$ \\
\hline $1 / 150$ & $\begin{array}{l}\text { Fissuras com grandes aberturas começam a surgir nas alvenarias. Surgimento } \\
\text { de danos nas peças estruturais. }\end{array}$ \\
\hline
\end{tabular}

Um projeto de pesquisa sobre condições de serviço de estruturas de alvenaria em desenvolvimento na Universidade de Newcastle, Austrália, foi descrito por MASIA et al. (1998). Os autores focalizaram sua atenção sobre os efeitos de movimentos da fundação sobre paredes de casas térreas em alvenaria. Observaram que as fissuras raramente são significantes do ponto de vista da estabilidade estrutural, sendo as principais preocupações relacionadas à estética e à estanqueidade.

Inicialmente foi realizada uma análise dos efeitos externos, a fim de estabelecer quais provocam fissuração em alvenaria com maior probabilidade. Em seguida foram ensaiados alguns painéis de alvenaria para determinar as suas respostas estruturais à deformação da fundação. A partir desses ensaios, foram apontados os principais fatores que influenciam a fissuração:

- a resistência à tração nas interfaces bloco-argamassa;

- a membrana de impermeabilização colocada próxima à base da parede;

- $\quad$ a rigidez da viga de fundação;

- o tamanho e a posição das aberturas;

- a existência de vergas.

Discutiu-se brevemente a modelagem numérica realizada para tentar simular o comportamento dos painéis, em que se aplicou o Método dos Elementos Finitos. Nesse trabalho foi prevista uma análise probabilística para a previsão das fissuras em alvenaria.

O modelo probabilístico derivado dessa pesquisa foi apresentado por MASIA et al. (2000). Trata-se de uma primeira tentativa desse tipo de modelagem com relação a paredes de alvenaria sobre fundações rasas submetidas a movimentações de solos reativos. Baseou-se em modelos simplificados para os movimentos do solo e para a resposta da estrutura, os quais merecem futuro aprimoramento, segundo as sugestões finais. 


\subsection{AÇÃO CONJUNTA PAREDE-VIGA}

Quando uma parede de alvenaria encontra-se sobre uma base deformável, como é o caso de uma viga sobre apoios discretos, as tensões verticais na base da parede tendem a se concentrar nas proximidades dos apoios. Por sua vez, além de suportar a parede, a viga passa a se comportar também como um tirante, impedindo o deslocamento horizontal das extremidades inferiores da parede. Este fenômeno constitui o chamado efeito arco.

Para que o efeito arco se forme completamente a altura da parede deve ser igual ou superior a $60 \%$ do vão entre os apoios, conforme WOOD (1952). Além disso, outro prérequisito é que a resistência ao cisalhamento na interface entre parede e viga seja suficiente para impedir grandes deslizamentos. Portanto, caso se projete uma estrutura considerando a atuação do efeito arco, deve-se ter o cuidado de manter a viga bem escorada durante a construção, pelo menos até que a parede atinja a altura e a resistência necessária para que o "arco" se forme.

A rigidez relativa entre a parede e a viga é determinante para o grau de formação do efeito arco. Quanto mais deformável for a viga em relação à parede, maiores serão as concentrações de tensões nas proximidades dos apoios, e mais perceptível será o fenômeno. Por outro lado, vigas mais rígidas receberão uma maior parcela de carga proveniente da parede, acarretando maiores momentos fletores.

Uma forma de estimar a rigidez relativa foi introduzida por RIDDINGTON \& STAFFORD SMITH (1978), considerando o parâmetro K:

$$
\mathrm{K}=\sqrt[4]{\frac{\mathrm{E}_{\mathrm{p}} \mathrm{t}_{\mathrm{p}} \mathrm{L}^{3}}{\mathrm{E}_{\mathrm{v}} \mathrm{I}_{\mathrm{v}}}},
$$

em que $E_{p}, t_{p}$ e L são o módulo de elasticidade, a espessura e o comprimento da parede, e $E_{v}$ e $\mathrm{I}_{\mathrm{v}}$ são o módulo de elasticidade e o momento de inércia da viga, respectivamente. Considera-se que a altura da parede é maior ou igual a $60 \%$ do vão, para que seja assegurada a formação do efeito arco. Adotando essa mesma consideração, outro parâmetro bastante semelhante foi apresentado por DAVIES \& AHMED $^{1}$ apud BARBOSA (2000), em que H é a altura da parede:

$$
\mathrm{R}=\sqrt[4]{\frac{\mathrm{E}_{\mathrm{p}} \mathrm{t}_{\mathrm{p}} \mathrm{H}^{3}}{\mathrm{E}_{\mathrm{v}} \mathrm{I}_{\mathrm{v}}}} .
$$

No sistema parede-viga podem surgir tensões verticais de tração na interface entre ambas. Quando essas tensões atingem valores superiores à máxima resistência à tração

\footnotetext{
1 DAVIES, S. R.; AHMED, A. E. (1977). An aproximate method for analysing composite walls/beams. In: INTERNATIONAL SYMPOSIUM ON LOAD-BEARING BRICKWORK, British Ceramic Society, London. p. 305-20 apud BARBOSA (2000).
} 
local, pode ocorrer separação entre a parede e a viga, acentuando ainda mais o efeito arco. A porção dessa interface que permanece em contato torna-se então um importante parâmetro em procedimentos simplificados de análise, já que é nessa região onde acontece a transferência de cargas.

Para a estimativa desse parâmetro, denominado comprimento de contato, RIDDINGTON \& STAFFORD SMITH (1978) apresentaram a seguinte expressão, baseada em resultados de estudos teóricos:

$$
\alpha=\frac{\mathrm{BL}}{\mathrm{K}}
$$

em que B é uma constante de calibração. Esse parâmetro é usado na estimativa dos valores máximos da tensão de compressão na parede $(\mathrm{B}=0,75)$, do momento fletor na viga $(\mathrm{B}=1,5)$ e da tensão de cisalhamento na interface parede-viga $(\mathrm{B}=1)$.

Os valores das tensões atuantes no sistema variam segundo diversos fatores, porém suas configurações típicas na base da parede podem ser representadas conforme as ilustrações da Figura 2.4, para a situação de uma parede sobre viga biapoiada. Segundo BARBOSA (2000), em casos usuais as tensões verticais e de cisalhamento são nulas na região central do vão. Com relação às tensões horizontais na linha vertical média do sistema, a linha neutra pode se localizar na viga ou na parede. No primeiro caso, tem-se uma configuração usual em vigas, em que a armadura inferior está tracionada, enquanto que a superior é comprimida. No segundo caso, a viga está trabalhando mais efetivamente como tirante do "arco", com toda a armadura longitudinal submetida à tração. Nota-se neste caso a presença de tensões horizontais de tração também na base da parede. 
(a)

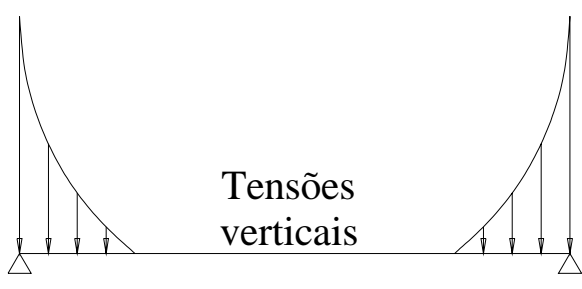

Tensões de cisalhamento

(b)

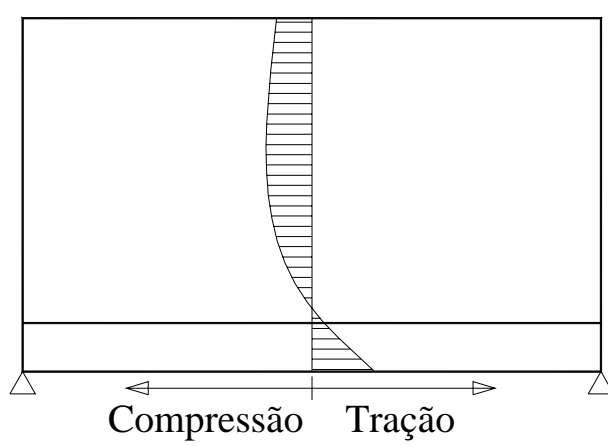

Figura 2.4 Distribuição de tensões no sistema parede-viga. (a) Concentrações de tensões na base da parede. (b) Tensões horizontais ao longo da linha média do sistema parede-viga. (BARBOSA, 2000)

Com a finalidade de simplificar as análises, HENDRY et al. (1981) afirmaram que se pode assumir uma distribuição linear, quadrática ou cúbica para as tensões verticais na base da parede. A configuração a ser adotada depende do valor do parâmetro R, de acordo com a Figura 2.5. Com relação à força axial na viga, HENDRY et al. (1981) sugerem uma distribuição linear, com valor máximo no centro do vão e nulo nos apoios.

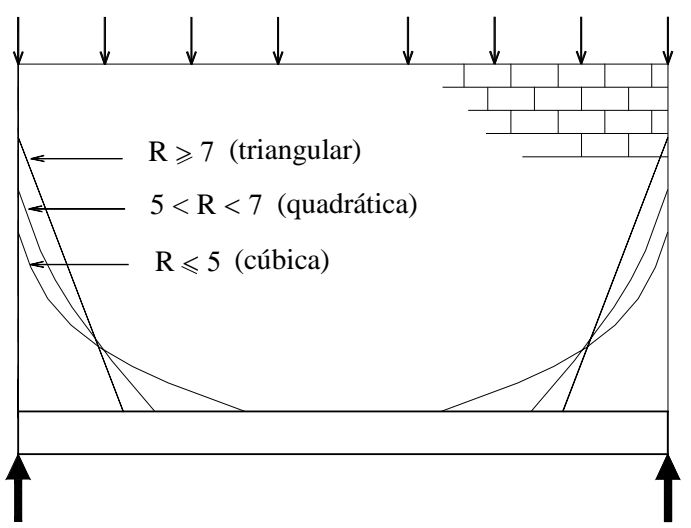

Figura 2.5 Distribuição das tensões verticais (HENDRY et al., 1981).

A presença de aberturas nos painéis de alvenaria pode ocasionar graves mudanças na configuração das tensões. São importantes tanto o tipo de abertura (portas ou janelas), quanto seu tamanho e sua localização. Por exemplo, aberturas de portas situadas próximas a um apoio podem acarretar grandes concentrações de tensões em uma de suas laterais, aumentando também os esforços na viga. 
Esta influência das aberturas já foi percebida no trabalho pioneiro de WOOD (1952). Trata-se de uma pesquisa experimental originalmente voltada para a determinação do dimensionamento mais econômico de vigas de fundação que suportam paredes de alvenaria, aplicada a edifícios com fundação em estacas escavadas regularmente espaçadas. Entretanto, os resultados obtidos podem ser aplicados em diversas outras situações. Como principais recomendações foram sugeridas as seguintes expressões para os valores de cálculo do momento fletor das vigas:

$\frac{\mathrm{PL}}{100}$ para paredes sem aberturas, ou quando estas se encontram apenas no centro do vão;

$\frac{\mathrm{PL}}{50} \quad$ para paredes com aberturas próximas aos apoios.

P é a carga total aplicada à parede mais seu peso próprio.

RIDDINGTON \& STAFFORD SMITH (1978) elaboraram um procedimento mais completo para o projeto estrutural do sistema parede-viga, preocupando-se também com as tensões desenvolvidas na alvenaria. Apresentaram algumas expressões para o dimensionamento da viga, de forma a prevenir contra a ruptura por compressão da alvenaria e por flexão da viga. Como restrições do método tem-se que a carga deve ser uniformemente distribuída ao longo do comprimento da parede e que não é permitida a presença de abertura na chamada região de formação do arco, definida como a região da parede compreendida entre duas semicircunferências com centro no meio do vão e raios $0,25 \mathrm{~L}$ e 0,6 L.

Este procedimento foi aplicado por HARDY (2000) para estabelecer comparações com seus resultados numéricos obtidos a partir de análises utilizando o método dos elementos finitos. Este trabalho, bastante recente, também visava o dimensionamento econômico de vigas biapoiadas que suportam paredes de alvenaria. Nele foi descartado o método simplificado proposto por Davies e Ahmed, pois, segundo Hardy, seus resultados não são bons devido à não consideração da perda de contato entre a parede e a viga.

Para uma maior concordância entre seus resultados numéricos e os obtidos com a aplicação do método de Riddington e Stafford Smith, HARDY (2000) propôs uma modificação deste último. A alteração consiste em se considerar uma distribuição quadrática para as tensões verticais na parede, em detrimento da distribuição linear originalmente adotada. Entretanto, ressaltou-se a necessidade de ensaios em laboratório para a validação dessa proposta.

Sem a preocupação imediata de aplicação ao projeto estrutural, mas com o intuito de verificar a influência da variação de certos parâmetros, alguns trabalhos experimentais podem ser citados. ROSENHAUPT (1962) ensaiou paredes de alvenaria em 
escala 1:2 sobre vigas biapoiadas até atingir a ruptura sob um carregamento uniformemente distribuído no topo. Foram observados quatro parâmetros: altura da parede; taxa de armadura na viga de fundação; tipo de material da alvenaria; e inclusão ou não de pilares verticais nas bordas.

Concluiu-se que a altura da parede tem influência sobre a flecha da viga e a carga causadora da primeira fissura. Em contrapartida, não foram encontradas diferenças consideráveis nos resultados devido à taxa de armadura da viga de fundação. O material utilizado na alvenaria, conforme esperado, demonstrou ser o principal fator determinante da resistência da estrutura e dos modos de ruptura. Os pilares de borda foram importantes na modificação das tensões internas da parede.

Os modos de ruptura observados foram: esmagamento da alvenaria acima do apoio; cisalhamento vertical próximo ao apoio; escoamento da armadura da viga de fundação; e fissuração entre os componentes. Verificou-se que os painéis ensaiados comportaram-se como vigas altas, com as tensões de tração acumuladas na viga de fundação e as de compressão distribuídas na parede de alvenaria, concentrando-se nas proximidades dos apoios.

O principal modo de ruptura detectado por BURHOUSE (1969) em seus ensaios em escala real foi o esmagamento por compressão da alvenaria nas proximidades dos apoios. Apenas no único painel de pequena altura $(\mathrm{H} / \mathrm{L}=0,33)$ a ruptura aconteceu por compressão da borda superior da alvenaria, aparecendo ainda uma grande fissura por cisalhamento. Este fato indicou que o arco realmente não se formou.

Para combater a ruptura por compressão nos cantos inferiores, nesses locais os tijolos foram substituídos por outros com resistência à compressão quadruplicada. Porém a carga de ruptura apenas duplicou, mostrando que esse reforço tem eficiência parcial.

Finalmente, recomendou-se a colocação de armaduras nas juntas horizontais da alvenaria como medida preventiva contra a fissuração.

\subsection{MODELAGEM NUMÉRICA DA ALVENARIA}

Dependendo dos níveis de acuidade e simplicidade procurados, a alvenaria pode ser numericamente representada basicamente de três formas distintas, segundo ROTS (1991) e LOURENÇO (1996). Cada uma dessas maneiras requer um conjunto próprio de características do material, e tem aplicação voltada para um tipo distinto de problema.

A micro-modelagem detalhada consiste na representação em separado das unidades (blocos, tijolos etc.) e das juntas de argamassa, ambas como elementos contínuos. A interface entre as unidades e a argamassa pode ser modelada como elementos descontínuos, representando potenciais planos de fissuração e deslizamento. São necessários 
os valores do módulo de elasticidade e do coeficiente de Poisson das unidades e da argamassa. Opcionalmente podem ser consideradas as propriedades inelásticas desses componentes. Este tipo de modelagem possibilita o estudo da interação entre as unidades e a argamassa, mostrando-se adequado para a verificação das tensões e deformações dos materiais.

Na micro-modelagem simplificada as unidades são ainda representadas por elementos contínuos. As juntas, por sua vez, são representadas por elementos de contato. A alvenaria fica então modelada como um conjunto de unidades, com propriedades elásticas, unidas por elementos de contato não-lineares, sendo possível simular a propagação de fissuras ao longo das juntas horizontais e verticais e de linhas preferenciais passando pelas unidades, caso sejam inseridos elemento de contato nesses locais. Para preservar a geometria, já que nessa representação as juntas perdem sua espessura, as dimensões das unidades são expandidas. Perde-se um pouco da precisão por não se considerar o coeficiente de Poisson da argamassa. Ambas as formas de micro-modelagem aplicam-se a detalhes estruturais, em que é necessário verificar o comportamento local com maior precisão.

$\mathrm{O}$ terceiro tipo de representação numérica da alvenaria corresponde à chamada macro-modelagem. Nela não se faz distinção entre blocos e argamassa, mas trata-se a alvenaria como um compósito que, dependendo dos dados disponíveis, pode ser considerado isotrópico ou anisotrópico. Necessita-se, portanto, dos valores dos parâmetros elásticos da alvenaria como um conjunto. Esta modelagem global da alvenaria é adequada para a análise de estruturas de grande escala, em que as dimensões do painel de alvenaria são grandes em relação às dimensões das unidades e à espessura das juntas.

$\mathrm{Na}$ linha da macro-modelagem, algumas pesquisas foram empreendidas com o objetivo de determinar os parâmetros elásticos da alvenaria. Dentre elas pode-se citar o trabalho de SCHUBERT (1979), que propôs expressões relacionando o módulo de elasticidade com a resistência à compressão. Com base nos resultados de diversos ensaios experimentais realizados até 1976, foram desenvolvidas expressões distintas para cada tipo de unidade e de argamassa estudado.

Para a estimativa do módulo de elasticidade secante da alvenaria foi sugerida a expressão $E_{a l v, 25}=2116 \sqrt{f_{\text {alv,c }}}$, em que $E_{a l v, 25}$ é o módulo de elasticidade secante da alvenaria até $25 \%$ da carga de ruptura e $\mathrm{f}_{\text {alv,c }}$ é a resistência à compressão da alvenaria. Afirmou-se também que o módulo de elasticidade da alvenaria encontra-se no intervalo entre $500 \mathrm{f}_{\text {alv,c }}$ e $1500 \mathrm{f}_{\text {alv,c. }}$. Entretanto, ressaltou-se a necessidade de mais pesquisas sobre o assunto, pois os valores que basearam as expressões apresentaram grande coeficiente de variação. 
Buscando respeitar a anisotropia do material em análises numéricas, PANDE et al. (1989) desenvolveram analiticamente expressões para o cálculo dos parâmetros elásticos da alvenaria de tijolos, com base em aproximação por um material hipotético equivalente. Como simplificação, adotaram-se a não ocorrência de escorregamento entre tijolos e argamassa e a continuidade das juntas verticais.

Foram apresentadas as expressões para o caso tridimensional e para estado plano de tensão. Advertiu-se que essa aproximação pode ser empregada para calcular a distribuição de tensões em painéis de alvenaria cujas dimensões são bem maiores que o máximo espaçamento das juntas e o comprimento dos tijolos, como usualmente é o caso.

Um modelo de representação da alvenaria para a determinação das suas propriedades mecânicas na fase elástica foi proposto por BATI et al. (1999). Consiste de uma matriz de argamassa em que se inserem tijolos cilíndricos com seção transversal elíptica. Tal formato foi determinado pelo modelo matemático disponível. Deve-se notar que, em contraste com a grande maioria dos modelos divulgados na literatura científica, este leva em consideração a continuidade da argamassa, ou seja, a conexão existente entre as juntas verticais e horizontais.

A validade do modelo proposto foi verificada experimentalmente comparando as previsões analíticas com resultados de ensaios, os quais consistiram de uma série de ensaios de compressão uniaxial em painéis de alvenaria. A previsão do valor do módulo de elasticidade foi muito boa, com erro de apenas 5\% com relação ao obtido no laboratório.

PAGE (1978) apresentou um método para a modelagem de painéis de alvenaria quando submetidos a carregamento no seu próprio plano. Considerou-se o material como um conjunto de tijolos, com propriedades elásticas, separados por juntas de argamassa, possuindo propriedades especiais e restritas. Portanto este tipo de representação corresponde à micro-modelagem simplificada. Os tijolos foram modelados usando elementos retangulares de oito nós em estado plano de tensão, com quatro graus de liberdade e propriedades elásticas. Por sua vez, as juntas foram modeladas como elementos de contato com resistência à tração limitada, alta resistência à compressão (com características de deformação nãolinear), e resistência ao cisalhamento variável em função do grau de compressão atuante.

O modelo foi verificado comparando os resultados da análise numérica com os de um ensaio experimental em um painel de alvenaria. Concluiu-se que a distribuição interna de tensões foi reproduzida pelo modelo analítico com um razoável grau de acuidade. Esses resultados também foram comparados com os obtidos a partir de uma análise numérica baseada em comportamento elástico e isotrópico para a alvenaria como um todo. Verificouse que os resultados provenientes dessa aproximação mais simplificada distanciaram-se 
progressivamente dos demais com o aumento da carga, enfatizando a natureza não-linear do material quando submetido a altas tensões.

A resposta não-linear produzida pelo modelo sugerido no artigo deve-se conjuntamente às propriedades não-lineares adotadas para a argamassa e à ruptura progressiva das juntas. Não se pôde conferir a evolução da fissuração prevista porque as fissuras não eram visíveis no ensaio. Afirmou-se que uma estimativa da carga de ruptura poderia ser obtida caso fosse incluído um critério de ruptura para os tijolos no modelo, o que se torna complicado principalmente devido ao complexo estado de tensão triaxial produzido pela interação bloco-argamassa.

Este modelo foi novamente aplicado pelo autor em uma pesquisa sobre o comportamento do sistema parede-viga (PAGE, 1979). Realizou-se um ensaio em escala 1:2, em que se empregou uma viga metálica com dimensões tais que a relação entre a rigidez da viga e a da parede se situasse entre valores típicos da prática australiana.

A análise não-linear produziu bons resultados, confirmando o efeito arco na parede e o desligamento na interface entre parede e viga, ambos percebidos nos resultados do ensaio. Este último efeito não pôde ser reproduzido em uma análise linear isotrópica do painel, porque neste caso não se permitem rupturas localizadas. Estudou-se também a sensibilidade dos resultados numéricos com relação às propriedades atribuídas à junta entre parede e viga, concluindo que este parâmetro é significante para o problema.

Uma formulação de macro-elementos para a modelagem do sistema parede-viga foi apresentada por SAW (1974). A partir dessa formulação, os resultados de análises elásticas lineares foram comparados com resultados experimentais previamente obtidos pelo mesmo ou por outros pesquisadores, concluindo-se que uma boa correlação foi conseguida. Concluiu-se também que para o caso de vigas relativamente flexíveis (de pequena altura) sua representação por elementos de barra é provavelmente preferível ao uso de um grande número de elementos planos.

A esta mesma conclusão também chegou BARBOSA (2000), que analisou casos de paredes sobre vigas biapoiadas por meio do método dos elementos finitos usando o processador numérico ANSYS. Diversas modelagens foram comparadas, concluindo-se que a macro-modelagem da parede utilizando elementos planos em estado plano de tensão sobre elementos de barra representativos da viga produz bons resultados.

Outro objetivo dessa pesquisa foi a verificação da influência da consideração de separações e deslizamentos ocorrentes na interface parede-viga. Essa interface foi modelada por elementos de contato disponíveis no programa utilizado. Em alguns casos estudados a influência do contato mostrou-se bastante importante na distribuição das tensões e na 
magnitude dos deslocamentos. Porém, para que melhores análises possam ser realizadas, ressaltou-se a necessidade de comparações com ensaios experimentais, em que se obtenha o maior número possível de parâmetros que permitam uma modelagem mais precisa do sistema parede-viga.

Com relação ao tipo de análise numérica, ANTHOINE (1997) estudou qual representação seria mais adequada para a alvenaria, sendo implementada a teoria de homogeneização de meios periódicos. Foram comparados o estado plano de tensão, o estado plano de deformação generalizado, e a modelagem tridimensional. Com esse objetivo, foram realizadas análises aplicando o modelo de dano definido por MAZARS ${ }^{2}$ apud ANTHOINE (1997).

A aproximação por estado plano de tensão é exata quando a espessura da parede pode ser desprezada, o estado plano de deformação generalizado é adequado para situações em que a espessura da parede tende a ser bem maior que as demais dimensões. A modelagem tridimensional produziu resultados melhores, apresentando modo de ruptura condizente com o observado na prática. Comparando os outros dois modelos concluiu-se que na fase linear ambos fornecem resultados satisfatórios. Entretanto, na fase não-linear a aproximação por estado plano de tensão pode conduzir a resultados errôneos, enquanto que o estado plano de deformação generalizado ainda produz resultados satisfatórios. Afirmou-se que esse fato deve-se à considerável espessura da parede de alvenaria quando comparada às dimensões de seus componentes.

Todavia, é interessante perceber que essas comparações foram feitas para uma "célula básica" composta por dois meio-blocos sobre um bloco. Em casos como esse, a espessura do bloco é bastante significativa, sendo realmente desaconselhável a representação por estado plano de tensão. Entretanto esta "célula básica" não pode ser considerada como representativa de uma parede, que normalmente possui dimensões em seu plano bem maiores que sua espessura.

MAMAGHANI et al. (1999) apresentaram um método de análise numérica de estruturas em alvenaria que acreditam ser bastante promissor no estudo desse tipo de material. Consiste de uma técnica baseada nos princípios do método dos elementos finitos, denominada Método Discreto dos Elementos Finitos. Basicamente é um modelo mecânico de representação de blocos deformáveis e modelos de contato que especificam a interação entre os primeiros. Utilizam-se uma lei constitutiva viscoelástica para o comportamento linear e outra viscoelastoplástica para o comportamento não-linear dos blocos e contatos, em

2 MAZARS, J. (1986). A description of micro- and macroscale damage of concrete structures. Engineering Fracture Mechanics, n. 25, p. 729-37 apud ANTHOINE (1997). 
conjunto com uma descrição lagrangiana atualizada. Permite-se a simulação de grandes deslocamentos.

No trabalho divulgado apresentou-se a formulação do método proposto e discutiram-se alguns resultados numéricos, tanto para ações estáticas quanto dinâmicas. A necessidade de ensaios experimentais para a avaliação dos parâmetros constitutivos de blocos e contatos foi ressaltada, antes da análise de grandes estruturas em alvenaria.

\subsection{ENSAIOS DE ALVENARIA EM ESCALA REDUZIDA}

Experimentos em laboratório utilizando modelos em escala reduzida têm-se mostrado há muitos anos como uma técnica bastante eficiente para o estudo das estruturas. Além de produzir bons resultados, esta técnica apresenta algumas vantagens sobre os ensaios de protótipos, uma vez que requer equipamentos de menor porte e gera economia de materiais e de espaço.

Embora ensaios em escala reduzida tenham sido largamente utilizados em problemas não-lineares de estruturas em concreto armado e protendido, sua aplicação ao estudo de edifícios em alvenaria é relativamente recente. A primeira tentativa divulgada para o meio científico foi empreendida por VOGT ${ }^{3}$ apud ABBOUD et al. (1990), em que se modelou a alvenaria de tijolos nas escalas 1:4 e 1:10. Seu caráter foi apenas exploratório, não conduzindo a resultados aplicáveis na prática.

Desde então diversas outras pesquisas foram desenvolvidas, das quais obtiveram-se melhores resultados. A capacidade de realização de ensaios mais eficientes deveu-se ao aprimoramento dos equipamentos, da instrumentação e da produção de blocos e tijolos em escala reduzida. ABBOUD et al. (1990) citaram vários trabalhos publicados, englobando temas como comportamento de pilares e de paredes, edifícios submetidos a ações horizontais e interação de painéis de alvenaria com pórticos de concreto. A técnica de modelagem da alvenaria em escala reduzida também foi aplicada com sucesso no estudo dos efeitos de abalos sísmicos (CHEN \& SHAH, 1988; TOMAZEVIC \& VELECHOVSKY, 1992) e nos problemas de pontes em arcos de alvenaria (ROYLES \& HENDRY, 1991; HOGG \& CHOO, 2000).

Uma das principais conclusões, comum a todos os pesquisadores citados, é a afirmação de que modelos podem ser efetivamente utilizados com êxito para a previsão do comportamento das estruturas em alvenaria. Contudo, para que este fato seja garantido, torna-se necessária uma prévia verificação se elementos simples construídos com os materiais em escala reduzida reproduzem os modos de ruptura observados na escala real. 
Outra afirmação comum nesses trabalhos é que a correlação entre modelo e protótipo é complexa. Ou seja, não se sabe ao certo como aplicar à escala real os resultados numéricos obtidos com os modelos. $\mathrm{O}$ fator de escala e as diferenças quanto às propriedades dos materiais são as principais dificuldades nessa extrapolação. Todavia, ROYLES \& HENDRY (1991) conseguiram obter uma correlação, que classificaram como satisfatória, para a carga máxima de pontes em arco.

Com o objetivo de tornar prescindível a análise experimental de pontes em arco de alvenaria por meio de ensaios em escala real, HOGG \& CHOO (2000) fizeram um estudo analítico do efeito de escala envolvido nesses casos. Os resultados mostraram ser possível prever a carga de ruptura de estruturas reais usando modelos reduzidos. Entretanto, não foi possível prever com precisão as flechas.

Afirmou-se que "a necessidade de calibrar métodos de análise permanecerá quando se pretender prever precisamente o comportamento de estruturas em escala real". Contudo, sugeriu-se que, "onde se requer técnicas analíticas para prever a carga de ruptura de estruturas em arco de alvenaria, ensaios em escala reduzida, em vez de em escala real, poderiam ser usados para essa calibração".

PAGE (1978) realizou diversos ensaios em laboratório para dar respaldo ao seu modelo analítico proposto e obter os valores dos parâmetros da alvenaria. Os ensaios foram realizados em escala reduzida de 1:2 com o objetivo de reduzir a capacidade requerida aos equipamentos. Não houve preocupação com os efeitos de escala, pois os resultados foram utilizados apenas para aferir um modelo analítico, com o qual foram realizadas análises numéricas de painéis também em escala 1:2. Esses efeitos tornar-se-iam significantes se o modelo analítico derivado em escala reduzida fosse usado para prever o comportamento da alvenaria em escala real. Nesse caso, os parâmetros deveriam ser obtidos a partir de ensaios em escala real.

Por conveniência a programação dos ensaios foi feita em ciclos de 7 dias. Justificou-se esse procedimento pelo fato da resistência à compressão da alvenaria desenvolver-se rapidamente, atingindo de $70 \%$ a $100 \%$ da resistência aos 28 dias em apenas 7 dias.

Os tijolos foram ensaiados em duas direções perpendiculares para a obtenção dos módulos de elasticidade e do coeficiente de Poisson. Pequenos painéis de alvenaria foram submetidos a ensaios de compressão uniaxial, inclusive com a carga aplicada a

\footnotetext{
${ }^{3}$ VOGT, H. (1956). Considerations and investigations on the basic principle of model tests in brickwork and masonry structures. Garston, Watford, Building Research Station. 30 p. (Library Communication n. 932) apud ABBOUD et al. (1990).
} 
ângulos variados em relação às juntas horizontais. Ensaios de tração uniaxial também foram realizados, utilizando conjuntos de dois tijolos unidos pela argamassa.

Os valores dos parâmetros elásticos foram determinados tomando médias dos resultados. Para a alvenaria foram construídos gráficos tensão-deformação. Os parâmetros da argamassa foram calculados em função dos demais, obtendo-se uma envoltória de ruptura das juntas.

Também com o intuito de validar modelos numéricos, HUGHES \& KITCHING (2000) empreenderam ensaios em escala reduzida. Todavia, o programa experimental publicado foi realizado previamente, objetivando verificar a possibilidade da utilização da escala 1:6. Os ensaios mostraram-se necessários porque normalmente se utilizam apenas escalas maiores que essa.

Basicamente foram ensaiados prismas de três tijolos à compressão, variando a configuração das juntas. Ensaios correspondentes em escala real foram utilizados para comparação. Observou-se que os modos de ruptura foram semelhantes, inferindo-se que os modelos reduzidos são capazes de reproduzir as principais características do comportamento resistente dos protótipos, mesmo variando o parâmetro adotado.

Verificaram ainda que o módulo de elasticidade da alvenaria em escala 1:6 apresentou um valor igual a cerca de 50\% do correspondente em escala real. Conclusão semelhante foi divulgada por EGERMAN ${ }^{4}$ et al. apud CAMACHO (1995). Nesse estudo observou-se que a relação módulo de elasticidade/resistência à compressão diminui conforme se reduz a escala.

No Brasil, pode-se citar o trabalho desenvolvido por CAMACHO (1995). Pesquisou-se a possibilidade da utilização de ensaios de blocos cerâmicos em escala reduzida para o estudo do comportamento da alvenaria estrutural cerâmica da forma como é feita no país. Realizaram-se ensaios de blocos, prismas e paredinhas à compressão. Também foram ensaiados prismas grauteados e prismas submetidos a carregamento lento e a ensaios de fluência. Aplicaram-se as escalas 1:3 e 1:5, cujos resultados foram confrontados com os de protótipos. Adicionalmente, torres nas duas escalas reduzidas foram construídas e ensaiadas. Adotaram-se como parâmetros de comparação as resistências à compressão, as deformações e os modos de ruptura apresentados pelos corpos-de-prova.

Em resumo, uma de suas conclusões foi "que o estudo do comportamento da alvenaria estrutural de blocos cerâmicos pode ser conduzido através de ensaios com modelos físicos reduzidos", seja ela grauteada ou não.

4 EGERMAN, R. et al. (1991). An investigation into the behaviour of scale-model brick walls. In: INTERNATIONAL BRICK/BLOCK MASONRY CONFERENCE, 9., Berlin, 1991. Proceedings. p. 628-35 apud CAMACHO (1995). 
Além disso, CAMACHO (1995) verificou que a granulometria da areia utilizada na argamassa não influencia nos resultados, sendo desnecessários, portanto, maiores cuidados com relação a essa variável. Contudo, alguns pesquisadores citados anteriormente, embora não controlem completamente a granulometria da areia, descartam os grãos maiores por meio de peneiramento. Essa providência visa a viabilizar a confecção de juntas de pequena espessura. Porém não há consenso quanto à dimensão máxima dos grãos para cada escala.

\subsection{RESISTÊNCIA AO CISALHAMENTO DA JUNTA DE ARGAMASSA}

As características da junta de argamassa foram apontadas em diversas pesquisas como bastante importantes para a modelagem da alvenaria. Em especial para o sistema parede-viga, torna-se interessante a determinação da resistência ao cisalhamento da junta que une as duas partes do sistema.

Vários fatores interferem na resistência ao cisalhamento das juntas, como tipo de unidade e de argamassa. Como os materiais componentes da alvenaria são muito diversificados, variando também conforme a região, a pesquisa em busca da padronização de ensaios de simples execução tem sido constante (DRYSDALE et al., 1979; GHAZALI \& RIDDINGTON, 1988; RIDDINGTON \& JUKES, 1994; OLIARI \& DUARTE, 2000).

Porém, quando as variáveis referentes ao material estão previamente definidas, o parâmetro mais importante passa a ser a pré-compressão aplicada à alvenaria. Até um nível de pré-compressão $\left(\sigma_{\mathrm{c}}\right)$ de $2 \mathrm{MPa}$, a resistência ao cisalhamento $\left(\tau_{\mathrm{u}}\right)$ das juntas pode ser dada por uma expressão do tipo Coulomb, da seguinte forma:

$$
\tau_{\mathrm{u}}=\tau_{0}+\mu \sigma_{\mathrm{c}}
$$

em que $\tau_{0}$ é a resistência ao cisalhamento na ausência de pré-compressão, e $\mu$ é o coeficiente de atrito interno (curva A da Figura 2.6). De acordo com DRYSDALE et al. (1979) e ROMAN (1991), para altos níveis de pré-compressão sua relação com a resistência ao cisalhamento passa a ser não-linear.

Por sua vez, RIDDINGTON \& GHAZALI (1990) observaram que a razão de crescimento da resistência ao cisalhamento começa a se reduzir para altos níveis de précompressão, notadamente após valores em torno de $2 \mathrm{MPa}$, de acordo com a curva $\mathrm{B}$ da Figura 2.6. Concluiu-se que a partir daí a ruptura deixa de ser governada pelo deslizamento na junta, passando a se iniciar por ruptura à tração na argamassa. Quando as tensões de compressão atingem valores muito altos, a ruptura acontece por compressão da alvenaria. $\mathrm{Na}$ figura seguinte apresenta-se um esboço do critério de ruptura das juntas, contemplando os três tipos de ruptura. 


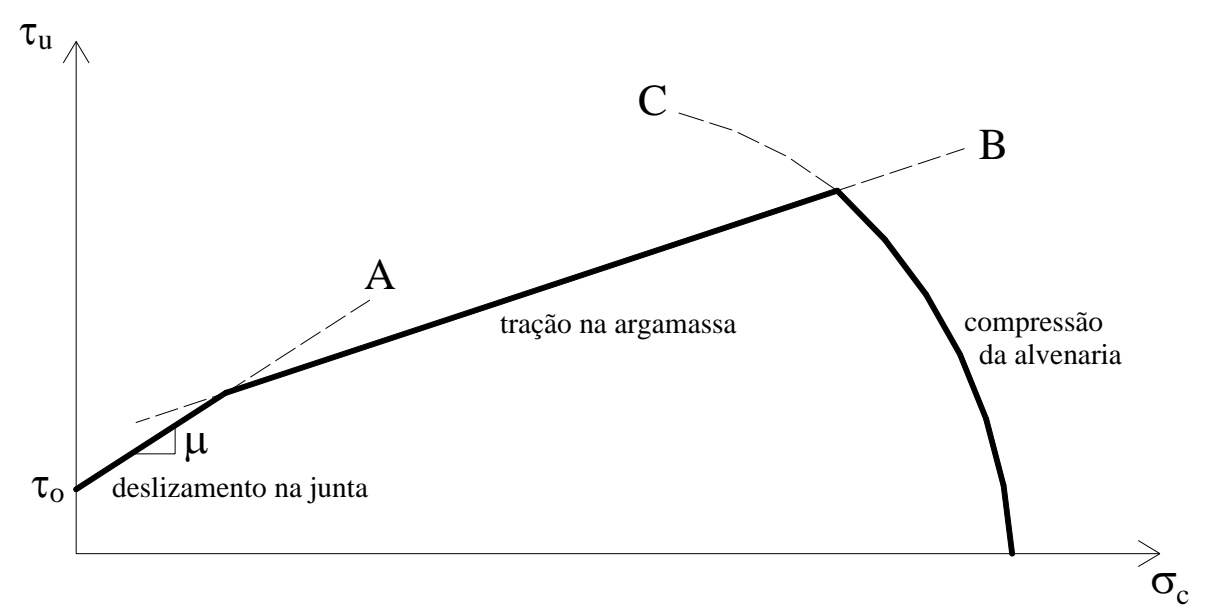

Figura 2.6 Critério de ruptura das juntas.

JUKES \& RIDDINGTON (1997) compararam diversos tipos de ensaios para a determinação dos parâmetros da equação linear acima, com o respaldo de análises numéricas empreendidas por RIDDINGTON et al. (1997). Realizaram-se análises elásticas lineares por meio do método dos elementos finitos com o emprego do processador ANSYS. Foram utilizados os seguintes critérios para a comparação dos ensaios:

- A uniformidade das tensões normais e de cisalhamento ao longo do comprimento da junta;

- O comprimento da junta próximo à ruptura quando esta se inicia num ponto;

- O surgimento de tensões de tração perpendiculares à junta, que poderiam influenciar a carga de ruptura;

- A posição ao longo da junta do ponto onde a ruptura teve início;

- A dificuldade de realização do ensaio, com respeito ao tipo de corpo-de-prova e do aparato necessário.

Concluiu-se que, embora ainda não se tenha conhecimento de um ensaio ideal, o que melhor atendeu aos critérios apresentados foi o ensaio de tripletas de acordo com o esquema da Figura 2.7. Resultados já obtidos com esse tipo de ensaio mostraram-se bastante consistentes, especialmente com relação ao ângulo de atrito interno. Por sua vez, afirmou-se que o valor real de $\tau_{0}$ é cerca de $50 \%$ maior que o calculado com valores médios da tensão de cisalhamento obtidos no ensaio de tripletas. 


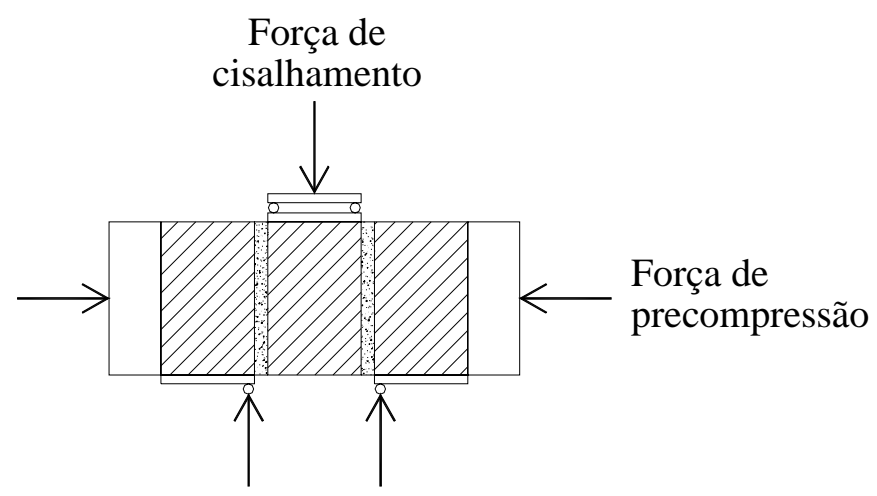

Figura 2.7 Esquema do ensaio de cisalhamento usando tripletas.

Com base nessas indicações, OLIARI \& DUARTE (2000) realizaram uma série de ensaios desse tipo para verificar sua eficiência. Concluíram que "se trata de um método que apresenta relativa simplicidade e utiliza espécimes de fácil construção, mostrando-se capaz de fornecer resultados consistentes". Dessa forma, recomendaram seu uso para aferir o desempenho das alvenarias frente às solicitações de cisalhamento, salientando a necessidade de correlacionar os resultados dos corpos-de-prova com os de paredes reais. Além disso, assim como os demais pesquisadores citados, relataram que os valores experimentais são superiores aos sugeridos pelas normas vigentes.

Devido à dificuldade de realização do ensaio de tripletas com pré-compressão, GHAZALI \& RIDDINGTON (1988) apresentaram um novo método para a obtenção da constante $\mu$. Embora ele seja bastante eficaz para o caso de tripletas confeccionadas com tijolos comuns, RIDDINGTON \& JUKES (1994) desaconselharam seu uso com blocos, uma vez que os espécimes assim constituídos são frágeis.

\subsection{CONSIDERAÇÕES FINAIS}

Os conhecimentos adquiridos com a revisão bibliográfica serviram como embasamento teórico deste trabalho. Diversos conceitos foram aplicados no decorrer da pesquisa. A seguir se apresenta uma súmula das principais informações encontradas.

A fissuração é uma das causas mais freqüentes de falha de desempenho da alvenaria. Vários fatores distintos podem induzir a formação das fissuras. Dentre eles, os recalques são classificados como um tipo de ação externa. Normalmente as fissuras provocadas por recalques são verticais ou diagonais, apresentando variação da abertura ao longo do comprimento.

Em geral, a fissuração provocada pela ação de recalques constitui danos arquitetônicos e funcionais, mas não estruturais. Entretanto, deve-se ressaltar que em alguns casos, como o de paredes não-armadas em que os recalques provoquem uma configuração 
deformada da fundação com concavidade para baixo, pode haver colapso devido à falta de impedimento para a propagação das fissuras.

Nos trabalhos citados puderam ser colhidas algumas recomendações com o objetivo de evitar a ocorrência de fissuração da alvenaria. Foram sugeridos principalmente valores máximos de parâmetros considerados importantes, como os de estimativa da curvatura da fundação. Na tabela seguinte apresenta-se um resumo dessas recomendações.

Tabela 2.2 Recomendações de valores limites para evitar fissuração.

\begin{tabular}{lccc}
\hline REFERÊNCIA & $\delta / \ell$ & $\Delta / \mathrm{L}$ & TENSÃO DE TRAÇÃO \\
\hline Meyerhof (1953) & - & $1 / 2000$ & $0,21 \mathrm{MPa}$ \\
Skempton \& MacDonald (1956) & $1 / 300$ & - & - \\
Polshin \& Tokar (1957) & - & 0,0003 a 0,0007 & - \\
Grant et al. (1974) & $1 / 300$ & - & - \\
Komornik \& Mazurik (1977) & - & $1 / 1000$ & - \\
Beranek (1987) & - & - & 0,1 a $0,3 \mathrm{MPa}$ \\
Thomaz (1998b) & $1 / 300$ & - & - \\
\hline
\end{tabular}

Observa-se que não há consenso quanto ao valor limite do parâmetro de curvatura $\Delta / L$, que varia entre 1/1000 e 1/3333. Em contrapartida, há consenso absoluto com relação à rotação relativa $\delta / \ell$, existindo somente o valor $1 / 300$. Entretanto, deve-se ressaltar que este limite teve praticamente apenas uma origem.

Desta forma, não foi possível obter uma opinião conclusiva, de modo a se estabelecer um valor máximo de recalque a ser aplicado nas análises numéricas e experimentais desta pesquisa. Conforme será comentado adiante em outros capítulos, nas análises optou-se por aplicar recalque aos apoios até que sua reação fosse anulada.

Para fins de comparação com os resultados experimentais, adotou-se como recomendações da literatura o limite $\delta / \ell=1 / 300$ e o valor intermediário $\Delta / \mathrm{L}=1 / 2000$.

Tipicamente em casos de paredes sobre vigas deformáveis há a formação do efeito arco, desde que a altura da parede seja igual ou superior a $60 \%$ do vão livre e a resistência ao cisalhamento na interface parede-viga seja suficiente para evitar grandes deslizamentos. A rigidez relativa entre a parede e a viga é determinante para o grau de formação do efeito arco, que também é influenciado pela presença, tipo, tamanho e posição das aberturas.

Ao se formar o arco, as tensões verticais de compressão tendem a se concentrar nas regiões acima dos apoios e surgem concentrações de tensões de cisalhamento também nessas proximidades. Alguns procedimentos simplificados de análise foram apresentados para o caso de parede sobre viga biapoiada, porém sem comentários sobre a situação em que há apoios intermediários. 
Dentre as formas de representação numérica da alvenaria, pode-se considerar que a macro-modelagem é adequada para as análises numéricas desta pesquisa. Isto se justifica por se ter como objetivo a reprodução do comportamento global de painéis cujas dimensões são significativamente maiores que as de seus componentes e que a espessura das juntas. Da mesma forma, como a espessura dos painéis é pequena em relação às suas outras dimensões, o estado plano de tensão pode ser considerado.

Em casos de painéis constituídos de parede sobre viga, a não-linearidade de contato entre ambas pode exercer grande influência, especialmente quando a viga é submetida a grandes deformações. A avaliação da importância de consideração dessa nãolinearidade pode ser feita numericamente com o emprego de elementos de contato na região de interface. Nesse caso, torna-se necessária a validação experimental, uma vez que esse estudo não foi encontrado na literatura.

Ensaios em escala reduzida têm se mostrado bastante adequados para o estudo do comportamento das estruturas em geral. No caso da alvenaria, para que os resultados experimentais possam ser considerados como representativos de estruturas em escala real, afirma-se que é necessário fazer uma prévia avaliação. Esta avaliação consiste em verificar, por meio de ensaios, se elementos simples construídos com os materiais em escala reduzida reproduzem os modos de ruptura de seus correspondentes em escala real.

A correlação entre modelo e protótipo é complexa, devido ao fator de escala e às diferenças de propriedades dos materiais. Para que se obtenha êxito nessa área, é imprescindível a realização de diversos ensaios correlatos nas escalas reduzida e real, que possam respaldar os fatores de conversão.

Em contrapartida, ensaios em escala reduzida podem ser diretamente utilizados para a validação de modelos numéricos, desde que as propriedades dos materiais tenham sido obtidas experimentalmente com os mesmos materiais, na mesma escala.

Para possibilitar a confecção das juntas de pequena espessura da alvenaria em escala reduzida, a maioria dos autores descartou os maiores grãos de areia por meio de peneiramento. Contudo, não se fez menção ao controle da composição granulométrica, tampouco há consenso quanto à dimensão máxima dos grãos para cada escala.

A resistência à compressão da alvenaria desenvolve-se rapidamente, o que possibilita a realização de ensaios a partir de sete dias após a construção dos elementos. Recomenda-se como boa prática a comprovação prévia desta afirmação a partir de ensaios de elementos simples, como prismas.

Verificou-se que na presente pesquisa é importante caracterizar a junta da interface entre parede e viga para a correta representação da região de contato. O critério de 
ruptura das juntas, quando submetidas a tensões de compressão e de cisalhamento, é definido por três tipos possíveis de ruptura: deslizamento na junta, tração na argamassa e compressão da alvenaria.

As curvas dos dois primeiros tipos podem ser obtidas a partir do ensaio de cisalhamento de tripletas. Neste trabalho as tripletas foram confeccionadas com um bloco cerâmico no meio de duas peças maciças do mesmo concreto das vigas. Desta forma obtiveram-se as propriedades da junta da interface parede-viga. 


\section{ESTUDO EXPERIMENTAL}

A preparação e a programação dos ensaios dos modelos físicos de painéis são apresentadas neste capítulo. Inicia-se com a análise numérica preliminar empreendida, que forneceu subsídios para o detalhamento do programa de ensaios. Em seguida descreve-se todo o programa experimental, incluindo os procedimentos para a realização dos ensaios. Finalmente é apresentada a caracterização dos materiais empregados.

\subsection{INVESTIGAÇÃO NUMÉRICA PRELIMINAR}

Diversas análises numéricas foram realizadas com o auxílio do programa ANSYS. Nesta seção apresentam-se sucintamente os principais resultados e conclusões dessas investigações. Como objetivos específicos desta etapa da pesquisa citam-se:

- Selecionar a melhor forma de modelagem, buscando um modelo numérico simples;

- Verificar previamente o comportamento do sistema estudado;

- Avaliar os efeitos dos recalques nas paredes de alvenaria;

- Distinguir os principais parâmetros a serem observados nos ensaios em laboratório;

- Estabelecer alguns casos para serem ensaiados.

\subsubsection{Modelo numérico}

Com base na revisão da literatura sobre o tema, examinou-se a possibilidade de representação do sistema parede-viga a partir de algumas modelagens distintas, tanto planas quanto tridimensionais. Optou-se por adotar uma modelagem em estado plano de tensão, utilizando elementos finitos quadrilaterais para a discretização da parede e elementos de barra para a representação da viga. Estes mesmos elementos foram utilizados com êxito por BARBOSA (2000).

O elemento plano possui quatro nós, com dois graus de liberdade por nó (translações nas direções $x$ e $y$ ). O elemento barra possui dois nós, com três graus de liberdade por nó (translações nas direções $x$ e $y$ e rotação em torno do eixo $z$ ). Dentro do programa ANSYS, esses elementos são respectivamente denominados PLANE42 e BEAM3.

Considerou-se importante também a modelagem da interface entre parede e viga, uma vez que há probabilidade de ocorrerem separações e deslizamentos nessa região. 
Dessa forma, foram utilizados os elementos de contato CONTA171 e TARGE169, que constituem o par mais adequado para a situação analisada. As separações entre as superfícies de contato são controladas pelo coeficiente de rigidez normal, enquanto que os deslizamentos dependem do coeficiente de atrito entre parede e viga e da tensão de cisalhamento máxima da região. Maiores detalhes sobre os elementos de contato podem ser encontrados em BARBOSA (2000) e ANSYS RELEASE 5.5.1 (1998).

Modelou-se uma parede de alvenaria com $2,6 \mathrm{~m}$ de altura e $8,0 \mathrm{~m}$ de comprimento sobre uma viga de concreto com três apoios discretos, conforme a Figura 3.1. Devido às grandes dimensões do painel com relação à espessura das juntas (normalmente $1 \mathrm{~cm}$ ), optou-se por aplicar a macro-modelagem. Além disso, este tipo de representação mostrou-se adequado para alcançar os objetivos visados.
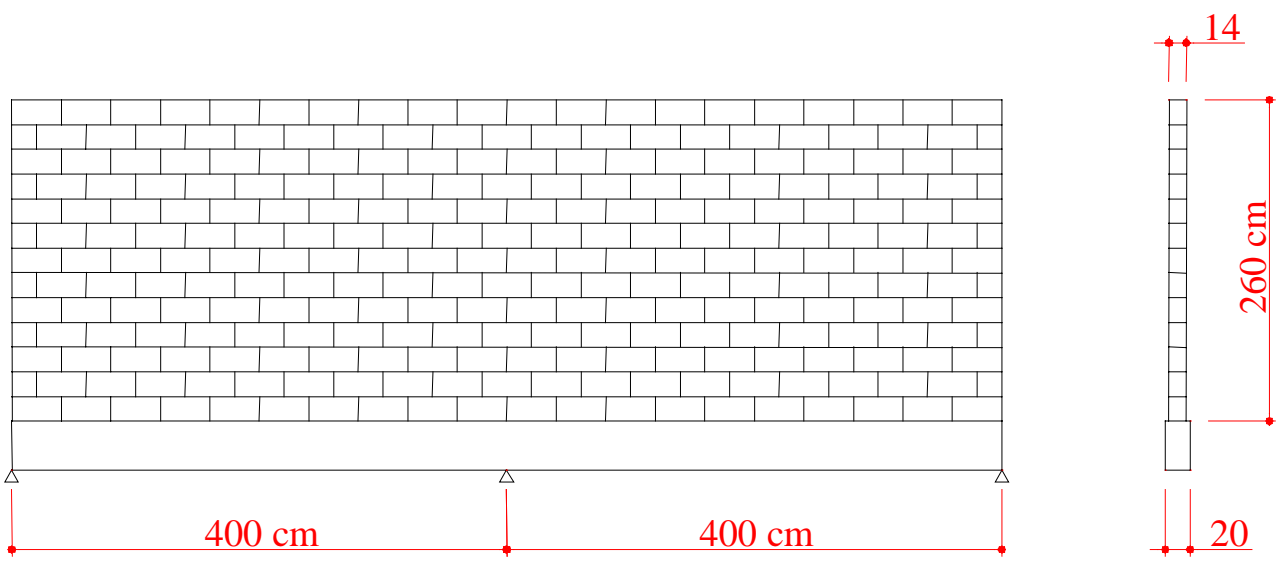

Figura 3.1 Painel adotado nas análises numéricas.

Os materiais alvenaria e concreto foram considerados elásticos, lineares e isotrópicos. As suas propriedades foram estimadas com base nas normas NBR 10837 (1989), BS 5628 (1992) e NBR 6118 (2000). Na Tabela 3.1 encontram-se os valores empregados.

Tabela 3.1 Propriedades dos materiais.

\begin{tabular}{lcc}
\hline \multicolumn{1}{c}{ PARÂMETRO } & VALOR & REFERÊNCIA \\
\hline ALVENARIA & & \\
Módulo de elasticidade $\left(\mathrm{E}_{\text {alv }}\right)$ & $384 \mathrm{kN} / \mathrm{cm}^{2}$ & NBR 10837 (1989) \\
Coeficiente de Poisson $\left(v_{\text {alv }}\right)$ & 0,2 & Valor adotado \\
\hline CONTATO & 0,6 & BS $5628(1992)$ \\
Coeficiente de atrito $(\mu)$ & $0,175 \mathrm{kN} / \mathrm{cm}^{2}$ & BS $5628(1992)$ \\
Tensão máxima de cisalhamento $\left(\tau_{\text {máx }}\right)$ & & \\
\hline VIGA & $2380 \mathrm{kN} / \mathrm{cm}^{2}$ & NBR 6118 (2000) \\
Módulo de elasticidade $\left(\mathrm{E}_{\mathrm{c}}\right)$ & 0,2 & NBR 6118 (2000) \\
Coeficiente de Poisson $\left(v_{\mathrm{c}}\right)$ & &
\end{tabular}

Buscando representar um painel pertencente ao pavimento térreo de um edifício, aplicou-se um carregamento aproximadamente correspondente à tensão de 
compressão admissível, de acordo com a NBR 10837 (1989). Para esta análise, adotou-se um bloco com características mecânicas aproximadamente equivalentes às de blocos de concreto com resistência à compressão de $6 \mathrm{MPa}$. Assim, foi aplicada uma tensão uniformemente distribuída de 1 MPa no topo da parede.

O recalque foi simulado estabelecendo-se o deslocamento vertical dos apoios, após a etapa de carregamento do painel. Considerando a falta de consenso entre os pesquisadores quanto ao valor do recalque causador de danos na alvenaria, decidiu-se deixar o apoio deslocar-se até que sua reação fosse anulada. Duas simulações foram feitas: recalque do apoio central e recalque do apoio de extremidade.

Quatro tipos de painel, quanto à presença de aberturas, foram estudados: sem aberturas; com abertura de janela; com abertura de porta; com aberturas de porta e janela. Por simplicidade, as aberturas foram sempre posicionadas nos meios dos vãos.

\subsubsection{Dimensionamento da viga}

A viga foi dimensionada de duas maneiras. A primeira consistiu em se aplicar o carregamento distribuído diretamente sobre a viga, sem consideração da parede. Esta alternativa equivale à prática usual. A segunda maneira de cálculo dos esforços na viga considerou a presença da parede. Dessa forma, o carregamento da viga concentrou-se nas proximidades dos apoios, conforme discutido no item 2.3, diminuindo principalmente o momento fletor em relação à primeira maneira de carregamento. Como este esforço foi determinante para o dimensionamento da viga, suas dimensões puderam ser reduzidas consideravelmente. Adotando-se uma largura de $20 \mathrm{~cm}$, a altura necessária para os dois casos foi respectivamente de $70 \mathrm{~cm}$ e $40 \mathrm{~cm}$. A Figura 3.2 esquematiza a carga e o diagrama de momento da viga, bem como a seção transversal obtida. 


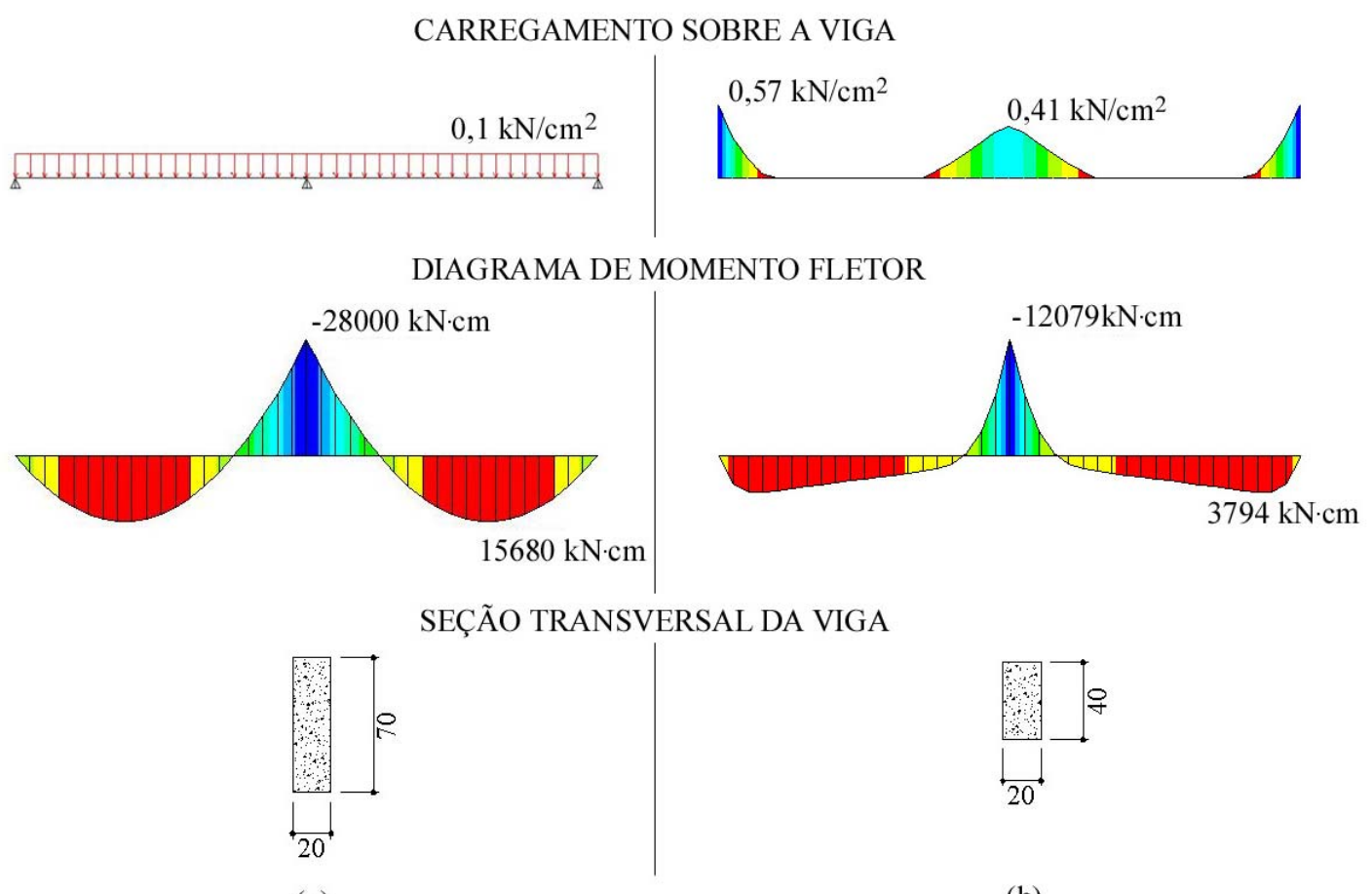

(a)

(b)

Figura 3.2 Dimensionamento da viga. (a) Carregamento uniformemente distribuído.

(b) Carregamento decorrente do efeito arco.

\subsubsection{Resultados}

Neste item será apresentada apenas uma análise qualitativa das tensões nos painéis, reservando-se uma análise mais completa dos seus valores para quando puder ser feita a comparação com resultados experimentais. Portanto, apresentam-se a seguir figuras correspondentes às paredes analisadas, contendo a representação vetorial das tensões principais. Os resultados correspondem ao caso da viga mais flexível, salientando-se que a rigidez da viga interfere nos valores dos esforços e deslocamentos, mas não nas suas configurações gerais.

Para cada caso de painel (com ou sem aberturas) e de recalque (central ou de extremidade), foram realizadas análises com e sem elementos de contato na interface paredeviga. Procura-se observar qual representação mostra-se mais adequada para o problema. Nas figuras seguintes verifica-se que há diferenças no fluxo das tensões e na magnitude dos esforços quando se utilizam ou não os elementos de contato.

Inicialmente apresentam-se os resultados para a situação dos apoios fixos. A coluna "a" da Figura 3.3 contém as representações obtidas com a modelagem utilizando elementos de contato para os quatro tipos de painel. A modelagem sem elementos de contato produziu os resultados da coluna "b". Fica evidente a concentração de tensões nas proximidades das aberturas. Além disso, com ambas as modelagens observa-se com clareza 
a formação do efeito arco. A viga trabalha então como tirante dos dois arcos que surgiram. Porém, quando se permite a separação entre a parede e a viga, aparecem tensões de tração na base da parede entre os apoios.

Outra diferença entre os resultados das modelagens pode ser verificada para os casos de painéis com abertura de porta. O deslizamento permitido pelos elementos de contato alterou a distribuição das tensões nos trechos entre a abertura e a borda do painel. Nesses trechos percebe-se uma distribuição praticamente uniforme das tensões verticais, em detrimento do arco ainda observado quando não se utilizam os elementos de contato.
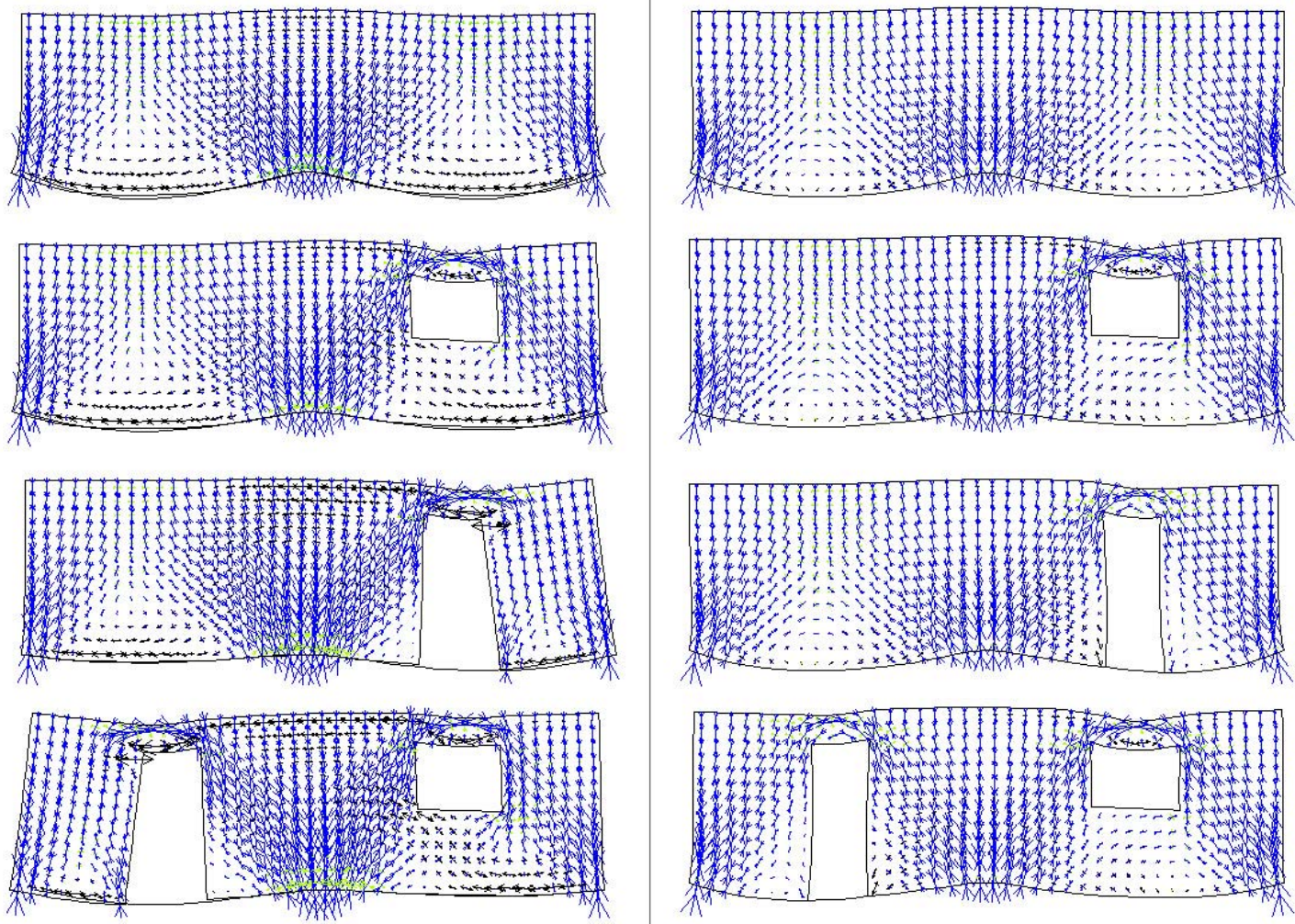

(a)

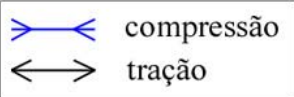

(b)

Figura 3.3 Representação vetorial das tensões principais: apoios fixos. Modelagens (a) com e (b) sem elementos de contato.

A Figura 3.4 apresenta as configurações de tensões dos mesmos painéis, desta vez referentes ao caso extremo de total retirada do apoio central. Neste caso o vão entre os apoios passa a ser o dobro daqueles da situação anterior. Como a relação altura/vão torna-se menor que 0,6 o arco não consegue se desenvolver completamente e o painel passa a atuar como uma viga-parede. Surgem então grandes tensões de cisalhamento próximo às extremidades da parede. 
Observa-se, ainda, o aparecimento de maiores tensões de tração na base da parede na modelagem com elementos de contato. Os cantos das aberturas tornam-se ainda mais solicitados do que no caso dos três apoios fixos.

O mesmo fato curioso com relação ao trecho da parede entre a abertura de porta e a extremidade do painel pode ser percebido aqui: as tensões verticais são praticamente uniformes quando se empregam os elementos de contato. Porém na modelagem sem elementos de contato surgem tensões de tração muito grandes entre a parede e a viga. Este fato é improvável, uma vez que a resistência à tração das juntas na direção perpendicular às mesmas é pequena.
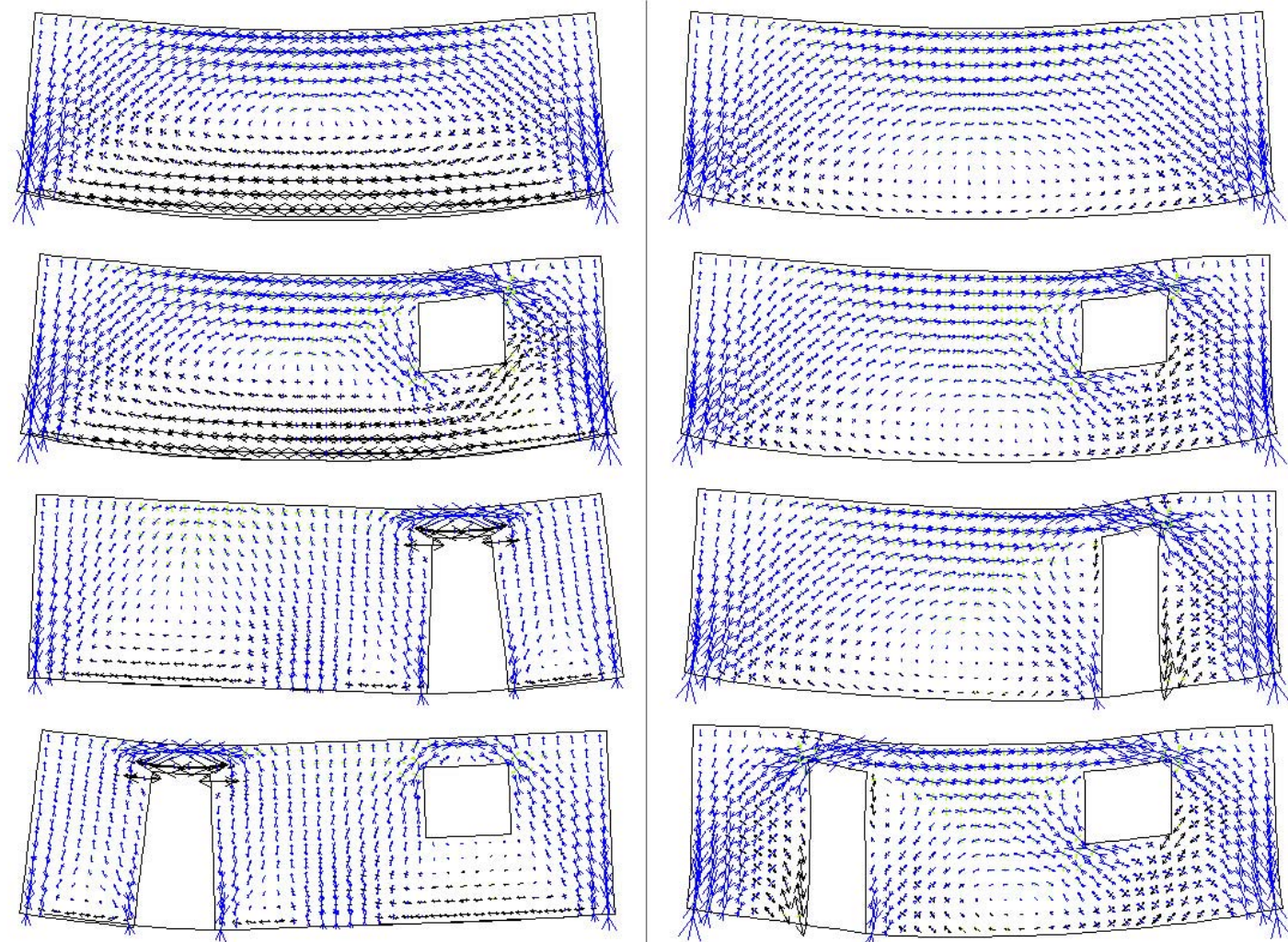

(a)

$$
\begin{aligned}
& ><\text { compressão } \\
& \longleftrightarrow \text { tração }
\end{aligned}
$$

Figura 3.4 Representação vetorial das tensões principais: apoio central retirado. Modelagens (a) com e (b) sem elementos de contato.

Conclusões semelhantes são aplicáveis ao caso de total retirada do apoio de extremidade, cujas ilustrações encontram-se na Figura 3.5. Verifica-se, contudo, que as tensões de compressão concentram-se no apoio central, enquanto surgem tensões de tração significantes na borda superior da parede. Além disso, percebe-se que os lintéis acima das aberturas tornam-se muito solicitados. 

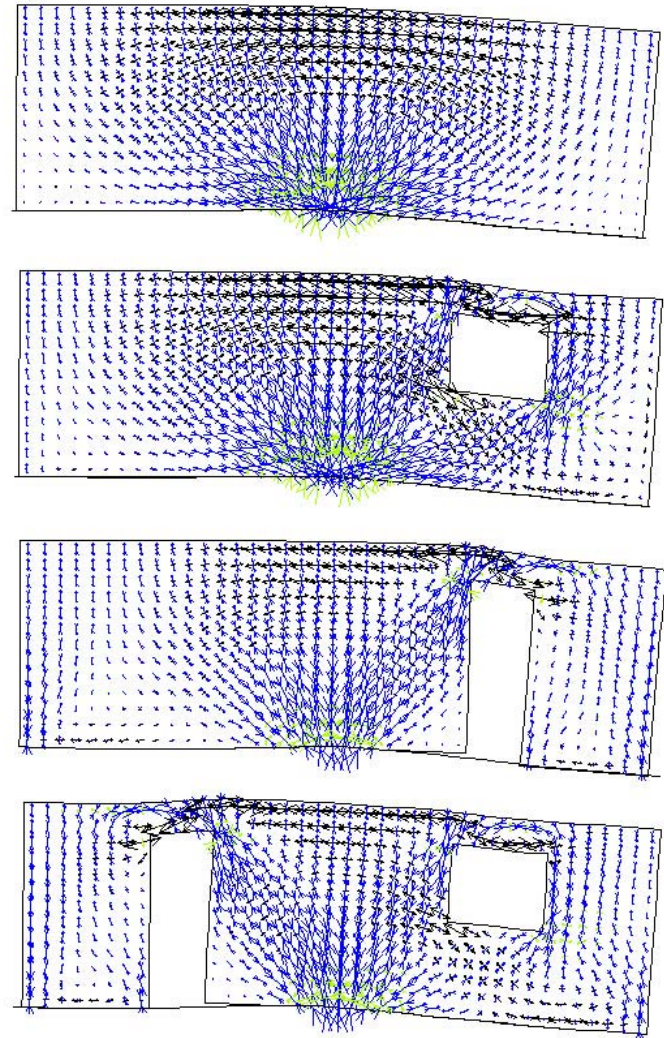

(a)
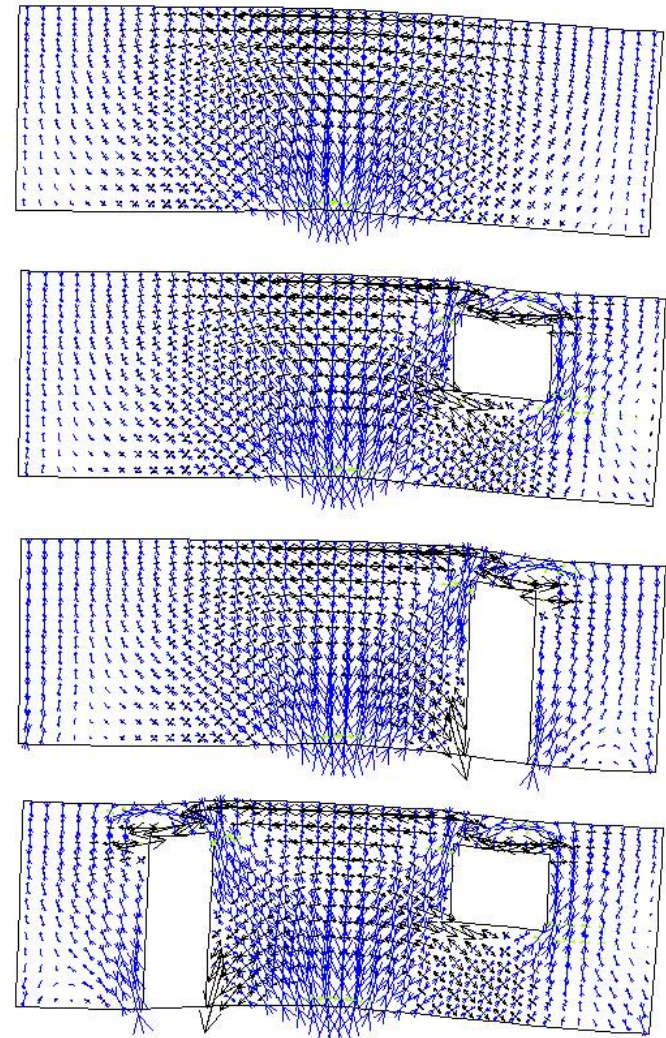

(b)

Figura 3.5 Representação vetorial das tensões principais: apoio extremo retirado. Modelagens (a) com e (b) sem elementos de contato.

As diferenças observadas comparando as modelagens com e sem elementos de contato justificam a instrumentação a ser aplicada na região da interface parede-viga nos ensaios em laboratório. É necessário verificar qual modelagem mostra-se mais adequada e, se for o caso, ajustar os parâmetros dos elementos de contato. Ilustram-se a seguir as separações e os deslizamentos entre parede e viga estimados nas análises numéricas com emprego dos elementos de contato. São apresentados na Figura 3.6 os resultados relativos ao painel sem aberturas para as três condições de apoio discutidas anteriormente. 


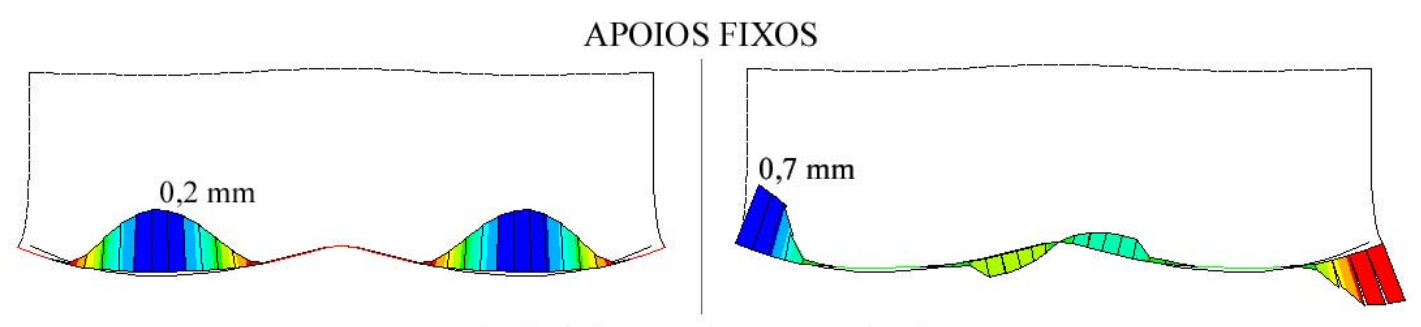

APOIO CENTRAL RETIRADO

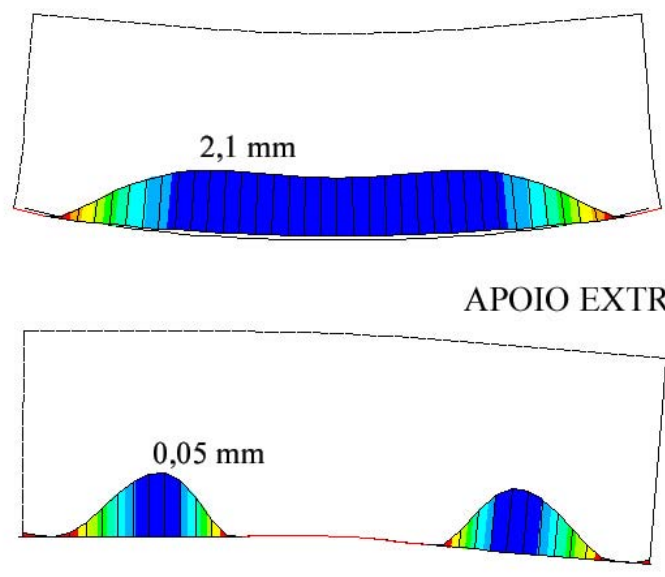

(a)
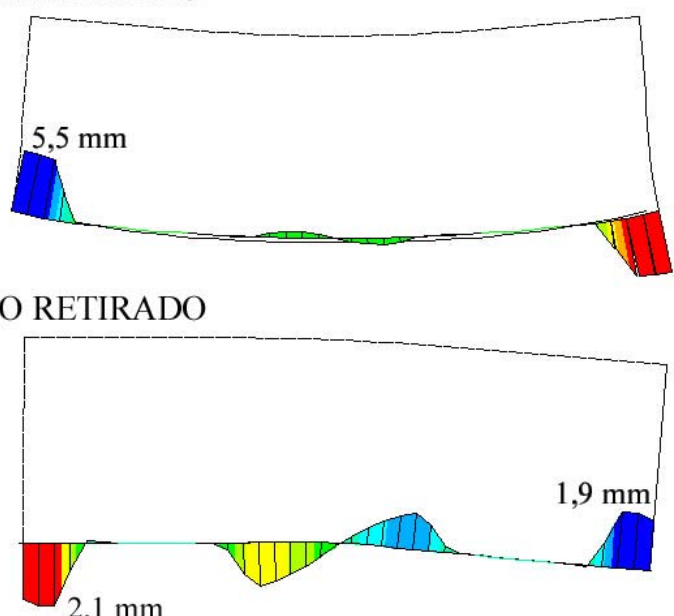

(b)

Figura 3.6 (a) Separações e (b) deslizamentos na região do contato.

\subsubsection{Considerações finais}

Com as análises numéricas realizadas, ratificou-se que a macro-modelagem é adequada para a observação do comportamento global de painéis e que a consideração de estado plano de tensão é razoável.

Observou-se também que há diferenças significativas entre os resultados das análises com e sem elementos de contato, especialmente na região inferior da parede e no pequeno trecho de parede que sofreu grandes deslizamentos quando da presença de porta. Dessa forma, torna-se necessária a verificação experimental da importância da nãolinearidade de contato, uma vez que não foram encontrados estudos conclusivos sobre este assunto específico.

Deve-se, portanto, instrumentar corretamente a região da interface parede-viga nos ensaios, de forma a serem obtidos resultados apropriados para a comparação com os resultados numéricos. Mais especificamente, é interessante obter medidas de deslizamentos, principalmente nas extremidades do painel, onde eles são geralmente maiores, medidas de penetrações e separações, na direção normal à interface, ao longo do comprimento do painel e medidas de variação da abertura de portas.

A colocação de instrumentos de medição de forma a captar o caminhamento das tensões no trecho de parede entre a abertura de porta e a borda do painel também pode 
auxiliar na verificação da importância da não-linearidade de contato, caso ocorram grandes deslizamentos entre parede e viga.

A realização de ensaios de painéis com aberturas torna-se interessante, uma vez que elas foram responsáveis por alterações no fluxo e pelo surgimento de concentrações de tensão. Decidiu-se por variar o tipo e a quantidade de aberturas por painel, de acordo com os modelos numéricos apresentados.

A adoção de três apoios discretos permite a verificação de duas situações distintas de recalques: deslocamento do apoio central e do apoio de extremidade. Assim torna-se possível também a observação do comportamento do painel nos dois principais casos de configuração deformada da fundação para paredes de alvenaria: concavidade para baixo e concavidade para cima.

\subsection{PROGRAMA EXPERIMENTAL}

O programa experimental empreendido compôs-se de ensaios de paredes de alvenaria sobre vigas. Desta maneira, buscou-se simular um painel pertencente ao primeiro pavimento de um edifício de alvenaria estrutural. A viga foi adotada como representação da estrutura de fundação ou do pilotis.

Todo esse sistema foi posicionado sobre três apoios discretos, regularmente espaçados, para que se pudesse simular duas configurações distintas de recalque: do apoio central e do apoio de extremidade. Para que isso fosse possível, estes apoios consistiram basicamente de cilindros hidráulicos, permitindo-se assim o deslocamento vertical nestas posições e seu devido controle. Esse deslocamento foi restringido no outro apoio de extremidade, o qual foi denominado como "apoio fixo".

Devido à concentração de tensões, tornou-se interessante o ensaio de painéis com aberturas. Também foi ensaiado um painel com viga mais rígida, a fim de que se verificasse a influência desse parâmetro e, conseqüentemente, do método de dimensionamento da viga de fundação.

Procurou-se aplicar um carregamento uniformemente distribuído no topo do painel, com intensidade equivalente a situações normais de serviço. A carga foi estimada segundo a norma brasileira NBR 10837 (1989), utilizando-se os valores obtidos com a caracterização dos materiais. Adotou-se, a partir desse procedimento, a aplicação de uma tensão de $2 \mathrm{MPa}$ nos trechos de parede. Para o cálculo da carga total foram descontadas as áreas correspondentes às aberturas, quando presentes. A carga assim determinada foi distribuída uniformemente no topo de cada painel.

Todos os ensaios foram realizados em escala reduzida (1:3) para viabilizar a sua execução com os equipamentos disponíveis e para que fossem minimizados os problemas 
relacionados a espaço, transporte e montagem. As paredes foram, portanto, construídas com blocos de dimensões reduzidas, especialmente desenvolvidos para esse fim. As dimensões máximas dos demais materiais, como as armaduras e os agregados miúdos e graúdos, também respeitaram a escala reduzida.

\subsubsection{Objetivos específicos do programa experimental}

A seguir citam-se os principais objetivos almejados na parte experimental desta pesquisa:

- Verificar experimentalmente o comportamento de painéis de alvenaria estrutural quando submetidos a recalques dos apoios;

- Verificar que valores máximos de recalque diferencial provocam início de fissuração na alvenaria, para comparação com valores obtidos da literatura;

- Validar as análises numéricas realizadas com o auxílio do programa computacional ANSYS, bem como calibrar os parâmetros do problema;

- Verificar a eficiência de uma possível minimização do problema, a partir da avaliação de alternativas de simples execução.

\subsubsection{Características gerais dos modelos}

Foram ensaiados sete modelos, agrupados em três séries, cujas características gerais e dimensões encontram-se na Tabela 3.2 e na Figura 3.7. Na mesma tabela cita-se a finalidade principal de cada modelo, onde se observa que as séries 1 e 2 correspondem aos ensaios para verificar o comportamento do sistema parede-viga quando submetido a recalques. A partir de seus resultados procurou-se atingir os três primeiros objetivos específicos da parte experimental desta pesquisa. O quarto objetivo induziu a inserção da Série 3, com a qual se buscou avaliar a eficácia de alternativas de simples execução na minimização dos efeitos dos recalques nos painéis.

Todas as paredes foram construídas com $180 \mathrm{~cm}$ de comprimento e $86,7 \mathrm{~cm}$ de altura. As dimensões das seções transversais das vigas variaram de acordo com a Tabela 3.2, porém mantendo-se todas com comprimento de $190 \mathrm{~cm}$, para permitir a colocação dos apoios de extremidade.

Por simplicidade, as aberturas foram posicionadas no meio dos vãos entre apoios. Obedeceu-se às dimensões usuais de portas e janelas utilizadas em edifícios de alvenaria estrutural ao se determinar as medidas reduzidas das aberturas. Em todos os modelos adotou-se o uso de vergas; a eficiência das contravergas para o combate à fissuração foi avaliada apenas no sétimo modelo. Devido à inexistência de blocos canaleta disponíveis para serem utilizados nos painéis da Série 2, as vergas e contravergas foram prémoldadas no próprio laboratório com concreto de maior resistência. Adotou-se alta taxa de 
armadura para as vergas $(3 \varnothing 6,3 \mathrm{~mm})$, pois a carga total seria distribuída uniformemente em toda a extensão do topo do painel.

Tabela 3.2 Características gerais dos modelos.

\begin{tabular}{cclcc}
\hline SÉRIE & MODELO & FINALIDADE & ABERTURA & $\begin{array}{c}\text { VIGA } \\
(\mathrm{cm})\end{array}$ \\
\hline \multirow{2}{*}{1} & 1 & $\begin{array}{l}\text { Verificação de comportamento } \\
\text { Ensaio piloto } \\
\text { Modelo básico para comparação }\end{array}$ & - & $8 \times 18$ \\
& 2 & Verificação de comportamento & Janela & $8 \times 18$ \\
2 & 3 & Verificação de comportamento & Porta & $8 \times 18$ \\
& 4 & Verificação de comportamento & Janela + porta & $8 \times 18$ \\
& 5 & Verificação de comportamento & - & $8 \times 22$ \\
\hline \multirow{2}{*}{3} & 6 & Avaliação de alternativa & - & $8 \times 18$ \\
& 7 & Avaliação de alternativa & Janela + porta & $8 \times 18$ \\
\hline
\end{tabular}
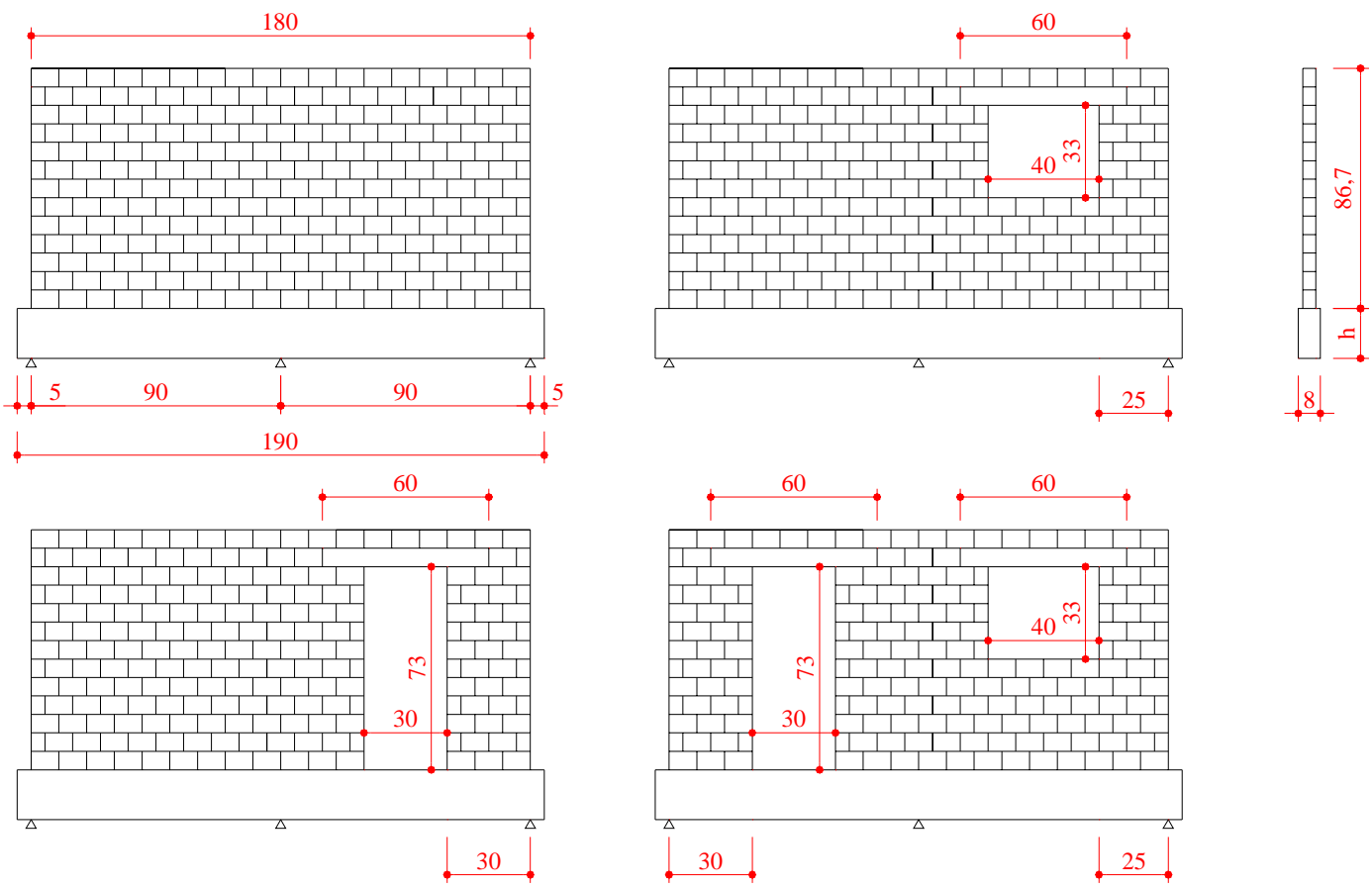

Figura 3.7 Dimensões dos modelos (cm).

\subsubsection{Tipologia e procedimentos gerais dos ensaios}

Com cada modelo foram realizados dois ensaios, ou seja, simulou-se recalque no apoio central e num apoio de extremidade, separadamente. A Figura 3.8 ilustra o procedimento, idêntico para todos os modelos, que é descrito a seguir. 


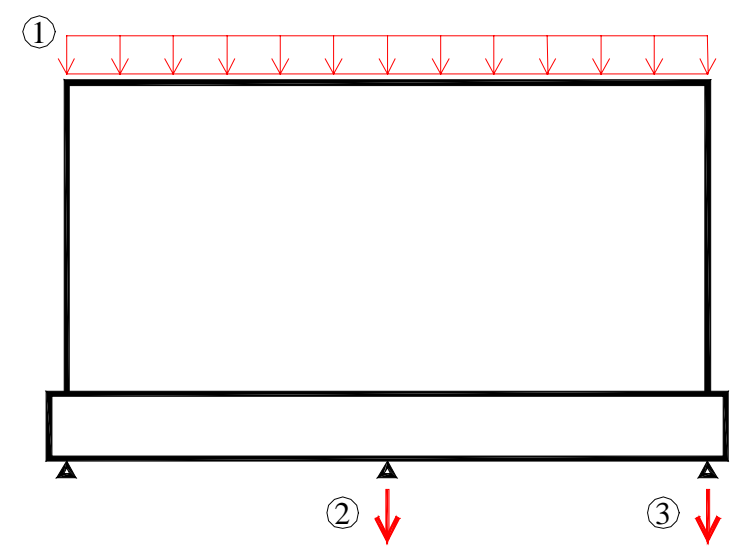

Figura 3.8 Ações aplicadas ao modelo.

- Inicialmente aplica-se o carregamento uniformemente distribuído (designado por (1) na Figura 3.8) no topo do painel, o qual é mantido constante durante todo o processo.

- Em seguida desloca-se verticalmente para baixo o apoio central até que sua reação seja anulada (2). Nesse instante o ensaio é paralisado e retorna-se o apoio à posição original.

- Mantendo o carregamento (1), repete-se o procedimento anterior deslocando-se o apoio da direita (3)).

Durante todo o processo são feitas algumas pausas para marcação de fissuras. Ressalta-se, ainda, que o ensaio de cada painel iniciou-se com a aplicação e retirada de $20 \%$ da carga total com o objetivo de acomodação do sistema.

Apresenta-se o esquema de ensaio na Figura 3.9. A carga total foi aplicada por meio de um atuador servo-controlado da marca Instron, com capacidade nominal de $500 \mathrm{kN}$. As intensidades variaram conforme a presença de aberturas, como mostra a Tabela 3.3. Utilizaram-se cilindros hidráulicos da marca Enerpac, com capacidade nominal de $300 \mathrm{kN}$, como apoios. Rosqueadas a eles foram instaladas células de carga para captar e controlar as reações de apoio. Bombas hidráulicas manuais foram utilizadas para aplicar os deslocamentos dos pistões. 


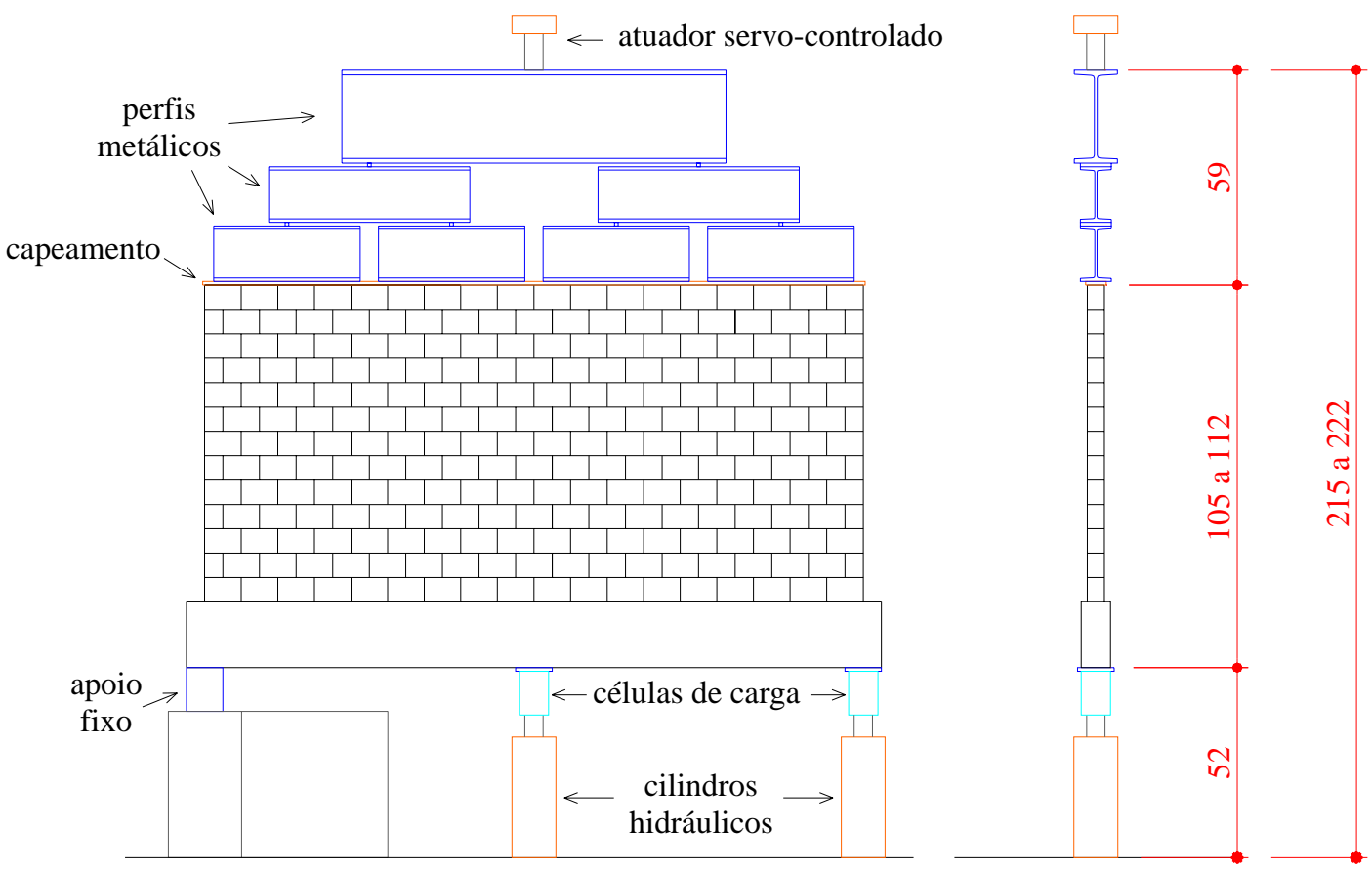

Figura 3.9 Esquema de ensaio (medidas aproximadas em $\mathrm{cm}$ ).

Tabela 3.3 Carga total aplicada aos modelos.

\begin{tabular}{|c|c|c|c|}
\hline \multicolumn{2}{|c|}{ MODELOS } & ABERTURA & $\begin{array}{c}\text { CARGA TOTAL } \\
(\mathrm{kN})\end{array}$ \\
\hline 1 & 6 & - & 167 \\
\hline \multicolumn{2}{|c|}{3} & Janela & 130 \\
\hline \multicolumn{2}{|c|}{4} & Porta & 139 \\
\hline 5 & 7 & Janela + porta & 102 \\
\hline
\end{tabular}

Cada ensaio envolveu três etapas de preparação: concretagem e cura da viga; construção das paredes sobre as vigas; e instrumentação e montagem do esquema de ensaio. As vigas ficaram em processo de cura em câmara úmida por no mínimo 6 dias. As paredes foram construídas por um mesmo pedreiro, sob supervisão e orientação dos pesquisadores. Nas datas dos ensaios, as idades mínimas do concreto e da alvenaria foram, respectivamente, 27 e 16 dias.

$\mathrm{Na}$ figura seguinte apresenta-se a fotografia de um ensaio montado, estando o painel já posicionado, com toda a instrumentação ligada ao sistema de aquisição de dados. 


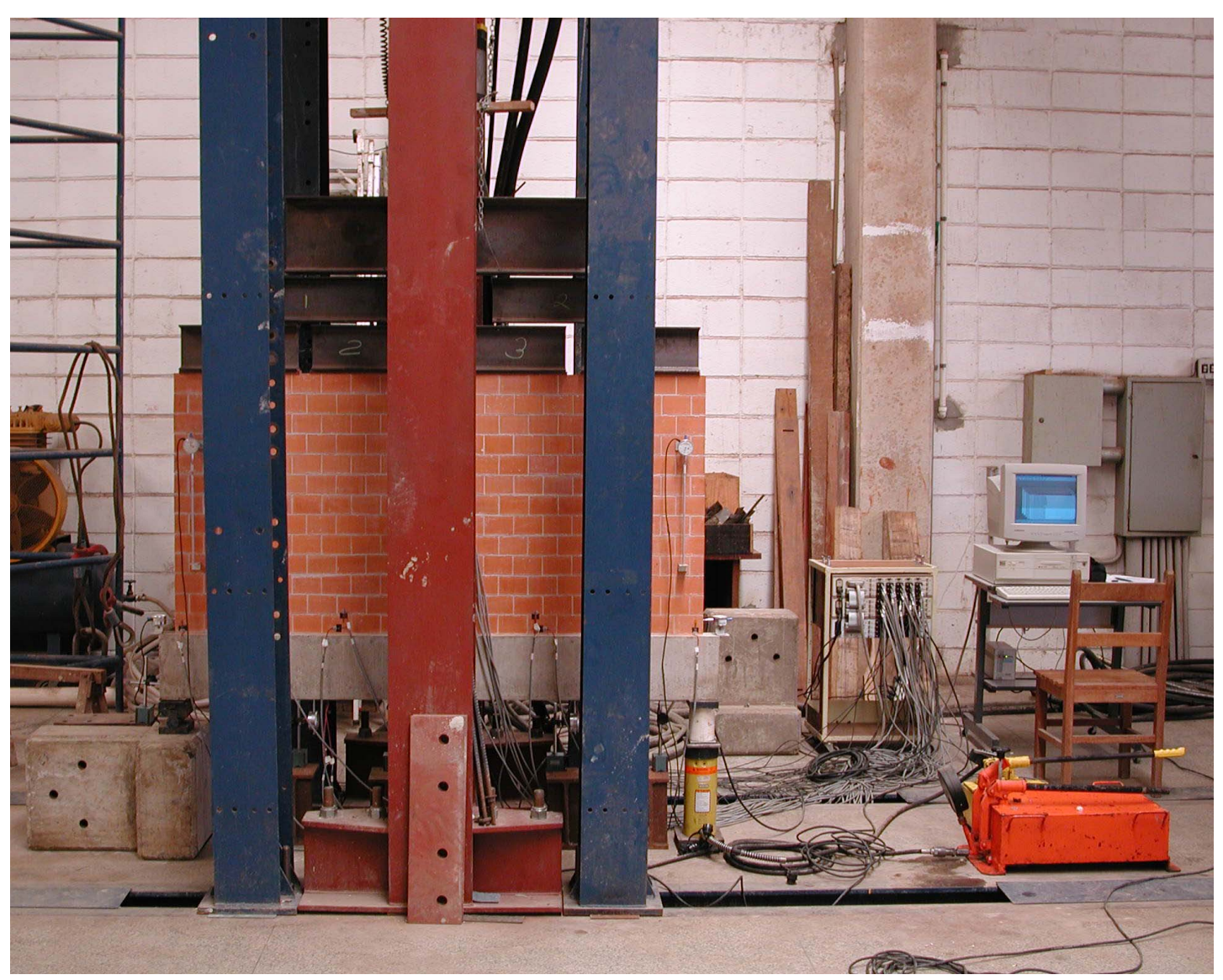

Figura 3.10 Fotografia de um ensaio preparado.

\subsubsection{Instrumentação}

Com base principalmente na investigação numérica preliminar foi determinada a instrumentação dos modelos. Buscou-se obter dados sobre a deformação da parede e da viga, e, em especial, sobre os deslocamentos entre ambas na interface. Atenção particular foi também dispensada às regiões próximas às aberturas, quando existentes, onde se procurou perceber o caminhamento e a intensidade das tensões desenvolvidas.

$\mathrm{Na}$ Tabela 3.4 discriminam-se os instrumentos de medição empregados em todos os ensaios, citando a utilização de cada um. A coleta e a gravação das leituras foi feita automaticamente por um sistema de aquisição de dados. 
Tabela 3.4 Instrumentos de medição utilizados.

\begin{tabular}{lll}
\hline INSTRUMENTO & CARACTERÍSTICA & FINALIDADE \\
\hline \multirow{2}{*}{$\begin{array}{l}\text { Transdutor de } \\
\text { deslocamento }\end{array}$} & $\begin{array}{l}\text { Curso: } 10 \mathrm{~mm} \\
\text { Sensibilidade: } 0,003 \mathrm{~mm}\end{array}$ & $\begin{array}{l}\text { Medição de deslocamentos relativos entre } \\
\text { pontos de referência na parede ou entre } \\
\text { parede e viga }\end{array}$ \\
\cline { 2 - 3 } & $\begin{array}{l}\text { Curso: } 20 \mathrm{~mm} \\
\text { Sensibilidade: } 0,005 \mathrm{~mm}\end{array}$ & $\begin{array}{l}\text { Medição dos deslocamentos verticais de } \\
\text { pontos de referência na viga }\end{array}$ \\
\cline { 2 - 3 } & $\begin{array}{l}\text { Curso: } 50 \mathrm{~mm} \\
\text { Sensibilidade: } 0,02 \mathrm{~mm}\end{array}$ & $\begin{array}{l}\text { Medição do deslocamento horizontal na } \\
\text { direção perpendicular ao painel para controle } \\
\text { da excentricidade lateral do carregamento }\end{array}$ \\
\hline $\begin{array}{l}\text { Extensômetro } \\
\text { elétrico uniaxial }\end{array}$ & Base: $10 \mathrm{~mm}$ & $\begin{array}{l}\text { Medição de deformações nos blocos } \\
\text { vigas e vergas }\end{array}$ \\
\hline
\end{tabular}

Nota: Todos os instrumentos são da marca Kyowa.

A Figura 3.11 ilustra a instrumentação do ensaio piloto, ou seja, Modelo 1. Os transdutores numerados de 1 a 6 foram colocados para controlar a deformação vertical da parede quando da aplicação da força vertical e para verificar os alívios e concentrações de tensões ao serem deslocados os apoios.

O acompanhamento dos deslocamentos na interface parede-viga foi realizado por meio dos transdutores 7 a 11. Para medir o deslizamento entre parede e viga colocaramse os transdutores 7 e 8 nas extremidades do painel, onde se esperavam os maiores deslocamentos relativos. Os três últimos, posicionados acima dos apoios, mediam as separações e as "penetrações". Vale ressaltar que o termo "penetração", importado da formulação do modelo de contato do programa computacional ANSYS, neste caso significa uma aproximação dos pontos de medida devido a uma deformação por compressão entre eles. Pontos acima dos apoios foram escolhidos por apresentarem as maiores penetrações na investigação numérica. Com as informações referentes a deslizamentos e penetrações entre parede e viga, almejou-se verificar que tipo de modelagem é mais adequado para essa região.

Para monitorar a deformação vertical da viga, utilizaram-se cinco transdutores, posicionados nos apoios e nos centros dos vãos. As leituras dos transdutores 14 e 16 correspondem aos deslocamentos verticais dos apoios móveis.

A armadura da viga foi instrumentada com pares de extensômetros colocados nas barras longitudinais externas. A partir das leituras dos extensômetros 1 e 2 verificou-se a ocorrência de tração ou compressão na parte superior da viga. Os demais extensômetros tinham como objetivo monitorar as deformações da armadura positiva. Perceberam-se assim as mudanças de sinal das deformações e suas magnitudes durante a aplicação dos recalques. 
Extensômetros na direção horizontal foram colados na linha média vertical da parede (9 a 15) e em alguns blocos da primeira fiada (15 a 18). Pretendia-se verificar o desenvolvimento de tensões horizontais de tração, especialmente na base da parede.

A primeira fiada também foi instrumentada com extensômetros na direção vertical (20 a 26), para que se avaliasse a transferência das tensões verticais da parede para a viga.
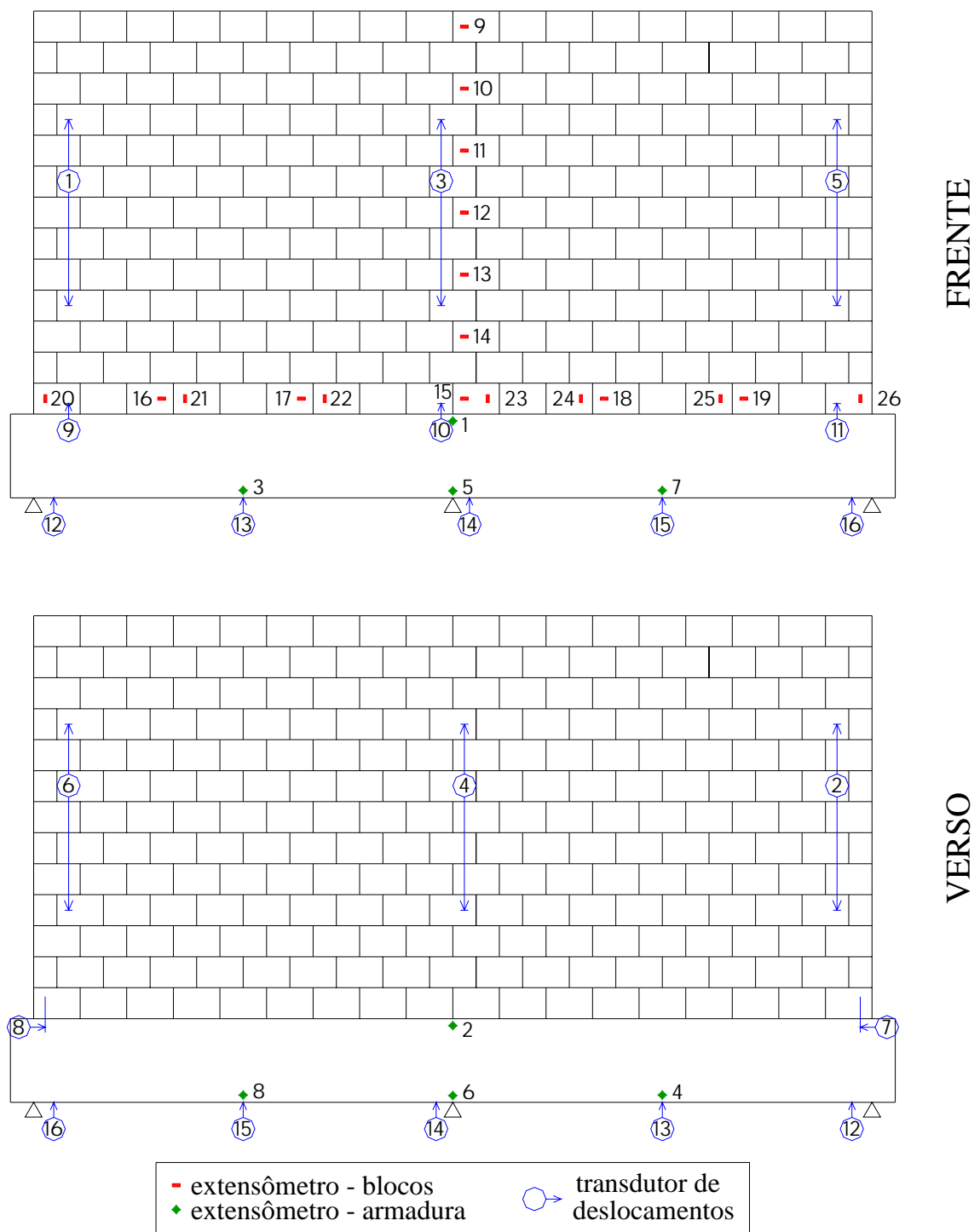

Figura 3.11 Instrumentação do Modelo 1.

Após o ensaio piloto alguns pontos de instrumentação sofreram uma pequena mudança para posições mais adequadas. Além disso, adicionaram-se dois transdutores de deslocamento nos meios dos vãos para captar dados referentes à separação entre parede e viga. Essas medidas se fizeram necessárias para uma melhor observação do comportamento da interface de contato. 
O Modelo 2, por possuir uma abertura de janela, foi instrumentado com mais dois extensômetros, posicionados na armadura da verga. Adicionalmente foram colocados dois transdutores em " $x$ " abaixo da janela para que se pudesse acompanhar a evolução das deformações nessa região onde se esperava grande concentração de tensões, conforme se verificou anteriormente nas análises numéricas. A Figura 3.12 apresenta como foi feita a instrumentação do segundo modelo.
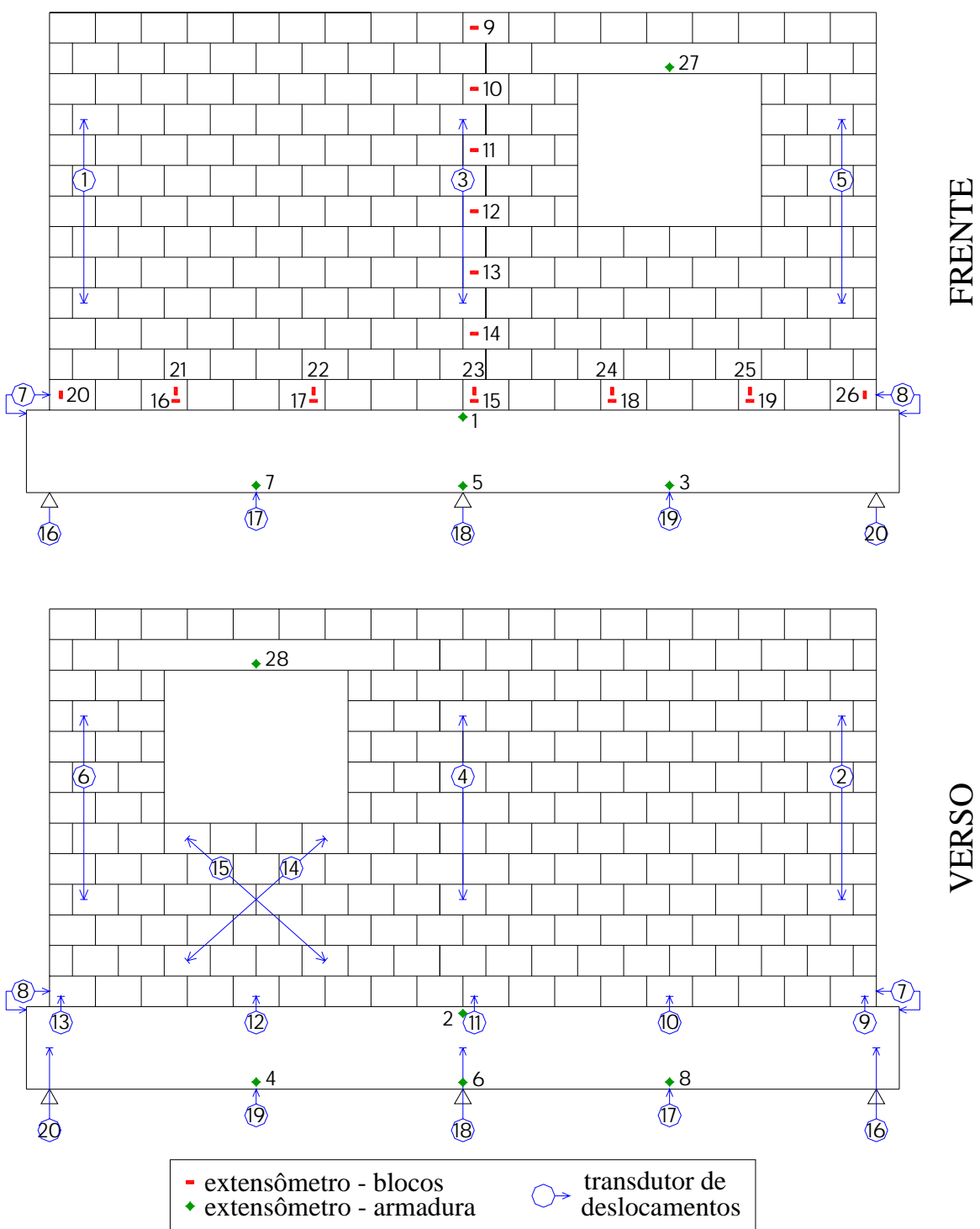

Figura 3.12 Instrumentação do Modelo 2.

Quando o modelo possui uma abertura de porta, verificou-se na investigação numérica preliminar uma sensível diferença de comportamento ao se comparar as análises com e sem elementos de contato. No primeiro tipo de modelagem, observou-se um grande deslizamento entre parede e viga no trecho entre a abertura e a borda do painel mais próxima. Nesse caso as tensões verticais nesse trecho de parede distribuíram-se de maneira 
bastante uniforme. Contudo, quando não se empregaram os elementos de contato na modelagem, observou-se a formação do arco no trecho em questão.

Portanto, com o objetivo de verificar experimentalmente o que realmente ocorre dentre as situações descritas, dois pares de transdutores foram posicionados ao lado da abertura, como ilustrado na Figura 3.13. Seguindo a numeração do Modelo 3, a idéia consiste basicamente em comparar as leituras dos transdutores 16 e 17. Se forem iguais, aconteceu o previsto pela modelagem com elementos de contato. Os transdutores 14 e 15 têm função semelhante, ou seja, foram utilizados para observar a ocorrência do arco do outro lado da abertura.
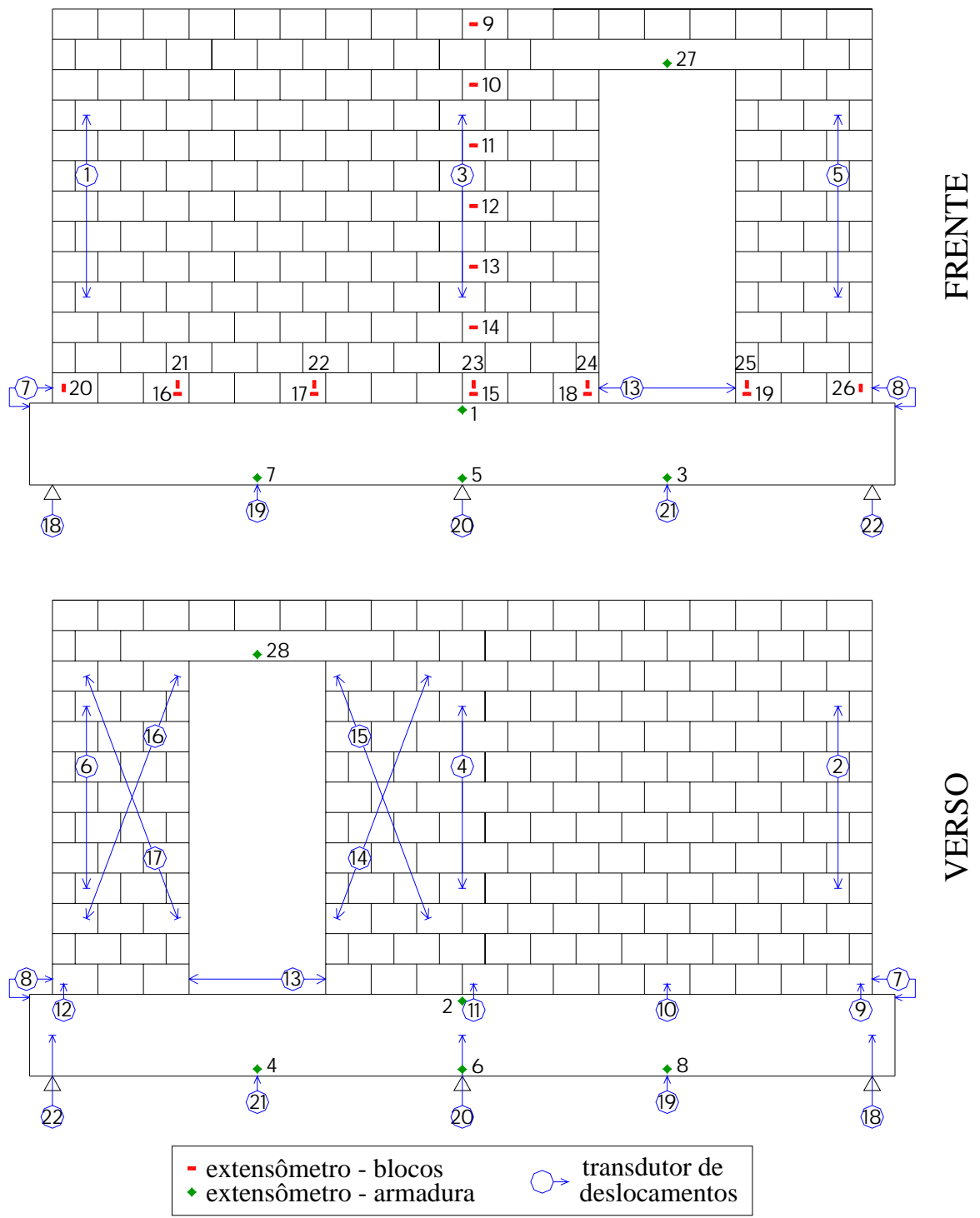

Figura 3.13 Instrumentação do Modelo 3.

O Modelo 4 equivale à reunião dos dois tipos de abertura em um mesmo painel. Logo, sua instrumentação corresponde à sobreposição daquelas dos modelos anteriores. 
Os demais modelos foram instrumentados como seus semelhantes já apresentados, com pequenas alterações. As paredes da Série 3 não foram instrumentadas com extensômetros na direção horizontal porque as medidas obtidas nos modelos anteriores foram muito pequenas e incoerentes em sua maioria.

As figuras ilustrativas dos esquemas de instrumentação de todos os modelos serão apresentadas no próximo capítulo, juntamente com os resultados dos ensaios.

\subsection{DIMENSIONAMENTO E DETALHAMENTO DA VIGA}

A viga foi dimensionada de duas maneiras: com e sem a consideração do efeito de interação com a parede, conforme discussão apresentada no item 3.1.2. Sua altura foi determinada em função do momento máximo negativo, que ocorre na posição do apoio central.

Para o caso do carregamento distribuído aplicado no topo da parede tem-se a seguinte distribuição de tensões transmitidas à viga, da qual decorrem os diagramas de esforços solicitantes:

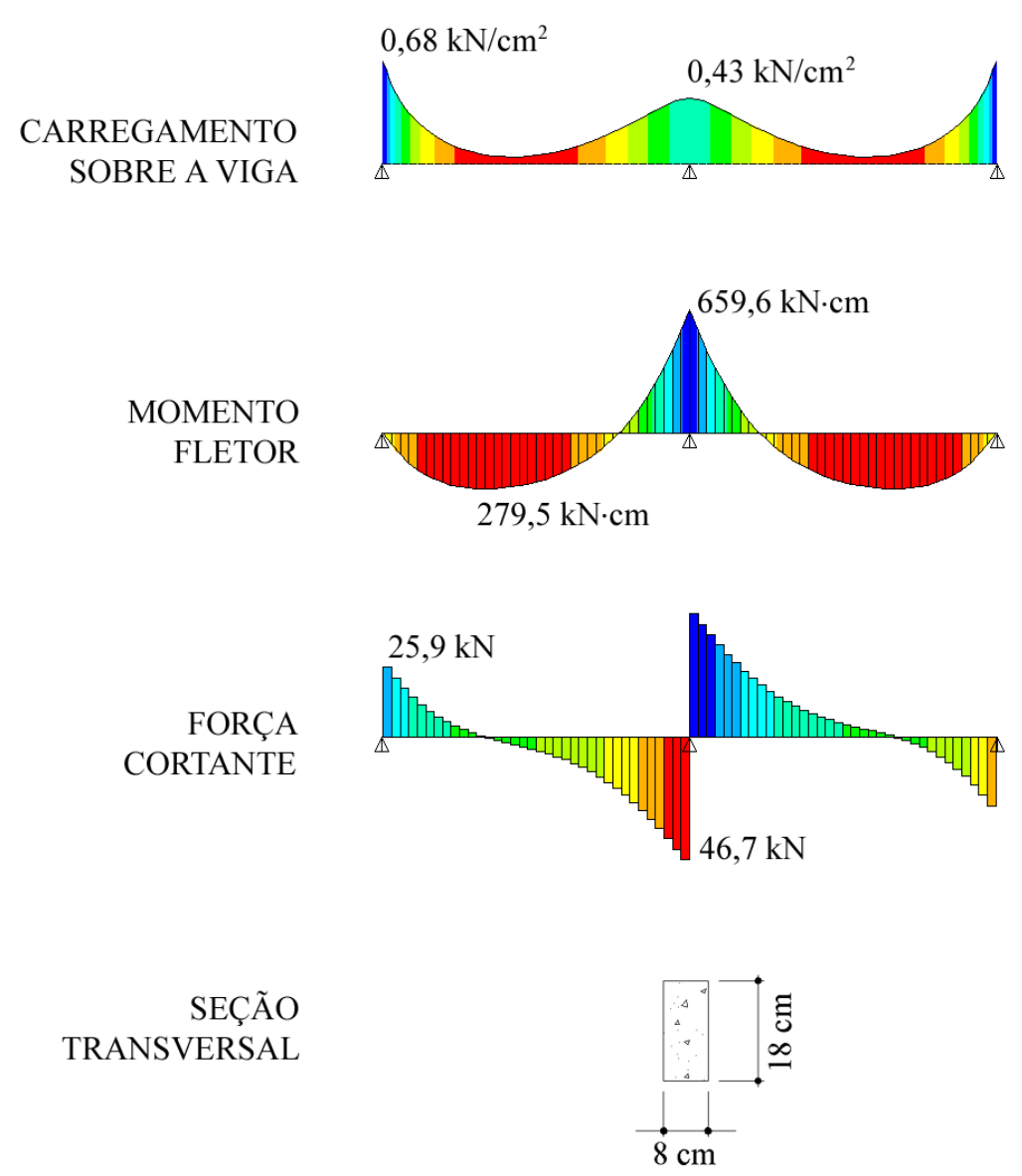

Figura 3.14 Dimensionamento da viga dos modelos 1 a 4, 6 e 7. 
No cálculo da armadura negativa aplicou-se o arredondamento do diagrama de momentos fletores permitido pela NBR 6118 (2001) no item 14.6.3. Assim, sabendo-se que o apoio central possuía $10 \mathrm{~cm}$ de largura e reação igual a $102,5 \mathrm{kN}$, tem-se:

$$
\left.\begin{array}{l}
\mathrm{M}_{\mathrm{k}}=659,6 \mathrm{kN} \cdot \mathrm{cm} \\
\Delta \mathrm{M}=\mathrm{R} \frac{\mathrm{t}}{8}=102,5 \cdot \frac{10}{8}=128,1 \mathrm{kN} \cdot \mathrm{cm}
\end{array}\right\} \mathrm{M}_{\mathrm{d}}=1,4\left(\mathrm{M}_{\mathrm{k}}-\Delta \mathrm{M}\right)=744,1 \mathrm{kN} \cdot \mathrm{cm}
$$

Adotando-se aço tipo CA-50 e $\mathrm{f}_{\mathrm{ck}}=20 \mathrm{MPa}$, chega-se ao seguinte valor da armadura negativa:

$$
\mathrm{A}_{\mathrm{s}}^{\prime}=1,32 \mathrm{~cm}^{2} \quad \Rightarrow \quad 5 \varnothing 6,3 \mathrm{~mm}
$$

Analogamente, calculou-se a armadura positiva:

$$
\begin{array}{ll}
\mathrm{M}_{\mathrm{k}}=279,5 \mathrm{kN} \cdot \mathrm{cm} & \Rightarrow \quad \mathrm{M}_{\mathrm{d}}=391,3 \mathrm{kN} \cdot \mathrm{cm} \\
\mathrm{A}_{\mathrm{s}}=0,62 \mathrm{~cm}^{2} & \Rightarrow \quad 2 \varnothing 6,3 \mathrm{~mm}
\end{array}
$$

Ambas as armaduras longitudinais ficaram acima do valor mínimo segundo a NBR 6118 (2001).

De acordo com a mesma norma determinou-se a armadura transversal. Aplicouse a redução permitida para o esforço cortante, adotando-se no diagrama o valor correspondente a uma seção distante $\mathrm{d} / 2$ da face do apoio, em que $\mathrm{d}=15,8 \mathrm{~cm}$ é a altura útil da seção transversal da viga. Dessa forma:

$$
\mathrm{V}_{\mathrm{sd}}=1,4 \cdot 30,2=42,3 \mathrm{kN}
$$

Pelas verificações prescritas,

$$
\mathrm{V}_{\mathrm{sd}}<\mathrm{V}_{\mathrm{Rd} 2}
$$$$
\mathrm{V}_{\mathrm{sd}}<\mathrm{V}_{\mathrm{Rd} 3}=\mathrm{V}_{\mathrm{c}}+\mathrm{V}_{\mathrm{sw}}
$$

e adotando aço CA-60, chega-se a:

$$
\frac{\mathrm{A}_{\mathrm{sw}}}{\mathrm{s}}=0,046 \frac{\mathrm{cm}^{2}}{\mathrm{~cm}} \Rightarrow \quad \varnothing 4,2 \mathrm{~mm} \mathrm{c} 6,0 \mathrm{~cm}
$$

Porém, o espaçamento máximo especificado para o caso de $V_{d}>0,67 V_{R d 2}$ é: $\mathrm{S}_{\text {máx }}=0,3 \mathrm{~d}=4,74 \mathrm{~cm}$

Adotou-se então para a armadura transversal:

$\varnothing 4,2 \mathrm{~mm} \mathrm{c} 4,5 \mathrm{~cm}$

Seria interessante usar aço de menor bitola, já que o modelo é feito em escala reduzida, entretanto não se conseguiu obter diâmetros menores no mercado. Além disso, trabalhar-se-ia com espaçamentos menores, o que seria inconveniente.

$\mathrm{Na}$ Figura 3.15 encontra-se o detalhamento completo da viga. 

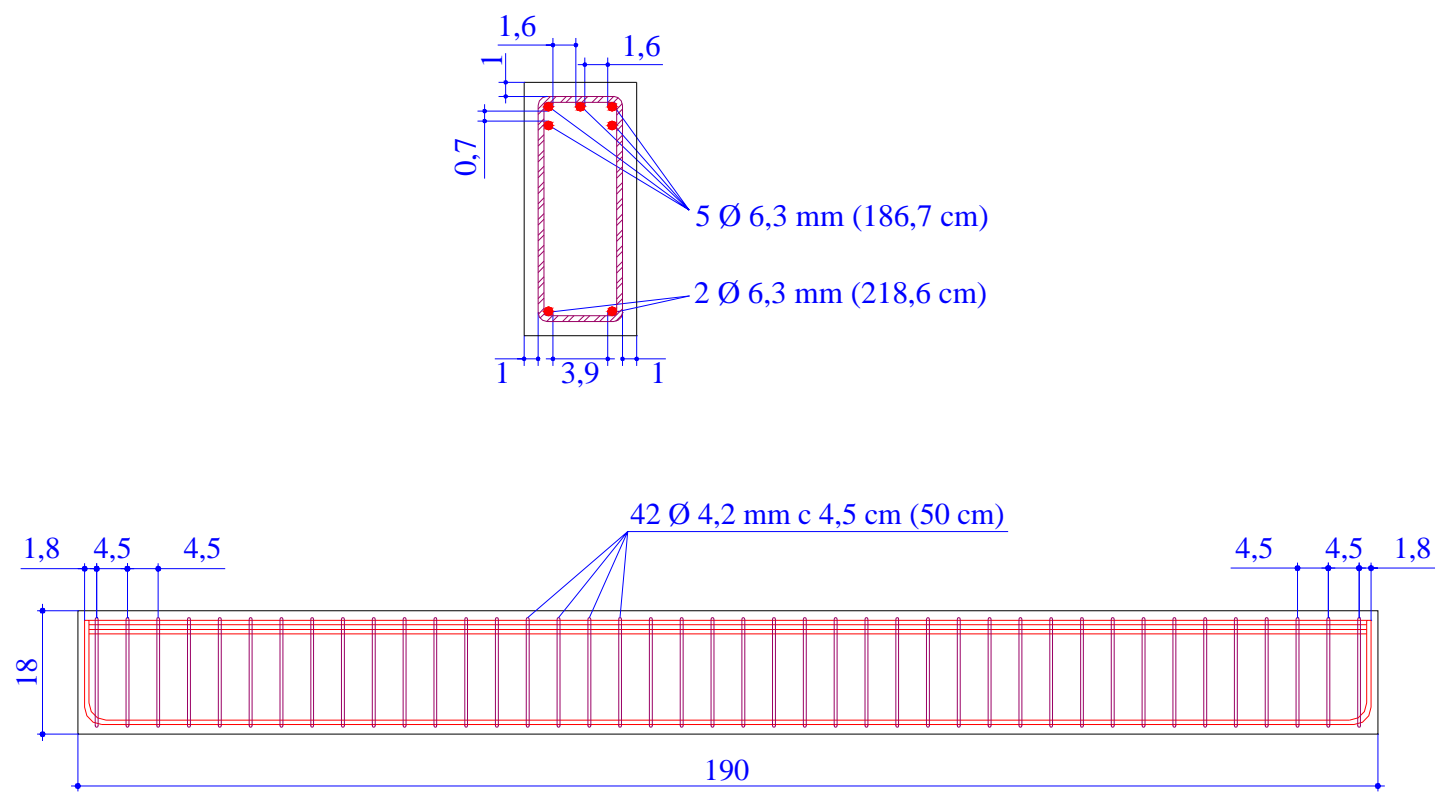

186,7

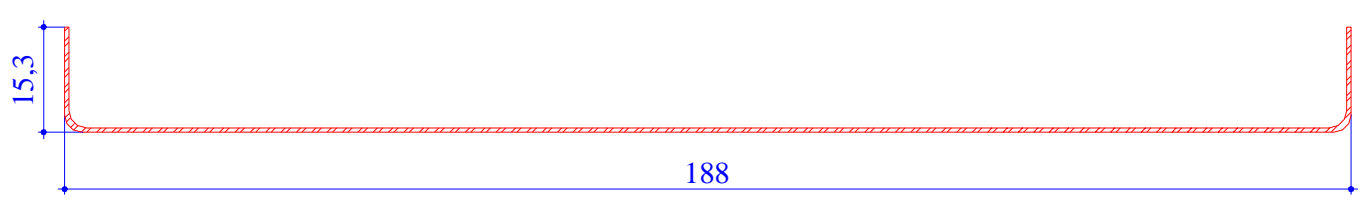

Figura 3.15 Detalhamento da viga dos modelos 1 a 4, 6 e 7 .

A viga do Modelo 5 foi dimensionada considerando o carregamento distribuído uniformemente sobre a própria viga. Portanto, obtém-se os diagramas da Figura 3.16. 
CARREGAMENTO SOBRE A VIGA
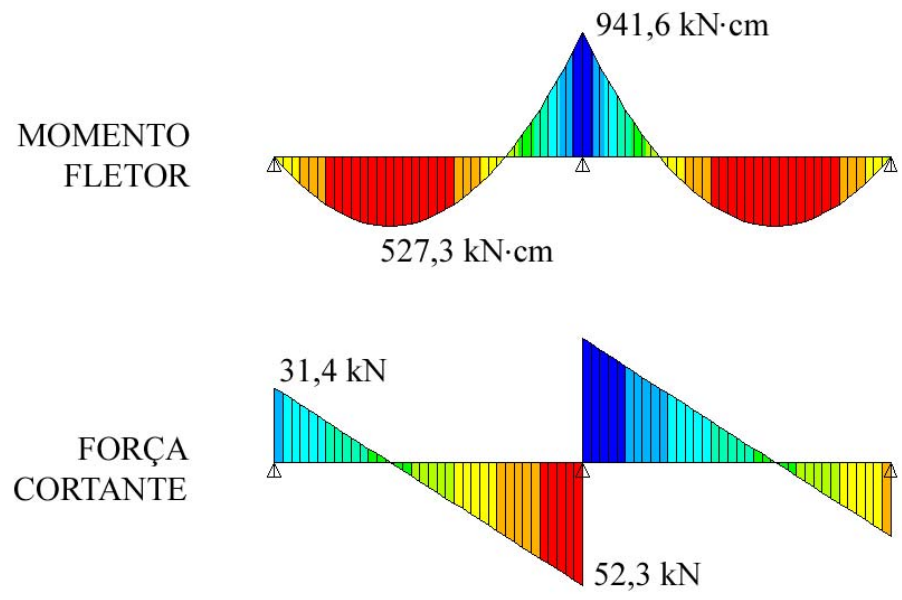

SEÇÃO

TRANSVERSAL

$0,2 \mathrm{kN} / \mathrm{cm}^{2}$

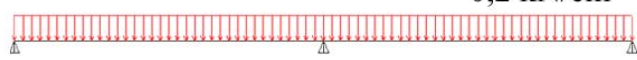

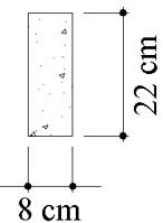

Figura 3.16 Dimensionamento da viga do Modelo 5.

Detalhou-se seguindo um procedimento idêntico ao anterior. Em seguida são apresentados os resultados dos cálculos e o esquema de armação da viga.

$$
\begin{aligned}
& \mathrm{A}_{\mathrm{s}}^{\prime}=1,62 \mathrm{~cm}^{2} \Rightarrow 6 \varnothing 6,3 \mathrm{~mm} \\
& \mathrm{~A}_{\mathrm{s}}=0,95 \mathrm{~cm}^{2} \Rightarrow 3 \varnothing 6,3 \mathrm{~mm} \\
& \frac{\mathrm{A}_{\mathrm{sw}}}{\mathrm{s}}=0,047 \frac{\mathrm{cm}^{2}}{\mathrm{~cm}} \Rightarrow \varnothing 4,2 \mathrm{mmc} 6,0 \mathrm{~cm} \Rightarrow \varnothing 4,2 \mathrm{~mm} 5,5 \mathrm{~cm}
\end{aligned}
$$

Alterou-se o espaçamento por causa das posições dos extensômetros. 

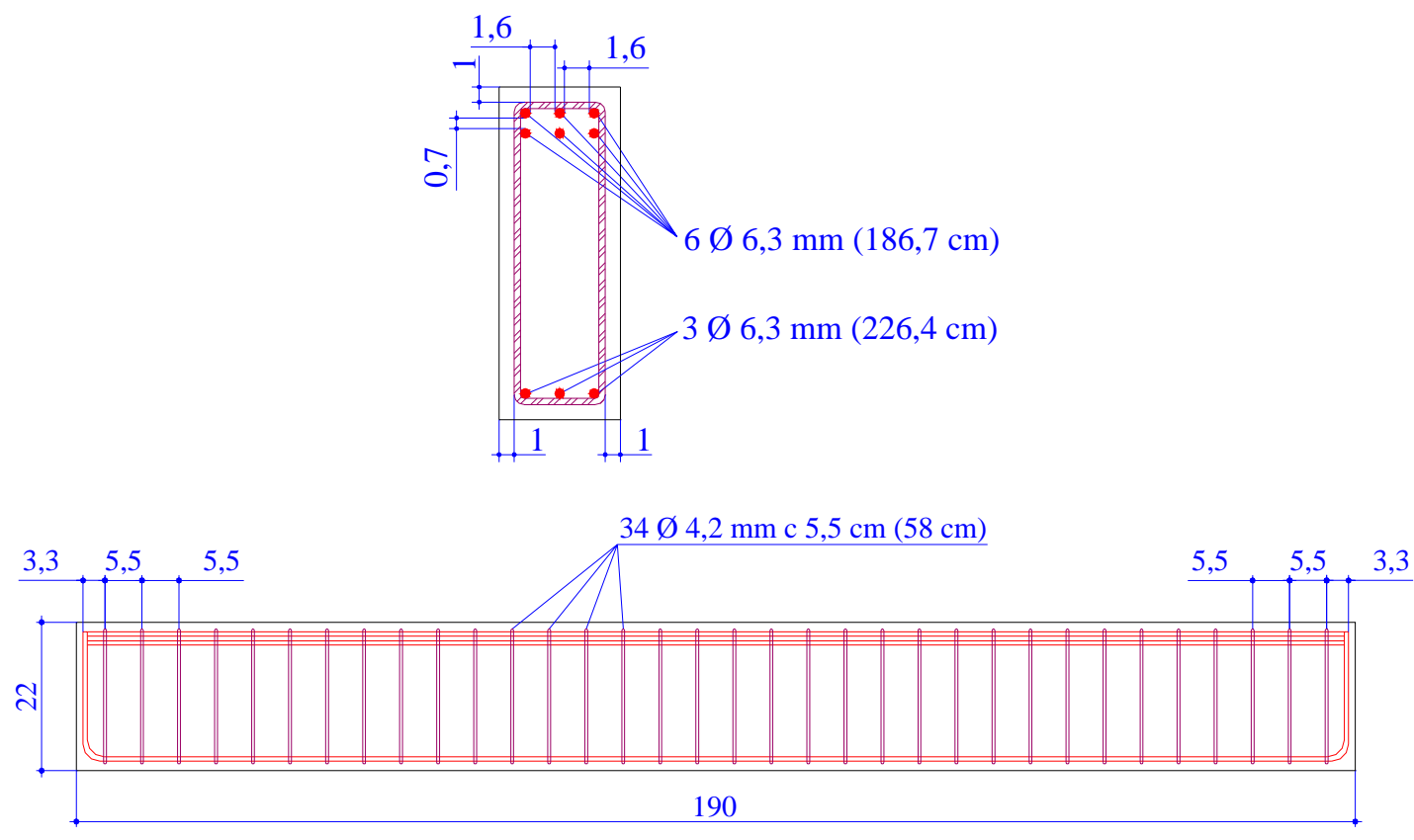

186,7

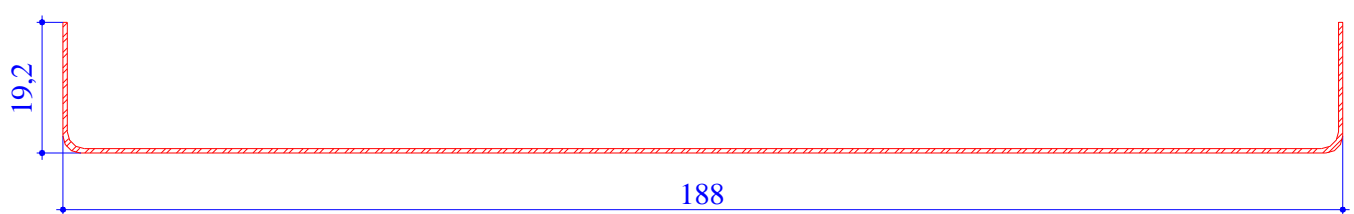

Figura 3.17 Detalhamento da viga do Modelo 5.

\subsection{CONSTRUÇÃO E TRANSPORTE DOS PAINÉIS}

Descrevem-se neste item os procedimentos empregados na construção de um painel, bem como no seu transporte para o pórtico de ensaio. Os métodos foram os mesmos para todos os modelos.

Após o período de cura da viga, ela foi transportada para o galpão de ensaios e posicionada sobre dois apoios de extremidade para que ficasse um pouco elevada em relação ao piso. Esse cuidado possibilitaria a futura operação de transporte. Deu-se bastante atenção para o nivelamento da viga, tanto na direção axial quanto transversal. Demarcou-se a lápis na face da viga a localização da parede, que facilitaria o posicionamento do gabarito metálico utilizado na construção da parede.

Este gabarito foi confeccionado especialmente para a execução da alvenaria em escala reduzida, a fim de que se garantisse o prumo e o alinhamento da parede, o nivelamento das fiadas e, conseqüentemente, a espessura das juntas de argamassa. Com essas 
finalidades, foram feitas marcações equivalentes à altura das fiadas ao longo das réguas verticais, e equivalentes às posições dos blocos e meio-blocos ao longo da régua horizontal. Optou-se por confeccioná-lo com perfis de alumínio, objetivando durabilidade, rigidez e precisão dimensional.

A fim de posicionar corretamente o gabarito em relação à viga, foram construídas duas estruturas auxiliares. Consistiram de caixotes de madeira compensada, com altura igual à da viga já apoiada, onde se parafusou o gabarito. Dentro dos caixotes foram colocadas peças com peso suficiente para impedir o tombamento e a translação do gabarito durante a construção da parede.

O sistema assim montado foi então posicionado de maneira que a régua horizontal do gabarito coincidisse com a marcação prévia na face superior da viga. Verificou-se com atenção o prumo e o nível do gabarito.

Terminada a fase de preparação, iniciou-se a construção da parede. Borrifou-se um pouco de água na face da viga para que o concreto não absorvesse de imediato a água de amassamento da argamassa. Após construída cada fiada, elevava-se a régua horizontal do gabarito até a próxima marcação das réguas verticais, conferindo seu nivelamento, para que se iniciasse a fiada imediatamente superior. As fotos seguintes ilustram o processo, que tinha a duração de um dia para cada painel. 

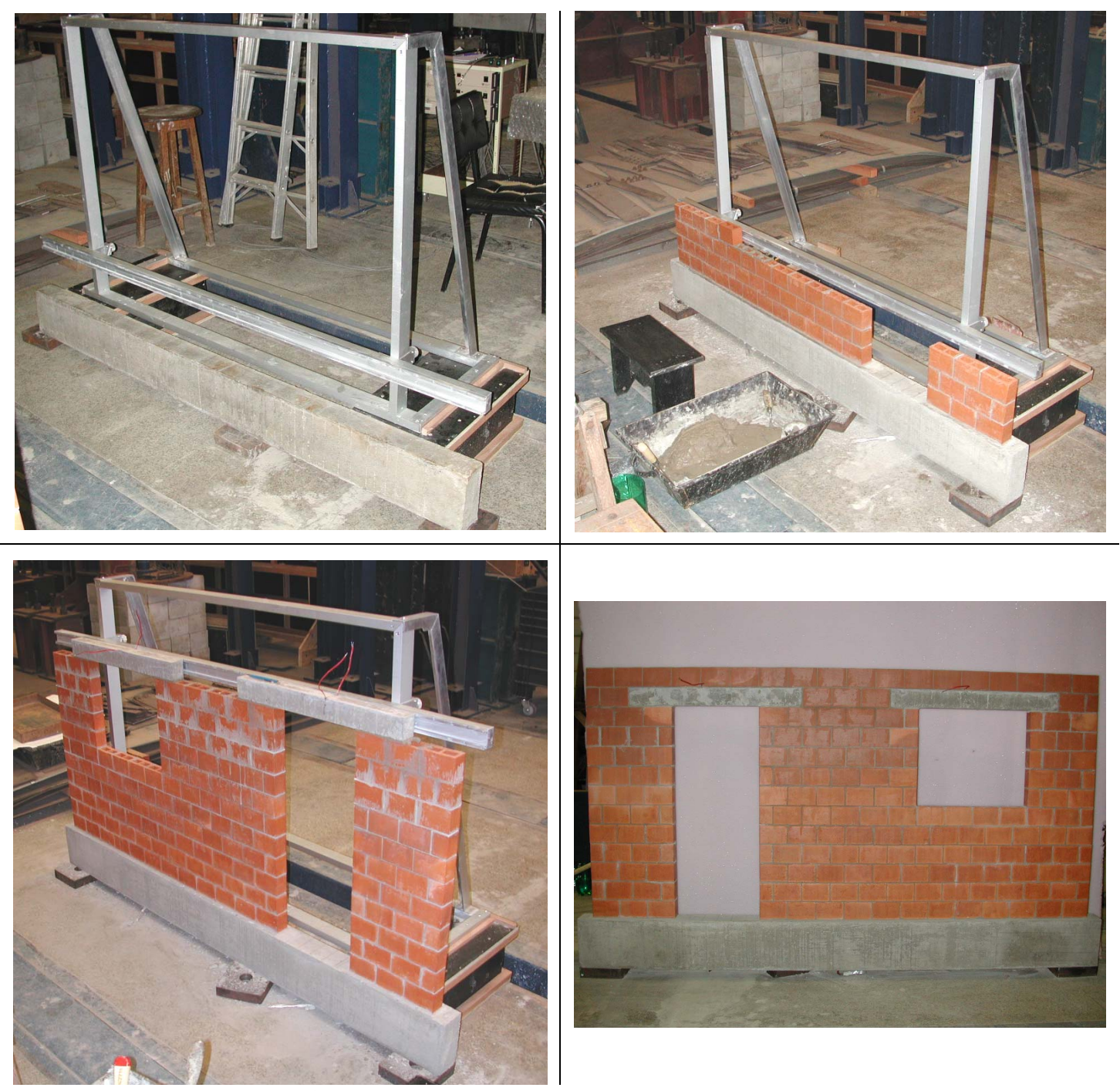

Figura 3.18 Processo de construção dos painéis.

A argamassa era preparada manualmente, em porções aproximadamente equivalentes a um sexto do volume total. Os blocos eram imersos em água por um período mínimo de duas horas antes de serem usados. Foram confeccionados 6 corpos-de-prova de argamassa e 3 prismas para cada parede.

As paredes da Série 3 foram construídas em três etapas para que fossem respeitadas as recomendações das normas NBR 8798 (1985) e NBR 8949 (1985) com relação ao grauteamento. Inicialmente foram feitas as fiadas até cerca de meia-altura da parede, com o cuidado de posicionar blocos com faces cortadas na base de cada furo a ser grauteado, possibilitando a remoção de restos da argamassa de assentamento. Após 24 horas, procedeu-se com o grauteamento, utilizando uma barra de aço como soquete. A operação é ilustrada na Figura 3.19. 

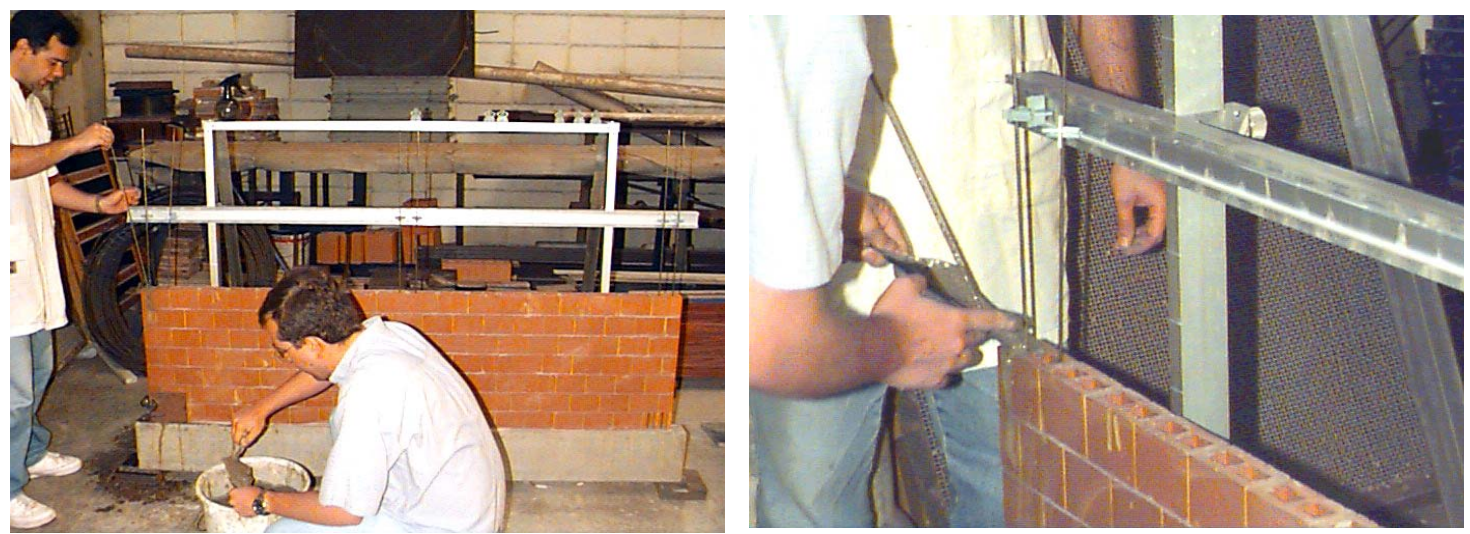

Figura 3.19 Operação de grauteamento do Modelo 6.

Repetiu-se o procedimento até a última fiada a ser grauteada. Em seguida, as paredes foram concluídas, terminando com uma fiada adicional de blocos canaleta, que foi posteriormente grauteada, formando uma cinta, ilustrada na fotografia seguinte.

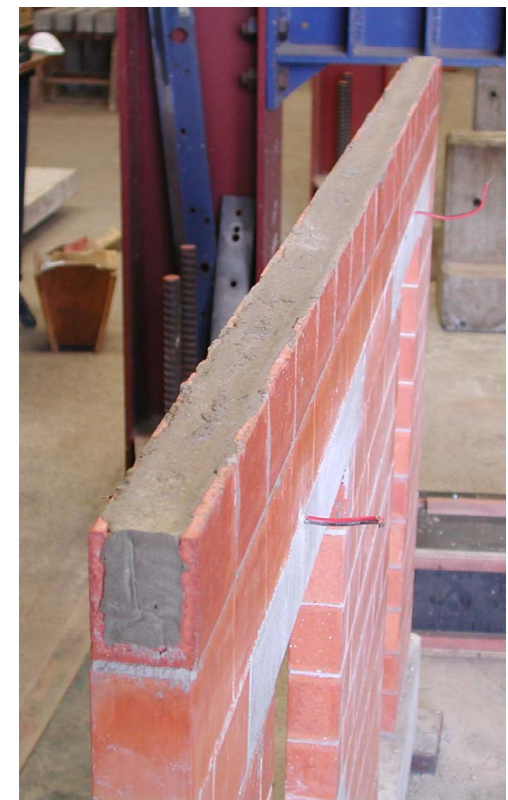

Figura 3.20 Cinta do Modelo 7.

O transporte dos modelos para o pórtico foi realizado com emprego da ponte rolante do galpão de ensaios. Passavam-se duas cintas por baixo da viga, de forma a erguer o painel sem incliná-lo. Os painéis foram movimentados estando a alvenaria com no mínimo 12 dias de idade. Na Figura 3.21 ilustra-se o procedimento de transporte. 


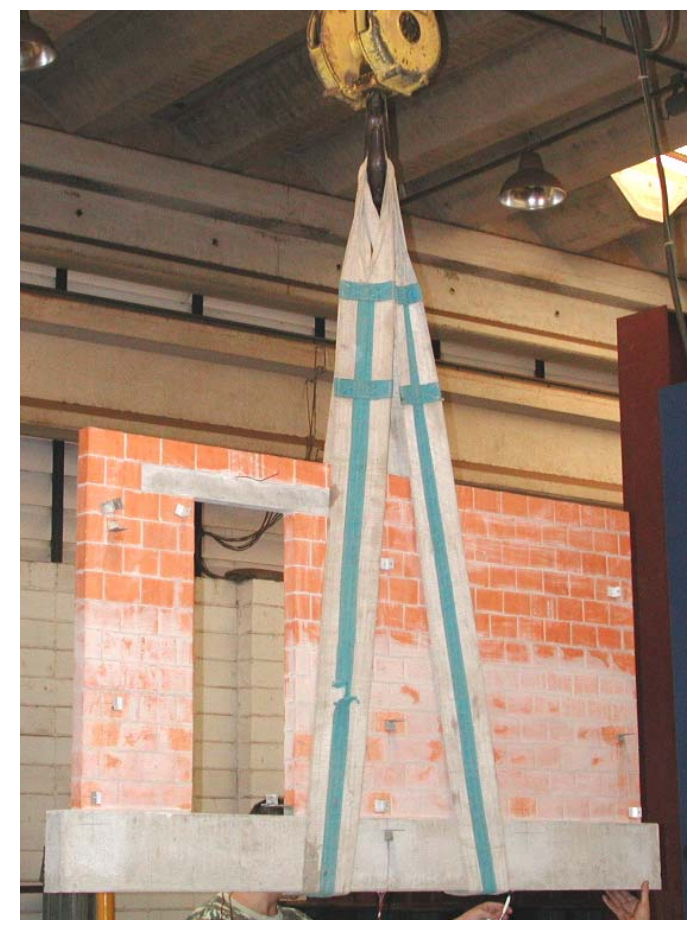

Figura 3.21 Transporte dos modelos.

\subsection{ENSAIOS DE CARACTERIZAÇÃO}

Com o objetivo de determinar as propriedades dos materiais utilizados na pesquisa, foi realizada uma série de ensaios preliminares de caracterização. Executaram-se os ensaios citados na Tabela 3.5, além da caracterização granulométrica das areias e do pedrisco, utilizados na confecção da argamassa e do concreto.

Tabela 3.5 Ensaios de caracterização.

\begin{tabular}{cl}
\hline $\begin{array}{c}\text { COMPONENTE } \\
\text { ou ELEMENTO }\end{array}$ & TIPO DE ENSAIO \\
\hline \multirow{2}{*}{ Blocos } & $\begin{array}{l}\text { Precisão dimensional } \\
\text { Compressão } \\
\text { Teor de umidade, absorção de água e área líquida }\end{array}$ \\
\hline Argamassa & Compressão \\
\hline Prismas & Compressão \\
\hline Paredinhas $^{5}$ & $\begin{array}{l}\text { Compressão } \\
\text { Compressão diagonal }\end{array}$ \\
\hline Juntas & Cisalhamento \\
\hline
\end{tabular}

Os resultados foram utilizados tanto no dimensionamento e no detalhamento dos modelos, quanto na sua modelagem numérica. Buscou-se obter principalmente dados de resistência à compressão dos materiais e dos elementos por eles constituídos, bem como valores do coeficiente de Poisson e dos módulos de elasticidade longitudinal e transversal da

\footnotetext{
${ }^{5}$ Embora pareça ter significado genérico, "paredinha" é o termo mais difundido para designar corpo-de-prova de parede, normalmente com dimensões $1,20 \mathrm{~m}$ x 1,20 m em escala real.
} 
alvenaria. Como o cisalhamento das juntas revelou-se importante para a modelagem numérica, procurou-se caracterizar também os parâmetros da equação que rege o problema, de acordo com o item 2.6.

Nas seções a seguir apresentam-se, de forma sucinta, os resultados dos ensaios de caracterização e as demais características dos materiais.

\subsubsection{Blocos}

Utilizaram-se blocos cerâmicos em escala 1:3, constituintes de um único lote produzido pela ST Indústria Cerâmica Ltda. Foram fornecidos blocos e meio-blocos, cuja fotografia se encontra na Figura 3.22. As dimensões foram determinadas por medição direta de nove blocos e nove meio-blocos, escolhidos aleatoriamente. Para cada bloco foram feitas duas medidas da altura e da largura, uma de cada extremidade. Os valores estão organizados nas tabelas seguintes.

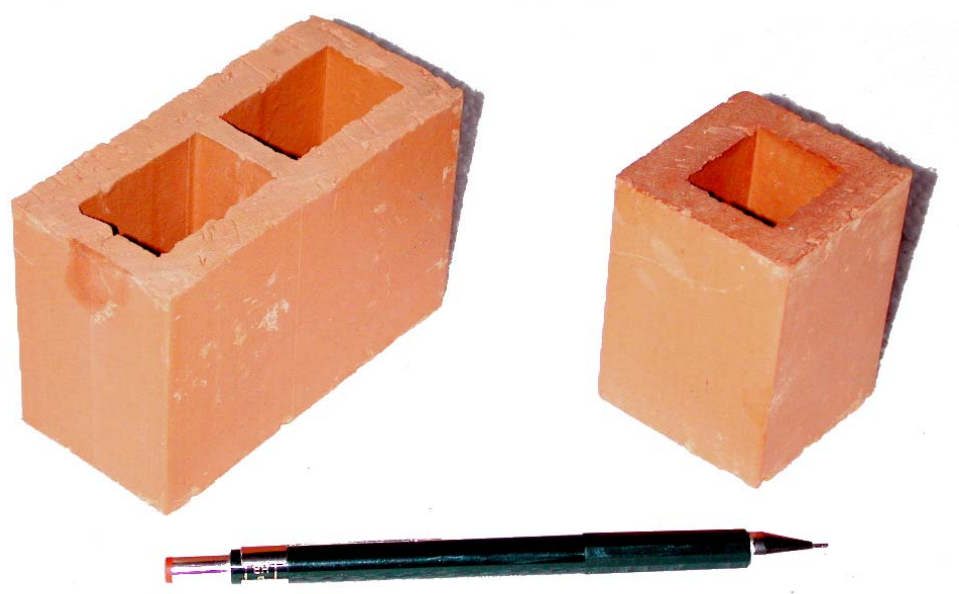

Figura 3.22 Bloco e meio-bloco utilizados na pesquisa.

Tabela 3.6 Dimensões dos blocos $(\mathrm{cm})$.

\begin{tabular}{|c|c|c|c|c|c|}
\hline AMOSTRA & COMPRIMENTO & \multicolumn{2}{|c|}{ ALTURA } & \multicolumn{2}{|c|}{ LARGURA } \\
\hline 1 & 9,67 & 6,31 & 6,42 & 4,63 & 4,59 \\
\hline 2 & 9,80 & 6,42 & 6,44 & 4,66 & 4,69 \\
\hline 3 & 9,81 & 6,34 & 6,44 & 4,66 & 4,70 \\
\hline 4 & 9,68 & 6,40 & 6,32 & 4,62 & 4,59 \\
\hline 5 & 9,79 & 6,40 & 6,44 & 4,65 & 4,66 \\
\hline 6 & 9,80 & 6,41 & 6,33 & 4,65 & 4,68 \\
\hline 7 & 9,78 & 6,46 & 6,50 & 4,65 & 4,64 \\
\hline 8 & 9,71 & 6,49 & 6,39 & 4,63 & 4,59 \\
\hline 9 & 9,82 & 6,40 & 6,52 & 4,68 & 4,65 \\
\hline $\begin{array}{l}\text { Média } \\
\text { C.V. }\end{array}$ & $\begin{array}{r}9,76 \\
0,6 \%\end{array}$ & \multicolumn{2}{|c|}{$\begin{array}{r}6,41 \\
0,9 \% \\
\end{array}$} & \multicolumn{2}{|c|}{$\begin{array}{r}4,65 \\
0,7 \% \\
\end{array}$} \\
\hline $\begin{array}{l}\text { Medidas } \\
\text { ideais }\end{array}$ & 9,67 & \multicolumn{2}{|c|}{6,33} & \multicolumn{2}{|c|}{4,67} \\
\hline Diferença & $1,0 \%$ & \multicolumn{2}{|c|}{$1,3 \%$} & \multicolumn{2}{|c|}{$-0,5 \%$} \\
\hline
\end{tabular}


Tabela 3.7 Dimensões dos meio-blocos $(\mathrm{cm})$.

\begin{tabular}{c|c|c|c}
\hline AMOSTRA & COMPRIMENTO & ALTURA & LARGURA \\
\hline 1 & 4,64 & 6,30 & 4,68 \\
2 & 4,65 & 6,33 & 4,68 \\
3 & 4,66 & 6,34 & 4,68 \\
4 & 4,63 & 6,46 & 4,68 \\
5 & 4,65 & 6,30 & 4,67 \\
6 & 4,65 & 6,39 & 4,68 \\
7 & 4,65 & 6,35 & 4,69 \\
8 & 4,65 & 6,47 & 4,69 \\
9 & 4,65 & 6,35 & 4,68 \\
\hline Média & $\mathbf{4 , 6 5}$ & $\mathbf{6 , 3 7}$ & $\mathbf{4 , 6 8}$ \\
C.V. & $\mathbf{0 , 2 \%}$ & $\mathbf{1 , 0 \%}$ & $\mathbf{0 , 1 \%}$ \\
\hline Medidas & $\mathbf{4 , 6 7}$ & $\mathbf{6 , 3 3}$ & $\mathbf{4 , 6 7}$ \\
ideais & $\mathbf{0 , 4 \%}$ & $\mathbf{0 , 5 \%}$ & $\mathbf{0 , 3 \%}$ \\
Diferença & & &
\end{tabular}

Pelas tabelas é possível concluir que os blocos apresentam boa estabilidade dimensional, uma vez que o coeficiente de variação máximo foi de $1,0 \%$. Além disso, as dimensões reais estão muito próximas das ideais para escala 1:3, obtidas por meio da divisão das medidas do bloco em escala real $(29 \times 19 \times 14 \mathrm{~cm})$ pelo fator de escala. A diferença percentual entre as medidas reais e ideais variou entre $-0,4 \%$ e $1,3 \%$.

Para o ensaio de resistência à compressão foram retirados seis blocos do lote. Utilizaram-se placas de fibra de madeira tipo "soft" com espessura de $10 \mathrm{~mm}$ como capeamento. Dentre os blocos ensaiados à compressão, cinco foram instrumentados com extensômetros elétricos para que se pudesse estimar o módulo de elasticidade $\left(\mathrm{E}_{\mathrm{b}}\right)$ a partir dos gráficos tensão-deformação, condensados na Figura 3.23. Calculou-se o módulo de elasticidade de cada bloco como a inclinação do trecho linear do gráfico. Adotou-se que esse trecho está compreendido entre 5\% e 33\% da tensão de ruptura, seguindo a recomendação do ACI 530R-92 (1994) para alvenaria. A Tabela 3.8 apresenta os resultados obtidos. 


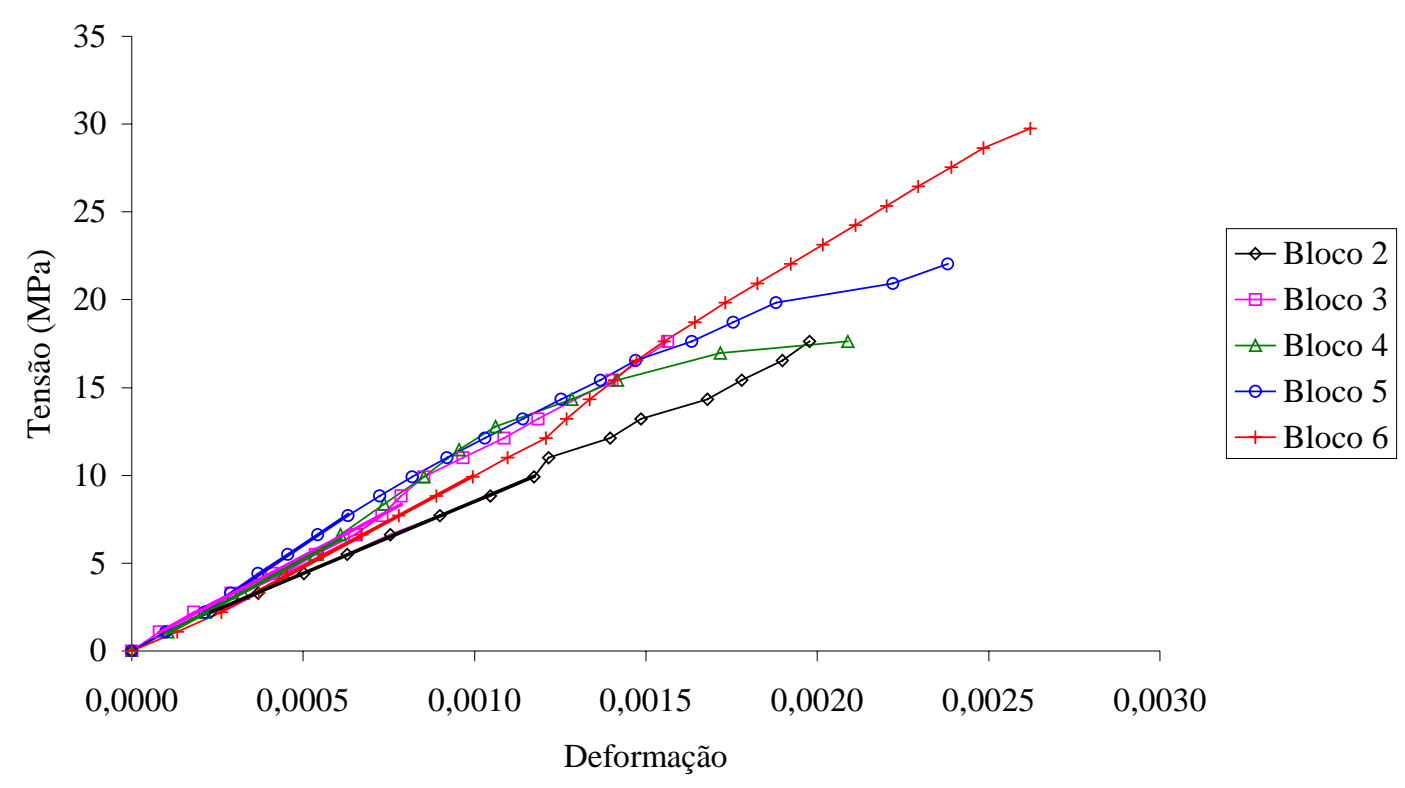

Figura 3.23 Gráficos tensão-deformação dos blocos.

Tabela 3.8 Resultados dos ensaios de compressão dos blocos.

\begin{tabular}{cccc}
\hline \multirow{2}{*}{ AMOSTRA } & $\begin{array}{c}\text { CARGA DE } \\
\text { RUPTURA }(\mathrm{kN})\end{array}$ & $\begin{array}{c}\text { TENSÃO NA } \\
\text { RUPTURA }(\mathrm{MPa})\end{array}$ & $\begin{array}{c}\mathrm{E}_{\mathrm{b}} \\
(\mathrm{MPa})\end{array}$ \\
\hline 1 & 168,6 & 37,15 & - \\
2 & 136,3 & 30,03 & 8178 \\
3 & 122,6 & 27,01 & 10334 \\
4 & $*$ & $*$ & 10646 \\
5 & 101,3 & 22,32 & 13126 \\
6 & 136,3 & 30,03 & 10487 \\
\hline Média & & $\mathbf{2 9 , 3 1}$ & $\mathbf{1 0 5 5 4}$ \\
C.V. & & $\mathbf{1 8 \%}$ & $\mathbf{1 7 \%}$ \\
\hline
\end{tabular}

(*) Valor desprezado devido a problemas no ensaio após ultrapassado o limite de comportamento no regime linear.

Também foram determinados o teor de umidade, a absorção de água e a área líquida dos blocos com base na NBR 8043 (1983). Os resultados encontram-se na Tabela 3.9. 
Tabela 3.9 Teor de umidade, absorção de água e área líquida dos blocos.

\begin{tabular}{ccccc}
\hline AMOSTRA & UMIDADE & $\begin{array}{c}\text { ABSORÇÃO } \\
\text { DE ÁGUA }\end{array}$ & $\begin{array}{c}\text { ÁREA LÍQUIDA } \\
\left(\mathrm{cm}^{2}\right)\end{array}$ & $\mathrm{A}_{\text {liq }} / \mathrm{A}_{\text {bruta }}$ \\
\hline 1 & $1,2 \%$ & $13,2 \%$ & 25,35 & $56 \%$ \\
2 & $1,5 \%$ & $12,3 \%$ & 24,99 & $55 \%$ \\
3 & $1,6 \%$ & $13,5 \%$ & 25,04 & $55 \%$ \\
4 & $1,0 \%$ & $13,7 \%$ & 24,02 & $53 \%$ \\
5 & $1,2 \%$ & $13,8 \%$ & 24,35 & $54 \%$ \\
6 & $1,4 \%$ & $12,5 \%$ & 25,18 & $55 \%$ \\
7 & $1,4 \%$ & $13,5 \%$ & 25,02 & $55 \%$ \\
8 & $1,4 \%$ & $13,1 \%$ & 24,82 & $55 \%$ \\
9 & $1,0 \%$ & $13,2 \%$ & 23,84 & $53 \%$ \\
\hline Média & $\mathbf{1 , 3 \%}$ & $\mathbf{1 3 , 2 \%}$ & $\mathbf{2 4 , 7 4}$ & $\mathbf{5 5 \%}$ \\
C.V. & $\mathbf{1 8 \%}$ & $\mathbf{4 \%}$ & $\mathbf{2 \%}$ & $\mathbf{2 \%}$ \\
\hline
\end{tabular}

Para a confecção da cinta grauteada dos modelos da Série 3 foram utilizados blocos canaleta, fornecidos pela Cerâmica Maristela, disponíveis apenas a partir daquela ocasião. Suas medidas encontram-se reunidas na Tabela 3.10, da qual se verifica que são próximas às dimensões dos demais blocos utilizados. A resistência à compressão média dos blocos de dois furos do mesmo lote dos blocos canaleta foi equivalente a 23,20 MPa. Essas características semelhantes possibilitaram o uso das canaletas.

Tabela 3.10 Dimensões dos blocos canaleta $(\mathrm{cm})$.

\begin{tabular}{c|c|c|c}
\hline AMOSTRA & COMPRIMENTO & ALTURA & LARGURA \\
\hline 1 & 9,37 & 6,27 & 4,72 \\
2 & 9,39 & 6,27 & 4,73 \\
3 & 9,51 & 6,28 & 4,73 \\
4 & 9,35 & 6,22 & 4,73 \\
5 & 9,30 & 6,18 & 4,70 \\
6 & 9,41 & 6,23 & 4,75 \\
7 & 9,53 & 6,25 & 4,74 \\
8 & 9,49 & 6,30 & 4,75 \\
9 & 9,38 & 6,30 & 4,72 \\
\hline Média & $\mathbf{9 , 4 1}$ & $\mathbf{6 , 2 6}$ & $\mathbf{4 , 7 3}$ \\
C.V. & $\mathbf{1 , 1 \%}$ & $\mathbf{0 , 6 \%}$ & $\mathbf{0 , 3 \%}$ \\
\hline Medidas & $\mathbf{9 , 6 7}$ & $\mathbf{6 , 3 3}$ & $\mathbf{4 , 6 7}$ \\
ideais & $\mathbf{- 2 , 7 \%}$ & $\mathbf{- 1 , 1 \%}$ & $\mathbf{1 , 3 \%}$ \\
Diferença & \multicolumn{3}{|c}{}
\end{tabular}




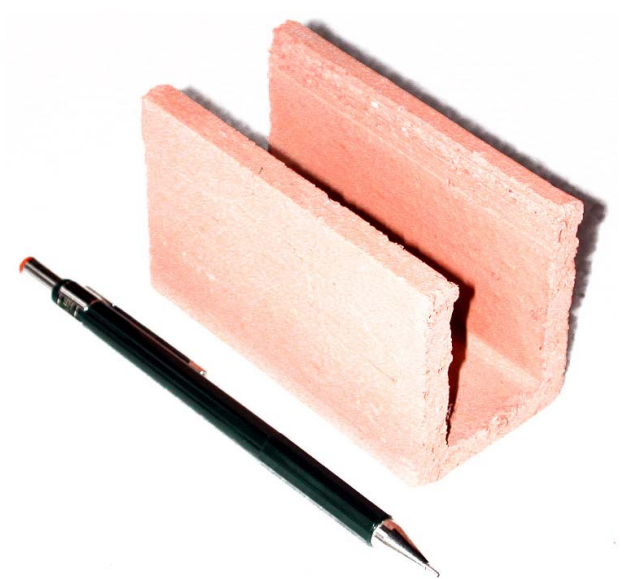

Figura 3.24 Bloco canaleta utilizado na pesquisa.

\subsubsection{Argamassa}

Para o assentamento da alvenaria confeccionou-se argamassa mista de cal e cimento com traço 1:0,5:4,5 em volume. O controle das quantidades foi feito em massa, utilizando o traço equivalente 1:0,31:5,80 em massa. Experimentou-se previamente qual quantidade de água seria necessária para se conseguir boa trabalhabilidade, chegando-se a um fator água/cimento de 1,23. Os insumos utilizados foram: cimento CP-V ARI, cal hidratada CH III e areia quartzosa muito fina.

Foram ensaiados 20 corpos-de-prova cilíndricos à compressão, com base na especificação da NBR 13279 (1995), sendo metade aos 14 dias e o restante aos 42 dias. Os resultados podem ser encontrados na Tabela 3.11. 
Tabela 3.11 Resistência da argamassa à compressão.

\begin{tabular}{cccc}
\hline \multirow{2}{*}{ MMOSTRA } & $\begin{array}{c}\text { IDADE } \\
(\text { dias })\end{array}$ & $\begin{array}{c}\text { CARGA DE } \\
\text { RUPTUR }(\mathrm{kN})\end{array}$ & $\begin{array}{c}\text { TENSÃO NA } \\
\text { RUPURA }(\mathrm{MPa})\end{array}$ \\
\hline 1 & 14 & 26,9 & 13,70 \\
2 & 14 & 23,4 & 11,92 \\
3 & 14 & 15,2 & 7,74 \\
4 & 14 & 19,5 & 9,93 \\
5 & 14 & 17,9 & 9,12 \\
6 & 14 & 17,7 & 9,01 \\
7 & 14 & 17,7 & 9,01 \\
8 & 14 & 17,5 & 8,91 \\
9 & 14 & 21,2 & 10,80 \\
10 & 14 & 20,2 & 10,29 \\
\hline Média & & & $\mathbf{1 0 , 0 2}$ \\
C.V. & & & $\mathbf{1 7 \%}$ \\
\hline \hline 11 & 42 & 31,3 & 15,92 \\
12 & 42 & 23,8 & 12,10 \\
13 & 42 & 24,0 & 12,22 \\
14 & 42 & 21,3 & 10,82 \\
15 & 42 & 23,8 & 12,10 \\
16 & 42 & 25,0 & 12,73 \\
17 & 42 & 24,5 & 12,48 \\
18 & 42 & 21,4 & 10,90 \\
19 & 42 & 20,9 & 10,64 \\
20 & 42 & 26,4 & 13,45 \\
\hline Média & & & $\mathbf{1 2 , 2 1}$ \\
C.V. & & & $\mathbf{1 3 \%}$ \\
\hline & & &
\end{tabular}

Posteriormente foram ensaiados mais três corpos-de-prova de argamassa, confeccionados em outra ocasião. Estes foram instrumentados com dois extensômetros elétricos cada, para que se pudesse traçar as curvas tensão-deformação correspondentes, com o objetivo de estimar o módulo de elasticidade da argamassa. Os resultados obtidos encontram-se na Tabela 3.12, em que $\mathrm{E}_{\mathrm{ai}}$ é o módulo de elasticidade tangente inicial.

Tabela 3.12 Módulo de elasticidade da argamassa.

\begin{tabular}{ccccc}
\hline AMOSTRA & $\begin{array}{c}\text { IDADE } \\
\text { (dias) }\end{array}$ & $\begin{array}{c}\text { CARGA DE } \\
\text { RUPTURA }(\mathrm{kN})\end{array}$ & $\begin{array}{c}\text { TENSÃO NA } \\
\text { RUPTURA (MPa) }\end{array}$ & $\begin{array}{c}\mathrm{E}_{\mathrm{ai}} \\
(\mathrm{MPa})\end{array}$ \\
\hline 1 & 49 & 28,4 & 14,46 & 14810 \\
2 & 49 & 28,0 & 14,26 & 14879 \\
3 & 49 & 36,7 & 18,69 & 16122 \\
\hline Média & & & $\mathbf{1 5 , 8 1}$ & $\mathbf{1 5 2 7 0}$ \\
C.V. & & & $\mathbf{1 6 \%}$ & $\mathbf{5 \%}$ \\
\hline
\end{tabular}

\subsubsection{Prismas}

Utilizando os materiais descritos anteriormente, foram construídos 18 prismas de três blocos. Todos foram submetidos somente a ensaios de compressão. Optou-se por realizar os ensaios em diversas idades para verificar a evolução da resistência com o tempo. 
Assim pôde-se verificar experimentalmente a validade da afirmação contida em PAGE (1978) de que "a resistência à compressão da alvenaria desenvolve-se rapidamente, atingindo de $70 \%$ a $100 \%$ da resistência aos 28 dias em apenas sete dias". Os resultados estão apresentados na Tabela 3.13, enquanto que se observa pelo gráfico da Figura 3.25 a regressão linear caracterizando a constância da resistência com a idade, uma vez que sua inclinação é mínima.

Tabela 3.13 Resistência dos prismas à compressão.

\begin{tabular}{ccccc}
\hline AMOSTRA & $\begin{array}{c}\text { IDADE } \\
\text { (dias) }\end{array}$ & $\begin{array}{c}\text { CARGA DE } \\
\text { RUPTURA (kN) }\end{array}$ & $\begin{array}{c}\text { TENSÃO NA } \\
\text { RUPURA (MPa) }\end{array}$ & $\begin{array}{c}\text { Média (MPa) } \\
\text { e C.V. }\end{array}$ \\
\hline 1 & 8 & 92,2 & 20,32 & $\mathbf{1 9 , 5 7}$ \\
2 & 8 & 101,8 & 22,43 & $\mathbf{1 7 \%}$ \\
3 & 8 & 72,5 & 15,97 & \\
\hline 4 & 14 & 57,2 & $*$ & \\
5 & 14 & 91,2 & 20,10 & $\mathbf{1 8 , 7 2}$ \\
6 & 14 & 87,0 & 19,17 & $\mathbf{8 \%}$ \\
7 & 14 & 78,5 & 17,30 & \\
8 & 14 & 77,9 & 17,16 & \\
9 & 14 & 90,3 & 19,90 & $\mathbf{2 0 , 4 7}$ \\
10 & 21 & 93,0 & 20,49 & $\mathbf{1 3 \%}$ \\
11 & 21 & 105,1 & 23,16 & \\
12 & 21 & 80,6 & 17,76 & $\mathbf{9 \%}$ \\
\hline 13 & 28 & 89,0 & 19,61 & \\
14 & 28 & 86,2 & 18,99 & \\
15 & 28 & 69,1 & $*$ & \\
16 & 28 & 89,5 & 19,72 & \\
17 & 28 & 73,5 & 16,20 & \\
18 & 28 & 63,7 & $*$ & $\mathbf{1 9 , 2 2}$ \\
\hline Média & & & $\mathbf{1 2 \%}$ & \\
C.V. & & & & \\
\hline
\end{tabular}

(*) Valor desprezado devido à falta de prumo do prisma. 


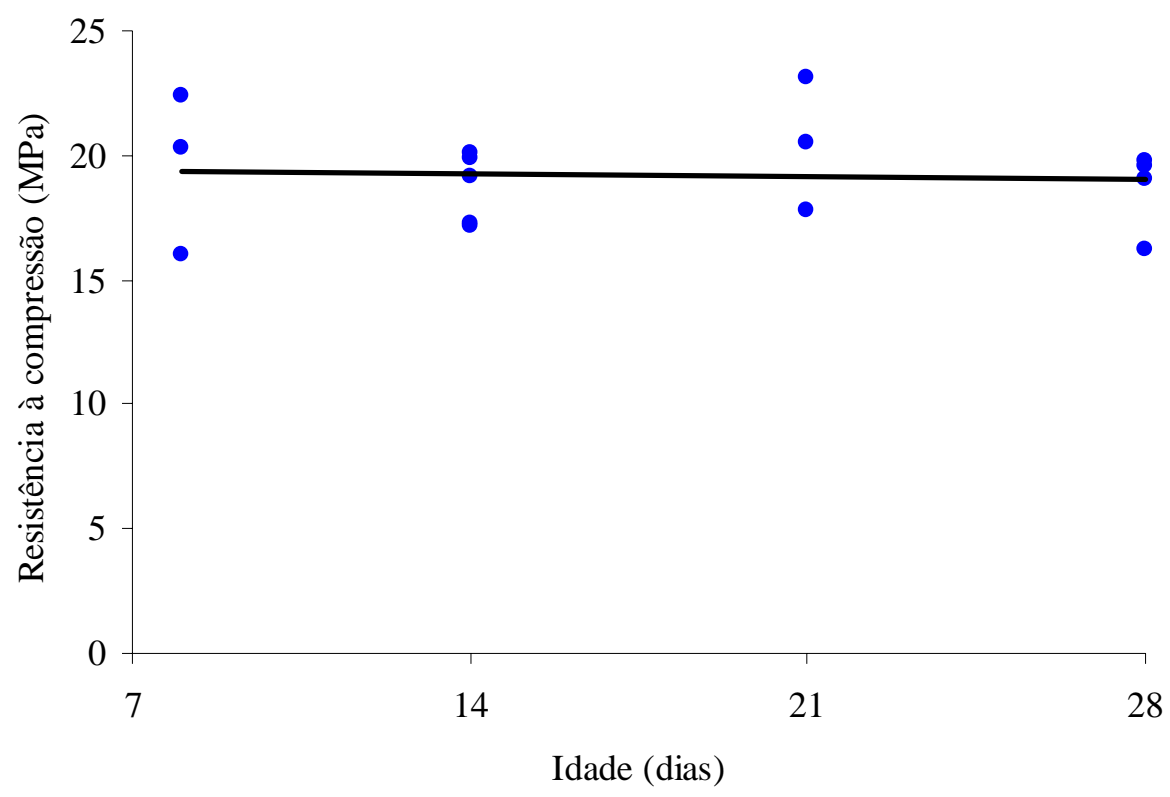

Figura 3.25 Evolução da resistência dos prismas com a idade.

\subsubsection{Paredinhas}

Com a finalidade de obtenção dos parâmetros elásticos da alvenaria propriamente dita, procedeu-se ao ensaio de paredinhas representativas do material alvenaria. Suas dimensões, determinadas por medição direta, encontram-se na Tabela 3.14. Foram realizados ensaios de compressão axial e de compressão diagonal, cada um aplicado a um conjunto de três paredinhas. Os esquemas dos ensaios podem ser visualizados na Figura 3.26.

Tabela 3.14 Dimensões das paredinhas (cm).

\begin{tabular}{c|c|c|c|c|c|c|c}
\hline \multirow{2}{*}{ PAREDE } & \multicolumn{3}{|c|}{ ALTURA } & \multicolumn{3}{c|}{ LARGURA } & \multirow{2}{*}{ TIPO DE } \\
\cline { 2 - 6 } & $1^{\text {a }}$ medida & $2^{\text {a }}$ medida & Média & $1^{\text {a }}$ medida & $2^{\text {a }}$ medida & Média & ENSAIO \\
\hline A1 & 40,6 & 40,4 & $\mathbf{4 0 , 5}$ & 39,7 & 39,8 & $\mathbf{3 9 , 7}$ & Compressão axial \\
A2 & 40,4 & 40,2 & $\mathbf{4 0 , 3}$ & 40,5 & 40,1 & $\mathbf{4 0 , 3}$ & Compressão axial \\
A3 & 40,4 & 40,5 & $\mathbf{4 0 , 5}$ & 40,2 & 40,1 & $\mathbf{4 0 , 2}$ & Compressão axial \\
\hline D1 & 40,4 & 40,2 & $\mathbf{4 0 , 3}$ & 40,5 & 40,2 & $\mathbf{4 0 , 3}$ & Compr. diagonal \\
D2 & 40,2 & 40,3 & $\mathbf{4 0 , 3}$ & 40,5 & 40,6 & $\mathbf{4 0 , 5}$ & Compr. diagonal \\
D3 & 40,4 & 40,3 & $\mathbf{4 0 , 4}$ & 40,4 & 40,2 & $\mathbf{4 0 , 3}$ & Compr. diagonal \\
\hline
\end{tabular}




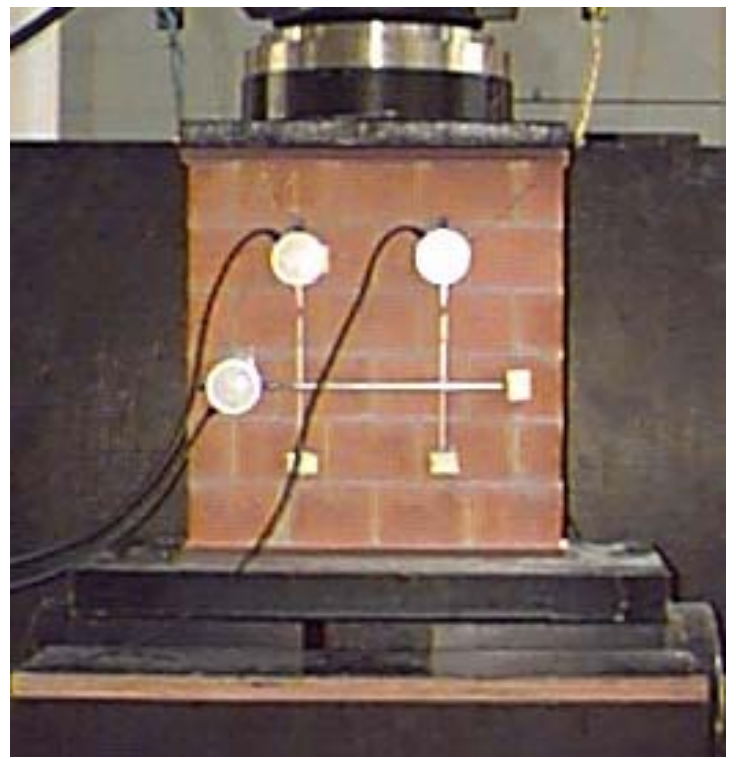

(a)

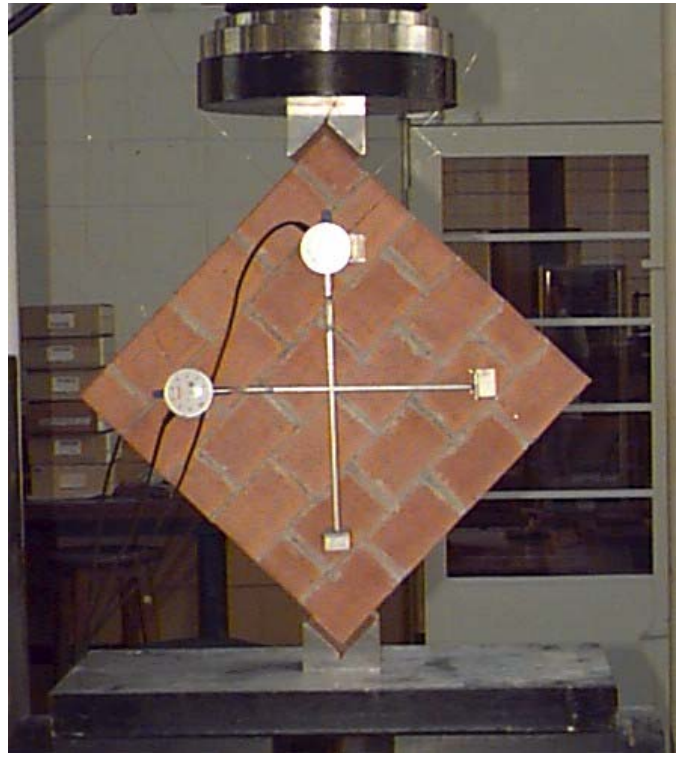

(b)

Figura 3.26 Esquemas de ensaio. (a) Compressão axial. (b) Compressão diagonal.

Nos ensaios de compressão axial, quatro medições de encurtamentos verticais foram tomadas em cada modelo, sendo duas por face, por meio de transdutores de deslocamento, conforme a fotografia da Figura 3.26a. Estes resultados foram utilizados na estimativa do módulo de elasticidade longitudinal da alvenaria na direção vertical. $\mathrm{O}$ valor adotado para este parâmetro corresponde à inclinação do gráfico tensão-deformação no seu trecho linear. Assumiu-se esse trecho como compreendido entre 5\% e 33\% da tensão de ruptura, de acordo com a recomendação apresentada no ACI 530R-92 (1994). O gráfico da Figura 3.27 contém os trechos lineares dos três modelos.

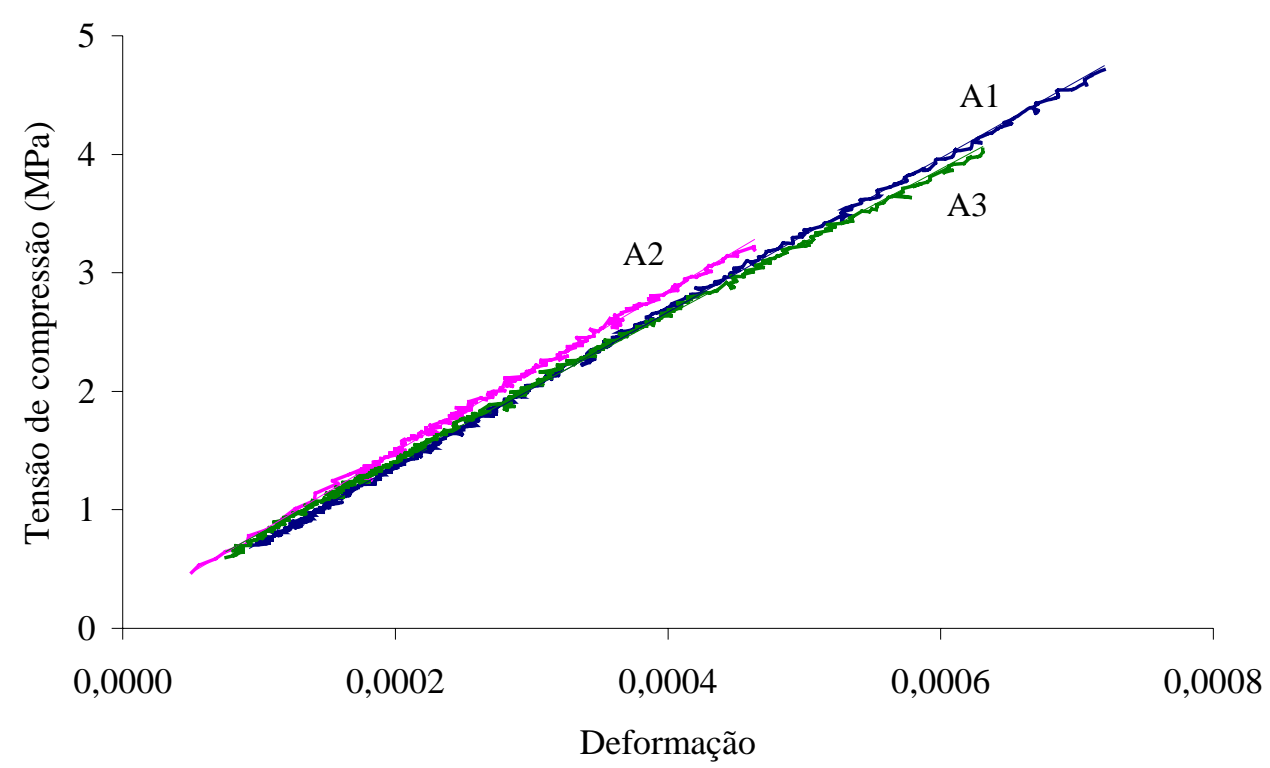

Figura 3.27 Trechos lineares dos gráficos tensão-deformação das paredinhas A1, A2 e A3. 
Neste ensaio buscou-se estimar também o coeficiente de Poisson da alvenaria com medições dos alongamentos transversais nas duas faces de cada paredinha, como ilustrado na Figura 3.26a. Para cada leitura, calculou-se este coeficiente como a razão entre a média das deformações horizontais e a média das deformações verticais. Finalmente, o coeficiente de Poisson estimado para cada modelo corresponde à média das razões anteriores compreendidas no intervalo do trecho linear, definido anteriormente.

Na Tabela 3.15 encontram-se organizados os valores das cargas e tensões de ruptura, dos módulos de elasticidade longitudinal e dos coeficientes de Poisson. Adotaram-se as médias desses valores como valores característicos da alvenaria utilizada nesta pesquisa.

Tabela 3.15 Resultados dos ensaios de compressão axial.

\begin{tabular}{ccccc}
\hline \multirow{2}{*}{ PAREDINHA } & $\begin{array}{c}\text { CARGA DE } \\
\text { RUPTURA }(\mathrm{kN})\end{array}$ & $\begin{array}{c}\text { TENSÃO NA } \\
\text { RUPTURA }(\mathrm{MPa})\end{array}$ & $\begin{array}{c}\mathrm{E}_{\text {alv }} \\
(\mathrm{MPa})\end{array}$ & $v$ \\
\hline A1 & 260,2 & 14,09 & 6493 & 0,09 \\
$\mathrm{~A} 2$ & 180,3 & 9,63 & 6796 & 0,11 \\
A3 & 226,5 & 12,13 & 6149 & 0,11 \\
\hline Média & $\mathbf{2 2 2 , 3}$ & $\mathbf{1 1 , 9 5}$ & $\mathbf{6 4 7 9}$ & $\mathbf{0 , 1 0}$ \\
C.V. & $\mathbf{1 8 \%}$ & $\mathbf{1 9 \%}$ & $\mathbf{5 \%}$ & $\mathbf{1 1 \%}$ \\
\hline
\end{tabular}

O ensaio de compressão diagonal foi realizado adaptando-se as prescrições da NBR 14321 (1999) para a escala 1:3. O esquema de ensaio está representado na Figura 3.26b. Para o valor do módulo de elasticidade transversal da alvenaria optou-se por adotar a inclinação da reta de regressão linear do trecho compreendido entre $20 \%$ e $50 \%$ da carga de ruptura da paredinha no gráfico (tensão de cisalhamento)-distorção, o que está representado na Figura 3.28. A Tabela 3.16 traz os valores calculados para o módulo de elasticidade transversal dos três modelos. 


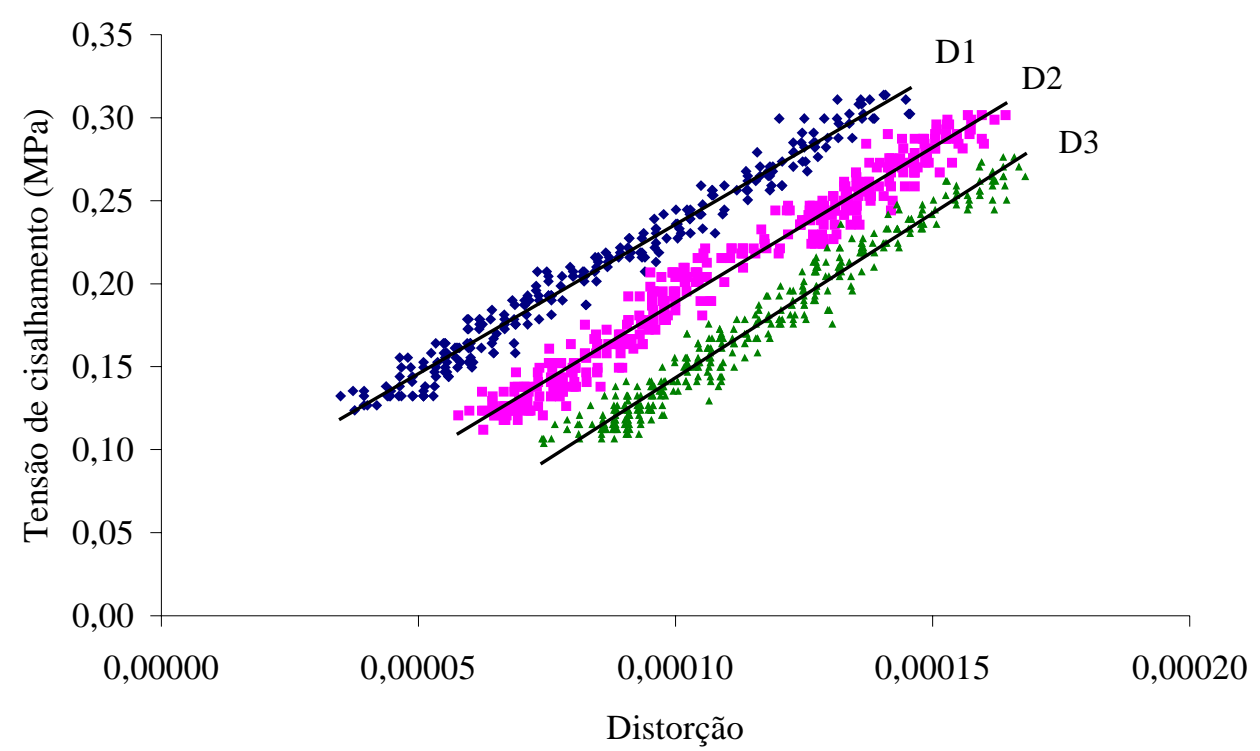

Figura 3.28 Trechos lineares dos gráficos (tensão de cisalhamento)-distorção das paredinhas D1, D2 e D3.

Tabela 3.16 Resultados dos ensaios de compressão diagonal.

\begin{tabular}{cccc}
\hline PAREDINHA & $\begin{array}{c}\text { CARGA DE } \\
\text { RUPTURA }(\mathrm{kN})\end{array}$ & $\begin{array}{c}\text { TENSÃO* NA } \\
\text { RUPTURA }(\mathrm{MPa})\end{array}$ & $\begin{array}{c}\mathrm{G}_{\text {alv }} \\
(\mathrm{MPa})\end{array}$ \\
\hline D1 & 16,6 & 0,63 & 1797 \\
D2 & 16,0 & 0,60 & 1869 \\
D3 & 14,3 & 0,54 & 1983 \\
\hline Média & $\mathbf{1 5 , 6}$ & $\mathbf{0 , 5 9}$ & $\mathbf{1 8 8 3}$ \\
C.V. & $\mathbf{8 \%}$ & $\mathbf{8 \%}$ & $\mathbf{5 \%}$ \\
\hline
\end{tabular}

(*) Tensão de cisalhamento.

\subsubsection{Juntas}

Seguindo as recomendações de JUKES \& RIDDINGTON (1997) e de OLIARI \& DUARTE (2000), optou-se por realizar ensaios de tripletas para caracterizar a resistência ao cisalhamento da junta de alvenaria. Como este estudo envolve paredes de alvenaria sobre vigas de concreto, e essa interface apresenta propriedades que podem ser importantes para o problema, procurou-se caracterizar as juntas que unem os blocos ao concreto por meio do ensaio de tripletas em que os blocos cerâmicos de extremidade foram substituídos por blocos maciços de concreto. Dessa forma têm-se duas juntas idênticas bloco-concreto.

Foram aplicados quatro níveis distintos de pré-compressão, entre 0 (zero) e $2 \mathrm{MPa}$ na área bruta, correspondente à tensão máxima aplicada à parede nos ensaios dos painéis. A Figura 3.29 apresenta com foi montado o esquema de ensaio. Os resultados obtidos estão organizados na Tabela 3.17. 


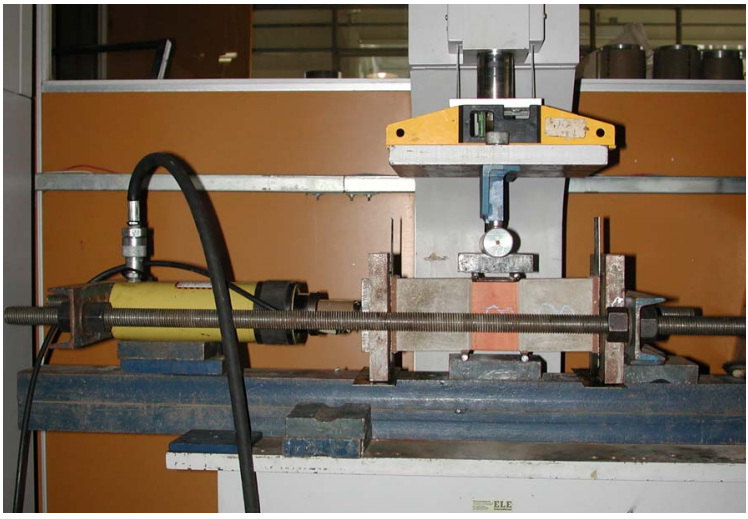

(a)

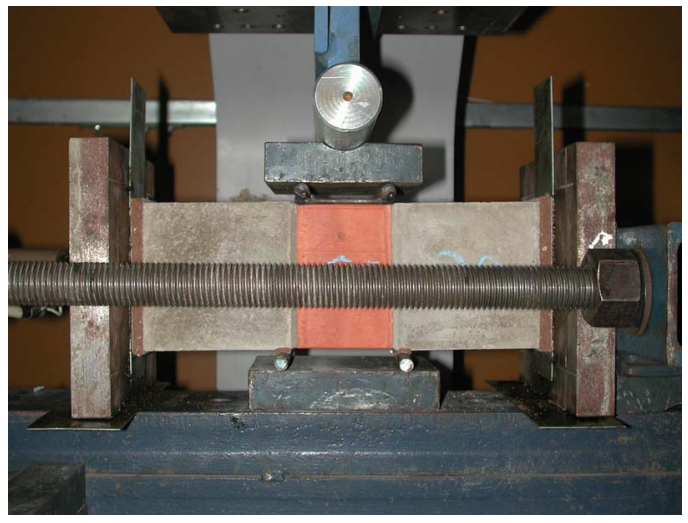

(b)

Figura 3.29 (a) Fotografia do ensaio em andamento. (b) Detalhe da tripleta.

Tabela 3.17 Resultados dos ensaios de cisalhamento nas juntas bloco-concreto.

\begin{tabular}{|c|c|c|c|c|c|c|c|}
\hline \multirow{3}{*}{ AMOSTRA } & \multirow{3}{*}{$\begin{array}{l}\text { IDADE } \\
\text { (dias) }\end{array}$} & \multicolumn{3}{|c|}{ PRECOMPRESSÃO } & \multirow{3}{*}{$\begin{array}{c}\text { CARGA DE } \\
\text { RUPTURA } \\
(\mathrm{kN})\end{array}$} & \multirow{2}{*}{\multicolumn{2}{|c|}{$\begin{array}{c}\text { TENSÃO NA } \\
\text { RUPTURA (MPa) }\end{array}$}} \\
\hline & & \multicolumn{2}{|c|}{ Tensão (MPa) } & \multirow{2}{*}{$\begin{array}{l}\text { Força } \\
(\mathrm{kN})\end{array}$} & & & \\
\hline & & $\mathrm{A}_{\text {bruta }}$ & $\mathrm{A}_{\text {líq }}$ & & & $\mathrm{A}_{\text {bruta }}$ & $\mathrm{A}_{\text {líq }}$ \\
\hline 1 & 13 & 0 & 0 & 0 & 4,17 & 0,46 & 0,84 \\
\hline 2 & 13 & 0 & 0 & 0 & 3,09 & 0,34 & 0,62 \\
\hline 3 & 13 & 0 & 0 & 0 & 3,01 & 0,33 & 0,60 \\
\hline 4 & 13 & 0 & 0 & 0 & 4,79 & 0,53 & 0,96 \\
\hline 5 & 13 & 0 & 0 & 0 & 3,89 & 0,43 & 0,78 \\
\hline 6 & 13 & 0 & 0 & 0 & 2,70 & 0,30 & 0,54 \\
\hline Média & & & & & 3,61 & 0,40 & $\mathbf{0 , 7 2}$ \\
\hline C.V. & & & & & & $22 \%$ & $22 \%$ \\
\hline 7 & 14 & 0,66 & 1,2 & 3 & 9,37 & 1,03 & 1,88 \\
\hline 8 & 14 & 0,66 & 1,2 & 3 & 12,28 & 1,35 & 2,46 \\
\hline 9 & 14 & 0,66 & 1,2 & 3 & 7,75 & 0,85 & 1,55 \\
\hline 10 & 14 & 0,66 & 1,2 & 3 & 10,04 & 1,11 & 2,01 \\
\hline Média & & & & & 9,86 & 1,09 & 1,98 \\
\hline C.V. & & & & & & $19 \%$ & $19 \%$ \\
\hline 11 & 14 & 1,33 & 2,4 & 6 & 15,49 & 1,71 & 3,10 \\
\hline 12 & 14 & 1,33 & 2,4 & 6 & 14,68 & 1,62 & 2,94 \\
\hline 13 & 14 & 1,33 & 2,4 & 6 & 12,17 & 1,34 & 2,44 \\
\hline 14 & 14 & 1,33 & 2,4 & 6 & 15,56 & 1,71 & 3,12 \\
\hline Média & & & & & 14,48 & 1,59 & 2,90 \\
\hline C.V. & & & & & & $11 \%$ & $11 \%$ \\
\hline 15 & 14 & 2 & 3,6 & 9 & 16,87 & 1,86 & 3,38 \\
\hline 16 & 14 & 2 & 3,6 & 9 & 17,42 & 1,92 & 3,49 \\
\hline 17 & 14 & 2 & 3,6 & 9 & 18,09 & 1,99 & 3,62 \\
\hline 18 & 14 & 2 & 3,6 & 9 & 16,04 & 1,77 & 3,21 \\
\hline Média & & & & & 17,11 & $\mathbf{1 , 8 8}$ & 3,43 \\
\hline C.V. & & & & & & $5 \%$ & $5 \%$ \\
\hline
\end{tabular}

Seguindo a recomendação da literatura, multiplicou-se o valor de $\tau_{0}$ por 1,5 para a construção do gráfico do critério de ruptura. Como os valores de pré-compressão aplicados ultrapassaram o limite de $2 \mathrm{MPa}$ na área líquida, duas retas foram obtidas. O valor do 
coeficiente de atrito interno foi obtido no gráfico. A equação do tipo Coulomb correspondente à primeira reta ficou então da seguinte forma (valores na área bruta):

$$
\tau_{\mathrm{u}}=0,6+0,75 \sigma_{\mathrm{c}} .
$$

Ou seja, $\tau_{0}=0,6 \mathrm{MPa}$ e $\mu=0,75$.

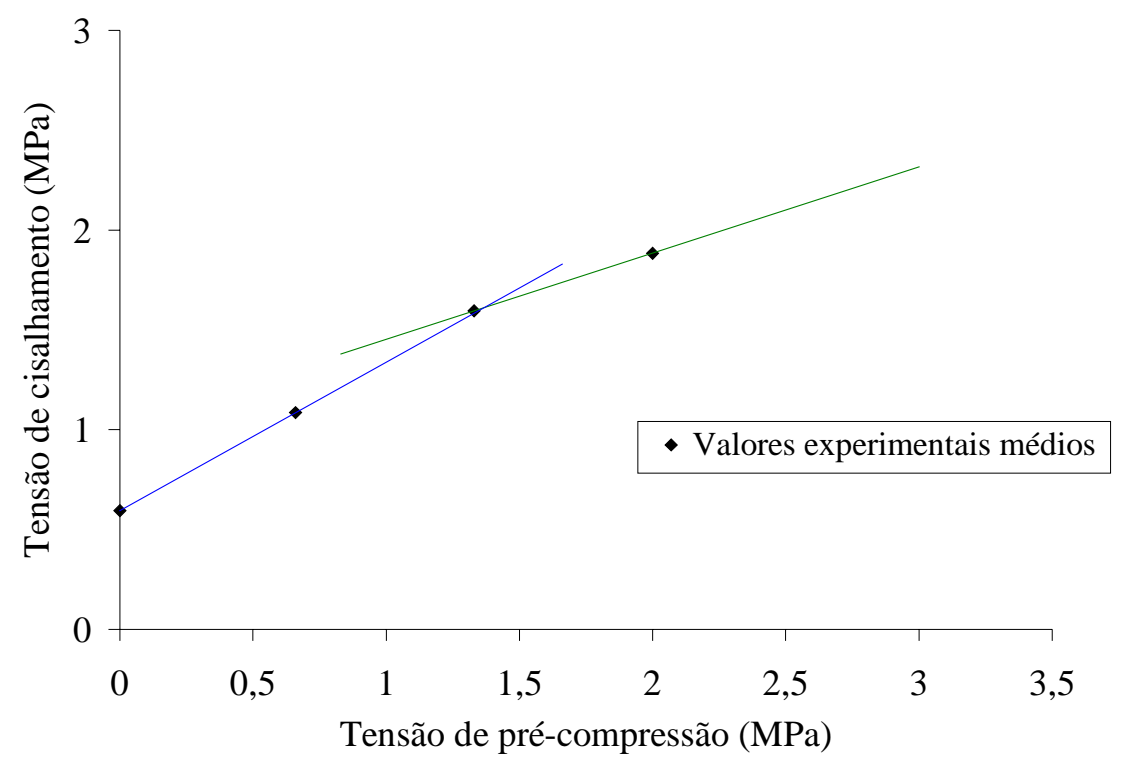

Figura 3.30 Ruptura ao cisalhamento das juntas bloco-concreto (valores de tensão na área bruta).

\subsubsection{Composições granulométricas}

Nesta seção são apresentados os resultados dos ensaios de granulometria dos agregados utilizados nesta pesquisa. Atenção especial foi dada à areia empregada na argamassa devido à exigência de finura para seu uso na alvenaria em escala reduzida. Em seguida trata-se dos agregados utilizados na mistura do concreto das vigas. Pelo mesmo motivo de redução da escala dos ensaios, a brita, normalmente utilizada no concreto, foi substituída por pedrisco a fim de que se obedecessem aos limites quanto à dimensão máxima do agregado, recomendados pela NBR 6118 (2001).

A fim de que fosse possível construir a alvenaria com juntas de espessura muito pequena, já que se empregou a escala reduzida 1:3 nos ensaios realizados, procurou-se adquirir uma areia muito fina para ser utilizada na argamassa. Sua composição granulométrica, cuja determinação foi realizada de acordo com a NBR 7217 (1987), encontra-se na Tabela 3.18. Nesta tabela também podem ser verificados os principais parâmetros granulométricos, calculados segundo a mesma norma. 
Tabela 3.18 Composição granulométrica da areia da argamassa.

\begin{tabular}{|c|c|c|c|c|c|c|}
\hline PENEIRA & \multicolumn{2}{|c|}{ 1슬 AMSTRA } & \multicolumn{2}{|c|}{$2^{\mathrm{a}}$ AMOSTRA } & \multicolumn{2}{|c|}{ MÉDIAS } \\
\hline $\begin{array}{l}\text { Abertura } \\
(\mathrm{mm})\end{array}$ & $\begin{array}{l}\text { Massa } \\
\text { retida }(g)\end{array}$ & $\%$ Retida & $\begin{array}{l}\text { Massa } \\
\text { retida }(\mathrm{g})\end{array}$ & $\%$ Retida & $\%$ Retida & $\begin{array}{l}\text { \% Retida } \\
\text { acumulada }\end{array}$ \\
\hline 9,5 & 0,0 & $0,0 \%$ & 0,0 & $0,0 \%$ & $0,0 \%$ & $0,0 \%$ \\
\hline 6,3 & 0,0 & $0,0 \%$ & 0,0 & $0,0 \%$ & $0,0 \%$ & $0,0 \%$ \\
\hline 4,8 & 0,0 & $0,0 \%$ & 0,0 & $0,0 \%$ & $0,0 \%$ & $0,0 \%$ \\
\hline 2,4 & 0,1 & $0,0 \%$ & 0,6 & $0,1 \%$ & $0,1 \%$ & $0,1 \%$ \\
\hline 1,2 & 0,3 & $0,1 \%$ & 0,3 & $0,1 \%$ & $0,1 \%$ & $0,1 \%$ \\
\hline 0,6 & 1,6 & $0,3 \%$ & 1,4 & $0,3 \%$ & $0,3 \%$ & $0,4 \%$ \\
\hline 0,3 & 237,0 & $47,4 \%$ & 253,9 & $50,9 \%$ & $49,2 \%$ & $49,6 \%$ \\
\hline 0,15 & 212,5 & $42,5 \%$ & 190,2 & $38,1 \%$ & $40,3 \%$ & $89,9 \%$ \\
\hline Fundo & 48,2 & $9,6 \%$ & 52,7 & $10,6 \%$ & $10,1 \%$ & $100,0 \%$ \\
\hline Soma & 499,7 & $100,0 \%$ & 499,1 & $100,0 \%$ & $100,0 \%$ & \\
\hline \multicolumn{5}{|c|}{$\begin{array}{l}\text { Dimensão máxima característica do agregado: } \\
\text { Módulo de finura: }\end{array}$} & $\begin{array}{c}0,6 \mathrm{~mm} \\
1,40\end{array}$ & \\
\hline
\end{tabular}

Verifica-se que, segundo os limites granulométricos estabelecidos pela NBR 7211 (1983), esta areia é classificada como muito fina, estando próxima ao limite mínimo dessa classificação, conforme pode ser visualizado na Figura 3.31. A argamassa feita com esta areia mostrou-se bastante adequada para a confecção das juntas da alvenaria.

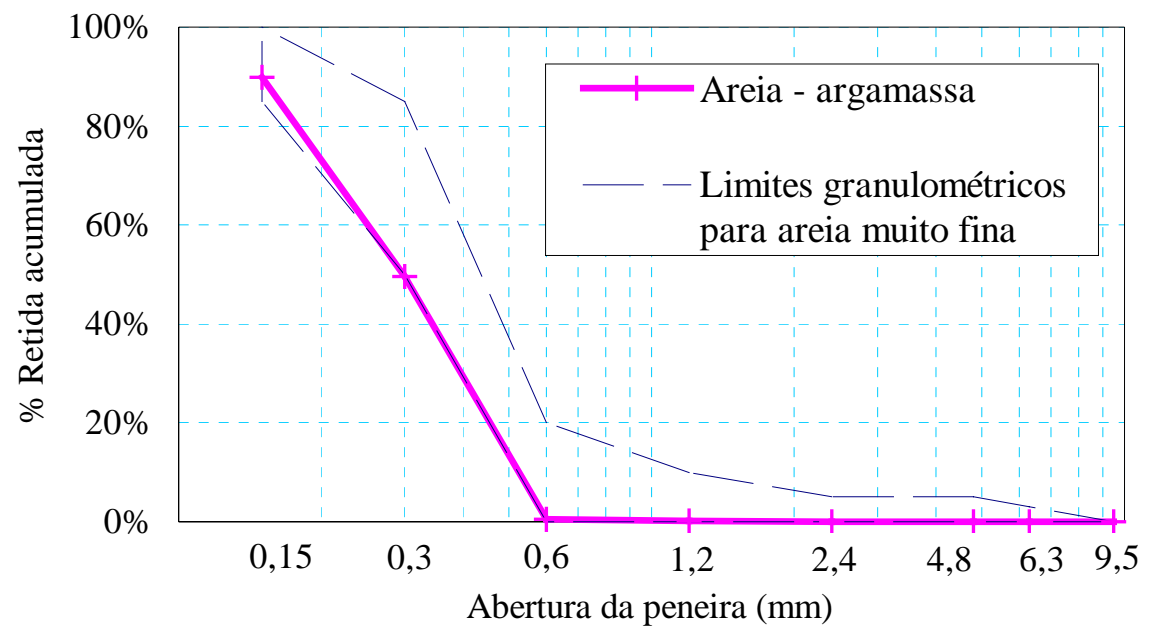

Figura 3.31 Curva granulométrica da areia da argamassa.

A areia utilizada para a confecção do concreto constituinte das vigas caracteriza-se como média a fina, segundo a NBR 7211 (1983). Os resultados do ensaio de granulometria são apresentados na Tabela 3.19. Na Tabela 3.20 encontra-se a composição granulométrica do pedrisco utilizado como agregado graúdo do concreto. 
Tabela 3.19 Composição granulométrica da areia do concreto.

\begin{tabular}{c|cc|cr|rr}
\hline PENEIRA & \multicolumn{2}{|c|}{$1^{\text {a }}$ AMOSTRA } & \multicolumn{2}{|c|}{$2^{-}$AMOSTRA } & \multicolumn{2}{c}{ MÉDIAS } \\
\hline $\begin{array}{c}\text { Abertura } \\
(\mathrm{mm})\end{array}$ & $\begin{array}{c}\text { Massa } \\
\text { retida }(\mathrm{g})\end{array}$ & $\%$ Retida & $\begin{array}{c}\text { Massa } \\
\text { retida }(\mathrm{g})\end{array}$ & $\%$ Retida & $\%$ Retida $\begin{array}{c}\text { \% Retida } \\
\text { acumulada }\end{array}$ \\
\hline 9,5 & 0,0 & $0,0 \%$ & 1,9 & $0,3 \%$ & $0,1 \%$ & $0,1 \%$ \\
6,3 & 4,1 & $0,6 \%$ & 2,3 & $0,4 \%$ & $0,5 \%$ & $0,6 \%$ \\
4,8 & 5,4 & $0,8 \%$ & 2,4 & $0,4 \%$ & $0,6 \%$ & $1,2 \%$ \\
2,4 & 26,3 & $3,8 \%$ & 27,4 & $4,3 \%$ & $4,0 \%$ & $5,2 \%$ \\
1,2 & 84,2 & $12,0 \%$ & 76,8 & $12,0 \%$ & $12,0 \%$ & $17,2 \%$ \\
0,6 & 172,3 & $24,7 \%$ & 155,9 & $24,4 \%$ & $24,5 \%$ & $41,8 \%$ \\
0,3 & 228,4 & $32,7 \%$ & 208,5 & $32,6 \%$ & $32,6 \%$ & $74,4 \%$ \\
0,15 & 159,9 & $22,9 \%$ & 147,2 & $23,0 \%$ & $22,9 \%$ & $97,3 \%$ \\
Fundo & 18,2 & $2,6 \%$ & 17,3 & $2,7 \%$ & $2,7 \%$ & $100,0 \%$ \\
\hline
\end{tabular}

Tabela 3.20 Composição granulométrica do pedrisco.

\begin{tabular}{c|cc|rr|rr}
\hline PENEIRA & \multicolumn{2}{|c|}{$1^{\text {a }}$ AMOSTRA } & \multicolumn{2}{|c|}{$2^{\text {a }}$ AMOSTRA } & \multicolumn{2}{c}{ MÉDIAS } \\
\hline $\begin{array}{c}\text { Abertura } \\
(\mathrm{mm})\end{array}$ & $\begin{array}{c}\text { Massa } \\
\text { retida }(\mathrm{g})\end{array}$ & $\%$ Retida & $\begin{array}{c}\text { Massa } \\
\text { retida }(\mathrm{g})\end{array}$ & $\%$ Retida & $\%$ Retida $\begin{array}{c}\text { \% Retida } \\
\text { acumulada }\end{array}$ \\
\hline 9,5 & 0,0 & $0,0 \%$ & 0,0 & $0,0 \%$ & $0,0 \%$ & $0,0 \%$ \\
6,3 & 54,0 & $4,2 \%$ & 57,1 & $4,4 \%$ & $4,3 \%$ & $4,3 \%$ \\
4,8 & 332,2 & $25,8 \%$ & 298,6 & $23,2 \%$ & $24,5 \%$ & $28,8 \%$ \\
2,4 & 719,6 & $55,9 \%$ & 751,3 & $58,4 \%$ & $57,1 \%$ & $85,9 \%$ \\
1,2 & 146,8 & $11,4 \%$ & 139,4 & $10,8 \%$ & $11,1 \%$ & $97,0 \%$ \\
0,6 & 23,3 & $1,8 \%$ & 26,0 & $2,0 \%$ & $1,9 \%$ & $98,9 \%$ \\
0,3 & 3,1 & $0,2 \%$ & 6,2 & $0,5 \%$ & $0,4 \%$ & $99,3 \%$ \\
0,15 & 1,3 & $0,1 \%$ & 2,0 & $0,2 \%$ & $0,1 \%$ & $99,4 \%$ \\
Fundo & 8,1 & $0,6 \%$ & 6,7 & $0,5 \%$ & $0,6 \%$ & $100,0 \%$ \\
\hline
\end{tabular}

\subsubsection{Considerações sobre os ensaios de caracterização}

A partir dos resultados apresentados podem ser calculadas as diversas eficiências entre os elementos e unidades de alvenaria. Define-se eficiência como a relação entre as resistências à compressão. Os valores obtidos estão condensados na Tabela 3.21.

Tabela 3.21 Eficiências de prismas e paredinhas.

\begin{tabular}{c|c|c}
\hline \multirow{2}{*}{$\begin{array}{c}\text { EFICIÊNCIA } \\
\text { DE... }\end{array}$} & \multicolumn{2}{|c}{ COM RELAÇ̃̃O A... } \\
\cline { 2 - 3 } & Bloco & Prisma \\
\hline Prisma & 0,66 & - \\
\hline Paredinha & 0,41 & 0,62 \\
\hline
\end{tabular}

Quanto aos modos de ruptura, verificou-se que os modelos reduzidos de unidades e elementos de alvenaria reproduziram fielmente as configurações normalmente 
observadas em escala real, de acordo com as descrições presentes em GALLEGOS (1989) e DRYSDALE et al. (1994). Os blocos e prismas apresentaram diversas fissuras verticais ao longo das quatro faces. A ruptura aconteceu de forma brusca, devido à elevada resistência à compressão e ao comportamento frágil dos blocos. Na Figura 3.32 encontram-se fotografias feitas após a realização dos ensaios de prismas.
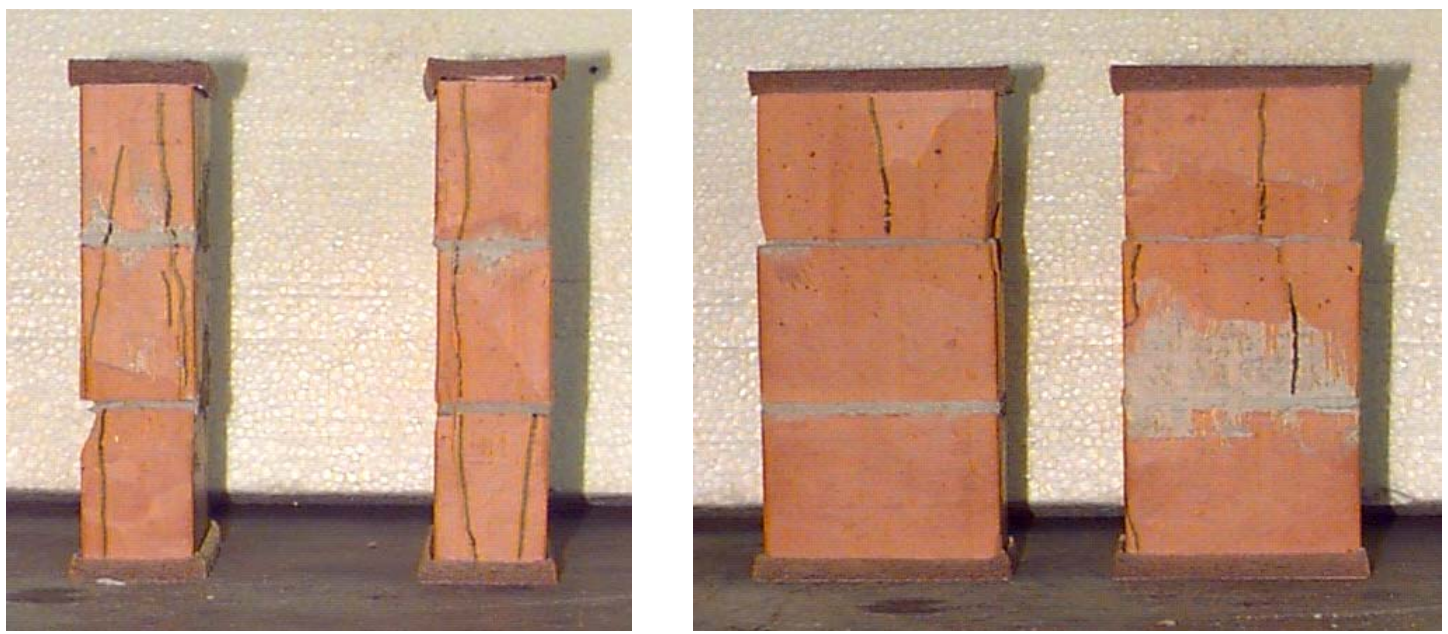

Figura 3.32 Modo de ruptura dos prismas.

As paredinhas submetidas à compressão axial também apresentaram fissuras verticais ao longo de suas faces. Normalmente, as fissuras passaram pelos blocos e pelas juntas verticais, separando bloco e argamassa. No instante da ruptura, alguns blocos chegaram a romper completamente. A Figura 3.33 ilustra o modo de ruptura observado nos ensaios.

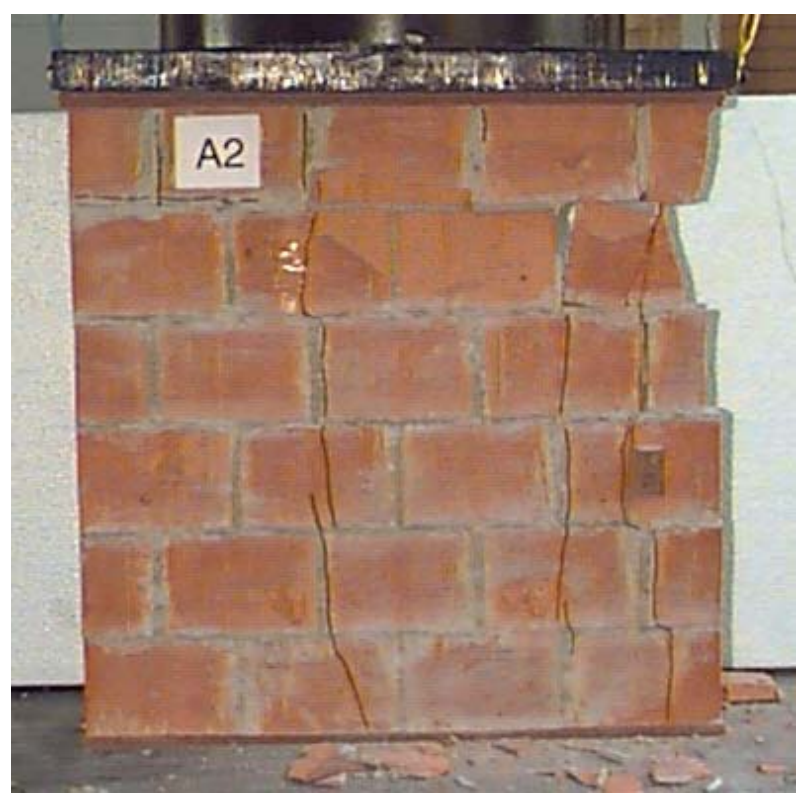

Figura 3.33 Modo de ruptura da paredinha A2. 
GALLEGOS (1989) apresenta três configurações possíveis para a ruptura das paredinhas submetidas ao ensaio de compressão diagonal: (a) fissura escalonada, passando sucessivamente por juntas verticais e horizontais; (b) deslizamento ao longo de juntas horizontais; e (c) fissura diagonal por tração atravessando blocos. A Figura 3.34 apresenta esquemas dos três modos de ruptura. Nos ensaios realizados observou-se basicamente um misto de formação de fissuras escalonadas e deslizamento ao longo das juntas horizontais, conforme ilustrado na fotografia da Figura 3.35.

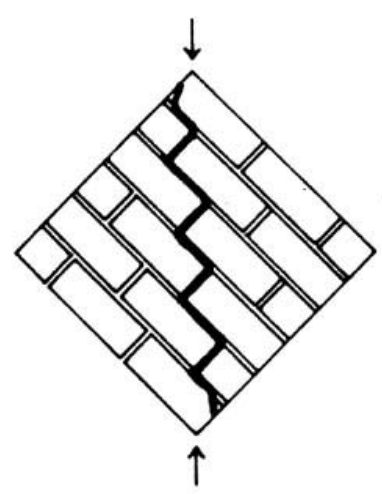

(a)

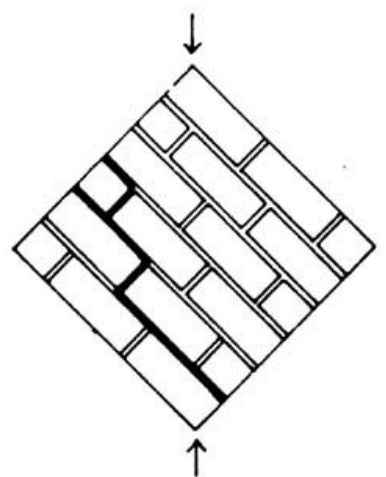

(b)

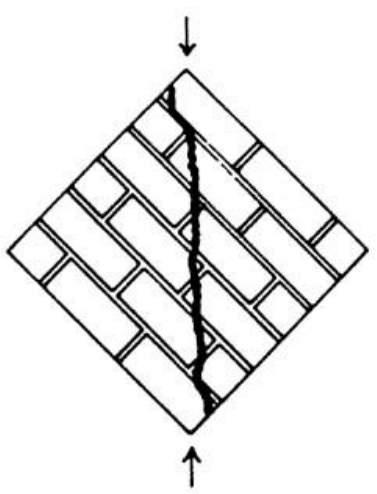

(c)

Figura 3.34 Modos de ruptura possíveis no ensaio de compressão diagonal (GALLEGOS, 1989).

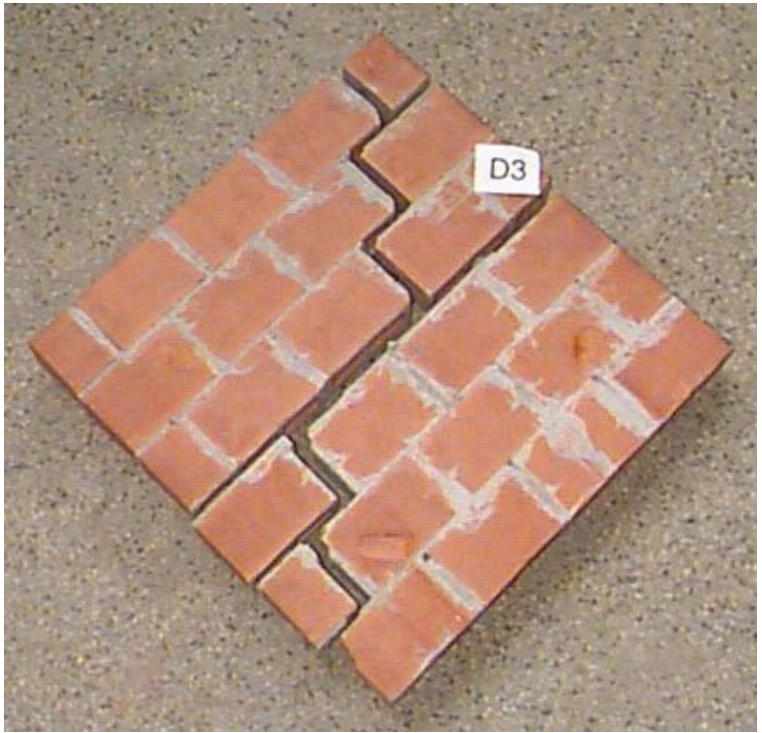

Figura 3.35 Modo de ruptura da paredinha D3. 


\section{RESULTADOS EXPERIMENTAIS}

Neste capítulo são apresentados e discutidos os fatos observados em cada ensaio, bem como os principais resultados obtidos. Os resultados específicos da região de contato, com as penetrações, separações e deslizamentos, são apresentados e discutidos no capítulo seguinte, em que se faz a comparação com as análises numéricas. Em anexo podem ser encontradas todas as leituras da instrumentação utilizada nos ensaios.

Antes, porém, definem-se os parâmetros relacionados ao recalque que serão utilizados na análise dos resultados. Na Figura 4.1 encontram-se esquematizadas de maneira genérica as configurações inicial e deformada das vigas dos modelos. Os pontos de referência (A a E) correspondem àqueles onde se fizeram as leituras durante os ensaios. Considere-se que, após a deformação da viga, esses pontos passaram paras as posições A' a E'. Daí são definidos os diversos parâmetros, definidos na literatura, que buscam caracterizar as curvaturas da viga. Dessa forma, tem-se:

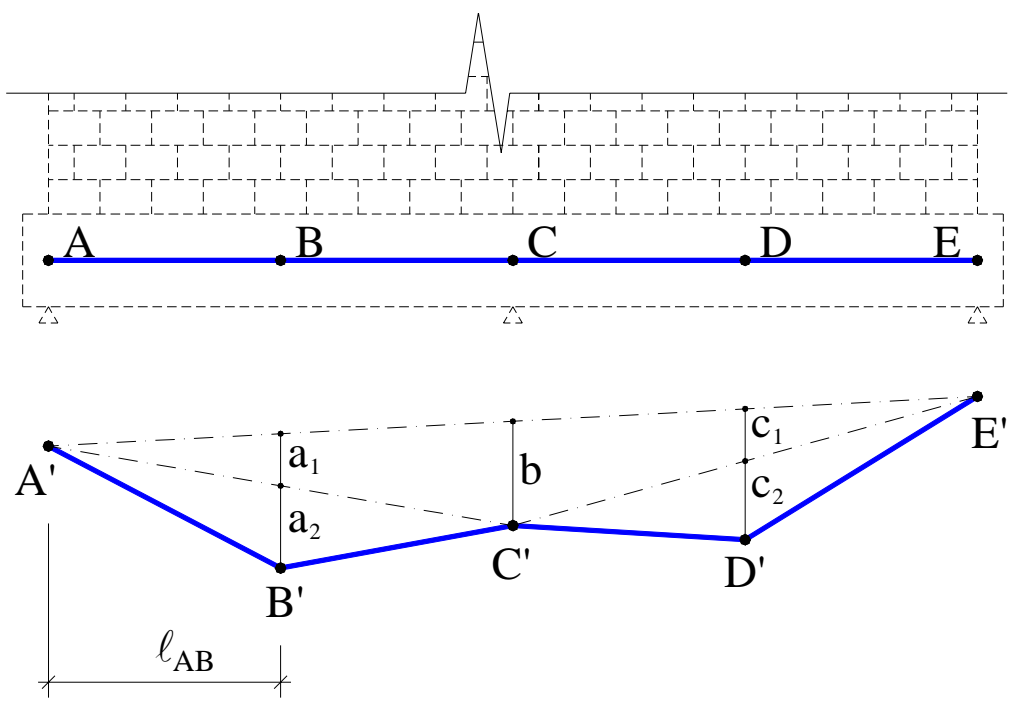

Figura 4.1 Movimentos da viga de fundação. 


$$
\begin{aligned}
& (\Delta / \mathrm{L})_{\mathrm{ACE}}=\frac{\mathrm{b}}{\ell_{\mathrm{AE}}} \\
& (\Delta / \mathrm{L})_{\mathrm{ABC}}=\frac{\mathrm{a}_{2}}{\ell_{\mathrm{AC}}} \\
& (\Delta / \mathrm{L})_{\mathrm{CDE}}=\frac{\mathrm{c}_{2}}{\ell_{\mathrm{CE}}}
\end{aligned}
$$

$$
\begin{aligned}
& (\delta / \ell)_{\mathrm{AB}}=\frac{\mathrm{a}_{1}+\mathrm{a}_{2}}{\ell_{\mathrm{AB}}} \\
& (\delta / \ell)_{\mathrm{BC}}=\frac{\mathrm{b}-\left(\mathrm{a}_{1}+\mathrm{a}_{2}\right)}{\ell_{\mathrm{BC}}} \\
& (\delta / \ell)_{\mathrm{CD}}=\frac{\left(\mathrm{c}_{1}+\mathrm{c}_{2}\right)-\mathrm{b}}{\ell_{\mathrm{CD}}} \\
& (\delta / \ell)_{\mathrm{DE}}=\frac{\mathrm{c}_{1}+\mathrm{c}_{2}}{\ell_{\mathrm{DE}}}
\end{aligned}
$$

Ressalta-se que para todos os modelos se assume que os recalques são aplicados aos pontos $\mathrm{C}$ e E. No texto, ao se fazer referências aos apoios, eles serão designados pelas letras correspondentes: o apoio A será sempre o apoio fixo, a letra $\mathrm{C}$ designará o apoio central e a letra E, o apoio móvel de extremidade.

\subsection{MODELO 1}

Este é o modelo básico para comparação de comportamento. Os demais painéis constituem variações do Modelo 1, seja pela inserção de aberturas, pela alteração da altura da viga, pelo grauteamento ou por combinação destas. 

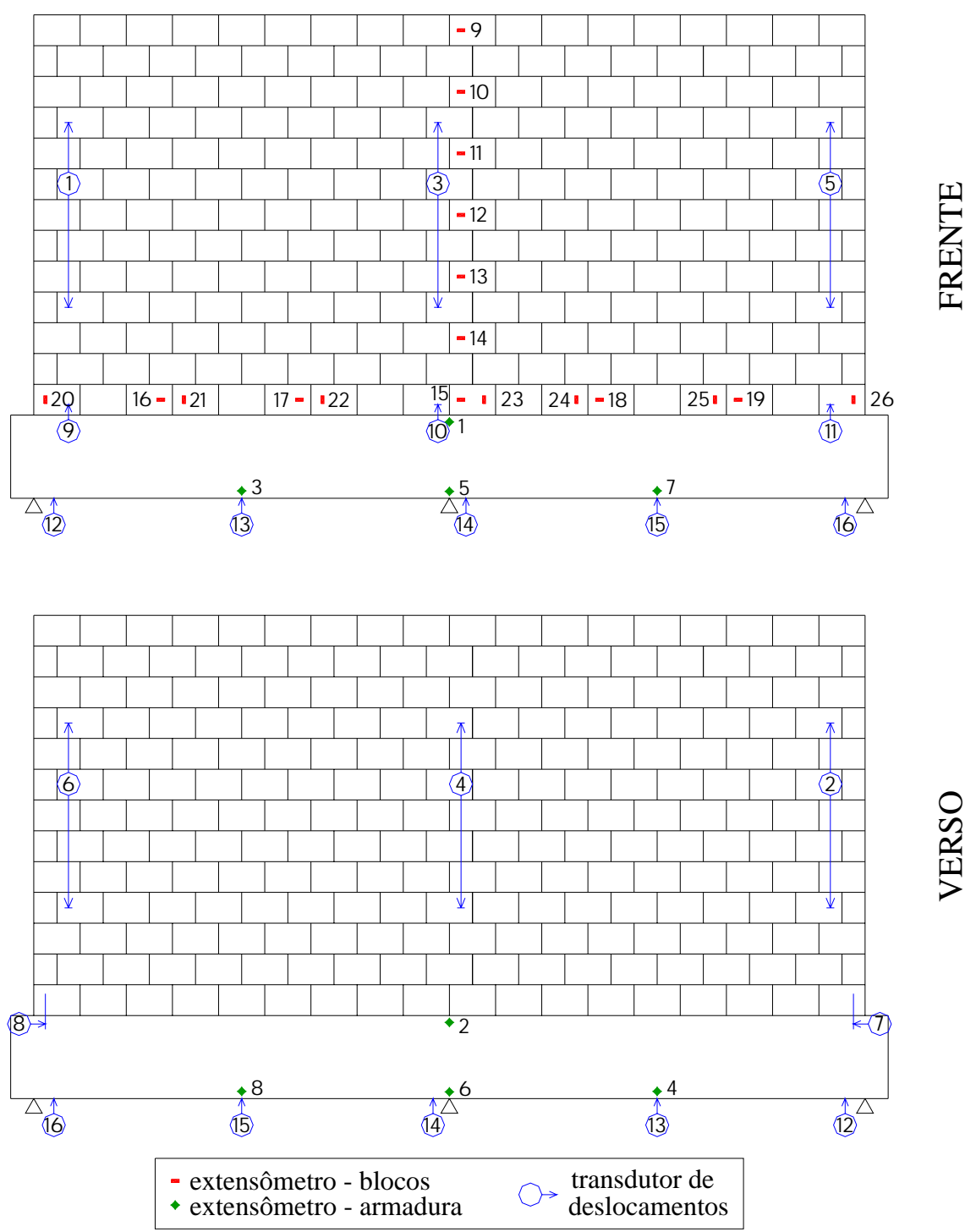

Figura 4.2 Instrumentação do Modelo 1.

\subsubsection{Situação 1: Aplicação do carregamento vertical}

Inicialmente aplicou-se a carga vertical de compressão. Nesta fase o painel comportou-se como esperado, não ocorrendo formação de fissuras, com a parede apresentando deformações de no máximo - $0,6 \%$, enquanto que se verificou nos ensaios de caracterização que a ruptura por compressão acontece a uma deformação de aproximadamente $-2,3 \%$.

A Figura 4.3 ilustra a configuração deformada da viga para alguns níveis de carregamento, indicados pela força total aplicada no topo da parede. Percebe-se que o vão $\mathrm{ABC}$ sofreu deformações maiores, provavelmente por ter recebido maior parcela de carga. 


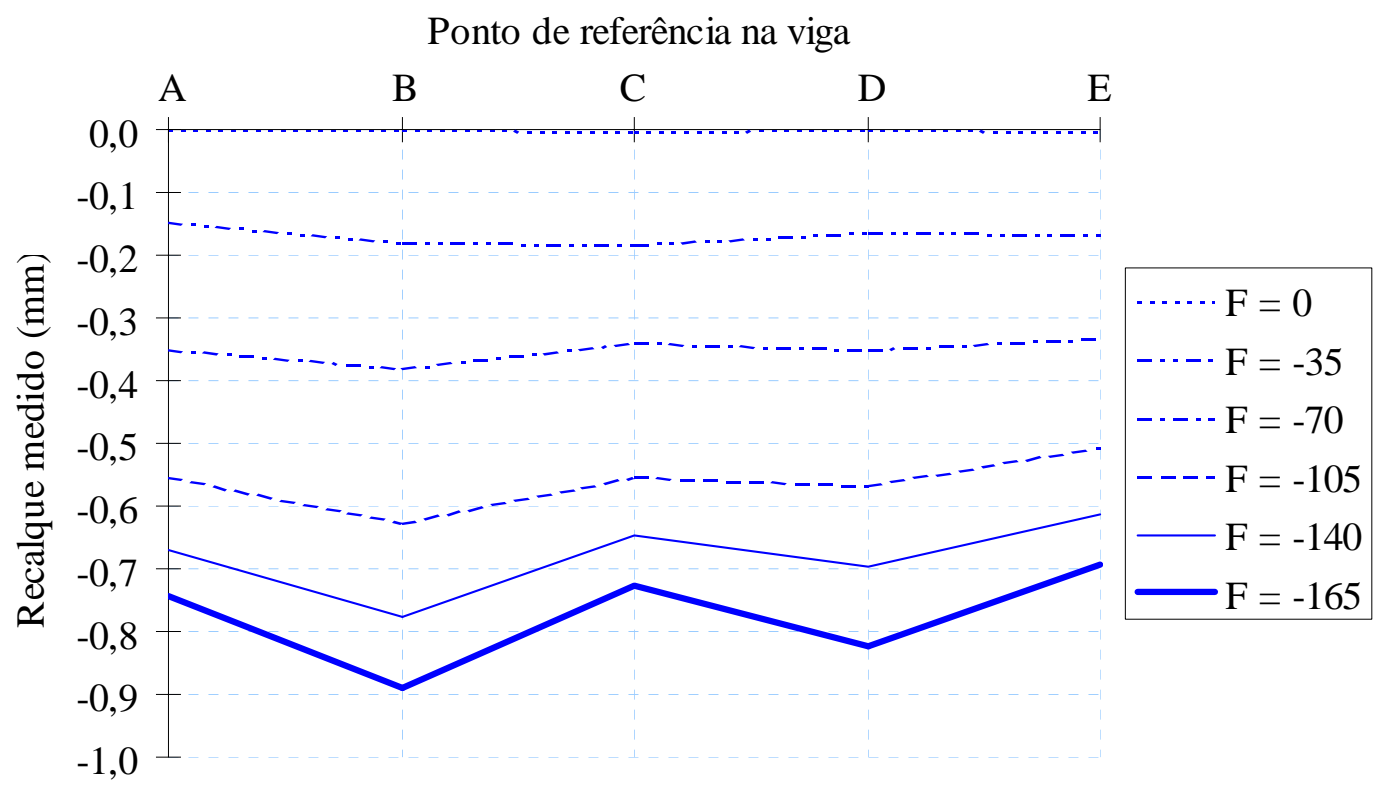

Figura 4.3 Configuração deformada da viga - Modelo 1, Situação 1. (F em kN)

Ao final desta etapa, o recalque diferencial do apoio central foi de $-0,009 \mathrm{~mm}$, descontados o recalque uniforme e a inclinação de $0,003 \%$ entre os apoios de extremidade.

Nas figuras seguintes visualizam-se as distribuições das reações de apoio e das deformações verticais na parede.

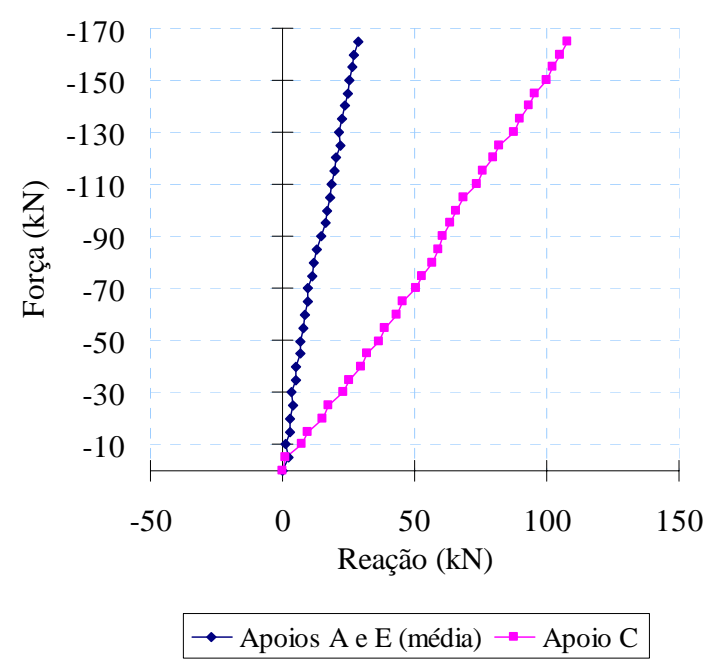

(a)

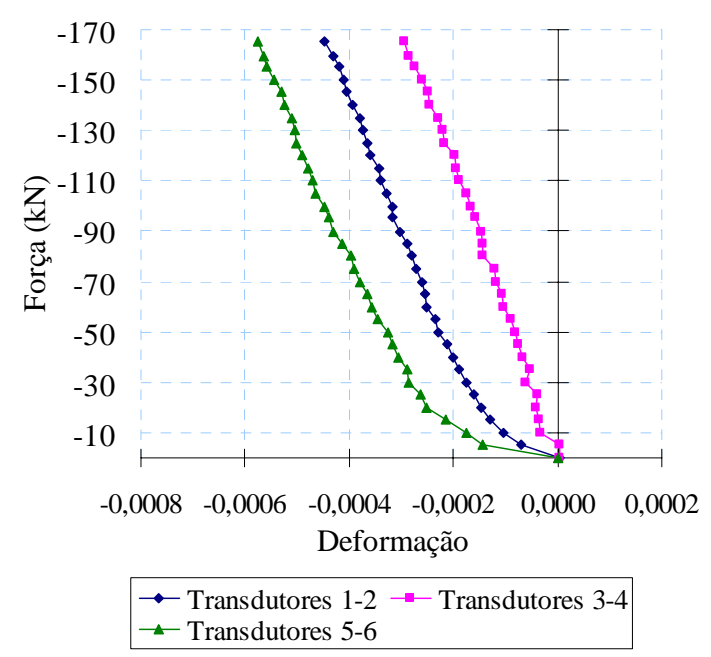

(b)

Figura 4.4 (a) Reações de apoio; (b) Deformação na parede - Modelo 1, Situação 1.

\subsubsection{Situação 2: Recalque do apoio central}

Nesta etapa deixou-se o apoio central deslocar-se lentamente para baixo, com pausas para observação da fissuração. Na Figura 4.5 ilustra-se a evolução da deformação da viga. As primeiras fissuras ocorreram quando o recalque diferencial $(\delta)$ do apoio central 
atingiu $-0,70 \mathrm{~mm}$, equivalente a $(\Delta / \mathrm{L})_{\mathrm{ACE}}=-1 / 2546$. A seguir calculam-se os principais parâmetros de recalque para esta situação no instante da primeira fissura:

$$
\begin{array}{ll}
(\Delta / \mathrm{L})_{\mathrm{ABC}}=-1 / 1751 & (\delta / \ell)_{\mathrm{AB}}=-1 / 516 \\
(\Delta / \mathrm{L})_{\mathrm{CDE}}=-1 / 2737 & (\delta / \ell)_{\mathrm{DE}}=-1 / 656
\end{array}
$$

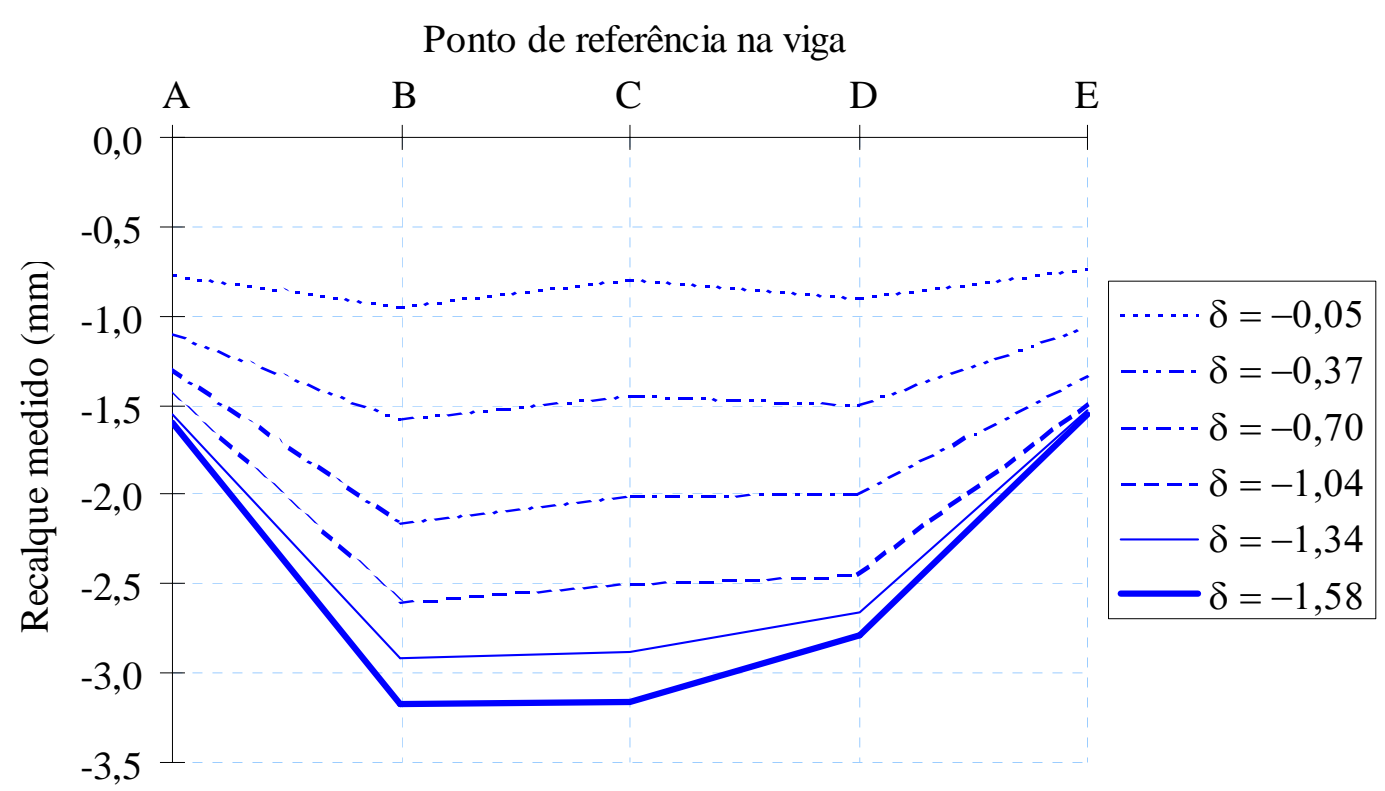

Figura 4.5 Configuração deformada da viga - Modelo 1, Situação 2. ( $\delta$ em mm)

Os limites citados na literatura para início de fissuração são $(\Delta / \mathrm{L})=1 / 2000$ e $(\delta / \ell)=1 / 300$. Portanto, percebe-se que o único valor que ultrapassa esses limites é o de $(\Delta / \mathrm{L})_{\mathrm{ABC}}$. Exatamente neste vão $(\mathrm{ABC})$ surgiram as primeiras fissuras na parede, provocadas por tração na direção perpendicular ao arco de compressão, nas proximidades do apoio A. Foram fissuras diagonais, passando por blocos e juntas verticais.

Esse quadro de fissuração aumentou até um recalque diferencial do apoio central de aproximadamente $-1,45 \mathrm{~mm}$, quando surgiram fissuras diagonais escalonadas de grande extensão, provavelmente causadas por tensões de cisalhamento. Elas tiveram início na porção já fissurada do painel, propagando-se para a região central. Os parâmetros referentes a esse instante possuem os seguintes valores:

$$
\begin{aligned}
& (\Delta / \mathrm{L})_{\mathrm{ACE}}=-1 / 1227 \\
& (\Delta / \mathrm{L})_{\mathrm{ABC}}=-1 / 1183 \\
& (\Delta / \mathrm{L})_{\mathrm{CDE}}=-1 / 1980
\end{aligned}
$$

$$
\begin{aligned}
& (\delta / \ell)_{\mathrm{AB}}=-1 / 299 \\
& (\delta / \ell)_{\mathrm{DE}}=-1 / 370
\end{aligned}
$$

Verifica-se que $(\delta / \ell)_{\mathrm{AB}}$ atingiu o limite para início de fissuração. Embora $(\Delta / \mathrm{L})_{\mathrm{CDE}}$ tenha ultrapassado por pouco o limite de $1 / 2000$, não se observou fissuração no lado direito do painel. 
No mesmo instante tornou-se visível uma separação entre as duas primeiras fiadas, na região central do painel. Esperava-se que esta separação por tração ocorresse na interface parede-viga, porém a aderência da argamassa com o concreto foi aparentemente maior que com o bloco cerâmico. A seguir, ao se analisar melhor as leituras obtidas com a instrumentação, conclui-se que esta fissura horizontal formou-se na realidade quando o recalque diferencial era de aproximadamente $-0,85 \mathrm{~mm}$.

$\mathrm{Na}$ viga, as primeiras fissuras visíveis, causadas por tração na flexão, surgiram para um recalque diferencial de $-0,75 \mathrm{~mm}$, ou seja, praticamente concomitante com a primeira fissuração da parede. Também ocorreu um pequeno esmagamento do cobrimento de concreto próximo ao apoio fixo A.

$\mathrm{O}$ recalque diferencial máximo que pôde ser aplicado ao apoio central do Modelo 1 foi de $-1,58 \mathrm{~mm}$. O painel atingiu uma configuração deformada estável após total retirada do apoio. Em praticamente todo o ensaio, os parâmetros de recalque do vão $\mathrm{CDE}$ do painel mantiveram-se abaixo dos limites citados na literatura. Como consequiência, não houve fissuração nessa região. Os valores dos parâmetros de curvatura relativos aos principais momentos do ensaio estão organizados na tabela seguinte.

Tabela 4.1 Parâmetros de curvatura - Modelo 1, Situação 2.

\begin{tabular}{|c|c|c|c|c|c|c|c|}
\hline \multicolumn{2}{|c|}{ RECALQUE (mm) } & \multirow{2}{*}{ OCORRÊNCIA } & \multirow{2}{*}{$(\Delta / \mathrm{L})_{\mathrm{ACE}}$} & \multirow{2}{*}{$(\Delta / \mathrm{L})_{\mathrm{ABC}}$} & \multirow{2}{*}{$(\Delta / \mathrm{L})_{\mathrm{CDE}}$} & \multirow{2}{*}{$(\delta / \ell)_{\mathrm{AB}}$} & \multirow{2}{*}{$(\delta / \ell)_{\mathrm{DE}}$} \\
\hline total & diferencial & & & & & & \\
\hline$-2,0$ & $-0,70$ & & $-1 / 2546$ & $-1 / 1751$ & & $1 / 516$ & $1 / 656$ \\
\hline$-2,3$ & $-0,85$ & herizenta & 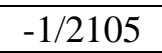 & 41700 & & $1 / 468$ & $1 / 530$ \\
\hline$-3,0$ & $-1,45$ & & $-1 / 1227$ & $-1 / 1183$ & $-1 / 1980$ & $1 / 299$ & $1 / 370$ \\
\hline$-3,2$ & $-1,58$ & Recalque máximo & $-1 / 1127$ & $-1 / 1115$ & $-1 / 2048$ & $1 / 279$ & $1 / 361$ \\
\hline
\end{tabular}

Nota: Valores negativos de $(\Delta / \mathrm{L})$ indicam concavidade para cima. $(\delta / \ell)$ em valores absolutos.

As figuras seguintes apresentam, respectivamente, um esquema da distribuição de fissuras e uma fotografia do painel após o ensaio. Pode-se visualizar a evolução da fissuração pelos valores de recalque do apoio central, que foram anotados ao lado da fissura correspondente. Na Figura 4.6 estão os valores de recalque diferencial e na Figura 4.7, os de recalque total. 


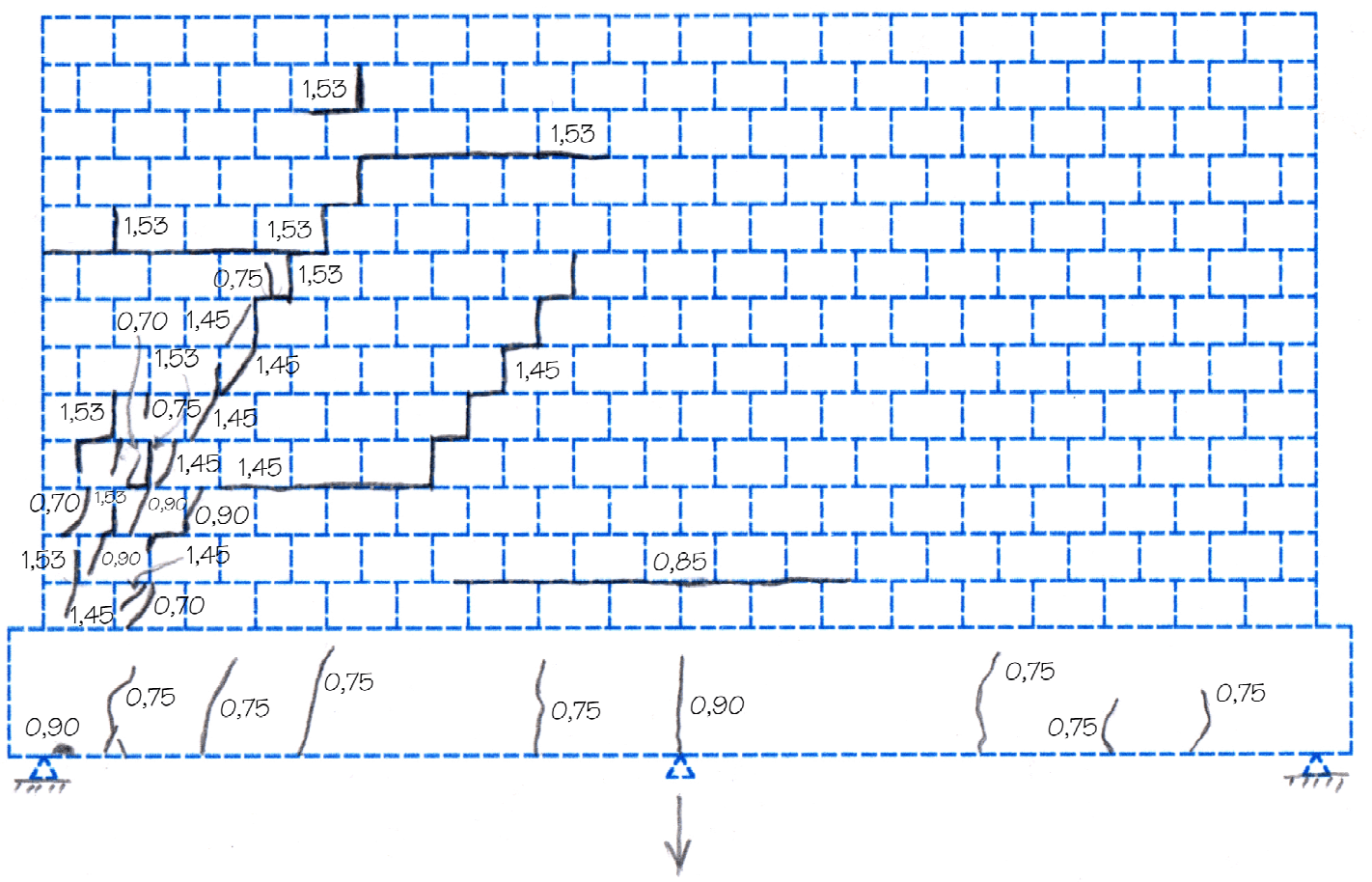

Figura 4.6 Distribuição de fissuras após ensaio - Modelo 1, Situação 2.

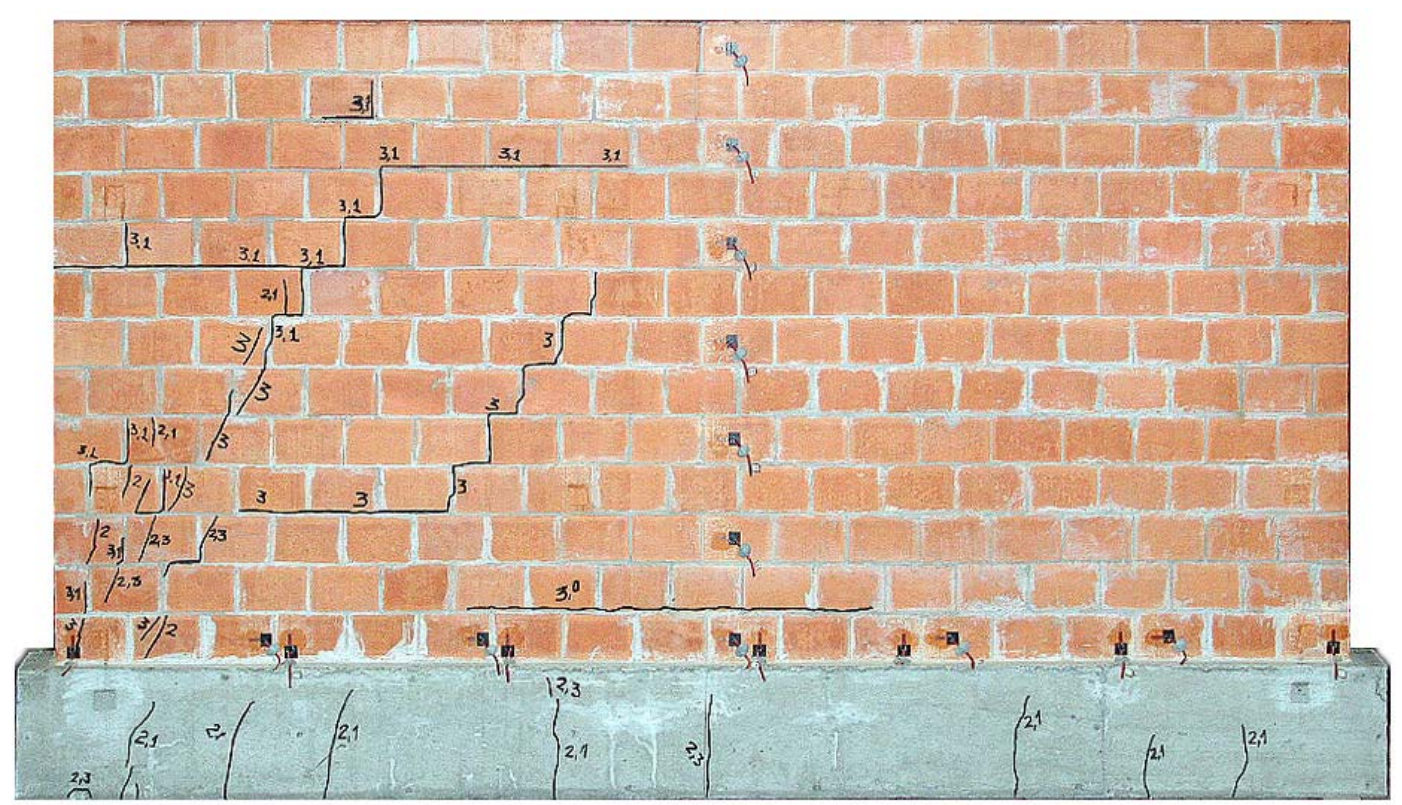

Figura 4.7 Fotografia do painel após ensaio - Modelo 1, Situação 2.

Com relação às reações de apoio, observou-se pelo gráfico da Figura 4.8a que elas se redistribuíram segundo uma função linear do recalque diferencial até um recalque próximo de $-0,85 \mathrm{~mm}$. A partir daí, as reações seguem curvas não-lineares até a retirada do apoio central. Comportamento semelhante foi detectado para o extensômetro vertical 26 da base da parede (não se obtiveram leituras com o extensômetro 20), e para os transdutores 
verticais 1, 2, 5 e 6 . As leituras dos transdutores 3 e 4 aparentemente não foram afetadas pela fissuração.

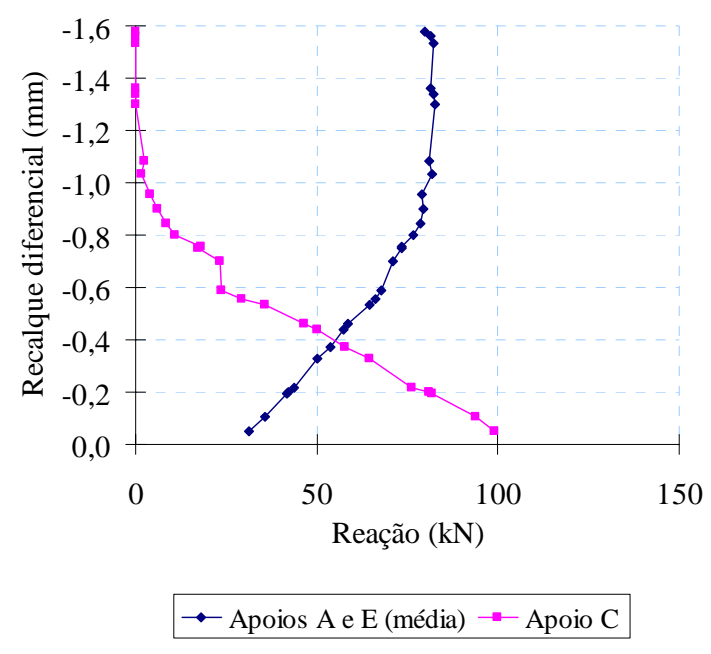

(a)

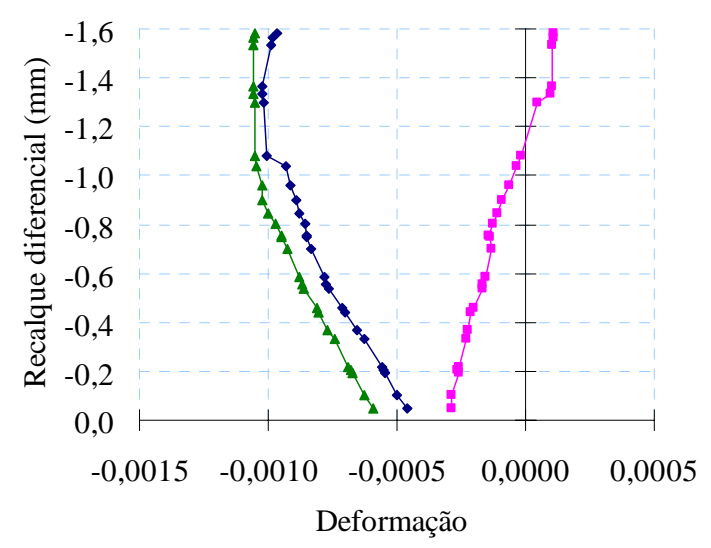

$\rightarrow$ Transdutores 1-2 - Transdutores 3-4

$\rightarrow$ Transdutores 5-6

(b)

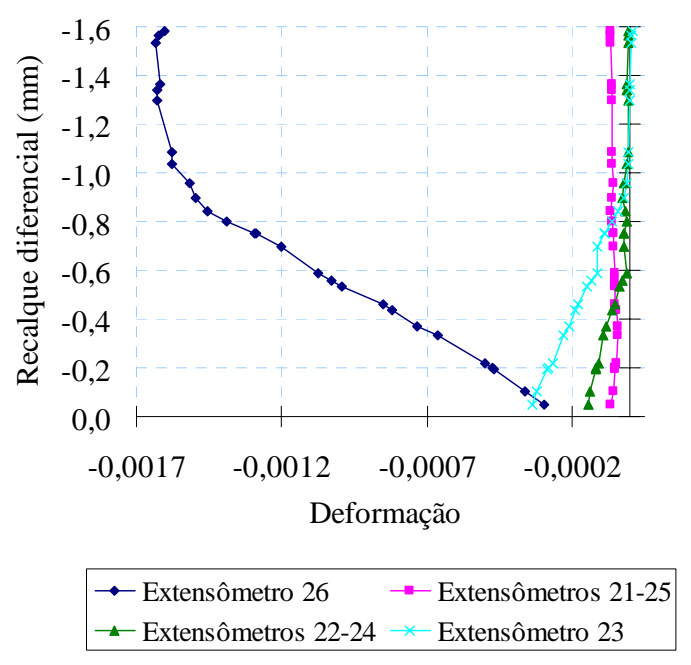

(c)

Figura 4.8 (a) Reações de apoio; (b) Deformação na parede; (c) Deformações na primeira fiada Modelo 1, Situação 2.

Da mesma forma, a curva das leituras do extensômetro 23 sofre uma variação da inclinação quando o recalque diferencial chega a $-0,85 \mathrm{~mm}$. O mesmo acontece com relação ao transdutor 8 , o que induz à conclusão de que a fissura horizontal aconteceu nesse instante, e não a um recalque de $-1,45 \mathrm{~mm}$, como descrito anteriormente. Portanto, na Figura 4.7, o recalque total correspondente ao aparecimento da fissura horizontal deve ser corrigido para $-2,3 \mathrm{~mm}$.

O diagrama de deformações na base da parede, apresentado na Figura 4.9, representa com boa aproximação as tensões nessa região e, por conseqüência, a transferência de esforços da parede para a viga. Percebe-se facilmente a redistribuição desses esforços em 
função do recalque do apoio central, com a tendência de haver concentração nas extremidades do painel, conforme seria esperado. Infelizmente o extensômetro 20 foi danificado, porém pela simetria do modelo e do carregamento, pode-se imaginar que suas leituras seriam próximas àquelas do extensômetro 26. Torna-se importante ressaltar que as linhas retas na figura apenas unem os pontos referentes aos resultados do ensaio, não significando a real distribuição das tensões.

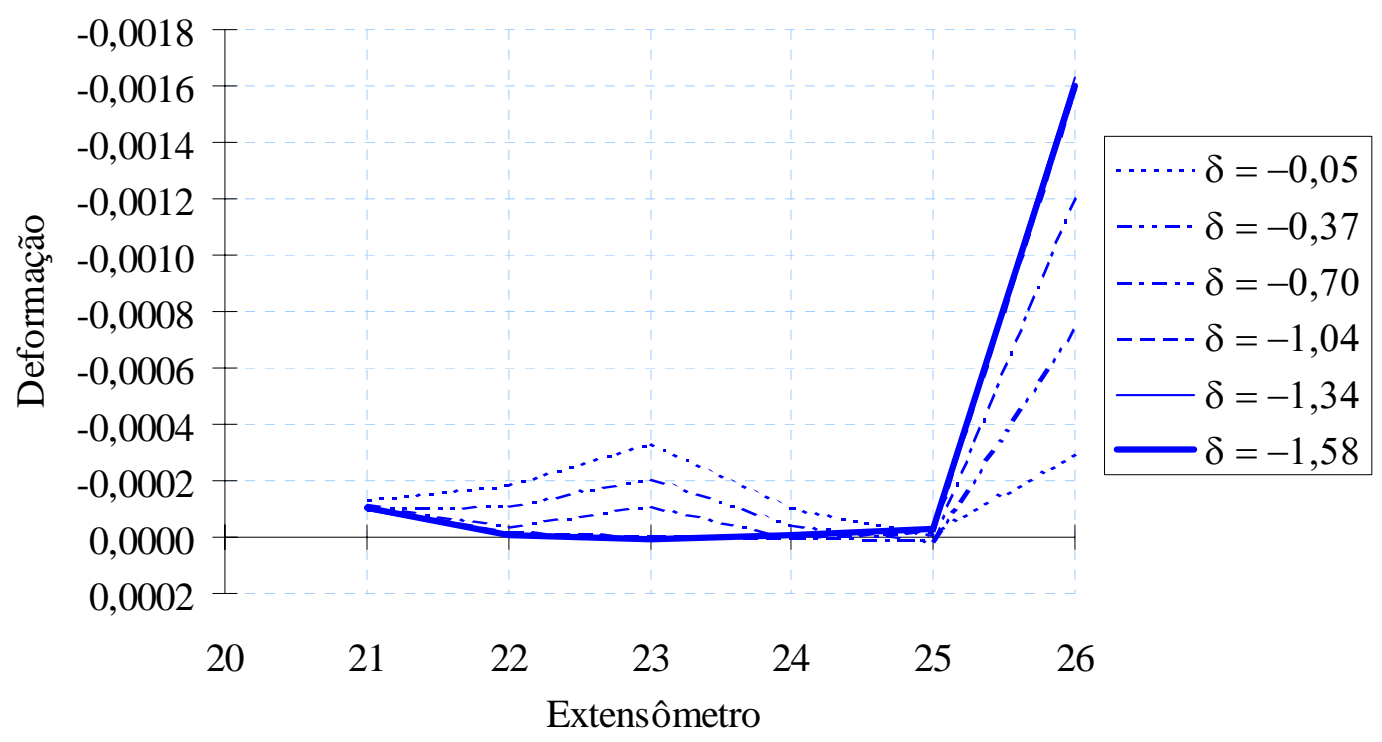

Figura 4.9 Deformações na base da parede - Modelo 1, Situação 2. ( $\delta$ em mm)

\subsubsection{Situação 3: Recalque do apoio de extremidade}

Para que se aplicasse recalque ao apoio de extremidade, deslocou-se o cilindro hidráulico para essa posição e colocou-se um apoio fixo no centro. Adverte-se que essa operação foi necessária apenas para o ensaio piloto, quando não se dispunha ainda dos anéis de travamento dos cilindros (v. item 4.9.1). Essa troca de apoios acarretou um desnível entre eles, que foi considerado ao se calcular o recalque diferencial retirando-se a parcela decorrente do giro do painel. Não se observou alteração no comportamento do modelo devido a esse problema.

A seguir apresenta-se um diagrama representando a evolução da configuração deformada da viga em função do recalque diferencial do apoio de extremidade. Dele se infere que o principal parâmetro de curvatura da viga nesta situação de recalque é $(\delta / \ell)_{\mathrm{CD}}$, além das medidas de curvaturas dos vãos $(\Delta / \mathrm{L})_{\mathrm{ACE}},(\Delta / \mathrm{L})_{\mathrm{ABC}} \mathrm{e}(\Delta / \mathrm{L})_{\mathrm{CDE}}$. 


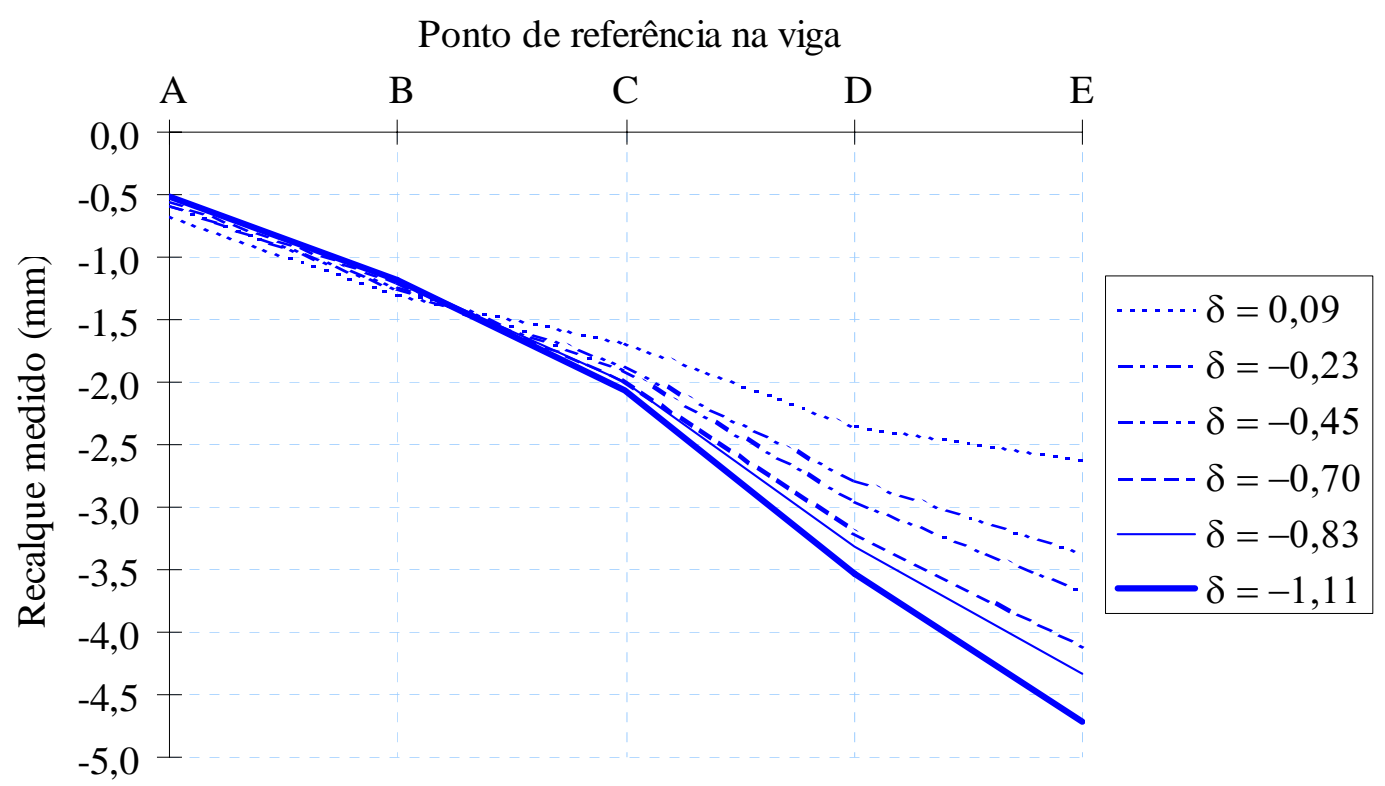

Figura 4.10 Configuração deformada da viga - Modelo 1, Situação 3. ( $\delta$ em mm)

A primeira fissura do painel ocorreu na borda superior da viga a um recalque diferencial de apenas $-0,10 \mathrm{~mm}$, que foi seguida por um esmagamento do concreto acima do apoio central. Logo após, quando o recalque diferencial do apoio de extremidade atingiu $-0,27 \mathrm{~mm}$, surgiu uma fissura vertical na parede, praticamente dividindo-a em duas metades.

Para este instante calculou-se $(\delta / \ell)_{\mathrm{CD}}=1 / 1468$ e $(\Delta / \mathrm{L})_{\mathrm{ACE}}=1 / 13264$. São valores pequenos, principalmente o segundo, o que deixa dúvidas quanto à sua precisão. Porém é importante salientar que esta situação de recalque é bastante diferente da anterior. Neste caso não são aplicáveis os limites máximos citados na literatura técnica para início de fissuração. Acredita-se que estes limites devem ser bem menores, provavelmente próximos aos obtidos no ensaio, referindo-se especialmente ao parâmetro $(\delta / \ell)_{\mathrm{CD}}$, cujo valor de curvatura reflete melhor a condição do painel quanto à probabilidade de fissuração.

Nesta situação, a concavidade da viga de fundação é para baixo. Isto caracteriza o caso de propagação de fissuras não-controlada, de acordo com BURLAND et al. (1977), já que a parede é constituída de alvenaria não-armada.

De fato, ao se aplicar maior recalque ao modelo, observou-se que praticamente nenhuma outra fissura se formou. Basicamente, houve apenas uma propagação da fissura inicial, concomitante com o aumento da sua abertura. Desta forma, verificaram-se algumas características de fissuras causadas por recalque: direção vertical e variação da abertura ao longo do seu comprimento, sendo maior na borda superior da parede, onde ela surgiu, diminuindo em direção à base do painel. 
O recalque máximo, em casos como este, depende quase que exclusivamente da capacidade resistente da viga, uma vez que a parede, partida ao meio, não contribui para resistir aos esforços de tração. Nesta hipótese não está sendo considerada a capacidade resistente de outros elementos da fundação, como estacas e sapatas.

Paralisou-se o ensaio do Modelo 1 quando o recalque diferencial atingiu $-1,11 \mathrm{~mm}$, após ter sido retirado totalmente o apoio de extremidade e o painel ter adquirido uma configuração momentaneamente estável.

Na Tabela 4.2 apresentam-se alguns parâmetros de curvatura para os principais instantes do ensaio. A Figura 4.11 ilustra a distribuição das fissuras. Ao lado da cada fissura está anotado o valor do recalque diferencial referente ao instante de seu surgimento. $\mathrm{Na}$ Figura 4.12 são apresentadas fotografias de alguns detalhes da fissuração, obtidas durante a execução do ensaio. Os valores anotados correspondem ao recalque total, os seja, ao deslocamento do apoio E.

Tabela 4.2 Parâmetros de curvatura - Modelo 1, Situação 3 .

\begin{tabular}{|c|c|c|c|c|c|c|}
\hline \multicolumn{2}{|c|}{ RECALQUE (mm) } & \multirow{2}{*}{ OCORRÊNCIA } & \multirow{2}{*}{$(\Delta / \mathrm{L})_{\mathrm{ACE}}$} & \multirow{2}{*}{$(\Delta / \mathrm{L})_{\mathrm{ABC}}$} & \multirow{2}{*}{$(\Delta / \mathrm{L})_{\mathrm{CDE}}$} & \multirow{2}{*}{$(\delta / \ell)_{\mathrm{CD}}$} \\
\hline total & diferencial & & & & & \\
\hline$-3,1$ & $-\mathbf{0 , 1 0}$ & $\begin{array}{l}\text { Primeira fissura } \\
\text { (tração na viga) }\end{array}$ & $1 / 35244$ & $-1 / 29084$ & $-1 / 5356$ & $1 / 2059$ \\
\hline$-3,4$ & $-0,27$ & $\begin{array}{l}\text { Primeira fissura na } \\
\text { parede (tração) }\end{array}$ & $1 / 13264$ & $-1 / 56586$ & $-1 / 5220$ & $1 / 1468$ \\
\hline$-4,7$ & $-1,11$ & Recalque máximo & $1 / 3213$ & $1 / 8259$ & $-1 / 6243$ & $1 / 645$ \\
\hline
\end{tabular}

Nota: Valores negativos de $(\Delta / \mathrm{L})$ indicam concavidade para cima. $(\delta / \ell)$ em valores absolutos.

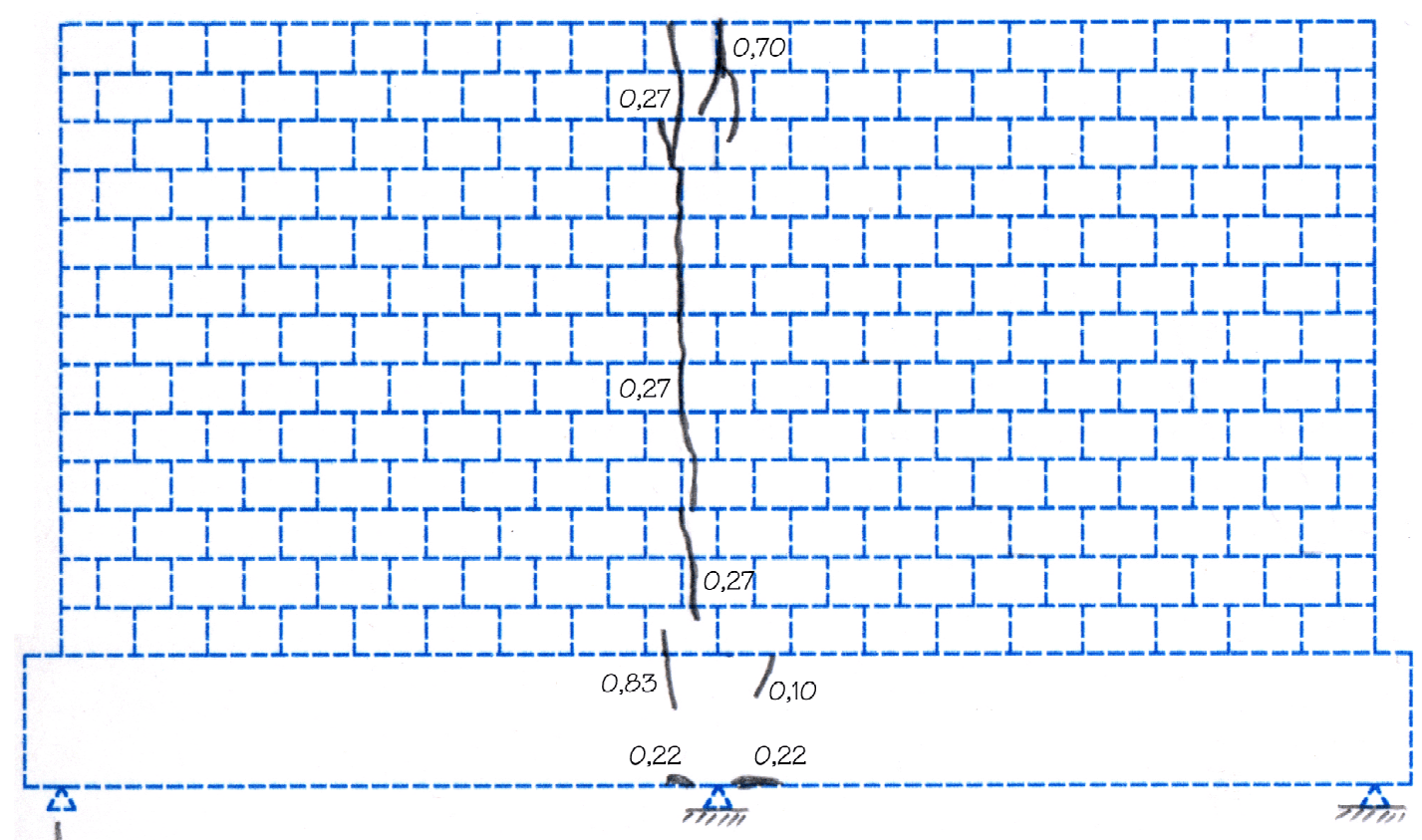

Figura 4.11 Distribuição de fissuras após ensaio - Modelo 1, Situação 3. 


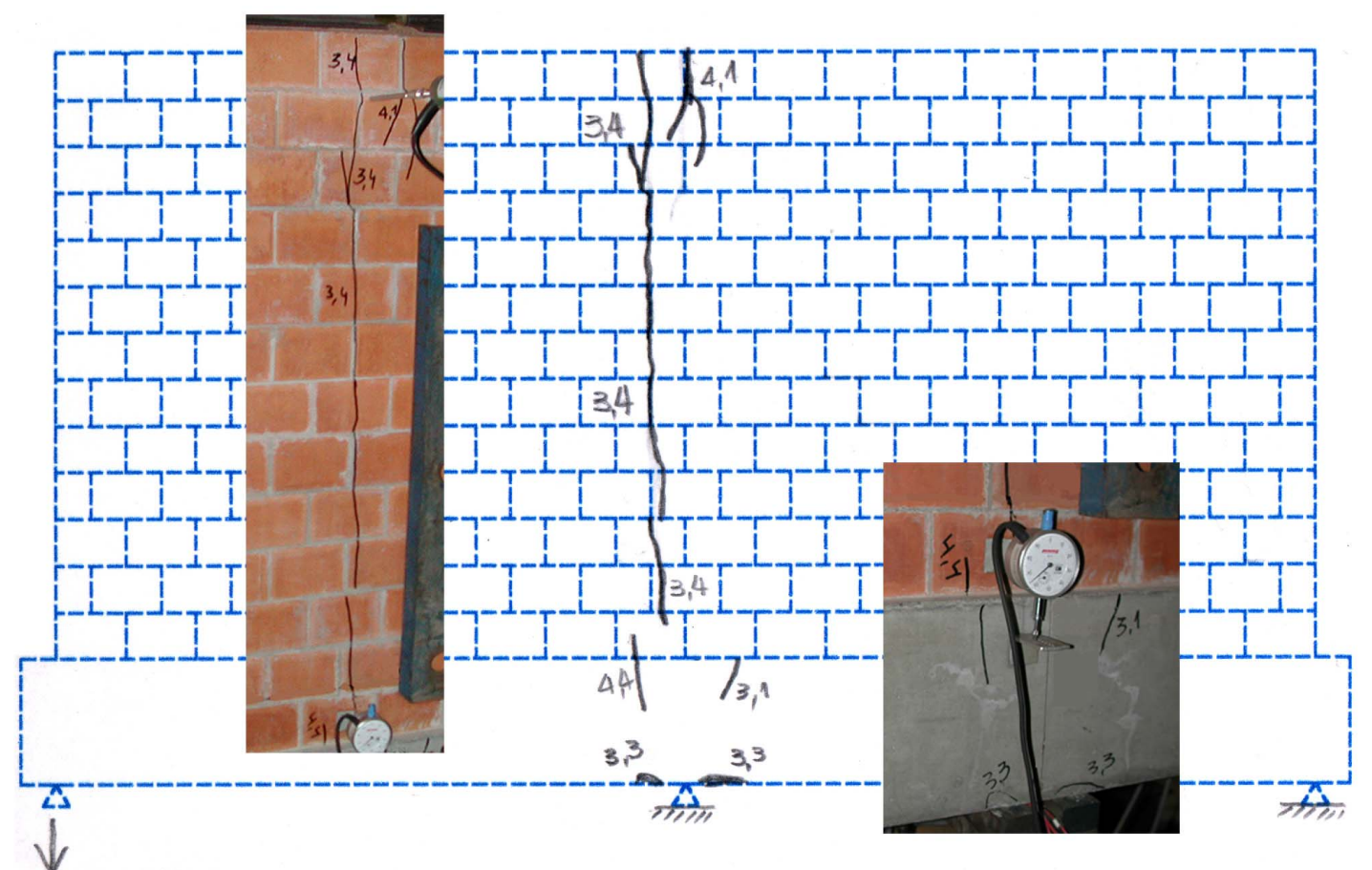

Figura 4.12 Fotografias de detalhes do painel após ensaio - Modelo 1, Situação 3.

A principal particularidade dos gráficos das leituras da instrumentação consistiu de uma descontinuidade provocada pela formação da fissura vertical. Praticamente todas as leituras foram afetadas, pois se criou uma nova situação em que as condições de contorno iniciais modificaram-se abruptamente, surgindo um modelo diferente, composto por duas paredes isoladas sobre uma viga comum.

Nesse instante foi notória a queda da reação do apoio central e, conseqüientemente, o aumento das reações dos apoios de extremidade. Fugindo à regra, as leituras de deformação vertical da parede não sofreram influência significativa, apenas mantendo suas tendências esperadas: aumento da deformação acima do apoio central e diminuição próximo às extremidades. 


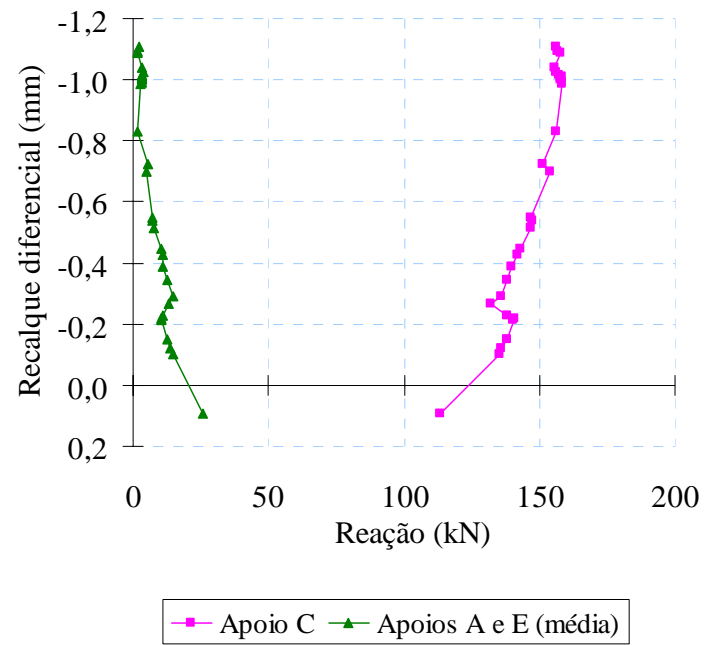

(a)

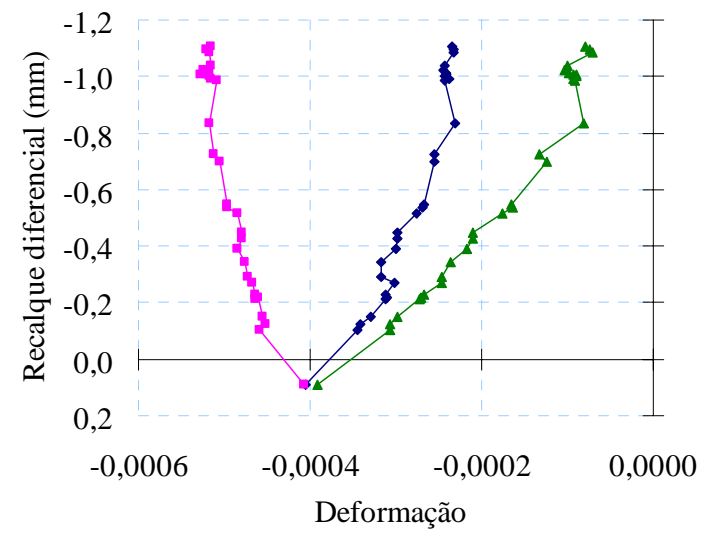

$\rightarrow$ Transdutores 1-2 $\rightarrow$ Transdutores 3-4 $\_$Transdutores 5-6

(b)

Figura 4.13 (a) Reações de apoio; (b) Deformação na parede - Modelo 1, Situação 3.

\subsection{MODELO 2}

Com este modelo verificou-se a influência da janela no comportamento do painel, pois as aberturas podem alterar a distribuição das tensões na parede, provocando concentrações excessivas. $\mathrm{O}$ aspecto da fissuração torna-se diferente, normalmente mais intenso. 

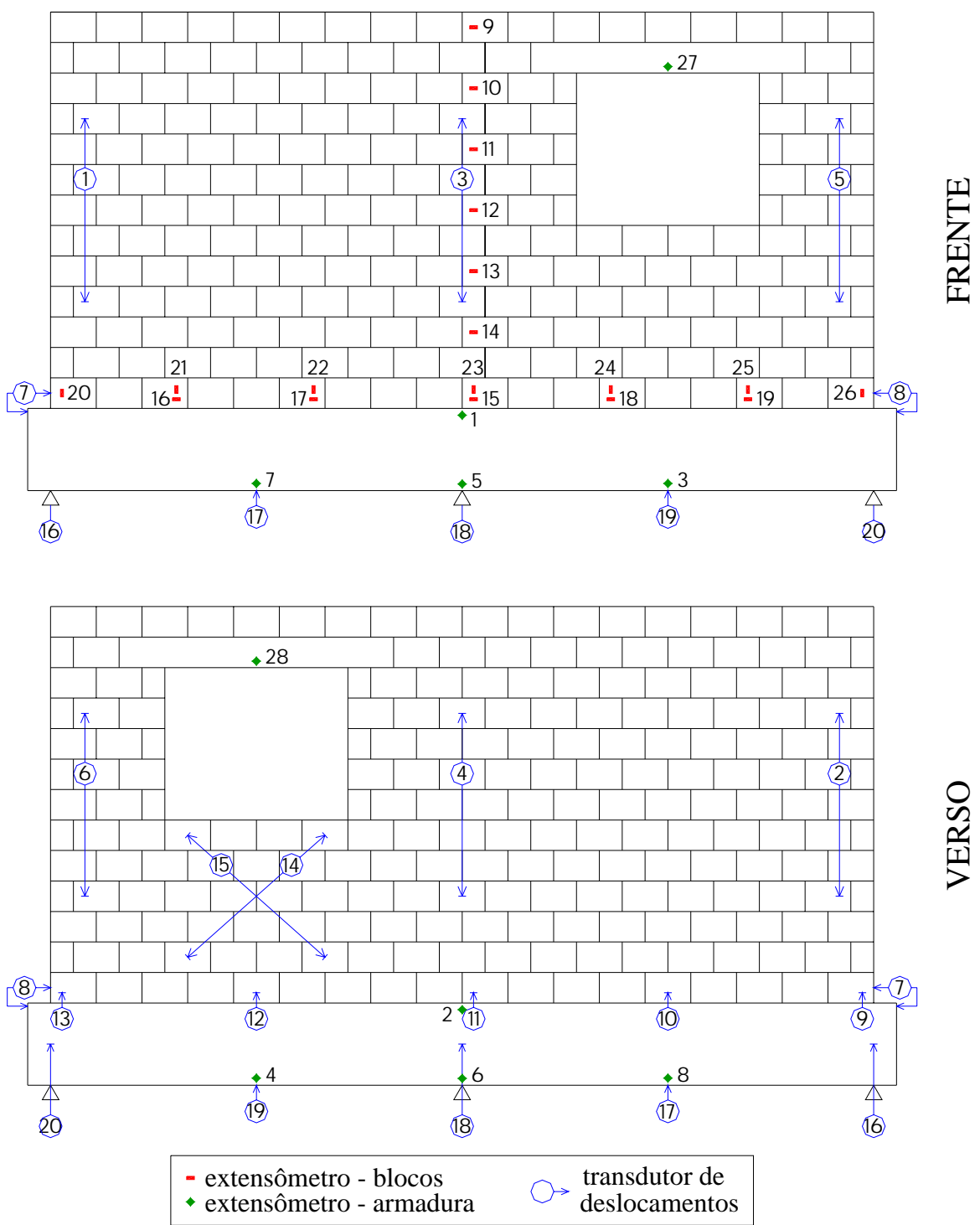

Figura 4.14 Instrumentação do Modelo 2.

\subsubsection{Situação 1: Aplicação do carregamento vertical}

Este foi o primeiro modelo em que foram usados os anéis de travamento nos cilindros hidráulicos dos apoios, cuja descrição se encontra adiante no item 4.9.1. A fase de carregamento foi, então, realizada sem interrupções para correção de recalques indesejáveis. Sabe-se, porém, que todos os apoios são deformáveis, embora não a ponto de inviabilizar o estudo. Por esse motivo, ao final desta etapa verificou-se ter ocorrido um recalque diferencial do apoio central de $-0,35 \mathrm{~mm}$, já se descontando a inclinação de $0,013 \%$ entre os pontos A e E na viga de fundação. Na Figura 4.15 encontra-se a evolução dos recalques medidos na viga. 


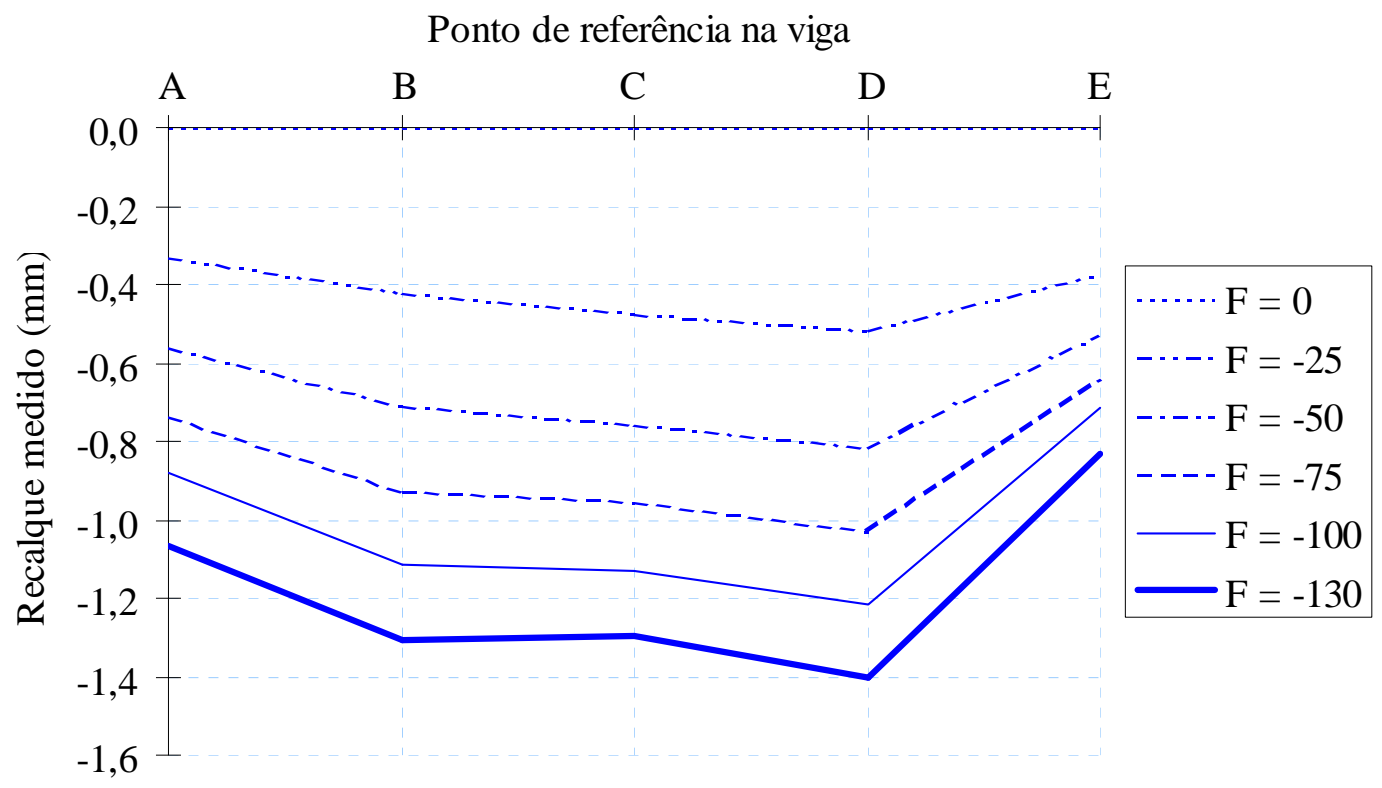

Figura 4.15 Configuração deformada da viga - Modelo 2, Situação 1. (F em kN)

A reação do apoio A esteve, durante esta etapa, em torno de $13 \%$ maior que a do apoio E. Porém, a deformação medida pelos transdutores 5 e 6 mostrou-se maior que a referente aos transdutores 1 e 2, provavelmente porque o trecho de medida dos transdutores mais próximos da janela compreendia maior parte do arco de compressão, que sofreu desvio por causa da presença da abertura.

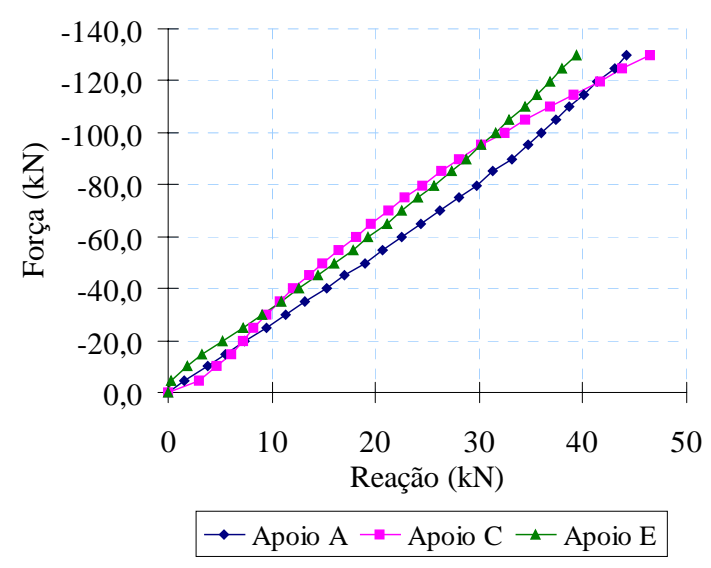

(a)

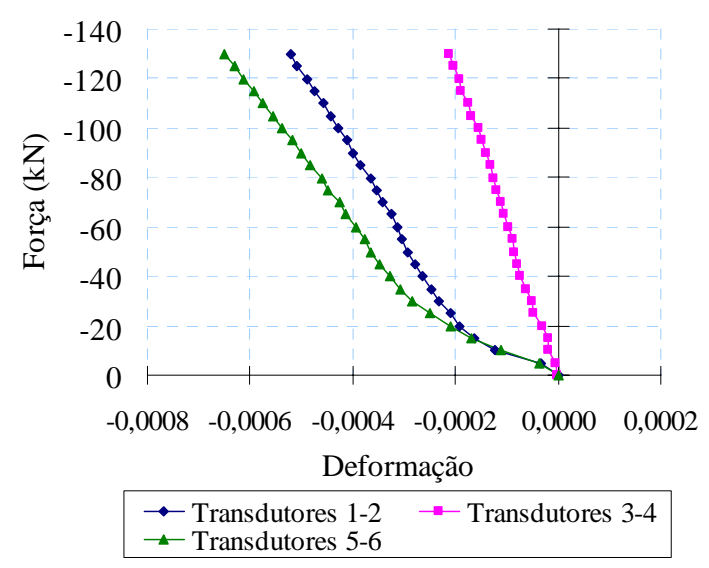

(b)

Figura 4.16 (a) Reações de apoio; (b) Deformação na parede - Modelo 2, Situação 1.

Quanto aos transdutores posicionados abaixo da janela, tem-se que as leituras nesta etapa foram muito pequenas, com o transdutor 14 medindo deformações devido a compressão. $\mathrm{O}$ transdutor 15 apresentou leitura praticamente nula. 


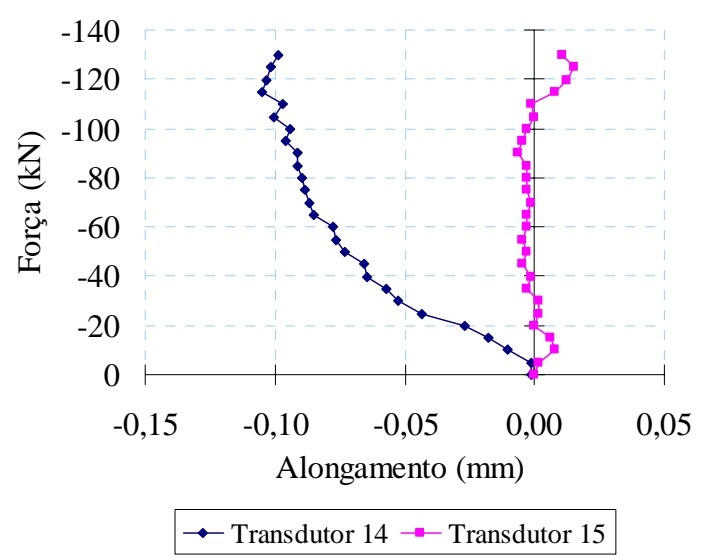

Figura 4.17 Leituras abaixo da janela - Modelo 2, Situação 1.

A seguir apresenta-se uma ilustração da deformação medida pelos extensômetros verticais da base da parede (20 a 26), que reflete bem o que acontece em termos de tensões. Este gráfico possui formato equivalente ao carregamento transmitido à viga. Nele se percebe que praticamente não há transferência de carga no trecho abaixo da janela.

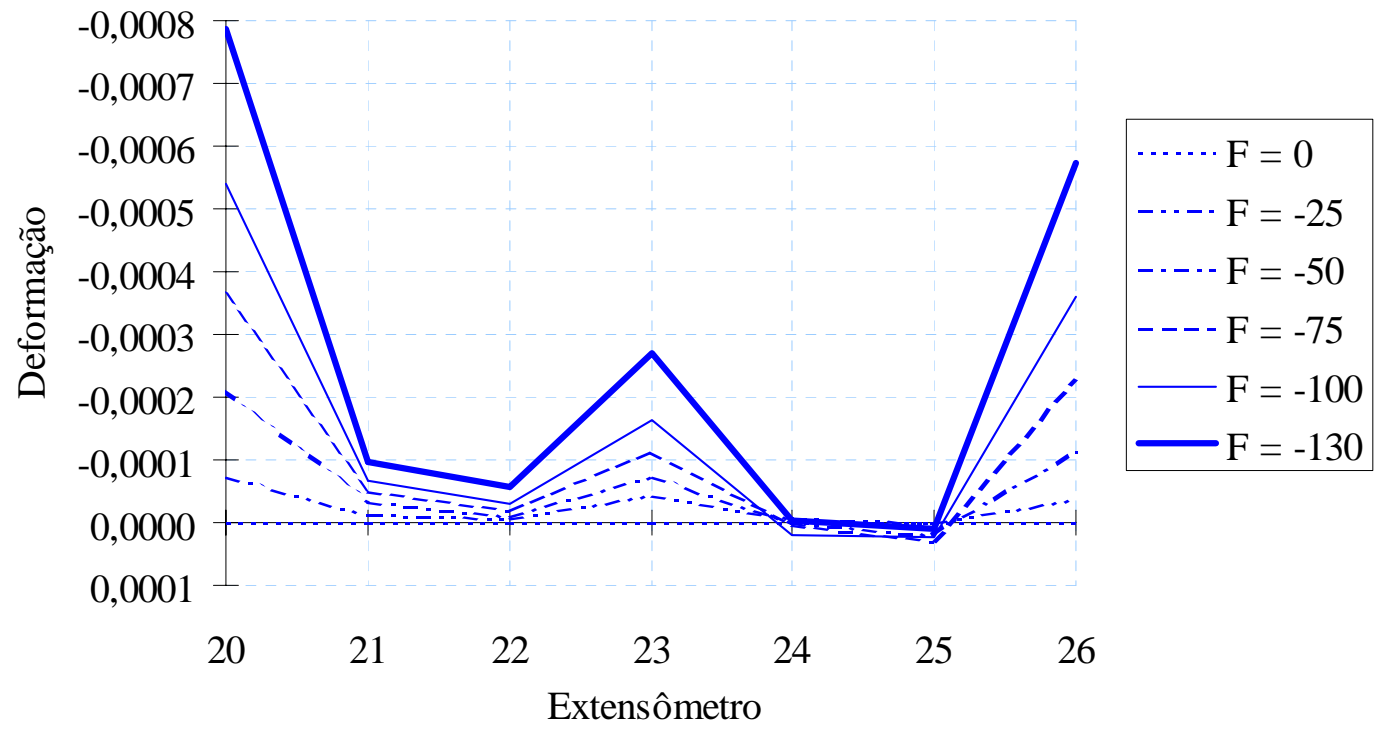

Figura 4.18 Deformações na base da parede - Modelo 2, Situação 1. (F em kN)

\subsubsection{Situação 2: Recalque do apoio central}

Finalizada a etapa de compressão do painel, aplicou-se uma pequena carga no cilindro central para que se pudesse retirar seu anel de travamento, e iniciou-se a etapa de aplicação do recalque do apoio central. As primeiras fissuras foram observadas quando o recalque diferencial chegou a $-0,91 \mathrm{~mm}$, correspondente a um recalque total de $-1,6 \mathrm{~mm}$. 
Surgiram fissuras diagonais na verga, nos pontos onde termina o vão livre, tanto em uma extremidade como na outra. Contudo, a fissura mais próxima da borda do painel pareceu ser mais importante, apresentando características de ter sido causada por tensões de cisalhamento.

No mesmo instante percebeu-se a formação de fissuras diagonais escalonadas abaixo da janela, dirigindo-se do apoio $\mathrm{E}$ ao canto inferior interno da abertura. Esse formato também indica que tensões de cisalhamento, desta vez na parede, foram determinantes.

Nesse instante, $(\Delta / \mathrm{L})_{\mathrm{ACE}}=-1 / 1968$ ultrapassou o limite de $1 / 2000 .(\Delta / \mathrm{L})_{\mathrm{CDE}}$, que já havia ultrapassado esse limite para o recalque diferencial a partir de $-0,44 \mathrm{~mm}$, chegou a -1/1372. Os demais parâmetros mantiveram-se com valores abaixo dos limites sugeridos. Os valores estão reunidos na Tabela 4.3.

A um recalque diferencial de $-1,12 \mathrm{~mm}$, surgiu uma fissura horizontal separando a verga da última fiada, que constituiu uma continuação da fissura de cisalhamento da verga. Esta fissura terminou num ramo ascendente próximo ao meio do vão da verga. Em todos os painéis com abertura ocorreu uma fissura com estas características para a mesma situação de recalque. Logo em seguida, para um recalque diferencial de $-1,26 \mathrm{~mm}$ apareceu uma continuação vertical da fissura de cisalhamento da verga.

Quando o recalque diferencial alcançou $-1,46 \mathrm{~mm}$, uma grande fissura horizontal dividiu as duas primeiras fiadas desde a região central do painel até próximo da extremidade oposta à janela. Esta foi uma fissura correlata à ocorrida no Modelo 1, porém afetada pela presença da abertura. Isso foi uma das ocorrências que indicou a formação de um arco de compressão na parede entre a abertura e a borda oposta do painel.

A última fissuração observada foi uma propagação da fissura diagonal escalonada abaixo da janela. Uma série de fissuras formou uma continuação da anterior e outras paralelas. Isto ocorreu a um recalque diferencial em torno de $-1,79 \mathrm{~mm}$.

Até o final desta etapa não houve formação de outras fissuras, mas o aumento da aberturas daquelas abaixo da janela. O recalque diferencial máximo para este modelo foi de -2,00 mm, 27\% maior que o do Modelo 1, que possuía uma rigidez maior. Na Figura 4.19 observa-se a evolução dos deslocamentos dos pontos de referência na viga em função do recalque aplicado. 


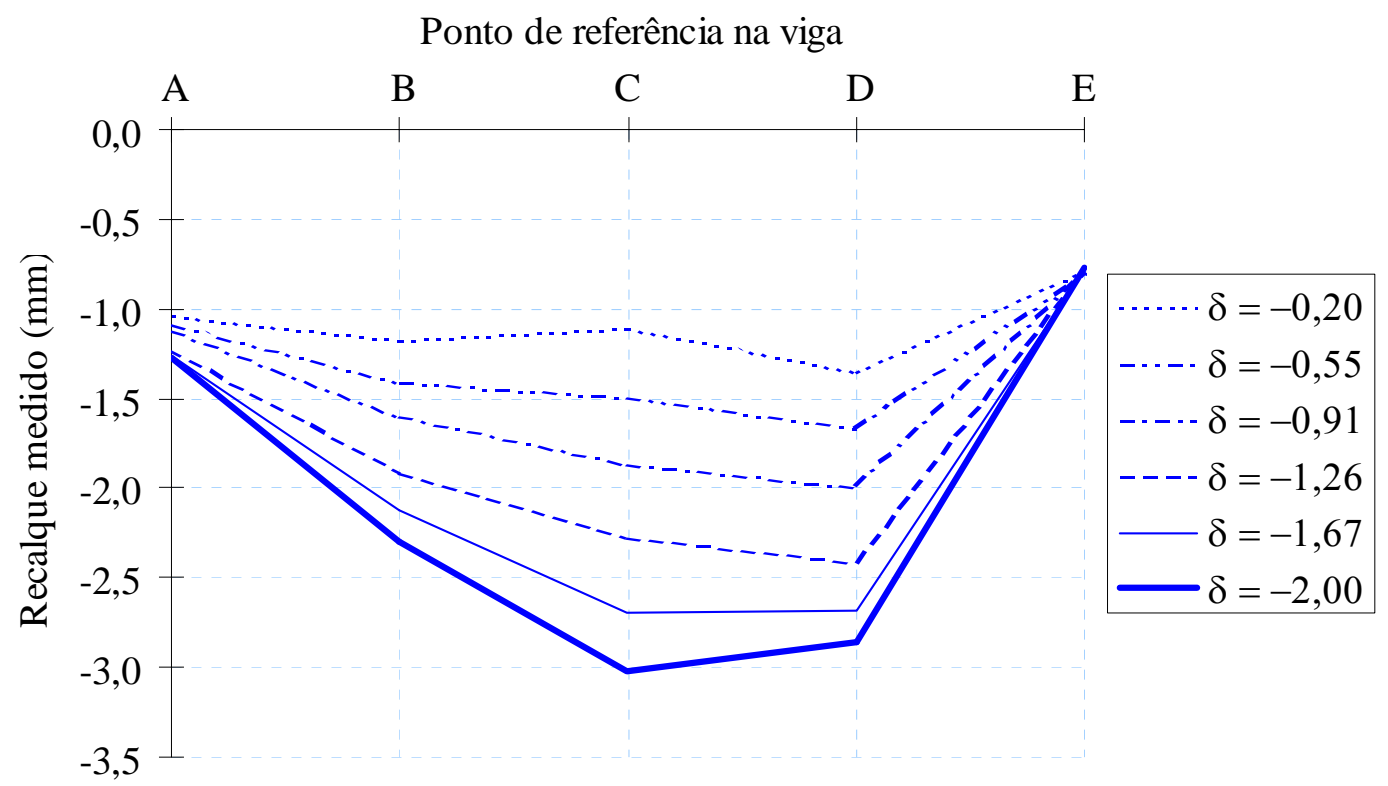

Figura 4.19 Configuração deformada da viga - Modelo 2, Situação 2. ( $\delta$ em mm)

Tabela 4.3 Parâmetros de curvatura - Modelo 2, Situação 2.

\begin{tabular}{c|c|l|c|c|c|c|c}
\hline \multicolumn{2}{c|}{ RECALQUE $(\mathrm{mm})$} & OCORRÊNCIA & $(\Delta / \mathrm{L})_{\mathrm{ACE}}$ & $(\Delta / \mathrm{L})_{\mathrm{ABC}}$ & $(\Delta / \mathrm{L})_{\mathrm{CDE}}$ & $(\delta / \ell)_{\mathrm{AB}}$ & $(\delta / \ell)_{\mathrm{DE}}$ \\
\hline \multicolumn{1}{c|}{ total } & diferencial & Orimeiras fissuras \\
\hline$-1,6$ & $\mathbf{- 0 , 9 1}$ & $\begin{array}{l}\text { Prima e abaixo da } \\
\text { (verga } \\
\text { janela) }\end{array}$ & $-1 / 1968$ & $-1 / 8618$ & $-1 / 1372$ & $1 / 801$ & $1 / 404$ \\
\hline$-2,2$ & $\mathbf{- 1 , 4 6}$ & Fissura horizontal & $-1 / 1236$ & $-1 / 6551$ & $-1 / 962$ & $1 / 520$ & $1 / 270$ \\
\hline$-2,5$ & $\mathbf{- 1 , 7 9}$ & $\begin{array}{l}\text { Propagação de } \\
\text { fissuras por } \\
\text { cisalhamento }\end{array}$ & $-1 / 1007$ & $-1 / 6212$ & $-1 / 947$ & $1 / 433$ & $1 / 244$ \\
\hline$-3,0$ & $\mathbf{- 2 , 0 0}$ & Recalque máximo & $-1 / 899$ & $-1 / 6168$ & $-1 / 934$ & $1 / 392$ & $1 / 229$ \\
\hline
\end{tabular}

Nota: Valores negativos de $(\Delta / \mathrm{L})$ indicam concavidade para cima. $(\delta / \ell)$ em valores absolutos.

Em seguida, na Figura 4.20, encontra-se o esquema de distribuição das fissuras do painel após o ensaio. Estão assinalados ao lado das fissuras os valores de recalque diferencial do apoio central relativo ao instante em que surgiram. A fotografia do painel ao final desta etapa é apresentada na Figura 4.21. Neste caso estão assinalados os valores de recalque total. 


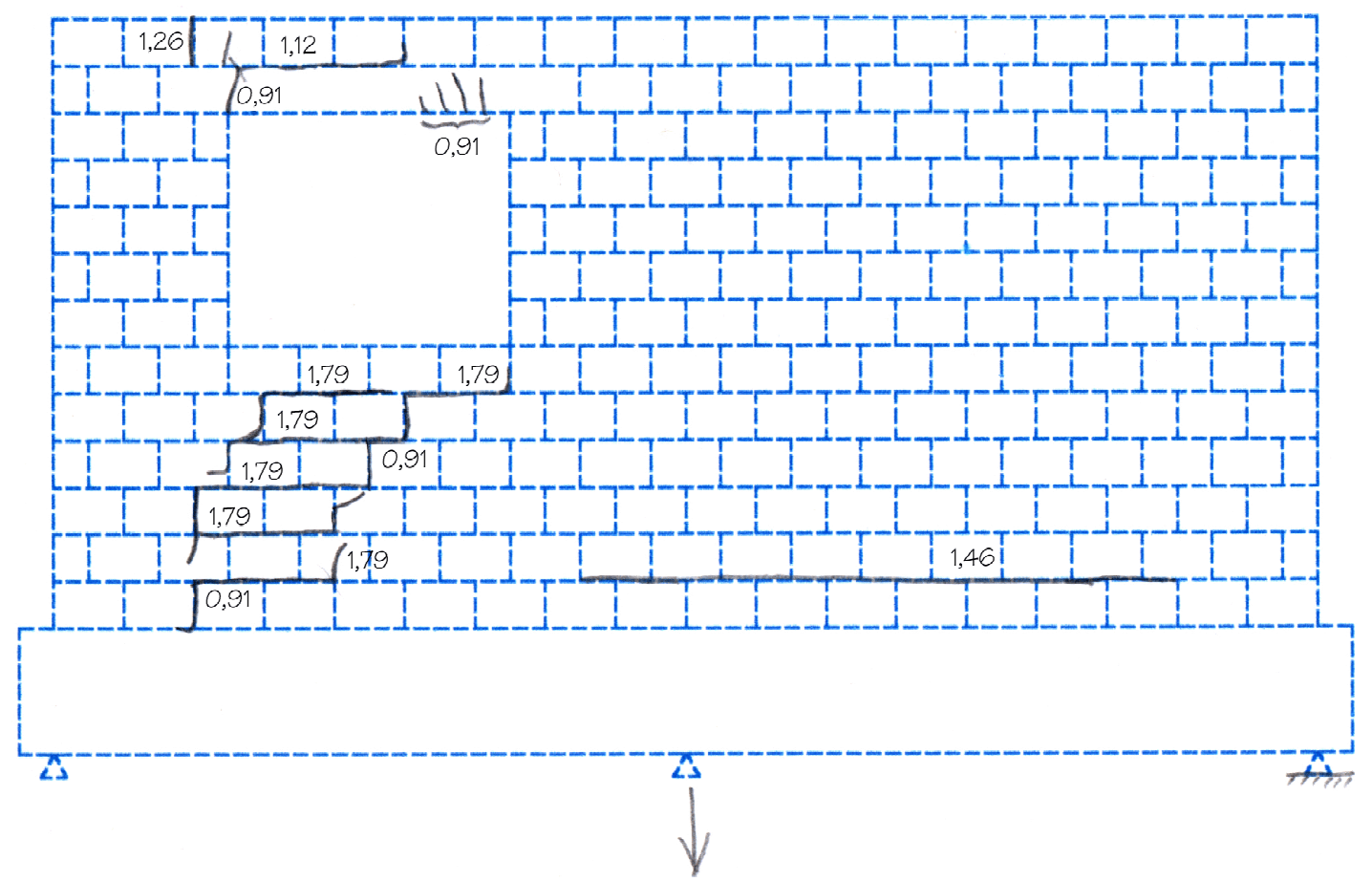

Figura 4.20 Distribuição de fissuras após ensaio - Modelo 2, Situação 2 (Verso do painel).

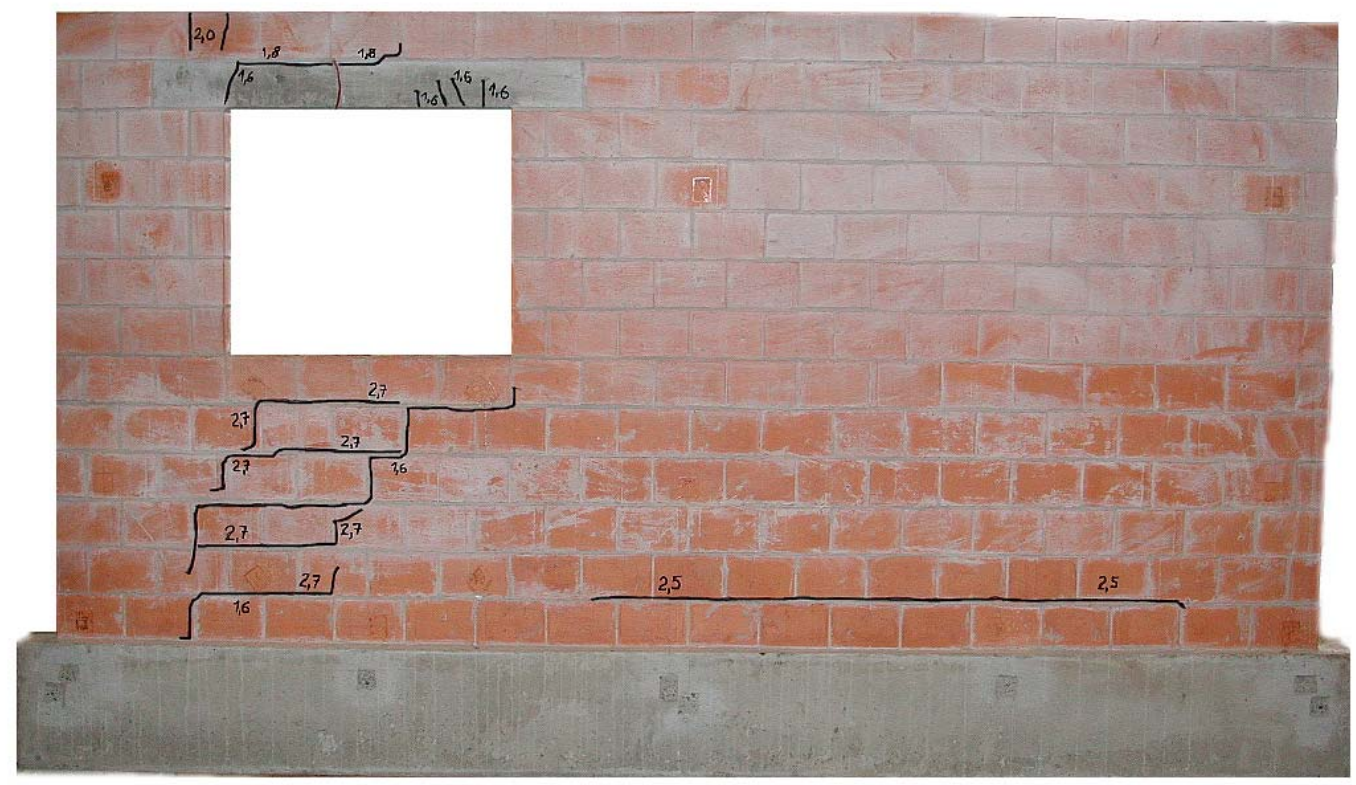

Figura 4.21 Fotografia do painel após ensaio - Modelo 2, Situação 2 (Verso do painel).

Da mesma forma que na situação anterior, a deformação vertical medida no trecho de parede entre a janela e a borda do painel foi maior, em torno de $12 \%$, que aquela da região próxima à borda oposta, embora tenha sido observado exatamente o contrário em relação às reações de apoio. 


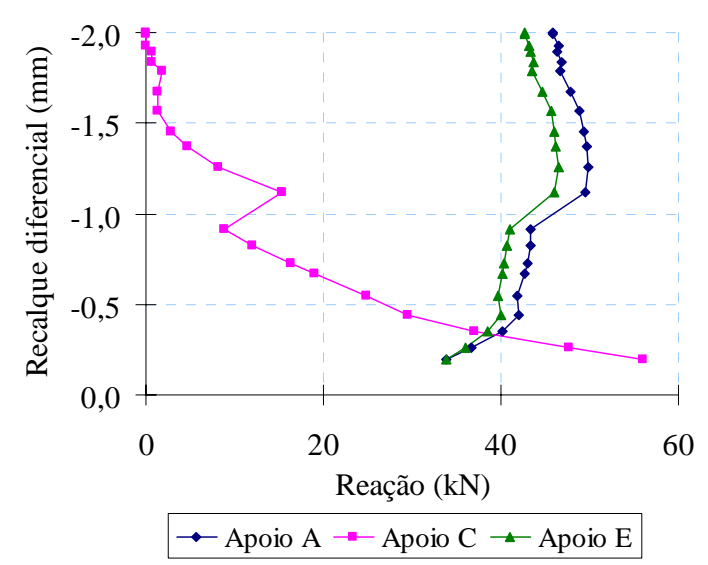

(a)

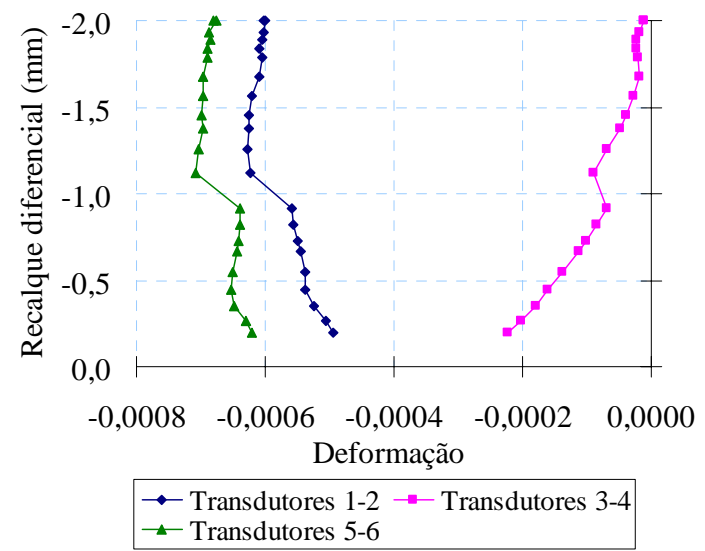

(b)

Figura 4.22 (a) Reações de apoio; (b) Deformação na parede - Modelo 2, Situação 2.

Os transdutores 14 e 15, posicionados abaixo da abertura, acusaram respectivamente um encurtamento de $-0,74 \mathrm{~mm}$ e um alongamento de $1,60 \mathrm{~mm}$ ao final da etapa. Suas curvas em função do recalque diferencial foram lineares, mesmo tendo ocorrido fissuração naquela região.

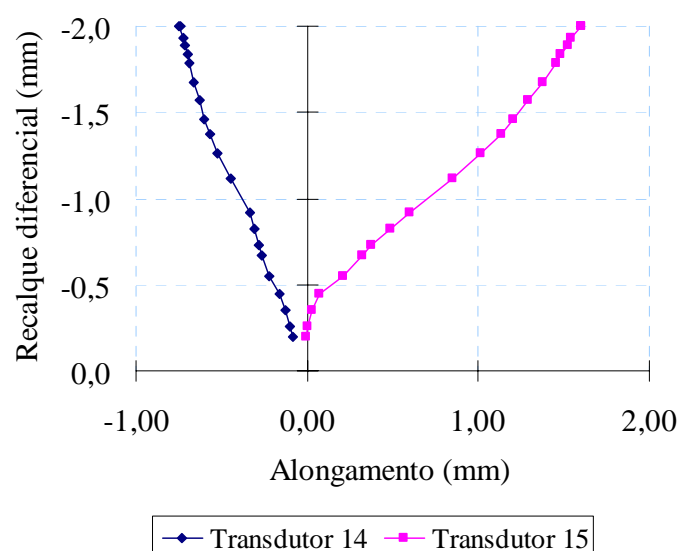

Figura 4.23 Leituras abaixo da janela - Modelo 2, Situação 2 .

$\mathrm{Na}$ base da parede, as tensões transmitidas à viga tiveram uma distribuição semelhante à da Figura 4.24. Este diagrama está coerente com a descrição da literatura para o caso de parede sobre viga biapoiada já a partir do recalque de $-0,91 \mathrm{~mm}$, quando a reação do apoio central era de apenas $7 \%$ da carga total aplicada. Um fato bastante interessante a ser notado é a compressão revelada pelo extensômetro 24 , a partir do mesmo valor de recalque. Isto indica que parte do arco de compressão da parede se desviou para a região interna à abertura, ou seja, entre a janela e a borda oposta do painel. A transferência de carga da parede à viga numa extensão entre os apoios concorre para aumentar a deformação e o momento fletor da viga no vão, o que realmente foi observado. 


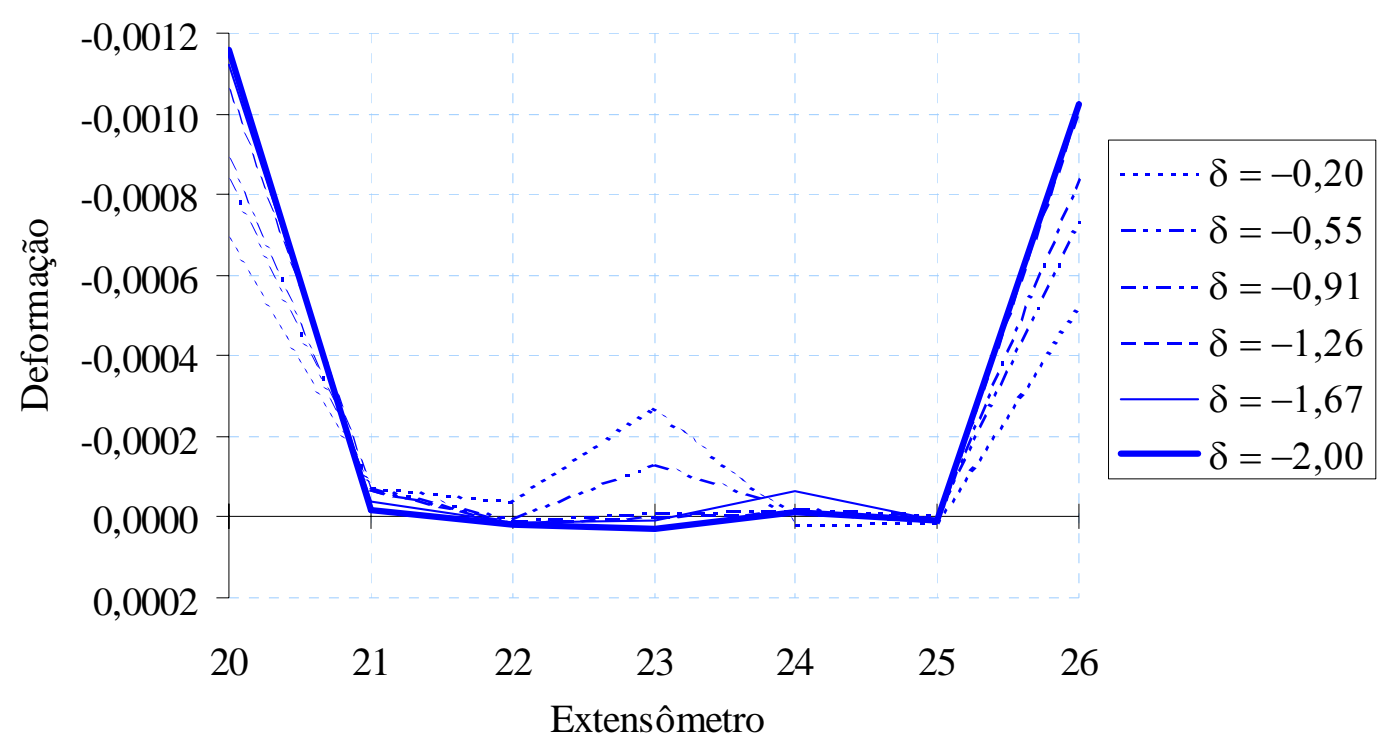

Figura 4.24 Deformações na base da parede - Modelo 2, Situação 2. ( $\delta$ em mm)

\subsubsection{Situação 3: Recalque do apoio de extremidade}

Nesta situação de recalque, as primeiras fissuras foram observadas para um recalque diferencial muito pequeno, de apenas $-0,05 \mathrm{~mm}$. Foram fissuras verticais na região central da borda superior da parede que, pela instrumentação, foram percebidas somente pelo extensômetro 9.

Quando o recalque diferencial do apoio E chegou a cerca de $-0,38 \mathrm{~mm}$, apareceu uma pequena fissura vertical na última fiada, acima do meio do vão da verga. Logo em seguida, para um recalque de $-0,47 \mathrm{~mm}$ surgiu uma fissura escalonada abaixo da abertura, com direção do apoio central para o meio da borda inferior da janela, mas sem atingir a interface parede-viga nem a borda da abertura. Apresentou também uma bifurcação em direção ao canto inferior interno da abertura. O painel continuou estável até o recalque diferencial de $-1,02 \mathrm{~mm}$, quando a fissura escalonada propagou-se atingindo as bordas da janela e da viga.

Quando o recalque diferencial atingiu o valor de $-1,37 \mathrm{~mm}$, surgiu uma fissura vertical na verga e acima dela dividindo o lintel acima da abertura na posição do canto superior interno da janela. Nesse instante se formou o conjunto de fissuras que dividiu a parede em duas partes, com a própria abertura da janela unindo as fissuras acima e abaixo de si. Como conseqüência imediata, a porção direita do painel cedeu, fazendo o recalque diferencial mudar repentinamente para $-2,35 \mathrm{~mm}$.

Logo em seguida formaram-se fissuras horizontais na borda direita do painel, a meia altura, e uma vertical na extremidade direita da verga. No final do ensaio esta última 
fissura aumentou em sentido descendente e surgiu uma outra fissura escalonada abaixo da janela, paralela à anterior. O recalque diferencial máximo foi de $-3,22 \mathrm{~mm}$, mas certamente seria maior, pois nesta etapa não se fez a correção final da carga de compressão aplicada ao painel.

Após a divisão da parede em duas partes, a abertura do conjunto de fissuras que a provocou passou a aumentar continuamente, sendo maior na fissura escalonada, próximo ao canto da janela. Neste ponto a abertura da fissura atingiu $0,8 \mathrm{~mm}$ ao final do ensaio, um valor bastante significativo.

A Figura 4.25 apresenta a deformação da viga em função do recalque e a Tabela 4.4 traz alguns valores dos parâmetros de curvatura. A distribuição final das fissuras, com os valores de recalque diferencial, pode ser visualizada na Figura 4.26 enquanto que na Figura 4.27 encontra-se a fotografia do Modelo 2 após o ensaio, onde foram anotados os valores de recalque total.

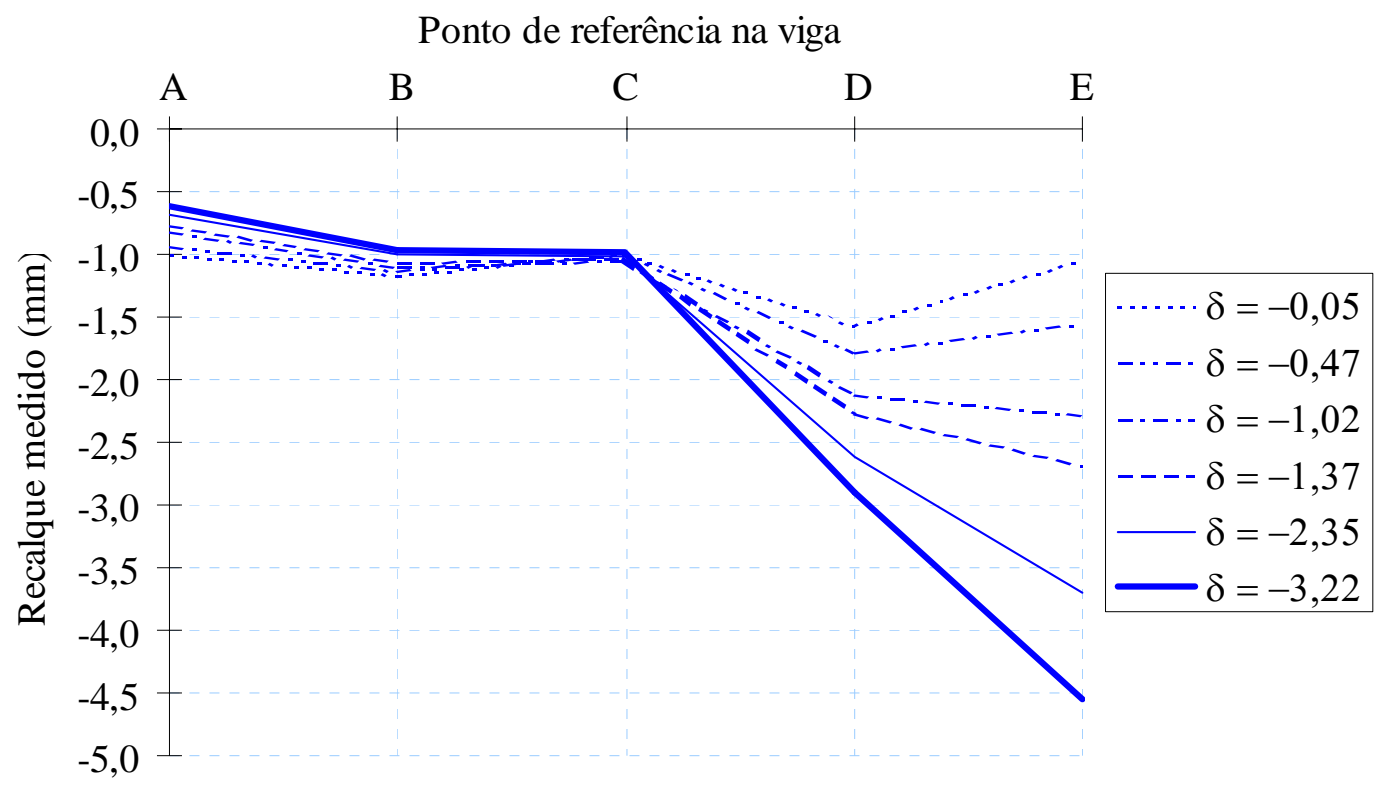

Figura 4.25 Configuração deformada da viga - Modelo 2, Situação 3. ( $\delta$ em mm) 
Tabela 4.4 Parâmetros de curvatura - Modelo 2, Situação 3.

\begin{tabular}{|c|c|c|c|c|c|c|}
\hline \multicolumn{2}{|c|}{ RECALQUE (mm) } & \multirow{2}{*}{ OCORRÊNCIA } & \multirow{2}{*}{$(\Delta / \mathrm{L})_{\mathrm{ACE}}$} & \multirow{2}{*}{$(\Delta / \mathrm{L})_{\mathrm{ABC}}$} & \multirow{2}{*}{$(\Delta / \mathrm{L})_{\mathrm{CDE}}$} & \multirow{2}{*}{$(\delta / \ell)_{\mathrm{CD}}$} \\
\hline total & diferencial & & & & & \\
\hline$-1,2$ & $-0,47$ & $\begin{array}{l}\text { Primeira fissura } \\
\text { escalonada }\end{array}$ & $1 / 7622$ & $-1 / 5458$ & $-1 / 1773$ & $1 / 605$ \\
\hline$-2,0$ & $-1,02$ & $\begin{array}{l}\text { Propagação da } \\
\text { primeira fissura }\end{array}$ & $1 / 3517$ & $-1 / 5561$ & $-1 / 2007$ & $1 / 469$ \\
\hline$-2,3$ & $-1,37$ & $\begin{array}{l}\text { Formação da fissura } \\
\text { divisora da parede }\end{array}$ & $1 / 2633$ & $-1 / 5641$ & $-1 / 2244$ & $1 / 415$ \\
\hline$-3,3$ & $-2,35$ & $\begin{array}{l}\text { Conseqüência da } \\
\text { fissura anterior }\end{array}$ & $1 / 1532$ & $-1 / 5655$ & $-1 / 3498$ & $1 / 314$ \\
\hline$-4,6$ & $-3,22$ & Recalque máximo & $1 / 1120$ & $-1 / 5605$ & $-1 / 6472$ & $1 / 258$ \\
\hline
\end{tabular}

Nota: Valores negativos de $(\Delta / \mathrm{L})$ indicam concavidade para cima. $(\delta / \ell)$ em valores absolutos.

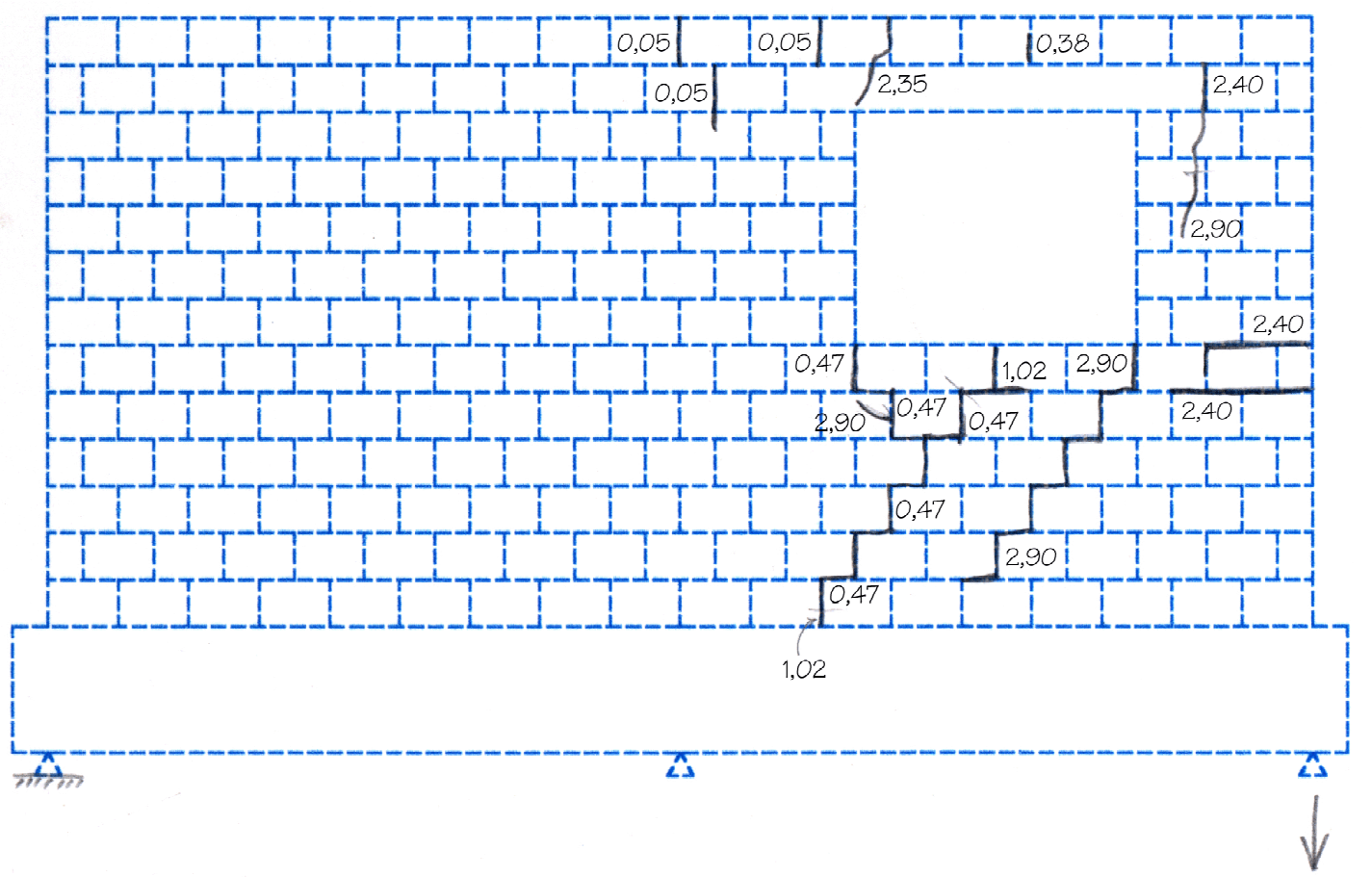

Figura 4.26 Distribuição de fissuras após ensaio - Modelo 2, Situação 3. 


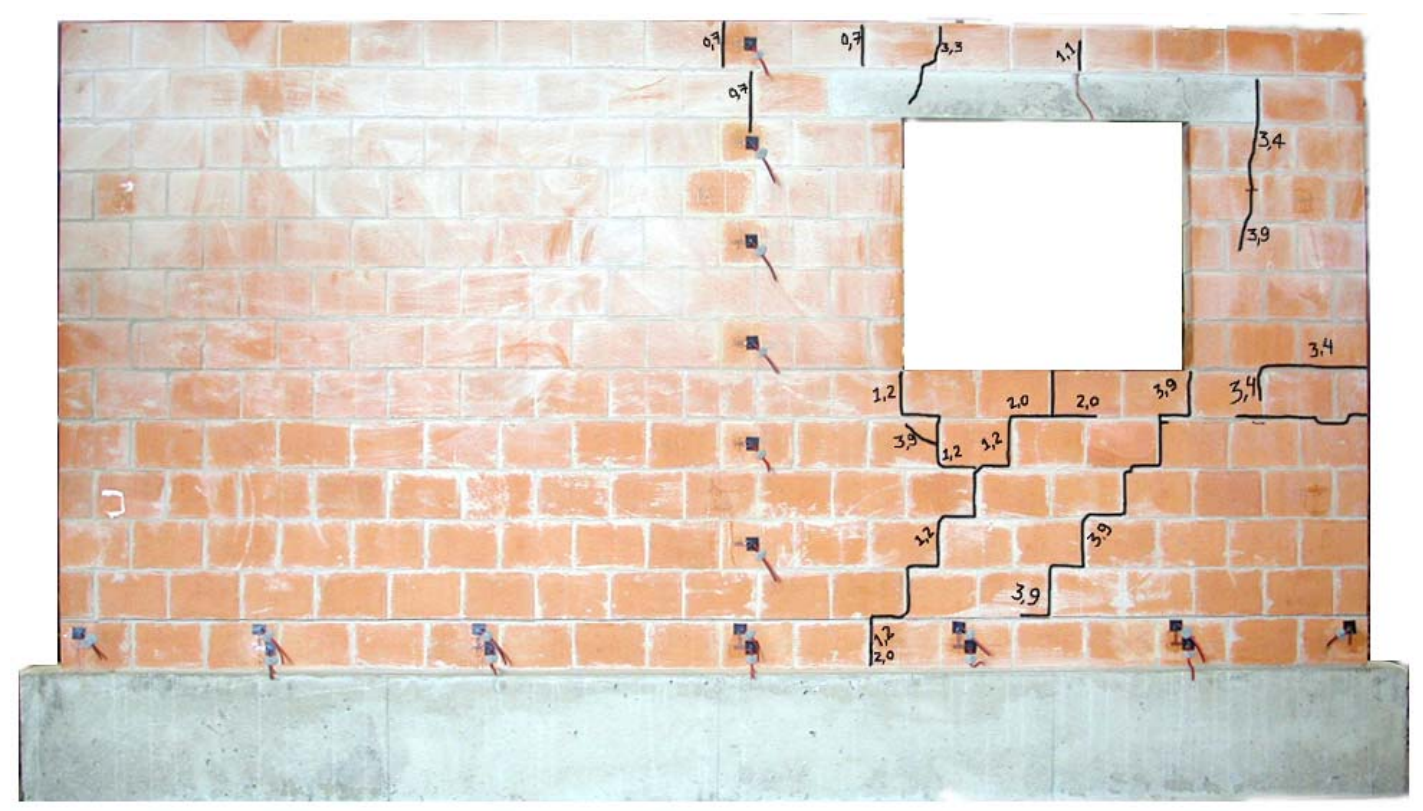

Figura 4.27 Fotografia do painel após ensaio - Modelo 2, Situação 3.

Depois da fissuração ocorrida ao recalque de $-0,47 \mathrm{~mm}$, parte da carga que competia ao apoio central foi redistribuída, o que foi percebido pelas deformações medidas pelos extensômetros da base da parede. Além disso, verificou-se o aumento da compressão na posição do extensômetro 25 , simulando um efeito análogo ao observado na situação de recalque central, em que o fluxo de tensões é alterado pela abertura de janela e parte da carga é transmitida da parede para a viga numa região intermediária do vão CDE.

$\mathrm{Na}$ parede, as deformações por compressão próximo às bordas diminuíram e, além disso, os transdutores 5 e 6 passaram a registrar grandes alongamentos. A mudança de comportamento desses transdutores começou também a partir do recalque de $-0,47 \mathrm{~mm}$.

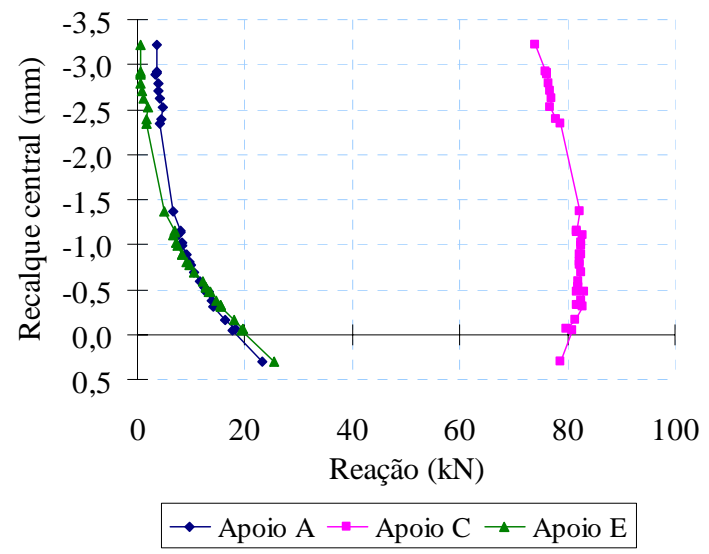

(a)

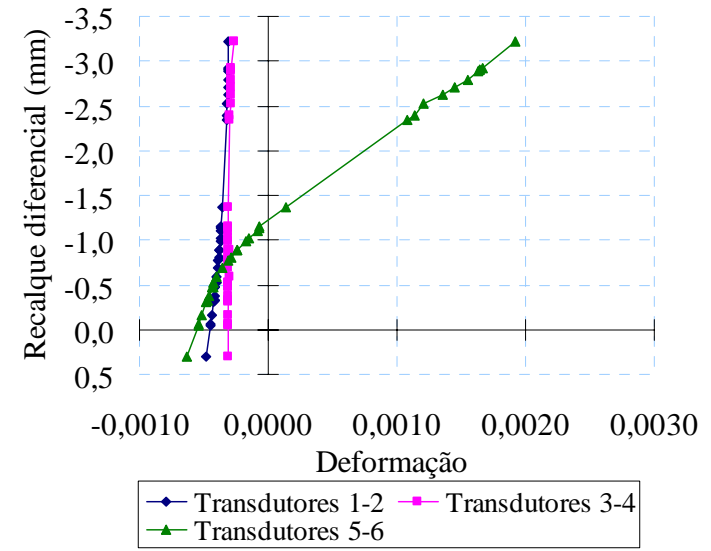

(b)

Figura 4.28 (a) Reações de apoio; (b) Deformação na parede - Modelo 2, Situação 3. 


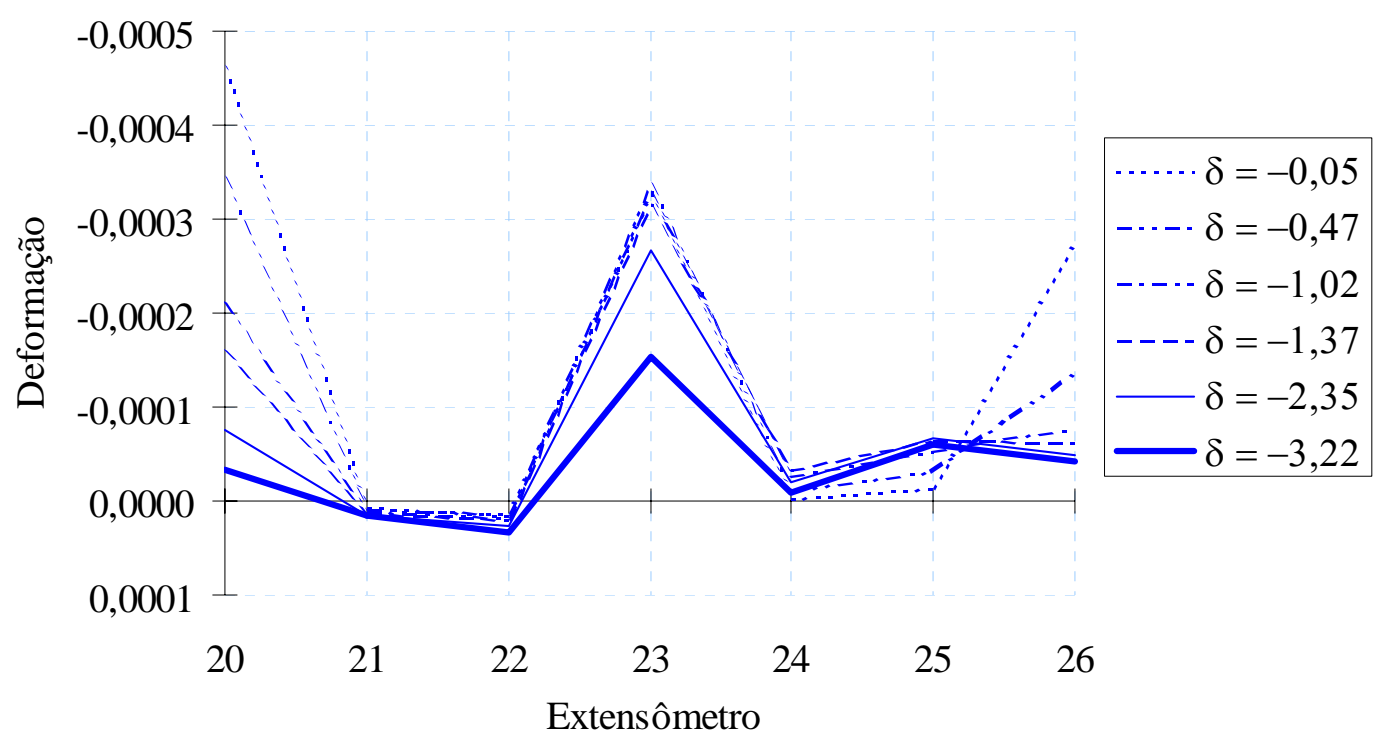

Figura 4.29 Deformações na base da parede - Modelo 2, Situação 3. ( $\delta$ em mm)

Abaixo da abertura, o transdutor 14 mediu grandes alongamentos de até 1,66 mm, dos quais $0,55 \mathrm{~mm}$ ocorreram no instante da divisão da parede. Até esse instante o encurtamento medido pelo transdutor 15 aumentou, depois permanecendo num patamar de $-0,07 \mathrm{~mm}$.

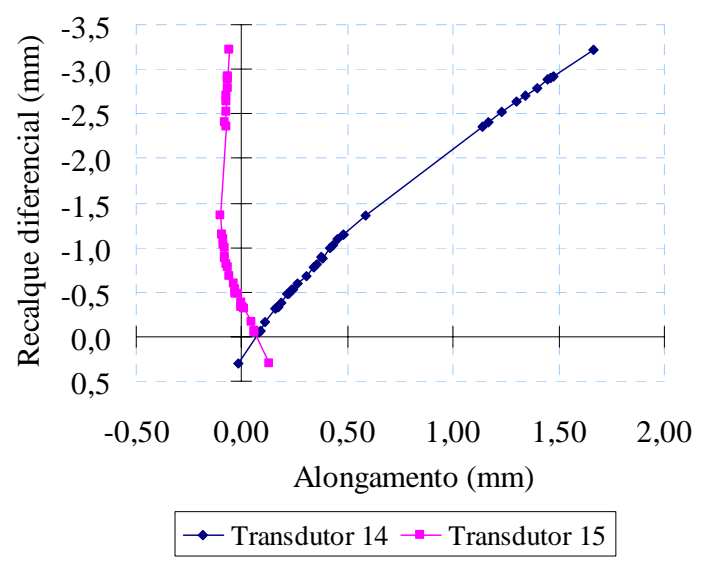

Figura 4.30 Leituras abaixo da janela - Modelo 2, Situação 3.

\subsection{MODELO 3}

A influência das aberturas de portas foi observada neste modelo. Em especial, buscou-se captar o caminhamento das tensões constituintes do arco de compressão e como se apresenta o aspecto da fissuração. 

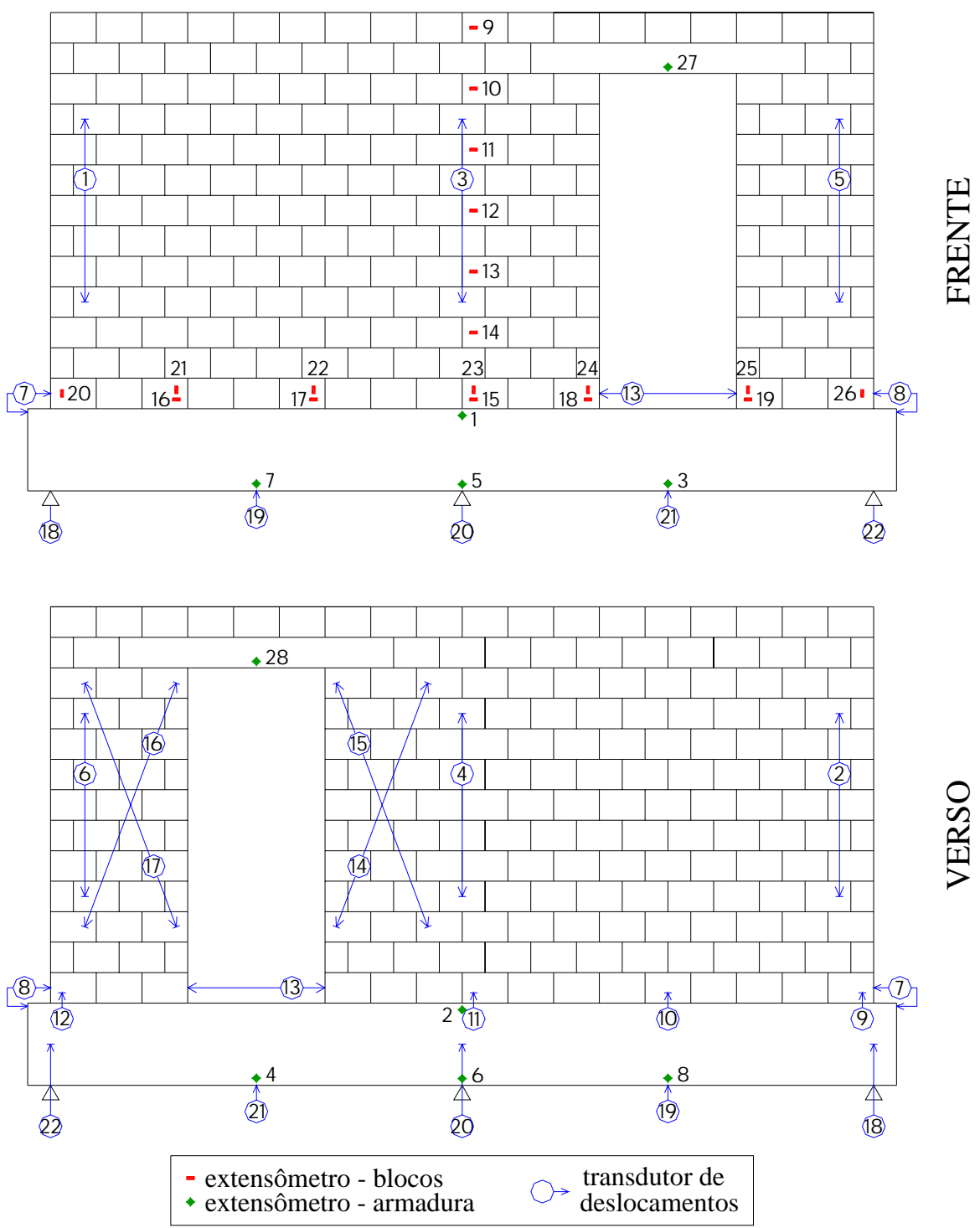

Figura 4.31 Instrumentação do Modelo 3.

\subsubsection{Situação 1: Aplicação do carregamento vertical}

Esta etapa foi realizada sem a observação de problemas quanto ao comportamento do painel. Aplicada a carga total de $135,0 \mathrm{kN}$, as reações se distribuíram conforme a tabela abaixo, onde também se encontram as deformações verticais da parede medidas a meia altura, acima dos apoios.

Tabela 4.5 Reações de apoio e deformações da parede - Modelo 3, Situação 1.

\begin{tabular}{rccc}
\hline APOIO & $\mathbf{A}$ & $\mathbf{C}$ & $\mathbf{E}$ \\
REAÇÃO $(\mathrm{kN})$ & 41,2 & 62,1 & 31,7 \\
\hline TRANSDUTORES & $\mathbf{1 ~ e ~ 2}$ & $\mathbf{3 ~ e ~ 4}$ & $\mathbf{5 ~ e ~ 6}$ \\
DEFORMAÇÃO & $-0,000432$ & $-0,000270$ & $-0,000506$ \\
\hline
\end{tabular}


Na Figura 4.32 se visualiza como se deformou a viga com a aplicação do carregamento de compressão.

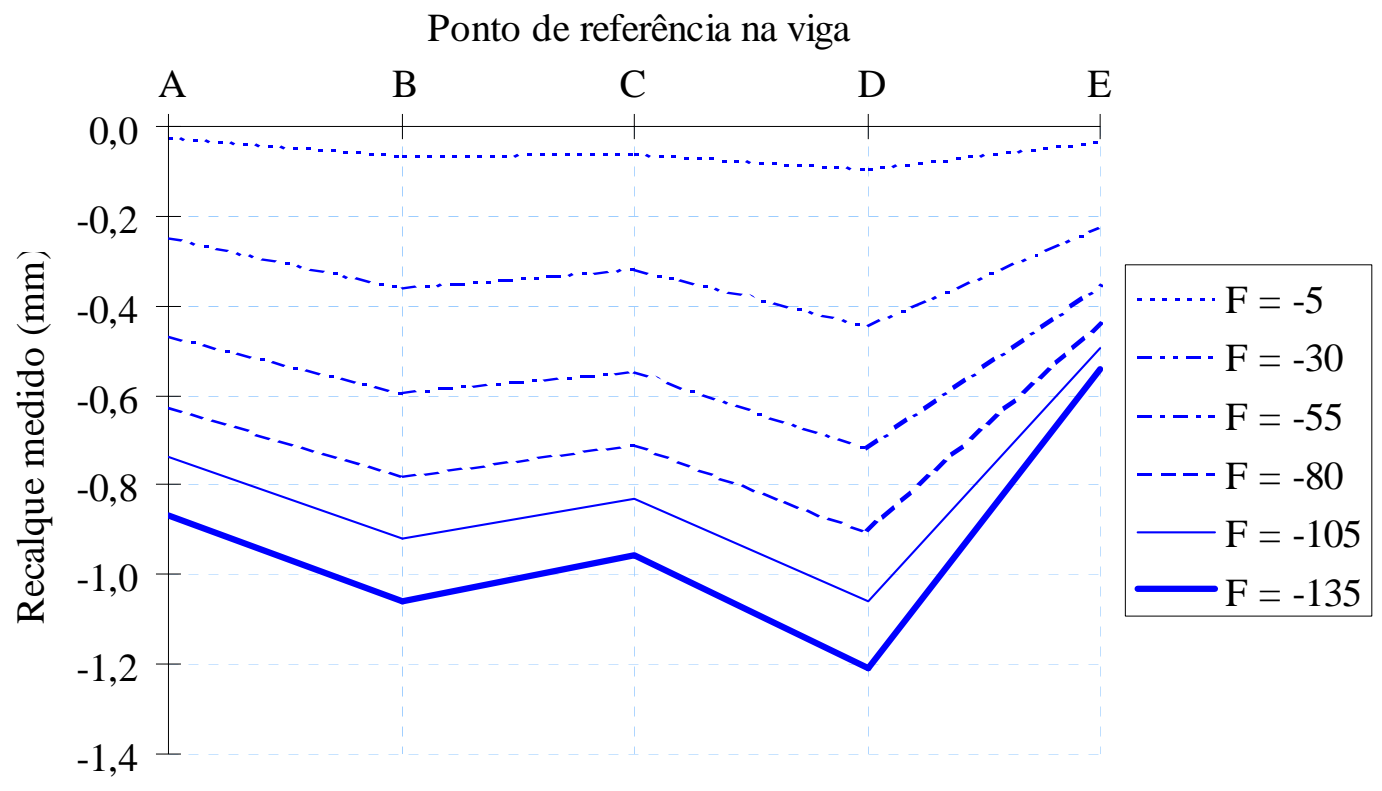

Figura 4.32 Configuração deformada da viga - Modelo 3, Situação 1. (F em kN)

A partir da força igual a $130 \mathrm{kN}$, o parâmetro de curvatura $(\Delta / \mathrm{L})_{\mathrm{CDE}}$ ultrapassou -1/2000. Porém, não foi observada nenhuma fissuração. Ao final desta etapa este parâmetro alcançou o valor máximo de -1/1917. Os demais apresentaram-se bastante pequenos.

Terminada a etapa de aplicação do carregamento vertical, registrou-se um recalque diferencial do apoio central de $-0,25 \mathrm{~mm}$, descontada a inclinação de $0,018 \%$ entre os apoios A e E.

A figura seguinte ilustra a evolução das reações de apoio e da deformação vertical da parede.

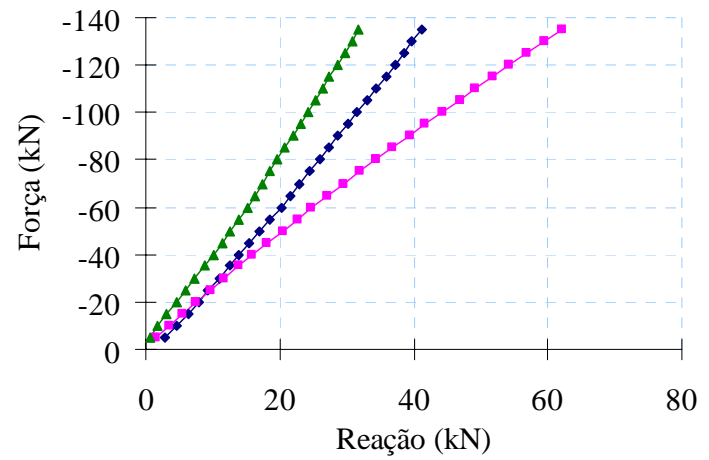

Apoio $\mathrm{A} \rightarrow$ Apoio $\mathrm{C} \rightarrow$ Apoio E

(a)

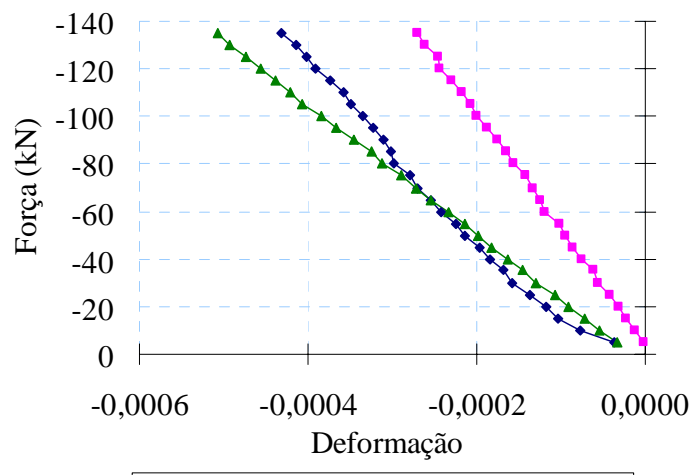

- - Transdutores 1-2 - - Transdutores 3-4 - Transdutores 5-6

(b)

Figura 4.33 (a) Reações de apoio; (b) Deformação na parede - Modelo 3, Situação 1. 
Dentre os transdutores colocados nas laterais da porta em forma de "X", o 16 mediu o maior encurtamento, enquanto os demais apresentaram valores praticamente iguais. Isso indica que o arco de compressão se formou passando por cima da abertura, sem derivar em direção ao canto inferior interno da porta.

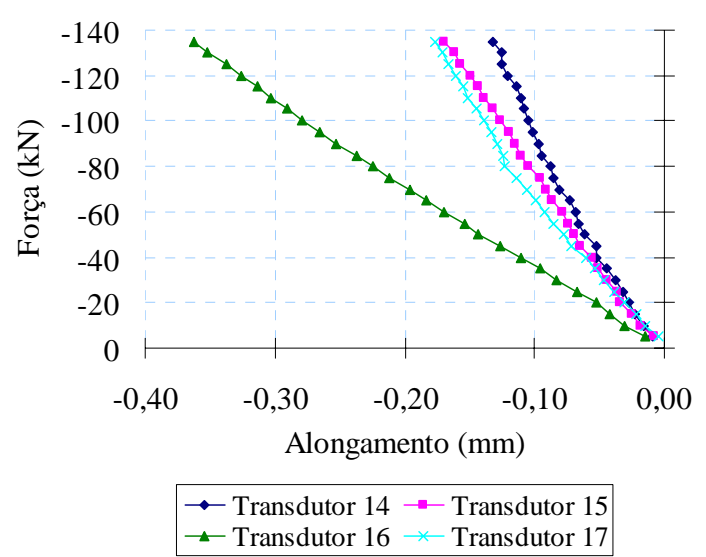

Figura 4.34 Leituras ao lado da porta - Modelo 3, Situação 1.

A seguir, na Figura 4.35, apresenta-se a distribuição das deformações na base da parede, em que se percebe que a simetria praticamente não foi afetada pela porta.

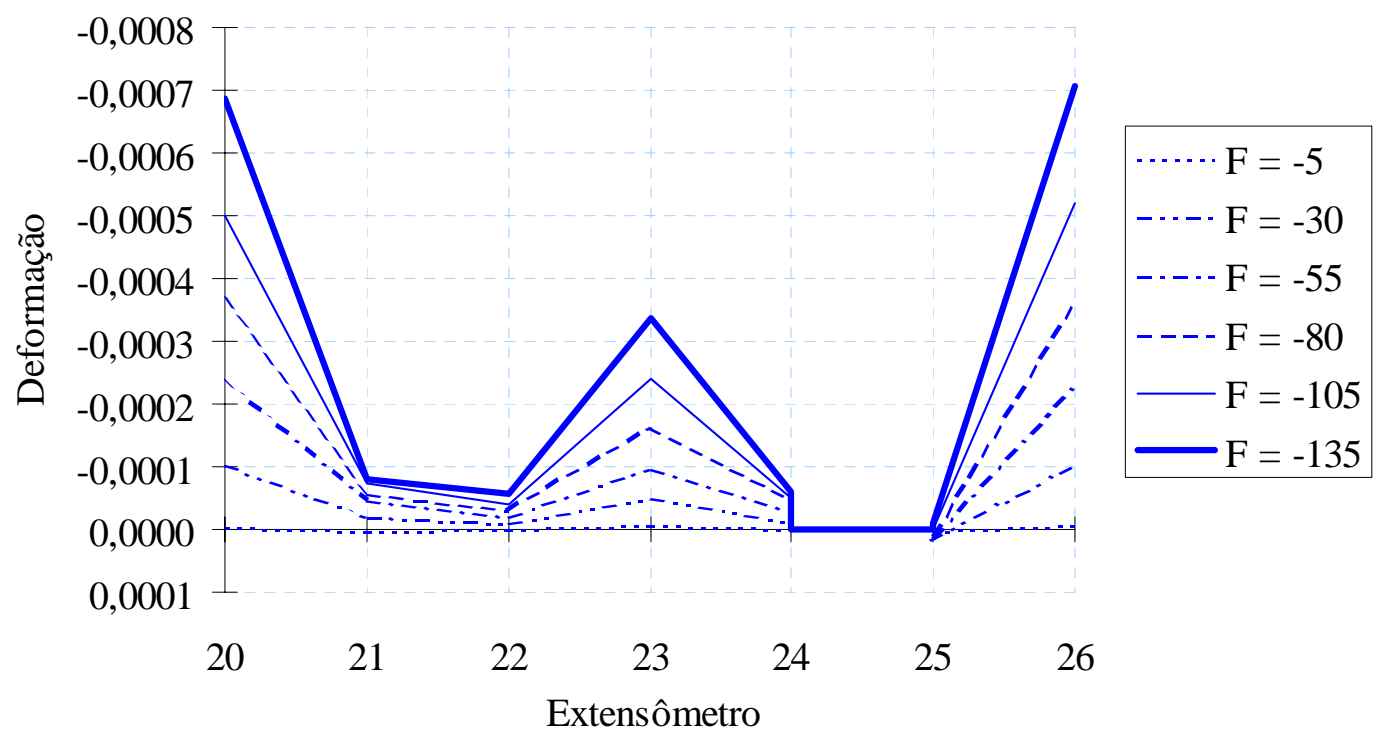

Figura 4.35 Deformações na base da parede - Modelo 3, Situação 1. (F em kN)

\subsubsection{Situação 2: Recalque do apoio central}

Observou-se a primeira fissura quando o recalque atingiu $-0,46 \mathrm{~mm}$. Foi uma fissura horizontal, no canto inferior da porta, com comprimento de pouco mais de meio bloco, separando a primeira fiada da segunda (v. Figura 4.38). Esperava-se que essa fissura 
ocorresse preferencialmente na interface parede-viga, mas neste caso a junta da interface foi mais forte. Com o aumento do recalque, a fissura propagou-se continuamente em direção ao canto inferior externo da parede.

Além de propagar-se, a fissura teve sua abertura aumentando consideravelmente durante toda esta etapa. De acordo com as características habituais de fissuras causadas por recalque, sua abertura variou ao longo do seu comprimento, sendo maior no ponto onde se iniciou. Após totalmente retirado o apoio central a abertura máxima da fissura chegou a 2,1 mm. Na fotografia da Figura 4.36 visualiza-se este caso.

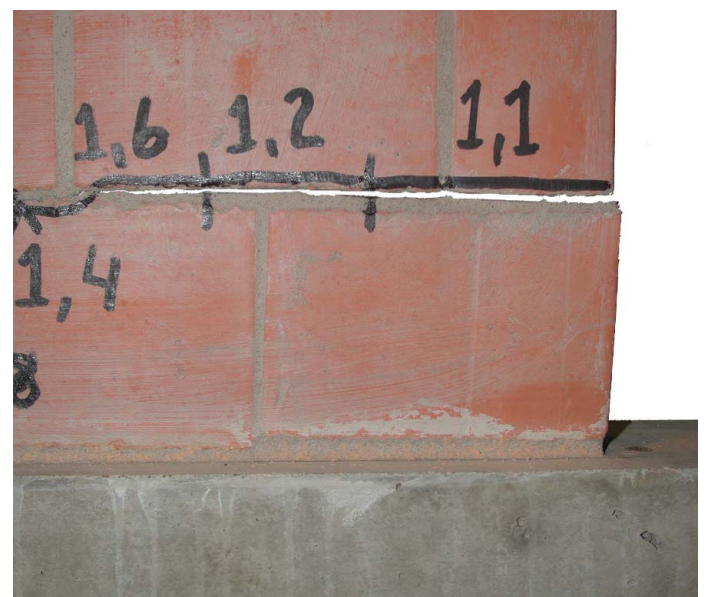

Figura 4.36 Detalhe da fissura no canto da porta - Modelo 3, Situação 2.

$\mathrm{Na}$ região da verga formou-se um conjunto de fissuras. Inicialmente, ao recalque diferencial de $-0,75 \mathrm{~mm}$, surgiu uma fissura diagonal na verga. Em seguida, quando o recalque aproximou-se de $-1,19 \mathrm{~mm}$, essa fissura se propagou em duas direções: verticalmente pela junta imediatamente superior, e horizontalmente pela junta que separa a verga da última fiada até um ponto próximo ao meio do vão da porta, a partir do qual subiu pela junta vertical adjacente.

Continuando o procedimento de ensaio, apareceram mais algumas pequenas fissuras verticais na última fiada, na região central do vão da porta, além de uma fissura horizontal iniciando no canto superior interno da porta, separando a verga de um bloco da fiada imediatamente inferior. Por fim, houve fissuração na junta vertical da extremidade interna da verga. $\mathrm{O}$ aspecto da fissuração na região da verga foi comum para todos os painéis com abertura.

A fissura horizontal no centro da parede, sempre recorrente em todos os ensaios, apareceu quando o recalque atingiu aproximadamente $-2,75 \mathrm{~mm}$. Como nos outros modelos, separou as duas primeiras fiadas, localizando-se na região central do painel, mas um pouco desviada para o lado oposto ao da abertura. Esta fissura delimita com boa aproximação o comprimento de contato entre parede e viga. 
O recalque diferencial máximo aplicado ao Modelo 3, tendo sido retirado completamente o apoio central, foi de $-3,34 \mathrm{~mm}$. O esquema da deformação da viga ao longo desta etapa encontra-se na Figura 4.37. Na Tabela 4.6 são apresentados os valores dos parâmetros de curvatura para os principais níveis de recalque. $\mathrm{O}$ aspecto final da fissuração pode ser visualizado com os valores de recalques diferenciais (Figura 4.38) ou totais (Figura 4.39).

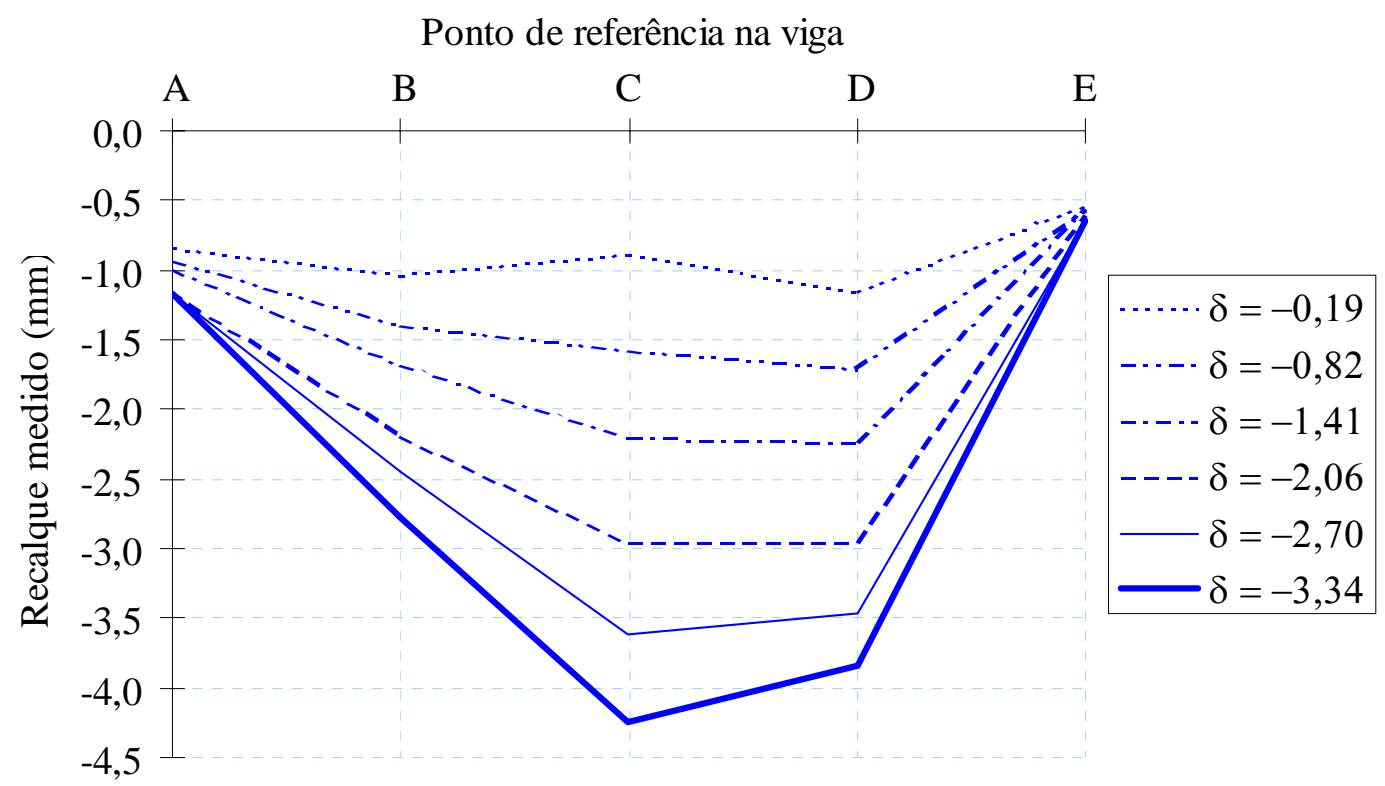

Figura 4.37 Configuração deformada da viga - Modelo 3, Situação 2. ( $\delta$ em mm)

Tabela 4.6 Parâmetros de curvatura - Modelo 3, Situação 2.

\begin{tabular}{|c|c|c|c|c|c|c|c|}
\hline \multicolumn{2}{|c|}{ RECALQUE (mm) } & \multirow{2}{*}{ OCORRÊNCIA } & \multirow{2}{*}{$(\Delta / \mathrm{L})_{\mathrm{ACE}}$} & \multirow{2}{*}{$(\Delta / \mathrm{L})_{\mathrm{ABC}}$} & \multirow{2}{*}{$(\Delta / \mathrm{L})_{\mathrm{CDE}}$} & \multirow{2}{*}{$(\delta / \ell)_{\mathrm{AB}}$} & \multirow{2}{*}{$(\delta / \ell)_{\mathrm{DE}}$} \\
\hline total & diferencial & & & & & & \\
\hline$-1,1$ & $-0,46$ & Primeira fissura & $-1 / 3914$ & $-1 / 5737$ & $-1 / 1746$ & $1 / 1163$ & $1 / 604$ \\
\hline$-1,4$ & $-0,75$ & $\begin{array}{l}\text { Fissura diagonal } \\
\text { na verga }\end{array}$ & $-1 / 2416$ & $-1 / 6338$ & $-1 / 1436$ & $1 / 875$ & $1 / 450$ \\
\hline$-3,6$ & $-2,75$ & Fissura horizontal & $-1 / 654$ & $-1 / 16124$ & $\begin{array}{l}-1 / 664 \\
\end{array}$ & $1 / 314$ & $1 / 165$ \\
\hline$-4,2$ & $-3,34$ & Recalque máximo & $-1 / 539$ & $-1 / 11712$ & $-1 / 643$ & $1 / 258$ & $1 / 147$ \\
\hline
\end{tabular}

Nota: Valores negativos de $(\Delta / \mathrm{L})$ indicam concavidade para cima. $(\delta / \ell)$ em valores absolutos. 


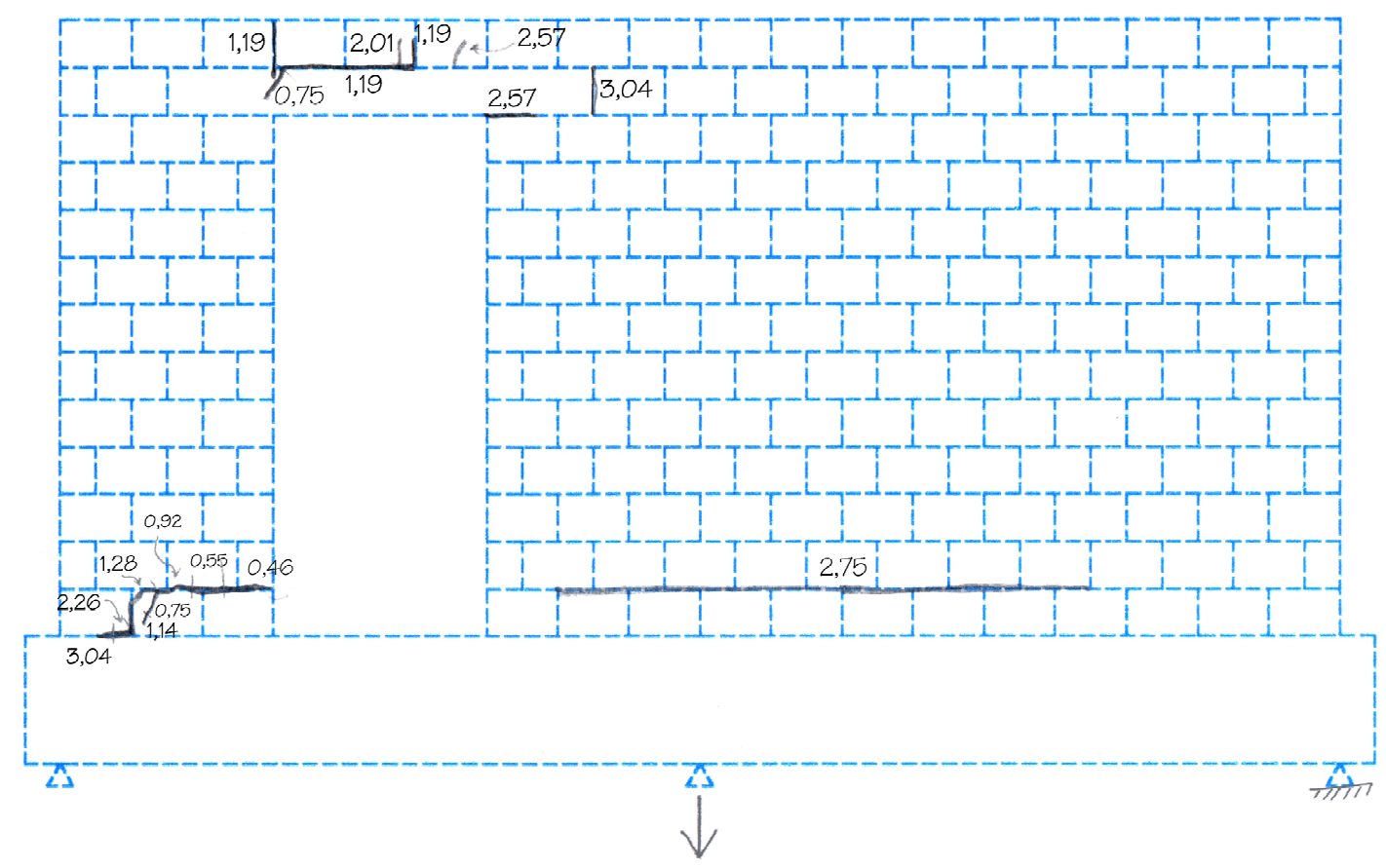

Figura 4.38 Distribuição de fissuras após ensaio - Modelo 3, Situação 2. (Verso do painel)

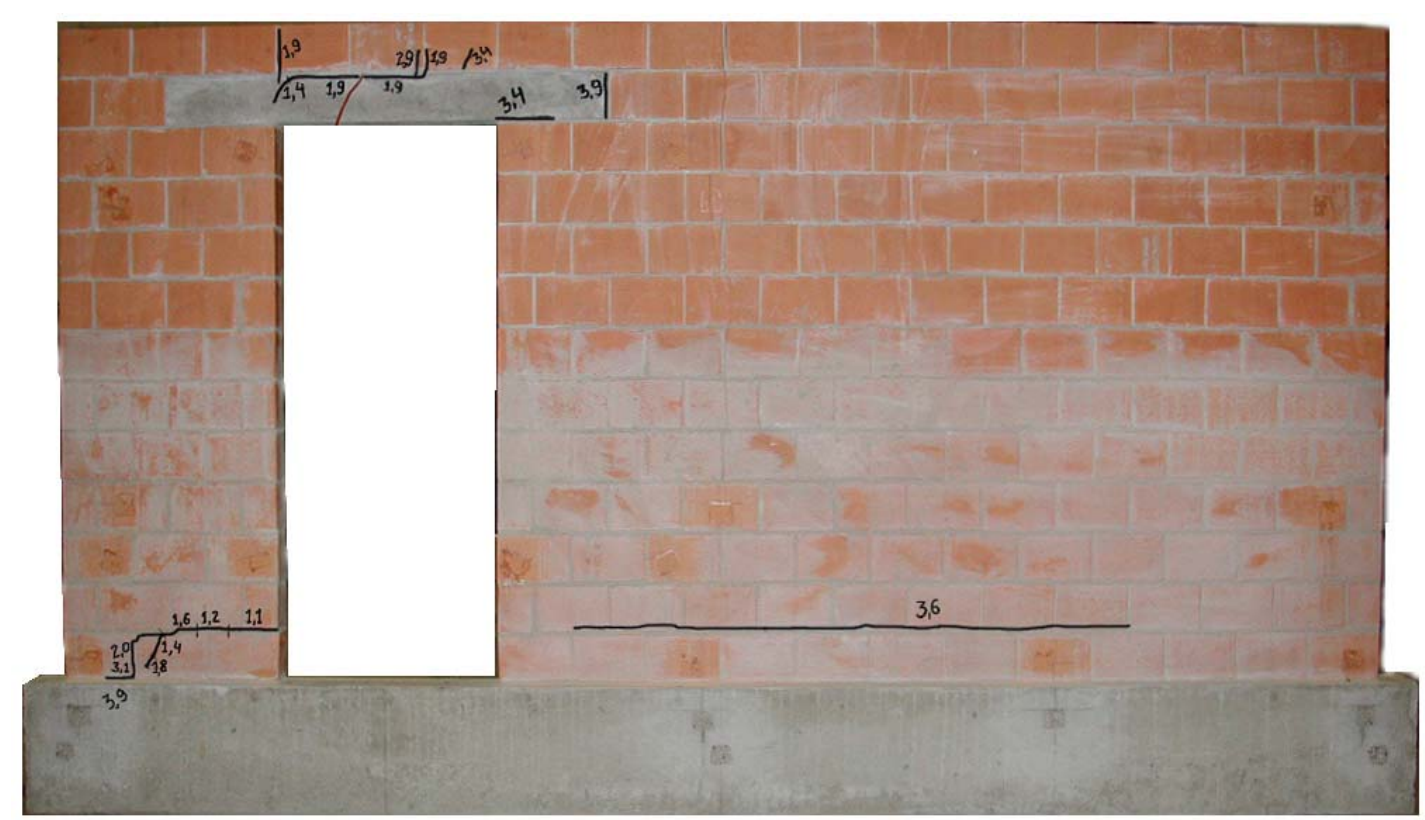

Figura 4.39 Fotografia do painel após ensaio - Modelo 3, Situação 2. (Verso do painel)

As tensões transferidas da parede à viga apresentaram o aspecto do diagrama da Figura 4.40. Percebe-se a pequena concentração de tensões de compressão no canto inferior interno da porta, indicando que parte do arco de compressão desviou-se para esse local, o que foi ratificado pelas leituras dos transdutores 14 a 17.

Para comparação com a modelagem numérica, é importante notar que em nenhum momento surgiram tensões de tração no canto inferior externo da porta. Na verdade, 
toda a transferência de carga para a viga no pequeno trecho de parede entre a abertura e a borda do painel passou a ser feita através de uma faixa de contato com comprimento equivalente a somente meio bloco.

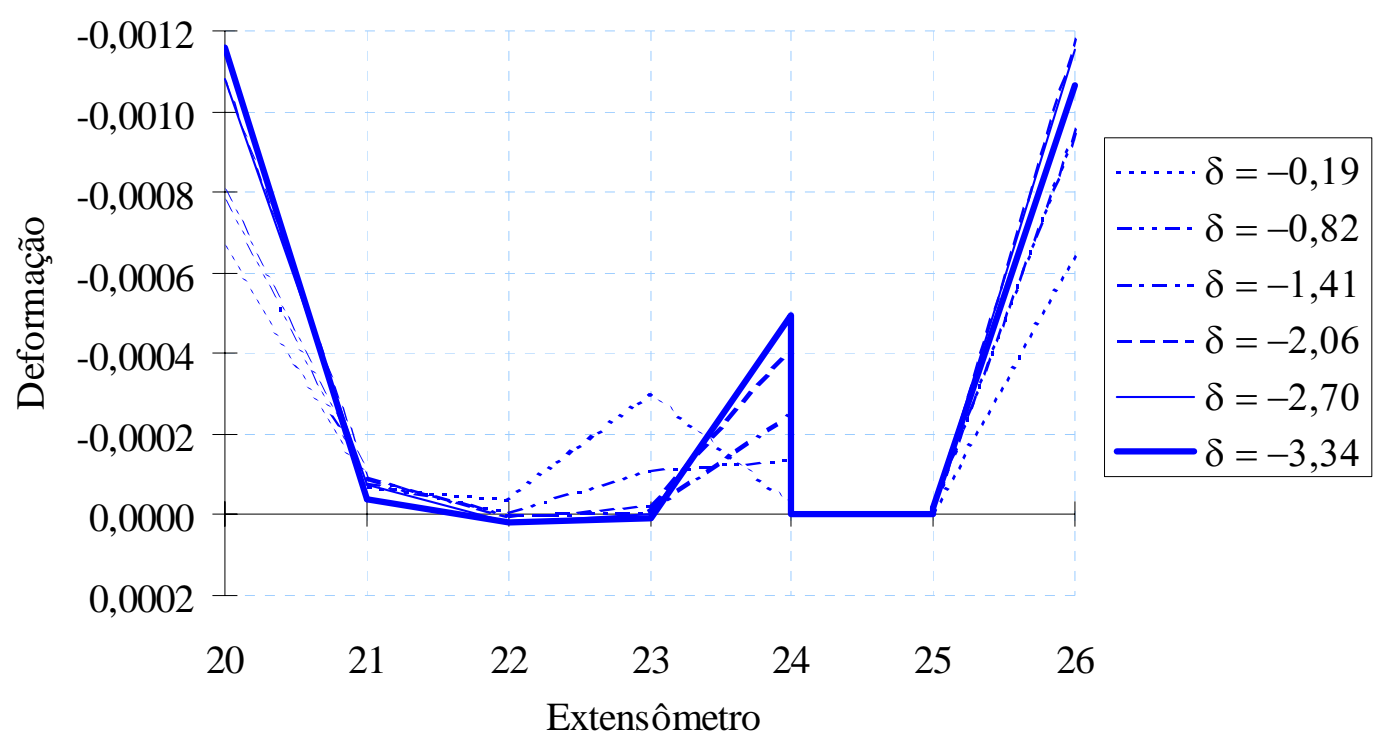

Figura 4.40 Deformações na base da parede - Modelo 3, Situação 2. ( $\delta$ em mm)

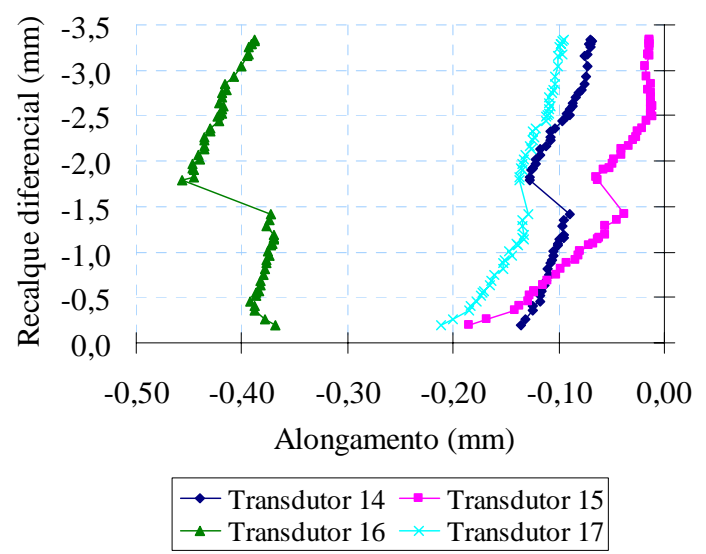

Figura 4.41 Leituras ao lado da porta - Modelo 3, Situação 2.

\subsubsection{Situação 3: Recalque do apoio de extremidade}

Logo no início da aplicação do recalque no apoio E apareceu a primeira fissura na verga. $O$ valor do recalque diferencial era de apenas $-0,05 \mathrm{~mm}$. No mesmo instante observou-se também uma fissura vertical numa junta de argamassa da última fiada, próximo ao centro do vão da porta. Uma continuação vertical da primeira fissura da verga surgiu quando o recalque atingiu $-0,51 \mathrm{~mm}$. A última fissura observada nessa região tinha direção 
diagonal, paralela à primeira fissura, e formou-se no bloco localizado imediatamente acima do centro da verga. Isso ocorreu já com um recalque de $-2,35 \mathrm{~mm}$.

Verificou-se a formação de uma fissura horizontal, iniciando na borda direita do painel, seguindo a junta entre a quarta e a quinta fiada, a um recalque de $-0,34 \mathrm{~mm}$. Essa é uma região onde realmente se esperavam alongamentos na parede devido ao deslocamento do apoio E, levando à fissuração. Mais tarde, quando o recalque aproximou-se de $-2,35 \mathrm{~mm}$, outra fissura horizontal surgiu, separando as duas primeiras fiadas. Ao recalque de $-3,07 \mathrm{~mm}$, esta fissura propagou-se formando um ramo descendente ao encontrar a primeira junta de argamassa.

A partir do canto inferior interno da porta formou-se uma fissura horizontal na interface, que em seguida propagou-se pela viga em direção ao apoio central. Isto aconteceu para um recalque de aproximadamente $-1,58 \mathrm{~mm}$. Aos $-2,78 \mathrm{~mm}$ de recalque surgiram, próximo a esse canto, duas fissuras escalonadas paralelas.

A fissura vertical, recorrente nesses casos de recalque do apoio de extremidade, iniciou-se para um recalque diferencial em torno de $-0,87 \mathrm{~mm}$, afetando somente a última fiada. A penúltima fiada foi atingida quando o recalque chegou a $-2,58 \mathrm{~mm}$. Propagou-se por mais duas fiadas ao recalque de $-3,30 \mathrm{~mm}$. O ensaio foi paralisado após a retirada total do apoio E, com recalque diferencial máximo de $-3,54 \mathrm{~mm}$. Entretanto, logo em seguida o painel partiu-se ao meio bruscamente com a propagação da fissura vertical central até a viga, voltando a se apoiar no cilindro da extremidade, resultando num outro valor para o recalque diferencial máximo: $-3,83 \mathrm{~mm}$. Portanto, poder-se-ia ainda continuar o ensaio, deslocando mais o apoio, mas decidiu-se parar por causa da grande instabilidade do modelo, que provavelmente não alcançaria mais uma configuração estável.

Finalizado o ensaio, a abertura da fissura vertical central atingiu um máximo de 2,5 mm no topo da parede. Na Figura 4.42 apresenta-se uma fotografia dessa região.

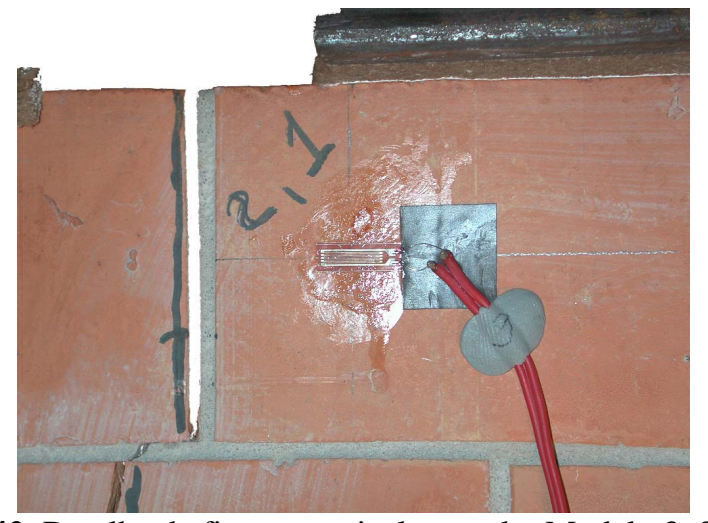

Figura 4.42 Detalhe da fissura vertical central - Modelo 3, Situação 3. 
A seguir apresentam-se uma ilustração da deformação da viga em função do recalque, a tabela com os valores dos parâmetros de curvatura nos momentos mais significativos, o diagrama da fissuração ocorrida e uma fotografia do modelo após o ensaio, com as fissuras demarcadas.

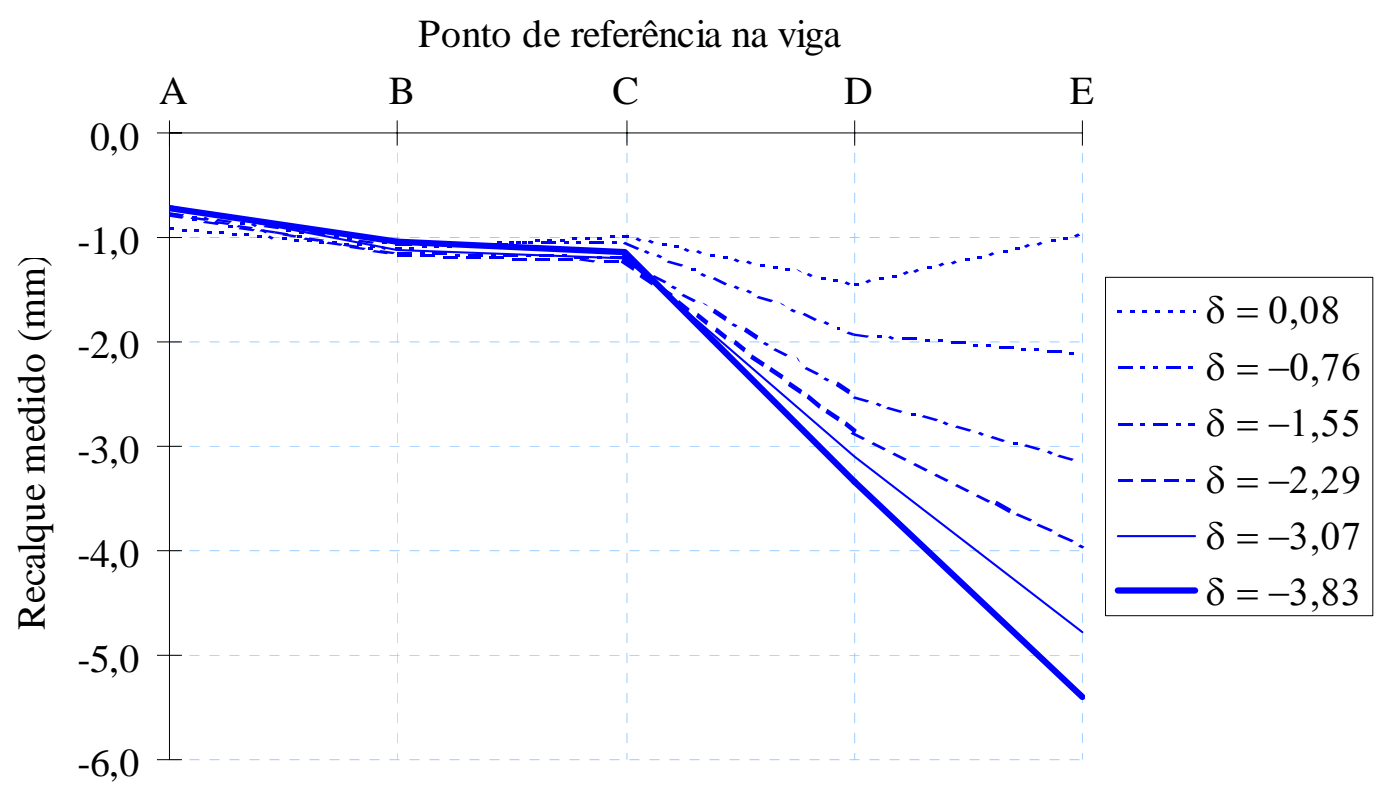

Figura 4.43 Configuração deformada da viga - Modelo 3, Situação 3. ( $\delta$ em mm)

Tabela 4.7 Parâmetros de curvatura - Modelo 3, Situação 3.

\begin{tabular}{|c|c|c|c|c|c|c|}
\hline \multicolumn{2}{|c|}{ RECALQUE (mm) } & \multirow{2}{*}{ OCORRÊNCIA } & \multirow{2}{*}{$(\Delta / \mathrm{L})_{\mathrm{ACE}}$} & \multirow{2}{*}{$(\Delta / \mathrm{L})_{\mathrm{ABC}}$} & \multirow{2}{*}{$(\Delta / \mathrm{L})_{\mathrm{CDE}}$} & \multirow{2}{*}{$(\delta / \ell)_{\mathrm{CD}}$} \\
\hline total & diferencial & & & & & \\
\hline$-1,0$ & $-0,05$ & $\begin{array}{l}\text { Primeira fissura } \\
\text { (verga) }\end{array}$ & $1 / 76433$ & $-1 / 5439$ & $-1 / 2009$ & $1 / 954$ \\
\hline$-2,1$ & $-0,87$ & $\begin{array}{l}\text { Início da fissura } \\
\text { vertical central }\end{array}$ & $1 / 4131$ & $-1 / 5951$ & $-1 / 2899$ & $1 / 603$ \\
\hline$-4,4$ & $-2,78$ & Fissura escalonada & $1 / 1295$ & $-1 / 5904$ & $-1 / 5221$ & $1 / 288$ \\
\hline$-5,3$ & $-3,54$ & Recalque máximo & $1 / 1017$ & $-1 / 6246$ & $-1 / 32045$ & $1 / 258$ \\
\hline
\end{tabular}

Nota: Valores negativos de $(\Delta / \mathrm{L})$ indicam concavidade para cima. $(\delta / \ell)$ em valores absolutos. 


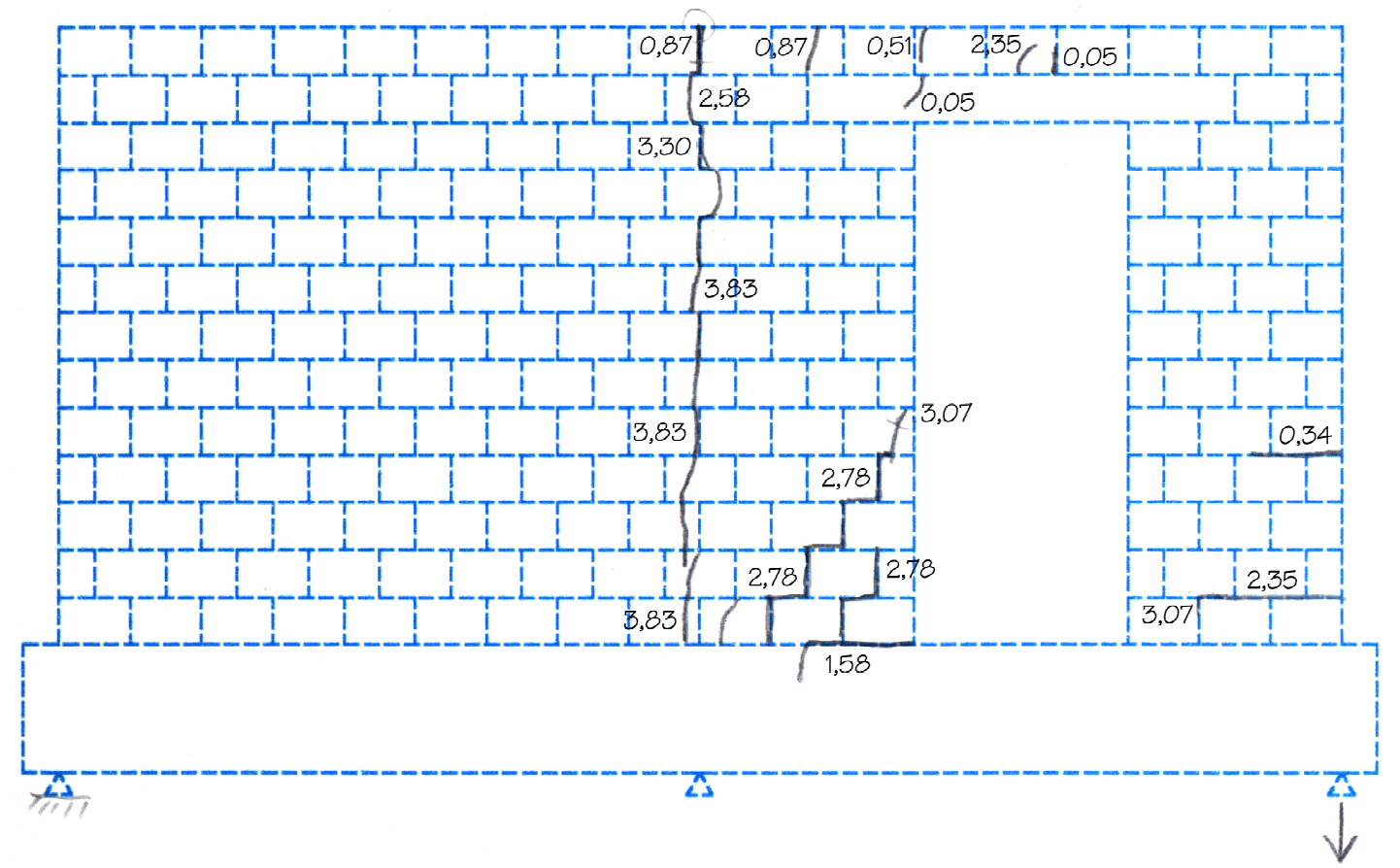

Figura 4.44 Distribuição de fissuras após ensaio - Modelo 3, Situação 3.

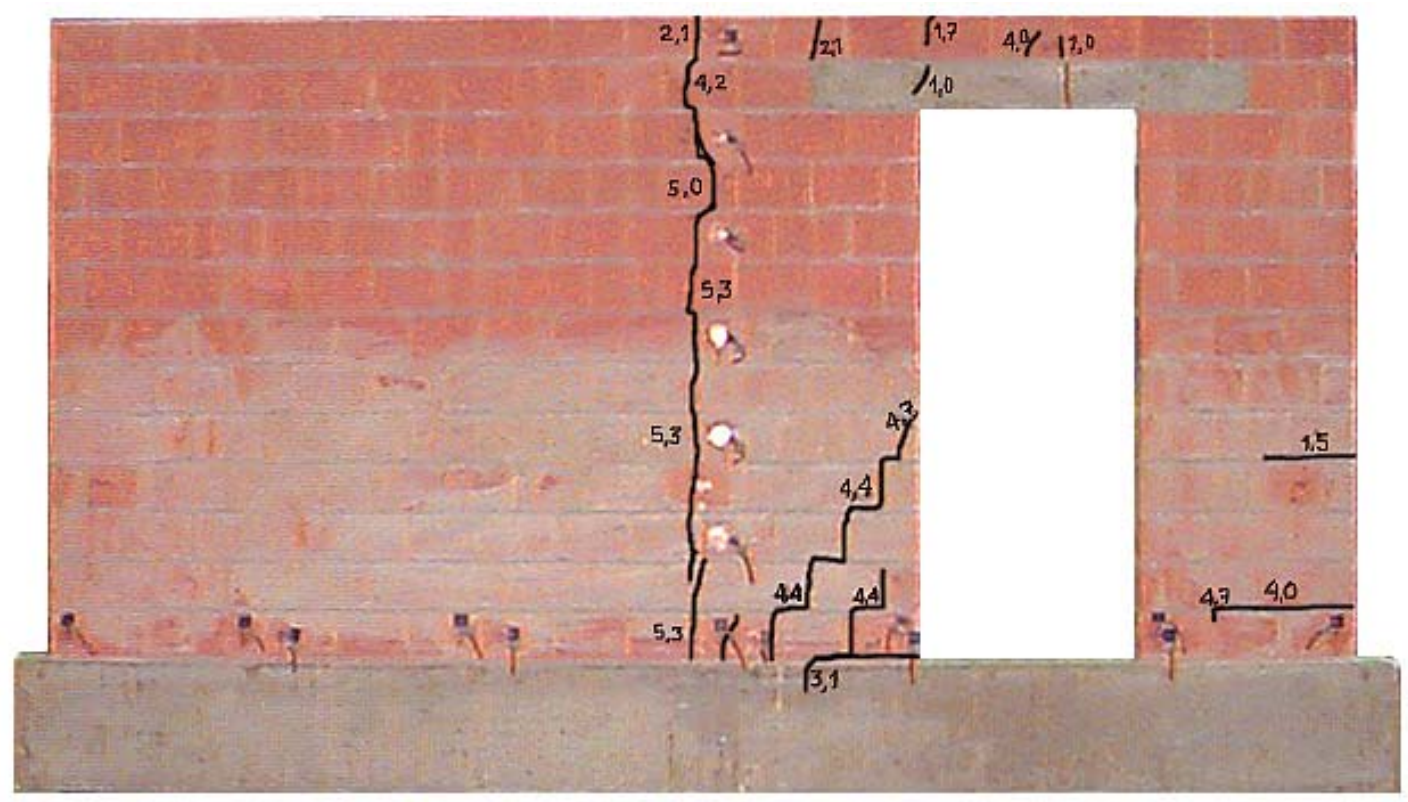

Figura 4.45 Fotografia do painel após ensaio - Modelo 3, Situação 3.

Os transdutores 5 e 6 mediram alongamentos, mas que não anularam o encurtamento devido à força de compressão. De fato, a fissuração nessa região foi menos intensa que a correspondente no Modelo 2, quando tais instrumentos mediram alongamentos absolutos. 


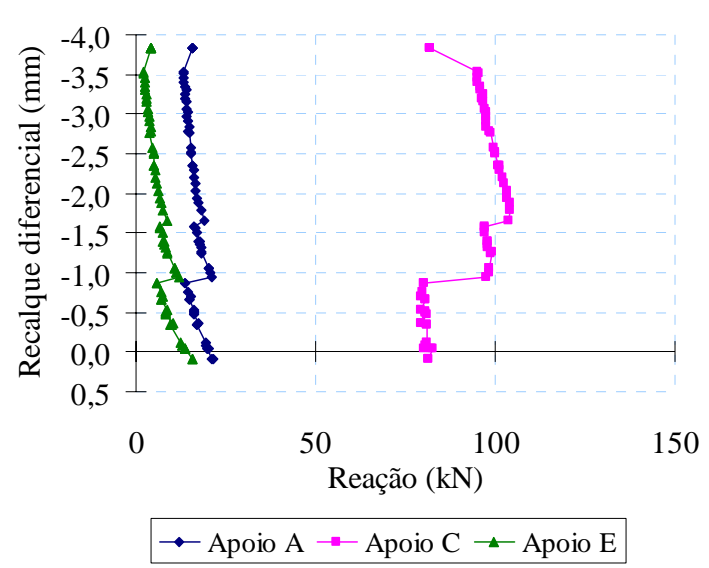

(a)

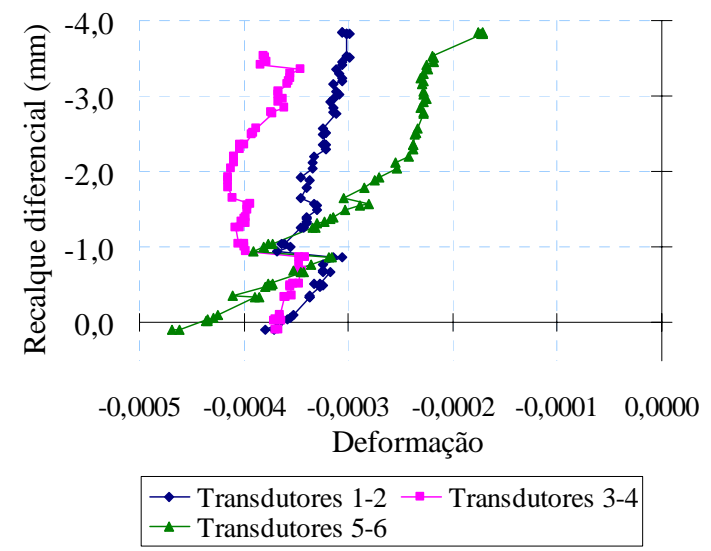

(b)

Figura 4.46 (a) Reações de apoio; (b) Deformação na parede - Modelo 3, Situação 3.

O transdutor 17 registrou o maior encurtamento dentre os transdutores posicionados nas laterais da abertura. Por sua vez, o transdutor 14 passou a acusar alongamento a partir da formação da fissura escalonada, tendo inclusive aumentado a sua taxa de variação em função do recalque.

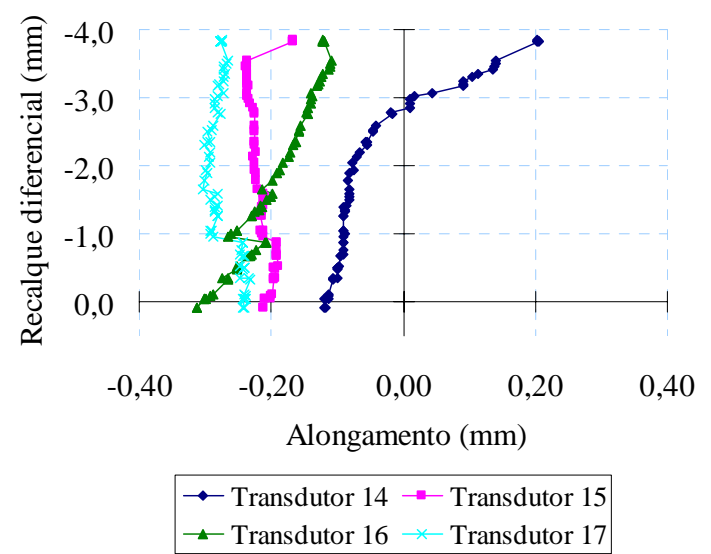

Figura 4.47 Leituras ao lado da porta - Modelo 3, Situação 3.

$\mathrm{Na}$ base da parede, as deformações distribuíram-se como apresentado na Figura 4.48. Verifica-se a grande concentração de esforços na posição do apoio central e no canto externo da porta. Nesse canto, as tensões eram transmitidas à viga através de uma área de contato com comprimento equivalente a um bloco. 


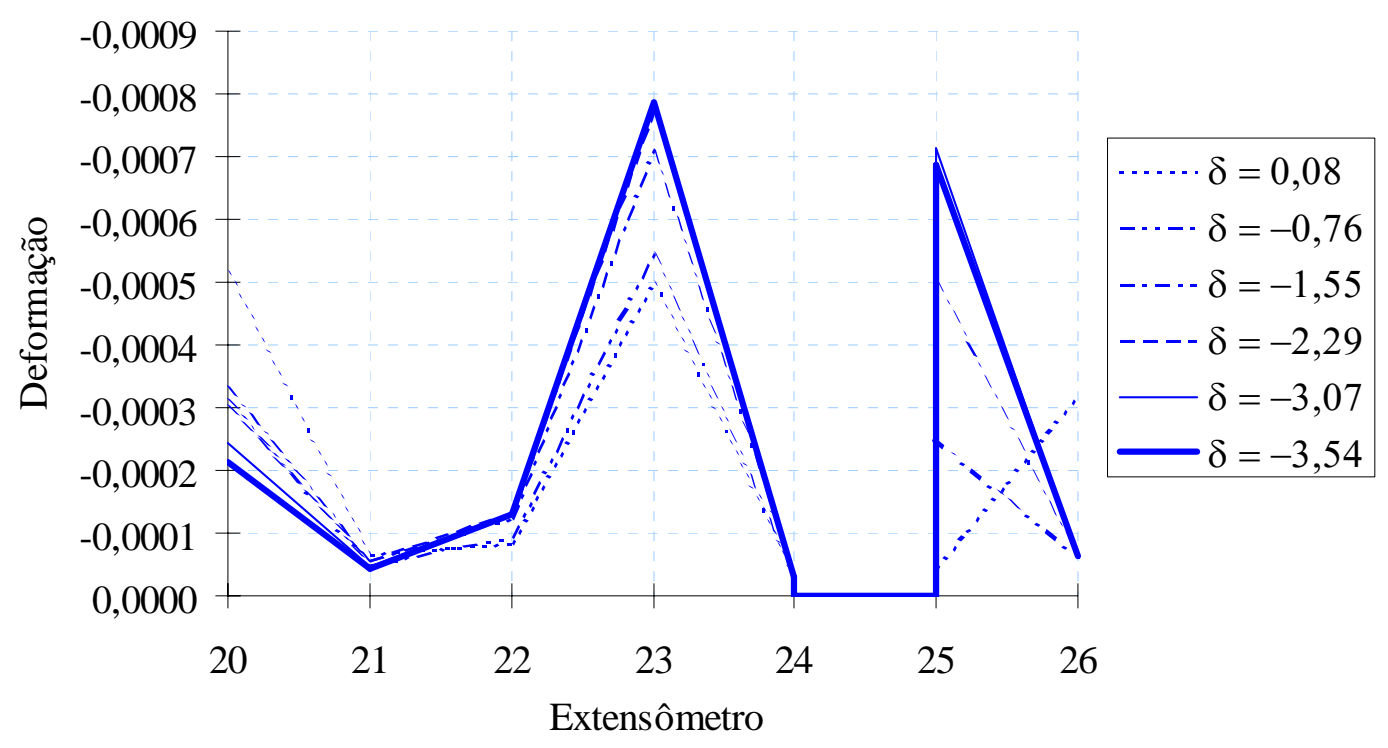

Figura 4.48 Deformações na base da parede - Modelo 3, Situação 3. ( $\delta$ em mm)

\subsection{MODELO 4}

Este modelo consistiu de uma superposição das aberturas dos dois modelos anteriores. Buscou-se avaliar a influência conjunta das aberturas de porta e janela num mesmo painel. 

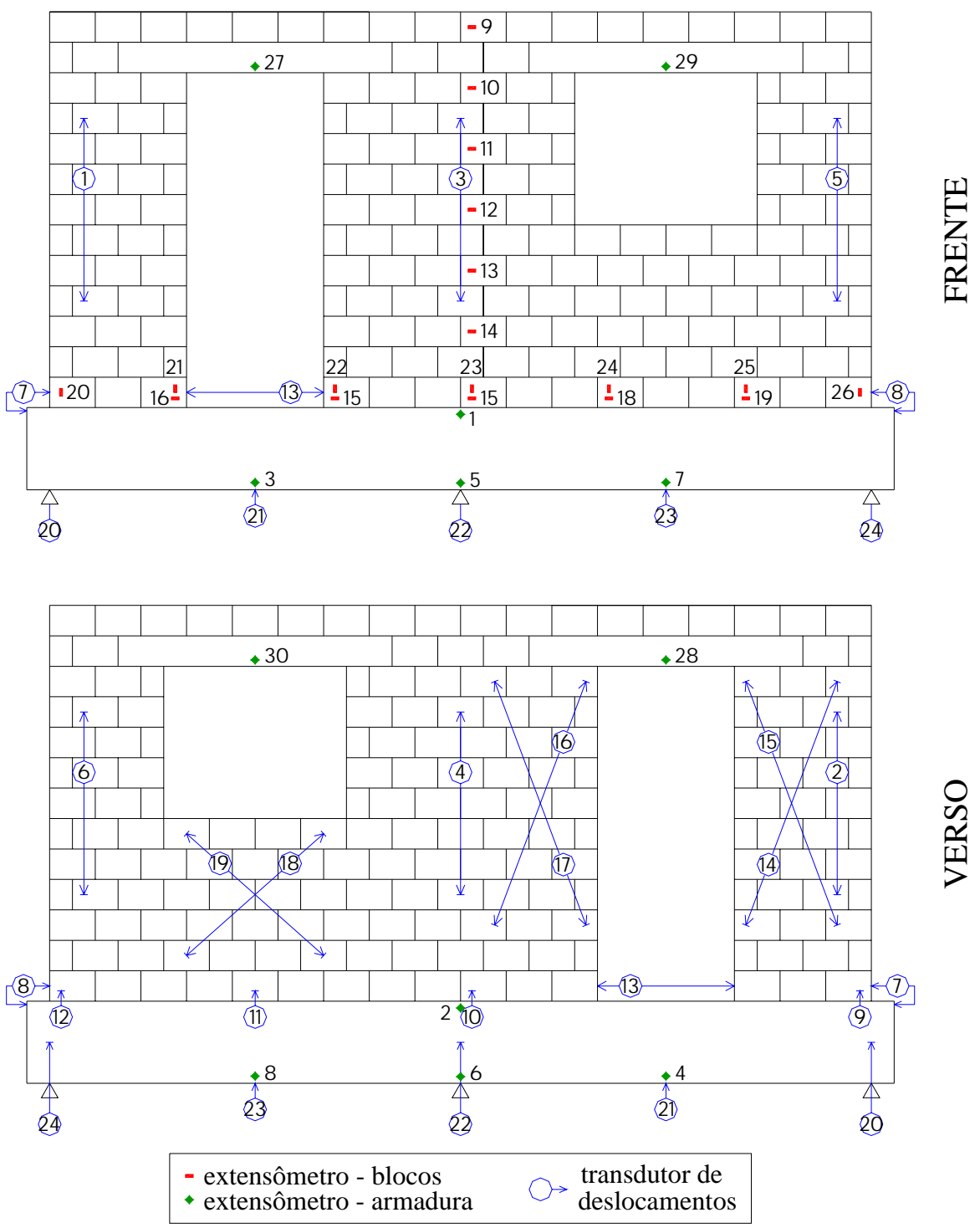

Figura 4.49 Instrumentação do Modelo 4.

\subsubsection{Situação 1: Aplicação do carregamento vertical}

As reações de apoio e as deformações verticais da parede alcançaram os seguintes valores máximos no final desta etapa, tendo sido aplicada a força total de compressão de 101,6 kN:

Tabela 4.8 Reações de apoio e deformações da parede - Modelo 4, Situação 1.

\begin{tabular}{rccc}
\hline APOIO & A & $\mathbf{C}$ & E \\
REAÇÃA $(\mathrm{kN})$ & 33,8 & 44,2 & 23,6 \\
\hline TRANSDUTORES & $\mathbf{1 ~ e ~ 2}$ & $\mathbf{3 ~ e ~ 4}$ & $\mathbf{5 ~ e ~ 6}$ \\
DEFORMAÇÃO & $-0,000524$ & $-0,000344$ & $-0,000462$ \\
\hline
\end{tabular}

Neste caso não se percebeu influência das aberturas na deformação da viga. Os parâmetros de curvatura mantiveram-se bem abaixo dos limites sugeridos na literatura para 
início de fissuração, e bastante próximos para os dois vãos. A seguir apresentam-se os valores finais nesta etapa:

$$
\begin{aligned}
& (\Delta / \mathrm{L})_{\mathrm{ACE}}=-1 / 12293 \\
& (\Delta / \mathrm{L})_{\mathrm{ABC}}=-1 / 3939 \\
& (\Delta / \mathrm{L})_{\mathrm{CDE}}=-1 / 4298
\end{aligned}
$$

$$
\begin{aligned}
& (\delta / \ell)_{\mathrm{AB}}=1 / 1492 \\
& (\delta / \ell)_{\mathrm{DE}}=1 / 1592
\end{aligned}
$$

Na Figura 4.50 ilustra-se a evolução da deformação da viga. O recalque diferencial final foi de aproximadamente $-0,15 \mathrm{~mm}$, e a inclinação entre os apoios A e $\mathrm{E}$ foi de $0,039 \%$.

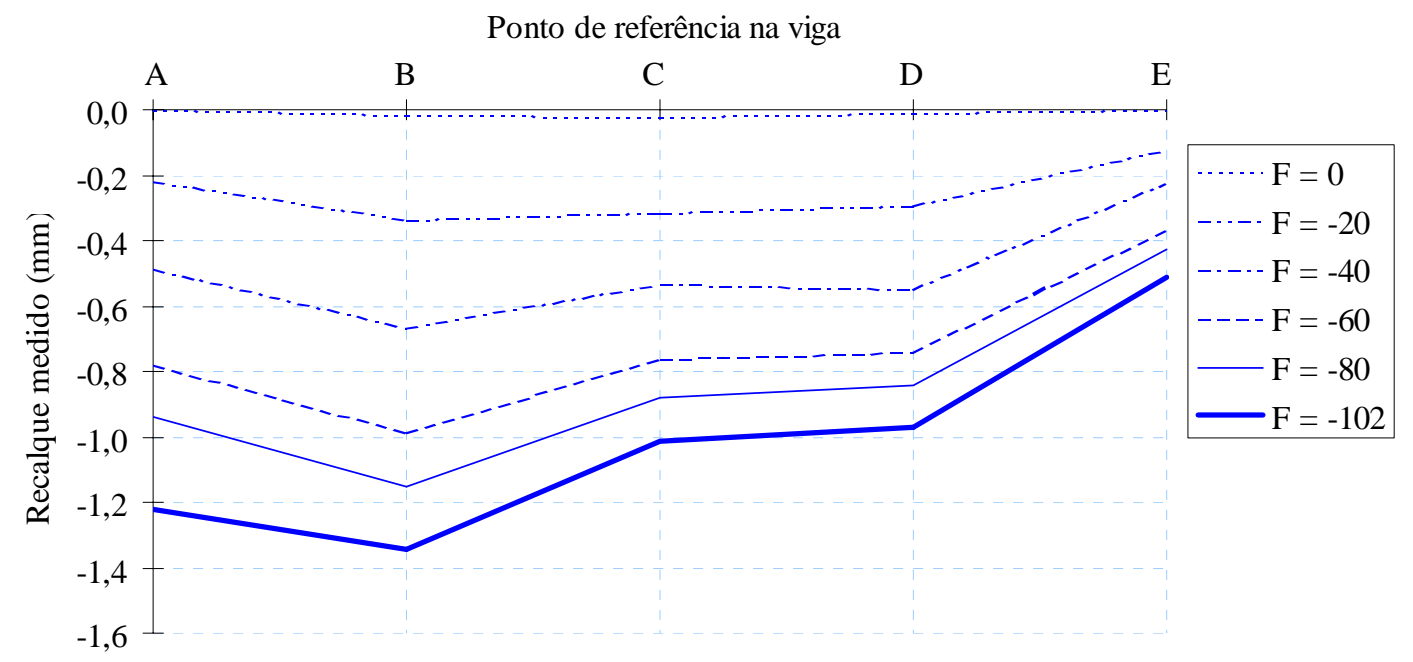

Figura 4.50 Configuração deformada da viga - Modelo 4, Situação 1. (F em kN)

Observa-se na figura seguinte a evolução das reações de apoio e da deformação vertical na parede durante a fase de aplicação do carregamento vertical.

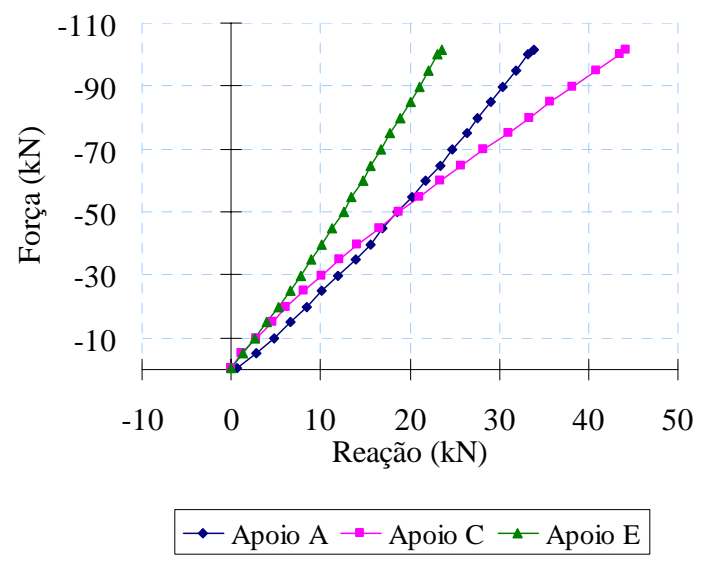

(a)

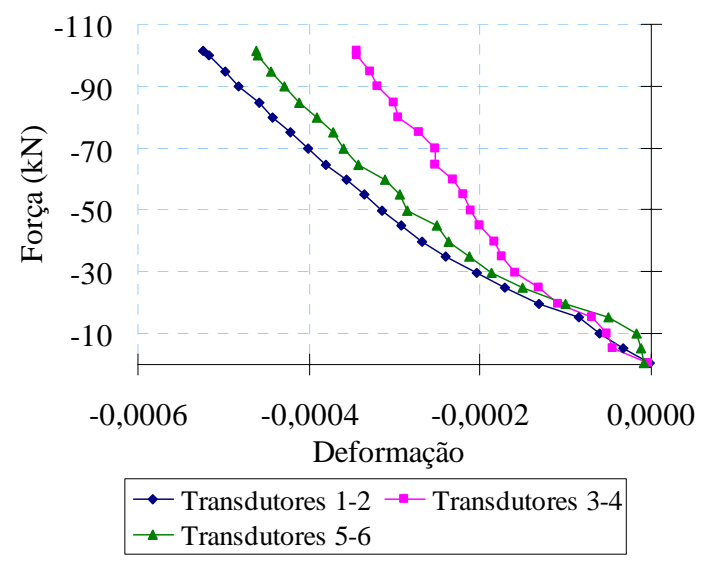

(b)

Figura 4.51 (a) Reações de apoio; (b) Deformação na parede - Modelo 4, Situação 1.

Os transdutores 14 a 17 indicaram que o arco de compressão formou-se por cima da porta, causando o maior encurtamento na região onde se encontra o transdutor 15 . 
Abaixo da janela, o encurtamento e o alongamento medidos respectivamente pelos transdutores 18 e 19 foram muito pequenos.
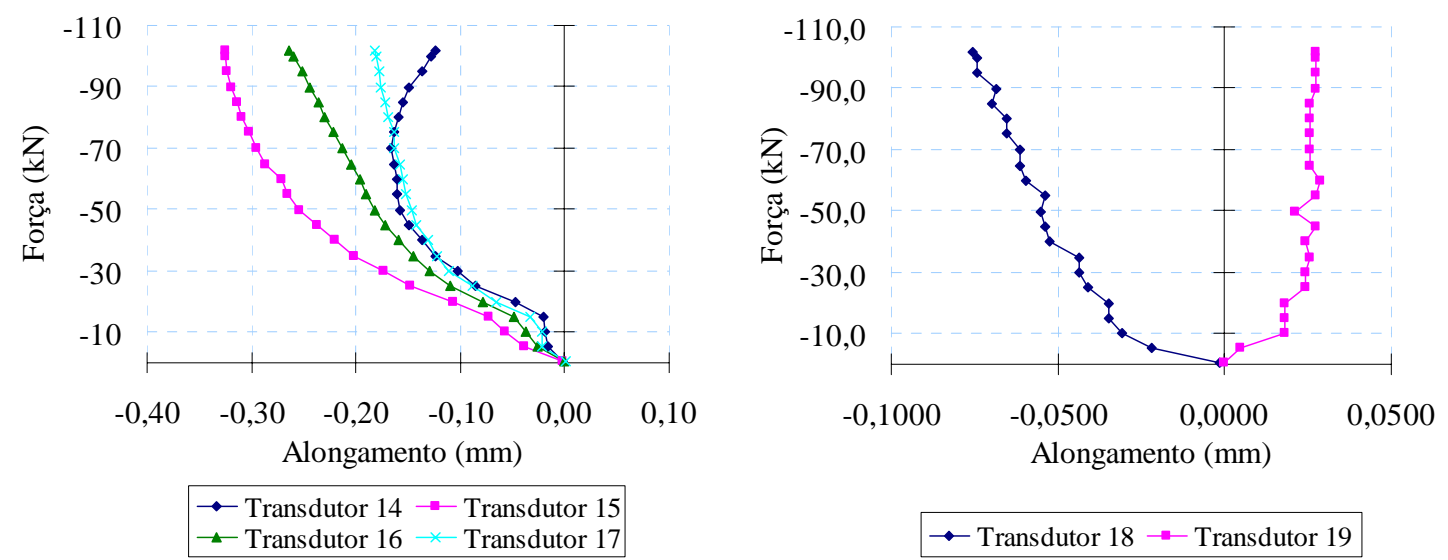

Figura 4.52 Leituras (a) ao lado da porta e (b) abaixo da janela - Modelo 4, Situação 1.

Na Figura 4.53 apresentam-se as deformações verticais medidas nos blocos da primeira fiada. O diagrama se assemelha aos demais, porém com uma menor concentração de esforços na extremidade direita. Observa-se também uma pequena concentração de tensões de compressão no canto inferior interno da porta.

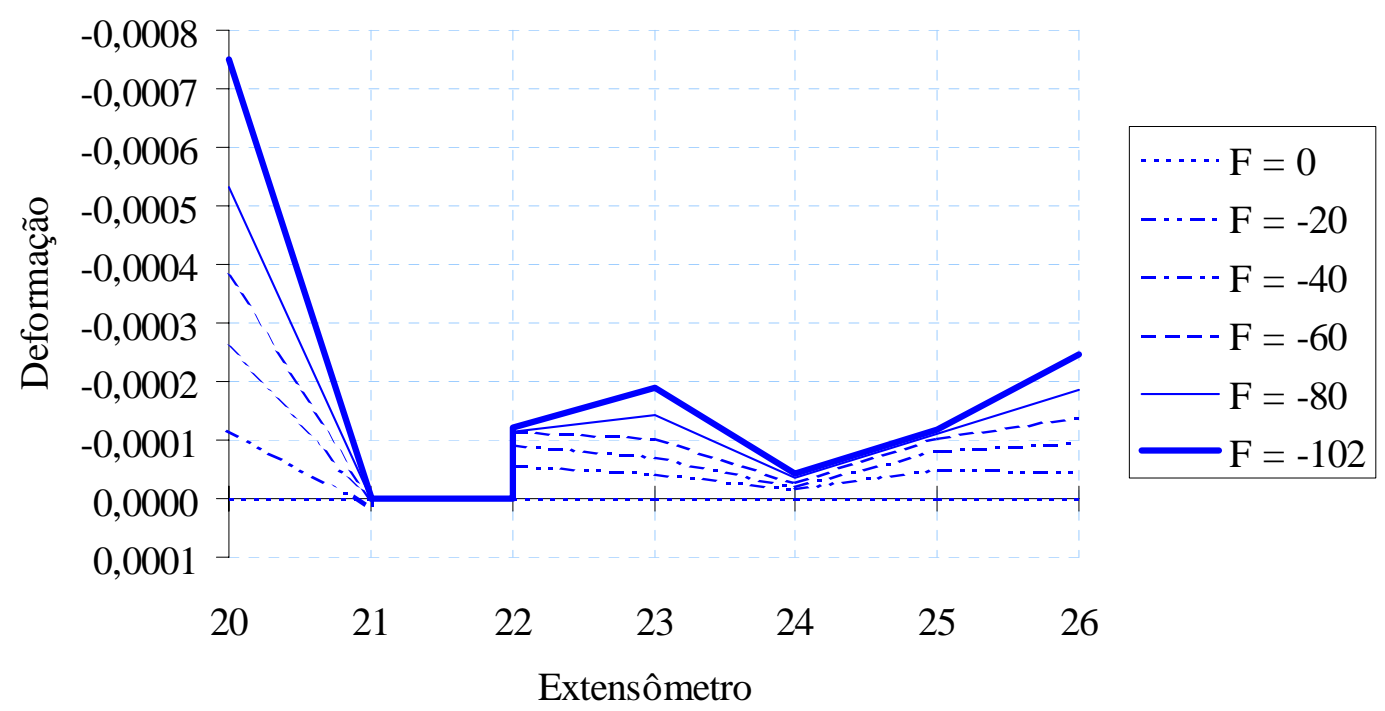

Figura 4.53 Deformações na base da parede - Modelo 4, Situação 1. (F em kN)

\subsubsection{Situação 2: Recalque do apoio central}

$\mathrm{O}$ aspecto da fissuração observada neste modelo foi correspondente a uma sobreposição daqueles dos outros painéis com abertura. As primeiras fissuras ocorreram no lado da porta, uma na verga e outra na interface a partir do canto inferior externo da abertura. 
$\mathrm{O}$ recalque nesse instante aproximava-se de $-0,63 \mathrm{~mm}$. Comparando com o Modelo 3 , verifica-se que foram praticamente as mesmas fissuras iniciais.

As fissuras na região da janela começaram a surgir com o recalque diferencial em torno de $-0,89 \mathrm{~mm}$, com direção diagonal. Aos $-1,27 \mathrm{~mm}$ de recalque diferencial começou a surgir uma fissura escalonada abaixo da janela.

Mesmo confinada a uma pequena região central próxima à base da parede, a fissura horizontal formou-se quando o recalque diferencial atingiu $-2,49 \mathrm{~mm}$. Iniciou-se entre as duas primeiras fiadas e atingiu a interface aos $-2,91 \mathrm{~mm}$ de recalque diferencial.

Observou-se que a maior abertura de fissura ocorreu no canto inferior da porta, atingindo $1,8 \mathrm{~mm}$ ao final do ensaio.

O máximo recalque diferencial aplicado ao Modelo 4 nesta situação foi $-3,22 \mathrm{~mm}$. Ao final do ensaio, a inclinação entre os apoios extremos valia 0,088\%. A configuração deformada da viga de fundação está representada na Figura 4.54.

A seguir apresentam-se os principais valores dos parâmetros de curvatura, o diagrama de distribuição das fissuras com valores de recalque diferencial e a fotografia do painel onde foram anotados os valores de recalque total medidos durante o ensaio.

Ponto de referência na viga

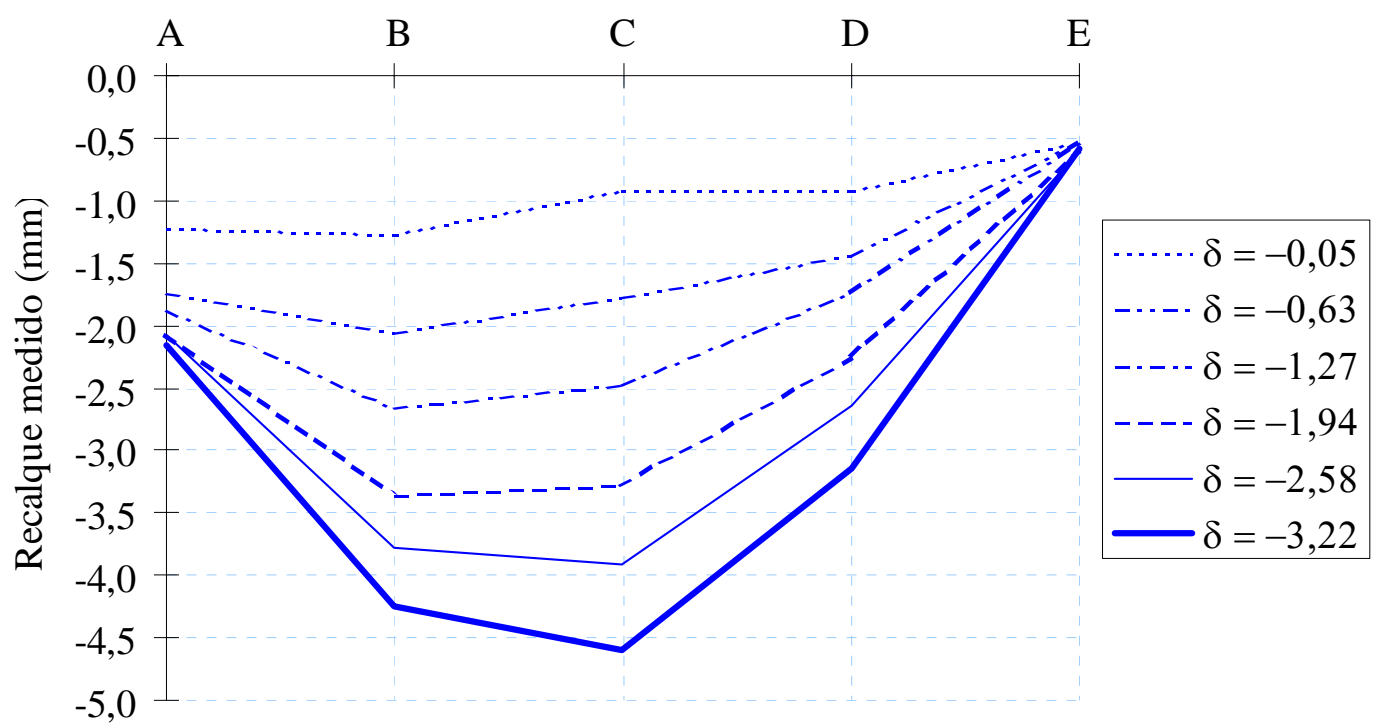

Figura 4.54 Configuração deformada da viga - Modelo 4, Situação 2. ( $\delta$ em mm) 
Tabela 4.9 Parâmetros de curvatura - Modelo 4, Situação 2.

\begin{tabular}{|c|c|c|c|c|c|c|c|}
\hline \multicolumn{2}{|c|}{ RECALQUE $(\mathrm{mm})$} & \multirow{2}{*}{ OCORRÊNCIA } & \multirow{2}{*}{$(\Delta / \mathrm{L})_{\mathrm{ACE}}$} & \multirow{2}{*}{$(\Delta / \mathrm{L})_{\mathrm{ABC}}$} & \multirow{2}{*}{$(\Delta / \mathrm{L})_{\mathrm{CDE}}$} & \multirow{2}{*}{$(\delta / \ell)_{\mathrm{AB}}$} & \multirow{2}{*}{$(\delta / \ell)_{\mathrm{DE}}$} \\
\hline total & diferencial & & & & & & \\
\hline$-1,9$ & $-0,63$ & $\begin{array}{l}\text { Primeira fissura } \\
\text { (porta) }\end{array}$ & $-1 / 2873$ & $-1 / 2946$ & $-1 / 3211$ & $1 / 727$ & $1 / 758$ \\
\hline$-2,2$ & $-0,89$ & $\begin{array}{l}\text { Primeira fissura } \\
\text { (janela) }\end{array}$ & $-1 / 2022$ & $-1 / 2393$ & $-1 / 3723$ & $1 / 548$ & $1 / 655$ \\
\hline$-2,6$ & $-1,12$ & $\begin{array}{l}\begin{array}{l}\text { Fissura escalonada } \\
\text { (janela) }\end{array} \\
\end{array}$ & $-1 / 1418$ & $-1 / 1883$ & $-1 / 3890$ & $1 / 405$ & $1 / 520$ \\
\hline$-4,0$ & $-2,49$ & Fissura horizontal & $-1 / 723$ & $-1 / 1124$ & $-1 / 2478$ & $1 / 220$ & $1 / 280$ \\
\hline$-4,6$ & $-3,22$ & Recalque máximo & $-1 / 558$ & $-1 / 1034$ & $-1 / 1638$ & $1 / 181$ & $1 / 208$ \\
\hline
\end{tabular}

Nota: Valores negativos de $(\Delta / \mathrm{L})$ indicam concavidade para cima. $(\delta / \ell)$ em valores absolutos.

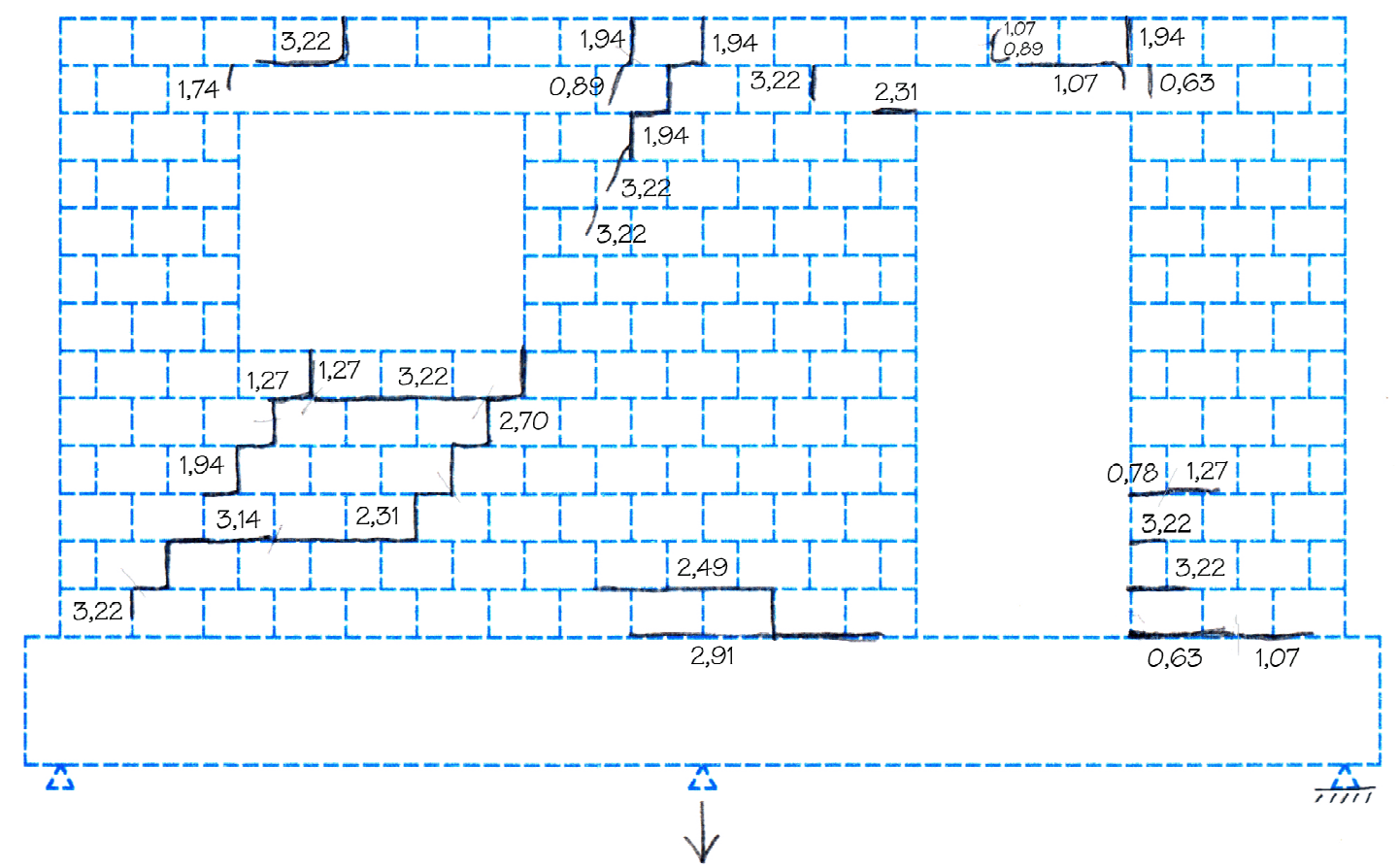

Figura 4.55 Distribuição de fissuras após ensaio - Modelo 4, Situação 2. (Verso do painel) 


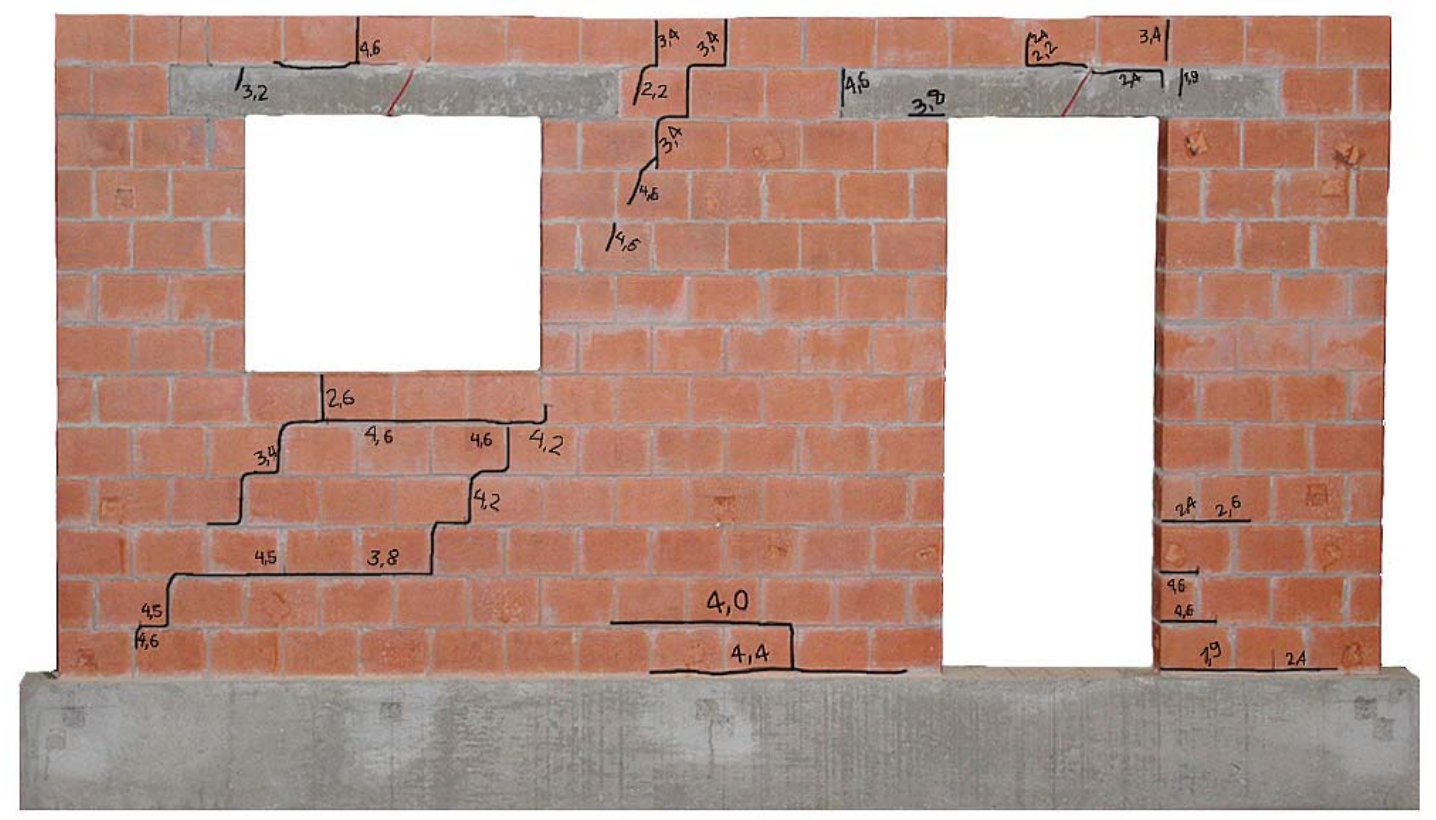

Figura 4.56 Fotografia do painel após ensaio - Modelo 4, Situação 2. (Verso do painel)

Pelos transdutores posicionados ao lado da porta, verificou-se mais uma vez que o arco de compressão se formou por cima da abertura, dirigindo-se para o apoio de extremidade.

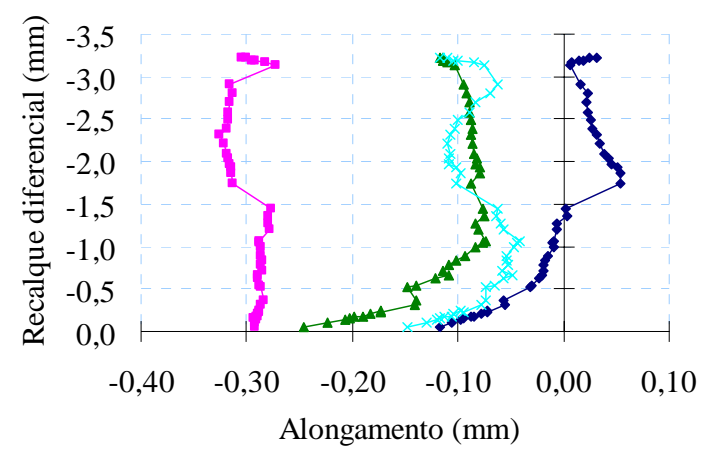

$\rightarrow-$ Transdutor $14 \rightarrow-$ Transdutor 15 $\rightarrow$ Transdutor $16 \div$ Transdutor 17

(a)

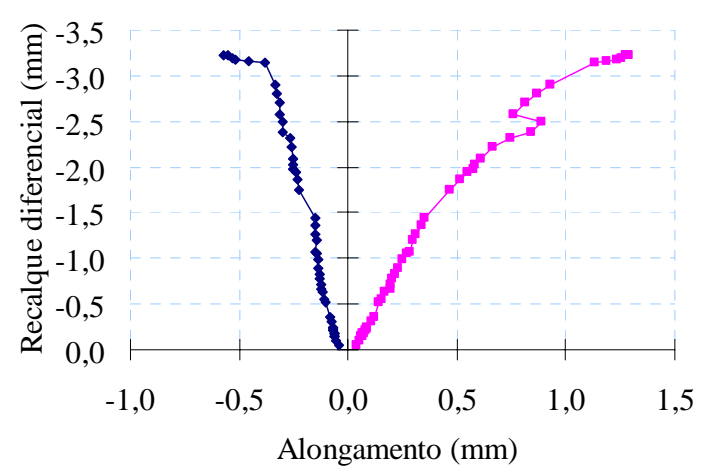

- Transdutor $18 \rightarrow-$ Transdutor 19

(b)

Figura 4.57 Leituras (a) ao lado da porta e (b) abaixo da janela - Modelo 4, Situação 2.

Observa-se na Figura 4.54 que o vão $\mathrm{ABC}$, correspondente à abertura de porta, apresentou maiores recalques. A transferência de esforços da parede para a viga no canto inferior interno da parede, conforme se conclui da Figura 4.58, contribuiu para que isso ocorresse. 


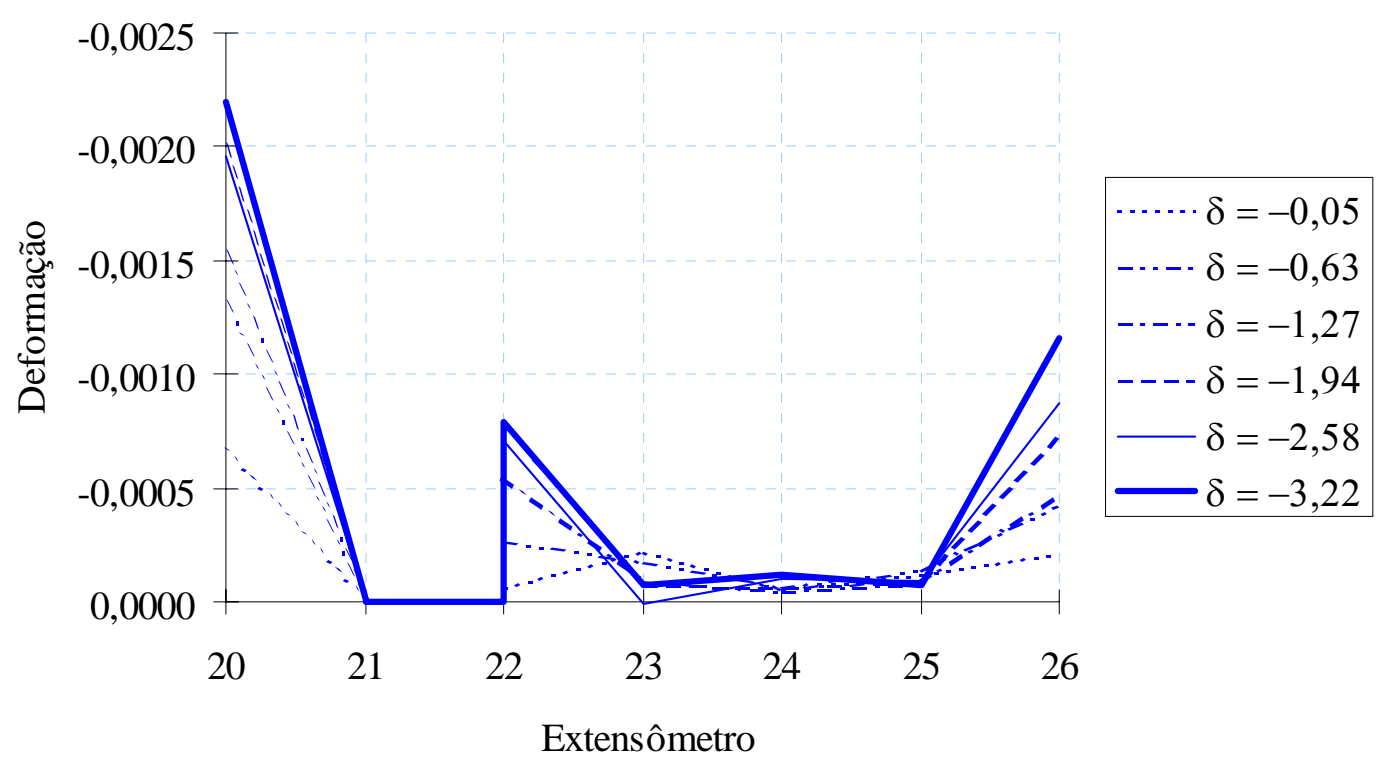

Figura 4.58 Deformações na base da parede - Modelo 4, Situação 2. ( $\delta$ em mm)

\subsubsection{Situação 3: Recalque do apoio de extremidade}

Nesta situação a fissuração da parede foi mais intensa no lado da janela, já que se deslocou o apoio E. O aspecto final nesse lado foi muito semelhante ao que ocorreu no Modelo 2.

As primeiras fissuras surgiram para um recalque diferencial de $-0,98 \mathrm{~mm}$. Consistiram de uma fissura diagonal escalonada abaixo da janela e de outra horizontal na interface.

Em seguida, ao recalque de $-1,57 \mathrm{~mm}$, se observou a formação de uma fissura horizontal na junta entre a sexta e a sétima fiada, que teve início na borda do painel mais próxima do apoio E. Sua causa mais provável são tensões de tração que surgiram ao longo dessa borda, devido ao deslocamento do apoio. Mais tarde essa fissura se uniria às fissuras diagonais da porção inferior à janela.

As regiões de vergas também apresentaram fissuras com aspecto similar ao ocorrido nos modelos 2 e 3.

O conjunto de fissuras causador da divisão da parede em duas partes formou-se a um recalque diferencial próximo de $-2,80 \mathrm{~mm}$, que imediatamente passou para $-4,27 \mathrm{~mm}$. Da mesma forma como no Modelo 2, a abertura da janela participou neste processo, unindo fissuras abaixo e acima de si.

Terminado o ensaio, verificou-se que a maior abertura de fissura ocorreu junto ao canto inferior interno da janela, com valor em torno de $2,0 \mathrm{~mm}$. $\mathrm{O}$ maior recalque aplicado à parede foi de $-5,67 \mathrm{~mm}$. Toda a fissuração pode ser visualizada na Figura 4.61, 
com valores de recalque diferencial, e na Figura 4.61, onde se apresenta uma fotografia do Modelo 4 após o ensaio. Antes, porém, são apresentadas a configuração deformada da viga e a tabela contendo os principais valores dos parâmetros de curvatura.

Ponto de referência na viga

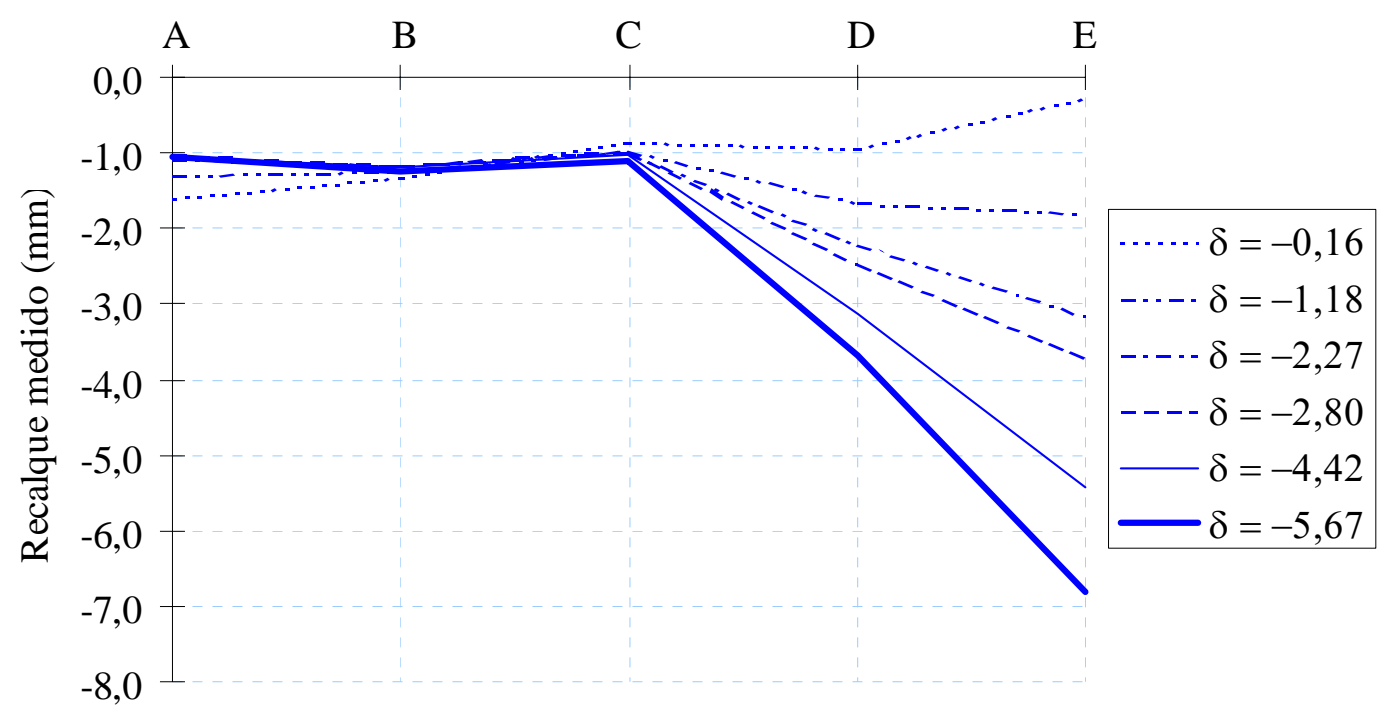

Figura 4.59 Configuração deformada da viga - Modelo 4, Situação 3. ( $\delta$ em mm)

Tabela 4.10 Parâmetros de curvatura - Modelo 4, Situação 3.

\begin{tabular}{|c|c|c|c|c|c|c|}
\hline \multicolumn{2}{|c|}{ RECALQUE (mm) } & \multirow{2}{*}{ OCORRÊNCIA } & \multirow{2}{*}{$(\Delta / \mathrm{L})_{\mathrm{ACE}}$} & \multirow{2}{*}{$(\Delta / \mathrm{L})_{\mathrm{ABC}}$} & \multirow{2}{*}{$(\Delta / \mathrm{L})_{\mathrm{CDE}}$} & \multirow{2}{*}{$(\delta / \ell)_{\mathrm{CD}}$} \\
\hline total & diferencial & & & & & \\
\hline$-1,5$ & $-0,98$ & Primeiras fissuras & $1 / 3690$ & $-1 / 6903$ & $-1 / 2922$ & $1 / 565$ \\
\hline$-2,3$ & $-1,57$ & Fissura horizontal & $1 / 2289$ & $-1 / 7078$ & $-1 / 3871$ & $1 / 442$ \\
\hline$-3,7$ & $-2,80$ & $\begin{array}{l}\text { Formação da fissura } \\
\text { divisora da parede }\end{array}$ & $1 / 1284$ & $-1 / 5108$ & $-1 / 8128$ & $1 / 298$ \\
\hline$-5,2$ & $-4,27$ & $\begin{array}{l}\text { Conseqüência da } \\
\text { fissura anterior }\end{array}$ & $1 / 844$ & $-1 / 5498$ & $1 / 10500$ & $1 / 220$ \\
\hline$-6,8$ & $-5,67$ & Recalque máximo & $1 / 635$ & $-1 / 5498$ & $1 / 3366$ & $1 / 175$ \\
\hline
\end{tabular}

Nota: Valores negativos de $(\Delta / \mathrm{L})$ indicam concavidade para cima. $(\delta / \ell)$ em valores absolutos. 


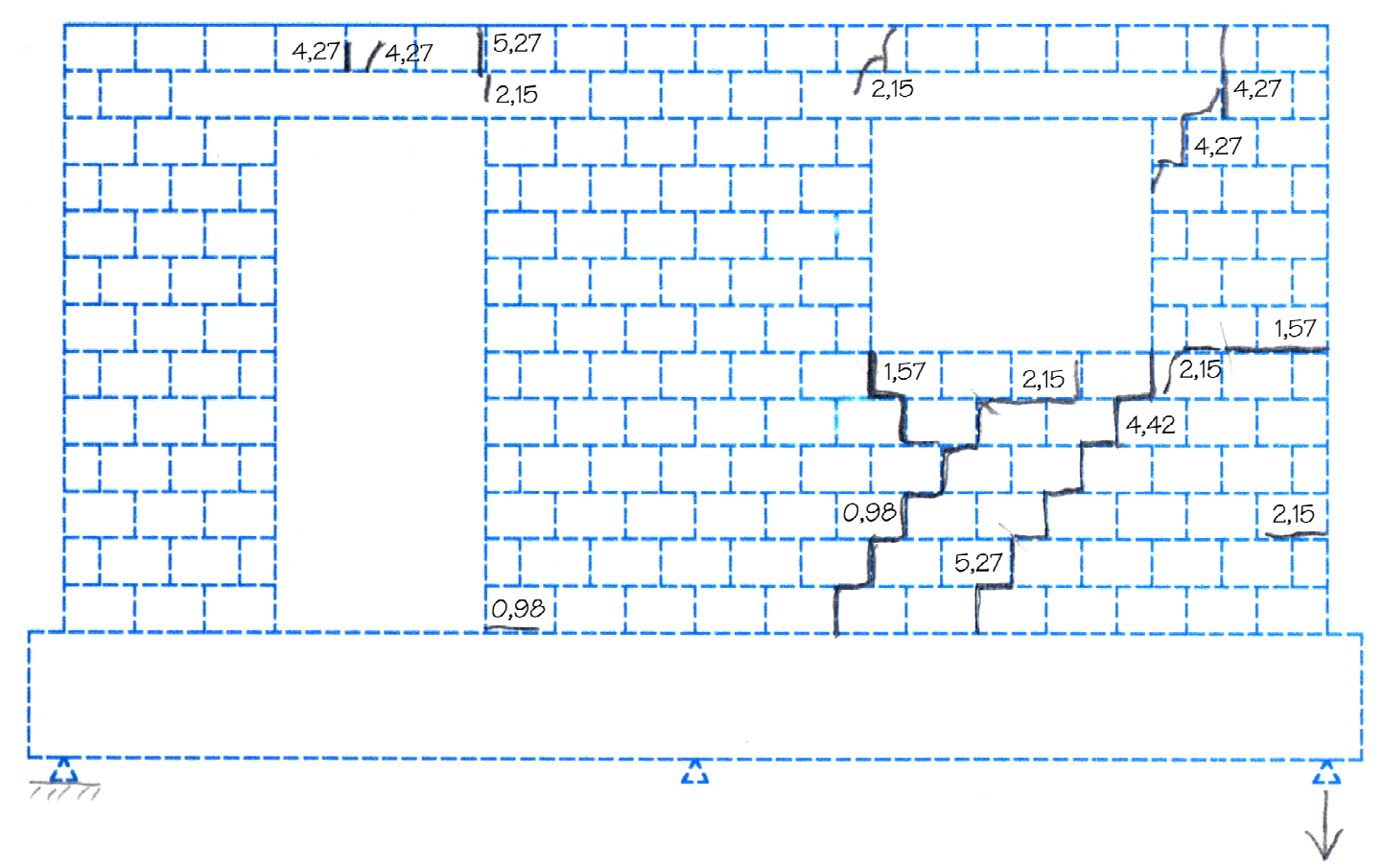

Figura 4.60 Distribuição de fissuras após ensaio - Modelo 4, Situação 3.

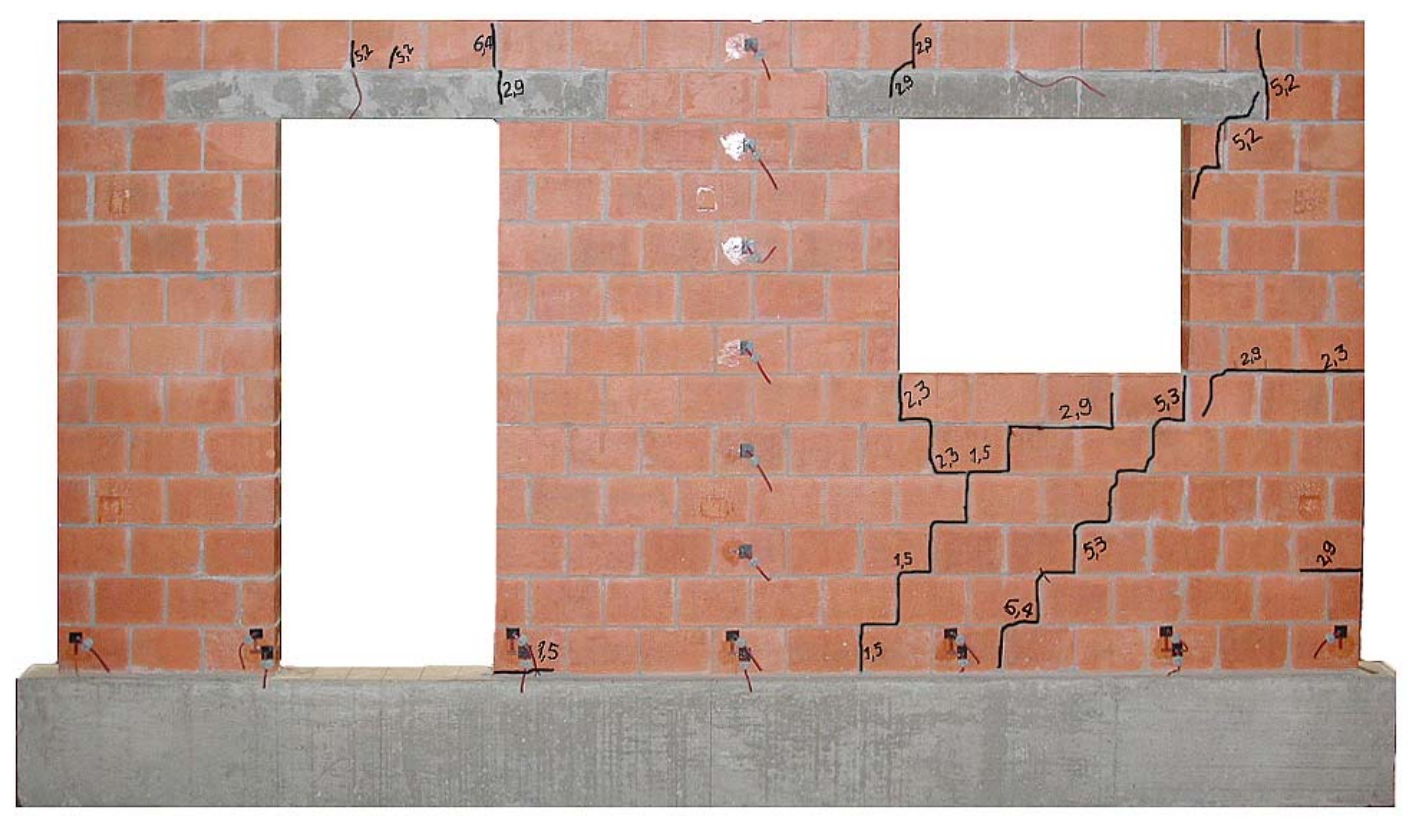

Figura 4.61 Fotografia do painel após ensaio - Modelo 4, Situação 3.

Provavelmente a fissura horizontal próxima à borda direita da parede surgiu antes do observado, a um recalque diferencial em torno de $-1,06 \mathrm{~mm}$, pois a partir desse valor a curva média dos transdutores 5 e 6 mudou de inclinação, passando a acusar alongamentos crescentes. A Figura $4.62 b$ ilustra o fato. 


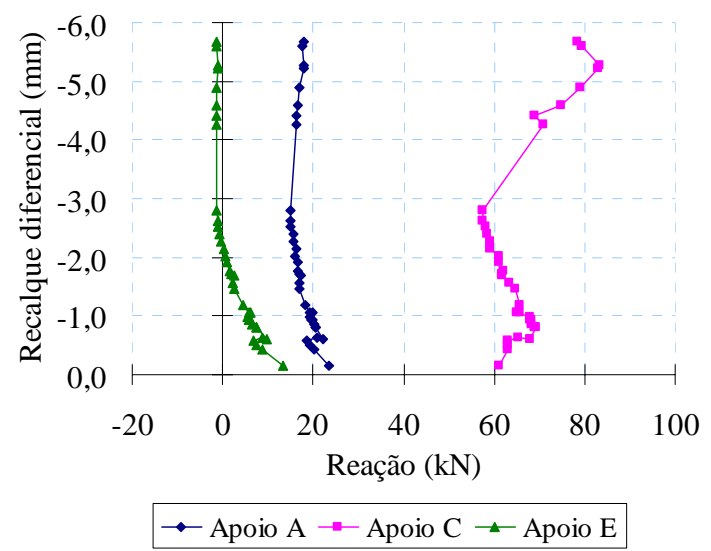

(a)

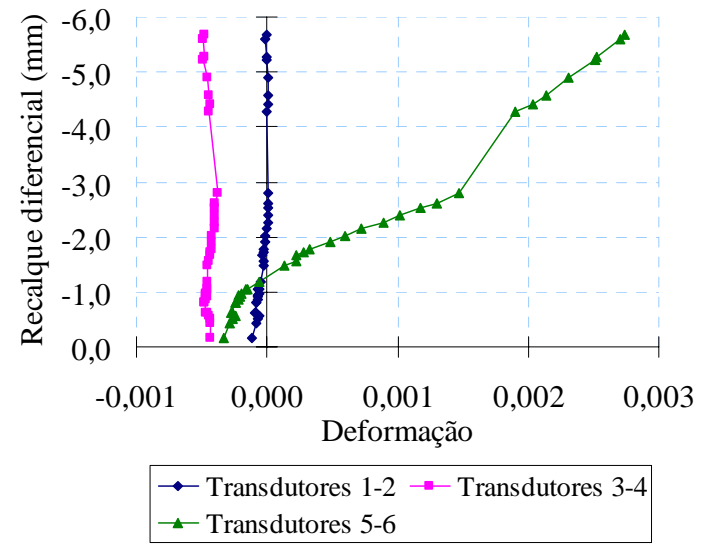

(b)

Figura 4.62 (a) Reações de apoio; (b) Deformação na parede - Modelo 4, Situação 3.

Ao lado da porta, o transdutor 16 registrou os maiores encurtamentos. Como esperado, abaixo da janela o transdutor 18 mediu grandes alongamentos, notoriamente após a primeira fissura diagonal, enquanto que o transdutor 19 mediu pequenos encurtamentos, que se tornaram constantes após o recalque de $-1,72 \mathrm{~mm}$.

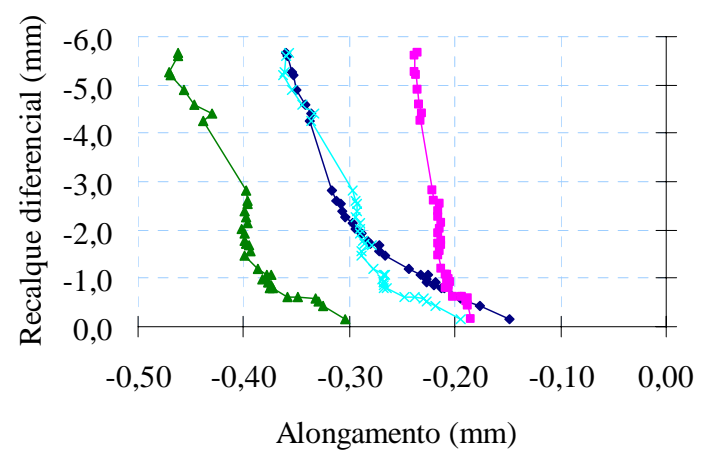

$\multimap$ Transdutor $14-$ Transdutor 15 $\rightarrow$ Transdutor $16 \rightarrow$ Transdutor 17

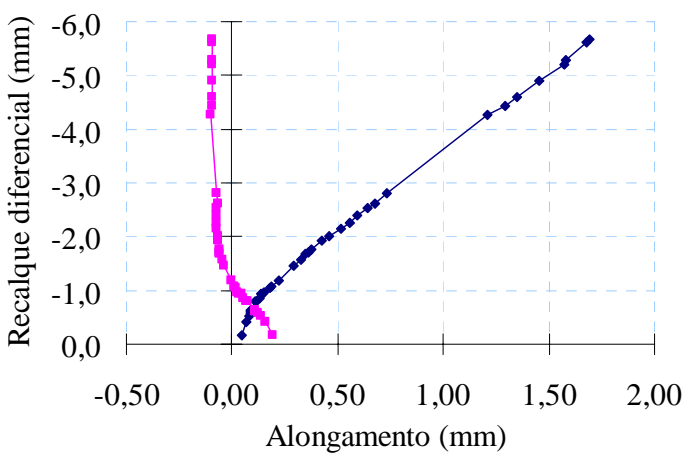

$\rightarrow$ Transdutor $18 \rightarrow$ Transdutor 19

Figura 4.63 Leituras (a) ao lado da porta e (b) abaixo da janela - Modelo 4, Situação 3.

Na Figura 4.64 encontra-se a distribuição da deformação na base da parede para alguns valores de recalque diferencial. Observa-se a concentração de esforços no centro e no canto externo da porta. Após a divisão da parede também se percebe uma pequena concentração na posição do extensômetro 25 , consequiência de uma redistribuição dos esforços provocada pela nova condição da parede. 


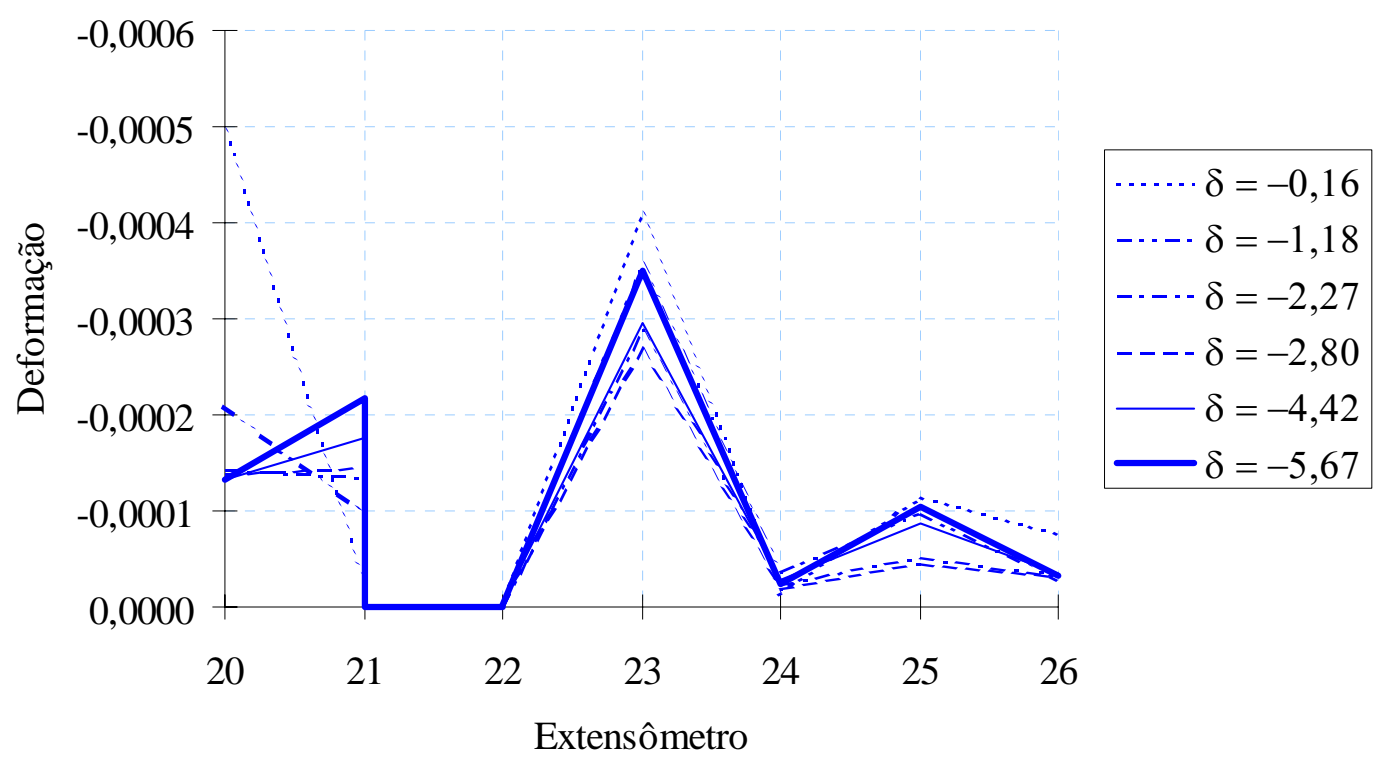

Figura 4.64 Deformações na base da parede - Modelo 4, Situação 3. ( $\delta$ em mm)

\subsection{MODELO 5}

A característica que difere o Modelo 5 dos demais, em especial do Modelo 1, é a altura da viga. Este é o único painel cuja viga possui $22 \mathrm{~cm}$ de altura, decorrente de um dimensionamento em que não se considerou a parede. Desta forma, o momento de inércia da viga $\left(7099 \mathrm{~cm}^{4}\right)$ ficou $83 \%$ maior, o que foi o principal responsável pelas mudanças de comportamento verificadas. 

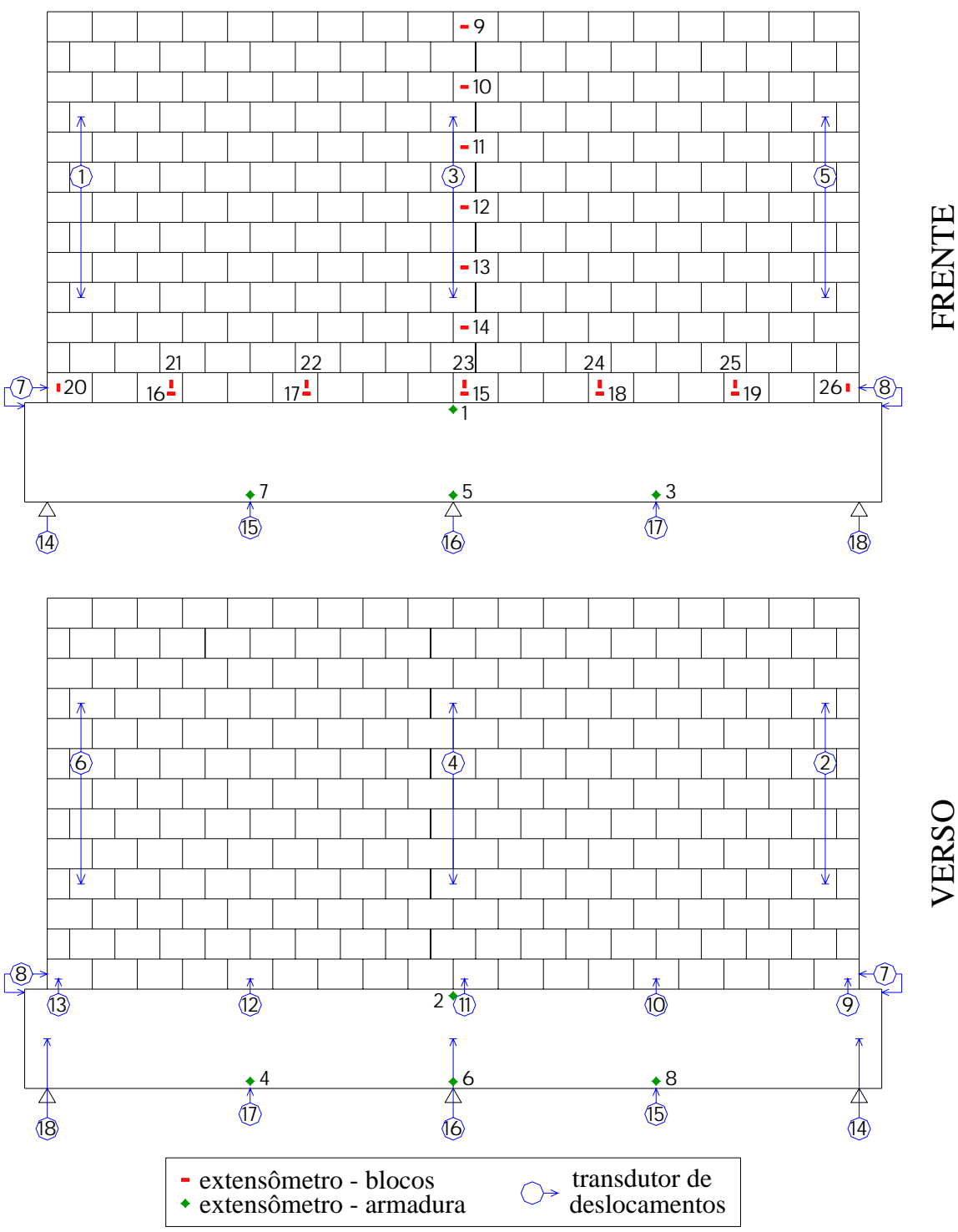

Figura 4.65 Instrumentação do Modelo 5.

\subsubsection{Situação 1: Aplicação do carregamento vertical}

Esta etapa de carregamento transcorreu normalmente, atingindo-se no final um recalque diferencial do apoio central de $-0,213 \mathrm{~mm}$, equivalente a $(\Delta / \mathrm{L})_{\mathrm{ACE}}=-1 / 8444$. A inclinação final entre os apoios de extremidade foi de $-0,001 \%$.

Ambos os vãos da viga deformaram-se igualmente, como se verifica na Figura 4.66. Não ocorreu fissuração e os parâmetros de recalque $(\Delta / \mathrm{L})_{\mathrm{ABC}}$ e $(\Delta / \mathrm{L})_{\mathrm{CDE}}$ atingiram máximos de -1/2179 e -1/2175 no final desta etapa, próximos mas abaixo do valor limite de 1/2000. Da mesma forma, os parâmetros $(\delta / \ell)_{\mathrm{AB}}$ e $(\delta / \ell)_{\mathrm{DE}}$ não ultrapassaram seus limites, atingindo, no final da aplicação do carregamento vertical, respectivamente -1/866 e $-1 / 865$. 


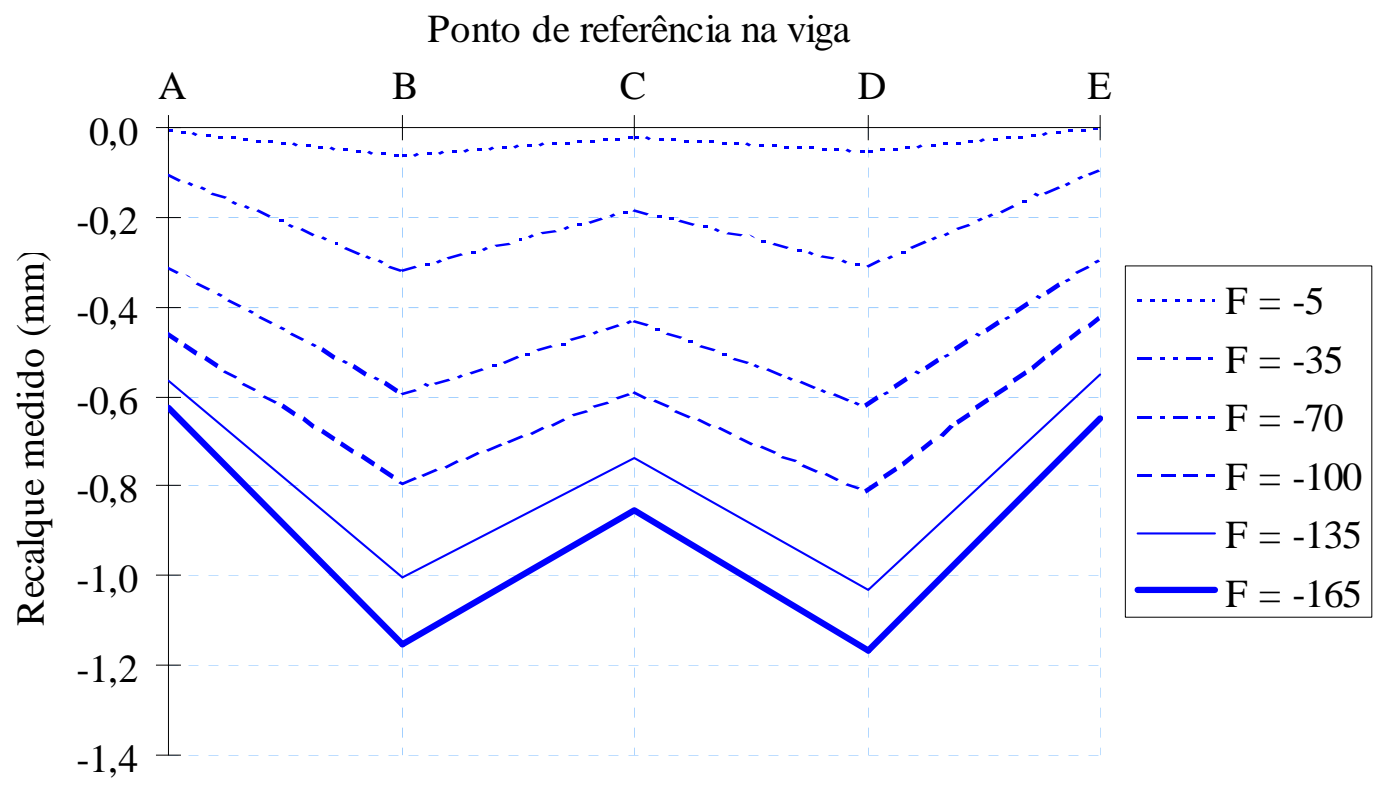

Figura 4.66 Configuração deformada da viga - Modelo 5, Situação 1. (F em kN)

Observou-se neste painel uma menor concentração de carga no apoio central, se comparada à ocorrida com o Modelo 1 . No Modelo 5 o apoio $\mathrm{C}$ recebeu em torno de $51 \%$ da carga total. No Modelo 1 esta proporção foi de aproximadamente 65\%. Esta diferença deve ser atribuída à diferença de rigidez da viga.

$\mathrm{Na}$ parede foram medidas pequenas deformações, em média as menores dentre os painéis das séries 1 e 2 .

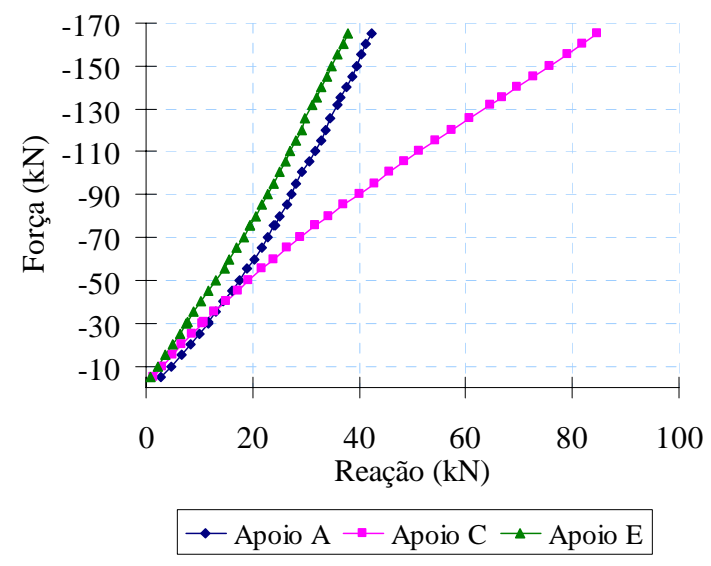

(a)

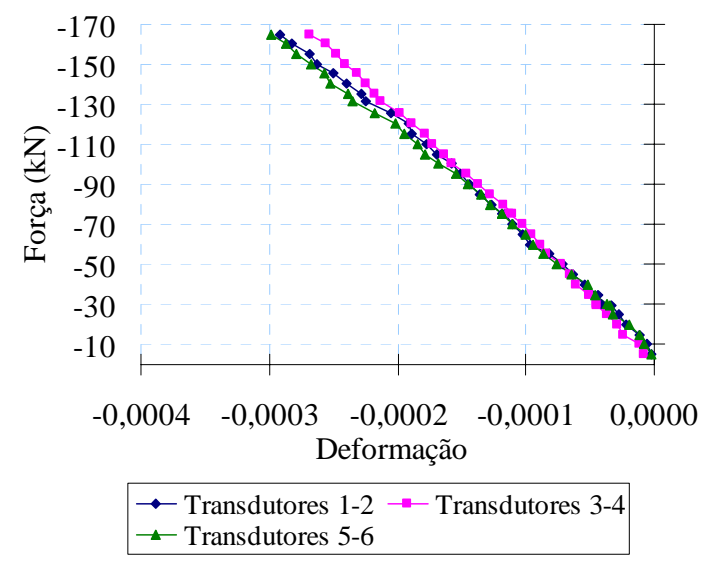

(b)

Figura 4.67 (a) Reações de apoio; (b) Deformação na parede - Modelo 5, Situação 1.

No diagrama seguinte apresenta-se distribuição da deformação vertical dos blocos ao longo da primeira fiada. Percebe-se a concentração de esforços acima dos apoios e uma pequena deformação por tração nos meios dos vãos. 


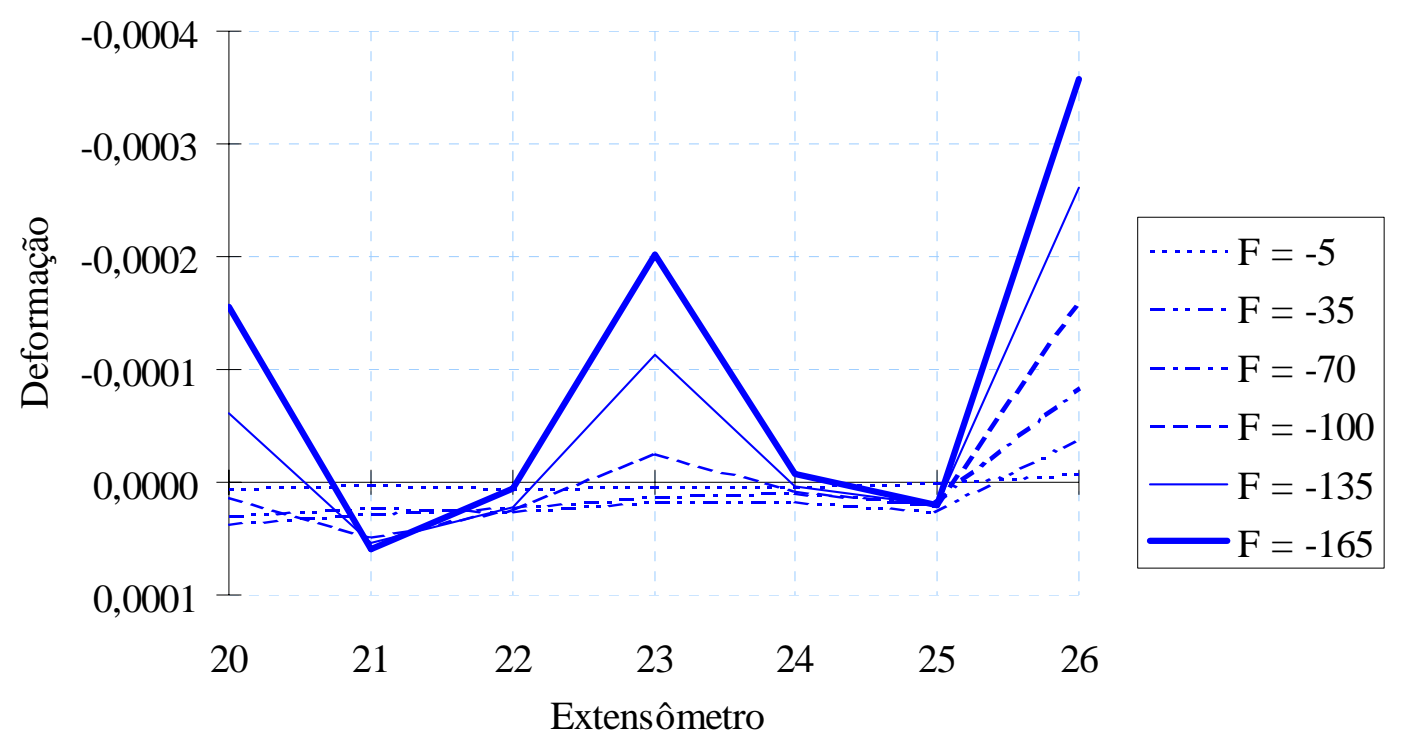

Figura 4.68 Deformações na base da parede - Modelo 5, Situação 1. (F em kN)

\subsubsection{Situação 2: Recalque do apoio central}

Com a aplicação do recalque no apoio central, sugiram apenas três fissuras na parede. A primeira foi horizontal, dividindo as duas primeiras fiadas. Durante o ensaio, ela tornou-se visível somente quando o recalque diferencial chegou a $-1,06 \mathrm{~mm}$. Porém, pelas leituras da instrumentação, inferiu-se que ela começou a se formar logo que o recalque diferencial aproximou-se de $-0,63 \mathrm{~mm}$. Dessa forma, no Modelo 5 a fissura horizontal formou-se a um recalque diferencial menor que no Modelo 1.

Uma segunda fissura horizontal, entre a segunda e a terceira fiada, foi percebida ao recalque diferencial de $-1,25 \mathrm{~mm}$. Logo após, ao recalque diferencial de $-1,47 \mathrm{~mm}$, surgiu uma fissura escalonada provocada por tensões de cisalhamento. Em seguida não foi mais possível aplicar maior recalque ao modelo, pois se atingiu uma configuração estável tendo sido retirado totalmente o apoio C. Portanto, o recalque diferencial máximo permitido pelo Modelo 5 foi somente 7\% menor se comparado ao Modelo 1.

Verifica-se que a fissuração ocorrida assemelha-se à do Modelo 1, porém com menor intensidade. Não se observou, entretanto, a formação de fissuras por tração na direção perpendicular ao arco comprimido. A viga mais rígida do Modelo 5 deve ter propiciado um maior comprimento de contato na interface, diminuindo a concentração de tensões no canto da parede.

Ao final do ensaio foram marcadas as fissuras da viga. Sua configuração deformada em função do recalque aplicado está apresentada na Figura 4.69. 


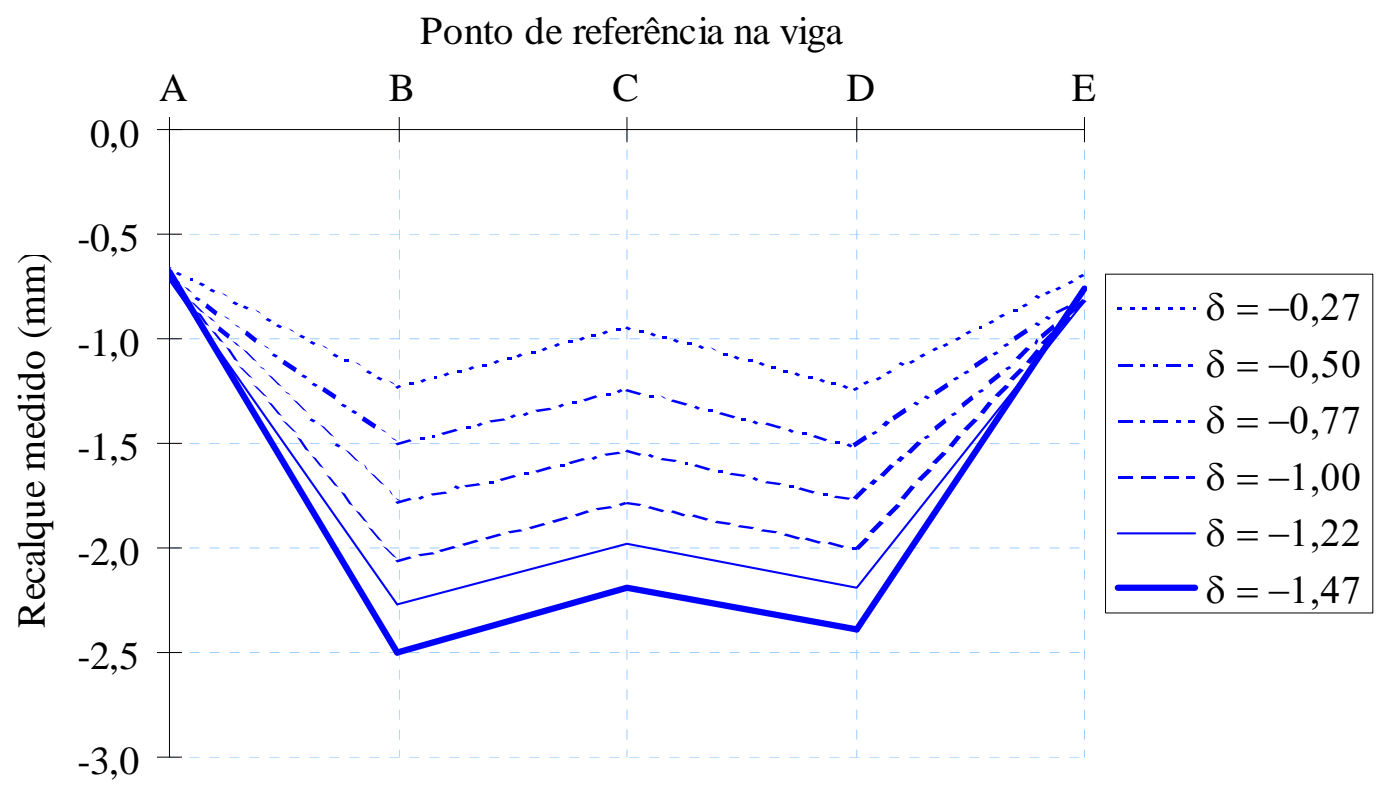

Figura 4.69 Configuração deformada da viga - Modelo 5, Situação 2. ( $\delta$ em mm)

Apresentam-se na Tabela 4.11 os parâmetros de recalque para os principais instantes do ensaio. Toda a fissuração pode ser visualizada a seguir.

Tabela 4.11 Parâmetros de curvatura - Modelo 5, Situação 2.

\begin{tabular}{|c|c|c|c|c|c|c|c|}
\hline \multicolumn{2}{|c|}{ RECALQUE (mm) } & \multirow{2}{*}{ OCORRÊNCIA } & \multirow{2}{*}{$(\Delta / \mathrm{L})_{\mathrm{ACE}}$} & \multirow{2}{*}{$(\Delta / \mathrm{L})_{\mathrm{ABC}}$} & \multirow{2}{*}{$(\Delta / \mathrm{L})_{\mathrm{CDE}}$} & \multirow{2}{*}{$(\delta / \ell)_{\mathrm{AB}}$} & \multirow{2}{*}{$(\delta / \ell)_{\mathrm{DE}}$} \\
\hline total & diferencial & & & & & & \\
\hline$-1,4$ & $-0,63$ & $\begin{array}{l}\text { Formação da } \\
\text { primeira fissura } \\
\text { horizontal }\end{array}$ & $-1 / 2852$ & $-1 / 1529$ & $-1 / 1648$ & $1 / 498$ & $1 / 522$ \\
\hline$-1,8$ & $-1,06$ & $\begin{array}{l}\text { Fissura horizontal } \\
\text { visível }\end{array}$ & $-1 / 1698$ & $-1 / 1060$ & $-1 / 1231$ & $1 / 326$ & $1 / 357$ \\
\hline$-2,0$ & $-1,25$ & $\begin{array}{l}\text { Segunda fissura } \\
\text { horizontal }\end{array}$ & $-1 / 1439$ & $-1 / 947$ & $-1 / 1102$ & $1 / 286$ & $1 / 312$ \\
\hline$-2,2$ & $-1,47$ & $\begin{array}{l}\text { Fissura por } \\
\text { cisalhamento e } \\
\text { recalque máximo }\end{array}$ & $-1 / 1224$ & $-1 / 848$ & $-1 / 992$ & $1 / 251$ & $1 / 274$ \\
\hline
\end{tabular}

Nota: Valores negativos de $(\Delta / \mathrm{L})$ indicam concavidade para cima. $(\delta / \ell)$ em valores absolutos. 


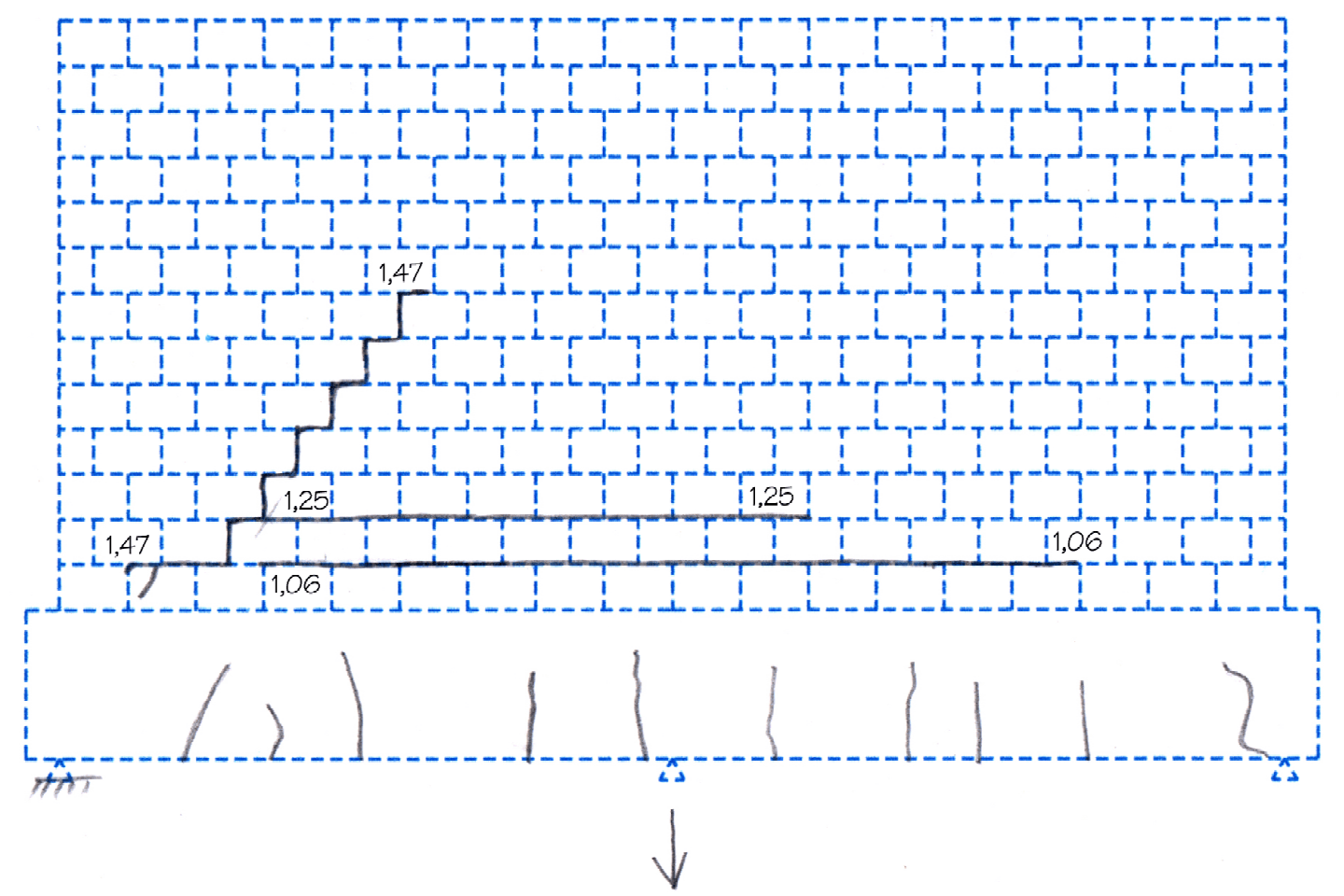

Figura 4.70 Distribuição de fissuras após ensaio - Modelo 5, Situação 2.

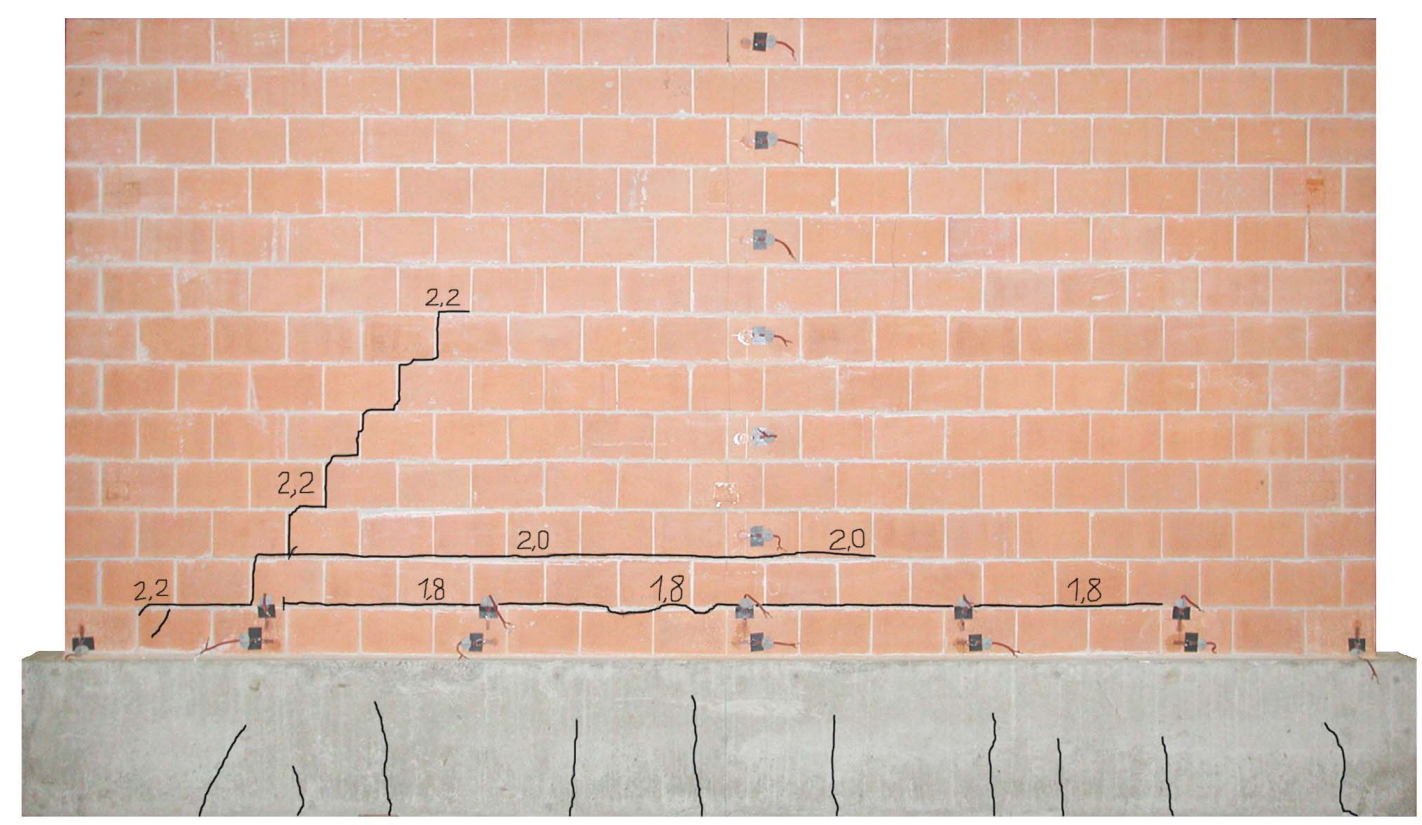

Figura 4.71 Fotografia do painel após ensaio - Modelo 5, Situação 2.

As curvas das reações de apoio em função do recalque diferencial mostram-se lineares até aproximadamente o instante em que a primeira fissura horizontal se tornou visível. As curvas de deformação vertical na parede seguiram a mesma tendência, sendo porém menos influenciadas pela fissuração considerada. 


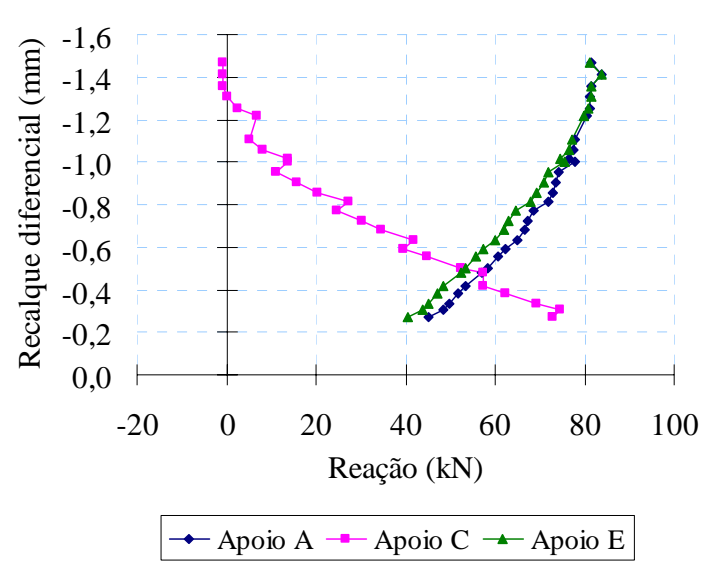

(a)

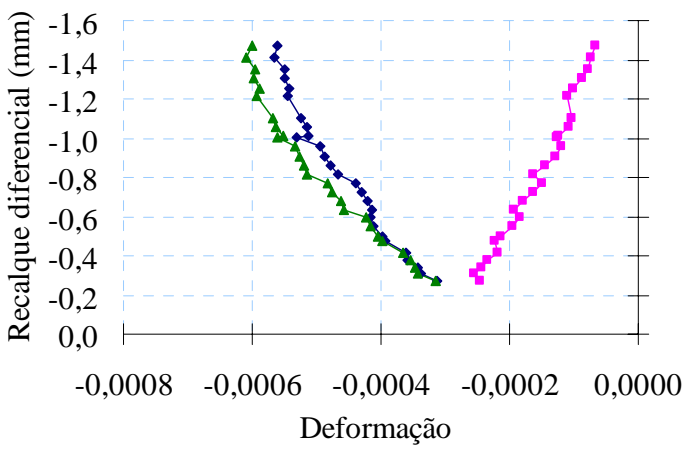

$\rightarrow$ Transdutores 1-2 - Transdutores 3-4 $\leftarrow$ Transdutores 5-6

(b)

Figura 4.72 (a) Reações de apoio; (b) Deformação na parede - Modelo 5, Situação 2.

A leitura que permitiu perceber o verdadeiro instante em que a fissura horizontal começou a se formar, embora invisível, foi do extensômetro vertical 23, posicionado no meio da primeira fiada. Pelo gráfico seguinte, verifica-se a mudança abrupta de comportamento para um recalque diferencial por volta de $-0,63 \mathrm{~mm}$.

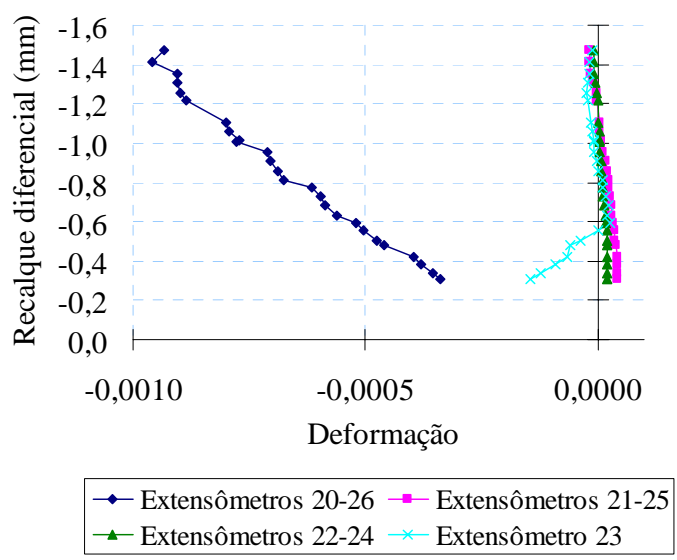

Figura 4.73 Deformações na primeira fiada - Modelo 5, Situação 2.

Na Figura 4.74 observa-se a distribuição dessas deformações ao longo da base da parede para vários níveis de recalque diferencial. 


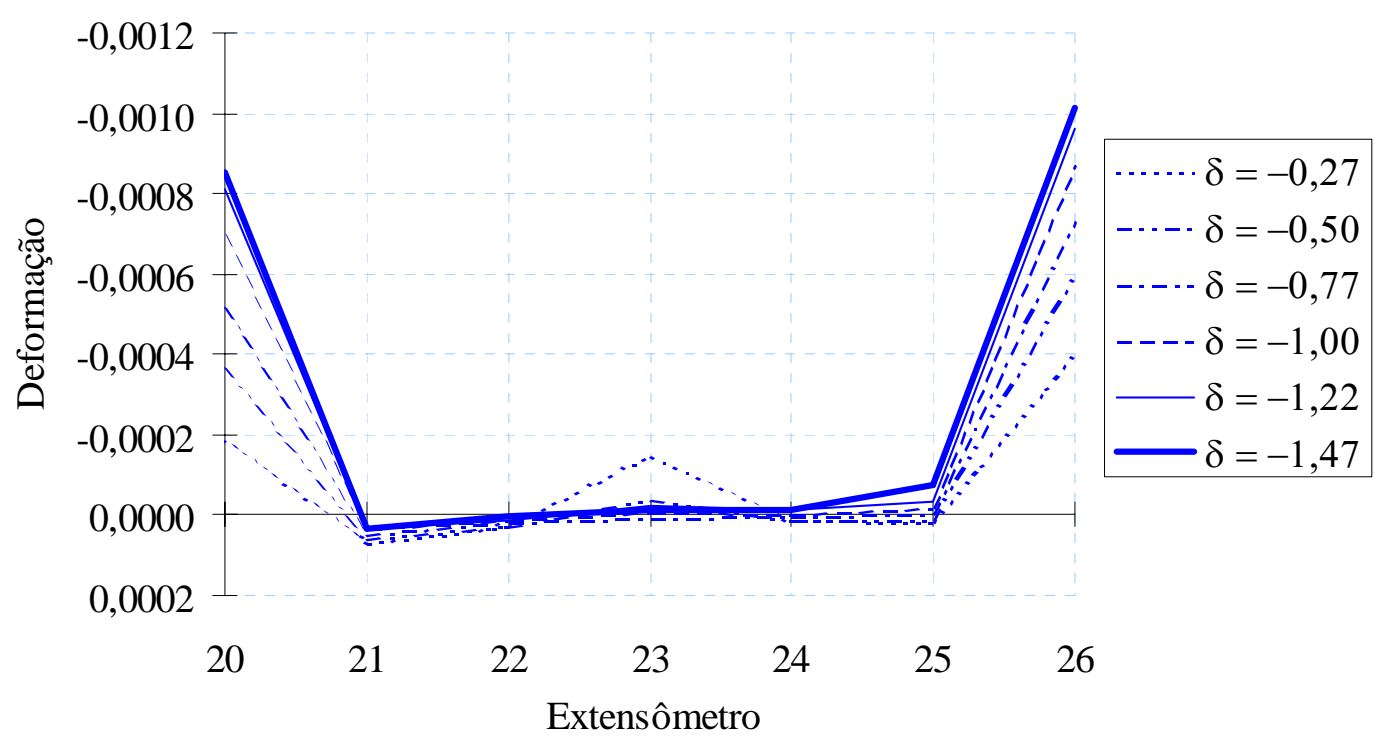

Figura 4.74 Deformações na base da parede - Modelo 5, Situação 2. ( $\delta$ em mm)

\subsubsection{Situação 3: Recalque do apoio de extremidade}

A primeira fissura nesta situação surgiu para um recalque diferencial do apoio de extremidade de $-0,10 \mathrm{~mm}$. Conforme esperado, a fissura se iniciou no topo do painel, dirigindo-se verticalmente para baixo, separando o painel em duas metades. Inicialmente atingiu apenas as duas últimas fiadas. Ao recalque diferencial de $-0,22 \mathrm{~mm}$ propagou-se por mais uma fiada.

A parede manteve-se estável até um recalque diferencial próximo a -0,34 mm. Nesse instante, a fissura vertical propagou-se até a base da parede, dividindo-a completamente em duas metades.

Continuou-se a aplicação de recalque ao apoio E, sem que outras fissuras surgissem. Verificava-se unicamente o aumento da abertura da fissura, que, no ponto em que se iniciou, ultrapassou $0,35 \mathrm{~mm}$ ao recalque diferencial de $-1,21 \mathrm{~mm}$. Considerou-se encerrado o ensaio tendo sido retirado o apoio $\mathrm{E}$, instante em que o painel permaneceu momentaneamente estável, atingindo-se um recalque diferencial máximo de $-1,52 \mathrm{~mm}$, correspondente ao recalque total de $-2,9 \mathrm{~mm}$.

Entretanto, inesperadamente a parede se partiu novamente, com o surgimento de uma grande fissura diagonal. A extremidade da viga que estava em balanço repousou novamente sobre o cilindro hidráulico (apoio E). Surgiram fissuras na viga, acima do apoio C. Ratificou-se dessa forma a condição de propagação de fissuras não-controlada. 
Apresentam-se a seguir o diagrama de deformação da viga, a tabela com alguns valores dos parâmetros de recalque, a ilustração da fissuração em função do recalque diferencial e uma fotografia do painel após o ensaio.

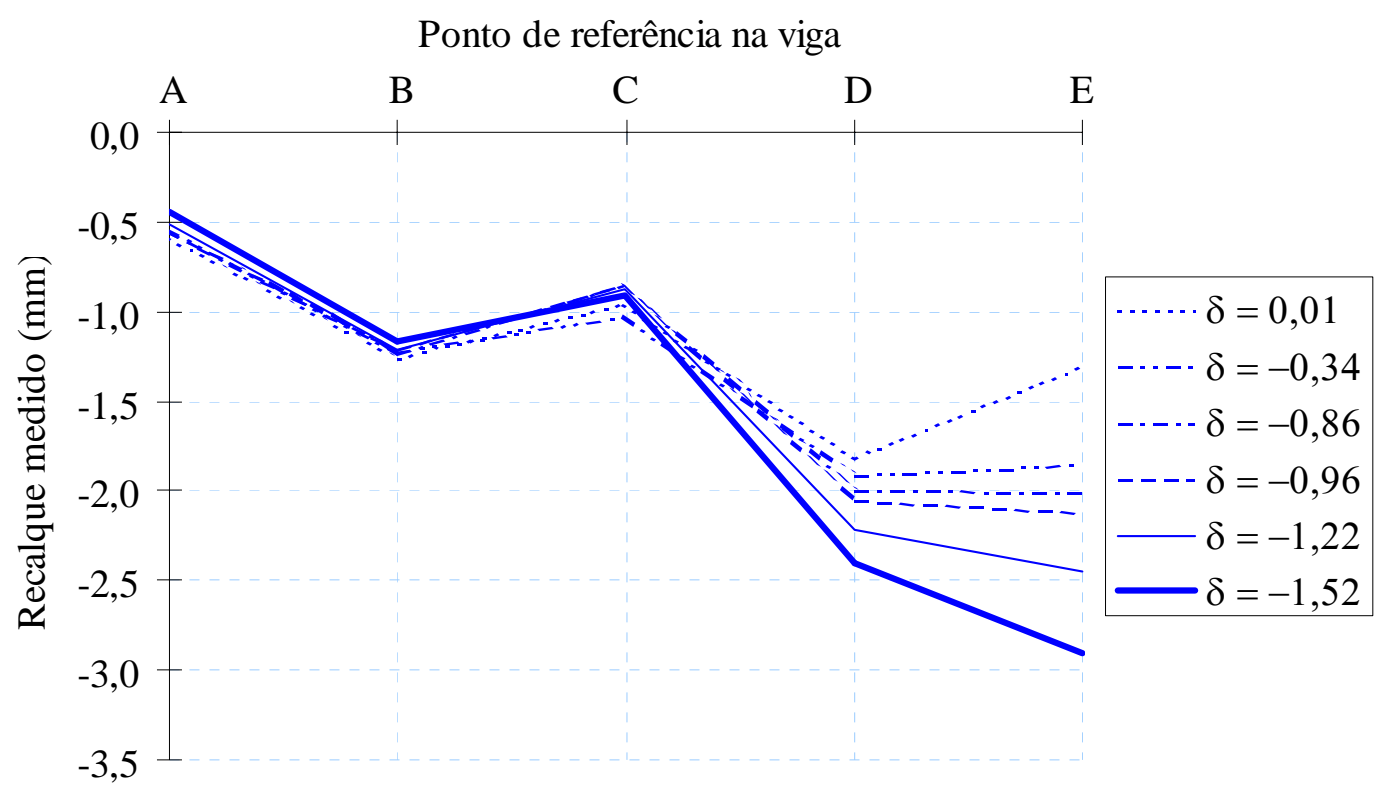

Figura 4.75 Configuração deformada da viga - Modelo 5, Situação 3. ( $\delta$ em mm)

Tabela 4.12 Parâmetros de curvatura - Modelo 5, Situação 3.

\begin{tabular}{|c|c|c|c|c|c|c|}
\hline \multicolumn{2}{|c|}{ RECALQUE (mm) } & \multirow{2}{*}{ OCORRÊNCIA } & \multirow{2}{*}{$(\Delta / \mathrm{L})_{\mathrm{ACE}}$} & \multirow{2}{*}{$(\Delta / \mathrm{L})_{\mathrm{ABC}}$} & \multirow{2}{*}{$(\Delta / \mathrm{L})_{\mathrm{CDE}}$} & \multirow{2}{*}{$(\delta / \ell)_{\mathrm{CD}}$} \\
\hline total & diferencial & & & & & \\
\hline$-1,5$ & $-0,10$ & Primeira fissura & $1 / 34662$ & $-1 / 1890$ & $-1 / 1541$ & $1 / 708$ \\
\hline$-1,9$ & $-0,34$ & Divisão da parede & $1 / 10513$ & $-1 / 2010$ & $-1 / 1879$ & $1 / 692$ \\
\hline$-2,9$ & $-1,52$ & $\begin{array}{l}\text { Recalque máximo } \\
\text { (convencional) }\end{array}$ & $1 / 2373$ & $1 / 1848$ & $-1 / 1815$ & $1 / 359$ \\
\hline
\end{tabular}

Nota: Valores negativos de $(\Delta / \mathrm{L})$ indicam concavidade para cima. $(\delta / \ell)$ em valores absolutos. 


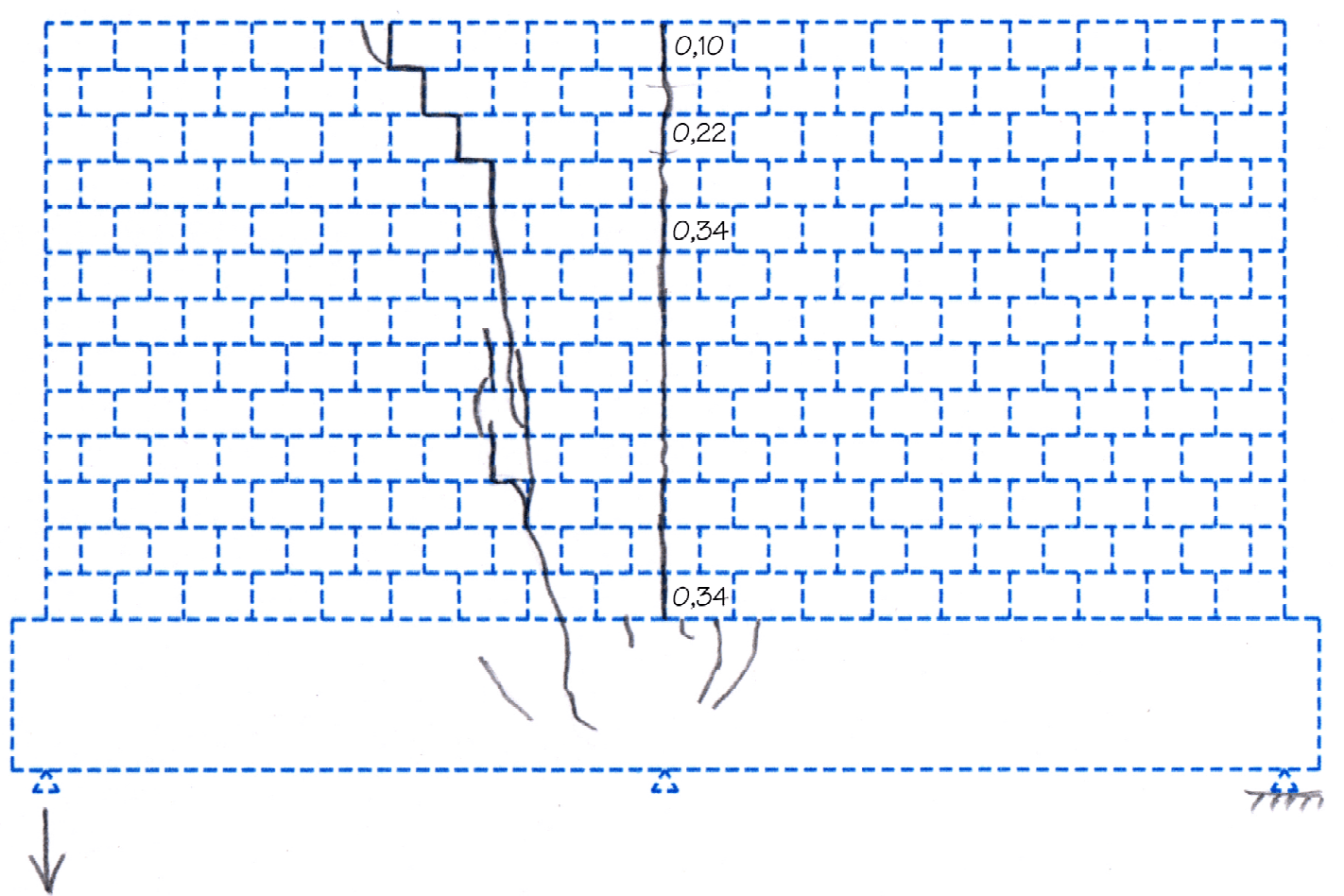

Figura 4.76 Distribuição de fissuras após ensaio - Modelo 5, Situação 3. (Verso do painel)

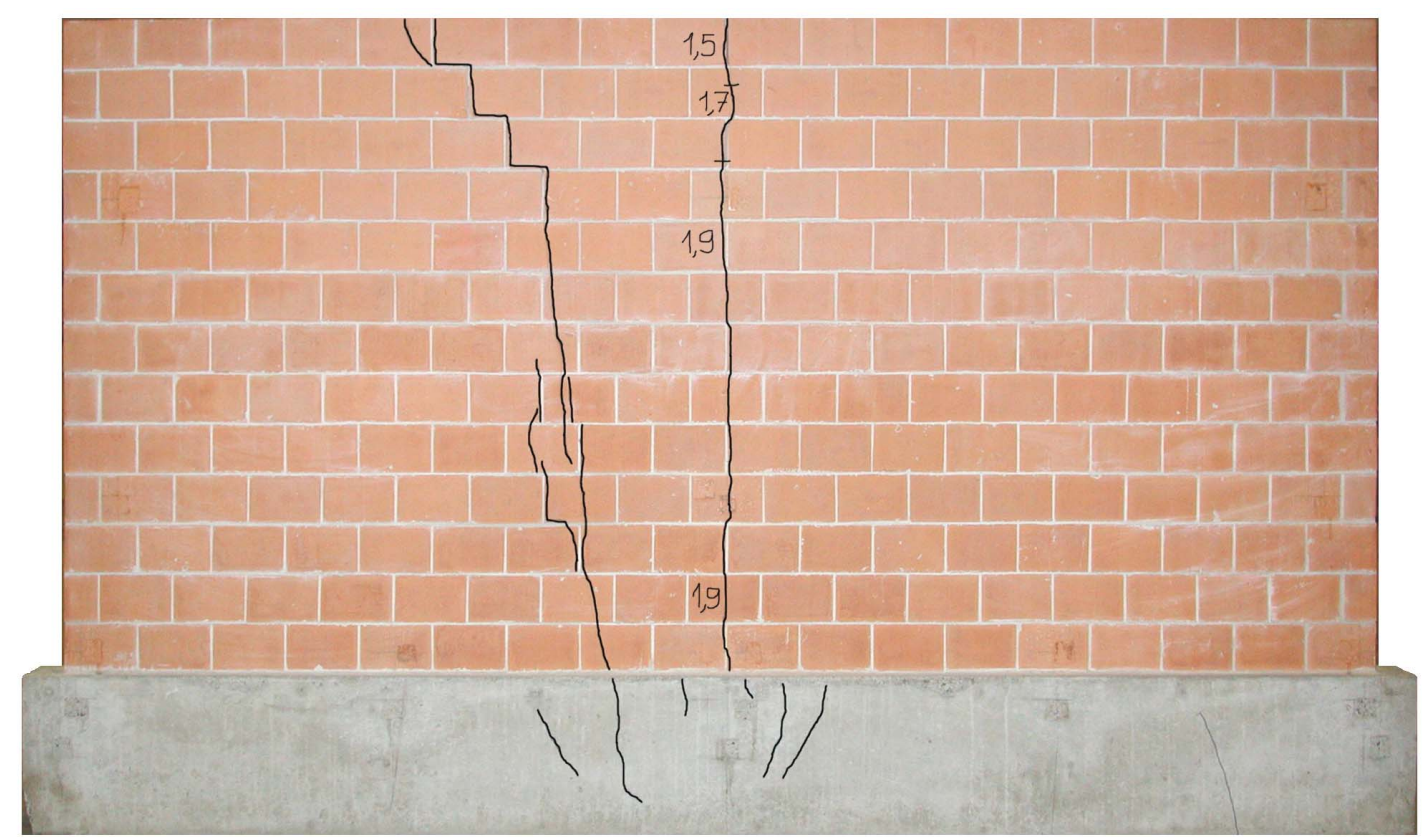

Figura 4.77 Fotografia do painel após ensaio - Modelo 5, Situação 3. (Verso do painel)

Os gráficos obtidos para esta situação de recalque são marcados pela descontinuidade provocada pela divisão da parede em duas metades. Na Figura 4.78 se observam os comportamentos das reações de apoios e das deformações na parede. As hastes dos transdutores 3 e 4 caíram no instante em que a parede se partiu, impossibilitando leituras 
posteriores. As curvas seguem as mesmas tendências observadas para o Modelo 1, inclusive apresentando valores aproximadamente iguais.

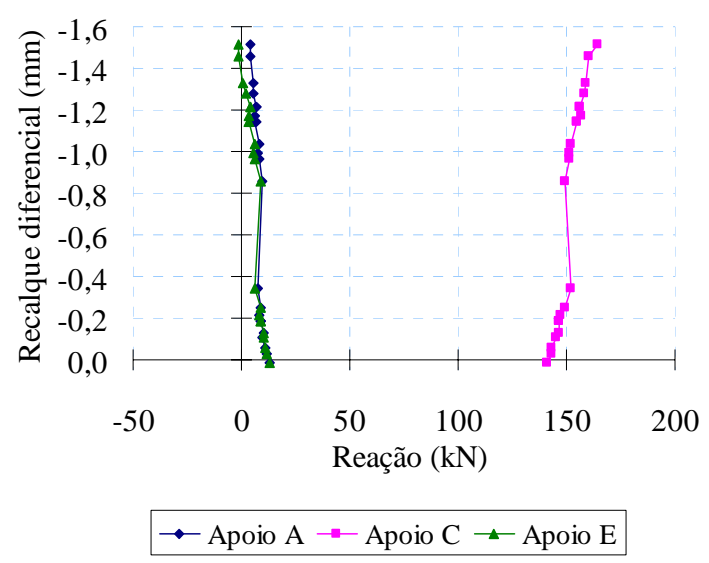

(a)

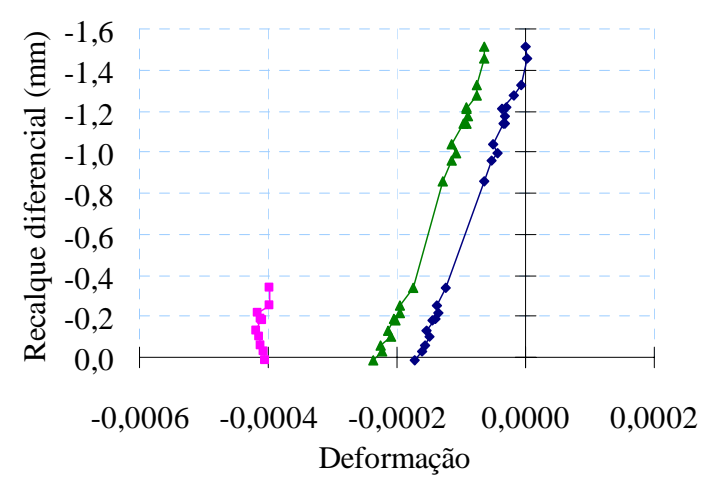

- Transdutores 1-2 - Transdutores 3-4 ^-Transdutores 5-6

(b)

Figura 4.78 (a) Reações de apoio; (b) Deformação na parede - Modelo 5, Situação 3.

A Figura 4.79 ilustra a distribuição de deformações na base da parede para diversos valores de recalque diferencial. Percebe-se a grande concentração de esforços no centro do painel. Porém a tensão nas extremidades não se anula, uma vez que o modelo, dividido ao meio, ainda precisa dos três apoios para manter o equilíbrio.

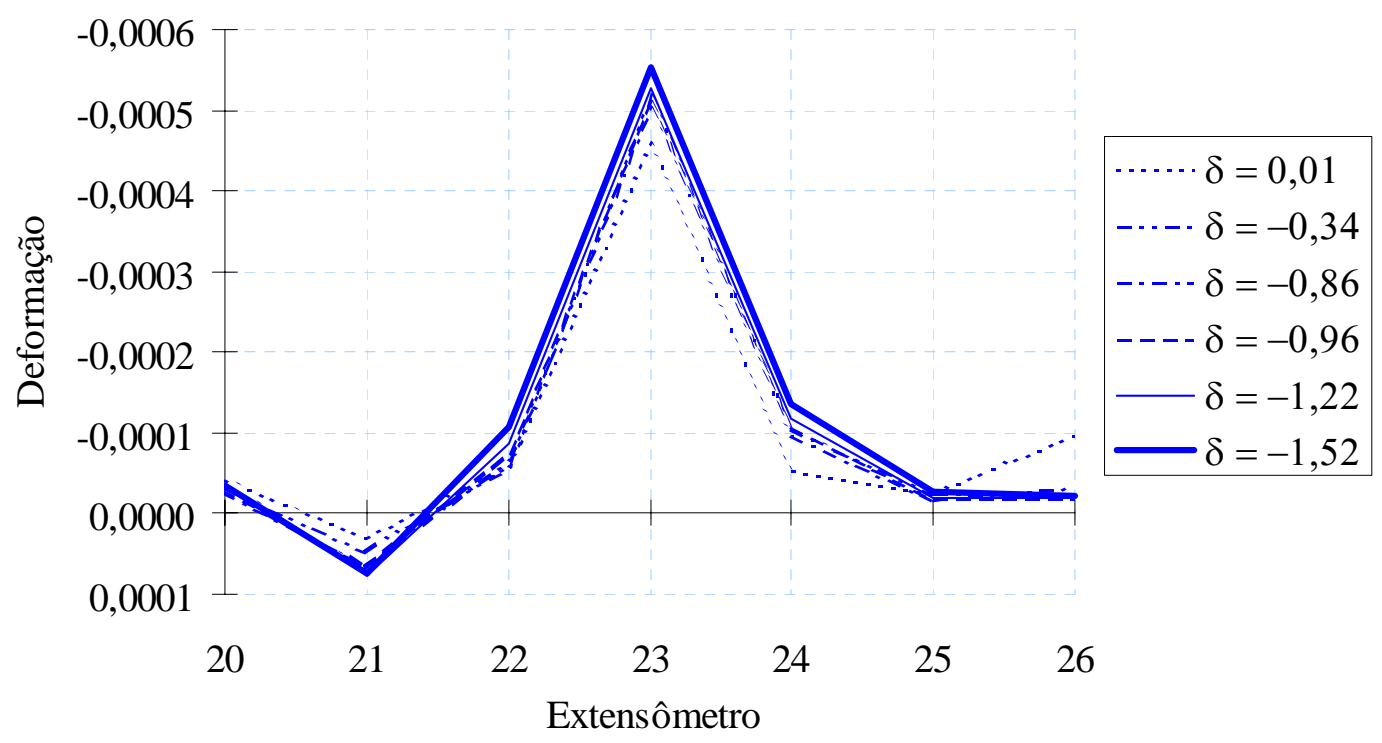

Figura 4.79 Deformações na base da parede - Modelo 5, Situação 3. ( $\delta$ em mm)

\subsection{MODELO 6}

O objetivo deste modelo foi verificar a eficácia de alternativas simples para o combate à fissuração provocada por recalques em paredes sem abertura. 
Para minimizar a formação de fissuras na situação de recalque do apoio central, adotou-se o grauteamento de furos localizados acima dos apoios, armados longitudinalmente com uma barra de 4,2 $\mathrm{mm}$ de diâmetro. Nas extremidades da parede, esse grauteamento evitaria a fissuração por compressão excessiva nos cantos. No meio da parede, a armadura impediria o aparecimento da fissura horizontal.

Para minimizar a fissuração vertical causada pela situação de recalque do apoio de extremidade e evitar o colapso do painel, adicionou-se uma cinta no topo da parede, constituída de blocos canaleta grauteados e armada longitudinalmente em toda a sua extensão com uma barra de 4,2 mm de diâmetro. Ressalta-se que somente houve disponibilidade de blocos canaleta na época de preparação dos ensaios da Série 3.

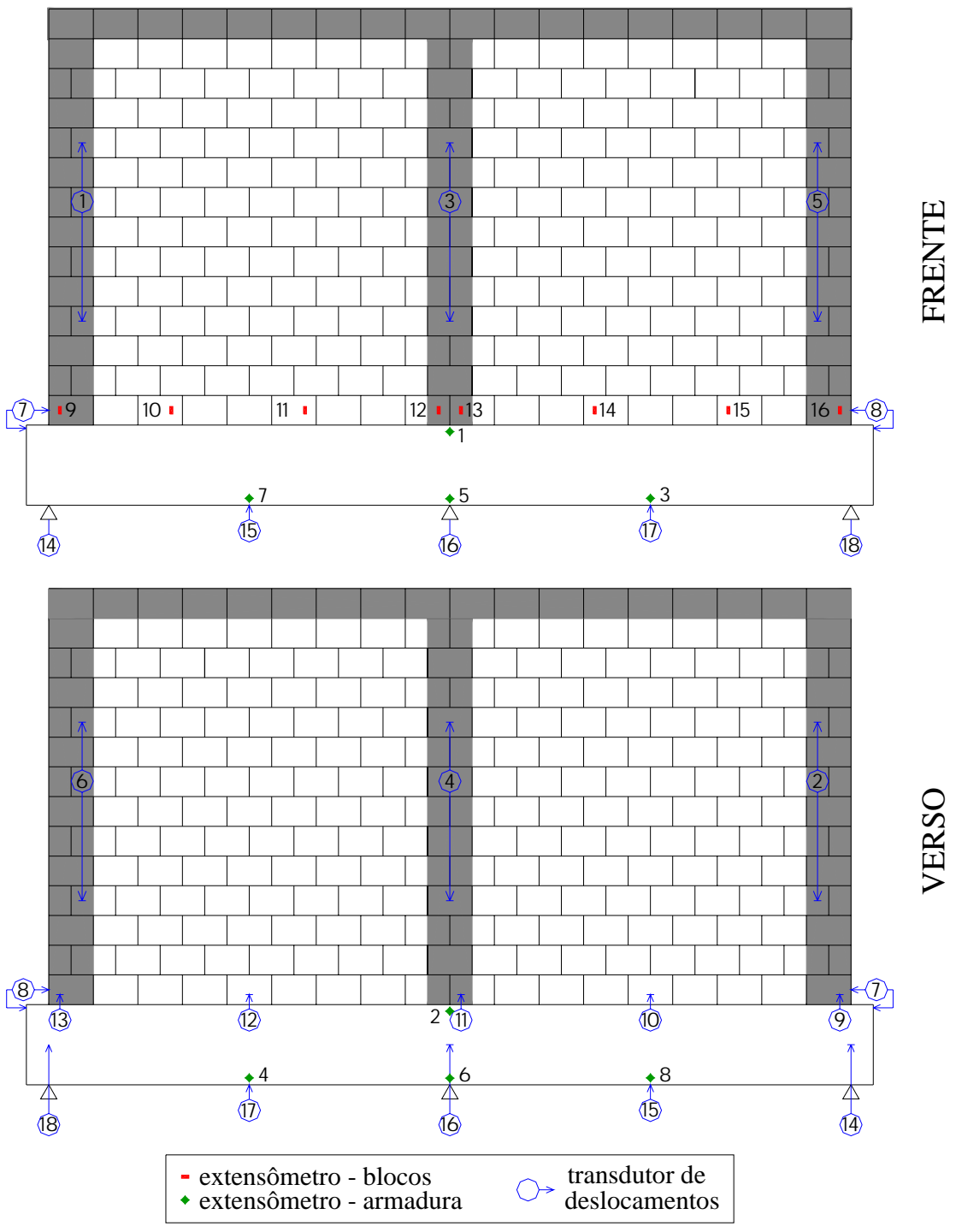

Figura 4.80 Instrumentação do Modelo 6. 


\subsubsection{Situação 1: Aplicação do carregamento vertical}

Ao final desta etapa, o recalque diferencial do apoio central era de $0,04 \mathrm{~mm}$, com uma inclinação entre os apoios de extremidade de $0,031 \%$. Os parâmetros de recalque mantiveram-se bastante pequenos durante toda a aplicação da compressão. Na Figura 4.81 verifica-se a evolução da deformação da viga, cujo apoio A sofreu deformações acima do esperado. Nenhuma fissura foi observada.

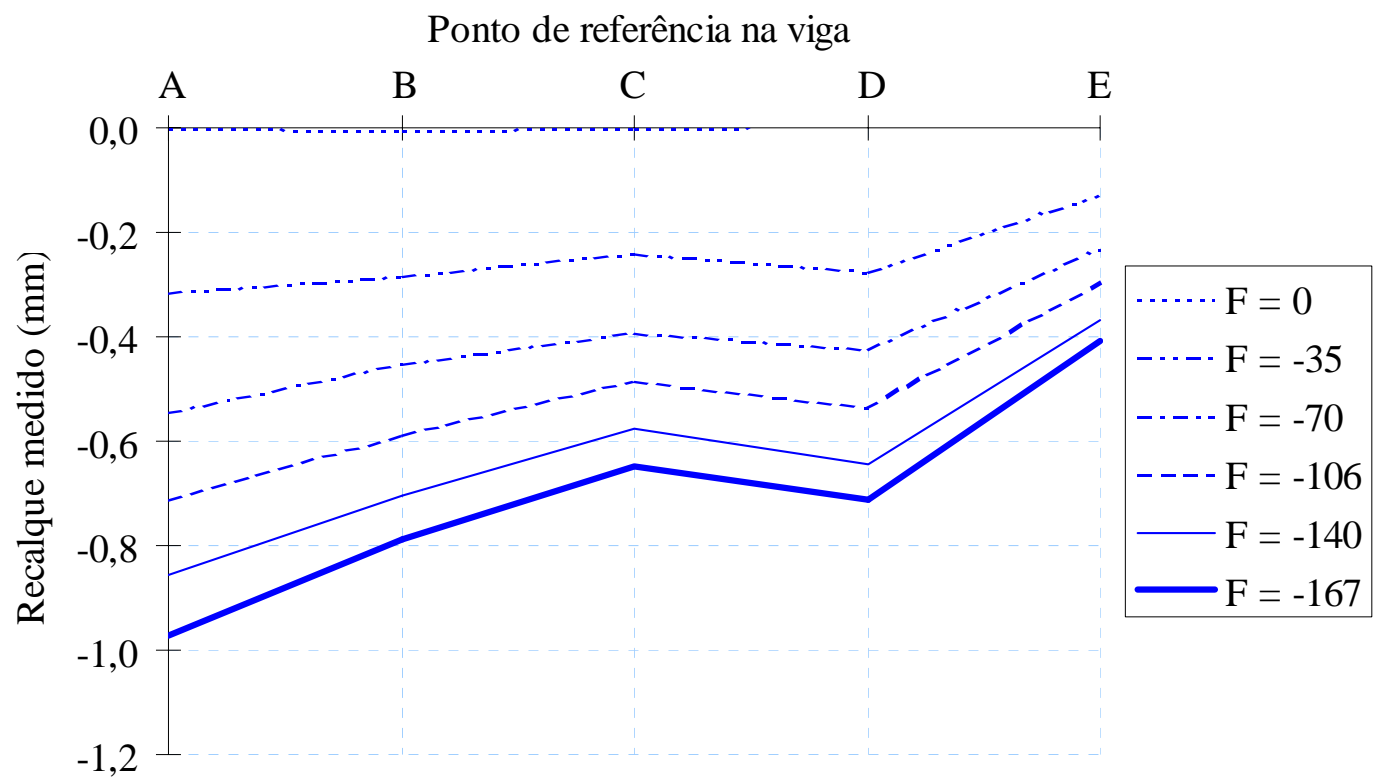

Figura 4.81 Configuração deformada da viga - Modelo 6, Situação 1. (F em kN)

Neste modelo a concentração de carga no apoio central também foi menor que no Modelo 1, sendo 58\% da força total aplicada. As deformações medidas pelos transdutores verticais da parede foram as menores dentre todos os modelos. Isto aconteceu porque as medidas foram feitas em locais onde havia graute, o que aumenta o módulo de elasticidade do local.

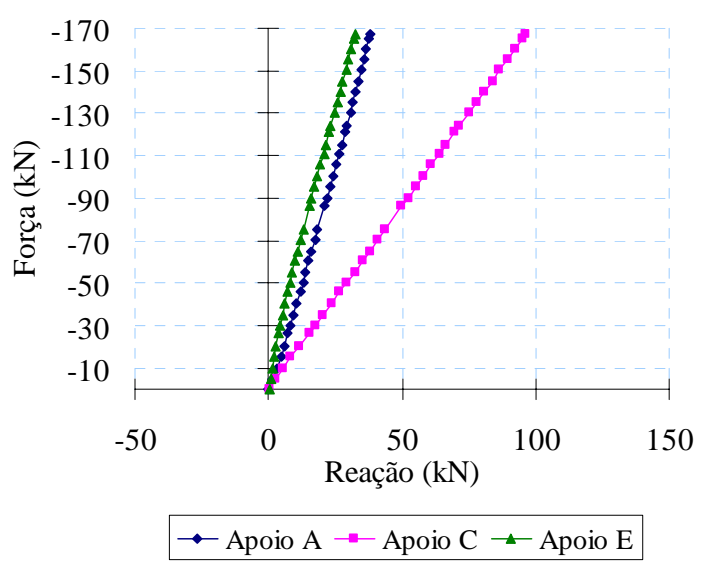

(a)

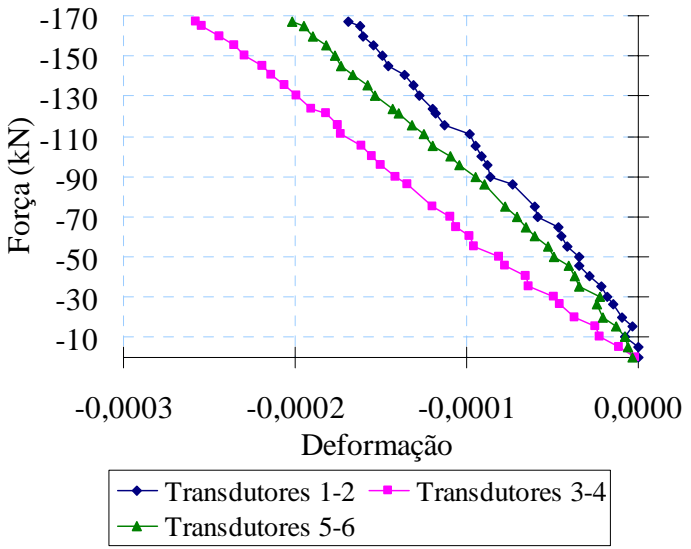

(b)

Figura 4.82 (a) Reações de apoio; (b) Deformação na parede - Modelo 6, Situação 1. 
As deformações nos blocos da primeira fiada distribuíram-se conforme a ilustração da Figura 4.83. Observa-se que houve maior transferência de carga da parede para a viga no vão $\mathrm{ABC}$, o que explica a maior deformação do apoio $\mathrm{A}$.

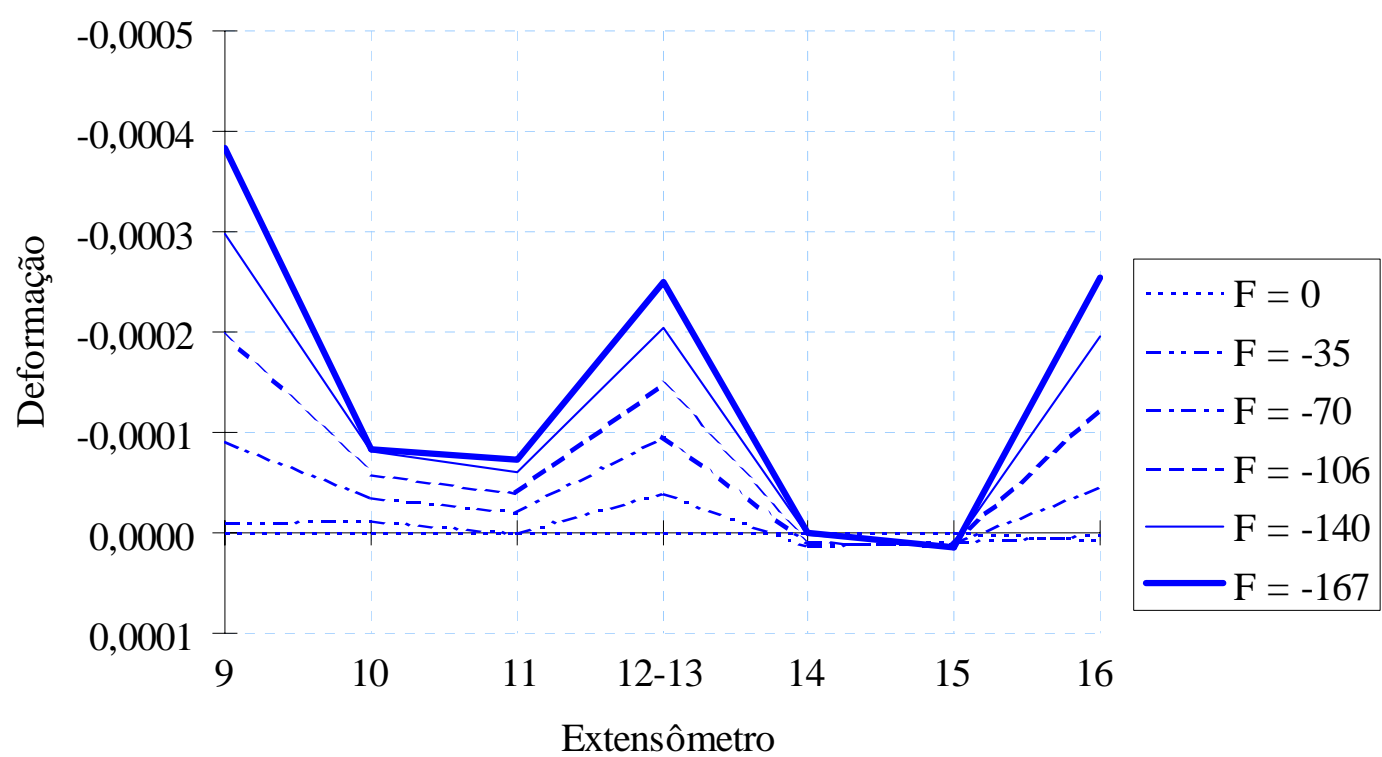

Figura 4.83 Deformações na base da parede - Modelo 6, Situação 1. (F em kN)

\subsubsection{Situação 2: Recalque do apoio central}

As regiões grauteadas atuaram de maneira similar a um pórtico e alteraram a distribuição das tensões na parede. O confinamento da alvenaria não-armada pelo "pórtico" de graute provocou um aumento das tensões de cisalhamento nos cantos superiores do painel. Como consequiência, numa dessas regiões surgiu a primeira fissura, diagonal e escalonada, ao recalque diferencial de $-0,29 \mathrm{~mm}$.

Essa fissura foi-se prolongando até o recalque diferencial de $-0,67 \mathrm{~mm}$, quando também surgiram as primeiras fissuras na viga.

Ao recalque diferencial de $-0,84 \mathrm{~mm}$ formaram-se novas fissuras diagonais escalonadas na parte não-grauteada da alvenaria, desta vez partindo das extremidades inferiores, inclusive separando parede e viga. As causas prováveis foram as altas tensões de cisalhamento nessas regiões. Em seguida surgiram outras fissuras diagonais, a partir do canto superior esquerdo ou paralelas às das regiões inferiores.

Retirando-se totalmente o apoio central, o recalque diferencial máximo obtido foi de $-1,21$ mm, equivalente a uma redução em torno de $23 \%$ com relação ao Modelo 1 .

Com o grauteamento buscou-se combater especificamente duas causas de fissuração da alvenaria: compressão excessiva nos cantos e tração vertical no centro do painel. De antemão, sabia-se que a fissuração por tensões de cisalhamento não seria evitada, 
sendo necessário adotar conjuntamente um outro tipo de solução. A partir do ensaio realizado, verificou-se que para os objetivos almejados o grauteamento mostrou-se eficaz, evitando completamente tais tipos de fissuras.

Entretanto, a indução da formação de fissuras diagonais nos cantos superiores do painel é indesejável. Por causa disso, inclusive, a primeira fissura surgiu a um recalque diferencial menor que nos modelos 1 e 6 .

Portanto, conclui-se que o grauteamento adotado constitui uma solução parcial para o problema da fissuração provocada por recalques do apoio central.

A seguir são apresentados o diagrama de deformação da viga, a tabela com valores dos parâmetros de recalque e as ilustrações de distribuição das fissuras ao final desta etapa do ensaio.

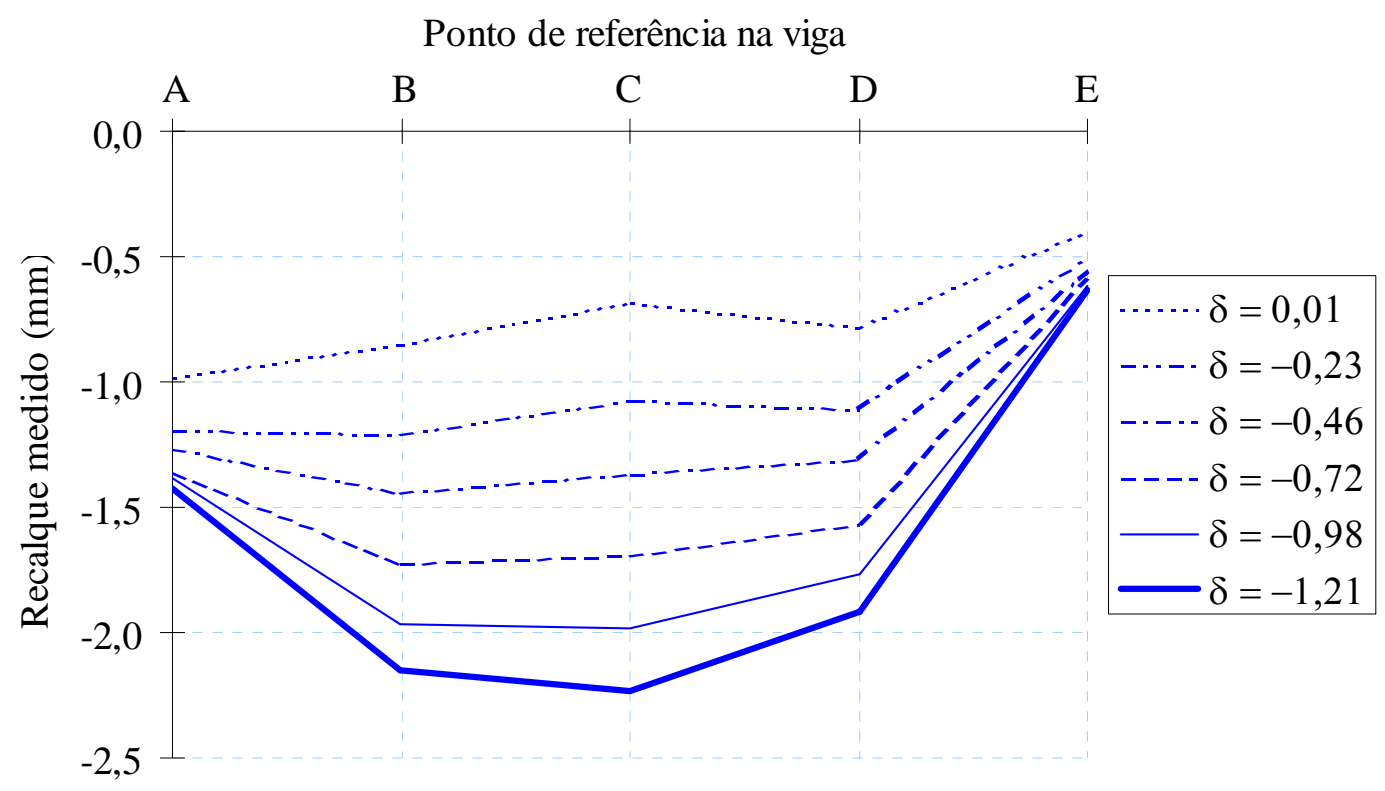

Figura 4.84 Configuração deformada da viga - Modelo 6, Situação 2. ( $\delta$ em mm)

Tabela 4.13 Parâmetros de curvatura - Modelo 6, Situação 2.

\begin{tabular}{|c|c|c|c|c|c|c|c|}
\hline \multicolumn{2}{|c|}{ RECALQUE (mm) } & \multirow{2}{*}{ OCORRÊNCIA } & \multirow[b]{2}{*}{$(\Delta / \mathrm{L})_{\mathrm{ACE}}$} & \multirow[b]{2}{*}{$(\Delta / \mathrm{L})_{\mathrm{ABC}}$} & \multirow[b]{2}{*}{$(\Delta / \mathrm{L})_{\mathrm{CDE}}$} & \multirow[b]{2}{*}{$(\delta / \ell)_{\mathrm{AB}}$} & \multirow[b]{2}{*}{$(\delta / \ell)_{\mathrm{DE}}$} \\
\hline total & diferencial & & & & & & \\
\hline$-0,9$ & $-0,29$ & $\begin{array}{l}\text { Primeira fissura } \\
\text { na parede }\end{array}$ & $-1 / 6211$ & $-1 / 12145$ & $-1 / 2893$ & $1 / 2055$ & $1 / 987$ \\
\hline$-1,4$ & $-0,67$ & $\begin{array}{l}\text { Primeira fissura } \\
\text { na viga }\end{array}$ & $-1 / 2695$ & $-1 / 4913$ & $-1 / 2306$ & $1 / 870$ & $1 / 621$ \\
\hline$-1,6$ & $-0,84$ & Fissuras diagonais & $-1 / 2144$ & $-1 / 3864$ & $-1 / 1979$ & $1 / 689$ & $1 / 515$ \\
\hline$-2,2$ & $-1,21$ & $\begin{array}{l}\text { Grande propagação } \\
\text { de fissuras e } \\
\text { recalque máximo }\end{array}$ & $-1 / 1492$ & $-1 / 2805$ & $-1 / 1872$ & $1 / 487$ & $1 / 415$ \\
\hline
\end{tabular}

Nota: Valores negativos de $(\Delta / \mathrm{L})$ indicam concavidade para cima. $(\delta / \ell)$ em valores absolutos. 


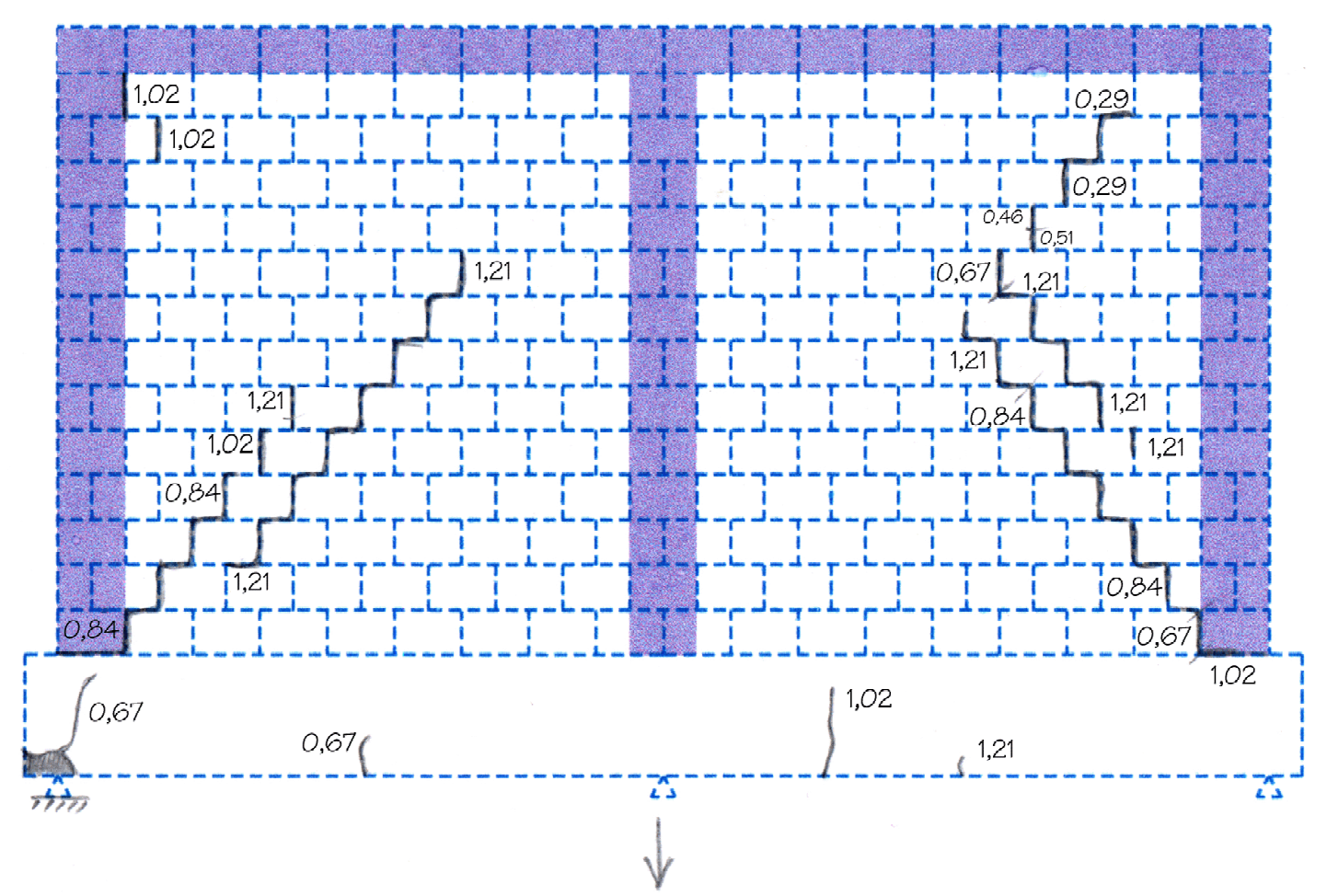

Figura 4.85 Distribuição de fissuras após ensaio - Modelo 6, Situação 2.

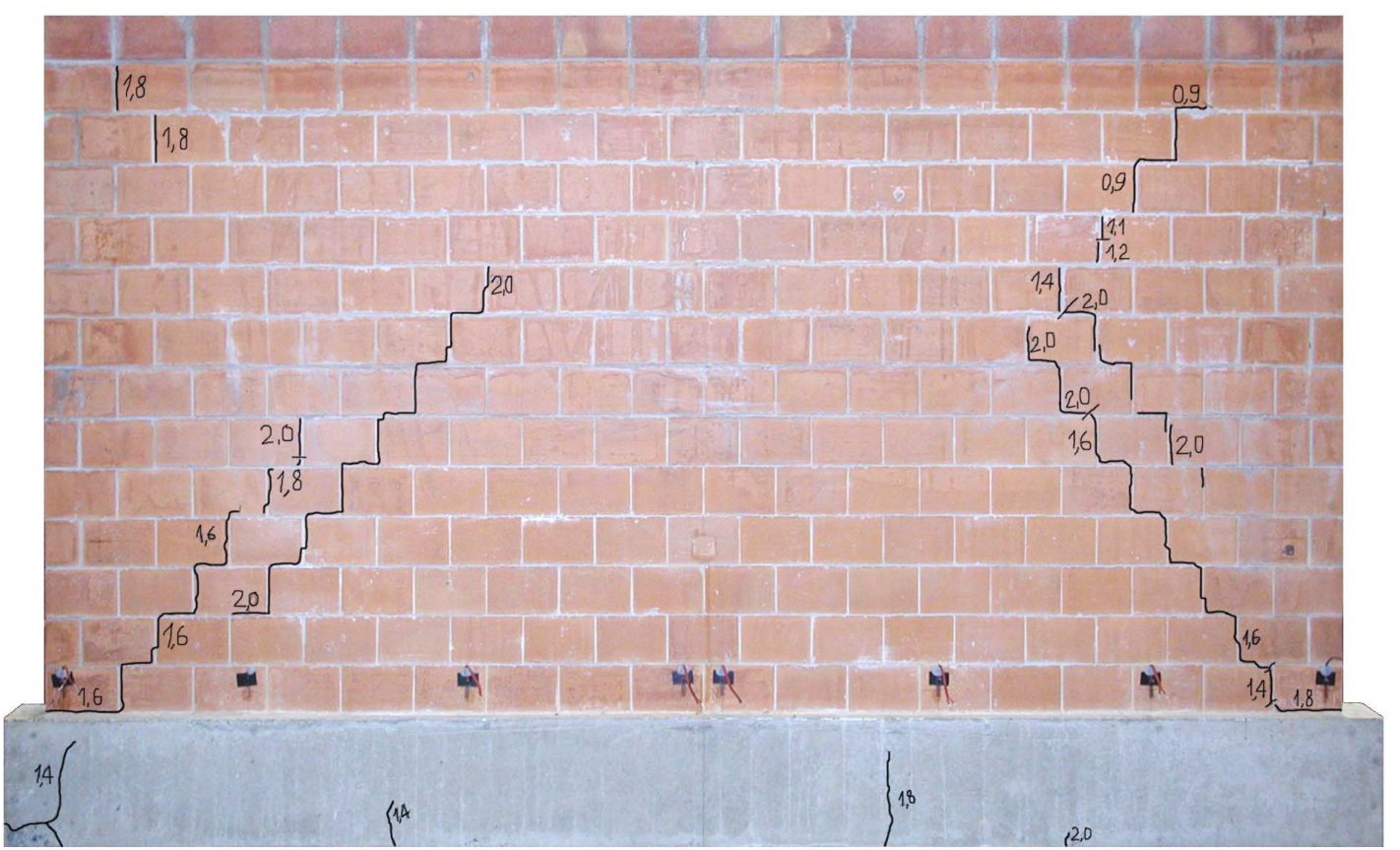

Figura 4.86 Fotografia do painel após ensaio - Modelo 6, Situação 2.

$\mathrm{Na}$ Figura 4.87 encontram-se os gráficos das reações de apoio e das deformações verticais na parede. Verifica-se que as deformações medidas nas bordas do painel são cerca de $60 \%$ menores que as correspondentes no Modelo 1. 


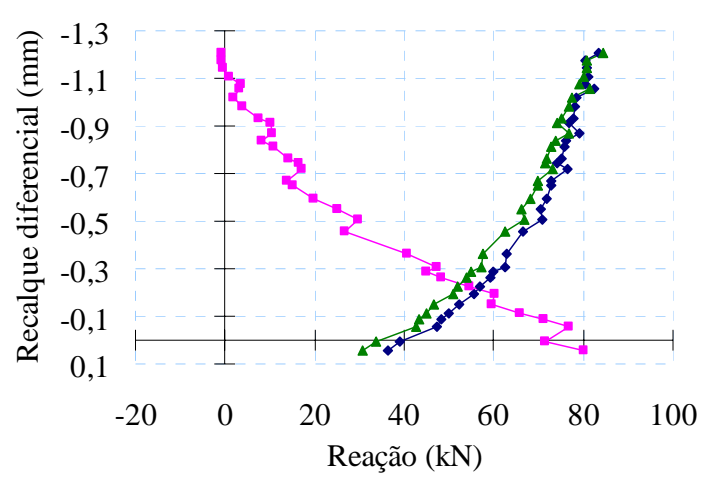

Apoio $\mathrm{A} \rightarrow-$ Apoio $\mathrm{C} \rightarrow$ Apoio $\mathrm{E}$

(a)

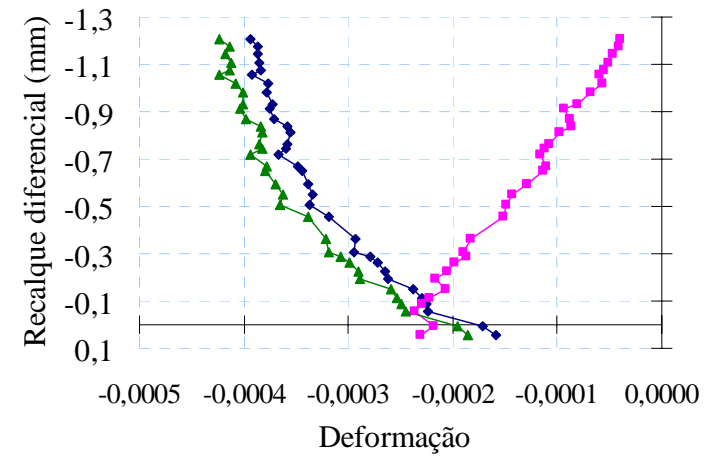

$\rightarrow-$ Transdutores 1-2 - - Transdutores 3-4 Transdutores 5-6

(b)

Figura 4.87 (a) Reações de apoio; (b) Deformação na parede - Modelo 6, Situação 2.

A distribuição das deformações verticais na base da parede pode ser visualizada na figura seguinte.

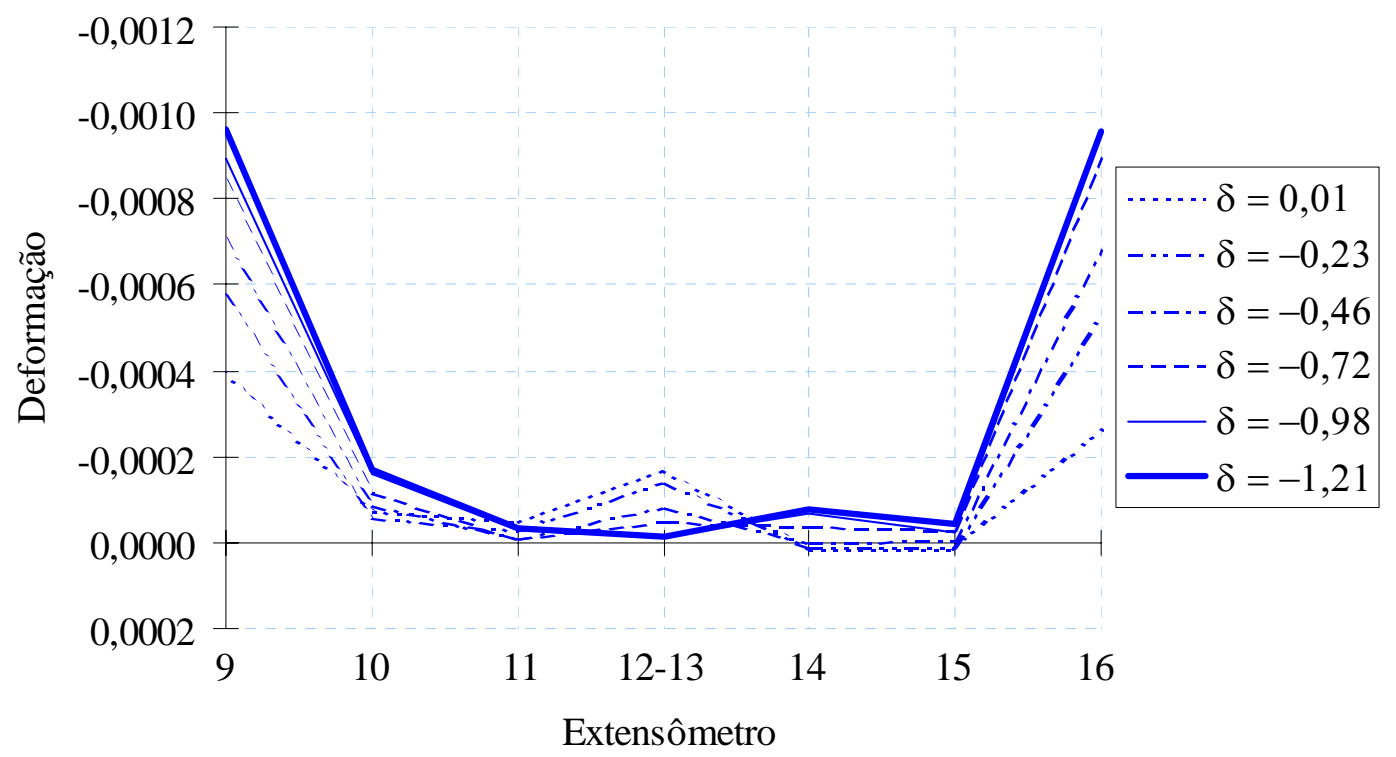

Figura 4.88 Deformações na base da parede - Modelo 6, Situação 2. ( $\delta$ em mm)

\subsubsection{Situação 3: Recalque do apoio de extremidade}

Na segunda configuração de recalque do Modelo 6, a primeira fissura surgiu ao recalque diferencial do apoio de extremidade de aproximadamente $-0,05 \mathrm{~mm}$. Foi uma fissura vertical, dividindo a última fiada ao meio. Esta se tornou a única fissura da parede, propagando-se continuamente e sem sobressaltos em direção à base da parede. A sua máxima extensão foi atingida quando o recalque diferencial chegou ao valor $-0,62 \mathrm{~mm}$. Assim, a parede ficou dividida ao meio desde a última fiada até a meia-altura da primeira fiada. 
Após a retirada total do apoio não houve ruptura brusca. A parede simplesmente permaneceu como estava, inclusive sem apresentar aberturas de fissura excessivas. Dessa forma atingiu-se um recalque diferencial máximo de $-1,04 \mathrm{~mm}$, correspondente ao recalque total de $-2,0 \mathrm{~mm}$.

Verifica-se, portanto, que após a fissuração vertical da parede, a armadura da cinta passou a trabalhar, não permitindo a ruptura repentina da parede e mantendo-a estável mesmo sem o apoio de extremidade. Logo, a cinta não retardou o aparecimento da primeira fissura, nem diminuiu sua extensão. Em contrapartida, controlou a sua propagação, limitou sua abertura e evitou o colapso do painel.

Na figura seguinte ilustra-se a evolução da configuração deformada da viga. As leituras para o ponto B foram descartadas por problemas apresentados pelo transdutor.

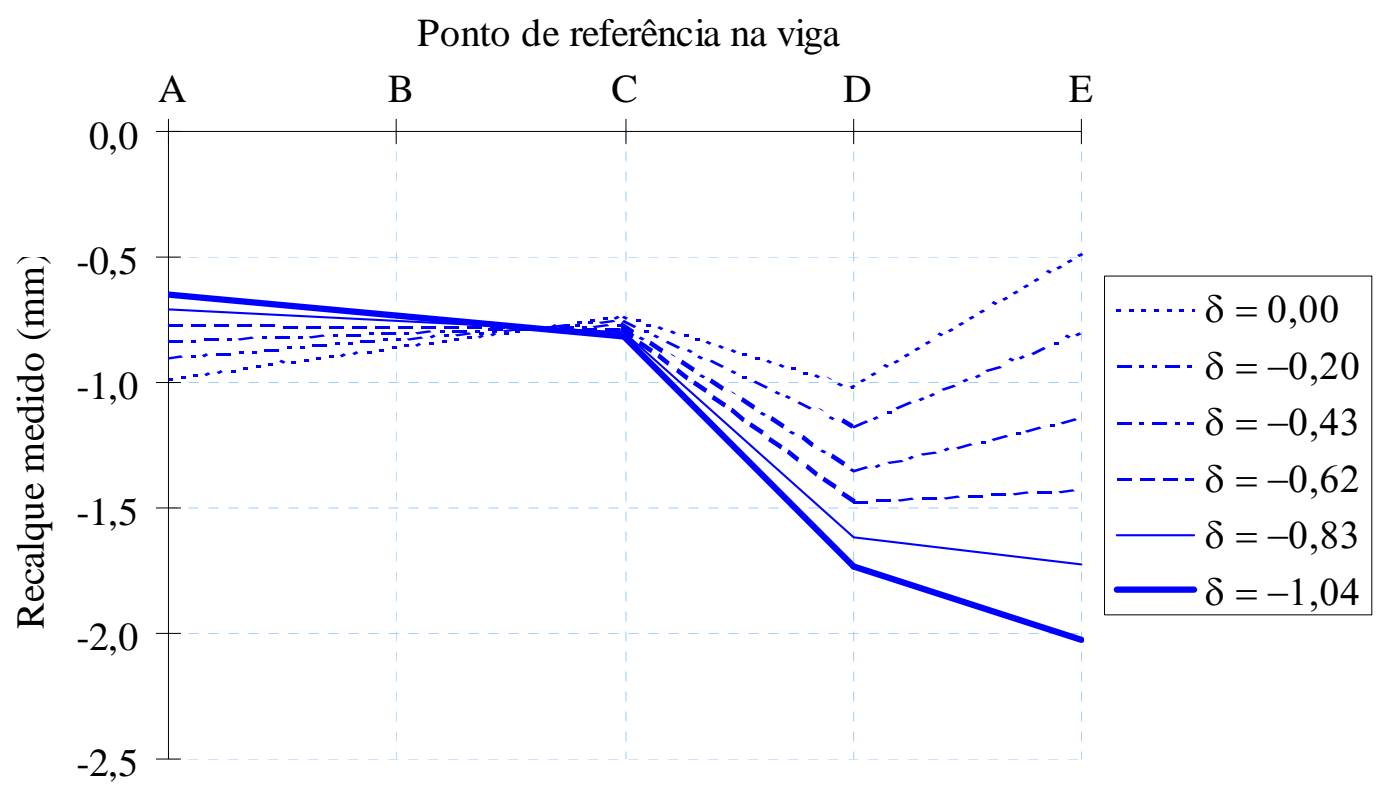

Figura 4.89 Configuração deformada da viga - Modelo 6, Situação 3. ( $\delta$ em mm)

Em seguida apresenta-se a tabela com alguns valores dos parâmetros de recalque, seguida pelas ilustrações do aspecto final da fissuração.

Tabela 4.14 Parâmetros de curvatura - Modelo 6, Situação 3.

\begin{tabular}{c|c|l|c|c|c}
\cline { 1 - 2 } RECALQUE $(\mathrm{mm})$ & \multirow{2}{*}{ OCORRÊNCIA } & $(\Delta / \mathrm{L})_{\mathrm{ACE}}$ & $(\Delta / \mathrm{L})_{\mathrm{CDE}}$ & $(\delta / \ell)_{\mathrm{CD}}$ \\
\hline$-0,3$ & $\mathbf{- 0 , 0 5}$ & Primeira fissura & $1 / 67378$ & $-1 / 2243$ & $1 / 1052$ \\
\hline$-1,2$ & $\mathbf{- 0 , 6 2}$ & $\begin{array}{l}\text { Propagação até } \\
\text { primeira fiada }\end{array}$ & $1 / 5770$ & $-1 / 2420$ & $1 / 658$ \\
\hline$-2,0$ & $\mathbf{- 1 , 0 4}$ & Recalque máximo & $1 / 3469$ & $-1 / 2867$ & $1 / 540$ \\
\hline
\end{tabular}

Nota: Valores negativos de $(\Delta / \mathrm{L})$ indicam concavidade para cima. $(\delta / \ell)$ em valores absolutos. 


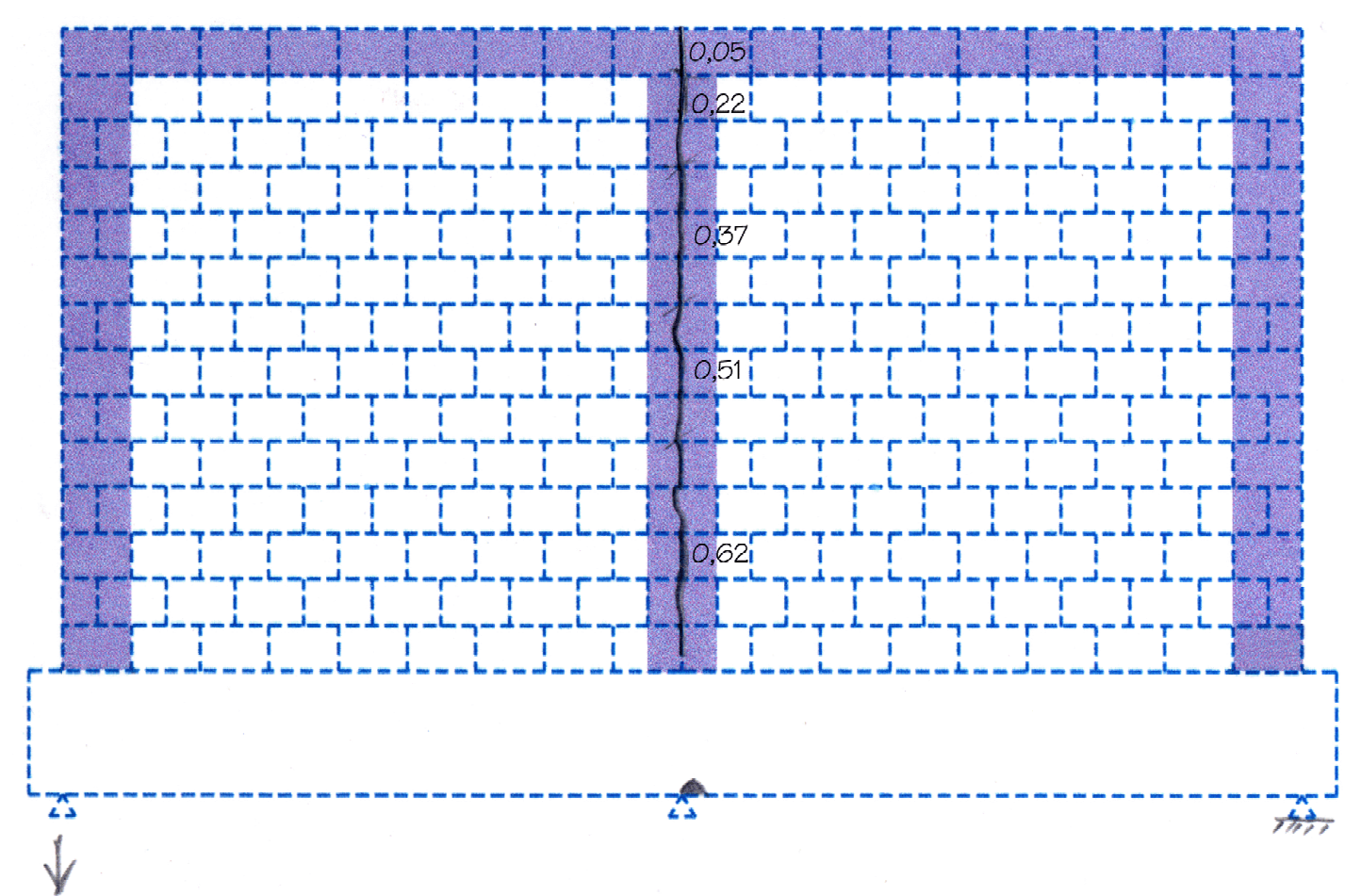

Figura 4.90 Distribuição de fissuras após ensaio - Modelo 6, Situação 3. (Verso do painel)

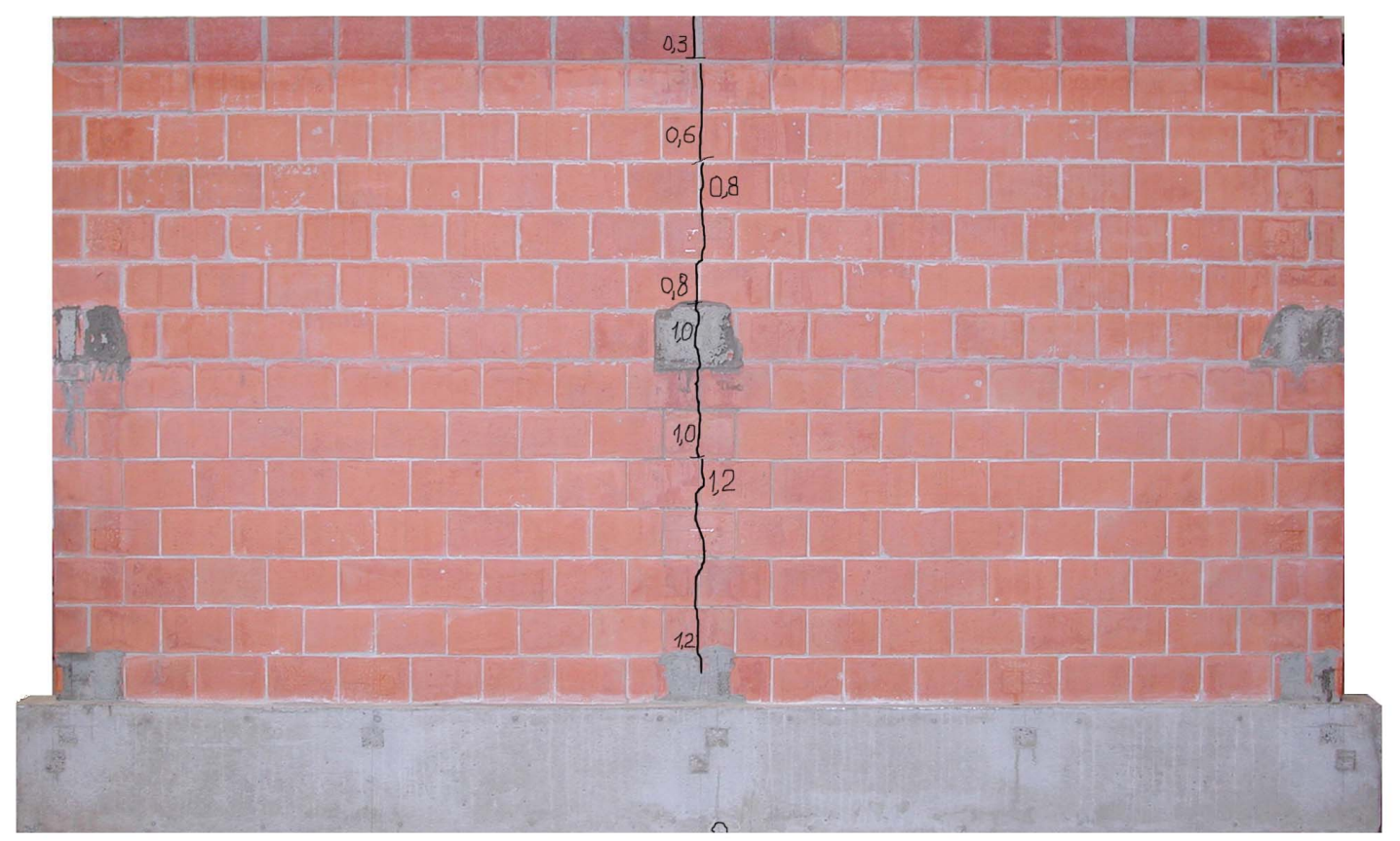

Figura 4.91 Fotografia do painel após ensaio - Modelo 6, Situação 3. (Verso do painel)

Nas figuras seguintes podem ser visualizados os gráficos de reações de apoio e deformação na parede. 


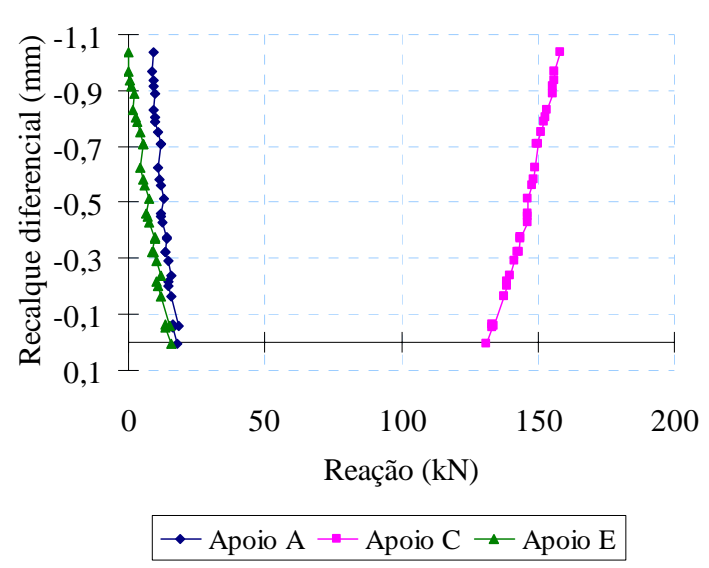

(a)

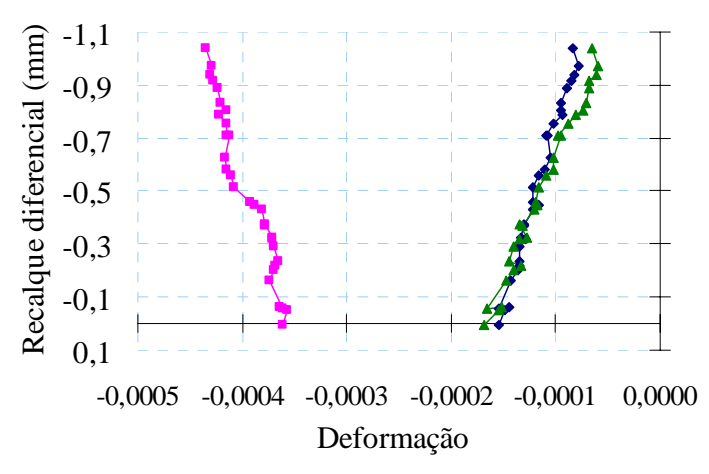

$\rightarrow-$ Transdutores 1-2 $\rightarrow$ - Transdutores 3-4 Transdutores 5-6

(b)

Figura 4.92 (a) Reações de apoio; (b) Deformação na parede - Modelo 6, Situação 3.

No diagrama de distribuição das deformações dos blocos da primeira fiada observa-se o desenvolvimento de tensões de tração nos cantos inferiores da parede, ao contrário do que se observou em todos os ensaios anteriores. Isto indica que o painel permaneceu íntegro, embora fissurado, sem a tendência de se transformar em duas estruturas separadas.

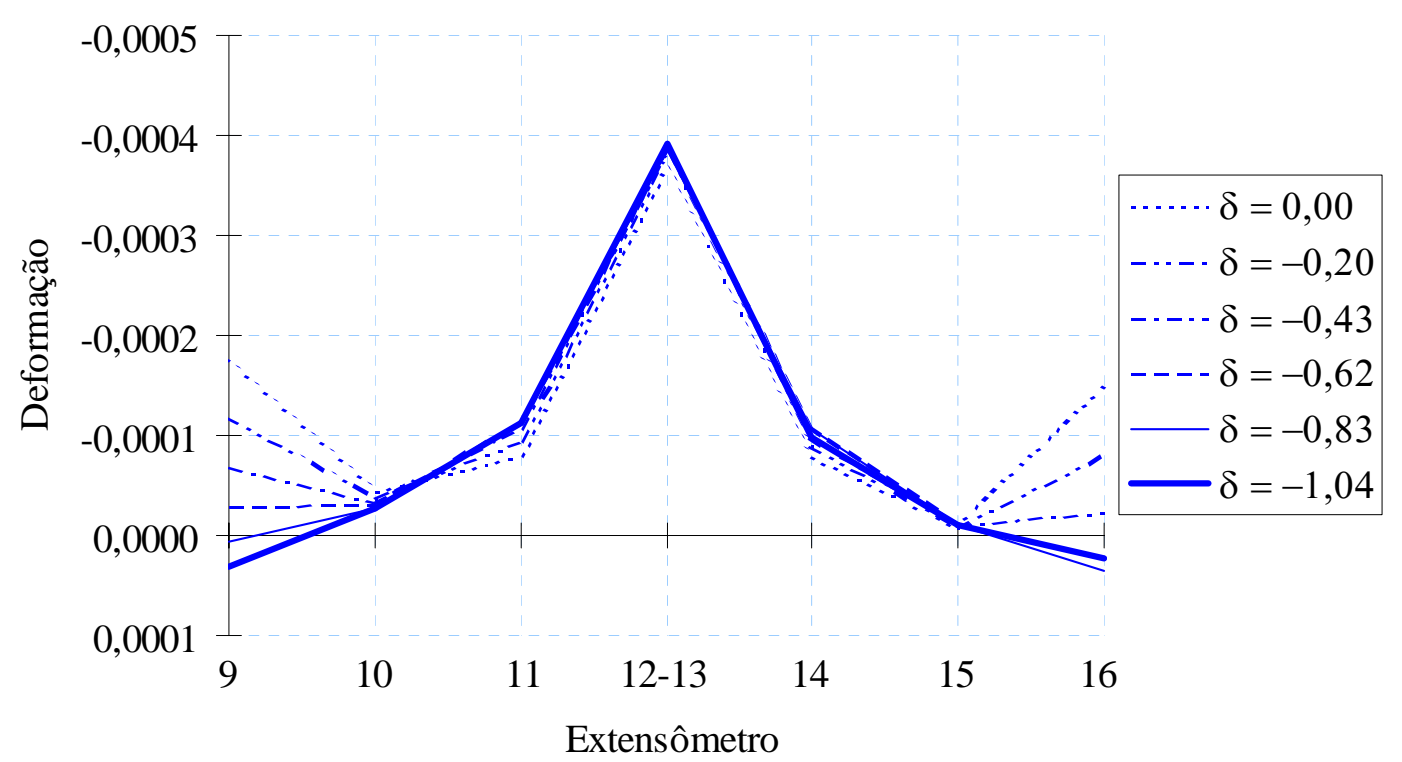

Figura 4.93 Deformações na base da parede - Modelo 6, Situação 3. ( $\delta$ em mm)

\subsection{MODELO 7}

Neste último modelo foram empregadas algumas alternativas simples de combate à fissuração em painéis com aberturas. Objetivou-se verificar a sua eficácia em situações de recalque dos apoios. Adotou-se o uso de contraverga na janela e de cinta como 
fiada adicional, ambas armadas com uma barra de 4,2 $\mathrm{mm}$ de diâmetro. Além disso, foram grauteadas e igualmente armadas as laterais das aberturas, como indicado na Figura 4.94.
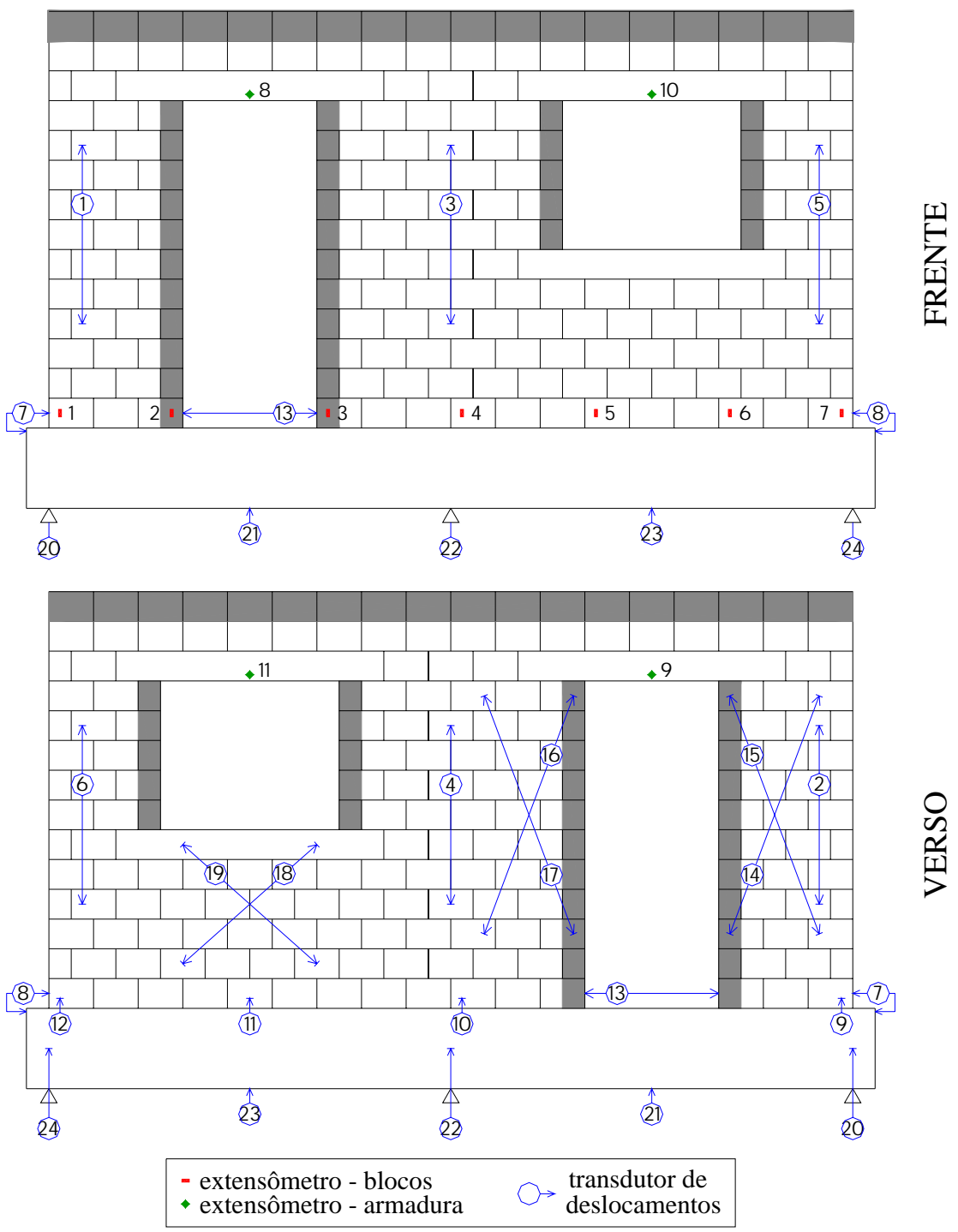

Figura 4.94 Instrumentação do Modelo 7.

Infelizmente, as leituras de toda a instrumentação foram perdidas, porque houve grande queda de tensão ao final do ensaio, prejudicando de forma irreparável o disco rígido do computador de aquisição de dados. Mesmo assim, as informações captadas durante a realização do ensaio, com relação ao comportamento do painel e à fissuração, possibilitaram a obtenção de algumas conclusões importantes.

A discussão dos resultados será feita em função do recalque total, medido durante o ensaio e anotado no próprio painel, ao lado das fissuras. Para os modelos anteriores, utilizou-se o recalque diferencial como parâmetro. 


\subsubsection{Situação 1: Aplicação do carregamento vertical}

Esta etapa foi realizada sem que se observasse qualquer problema. Não houve fissuração nem deformações excessivas.

\subsubsection{Situação 2: Recalque do apoio central}

Este modelo sofreu uma fissuração bastante intensa, com aspecto similar ao do Modelo 4, que, por sua vez, corresponde à sobreposição dos modelos 2 e 3.

As primeiras fissuras foram observadas nas vergas, aos $0,8 \mathrm{~mm}$ de recalque total. A fissuração inicial do painel predominou nessas regiões. Observou-se ao final do ensaio que uma das fissuras acima da porta apresentou abertura equivalente a $0,9 \mathrm{~mm}$.

Ao recalque de $-1,8 \mathrm{~mm}$ surgiu uma fissura horizontal na interface, iniciando no canto externo da porta. Neste local foi verificada a maior abertura de fissura, atingindo 2,5 $\mathrm{mm}$ no final desta etapa.

Abaixo da janela, a ocorrência de fissuras teve início quando o recalque total aproximou-se de $-2,5 \mathrm{~mm}$. No começo surgiu uma fissura horizontal abaixo da contraverga. Posteriormente foram observadas fissuras diagonais escalonadas dirigindo-se para o apoio de extremidade.

Também foram constatadas fissuras horizontais na porção inferior mediana da parede, entre as três primeiras fiadas.

No final do ensaio atingiu-se o valor máximo de $-5,4 \mathrm{~mm}$ para o recalque total do apoio C.

A partir dos modelos 3, 4 e 6, verifica-se que a porção inferior da lateral mais externa da porta constitui uma região muito afetada pelo recalque do apoio central. Nesses locais foram observadas as maiores aberturas de fissuras. Percebe-se no Modelo 6 que o grauteamento da lateral da porta evitou a fissuração ao longo da sua altura, transferindo-a para a interface. A importância do grauteamento nas laterais de janela não pôde ser aferida nesta situação, porque essa região não apresentou problemas em nenhum modelo. Quanto à contraverga, observou-se que ela não contribuiu no combate à fissuração.

Pode-se visualizar o aspecto final da fissuração na fotografia do painel. 


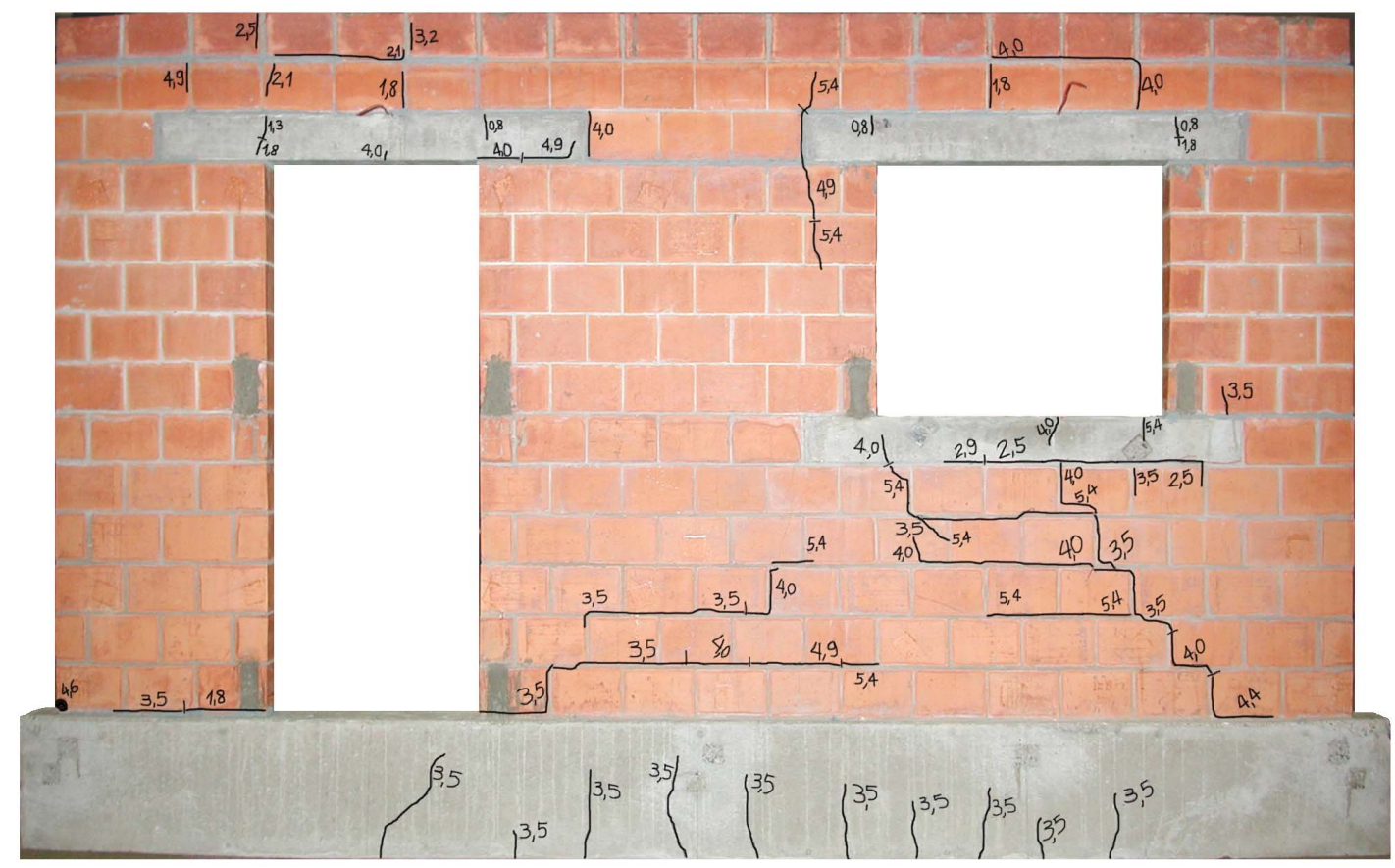

Figura 4.95 Fotografia do painel após ensaio - Modelo 7, Situação 2.

\subsubsection{Situação 3: Recalque do apoio de extremidade}

Também nesta situação o aspecto da fissuração foi muito semelhante aos dos modelos 2, 3 e 4, sendo até mais intensa. Como no Modelo 4, o lado da janela foi o mais danificado.

As fissuras tiveram início abaixo da janela, aos $-0,7 \mathrm{~mm}$ de recalque total do apoio E. Ao longo do ensaio, um conjunto de fissuras diagonais escalonadas se formou, e surgiu uma fissura horizontal abaixo da contraverga.

Próximo à porta, foram constatadas pequenas fissuras na região da verga e uma fissura horizontal partindo do canto inferior mais interno.

$\mathrm{Na}$ borda do painel acima do apoio $\mathrm{E}$, iniciaram várias fissuras horizontais, algumas com a tendência de se encontrar com as de baixo da janela.

Um grande conjunto de fissuras se formou nas proximidades da verga da janela, atingindo suas laterais grauteadas. A fissura divisora do painel uniu essa região ao meio da viga, inicialmente de forma brusca, aos $-2,9 \mathrm{~mm}$ de recalque, com propagação lenta.

A maior abertura de fissura foi percebida à meia-altura da parede na fissura divisora, atingindo $1,4 \mathrm{~mm}$ no final do ensaio.

Após a retirada total do apoio E, quando se atingiu o recalque total máximo de $-5,5 \mathrm{~mm}$, o painel permaneceu estável.

$\mathrm{Na}$ Figura 4.96 visualiza-se o aspecto final do painel. Percebe-se que o grauteamento lateral da janela e a contraverga não foram eficientes no combate à fissuração. 
A cinta, por sua vez, restringiu a abertura de fissuras na última fiada e evitou o colapso do modelo.

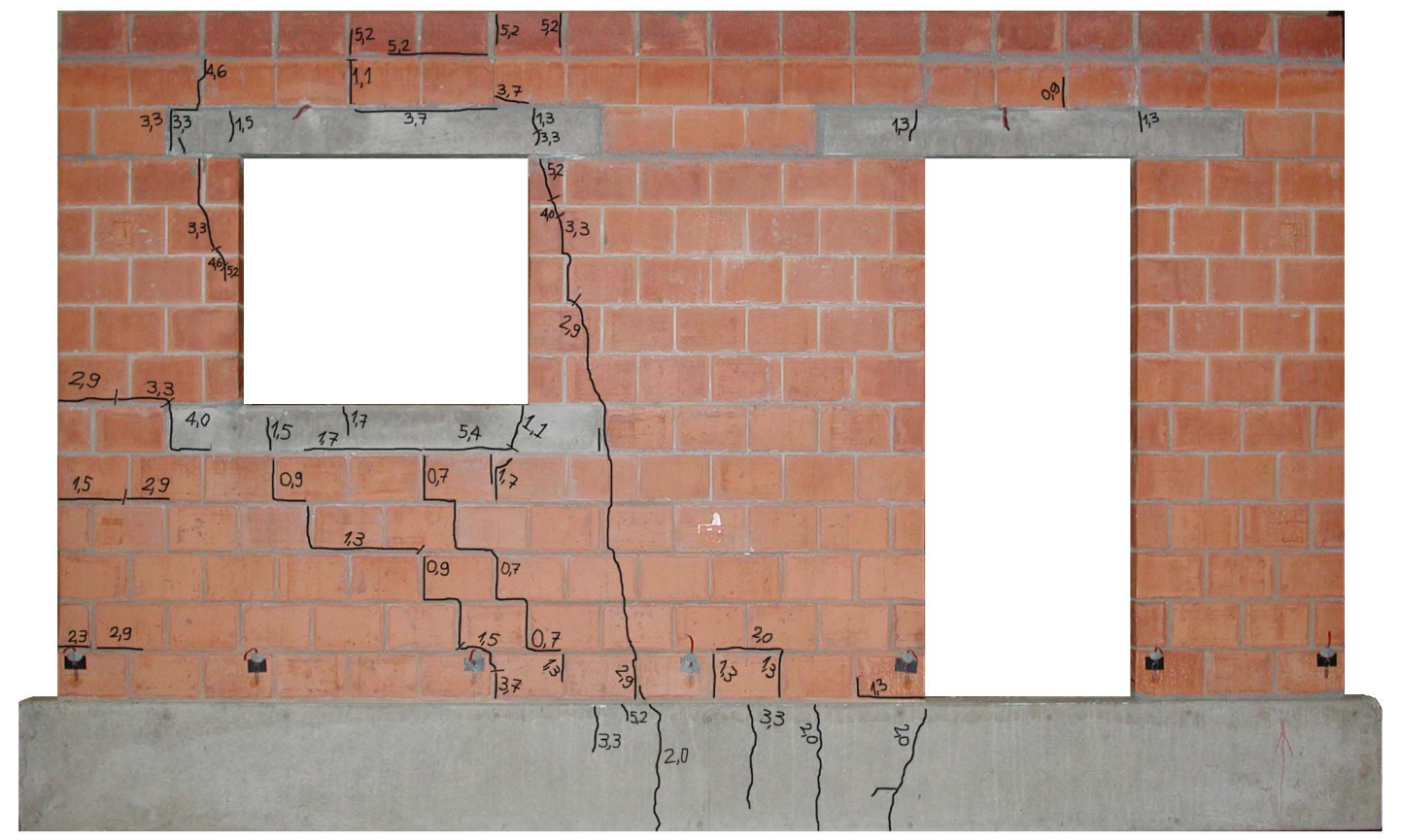

Figura 4.96 Fotografia do painel após ensaio - Modelo 7, Situação 3. (Verso do painel)

\subsection{RESULTADOS DOS CORPOS-DE-PROVA}

Tabela 4.15 Resistência média à compressão $(\mathrm{MPa})$ e coeficiente de variação.

\begin{tabular}{|c|c|c|c|c|c|}
\hline MODELO & PRISMA & ARGAMASSA & $\begin{array}{c}\text { CONCRETO } \\
\text { VIGAS } \\
\end{array}$ & $\begin{array}{c}\text { CONCRETO } \\
\text { VERGAS }\end{array}$ & GRAUTE \\
\hline \multirow{2}{*}{1} & 21,11 & 15,83 & 35,88 & - & - \\
\hline & $14 \%$ & $12 \%$ & $1 \%$ & - & - \\
\hline \multirow{2}{*}{2} & 17,11 & 12,91 & & & - \\
\hline & $8 \%$ & $5 \%$ & & & - \\
\hline \multirow{2}{*}{3} & 16,13 & 11,62 & 29,19 & 63,87 & - \\
\hline & $11 \%$ & $6 \%$ & $4 \%$ & $3 \%$ & - \\
\hline \multirow{2}{*}{4} & 16,78 & 11,77 & & & - \\
\hline & $12 \%$ & $17 \%$ & & & - \\
\hline \multirow{2}{*}{5} & 20,48 & 15,58 & & - & - \\
\hline & $3 \%$ & $8 \%$ & & - & - \\
\hline \multirow{2}{*}{6} & 20,93 & 15,37 & 31,79 & - & 74,29 \\
\hline & $5 \%$ & $13 \%$ & $6 \%$ & - & $17 \%$ \\
\hline \multirow{2}{*}{7} & 19,76 & 15,60 & & 75,50 & 83,40 \\
\hline & $15 \%$ & $7 \%$ & & $5 \%$ & $11 \%$ \\
\hline
\end{tabular}


Tabela 4.16 Resistência média à compressão diametral (MPa) e coeficiente de variação.

\begin{tabular}{|c|c|c|c|c|}
\hline MODELO & ARGAMASSA & CONCRETO VIGAS & CONCRETO VERGAS & GRAUTE \\
\hline \multirow{2}{*}{1} & - & 3,39 & - & - \\
\hline & - & $10 \%$ & - & - \\
\hline \multirow{2}{*}{2} & - & & & - \\
\hline & - & & & - \\
\hline \multirow{2}{*}{3} & - & 2,42 & 3,35 & - \\
\hline & - & $14 \%$ & $12 \%$ & - \\
\hline \multirow{2}{*}{4} & - & & & - \\
\hline & - & & & - \\
\hline \multirow{2}{*}{5} & 1,54 & & - & - \\
\hline & $9 \%$ & & - & - \\
\hline \multirow{2}{*}{6} & - & 2,75 & - & - \\
\hline & - & $5 \%$ & - & - \\
\hline \multirow{2}{*}{7} & - & & 5,46 & 5,25 \\
\hline & - & & $3 \%$ & $14 \%$ \\
\hline
\end{tabular}

Tabela 4.17 Módulo de elasticidade secante médio (MPa) e coeficiente de variação.

\begin{tabular}{|c|c|c|c|}
\hline MODELO & CONCRETO VIGAS & CONCRETO VERGAS & GRAUTE \\
\hline \multirow{2}{*}{1} & 20150 & - & - \\
\hline & $0 \%$ & - & - \\
\hline \multirow{2}{*}{2} & \multirow{6}{*}{$\begin{array}{c}18434 \\
4 \%\end{array}$} & \multirow{6}{*}{$\begin{array}{c}27022 \\
2 \%\end{array}$} & - \\
\hline & & & - \\
\hline \multirow{2}{*}{3} & & & - \\
\hline & & & - \\
\hline \multirow{2}{*}{4} & & & - \\
\hline & & & - \\
\hline \multirow{2}{*}{5} & \multirow{6}{*}{$\begin{array}{c}18300 \\
2 \%\end{array}$} & - & - \\
\hline & & - & - \\
\hline \multirow{2}{*}{6} & & - & 30524 \\
\hline & & - & $6 \%$ \\
\hline \multirow{2}{*}{7} & & 27160 & - \\
\hline & & $1 \%$ & - \\
\hline
\end{tabular}

\subsection{CONSIDERAÇÕES FINAIS}

\subsubsection{Principais dificuldades encontradas}

Na preparação do ensaio piloto deparou-se em princípio com dois problemas: a instabilidade lateral do conjunto de perfis utilizados para distribuir a carga de compressão; e a deslocabilidade dos pistões dos cilindros hidráulicos constituintes dos apoios da viga quando da aplicação da carga de compressão.

Para solucionar o primeiro problema montou-se um sistema para travar lateralmente os perfis de aço, sem impedir os deslocamentos verticais. Na Figura 4.97 podese visualizar o sistema já montado. Entre o travamento e os perfis foram colocadas chapas 
metálicas de pequena espessura, besuntadas com graxa. Esta solução mostrou-se bastante eficiente, sendo adotada nos demais ensaios.
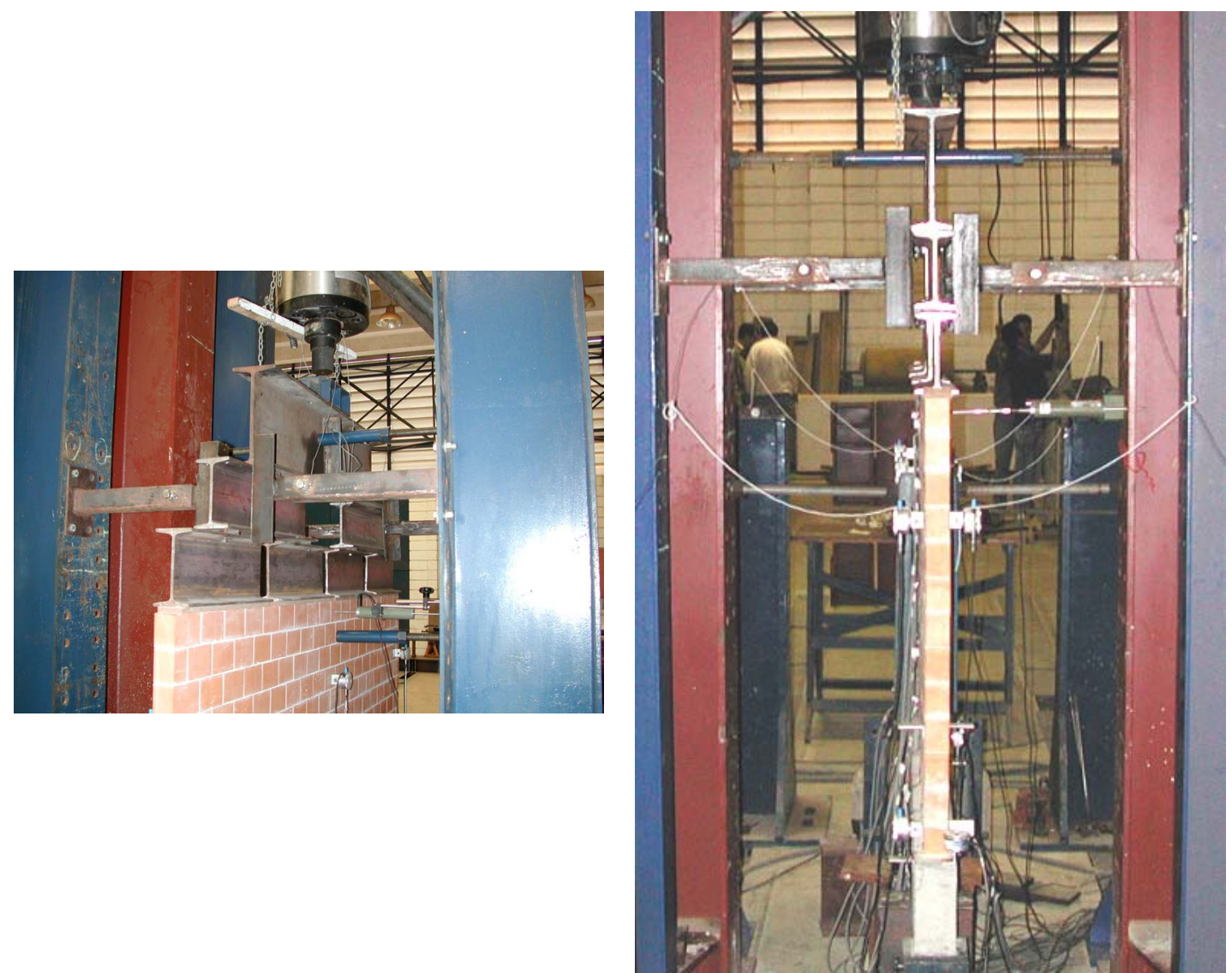

Figura 4.97 Sistema de travamento dos perfis metálicos.

Durante a realização do ensaio do Modelo 1, à medida que a carga vertical era aplicada ao painel, os pistões dos cilindros hidráulicos que constituíam os apoios da viga deslocavam-se para baixo. Essa ocorrência era indesejável, uma vez que já representava o desenvolvimento de recalques ainda na fase de aplicação do carregamento vertical. Optou-se, então, por realizar dois ensaios distintos com o Modelo 1, um para cada configuração de recalque. Desta forma, utilizou-se apenas um cilindro hidráulico e dois apoios fixos em cada ensaio. Assim, como o apoio móvel recalcava com a simples imposição da carga de compressão, esta foi aplicada em etapas de $10 \mathrm{kN}$, para que a posição do apoio fosse constantemente corrigida.

Para os demais ensaios, anéis de aço foram confeccionados para impedir o deslocamento vertical dos pistões. Cada cilindro recebeu um par de anéis, conforme a Figura 4.98. Após a compressão da parede, o anel maior (partido ao meio) era retirado do cilindro central, liberando seu deslocamento. Quando este apoio voltava à posição original, seu anel era recolocado, e retirava-se o anel do outro apoio para que se passasse à outra 
configuração de recalque. $\mathrm{O}$ anel menor se fez necessário para garantir a transferência de esforços da célula de carga para o pistão, de modo que a primeira não fosse danificada.
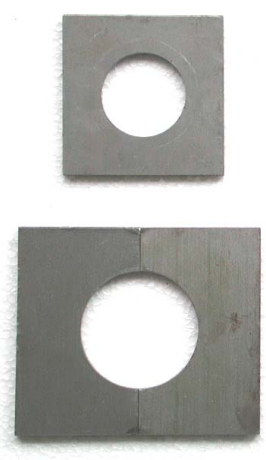

(a)
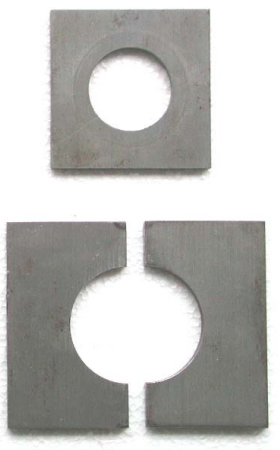

)

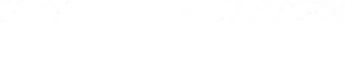

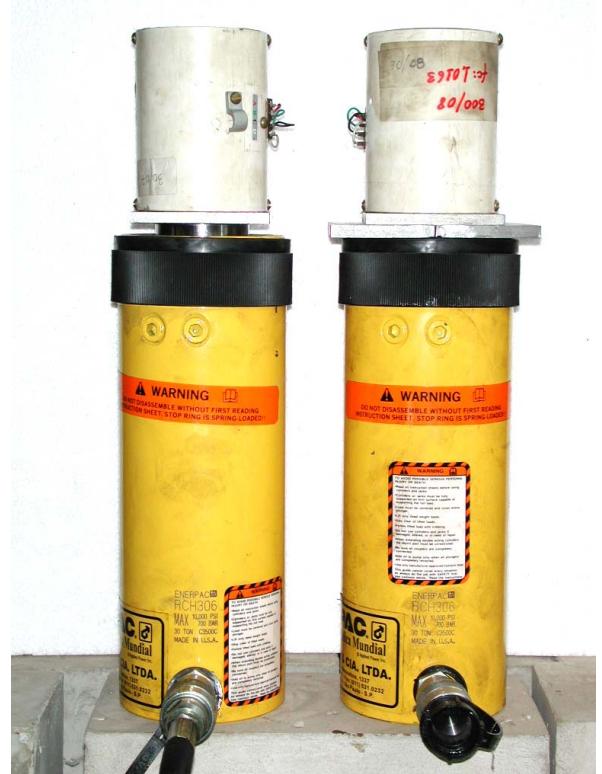

(b)

Figura 4.98 (a) Anéis de travamento. (b) Cilindro com deslocamento liberado (apenas com anel menor) e cilindro travado.

\subsubsection{Flecha máxima da viga}

Observou-se que a viga, dimensionada considerando a presença da parede, suportou muito bem os esforços a que foi submetida. Faz-se agora a verificação da flecha máxima, comparando-a com o valor limite estipulado pela NBR 6118 (2001) no item “13.3 Deslocamentos limites". Neste caso se aplica o limite de $\ell / 500$, em que $\ell$ é o vão livre. Logo:

$$
\text { flecha }_{\lim }=\frac{\ell}{500}=\frac{900}{500}=1,8 \mathrm{~mm} \text {. }
$$

A flecha máxima medida logo após a compressão do Modelo 1 corresponde ao deslocamento do ponto $\mathrm{B}$, reduzido da média dos deslocamentos dos apoios A e C:

$$
\text { flecha }_{\exp }=0,891-\frac{0,743+0,727}{2}=0,156 \mathrm{~mm} \text {. }
$$

Esta última é a flecha imediata, à qual deve ser acrescida uma parcela de flecha diferida, para considerar o efeito das cargas de longa duração em função da fluência. Fazendo-se o cálculo aproximado segundo o item 17.3.1.1.2 da NBR 6118 (2001), considerando que a carga de longa duração foi aplicada estando o concreto com 1 mês de idade, tem-se:

$$
\text { flecha }=\left(1+\alpha_{f}\right) \text { flecha }_{\exp }=(1+0,83) \cdot 0,156=0,285 \mathrm{~mm},
$$


que é um valor muito inferior ao limite máximo.

\subsubsection{Comprimento de contato}

Considerando o Modelo 1, ao final da etapa de recalque do apoio central, tem-se uma situação de parede sobre viga biapoiada submetida a um carregamento uniformemente distribuído no topo. Neste caso são aplicáveis os coeficientes de rigidez relativa parede-viga, definidos no item 2.3, calculados a seguir:

$$
\begin{aligned}
& \mathrm{K}=\sqrt[4]{\frac{\mathrm{E}_{\mathrm{p}} \mathrm{t}_{\mathrm{p}} \mathrm{L}^{3}}{\mathrm{E}_{\mathrm{v}} \mathrm{I}_{\mathrm{v}}}}=\sqrt[4]{\frac{648 \cdot 4,65 \cdot 180^{3}}{1830 \cdot 9607}}=5,62 \\
& \mathrm{R}=\sqrt[4]{\frac{\mathrm{E}_{\mathrm{p}} \mathrm{t}_{\mathrm{p}} \mathrm{H}^{3}}{\mathrm{E}_{\mathrm{v}} \mathrm{I}_{\mathrm{v}}}}=\sqrt[4]{\frac{648 \cdot 4,65 \cdot(86,7)^{3}}{1830 \cdot 9607}}=3,25
\end{aligned}
$$

Utilizaram-se as unidades $\mathrm{kN}$ e $\mathrm{cm}$ para todas as variáveis. Estimou-se $\mathrm{I}_{\mathrm{v}}$ como o momento de inércia da seção homogeneizada da viga.

Dessa forma, pode-se calcular o comprimento de contato, tomando-se para a constante B o valor unitário, já que se procura um valor mais próximo da realidade, sem coeficientes de segurança.

$$
\ell=\frac{\mathrm{BL}}{\mathrm{K}}=\frac{1 \cdot 180}{5,62}=32 \mathrm{~cm}
$$

De fato, pelo gráfico da Figura 4.9 observa-se que o contato entre parede e viga foi perdido no trecho entre os extensômetros 21 e 22, do lado esquerdo do painel, e no trecho entre os extensômetros 24 e 25, do outro lado. Os extensômetros 22 e 25 foram posicionados a distâncias aproximadas de $30 \mathrm{~cm}$ das extremidades mais próximas da parede. Portanto, verifica-se que $32 \mathrm{~cm}$ constituem uma boa aproximação para o comprimento de contato.

Assim sendo, verificando no gráfico que as tensões verticais se concentram nas extremidades e que a $30 \mathrm{~cm}$ de distância são bastante próximas de zero, e, ainda, considerando que a $32 \mathrm{~cm}$ se anulam, é muito improvável que sua distribuição seja linear. De fato, segundo HENDRY et al. (1981), se o coeficiente de rigidez relativa $\mathrm{R}$ for menor ou igual a 5, a distribuição dessas tensões segue aproximadamente uma parábola cúbica. Tal aspecto mostra-se realmente bastante coerente com os resultados disponíveis para este modelo.

\subsubsection{Diferença de rigidez entre apoios}

Pela diferença entre as peças constituintes de cada apoio dos painéis, produziuse uma condição indesejada: coeficientes de mola diferentes. Os cilindros hidráulicos travados com anéis mostraram-se mais rígidos que o conjunto de peças utilizado como apoio fixo. Como consequiência, nos ensaios a partir do Modelo 2, o apoio A recalcou um pouco 
mais que o apoio E nas duas primeiras situações de carregamento. Todavia, a influência desse fato nos resultados pôde ser desprezada, sem prejuízo nas análises.

\subsubsection{Aspecto provável da fissuração em função do apoio deslocado}

Pelos ensaios realizados, é possível estabelecer a configuração provável das fissuras, de acordo com o apoio que sofreu recalque. Deve-se ressaltar, entretanto, que foram ensaiados painéis construídos com blocos cerâmicos muito resistentes, em que a fragilidade maior está na aderência bloco-argamassa.

Quando não há aberturas, a curvatura da viga mostrou-se determinante. Painéis com dimensões semelhantes às dos modelos ensaiados provavelmente exibiriam fissuração similar à ilustrada na figura seguinte, em caso de serem submetidos a recalques dos apoios.
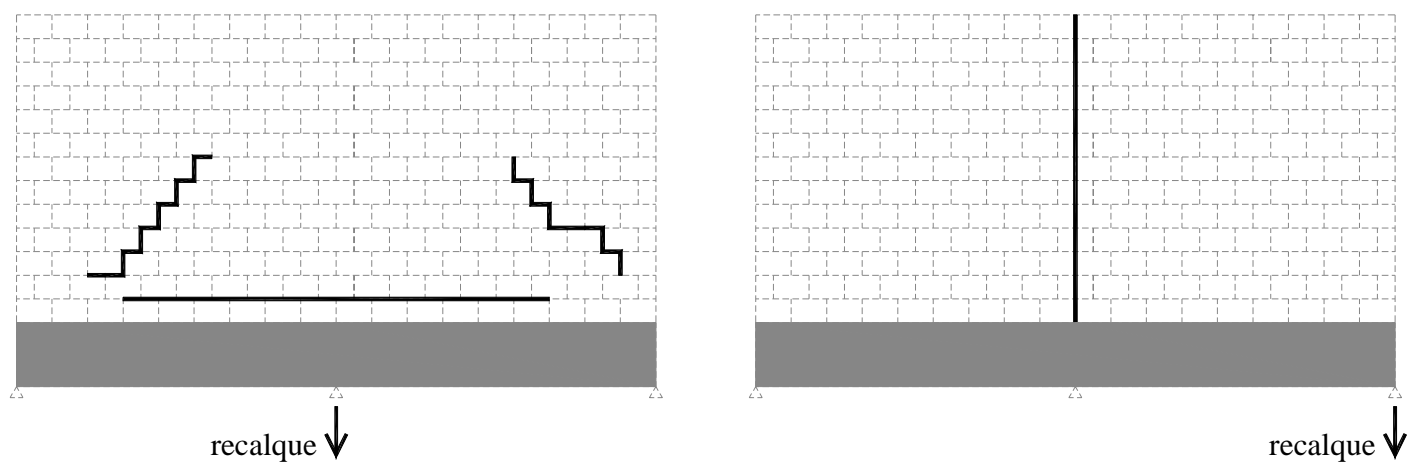

Figura 4.99 Aspecto provável da fissuração de painéis sem abertura.

No caso de painéis com aberturas, as fissuras provocadas por recalque provavelmente teriam os aspectos apresentados na Figura 4.100. Observou-se que essas distribuições são válidas tanto para recalque de apoio central quanto de extremidade. Devese considerar que todos os modelos ensaiados possuíam a mesma relação de vão entre apoios pelas dimensões da abertura. 

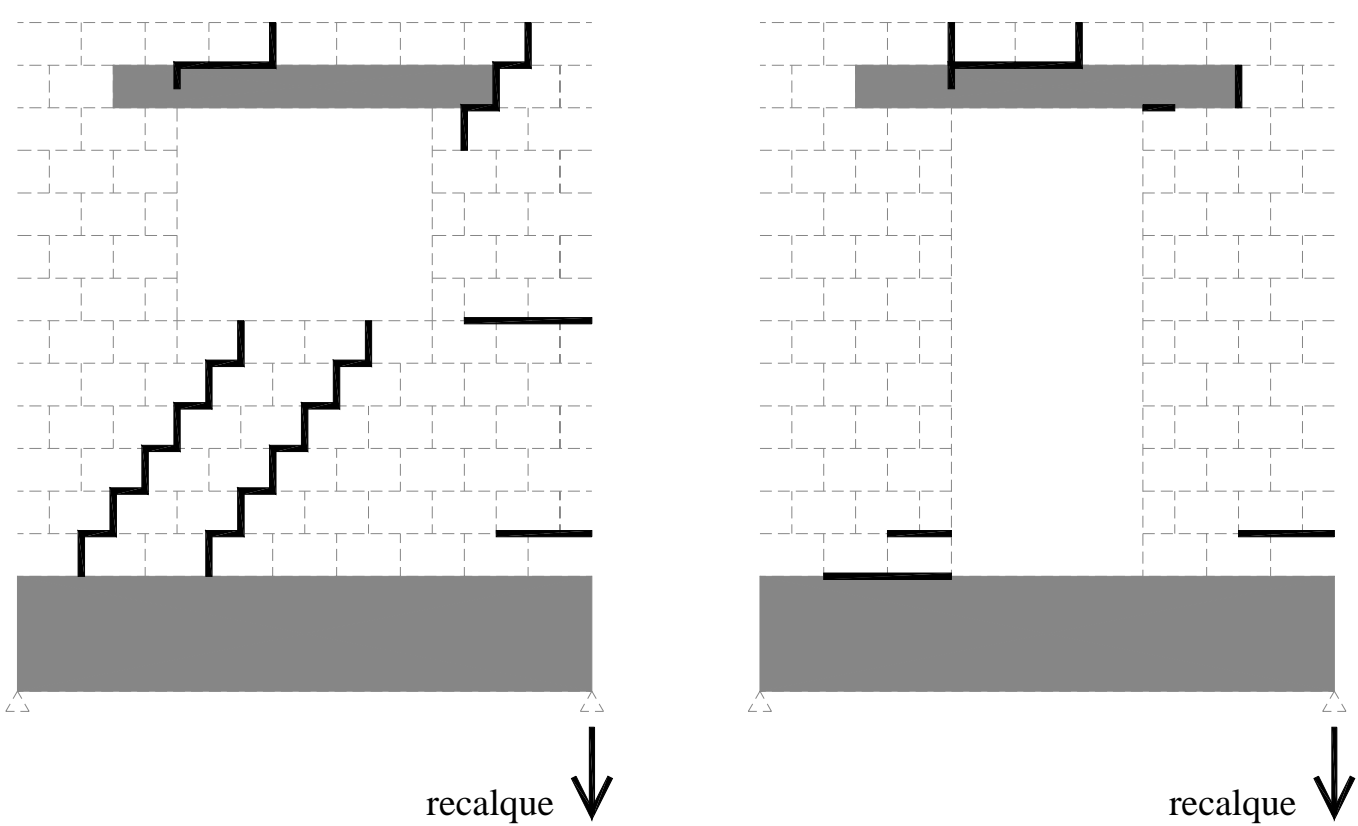

Figura 4.100 Aspecto provável da fissuração em porções de parede contendo aberturas. 


\section{ANÁLISE NUMÉRICA}

Os resultados experimentais dos ensaios de caracterização e dos painéis foram utilizados em novas análises numéricas, aplicadas a cada um dos modelos experimentais. Neste capítulo apresentam-se a modelagem adotada, com os valores de todos os parâmetros necessários, as propriedades físicas dos materiais, obtidas em laboratório, e os procedimentos de realização das análises.

Os principais objetivos desta etapa da pesquisa podem ser resumidos da seguinte forma:

- Verificar a validade do modelo numérico proposto nas análises preliminares;

- Avaliar a importância da consideração da não-linearidade de contato por meio dos elementos de contato disponíveis.

Todas as análises numéricas foram realizadas por meio do programa computacional ANSYS, baseado no Método dos Elementos Finitos.

\subsection{PROPRIEDADES DOS MATERIAIS}

Os valores numéricos das propriedades físicas dos materiais equivalem a médias dos resultados dos ensaios de caracterização. Eles estão organizados na tabela seguinte, já nas unidades $\mathrm{kN} \mathrm{e} \mathrm{cm,} \mathrm{que} \mathrm{foram} \mathrm{empregadas} \mathrm{nas} \mathrm{análises.}$ 
Tabela 5.1 Propriedades dos materiais.

\begin{tabular}{|c|c|}
\hline PARÂMETRO & VALOR \\
\hline \multicolumn{2}{|l|}{ ALVENARIA* } \\
\hline Módulo de elasticidade longitudinal $\left(\mathrm{E}_{\mathrm{alv}}\right)$ & $648 \mathrm{kN} / \mathrm{cm}^{2}$ \\
\hline Coeficiente de Poisson $\left(v_{\text {alv }}\right)$ & 0,10 \\
\hline Módulo de elasticidade transversal $\left(\mathrm{G}_{\mathrm{alv}}\right)$ & $188 \mathrm{kN} / \mathrm{cm}^{2}$ \\
\hline \multicolumn{2}{|l|}{ CONTATO } \\
\hline Coeficiente de atrito $(\mu)$ & 0,75 \\
\hline \multicolumn{2}{|l|}{ CONCRETO (vigas) } \\
\hline Módulo de elasticidade longitudinal ( $\left.\mathrm{E}_{\mathrm{c}-\mathrm{vi}}\right)$ & $1862 \mathrm{kN} / \mathrm{cm}^{2}$ \\
\hline Coeficiente de Poisson $\left(v_{c}\right)$ & $0,2 * *$ \\
\hline \multicolumn{2}{|l|}{ CONCRETO (vergas e contraverga) } \\
\hline Módulo de elasticidade longitudinal ( $\left.\mathrm{E}_{\mathrm{c}-\mathrm{ve}}\right)$ & $2706 \mathrm{kN} / \mathrm{cm}^{2}$ \\
\hline Coeficiente de Poisson $\left(v_{c}\right)$ & $0,2 * *$ \\
\hline \multicolumn{2}{|l|}{ GRAUTE } \\
\hline Módulo de elasticidade longitudinal $\left(\mathrm{E}_{\mathrm{g}}\right)$ & $3052 \mathrm{kN} / \mathrm{cm}^{2}$ \\
\hline Coeficiente de Poisson $\left(v_{\mathrm{g}}\right)$ & $0,2 * *$ \\
\hline \multicolumn{2}{|l|}{ ALVENARIA GRAUTEADA* } \\
\hline Módulo de elasticidade longitudinal ( $\left.\mathrm{E}_{\mathrm{alv}-\mathrm{g}}\right)$ & $2021 \mathrm{kN} / \mathrm{cm}^{2}$ \\
\hline Coeficiente de Poisson $\left(v_{\mathrm{g}}\right)$ & $0,2 * *$ \\
\hline
\end{tabular}

No caso da alvenaria grauteada, presente nos modelos 6 e 7, calculou-se o módulo de elasticidade longitudinal $\left(\mathrm{E}_{\mathrm{alv}-\mathrm{g}}\right)$ como a média ponderada com relação à área entre os valores referentes à alvenaria e ao graute. Como a área de vazios de um bloco (preenchida pelo graute) corresponde a $45 \%$ da sua área bruta e $E_{\text {alv }}$ já está em função da área bruta, tem-se:

$$
\mathrm{E}_{\mathrm{alv}-\mathrm{g}}=\mathrm{E}_{\mathrm{alv}}+0,45 \mathrm{E}_{\mathrm{g}}=2021 \mathrm{kN} / \mathrm{cm}^{2} .
$$

\subsection{MODELO NUMÉRICO}

Utilizou-se basicamente a mesma modelagem proposta anteriormente no Capítulo 3. A diferença reside na forma de discretização das vigas: optou-se pela substituição dos elementos de barra por elementos planos, melhorando a representação, já que as dimensões da viga foram previamente definidas e são significativas em relação à parede. Para as paredes foi adotada a macro-modelagem bidimensional. Assumiu-se estado plano de tensão com a consideração das espessuras. Os materiais foram considerados isotrópicos, elásticos e lineares.

Para a discretização das paredes e das vigas empregou-se um elemento finito plano quadrilateral, com quatro nós e dois graus de liberdade por nó. Este elemento é denominado no ANSYS como PLANE42. 
A não-linearidade de contato foi implementada com o uso do par mais adequado dentre os elementos de contato disponíveis. Assim, foram empregados os elementos de contato de superfície para representações planas CONTA171 e TARGE169. Quando usados em conjunto com PLANE42, tais elementos são lineares, possuindo dois nós e dois graus de liberdade por nó (translações nas direções $x$ e $y$ ). Eles devem ser conectados aos elementos planos, coincidindo com um de seus lados. O eixo local $x$ (longitudinal) de cada elemento CONTA171 deve ter orientação contrária à do eixo local $x$ do seu par TARGE169. O programa reconhece pares de elementos de contato quando a eles se atribui o mesmo tipo de material. Além de deslocamentos nodais, os elementos de contato fornecem outros resultados interessantes, como penetrações, separações e deslizamentos na superfície de contato.

\subsubsection{Coeficiente de rigidez normal (FKN)}

A intensidade da penetração ou separação entre as duas superfícies depende de um coeficiente de rigidez normal, denominado FKN. O ANSYS faz uma estimativa para a rigidez normal baseada nas características do material deformável ao qual o elemento de contato está ligado. Nos dados de entrada é necessário fornecer um valor para FKN, dentro do intervalo entre 0,001 e 100. Valores maiores de rigidez normal diminuem a penetração, mas podem acarretar dificuldades de convergência, e vice-versa. Segundo ANSYS RELEASE 5.5.1 (1998), o valor ideal para o coeficiente de rigidez normal é aquele que produz pequenas penetrações sem ocasionar problemas de convergência.

Portanto, uma das primeiras providências a serem tomadas ao se iniciar uma análise numérica com estes elementos de contato deve ser a calibração do parâmetro FKN. Neste trabalho este procedimento foi realizado com o objetivo de se atingir numericamente valores de penetração próximos aos obtidos nos ensaios. Ajustou-se o parâmetro por tentativas até que se determinou $\mathbf{F K N}=\mathbf{0 , 1 8}$ como valor adequado para todos os painéis.

Deve-se observar que este valor não pode ser utilizado como padrão para quaisquer análises de parede sobre viga, pois vários fatores o influenciam. Por exemplo, as dimensões dos elementos finitos (PLANE42, neste caso) aos quais os elementos de contato estão conectados são utilizadas no cálculo da rigidez normal, tornando o modelo de contato sensível à malha. Por isso, o fator FKN deve ser calibrado para cada análise a ser realizada. E uma vez definido, não se deve mais mudar a malha, sob pena de ser necessário calibrá-lo novamente.

Caso não existam dados experimentais, um bom procedimento para a calibração de FKN, aplicável à junta entre parede e viga, é o que foi adotado por BARBOSA (2000). Estipula-se um valor máximo de penetração, coerente com valores prováveis na realidade, e calibra-se FKN de forma a obter tais valores como resultados nas análises numéricas. Nestes 
ensaios em escala reduzida 1:3, foram verificadas penetrações da ordem de $0,1 \mathrm{~mm}$ nas extremidades do painel após a aplicação da carga vertical. Provavelmente seria atingido um valor em torno de $0,3 \mathrm{~mm}$ nas extremidades de um painel em escala real.

\subsubsection{Critério de ruptura ao cisalhamento na junta parede-viga}

O cisalhamento na junta é regido por uma lei do tipo Coulomb, cujos parâmetros são apenas $\mu$ e $\tau_{\text {máx }}$, de acordo com o gráfico da Figura 5.1. $\mu$ corresponde ao coeficiente de atrito e $\tau_{\operatorname{máx}}$, tensão máxima de cisalhamento, deve ser utilizada quando a pressão de contato se torna muito alta, como em casos de processos de formação de metais (ANSYS RELEASE 5.5.1, 1998). Neste caso de parede sobre viga, como as tensões desenvolvidas não atingem níveis dessa magnitude, aceitou-se o valor default deste parâmetro, definido como um valor muito alto $\left(10^{20}\right)$. Em outras palavras, no critério de cisalhamento adotado não se aplicou o limite superior dado por $\tau_{\text {máx }}$.

Nas análises numéricas preliminares do Capítulo 3, utilizou-se este parâmetro erroneamente como se fosse $\tau_{0}$. Entretanto, verifica-se pela Figura 5.1 que a propriedade representada por $\tau_{0}$ não é contemplada no modelo de contato utilizado, uma vez que o gráfico, por definição, inicia-se na origem dos eixos cartesianos.

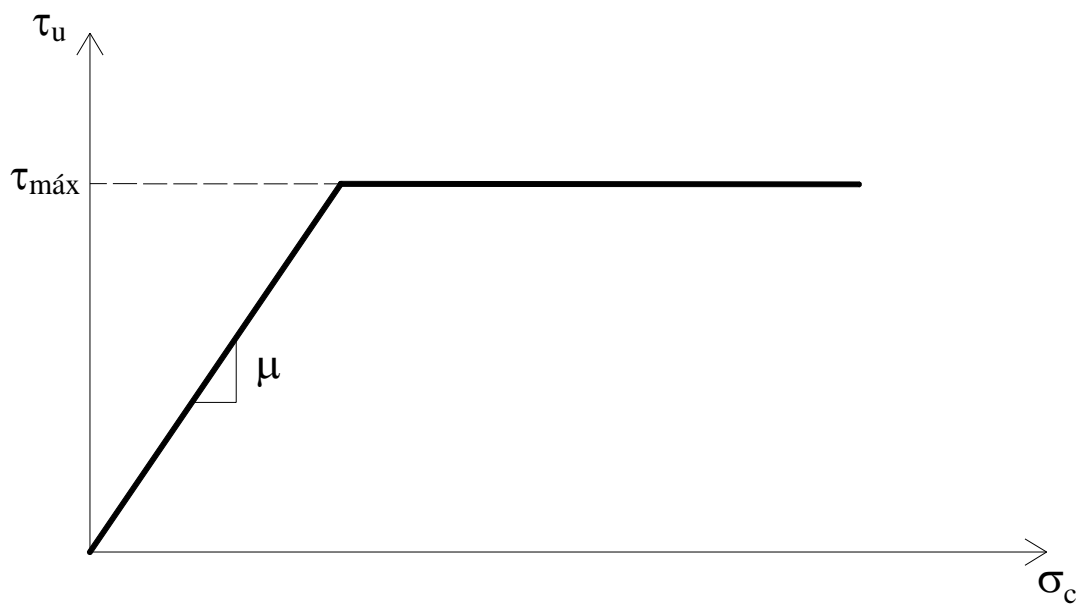

Figura 5.1 Modelo de atrito no contato do ANSYS.

Percebe-se, portanto, que o critério de ruptura mais adequado, apresentado na Figura 2.6, não pode ser fielmente respeitado. Entretanto, é possível conseguir uma aproximação adotando-se o mesmo coeficiente de atrito inicial. A validade desta aproximação é verificada a partir dos resultados numéricos.

No gráfico seguinte apresenta-se a curva adotada como critério de ruptura ao cisalhamento das juntas nas análises numéricas realizadas. Sua forma pode ser comparada às retas desenhadas a partir dos valores experimentais. 


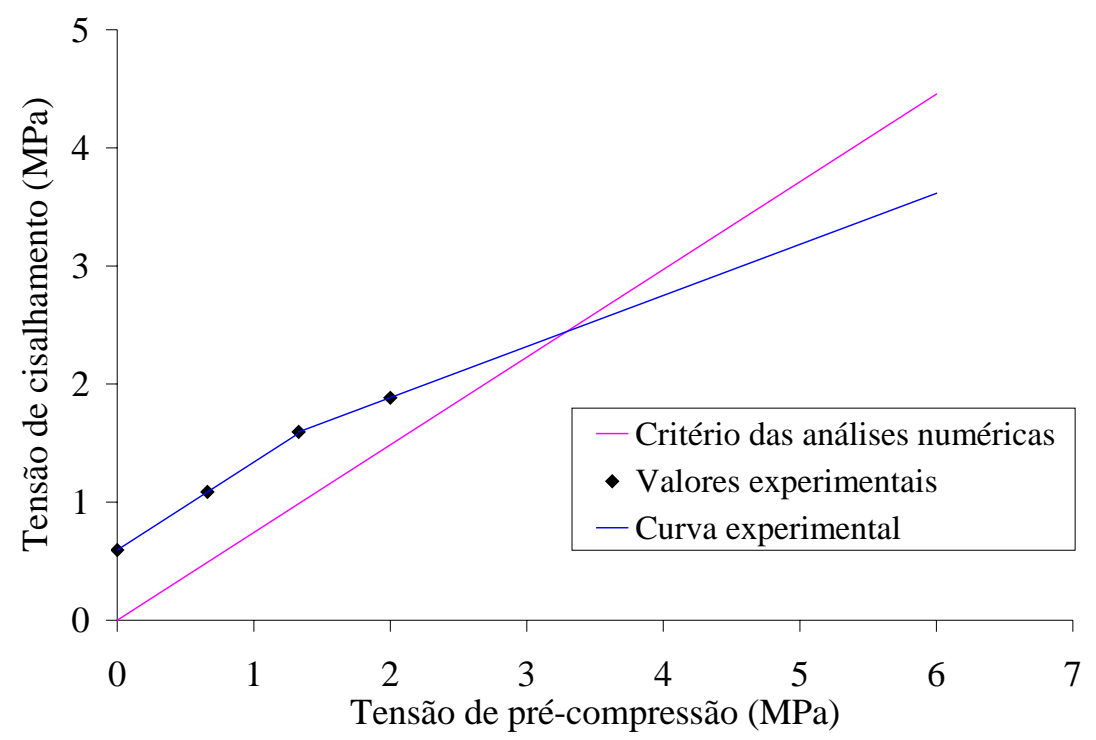

Figura 5.2 Critério adotado nas análises $\times$ valores experimentais.

\subsubsection{Características geométricas}

Foram respeitadas as mesmas dimensões apresentadas no item 3.2.2, correspondentes às medidas ideais em escala 1:3. A ilustração da Figura 5.3 reúne todas as medidas possíveis para todos os modelos. Para a parede adotou-se a espessura média dos blocos: 4,65 cm. A espessura da viga foi definida como $8 \mathrm{~cm}$.
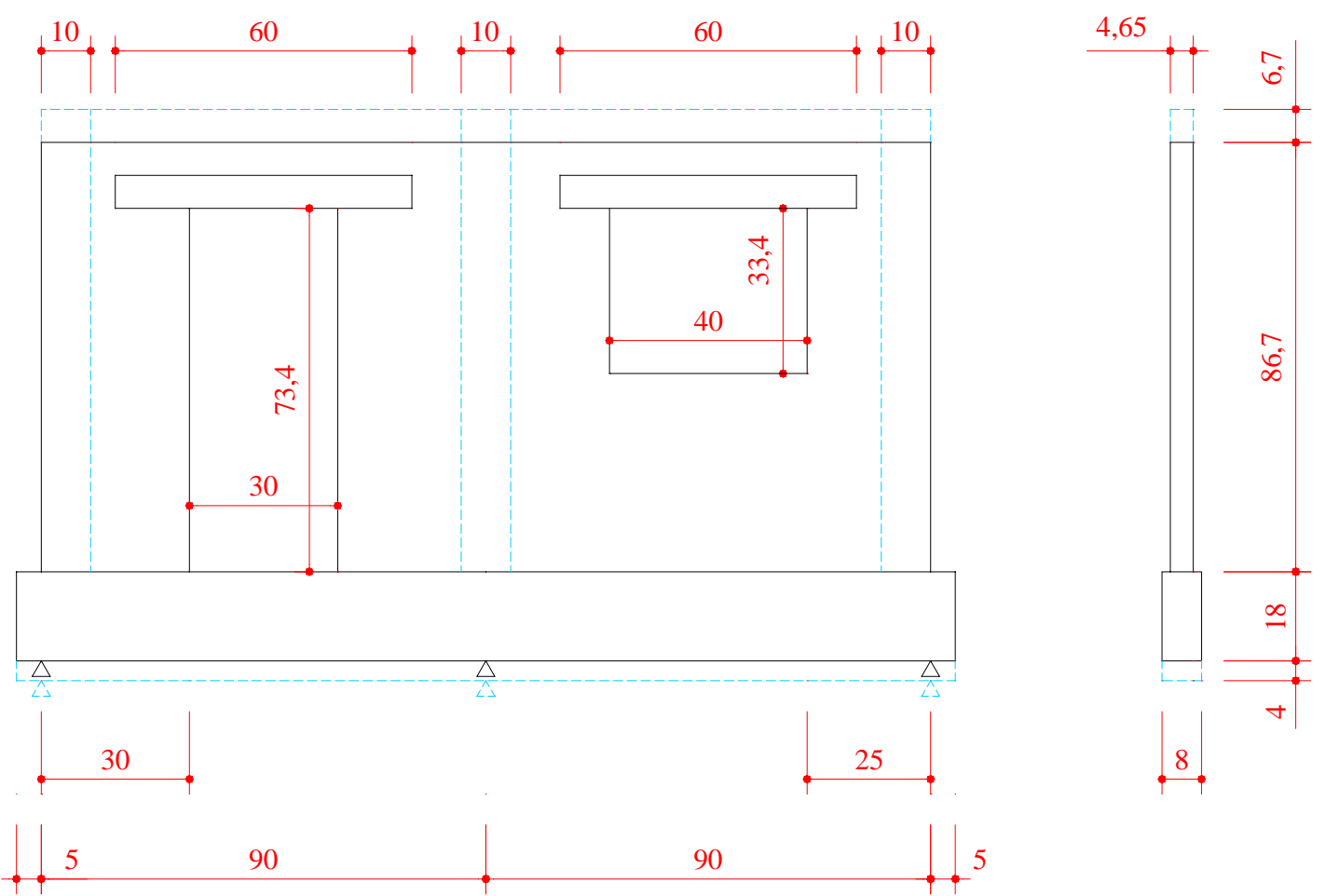

Figura 5.3 Características geométricas dos modelos numéricos $(\mathrm{cm})$. 
Apresenta-se na figura seguinte a discretização utilizada em cada modelo. Todos os elementos planos da parede possuem $2,5 \mathrm{~cm}$ de largura e $1 / 2$ fiada de altura. Os elementos planos da viga também possuem $2,5 \mathrm{~cm}$ de largura e altura equivalente a 1/6 da altura da viga. Os elementos de contato, quando presentes, são conectados à linha de base da parede e à de topo da viga. Cada um é sobreposto a um dos lados dos elementos planos e, portanto, possui $2,5 \mathrm{~cm}$ de comprimento. Na modelagem sem elementos de contato, os nós da base da parede coincidem com os do topo da viga.

Modelo 1

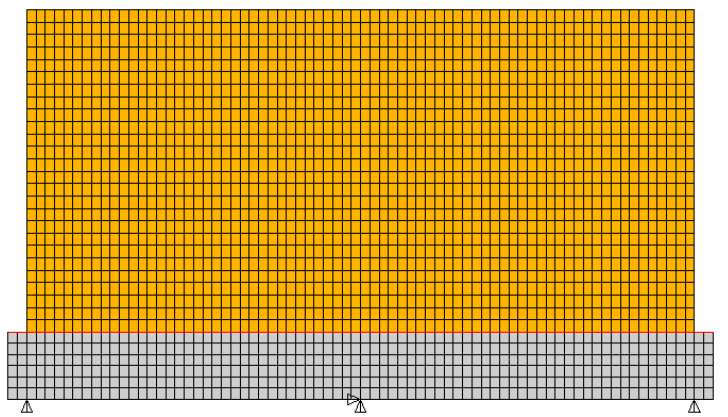

Modelo 3

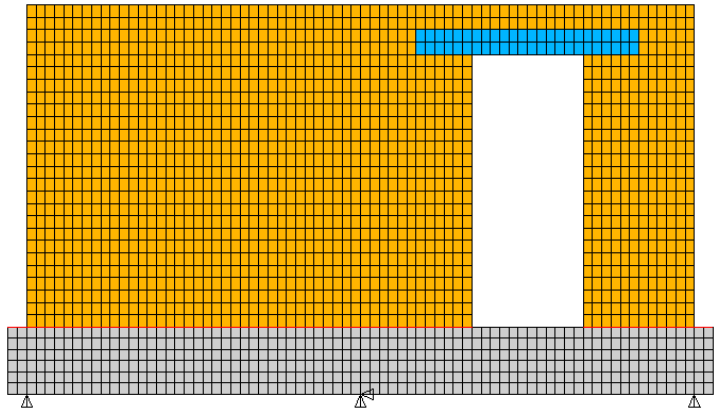

Modelo 5

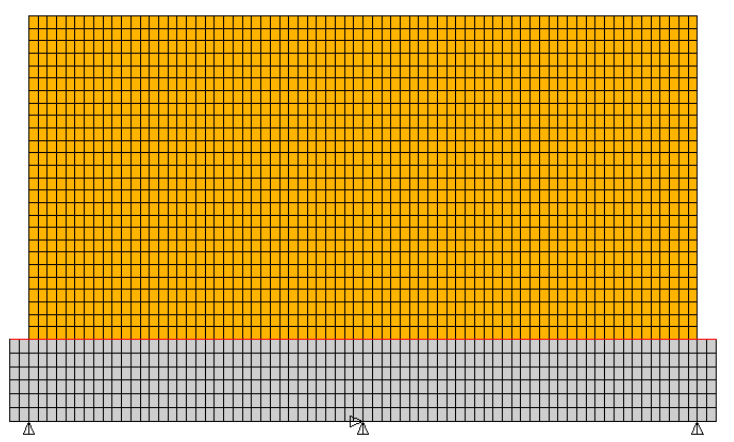

Modelo 2

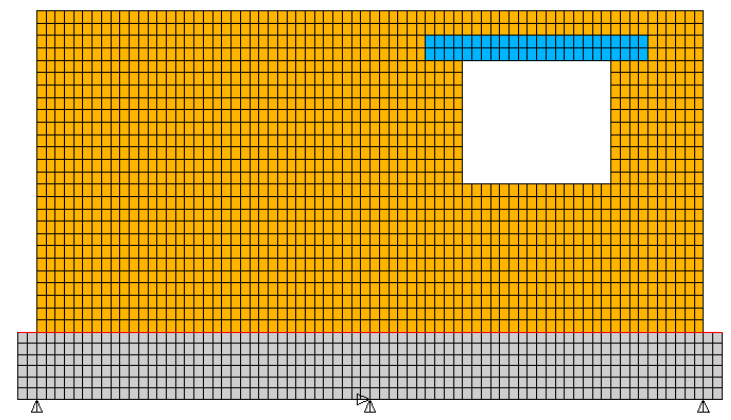

Modelo 4

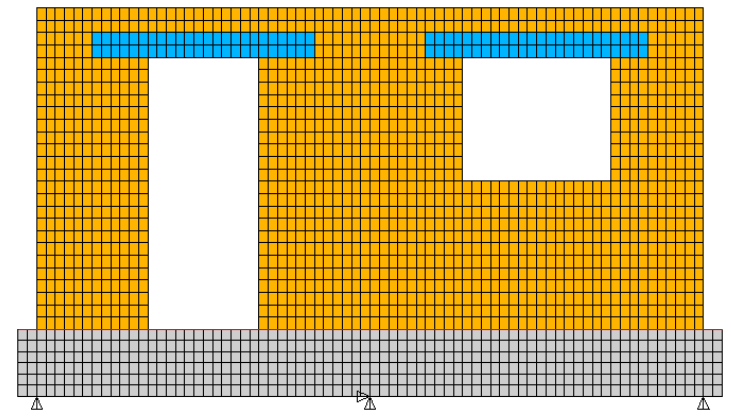

Modelo 6

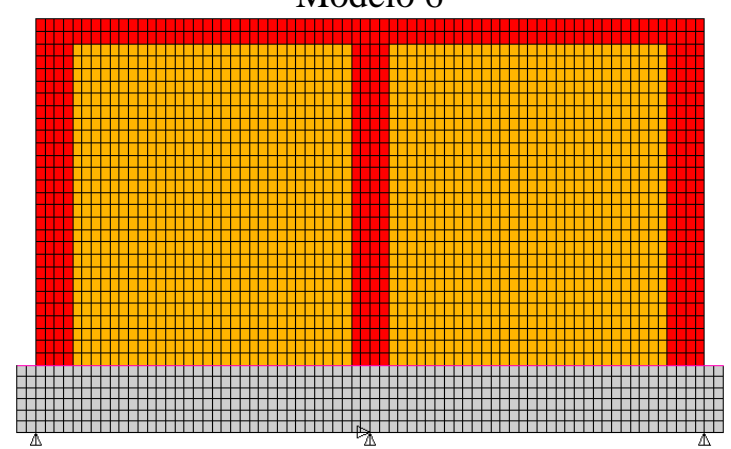

Figura 5.4 Discretização dos modelos.

\subsubsection{Carregamentos}

Foram aplicados quatro carregamentos consecutivos em cada análise, de forma a melhor representar as etapas dos ensaios. O procedimento é descrito na Tabela 5.2. Respeitaram-se os valores máximos de força total aplicada nos ensaios. Além disso, nas análises numéricas as deformações verticais dos apoios, observadas nos ensaios, também 
constituíram um tipo de carregamento. Todos os carregamentos foram aplicados gradualmente, em 20 passos de carga de mesma amplitude.

Tabela 5.2 Carregamentos aplicados nas análises numéricas.

\begin{tabular}{cl}
\hline CARREGAMENTO & DESCRIÇÃO \\
\hline 1 & Aplicação da carga total \\
\hline 2 & $\begin{array}{l}\text { Manutenção da carga total } \\
\text { Recalque do apoio C, até anular sua reação }\end{array}$ \\
\hline 3 & $\begin{array}{l}\text { Manutenção da carga total } \\
\text { Retorno do apoio C à posição original }\end{array}$ \\
\hline 4 & $\begin{array}{l}\text { Manutenção da carga total } \\
\text { Recalque do apoio E, até anular sua reação }\end{array}$
\end{tabular}

\subsection{ANÁLISE COMPARATIVA ENTRE OS RESULTADOS NUMÉRICOS E EXPERIMENTAIS}

Nesta seção os resultados numéricos são confrontados com aqueles obtidos em laboratório. Avalia-se a validade das modelagens adotadas, observando, em especial, qual a mais adequada: com ou sem elementos de contato. Para facilitar a comunicação, deste ponto em diante serão utilizadas as seguintes abreviaturas para os dois tipos de modelagem:

- MSC - Modelagem Sem elementos de Contato

- MCC - Modelagem Com elementos de Contato.

Para cada tipo de resultado, as análises comparativas dos modelos 1 a 6 foram agrupadas, conforme os itens adiante.

\subsubsection{Recalques máximos}

$\mathrm{Na}$ Tabela 5.3 são comparados os valores de recalque total máximo experimental com os resultados numéricos. Nesta avaliação são usados os valores de recalque da Situação 2: Recalque do apoio central. Os recalques máximos da Situação 3 não podem ser considerados nesta comparação porque, no laboratório, as condições de contorno dos painéis foram alteradas ao ocorrer a divisão da parede e este fato não foi reproduzido nas análises numéricas. Além disso, algumas vezes a última leitura de recalque em laboratório foi feita numa condição instável do painel.

Tabela 5.3 Comparação entre recalques totais máximos (mm).

\begin{tabular}{c|c|c|c|c|c}
\hline \multirow{2}{*}{ MODELO } & EXPERIMENTAL & \multicolumn{2}{|c|}{ MSC } & \multicolumn{2}{c}{ MCC } \\
\cline { 2 - 6 } & Recalque máximo & Rec. máx. & Diferença* & Rec. máx. & Diferença* \\
\hline 1 & $\mathbf{- 3 , 2}$ & $-2,78$ & $-12 \%$ & $-3,40$ & $8 \%$ \\
2 & $\mathbf{- 3 , 0}$ & $-2,12$ & $-30 \%$ & $-2,55$ & $-16 \%$ \\
3 & $\mathbf{4 , 2}$ & $-2,65$ & $-38 \%$ & $-3,81$ & $-10 \%$ \\
4 & $\mathbf{- , 6}$ & $-2,84$ & $-38 \%$ & $-3,70$ & $-19 \%$ \\
5 & $\mathbf{- 2 , 2}$ & $-1,79$ & $-18 \%$ & $-2,17$ & $-1 \%$ \\
6 & $\mathbf{2 , 2}$ & $-1,88$ & $-16 \%$ & $-2,15$ & $-4 \%$ \\
\hline
\end{tabular}

(*) Com relação ao valor experimental 
Verifica-se que a MCC conseguiu prever com boa aproximação os recalques totais máximos de todos os painéis. Com a MSC obtiveram-se valores menores, porém aceitáveis para os modelos sem aberturas.

Já em relação ao recalque diferencial máximo, cujos valores se encontram na Tabela 5.4, os resultados da MSC ficaram distantes dos reais. A MCC ainda conseguiu boas aproximações para quatro painéis, dentre os quais se encontram todos aqueles sem abertura. Portanto, no que se refere a recalques máximos, a MCC obteve melhor desempenho que a MSC.

Tabela 5.4 Comparação entre recalques diferenciais máximos (mm).

\begin{tabular}{c|c|c|c|c|c}
\hline \multirow{2}{*}{ MODELO } & EXPERIMENTAL & \multicolumn{2}{|c|}{ MSC } & \multicolumn{2}{c}{ MCC } \\
\cline { 2 - 6 } & Recalque máximo & Rec. máx. & Diferença* & Rec. máx. & Diferença* \\
\hline 1 & $\mathbf{- 1 , 6}$ & $-1,20$ & $-24 \%$ & $-1,82$ & $15 \%$ \\
2 & $\mathbf{- 2 , 0}$ & $-1,10$ & $-45 \%$ & $-1,53$ & $-24 \%$ \\
3 & $\mathbf{- 3 , 3}$ & $-1,74$ & $-48 \%$ & $-2,90$ & $-13 \%$ \\
4 & $\mathbf{- 3 , 2}$ & $-1,47$ & $-54 \%$ & $-2,33$ & $-28 \%$ \\
5 & $\mathbf{- 1 , 5}$ & $-1,07$ & $-27 \%$ & $-1,45$ & $-2 \%$ \\
6 & $\mathbf{- 1 , 2}$ & $-0,85$ & $-30 \%$ & $-1,12$ & $-7 \%$ \\
\hline
\end{tabular}

(*) Com relação ao valor experimental

Em geral, as previsões numéricas ficaram abaixo do valor real. Observou-se também que os modelos numéricos dos painéis com aberturas se mostraram aparentemente mais rígidos que os modelos físicos.

Pode-se afirmar que, se os recalques diferenciais máximos foram reproduzidos com boa aproximação pela MCC, as curvaturas das vigas também seriam. Curvaturas são grandezas adimensionais e, como tal, apresentam os mesmos valores em escalas reais e reduzidas, quando o modelo reduzido representa perfeitamente o protótipo. Desta forma, acredita-se que a MCC pode ser utilizada para uma avaliação prévia dos recalques máximos que podem ocorrer em painéis reais sem aberturas, que se mantenham íntegros após sofrerem esses deslocamentos.

\subsubsection{Reações de apoio}

$\mathrm{Na}$ etapa de aplicação do carregamento vertical dos painéis, pode-se considerar que as reações de apoio aumentaram linearmente em todos os modelos. Este comportamento foi reproduzido por ambas as modelagens, cujos resultados numéricos também ficaram muito próximos dos experimentais. Na Figura 5.5 encontram-se os gráficos dos seis modelos, em que estão reunidos os valores numéricos e experimentais. 

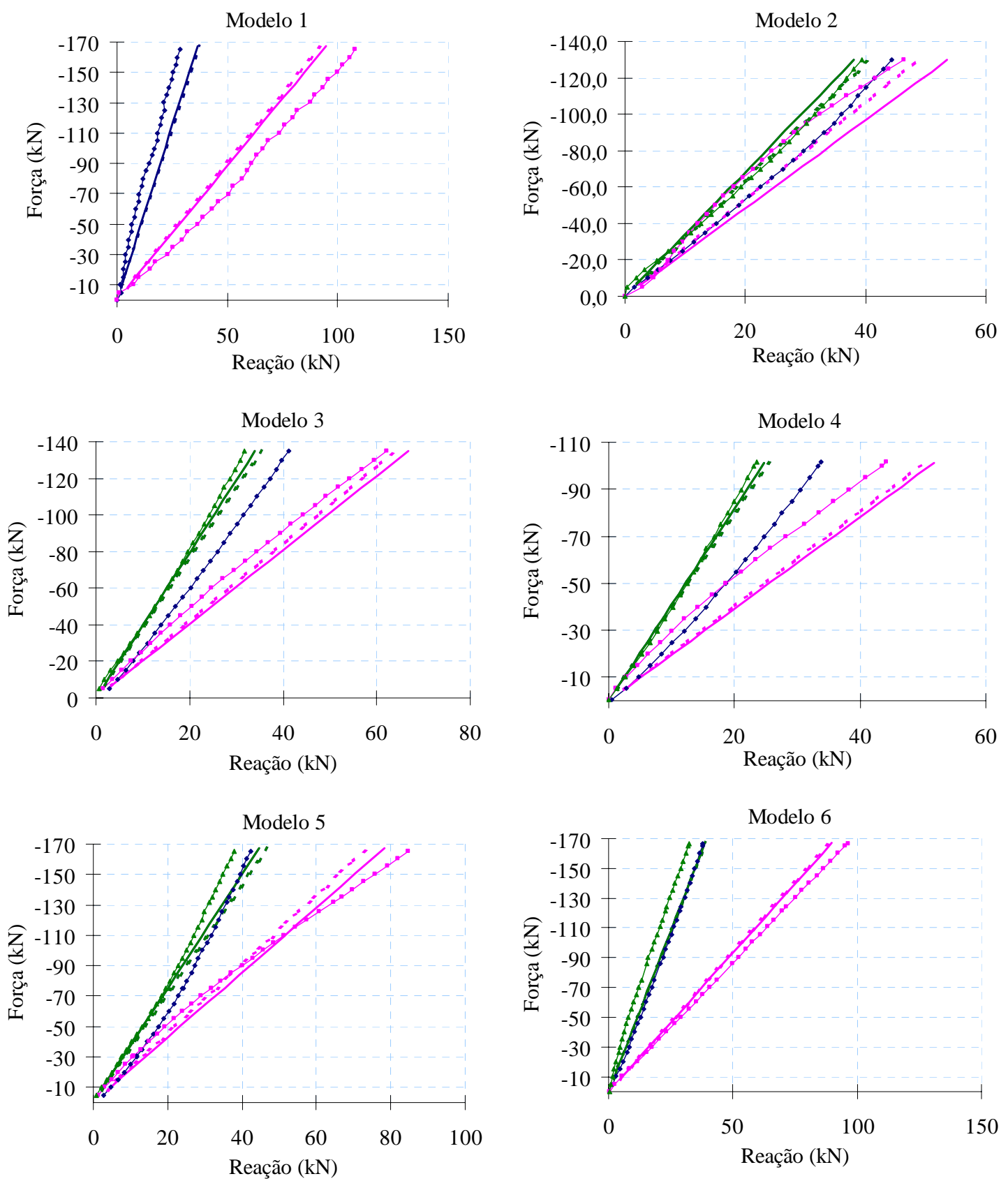

$$
\begin{array}{rrr}
\longrightarrow \text { Apoio A - EXP } & - \text { Apoio C - EXP } & \longrightarrow \text { Apoio E - EXP } \\
-- \text { Apoio A - MSC } & -- \text { Apoio C - MSC } & -- \text { Apoio E - MSC } \\
\text { Apoio A - MCC } & \text { Apoio C - MCC }
\end{array}
$$

Figura 5.5 Reações de apoio experimentais e numéricas - Situação 1.

Na Situação 2, quando o apoio central é deslocado, observa-se uma curva nãolinear das reações em função do recalque diferencial, principalmente após a fissuração inicial dos painéis. Este comportamento foi captado pela MCC. Neste caso a MSC, por ser linear, pôde conseguir uma boa aproximação apenas para o trecho inicial da curva. Os gráficos se encontram na Figura 5.6. 
Com relação ao Modelo 1, verifica-se grande similaridade entre as curvas experimentais e da MCC. A diferença de inclinação deve ser atribuída a variações nas propriedades da alvenaria. $\mathrm{O}$ aspecto diferente das curvas dos modelos 2,3 e 4 foi consequiência de falhas na correção da carga total durante os ensaios. Nesses casos, as reações dos apoios de extremidade foram mais influenciadas. Entretanto, acredita-se que as curvas apresentariam forma semelhante às dos demais modelos. Mesmo assim, observa-se grande proximidade entre os resultados experimentais e da MCC para o apoio C.

Os ensaios dos modelos 5 e 6 foram realizados com o melhor controle de execução. Exatamente com relação a eles foram conseguidas as maiores aproximações entre os resultados experimentais e numéricos. Percebe-se que a curva da MCC acompanha de perto as curvas experimentais, atingindo o final com valores muito próximos.

Considera-se, então, que a MCC reproduziu com bastante aproximação a evolução das reações de apoio durante o recalque do apoio central.

Na Situação 3, as curvas experimentais e numéricas das reações de apoio em função do recalque diferencial do apoio E em geral possuem inclinação semelhante. Porém os valores diferem muito entre si, provavelmente pela falta de consideração da nãolinearidade física dos materiais, que já acumularam fissuras na etapa anterior. 

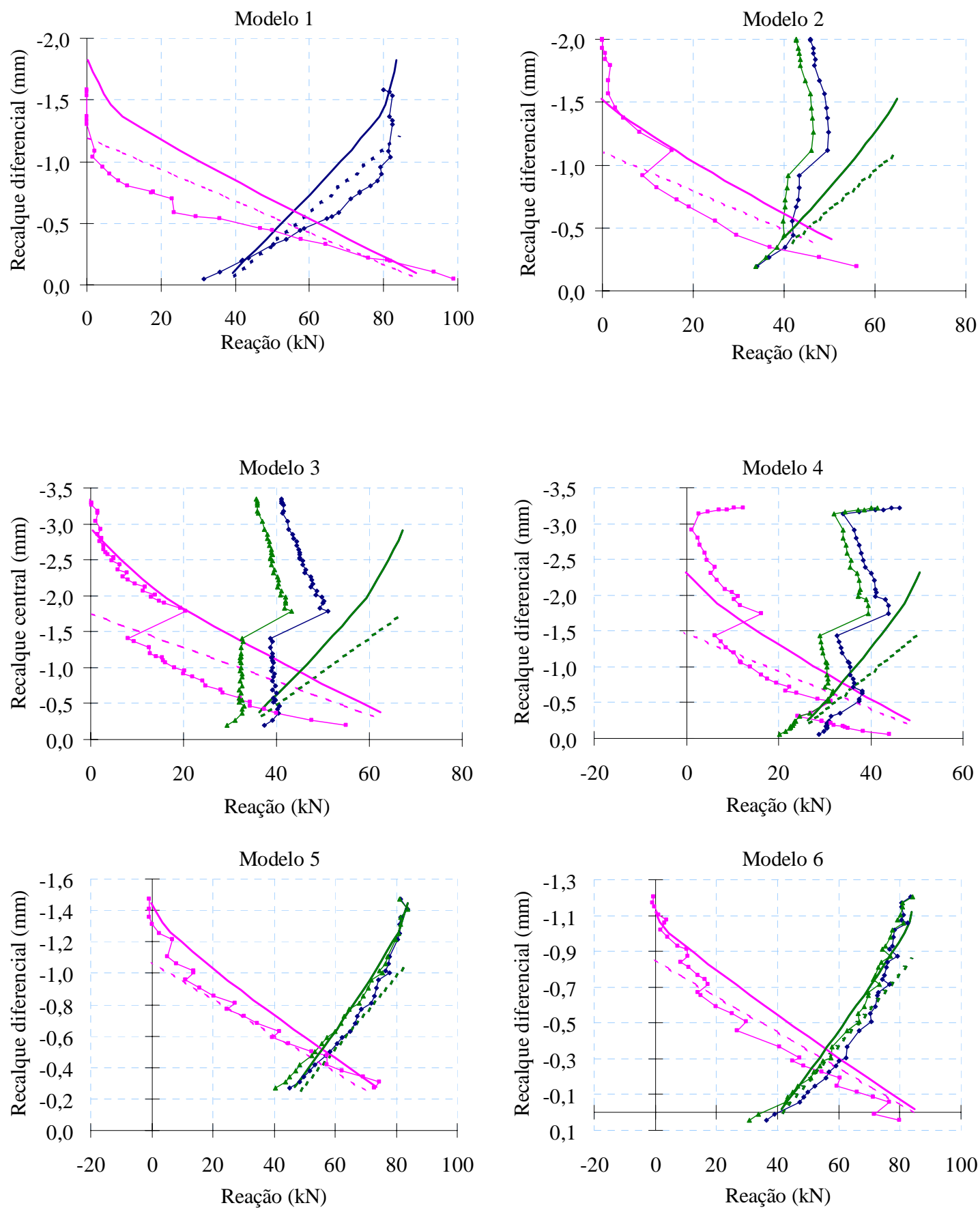

$$
\begin{array}{rrr}
\longrightarrow \text { Apoio A - EXP } & \text { Apoio C - EXP } & \text { Apoio E - EXP } \\
-- \text { Apoio A - MSC } & -- \text { Apoio C - MSC } & -- \text { Apoio E - MSC } \\
\text { Apoio A - MCC } & \text { Apoio C - MCC }
\end{array}
$$

Figura 5.6 Reações de apoio experimentais e numéricas - Situação 2. 
Modelo 1

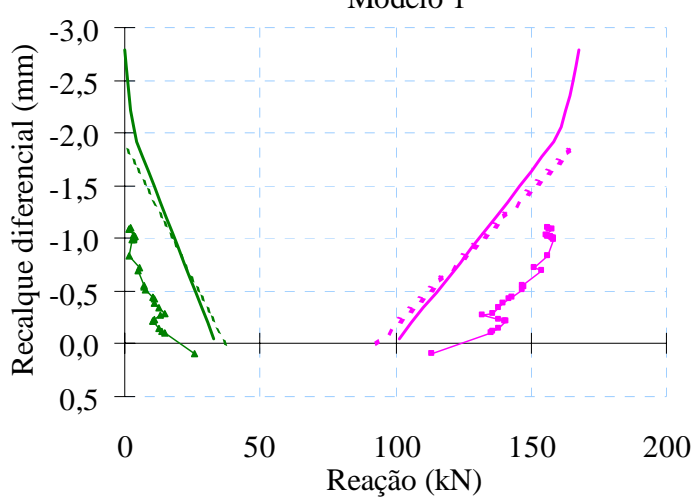

Modelo 3

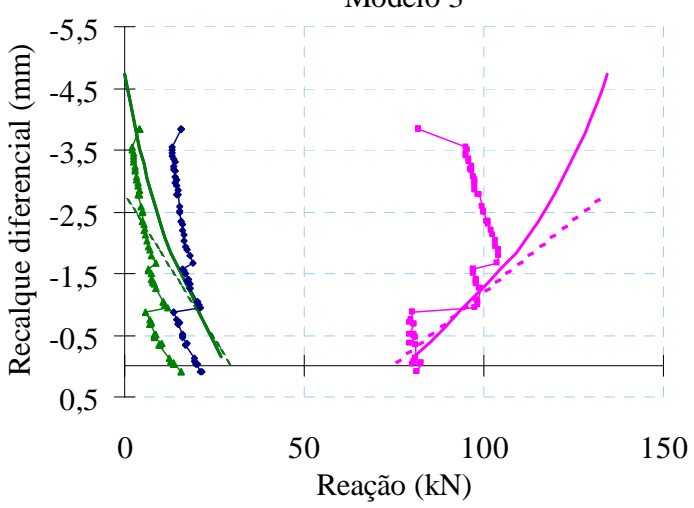

Modelo 5

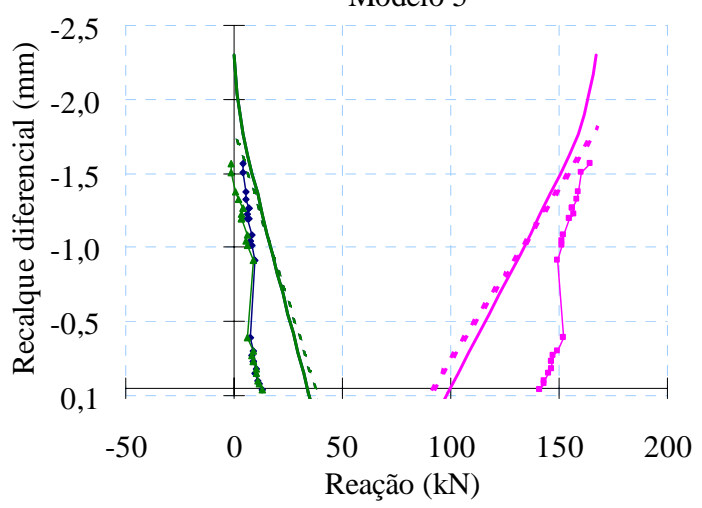

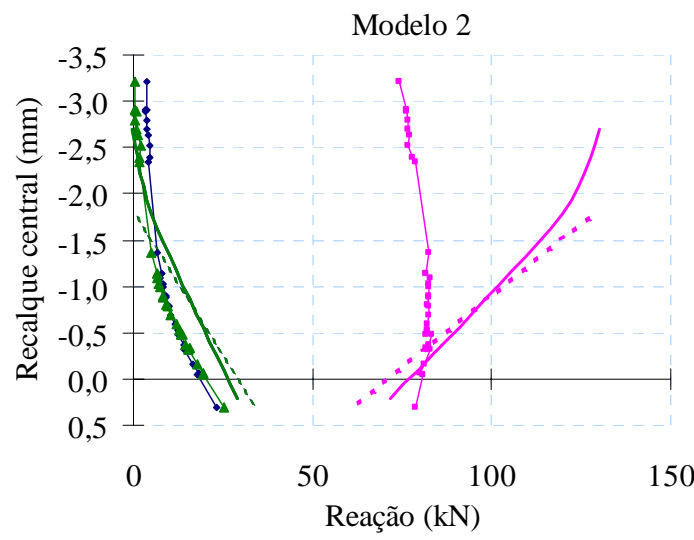

Modelo 4

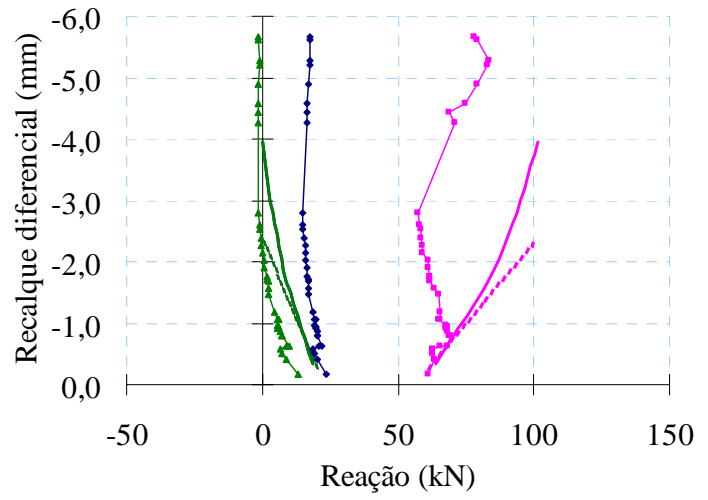

Modelo 6

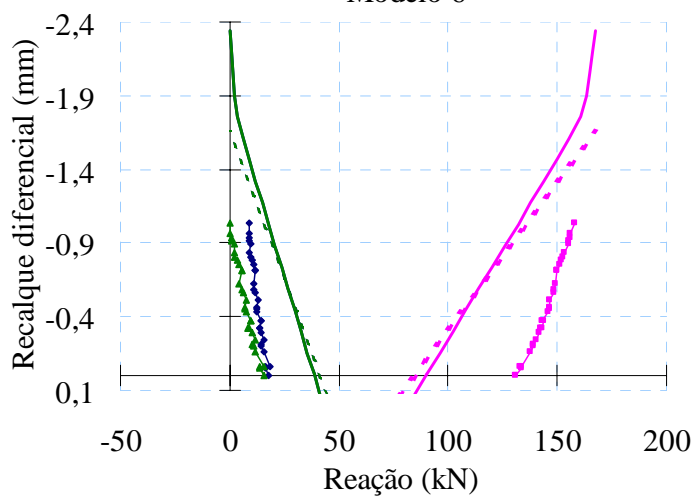

Figura 5.7 Reações de apoio experimentais e numéricas - Situação 3.

\subsubsection{Deformações verticais da parede}

Neste item comparam-se os valores experimentais e numéricos das deformações verticais da parede medidas nas posições dos transdutores 1 a 6 em todos os modelos. As duas modelagens forneceram curvas lineares na etapa de aplicação do carregamento vertical, 
como se verifica na Figura 5.8. As curvas experimentais são também em geral lineares, com exceção dos trechos iniciais, provavelmente por causa da acomodação dos painéis.

Aparentemente os modelos numéricos dos painéis com aberturas mostraram-se mais rígidos que os modelos físicos. O mesmo pode ser inferido com relação ao Modelo 1.
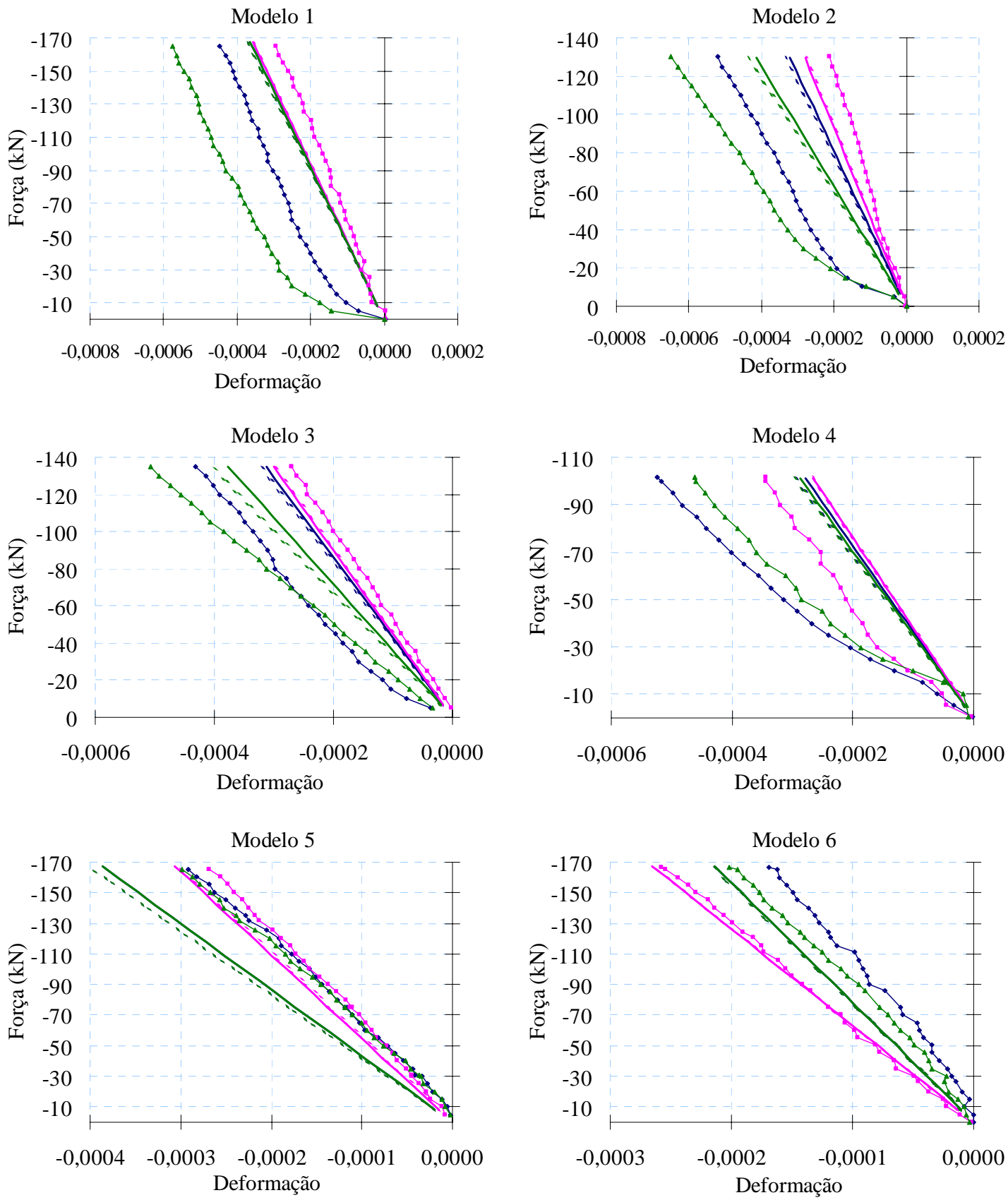

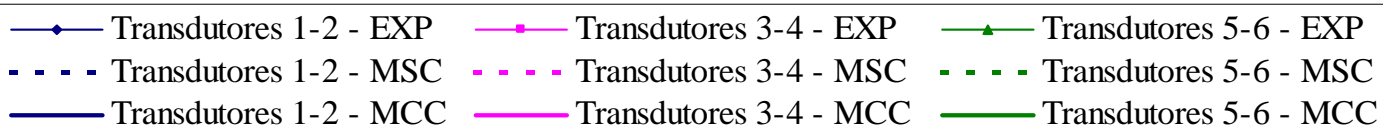

Figura 5.8 Deformações experimentais e numéricas na parede - Situação 1. 
Na Situação 2 percebe-se melhor a diferença de rigidez dos modelos numéricos com relação ao modelo físico do primeiro painel, uma vez que as deformações nas bordas do painel foram bem menores. As observações feitas no item sobre as reações de apoio são válidas também para estes resultados. Observa-se a grande aproximação entre os valores numéricos e experimentais para os modelos 5 e 6, com um melhor desempenho da MCC.

Modelo 1

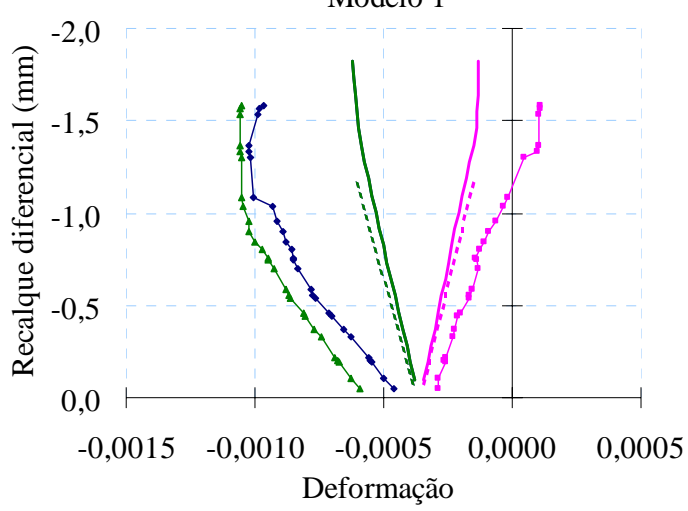

Modelo 3

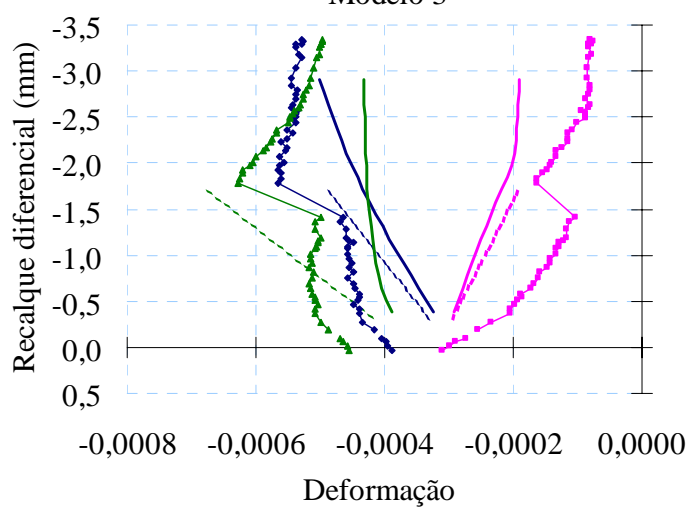

Modelo 5

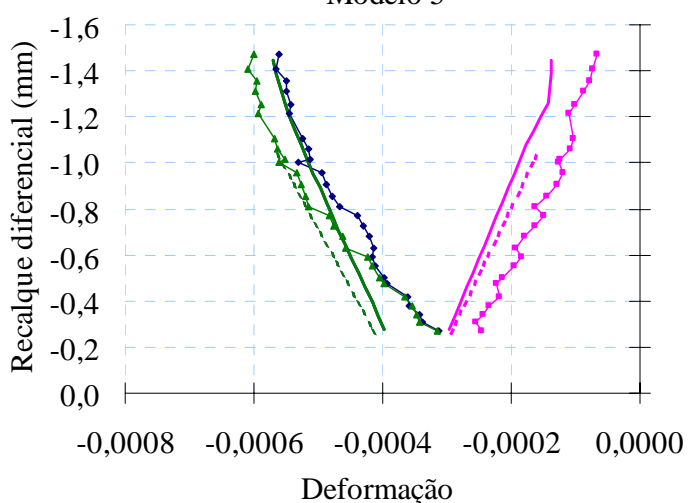

Modelo 2

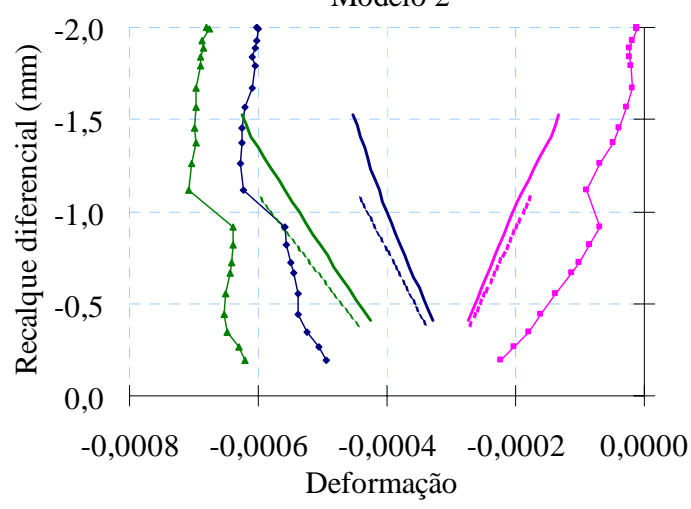

Modelo 4

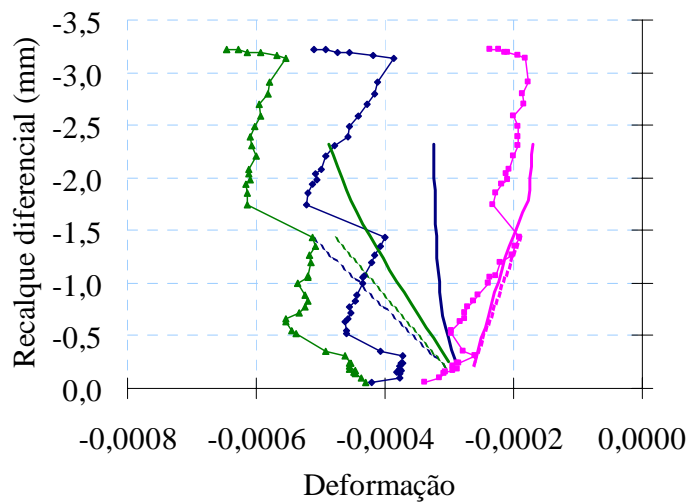

Modelo 6

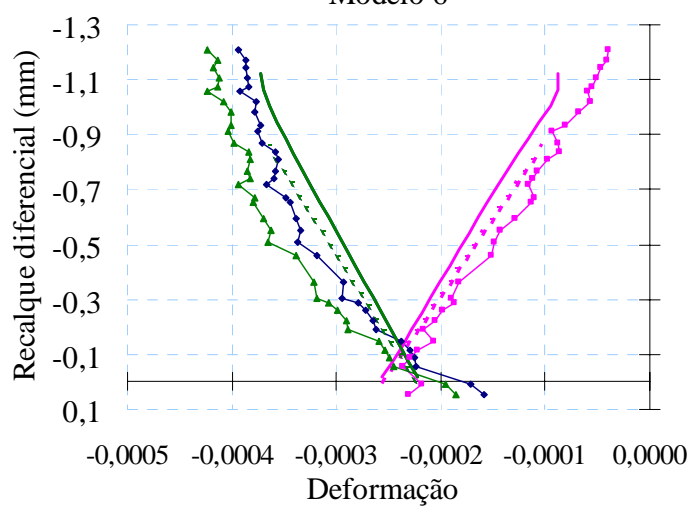

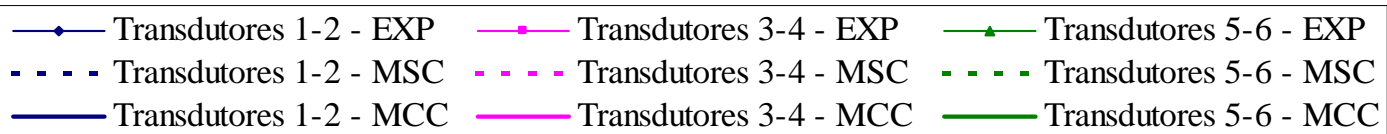

Figura 5.9 Deformações experimentais e numéricas na parede - Situação 2 . 
$\mathrm{Na}$ Situação 3 as modelagens numéricas reproduzem as tendências de crescimento das curvas experimentais, porém com valores bastante diferentes, o que se atribui à não-linearidade dos materiais, não considerada nas modelagens. Verifica-se a extrema influência da fissuração nas curvas experimentais dos transdutores 5 e 6 dos modelos 2 e 4 . A formação de fissuras no trecho de medição da deformação alterou completamente o comportamento da curva experimental.

Modelo 1

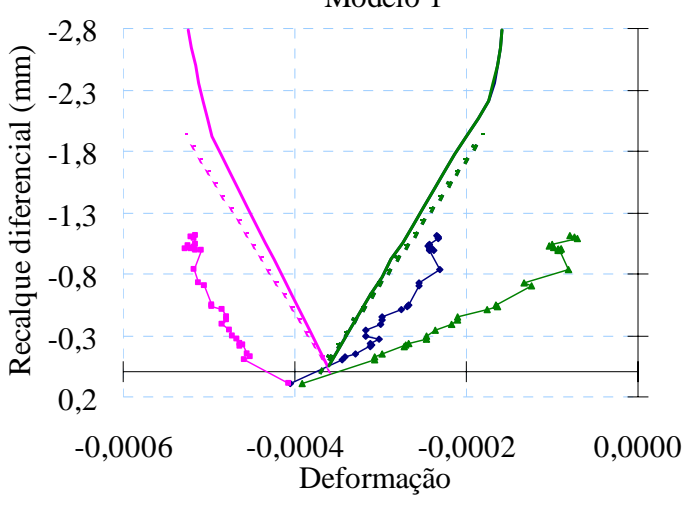

Modelo 3

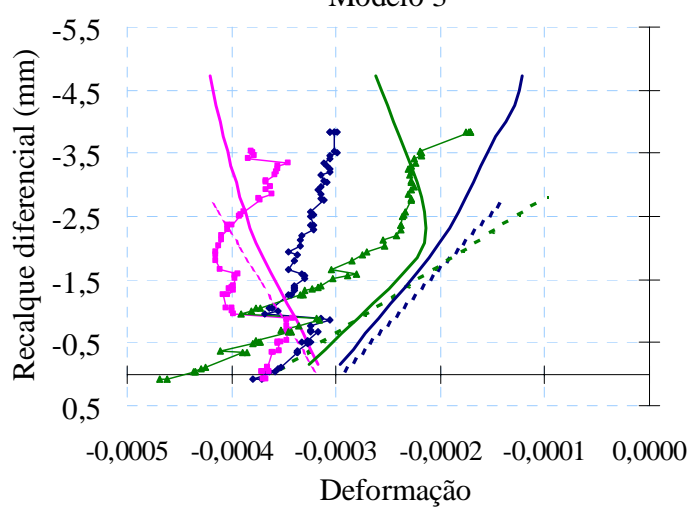

Modelo 5

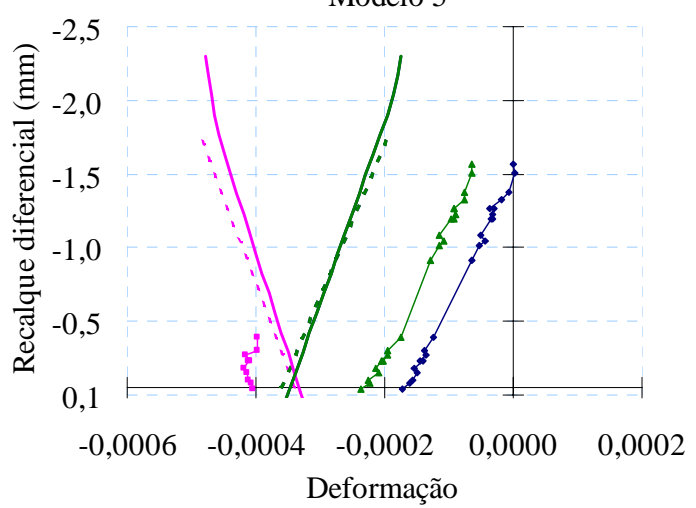

Modelo 2

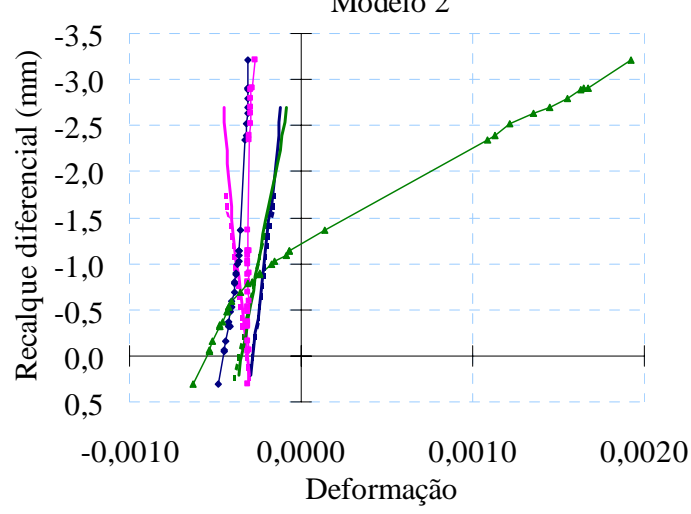

Modelo 4

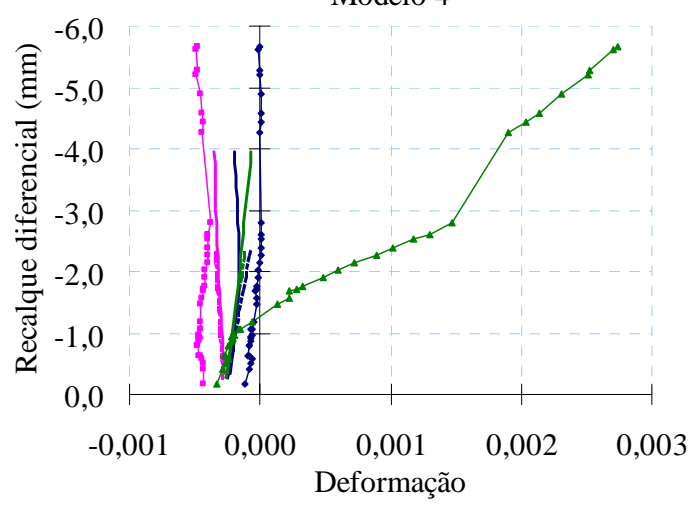

Modelo 6

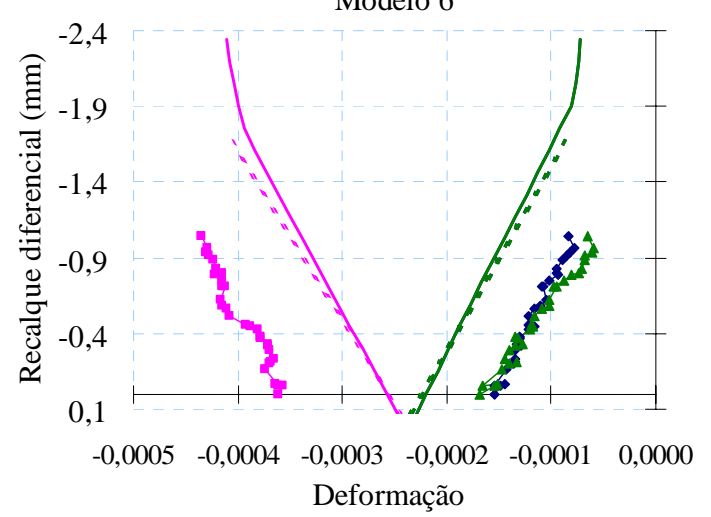

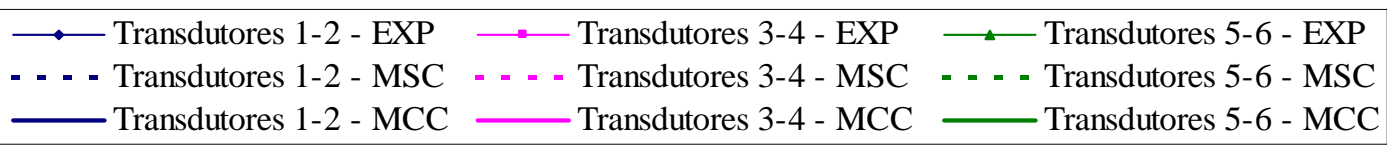

Figura 5.10 Deformações experimentais e numéricas na parede - Situação 3. 


\subsubsection{Deformações verticais ao longo da primeira fiada}

Nas três próximas figuras se encontram ilustrações da distribuição das deformações verticais ao longo da linha média da primeira fiada da parede. São distribuições obtidas no programa ANSYS, correspondentes ao final de cada situação dos ensaios. Todos os painéis estão representados.

Observando as figuras é possível comparar os resultados dos dois tipos de modelagem: sem elementos de contato (MSC) e com elementos de contato (MCC). Os valores apresentados equivalem às deformações verticais do material alvenaria nas respectivas posições ao longo da linha média da primeira fiada.

Pode-se, portanto, comparar os aspectos dos diagramas seguintes com os dos diagramas construídos a partir de valores experimentais e apresentados no capítulo anterior. Dessa forma, verifica-se que tipo de modelagem produz distribuições mais semelhantes à realidade. Os valores de deformações, todavia, não podem ser confrontados diretamente, porque dizem respeito a materiais distintos: no laboratório foram instrumentados os blocos com extensômetros, enquanto que numericamente foi modelado o material alvenaria.

Nos gráficos da Situação 1 (Figura 5.11), em que não ocorre deslocamento vertical dos apoios, há pouca diferença entre os resultados de ambas as modelagens. Apenas se observa uma maior concentração de esforços nas extremidades e no centro da parede na MSC.

Nas situações em que os recalques são aplicados, percebe-se uma diferença mais importante. Na MSC surgem grandes alongamentos nos cantos das portas e nas extremidades das paredes. Já na MCC, quando tensões de tração tendem a aparecer nesses locais, ocorre a separação entre parede e viga, permitida pelos elementos de contato. Dessa forma, a distribuição das deformações nessa região consiste de concentrações de encurtamentos por compressão, apenas.

Verifica-se nos diagramas experimentais, especialmente dos modelos 3 e 4 , que tais deformações por tração (alongamentos) realmente não ocorrem. Conclui-se, portanto, que a não utilização de elementos de contato em análises como estas pode acarretar distorções na distribuição de tensões na base da parede. 


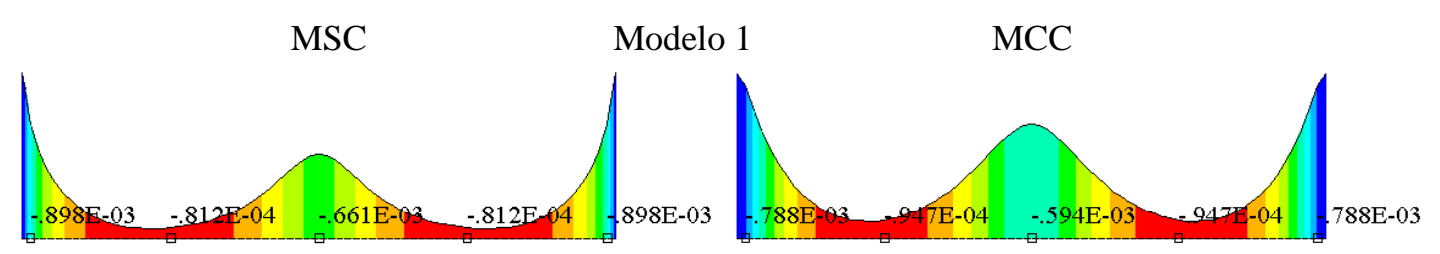

Modelo 2
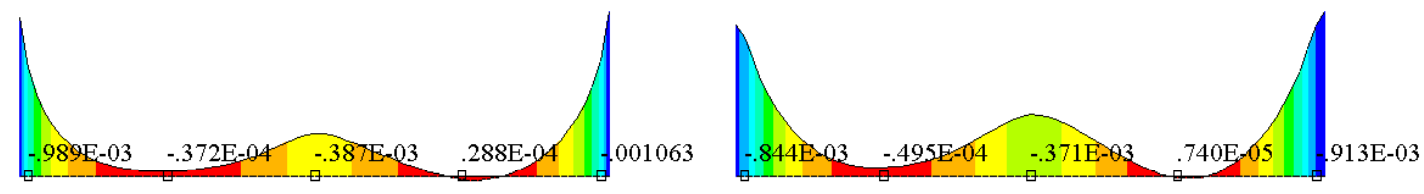

Modelo 3

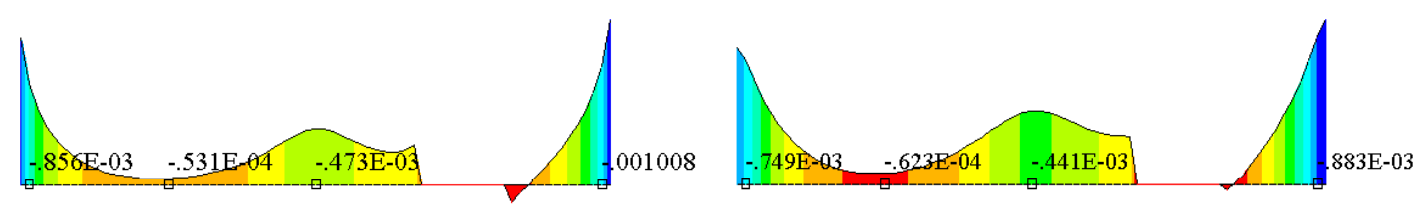

Modelo 4

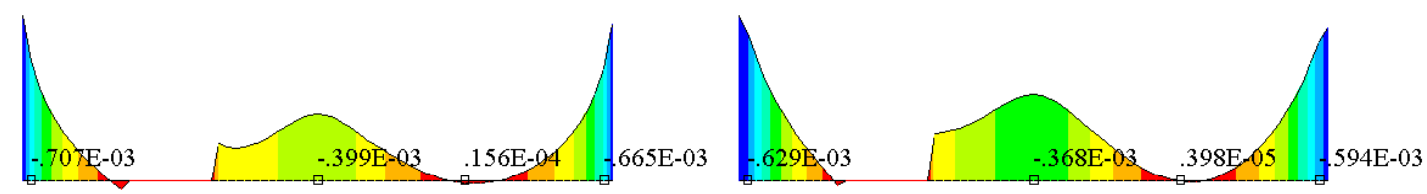

Modelo 5
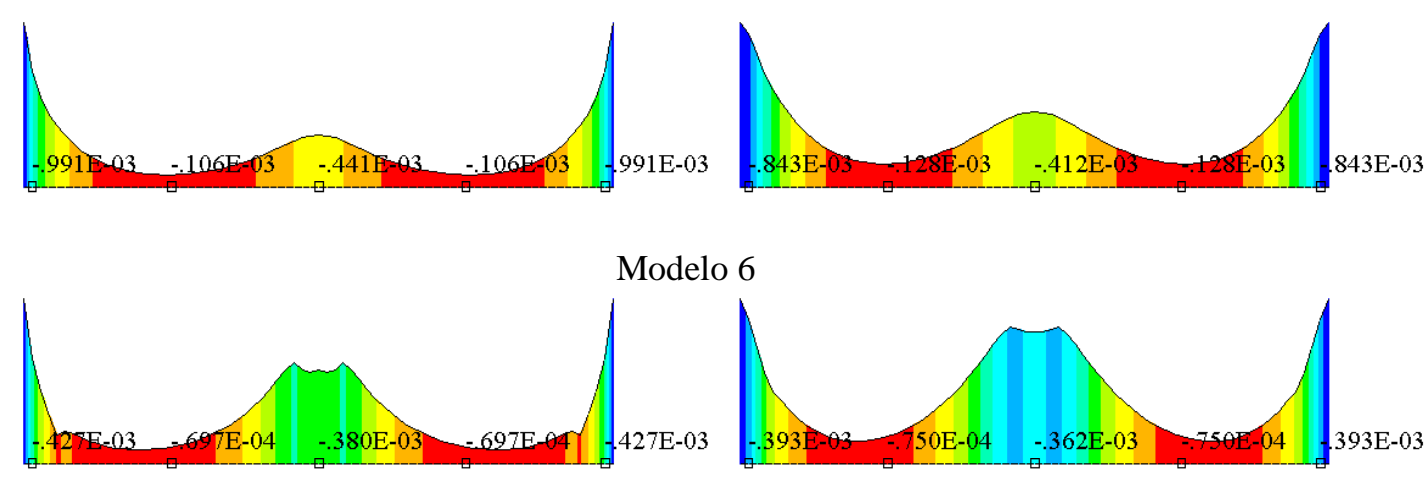

Figura 5.11 Deformações verticais na primeira fiada - Situação 1 . 


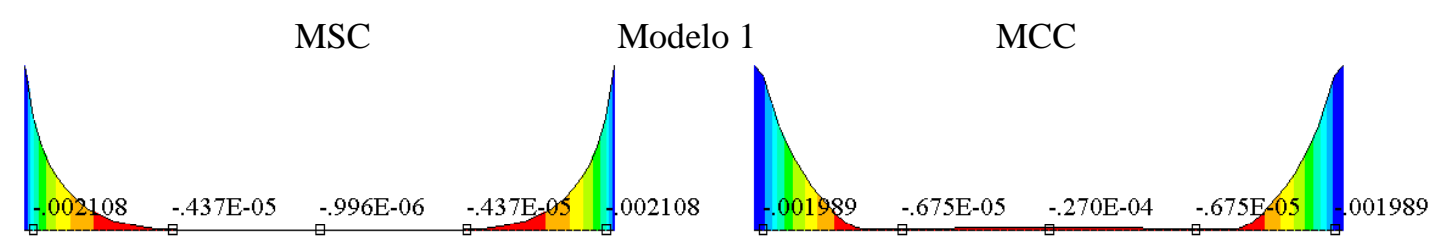

Modelo 2

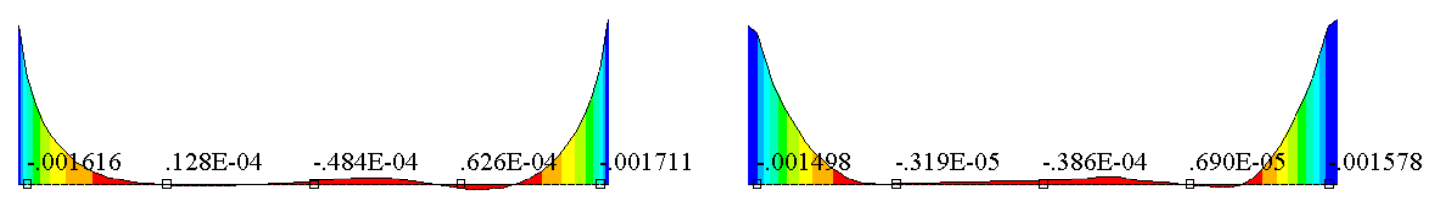

Modelo 3

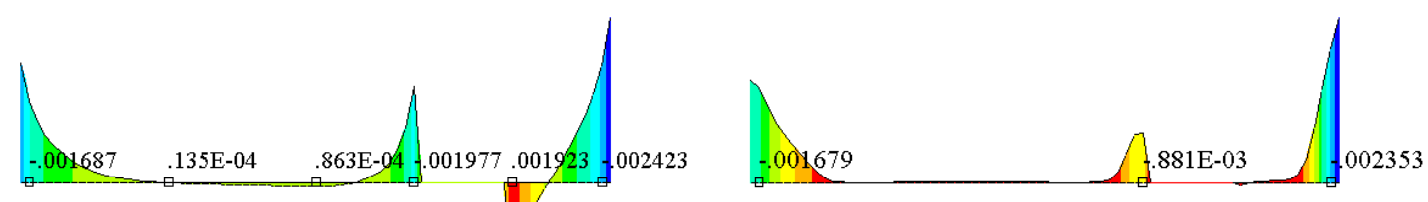

Modelo 4
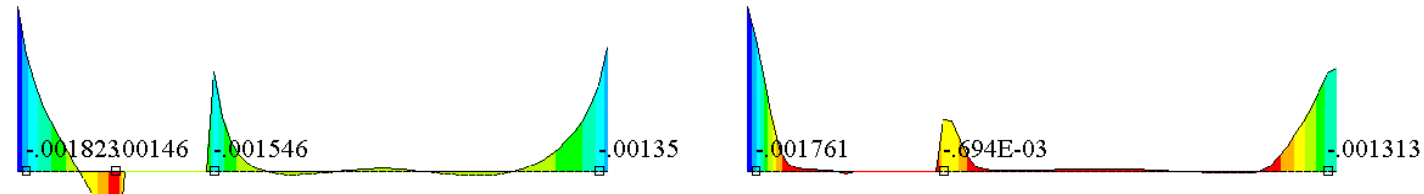

Modelo 5
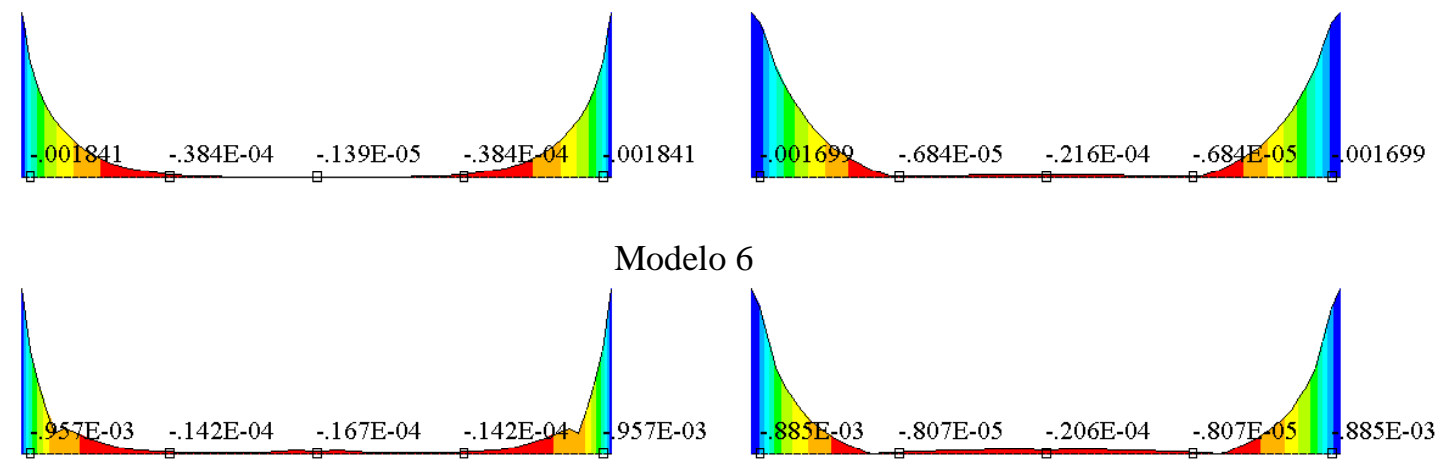

Figura 5.12 Deformações verticais na primeira fiada - Situação 2 . 


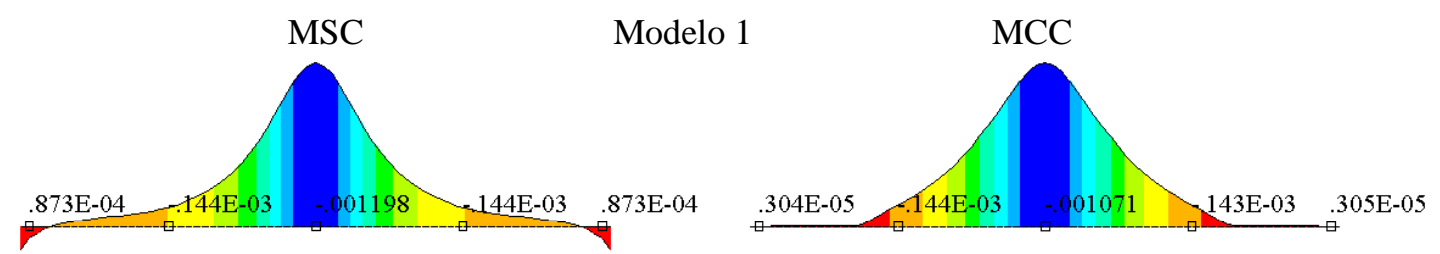

Modelo 2
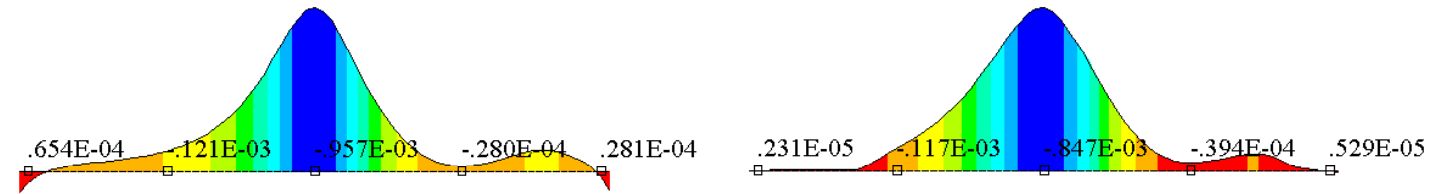

Modelo 3
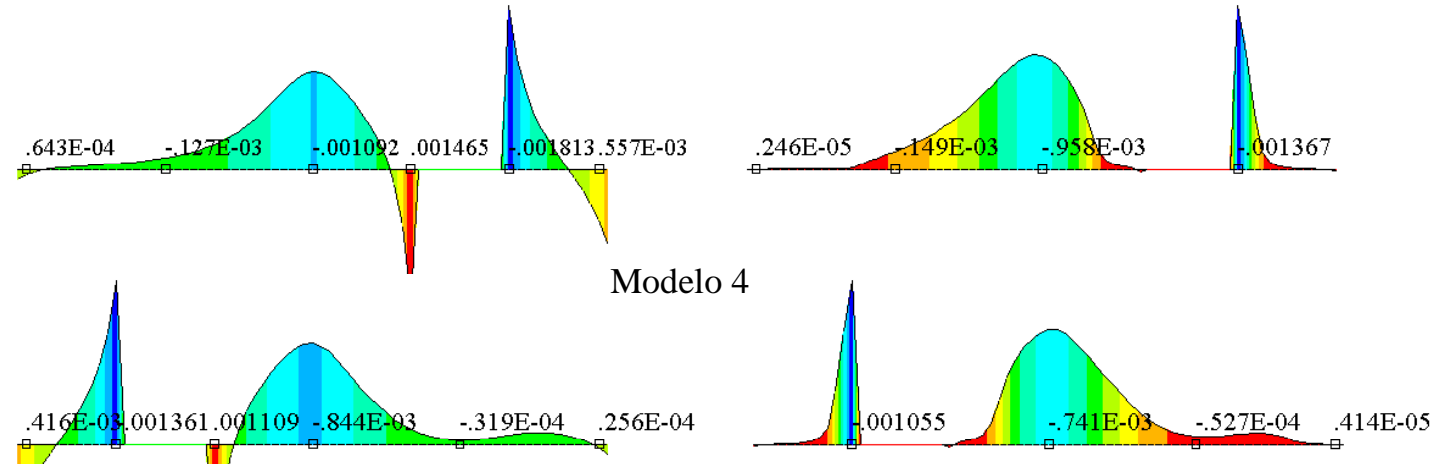

Modelo 5
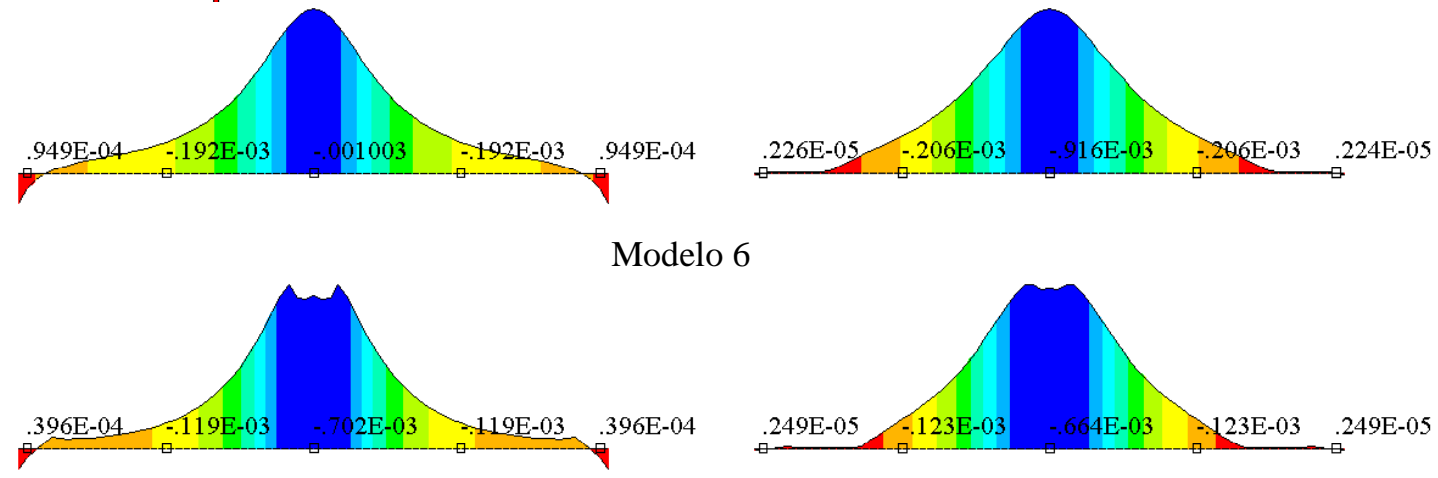

Figura 5.13 Deformações verticais na primeira fiada - Situação 3 .

\subsubsection{Deformações principais do painel}

Nos painéis com abertura de porta foram posicionados quatro transdutores nos lados da abertura para que se fizesse uma outra verificação qualitativa da melhor forma de modelagem dentre as duas estudadas. Nas análises numéricas preliminares observou-se que na MCC o deslizamento do trecho de parede compreendido entre a porta e a borda do painel alterou a distribuição dos esforços. Como consequiência, percebeu-se na Situação 2 que o arco de compressão do painel não passou por aquele trecho de parede, o qual se comportou isoladamente como se não pertencesse ao painel. Ao contrário, na MSC, o arco de compressão se formou em todo o painel, passando por cima da abertura de porta. 
Desta forma, pretendia-se verificar como se comporta o trecho de parede em questão. Verificou-se pelas leituras em laboratório, que houve formação do arco de compressão passando por cima da abertura de porta em ambos os modelos 3 e 4. Porém os diagramas de deformações principais produzidos pelo ANSYS para os dois tipos de modelagem, considerando as dimensões dos modelos 3 e 4, não diferem neste aspecto. Acredita-se que a relação entre vão e altura dos modelos ensaiados, bem menor que a do exemplo da investigação numérica preliminar, não foi suficiente para provocar as alterações anteriormente observadas. Portanto esta avaliação não foi conclusiva. Na figura seguinte se visualiza a representação vetorial das deformações principais dos modelos 3 e 4, em que os vetores azuis e pretos correspondem respectivamente a encurtamentos e alongamentos.
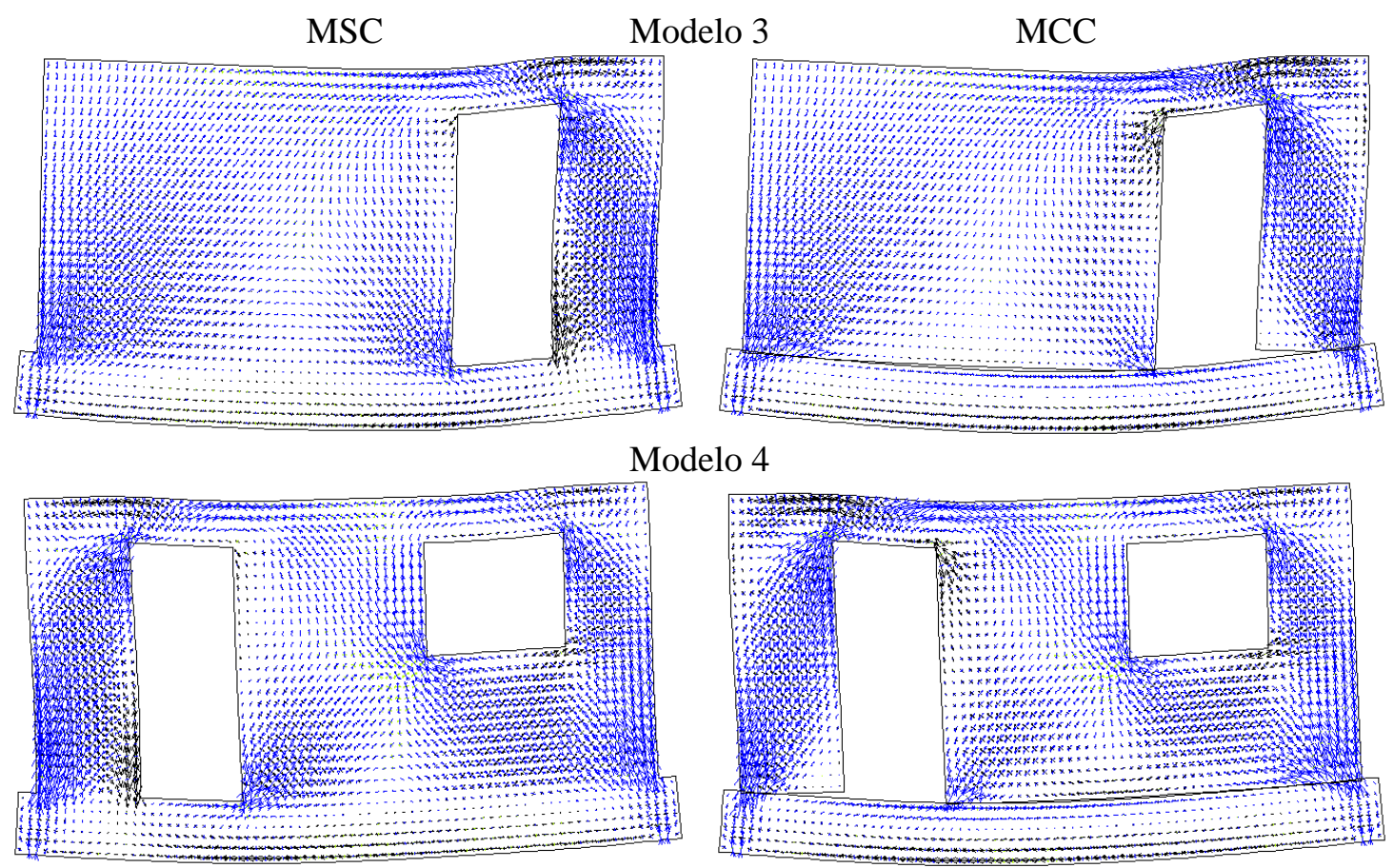

Figura 5.14 Deformações principais, Modelos 3 e 4 - Situação 2.

Ainda analisando a figura anterior, é possível verificar que a MCC indica separações entre parede e viga nos cantos das portas, que foram observadas nos ensaios exatamente como mostra a figura.

Também observando distribuições principais de deformação, com referência agora às da Figura 5.15, é possível perceber a mudança causada pelo grauteamento aplicado ao Modelo 6, comparando-o ao Modelo 1. Em ambas as modelagens, as deformações provocadas por tensões de cisalhamento tornaram-se mais intensas também em direção aos cantos superiores do painel, na parte não grauteada da alvenaria. Por isso foi observado no ensaio do Modelo 6 o aparecimento de fissuras diagonais nessa região. 


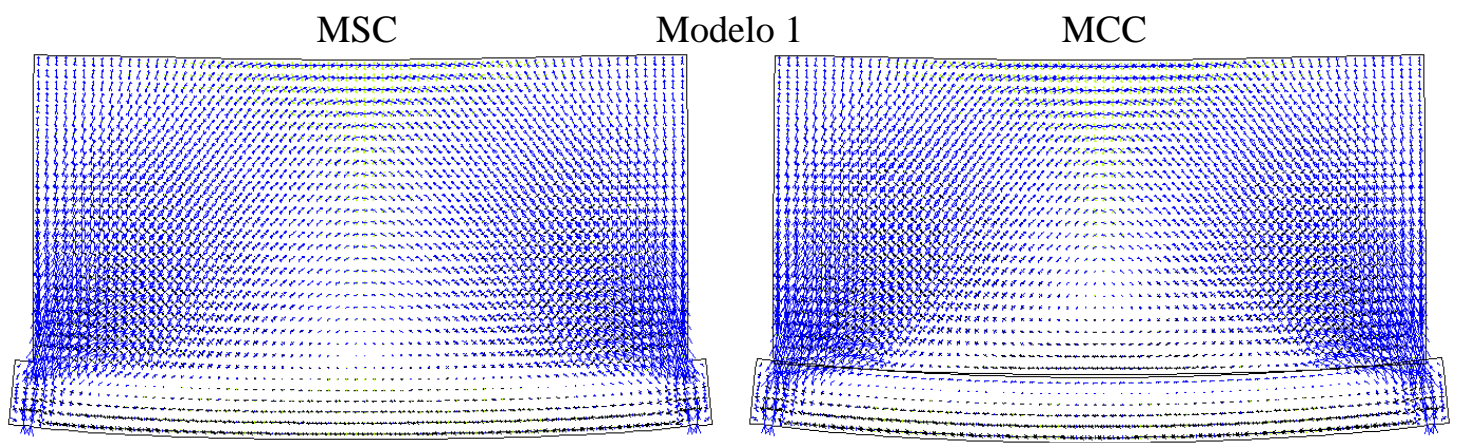

Modelo 6
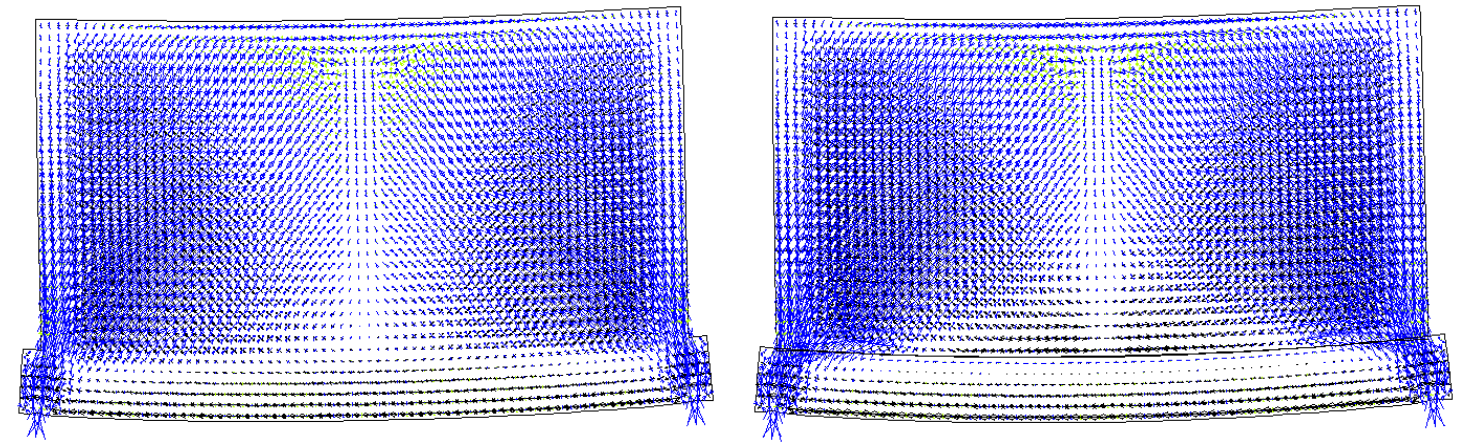

Figura 5.15 Deformações principais, Modelos 1 e 6 - Situação 2.

\subsubsection{Penetrações e separações na interface de contato}

A importância da consideração da não-linearidade de contato e a relativa adequação dos elementos de contato neste tipo de análise são ratificados na discussão que se segue. Neste item e nos próximos são comparados os resultados próprios dos elementos de contato com as leituras da instrumentação especificamente instalada para este fim, constituída pelos transdutores de medição de penetrações e separações na interface paredeviga, de deslizamentos relativos nas extremidades do painel, bem como de variações da abertura de porta.

Verifica-se que as penetrações experimentais foram muito bem reproduzidas pela modelagem numérica. Na Situação 1, as curvas experimentais e numéricas apresentam aspecto semelhante e com valores próximos. Ressalvas devem ser feitas com relação às leituras dos transdutores de extremidade do Modelo 1, que foram posicionados inadequadamente. As leituras de grandes penetrações observadas no início do ensaio para o Modelo 6 podem ter sido provocadas pela provável existência de uma abertura inicial devido à retração do graute.

$\mathrm{Na}$ Situação 2 verifica-se a proximidade entre as curvas experimentais e numéricas até o instante em que ocorre a separação no modelo numérico. Todavia, deve-se perceber que a instrumentação adotada não captou totalmente a separação prevista no modelo numérico porque ela aconteceu na verdade entre as primeiras fiadas, e não na 
interface parede-viga, onde foram posicionados os transdutores. Acredita-se que as curvas experimentais apresentariam comportamento semelhante ao das curvas numéricas caso a separação houvesse realmente surgido entre parede e viga.

Isto se justifica porque foi provavelmente o que aconteceu com relação ao Modelo 6. Neste caso, o grauteamento dos furos centrais da parede impediu a formação de fissuras horizontais entre as primeiras fiadas, mas aparentemente surgiu uma fissura imperceptível na interface, que foi captada pelo transdutor. Como conseqüência, verifica-se que a curva do transdutor 11 (central) é semelhante à da previsão numérica.

Também na Situação 3 as curvas experimentais e numéricas se assemelham até o instante da separação na interface do modelo numérico. Além disso, nesta última situação as leituras dos transdutores de extremidade não acompanham a tendência do modelo numérico por consequiência da divisão da parede no ensaio em laboratório.

Portanto, as penetrações previstas pela MCC mostraram-se bastante coerentes com os resultados experimentais. 

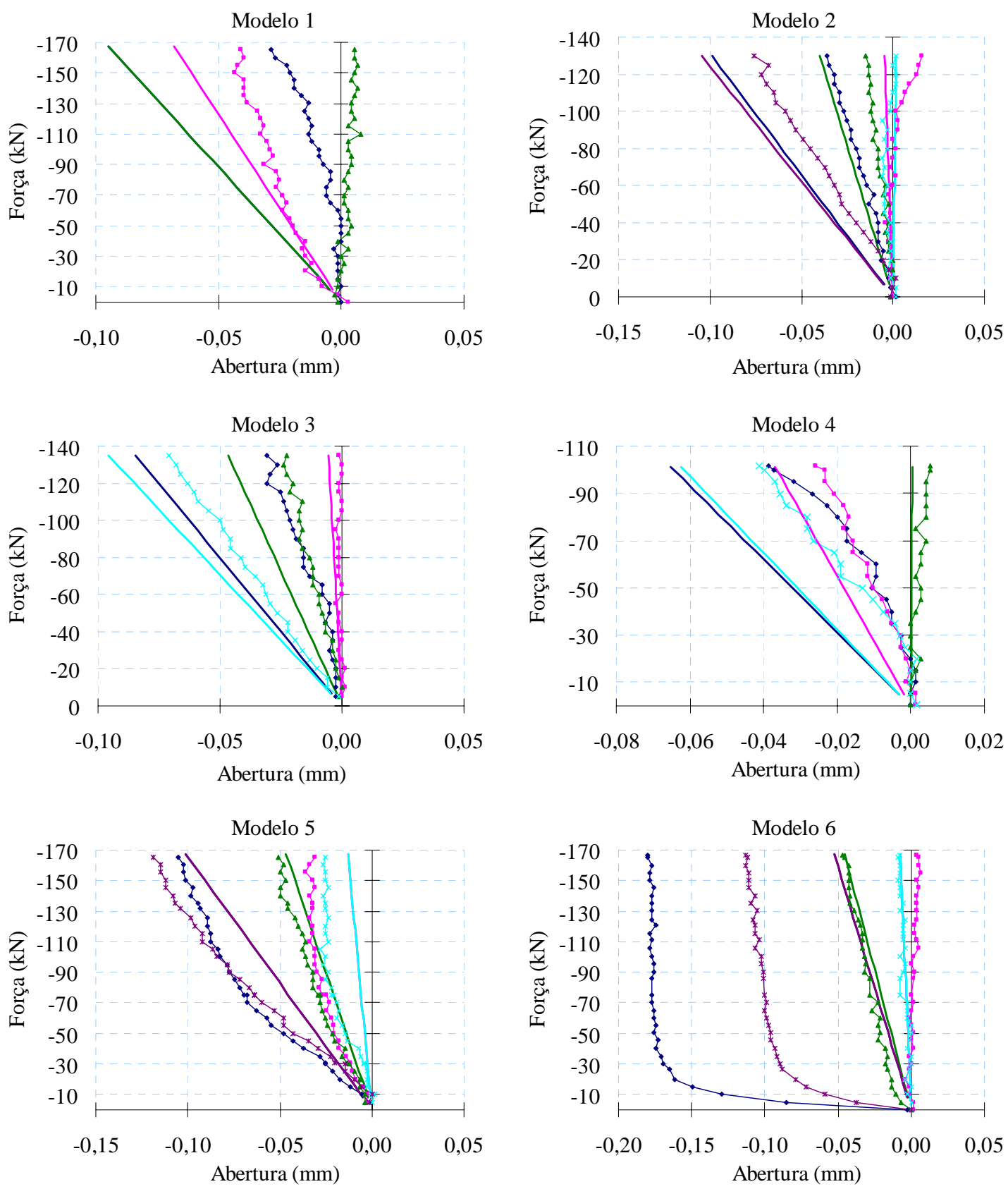

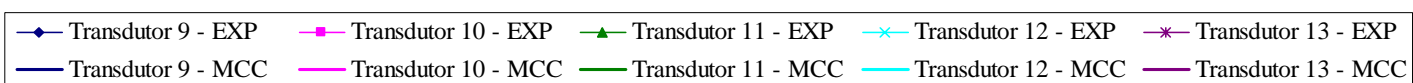

Figura 5.16 Penetrações (-) e separações (+) experimentais e numéricas - Situação 1. 

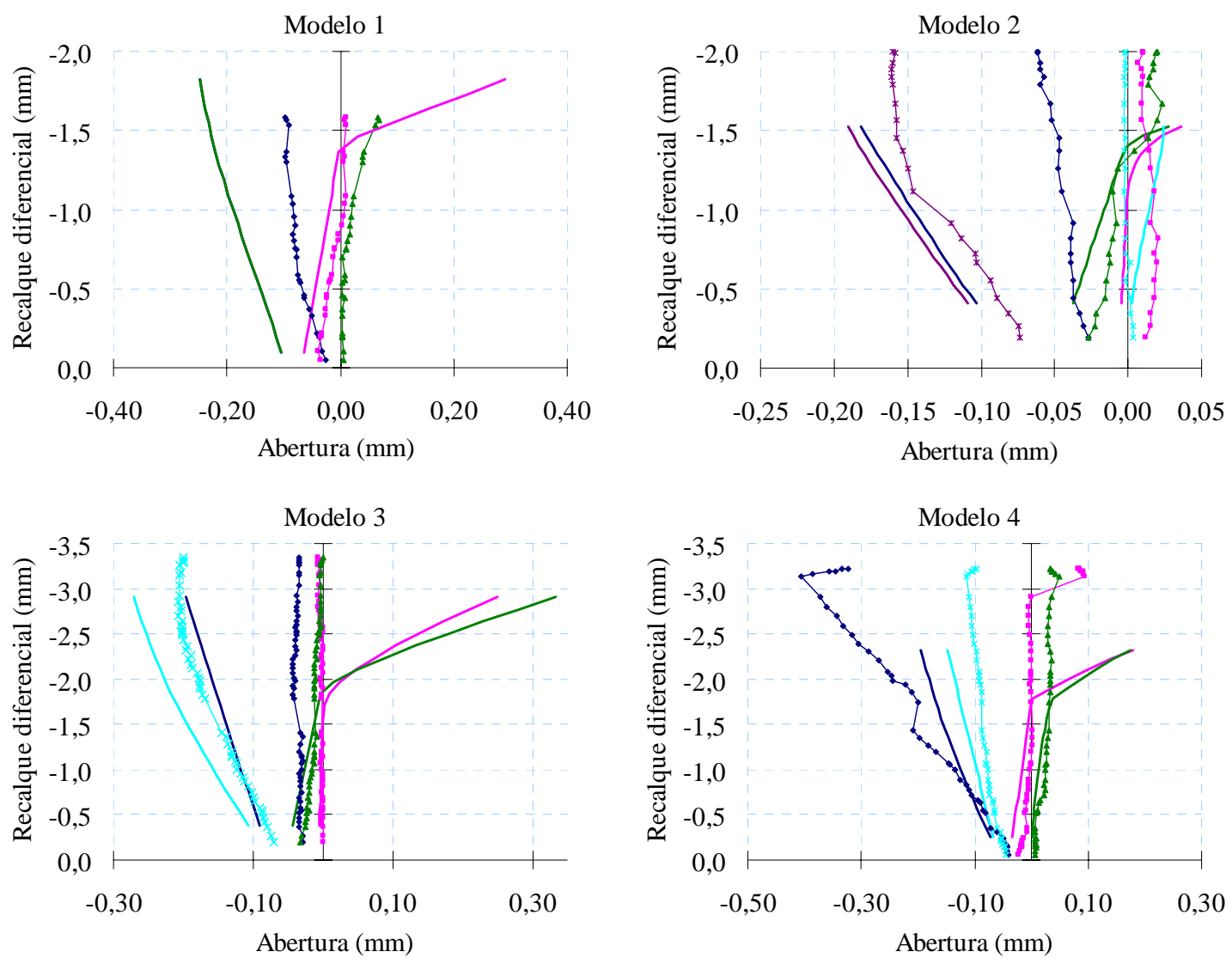

Modelo 5
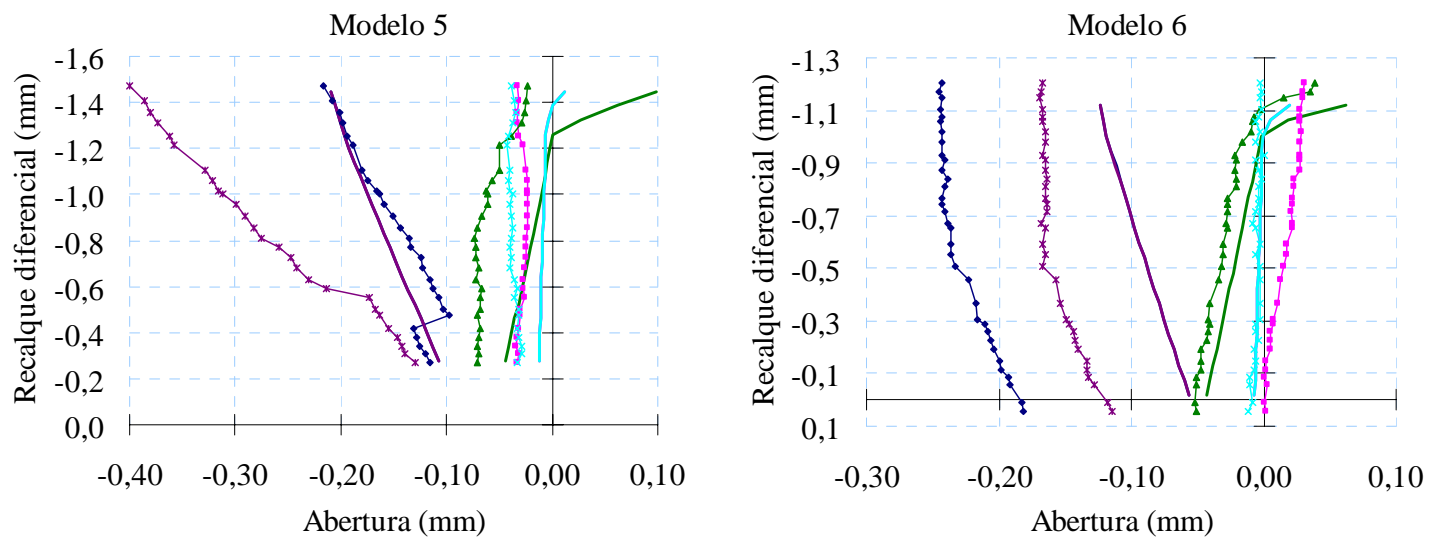

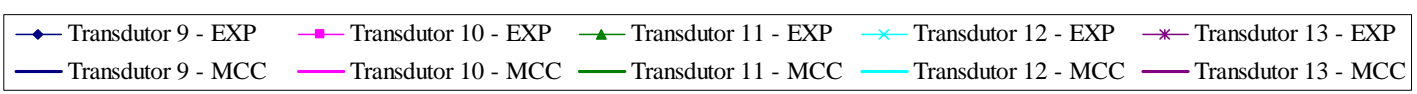

Figura 5.17 Penetrações (-) e separações (+) experimentais e numéricas - Situação 2. 

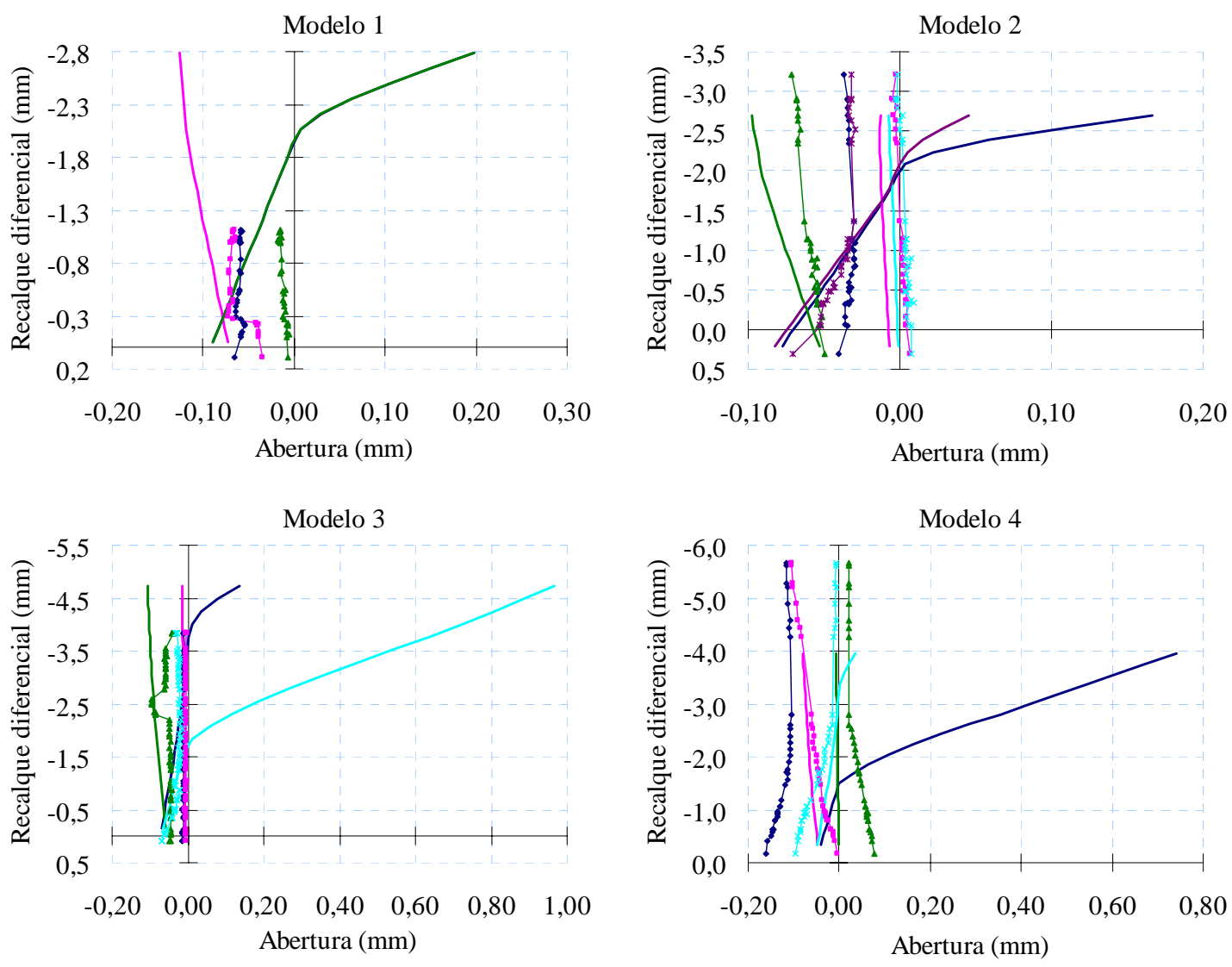

Modelo 5
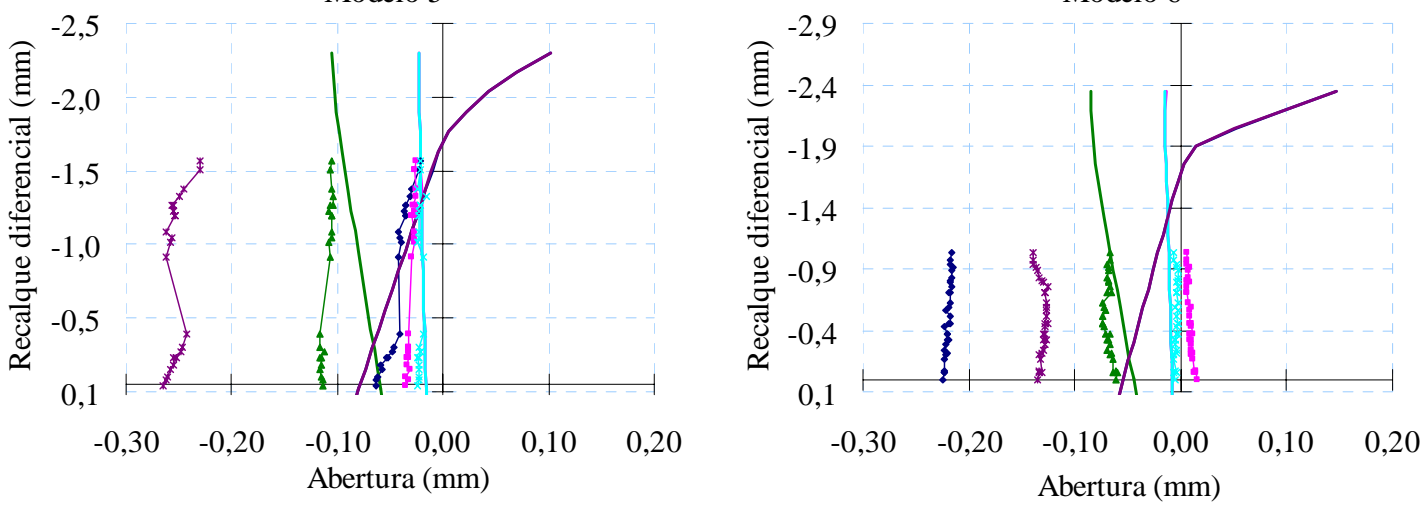

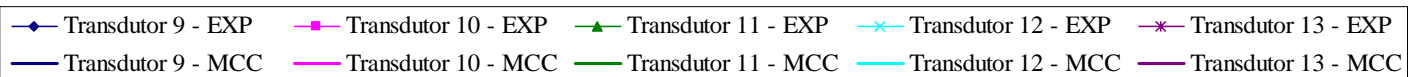

Figura 5.18 Penetrações (-) e separações (+) experimentais e numéricas - Situação 3.

\subsubsection{Deslizamentos na interface de contato}

Em laboratório os deslizamentos na interface de contato entre parede e viga foram medidos por transdutores posicionados nas extremidades dos painéis. Essas leituras foram confrontadas com os resultados numéricos correspondentes.

Verifica-se pelos gráficos das figuras seguintes que em geral os comportamentos experimentais foram bem reproduzidos pela simulação numérica em todas 
as etapas. Entretanto os valores ficaram sempre abaixo dos reais, ressalvado o caso do Modelo 1, cuja instrumentação foi posicionada diferentemente. Entende-se que essa diferença decorreu da inexatidão do critério de cisalhamento do modelo de contato utilizado, conforme discutido no item 5.2.2. Acredita-se que o aprimoramento desse critério, aproximando-o mais do que se verifica experimentalmente, pode melhorar a precisão dos resultados.
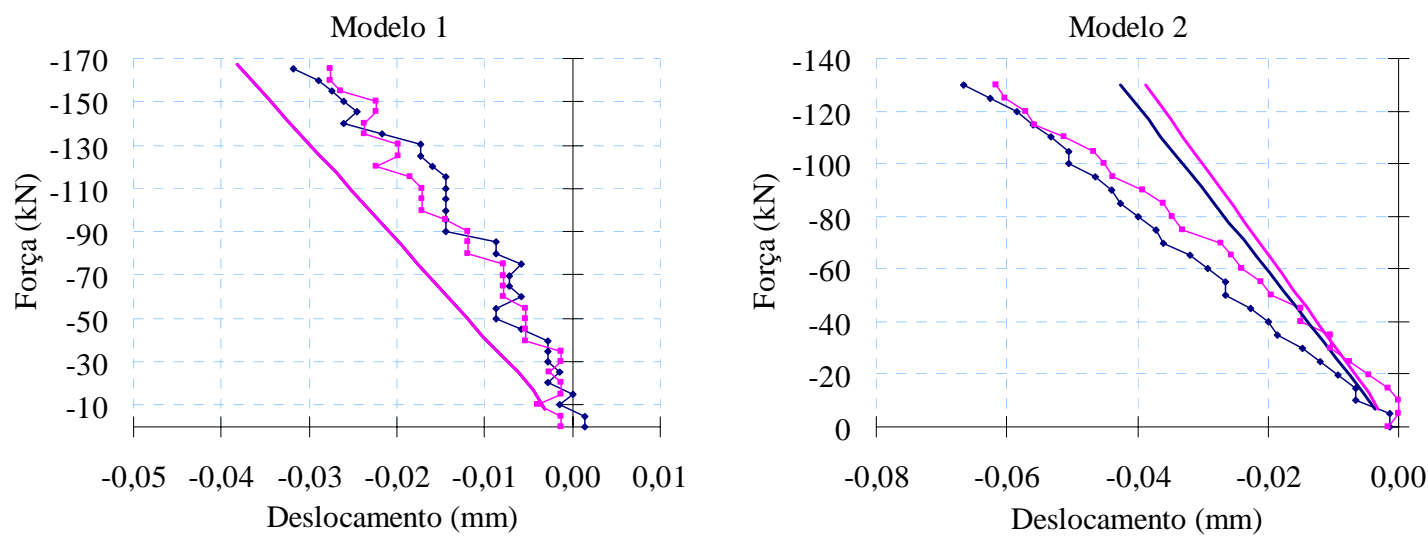

Modelo 3
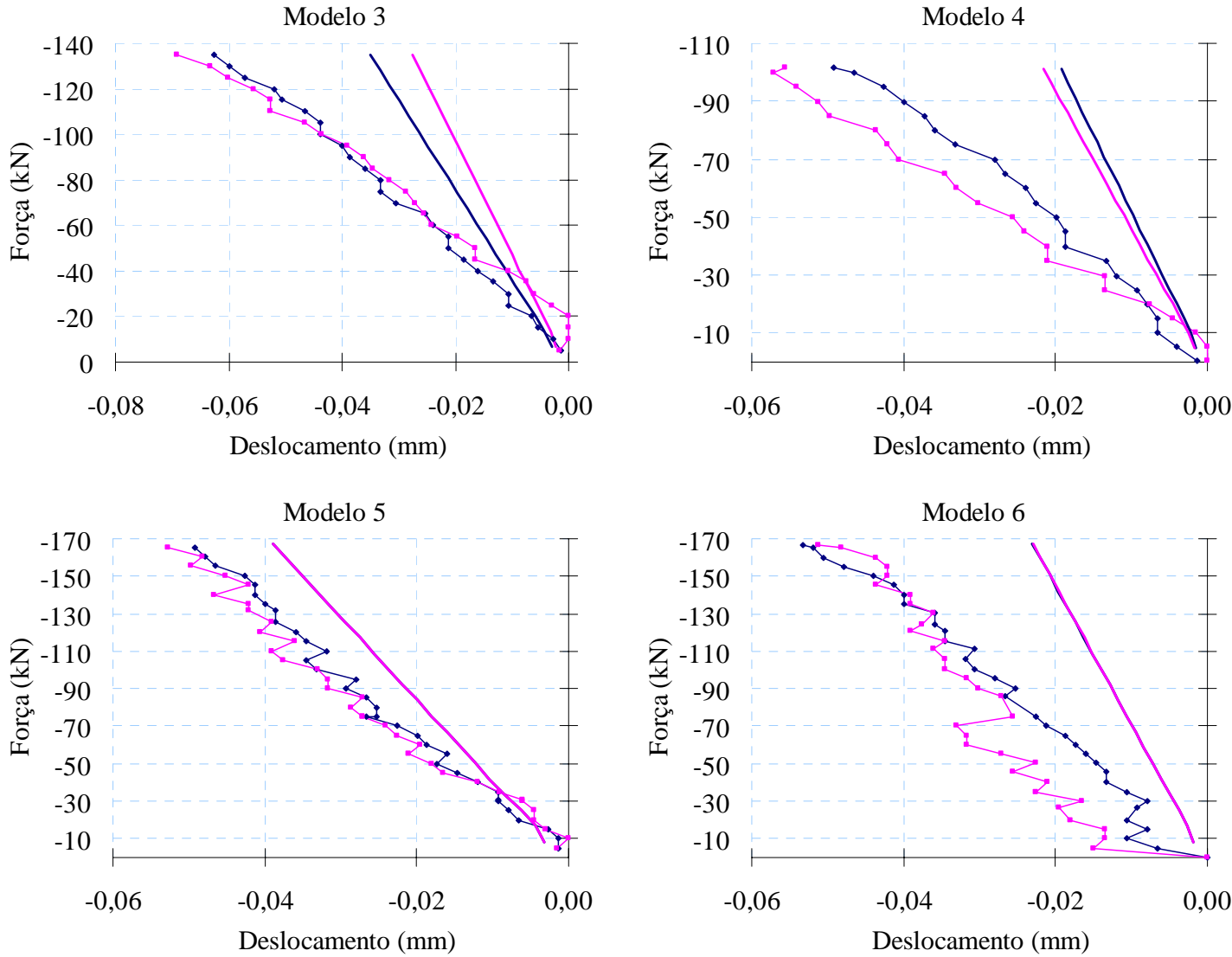

- Transdutor 7 - EXP - Transdutor 8 - EXP

Transdutor 7 - MCC — Transdutor 8 - MCC

Figura 5.19 Deslizamentos experimentais e numéricos - Situação 1. 

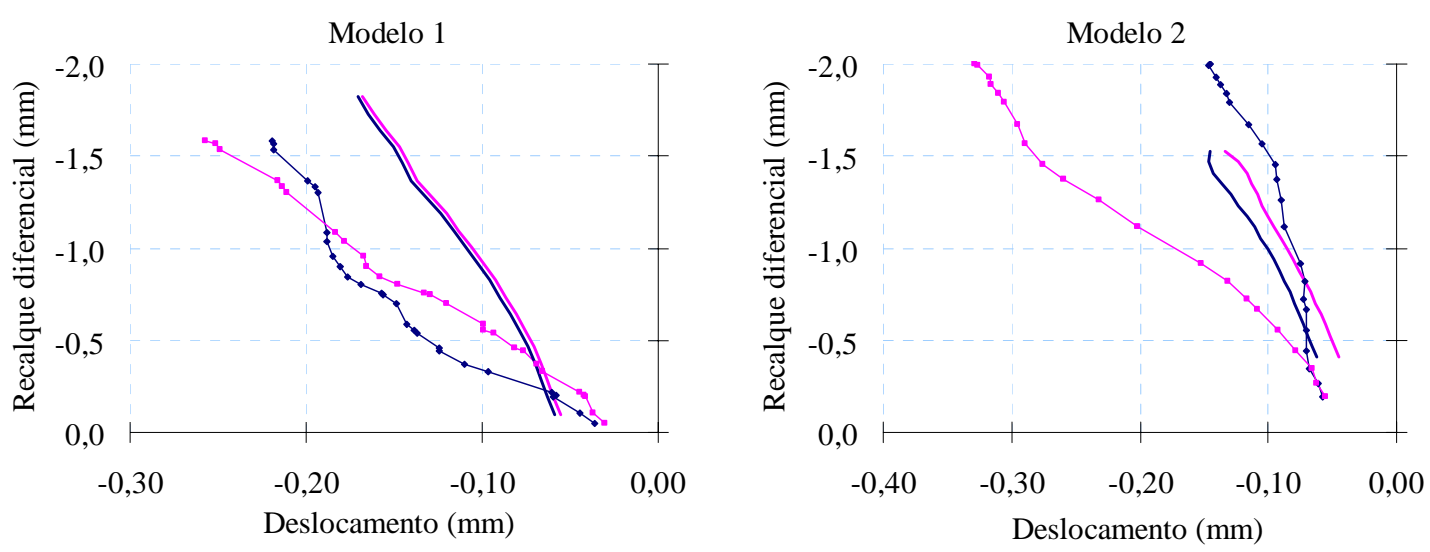

Modelo 3
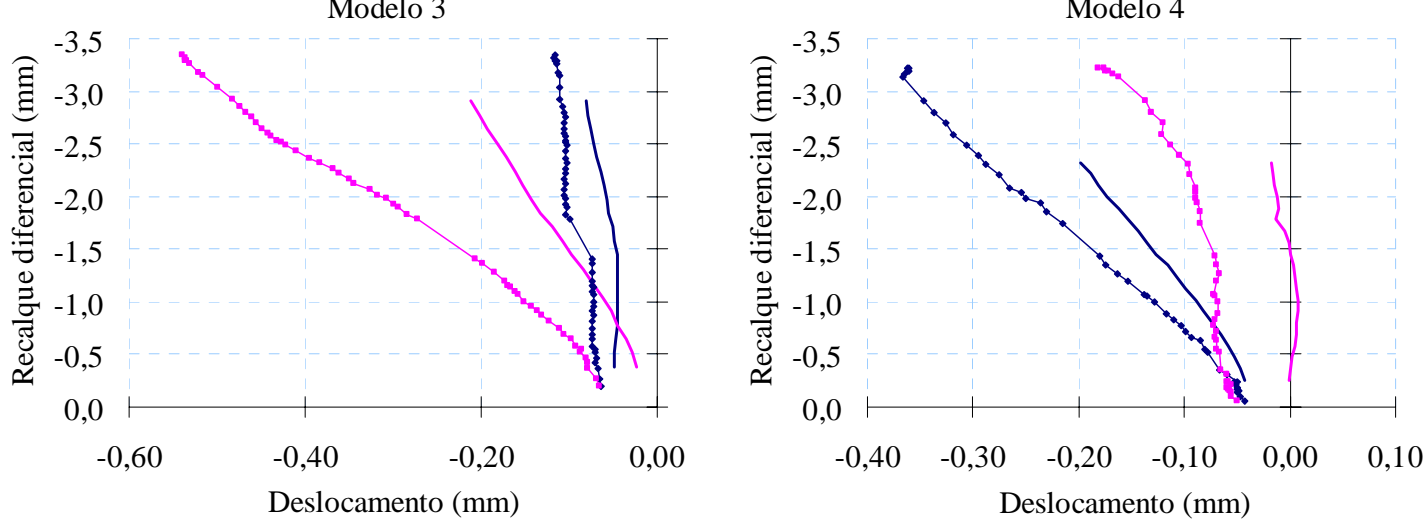

Modelo 5
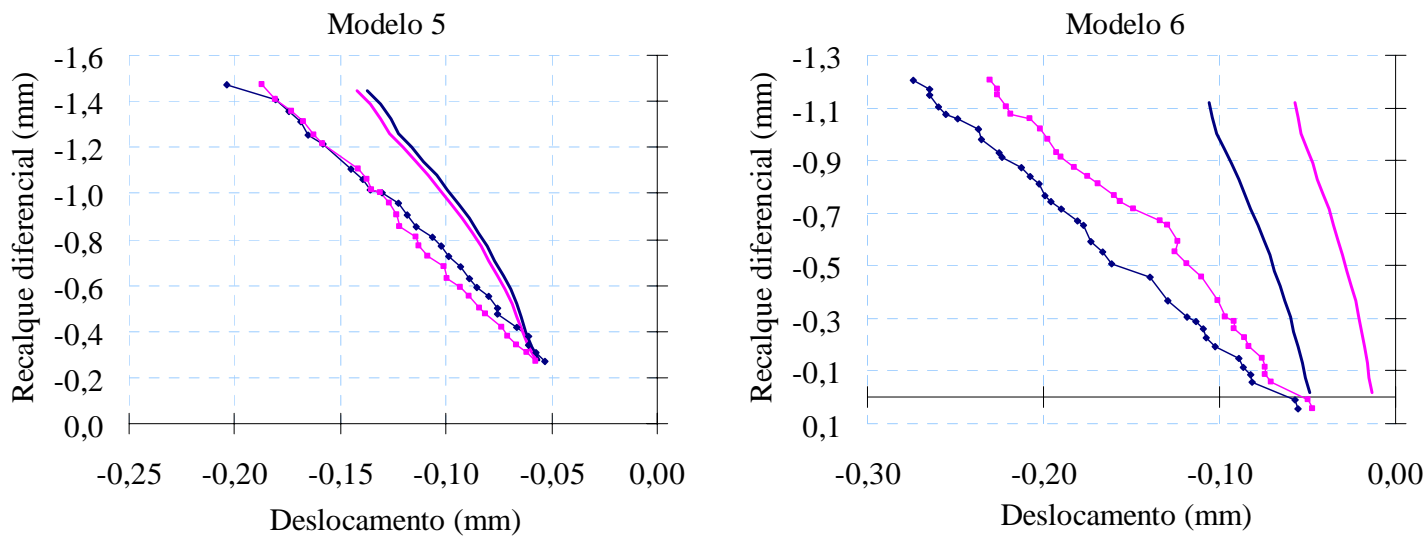

$\rightarrow$ Transdutor 7 - EXP $\rightarrow$ Transdutor 8 - EXP

- Transdutor 7 - MCC — Transdutor 8 - MCC

Figura 5.20 Deslizamentos experimentais e numéricos - Situação 2.

Quando ocorre separação entre os elementos de contato, numericamente não são mais calculados os valores de deslizamento. Por isso as curvas numéricas da Situação 3 apresentam trechos com valores constantes. 
Modelo 1

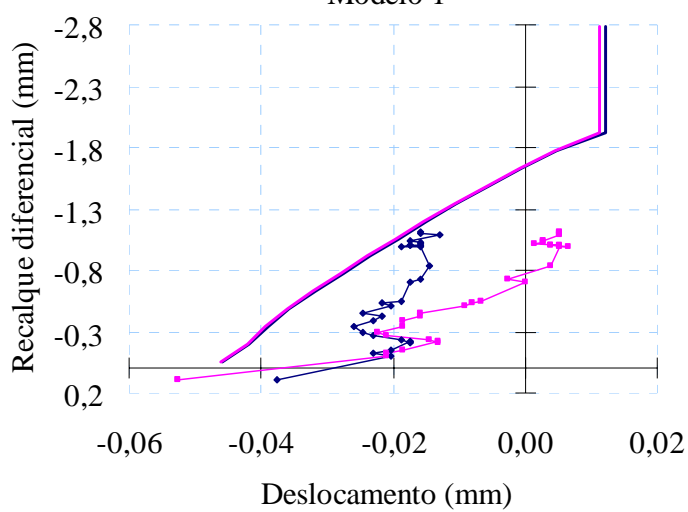

Modelo 3

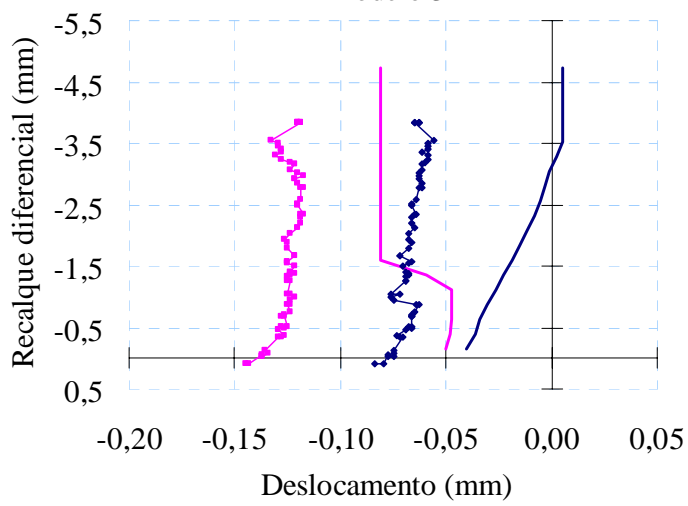

Modelo 5

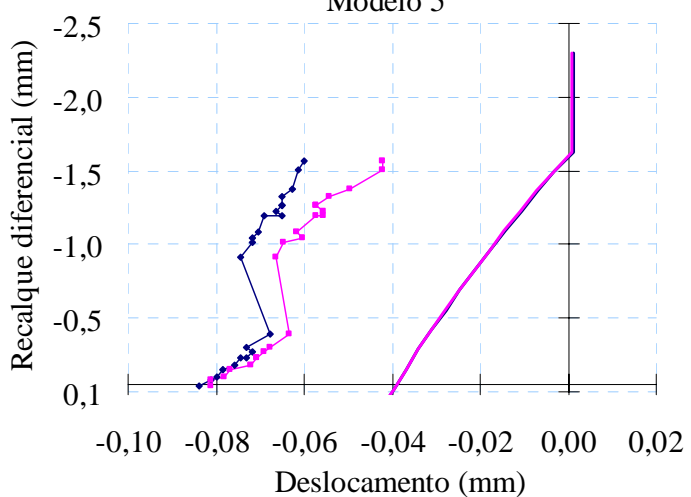

Modelo 2

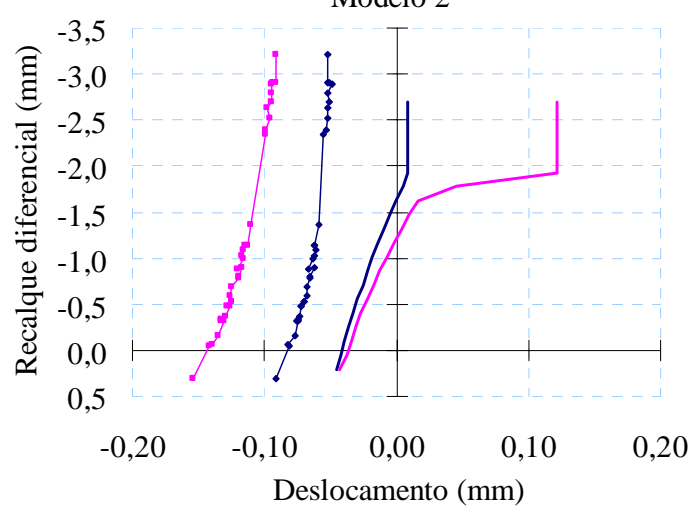

Modelo 4

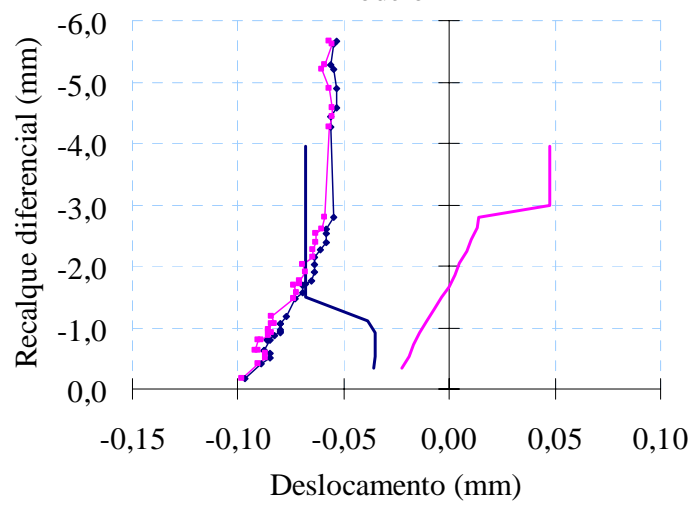

Modelo 6

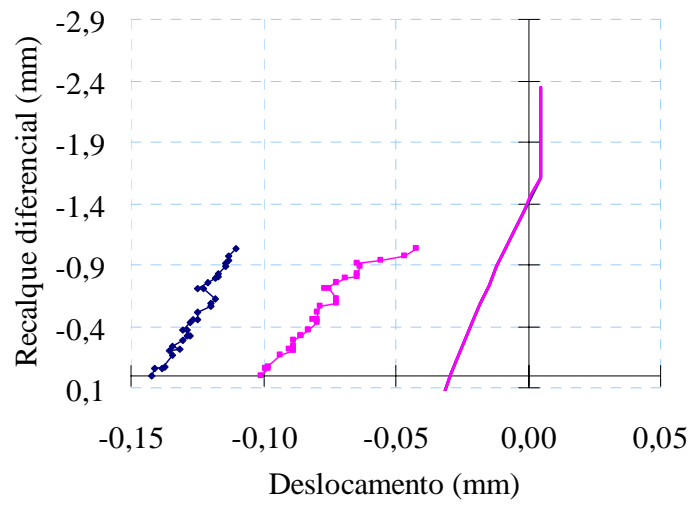

$\rightarrow$ Transdutor 7 - EXP $\rightarrow$ Transdutor 8 - EXP

- Transdutor 7 - MCC - Transdutor 8 - MCC

Figura 5.21 Deslizamentos experimentais e numéricos - Situação 3.

\subsubsection{Abertura de porta}

Observa-se na Figura 5.22 que os resultados numéricos de variação da abertura de porta dos modelos 3 e 4 estão coerentes com o comportamento verificado em laboratório. Os valores, entretanto, sofreram a mesma limitação dos deslizamentos, pois são conseqüência destes. 
Situação 1
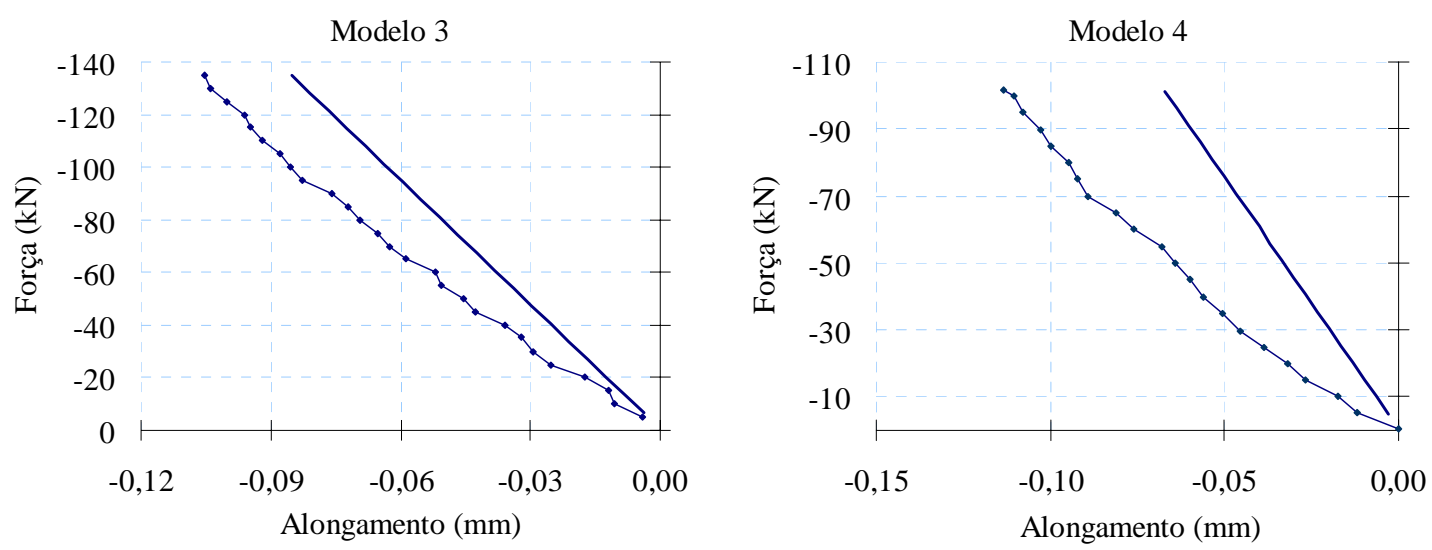

Situação 2

Modelo 3
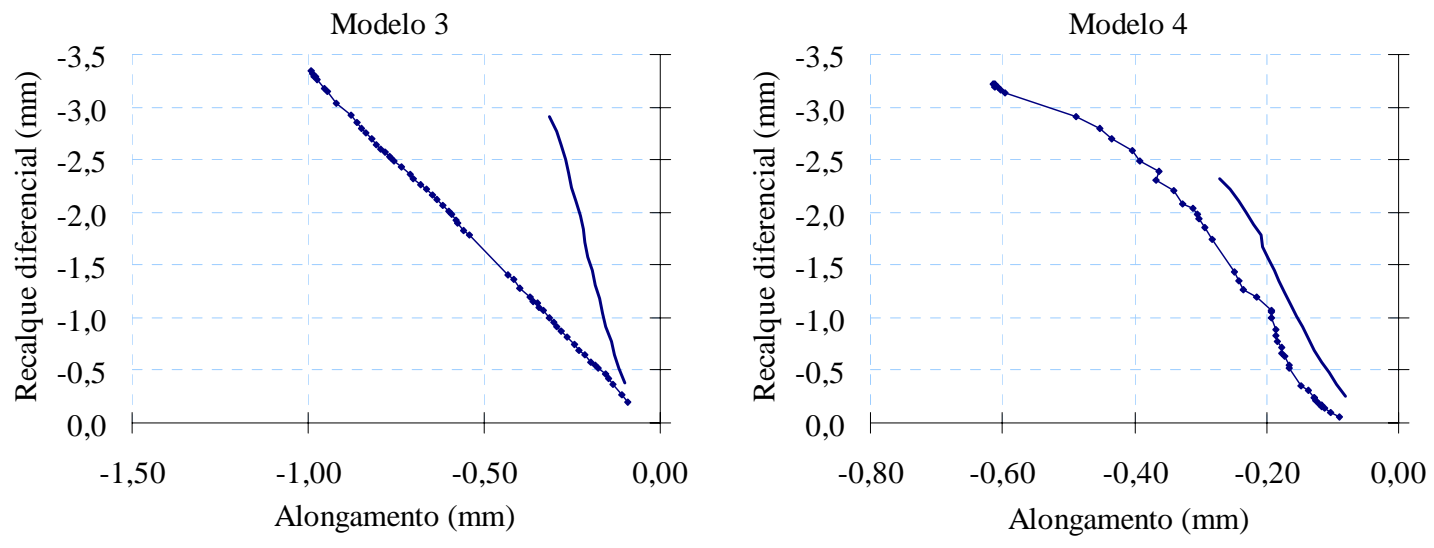

Situação 3

Modelo 3
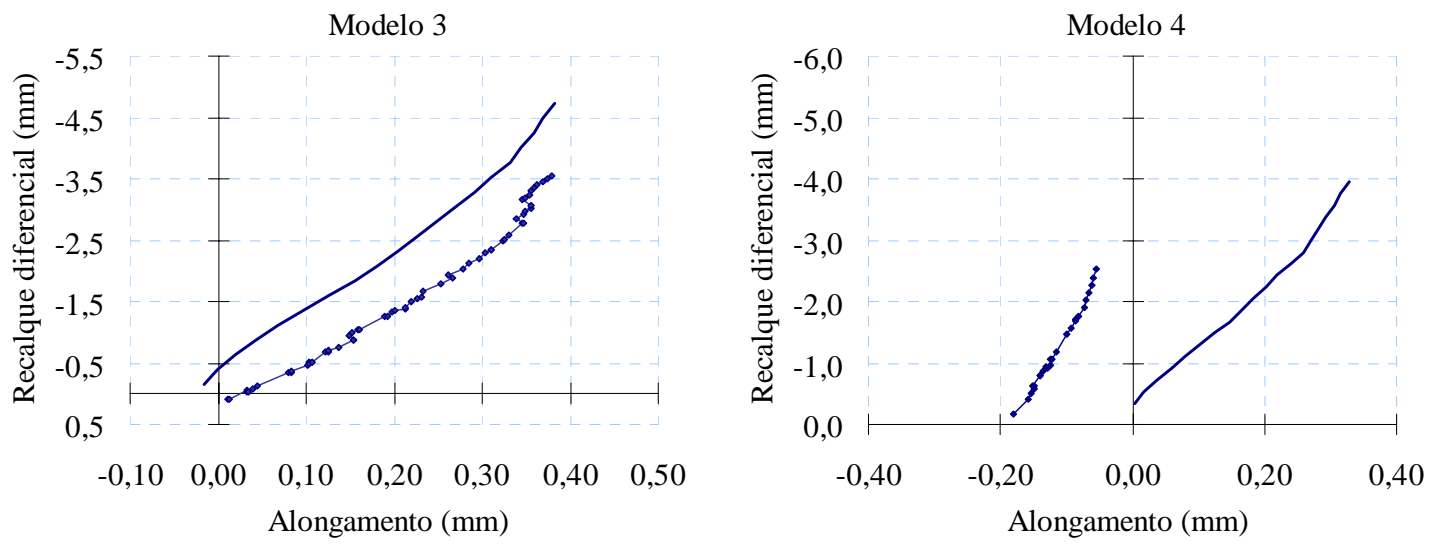

$\rightarrow$ Transdutor 13 - EXP — Transdutor 13 - MCC

Figura 5.22 Variação da abertura de porta: valores experimentais e numéricos.

\subsection{CONSIDERAÇÕES FINAIS}

A partir da comparação das análises numéricas com a experimental, verificou-se que os resultados da modelagem com elementos de contato (MCC) aproximaram-se mais dos experimentais que os da modelagem sem tais elementos (MSC). 
Com relação aos recalques totais e diferenciais máximos, a MCC forneceu boas aproximações em quase todos os casos, principalmente para os painéis sem abertura. Já os resultados da MSC ficaram, em geral, bem abaixo dos valores obtidos experimentalmente.

Nos gráficos de reações de apoio e deformações verticais da parede, as duas modelagens aproximaram-se bastante entre si e dos resultados experimentais na etapa de aplicação do carregamento vertical, quando o comportamento é predominantemente linear. Na Situação 2, as curvas da MCC acompanharam melhor, em comparação com as da MSC, o comportamento das curvas experimentais, apresentando valores próximos na maioria das comparações. Na Situação 3 as modelagens numéricas reproduzem as tendências de crescimento das curvas experimentais, porém com valores bastante diferentes, o que se atribui à não-linearidade dos materiais, não considerada nas modelagens.

Ao serem comparados qualitativamente os resultados, obtidos com ambas as modelagens, relacionados às deformações verticais ao longo da primeira fiada, foi possível observar uma distinção importante entre elas. Nas situações em que os recalques foram aplicados, a MSC acusou grandes deformações por tração nos cantos de portas e nas extremidades dos painéis. Porém, verificou-se experimentalmente que tais deformações não se desenvolveram. Como na MCC não surgiram esses grandes alongamentos e os aspectos dos diagramas correspondentes assemelharam-se aos experimentais, concluiu-se que neste caso a não-linearidade de contato também exerceu influência significativa.

A instrumentação empregada especialmente para fins de aferição dos resultados específicos dos elementos de contato forneceu valores muito coerentes com os numéricos. Verificou-se que as penetrações estimadas pelos elementos de contato mostraram-se bastante coerentes com os valores obtidos nos ensaios. Além disso, há indício de que as separações ocorridas no modelo numérico, forçadamente concentradas na interface parede-viga, distribuíram-se na forma de fissuras horizontais entre as primeiras fiadas dos painéis ensaiados.

Com relação aos deslizamentos e variações na abertura de portas, observou-se que eles realmente ocorreram e que os elementos de contato utilizados foram capazes de reproduzir os comportamentos experimentais, porém apresentando como resultados valores relativamente distantes dos obtidos nos ensaios. Essa imprecisão deve ser atribuída às limitações do modelo de contato utilizado.

Todas essas observações permitiram constatar a importância da consideração da não-linearidade de contato nas simulações numéricas.

O modelo de contato, entretanto, precisa ser aprimorado para que se obtenham resultados ainda melhores. O critério de cisalhamento, por exemplo, deveria contemplar mais 
parâmetros, como a resistência ao cisalhamento na ausência de pré-compressão $\left(\tau_{0}\right)$ e, se possível, permitir curvas bilineares.

Outra medida que pode ser adotada com o objetivo de melhorar os resultados numéricos é a incorporação da não-linearidade física dos materiais. Cabe avaliar, porém, se os ganhos em precisão valeriam a perda da simplicidade do modelo.

De modo geral, neste estudo verificou-se que problemas de paredes de alvenaria sobre vigas quando submetidas a recalques podem ser bem representados numericamente por uma modelagem relativamente simples, que considere a não-linearidade de contato. 


\section{CONCLUSÕES}

Nesta pesquisa foram estudados aspectos importantes relativos à patologia da alvenaria, com o auxílio de verificação experimental e simulação numérica. Dentre as causas de fissuração da alvenaria focalizou-se um tipo específico de ação externa: a ocorrência de recalques.

Os edifícios de alvenaria estrutural são mais suscetíveis a apresentar fissuras devido a recalques que edifícios com estrutura de concreto armado ou aço. Nestes casos, as estruturas de vedação, mais sensíveis quanto ao recalque, são colocadas depois de ocorrida uma certa acomodação. Ao contrário, quando o sistema construtivo é a alvenaria estrutural, a construção das paredes é simultânea à ocorrência dos recalques iniciais.

A fissuração decorrente dos recalques normalmente afeta as condições de serviço, prejudicando a estética, a estanqueidade e o conforto do usuário. Entretanto, danos estruturais podem ser percebidos, principalmente quando não há restrição suficiente para evitar a continuidade da propagação de fissuras.

Fissuras provocadas por recalque são caracterizadas por geralmente se desenvolverem em direção vertical ou diagonal, apresentando variação da abertura ao longo do comprimento. Esta afirmação foi comprovada experimentalmente, porém pode-se acrescentar a direção horizontal, nos casos em que a configuração deformada da fundação apresenta concavidade para cima. Em todos os modelos ensaiados se observou a formação de fissuras horizontais próximas à base da parede nesses casos.

Encontra-se na literatura que o principal parâmetro indicativo da probabilidade de danos às estruturas é a curvatura da fundação dada pelos recalques. Sendo grande a dificuldade de se medir curvatura, outros parâmetros que fornecem valores aproximados foram sugeridos: a razão de deflexão $\Delta / \mathrm{L}$ e a rotação relativa $\delta / \ell$. O primeiro constitui uma aproximação melhor para a curvatura, porém o segundo é de mais fácil obtenção.

Não há consenso quanto ao valor limite de $\Delta / \mathrm{L}$ a partir do qual podem ocorrer danos aos edifícios. As recomendações obtidas na literatura consultada variam entre 1/1000 e 
1/3333. Quanto ao parâmetro $\delta / \ell$, é mencionado que a partir do limite $1 / 300$ pode haver início de fissuração. Embora este valor tenha sido citado em três referências, pode-se dizer que ele possui basicamente apenas uma origem. Desta forma, não foi possível obter uma opinião mais conclusiva e geral.

Procurou-se, então, identificar limites para esses parâmetros a partir dos resultados dos ensaios realizados. Na comparação entre os valores dos parâmetros nos instantes de surgimento da primeira fissura de cada painel percebeu-se não haver concordância suficiente para se estabelecer um limite único.

Antes da realização dos ensaios dos modelos, verificou-se que elementos mais simples (prismas e paredinhas) confeccionados com os mesmos materiais em escala reduzida reproduziram os modos de ruptura observados em escala real. O sucesso obtido com esta avaliação é indicativo de que os resultados dos ensaios dos painéis podem ser utilizados como representativos de situações em escala real.

Uma visão relativamente abrangente sobre os efeitos de recalques em painéis de alvenaria foi possibilitada pela realização do programa experimental. Foram variados alguns dos parâmetros mais importantes: existência e tipo de abertura e rigidez da viga. Além disso, foram verificadas algumas alternativas de grauteamento. A disposição adotada para os apoios permitiu de maneira simples a aplicação das duas principais configurações deformadas da fundação representada pela viga: concavidade para cima e concavidade para baixo.

Os modelos de painéis foram ensaiados em três etapas:

- Situação 1: Aplicação do carregamento vertical;

- Situação 2: Recalque do apoio central;

- Situação 3: Recalque do apoio de extremidade.

Em geral, observou-se que na primeira situação os painéis se comportaram linearmente, conforme se esperava. Nas demais, foi possível distinguir algumas fissuras típicas em função da presença e do tipo de abertura.

Na Situação 2, percebeu-se em todos os modelos, com exceção do Modelo 6, a ocorrência de fissuras horizontais entre as primeiras fiadas nas proximidades do apoio central. Suas extensões foram aparentemente limitadas pelos arcos de compressão.

Nos modelos sem abertura surgiram fissuras diagonais escalonadas nas regiões de maior tensão de cisalhamento. Adicionalmente, no Modelo 1, formaram-se fissuras aparentemente provocadas por tensões de tração perpendiculares ao arco de compressão em 
um dos cantos do painel. A viga mais rígida do Modelo 5 deve ter propiciado um maior comprimento de contato, diminuindo a concentração de tensões nas extremidades do painel.

Aberturas de janela provocaram a concentração de tensões de cisalhamento logo abaixo delas. Isso provocou a formação de fissuras diagonais passando pelas juntas. Observou-se que estas regiões exibiram fissuração bastante intensa. No caso das portas, tensões de tração induzidas em um dos seus cantos inferiores provocaram a abertura de fissuras nesses locais. As regiões das vergas também concentraram fissuras por causa das altas tensões e das descontinuidades caracterizadas pelas aberturas.

A não ocorrência de fissuras horizontais entre as primeiras fiadas do Modelo 6 pode indicar que o grauteamento dos furos centrais foi eficiente para combatê-la. Em contrapartida, a modificação da distribuição das tensões na parede, induzida em conjunto pelo grauteamento e pela cinta, provocou o aparecimento indesejado de fissuras por cisalhamento também nos cantos superiores.

Com relação ao Modelo 7, não se percebeu contribuição da contraverga no combate à fissuração, pois a formação de fissuras foi tão ou até mais intensa que no Modelo 4. Por sua vez, a fissura horizontal no canto inferior da porta possivelmente seria evitada com a ancoragem na viga da armadura vertical do furo grauteado.

Na Situação 3, observou-se em quase todos os modelos a formação abrupta de uma fissura principal dividindo a parede ao meio. Nos painéis com abertura de janela, essa fissura foi desviada, passando pela própria janela. Assim como na situação anterior, as regiões abaixo das janelas, os cantos inferiores das portas e as regiões de vergas concentraram fissuração.

Verificou-se nos modelos 6 e 7 que a utilização da cinta de topo não evitou a divisão da parede, porém tornou a propagação da fissura mais lenta e deixou o painel em condição estável, mesmo após a retirada total do apoio de extremidade. Novamente a contraverga não se mostrou eficiente no combate à fissuração.

$\mathrm{Na}$ etapa de aplicação do carregamento vertical, pode-se considerar que as reações de apoio aumentaram linearmente em todos os modelos. Ao ser imposto o deslocamento ao apoio central percebeu-se nitidamente a redistribuição da carga que este suportava. As reações dos apoios de extremidade aumentaram gradativamente até que a carga total fosse dividida entre eles. Observou-se uma tendência da taxa de transferência de cargas ser linear até aproximadamente o instante da primeira fissura do painel, tornando-se então não-linear. Percebeu-se comportamento equivalente na Situação 3. 
Comparando-se os valores experimentais dos recalques diferenciais máximos de todos os painéis na Situação 2, verificou-se que as aberturas exerceram influência significante. Com relação ao Modelo 1, o recalque diferencial máximo do Modelo 2 foi $25 \%$ maior, enquanto que houve aumento de aproximadamente $100 \%$ para os modelos 3 e 4 .

Já no Modelo 5, o aumento de 83\% de rigidez da viga provocou uma queda de apenas cerca de $7 \%$ do recalque diferencial máximo com relação ao Modelo 1 . O grauteamento aplicado ao Modelo 6 foi mais eficiente, permitindo que o recalque diferencial máximo fosse 25\% menor que o do Modelo 1.

Os resultados dos ensaios físicos também foram utilizados para validar as simulações numéricas realizadas. Buscou-se representar o problema por meio de uma modelagem simples capaz de contemplar as principais características observadas nos ensaios. Foi empregado um programa computacional comercial baseado no Método dos Elementos Finitos.

De acordo com a revisão bibliográfica, adotou-se a macro-modelagem da alvenaria, uma vez que o objetivo era verificar o comportamento global de painéis com dimensões consideravelmente maiores que suas unidades constituintes. Considerou-se estado plano de tensão e aos materiais foram atribuídas propriedades elásticas, lineares e isotrópicas.

A importância de consideração da não-linearidade de contato foi verificada com o uso de elementos de contato representando a junta entre parede e viga. Desta forma, tornou-se necessária a caracterização dessa interface.

Os parâmetros de cisalhamento da junta parede-viga foram obtidos experimentalmente, adaptando-se o ensaio de cisalhamento de tripletas, o qual é indicado na literatura como capaz de produzir os melhores resultados, dentre os diversos tipos de ensaio de cisalhamento de juntas. A adaptação consistiu na substituição de dois blocos cerâmicos por paralelepípedos de dimensões similares, constituídos do mesmo concreto usado na viga. Considera-se que se obteve êxito nesta caracterização.

Então, foram realizadas análises numéricas com duas modelagens, que se distinguem pela utilização ou não dos elementos de contato. Os resultados de ambas foram confrontados com os experimentais.

Verificou-se que a modelagem com elementos de contato representou melhor o problema estudado. As curvas desenhadas a partir dos seus resultados acompanharam melhor as curvas experimentais, geralmente apresentando valores próximos. Em geral, esta modelagem também forneceu boas aproximações para os recalques máximos na Situação 2. 
Além disso, a distribuição das deformações ao longo da primeira fiada da parede foram mais bem representadas pela modelagem com elementos de contato, pois verificou-se experimentalmente não ocorrerem concentrações de tração nos cantos de aberturas de portas.

Os resultados específicos dos elementos de contato ficaram coerentes com as leituras da instrumentação da região de interface. Porém, concluiu-se que o critério de cisalhamento desses elementos necessita aprimoramento, de forma a representar melhor o modelo teórico e o comportamento experimental.

Em resumo, foi verificada a importância da consideração da não-linearidade de contato em problemas de paredes sobre vigas submetidas a recalques. Também se verificou que a modelagem adotada forneceu bons resultados.

Para pesquisas futuras pode-se citar como interessante o estudo experimental sistemático de painéis com o objetivo de determinar valores limites dos parâmetros de curvatura da fundação a partir dos quais surgiriam danos nas estruturas de alvenaria. Medições de campo podem ser utilizadas para enriquecer as análises.

Aumentar a ductilidade da alvenaria pode se mostrar como uma boa maneira de minimizar a fissuração. Dessa forma, a avaliação de alternativas como a colocação de armadura horizontal nas juntas torna-se um tema bastante relevante.

$\mathrm{Na}$ área de análise numérica, indicam-se a incorporação da não-linearidade física dos materiais e consideração da ortotropia da alvenaria nas simulações e o aprimoramento do modelo de contato. Tais medidas podem ser de grande valia para a obtenção de resultados mais próximos dos experimentais.

Além disso, consideram-se interessantes estudos de painéis com características diversas das avaliadas neste trabalho, possibilitando uma visão mais abrangente sobre o tema. Por exemplo, sugerem-se análises com a consideração do solo em vez dos apoios discretos e análises tridimensionais para a representação de cantos e encontros de paredes.

A correlação entre os resultados experimentais de modelos e protótipos constitui um tema importante para todas as pesquisas que envolvem ensaios de alvenaria em escala reduzida. Por sua complexidade, o assunto requer estudos aprofundados a fim de contemplar todas as variáveis envolvidas. Sem dúvida, o êxito nessa linha de pesquisa representaria um importante avanço científico.

$\mathrm{Na}$ literatura foram encontrados alguns procedimentos simplificados para a determinação dos esforços atuantes em sistemas compostos por parede sobre viga biapoiada e, conseqüentemente, para o dimensionamento do conjunto. A adaptação do método, abrangendo os casos de parede sobre viga contínua pode ser interessante. 


\section{ANEXO}

As leituras da instrumentação dos modelos 1 a 6 são apresentadas neste anexo em forma de gráficos. Foram omitidas as leituras dos extensômetros posicionados na direção horizontal, que não são confiáveis por serem muito pequenas. Todos os resultados estão organizados por modelo e por situação de carregamento.

\section{MODELO 1}

\section{Situação 1}
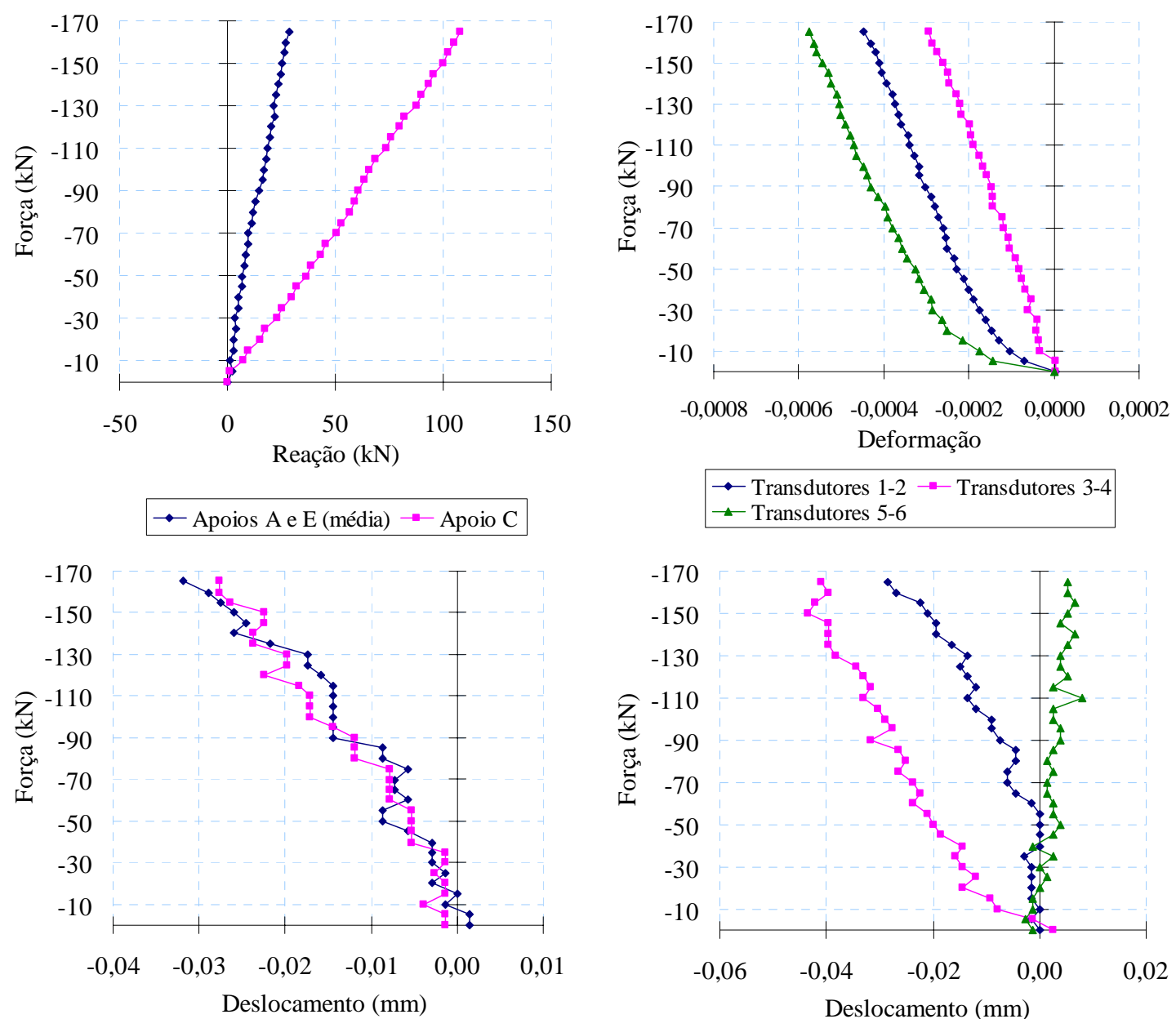

Transdutor $7 \rightarrow$ Transdutor 8

- Transdutores 1-2 - - Transdutores 3-4 Transdutores 5-6

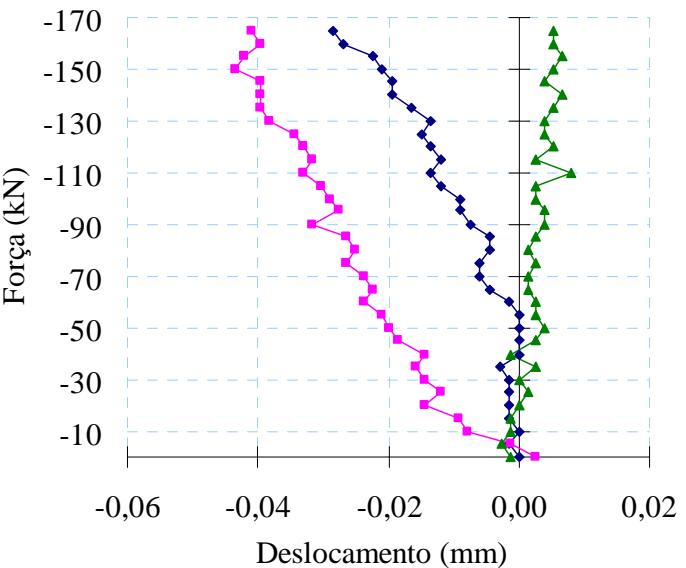

Transdutor $9 \rightarrow-$ Transdutor $10 \rightarrow$ Transdutor 11 


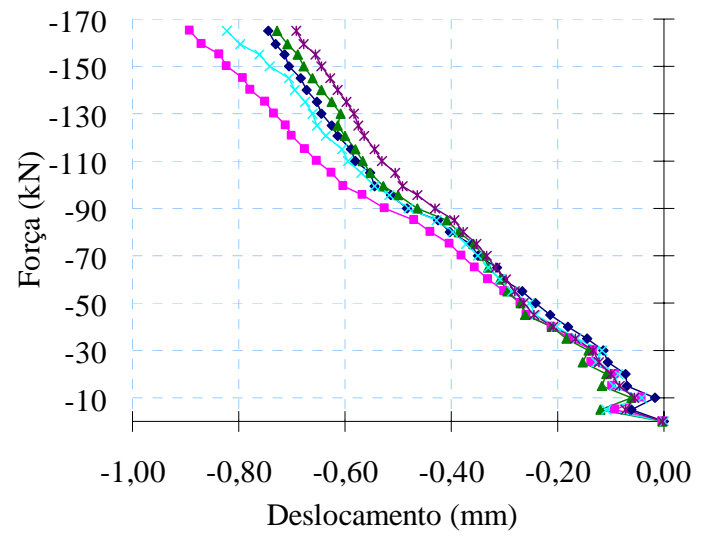

$\rightarrow$ Transdutor $12 \rightarrow$ Transdutor $13 \multimap$ Transdutor 14 Transdutor $15 \rightarrow-$ Transdutor 16

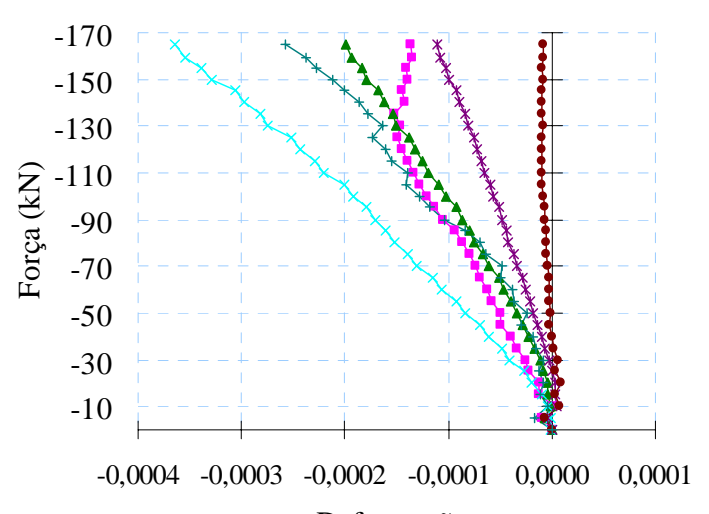

Deformação

$\begin{array}{ll}\rightarrow-\text { Extensômetro 21 } & \rightarrow \text { Extensômetro } 22 \\ \rightarrow \text { Extensômetro 23 } & \rightarrow \text { Extensômetro } 24 \\ \rightarrow \text { Extensômetro 25 } & \rightarrow \text { Extensômetro } 26\end{array}$

\section{Situação 2}

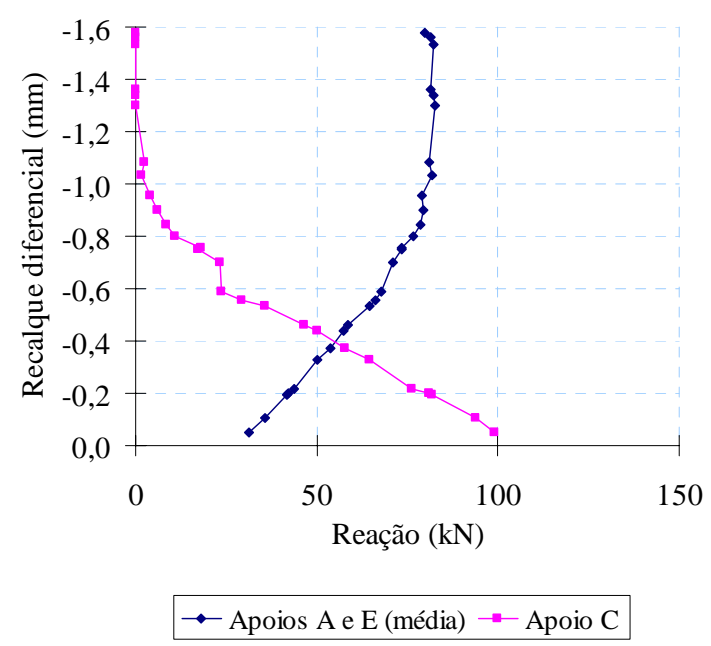

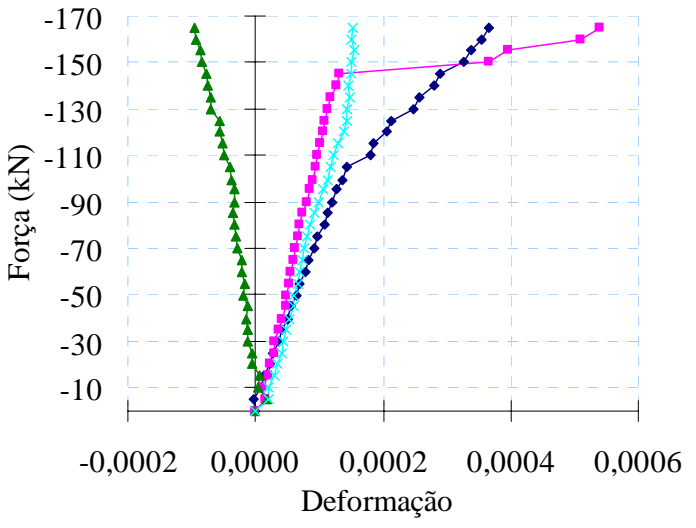

$\rightarrow$ Extensômetros 1-2 - - Extensômetros 3-4

- Extensômetros 5-6 $*$ Extensômetros 7-8

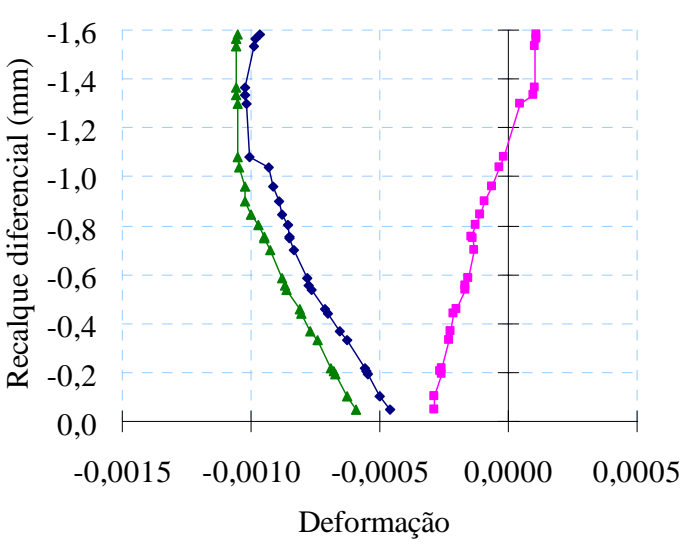

- Transdutores 1-2 - Transdutores 3-4

- Transdutores 5-6 

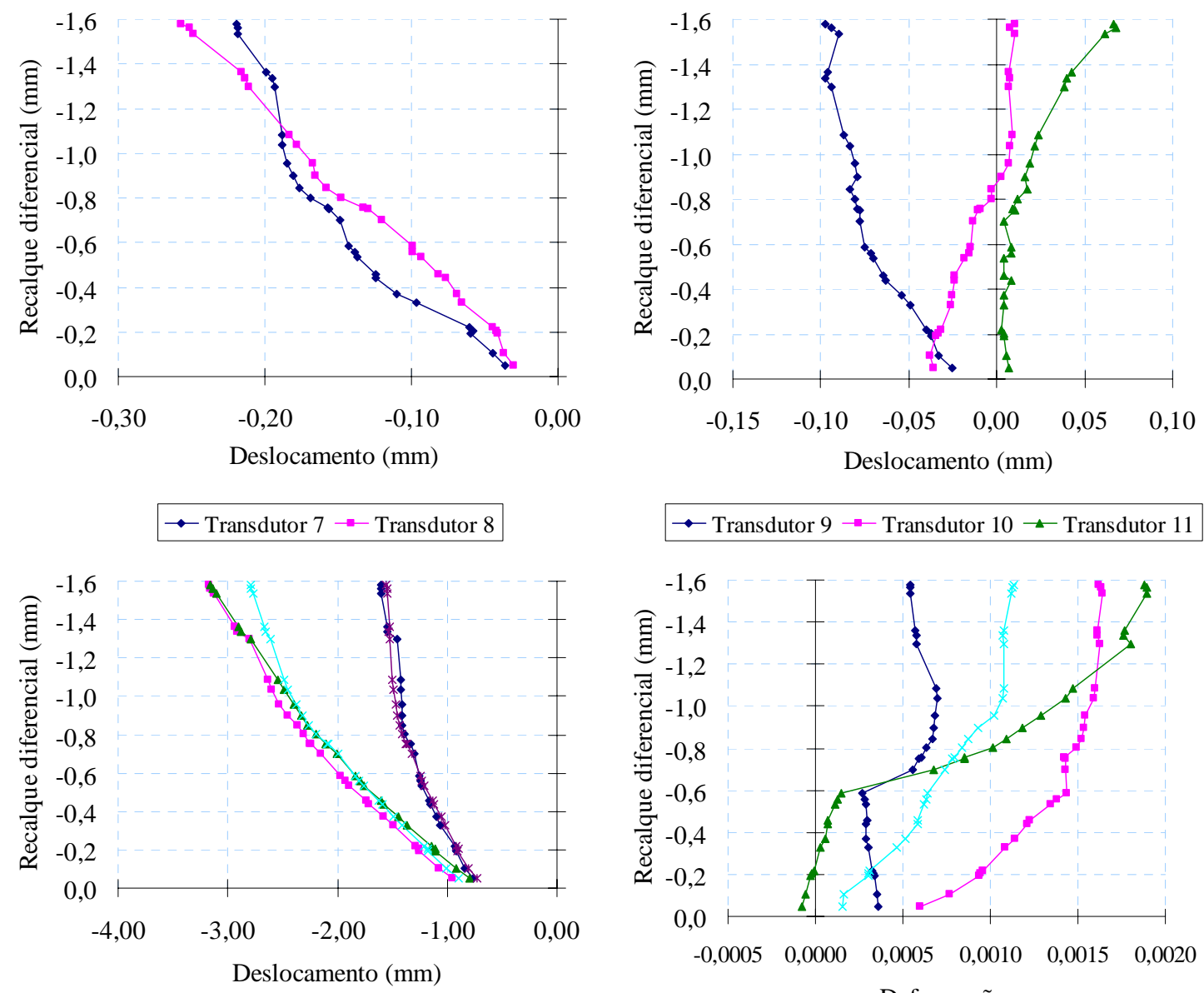

$\rightarrow$ Transdutor $9 \rightarrow-$ Transdutor $10 \rightarrow$ Transdutor 11

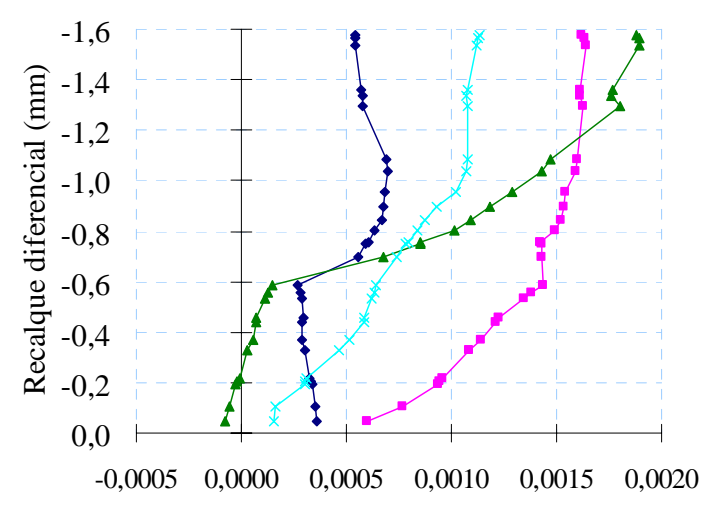

Deformação

$\rightarrow$ Transdutor $12-$ Transdutor $13 \rightarrow$ Transdutor 14 $\times$ Transdutor $15 *$ Transdutor 16

- Extensômetros 1-2 - Extensômetros 3-4

^-Extensômetros 5-6 $×$ Extensômetros 7-8

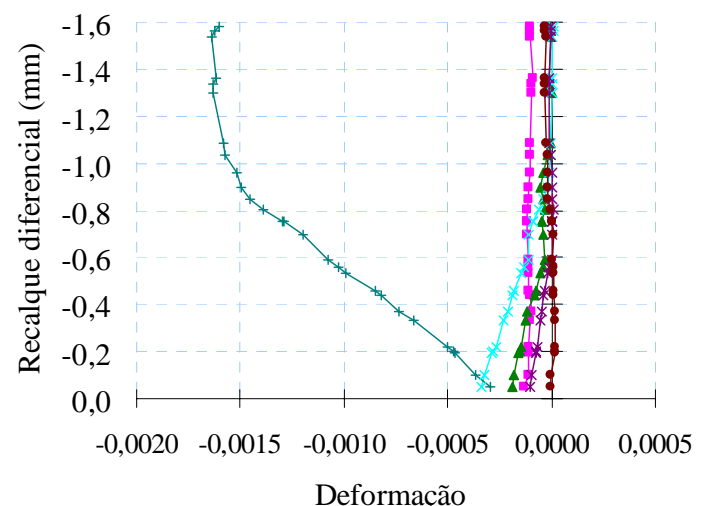

Deformação

$\begin{array}{ll}\rightarrow \text { - Extensômetro 21 } & \rightarrow \text { Extensômetro 22 } \\ \rightarrow \text { Extensômetro 23 } & * \text { Extensômetro 24 } \\ \rightarrow-\text { Extensômetro 25 } & \rightarrow \text { Extensômetro 26 }\end{array}$




\section{Situação 3}
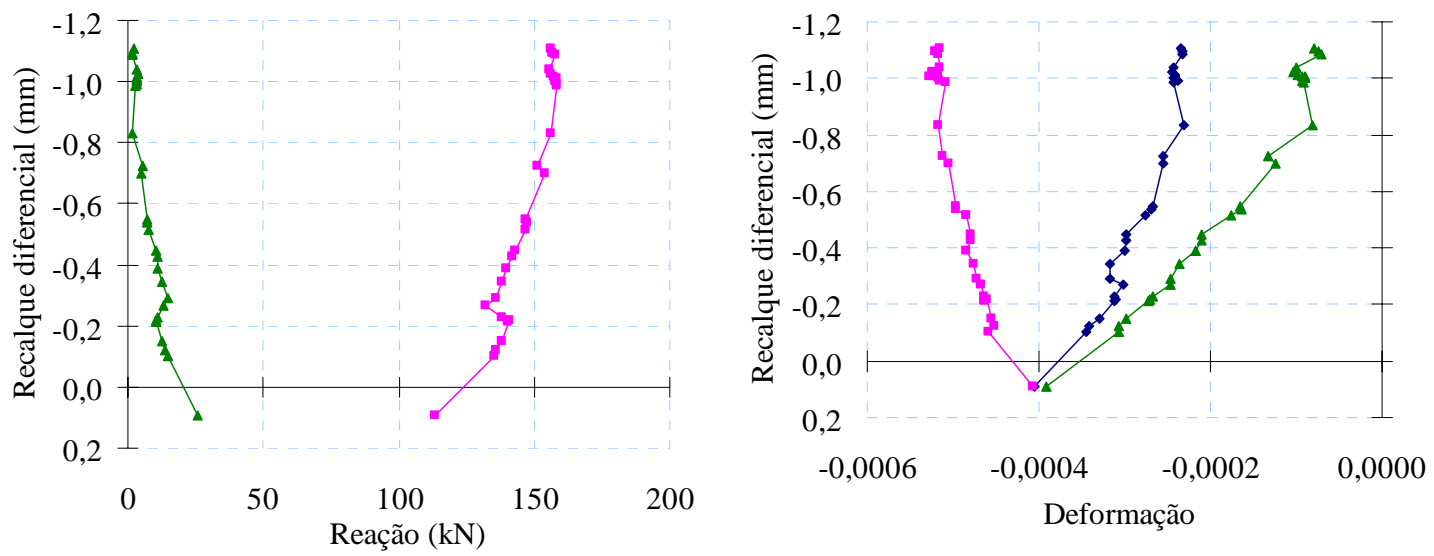

- Apoio C $\neg$ Apoios A e E (média)
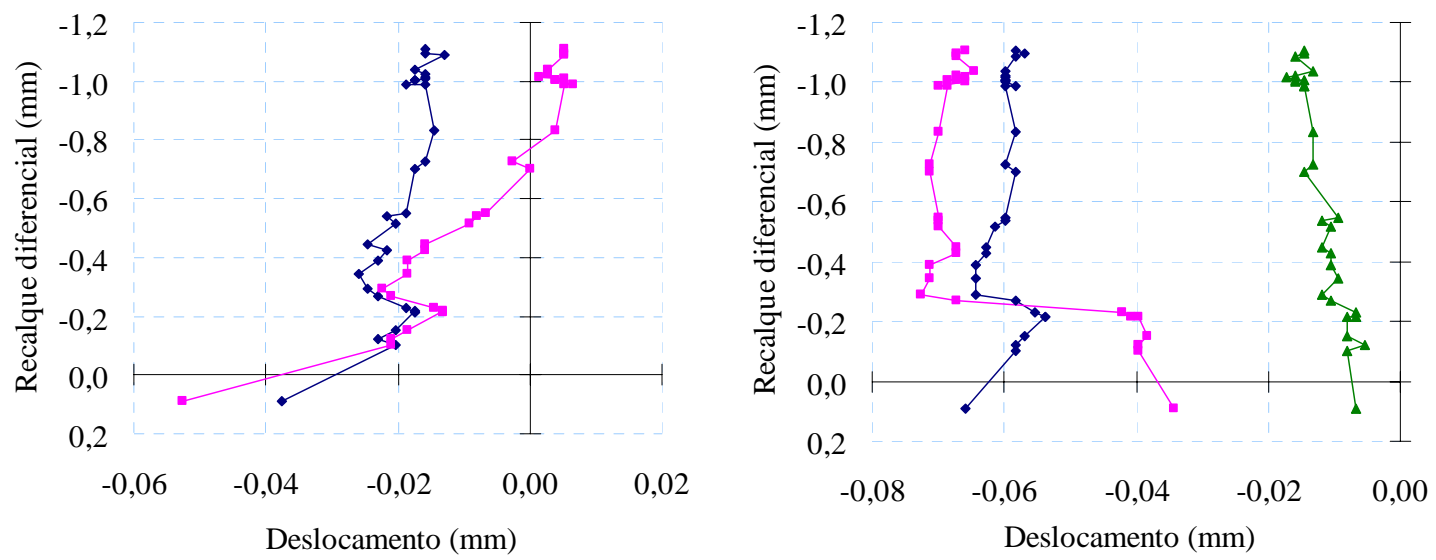

$\rightarrow$ Transdutor $7 \rightarrow$ Transdutor 8

- Transdutor $9 \rightarrow$ Transdutor $10 \multimap$ Transdutor 11
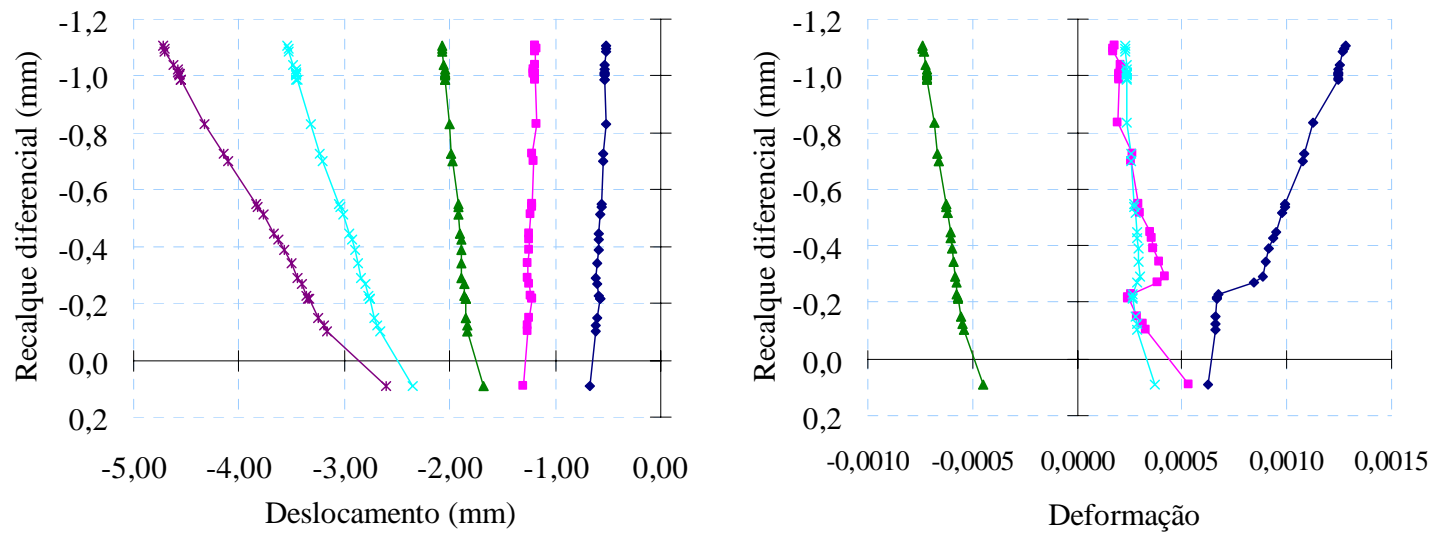

- Transdutor $12 \rightarrow$ Transdutor $13 \multimap$ Transdutor 14 Transdutor $15 \rightarrow$ Transdutor 16 


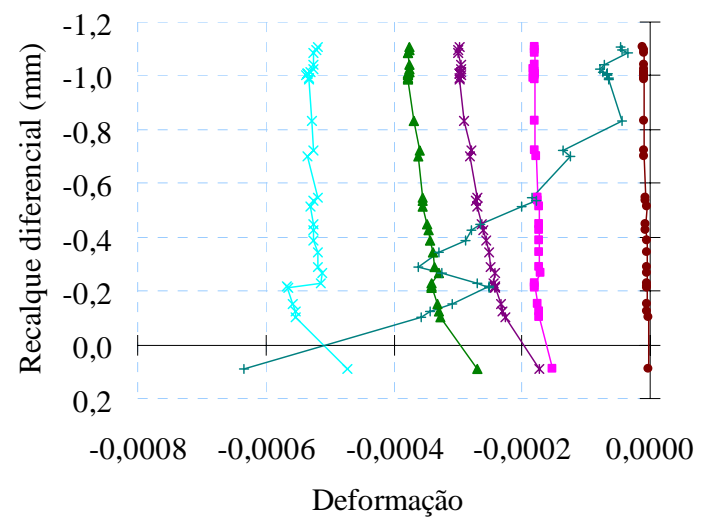

- Extensômetro $21 \leadsto$ Extensômetro 22

Extensômetro $23 \rightarrow$ * Extensômetro 24

Extensômetro $25 \div$ Extensômetro 26

\section{MODELO 2}

\section{Situação 1}
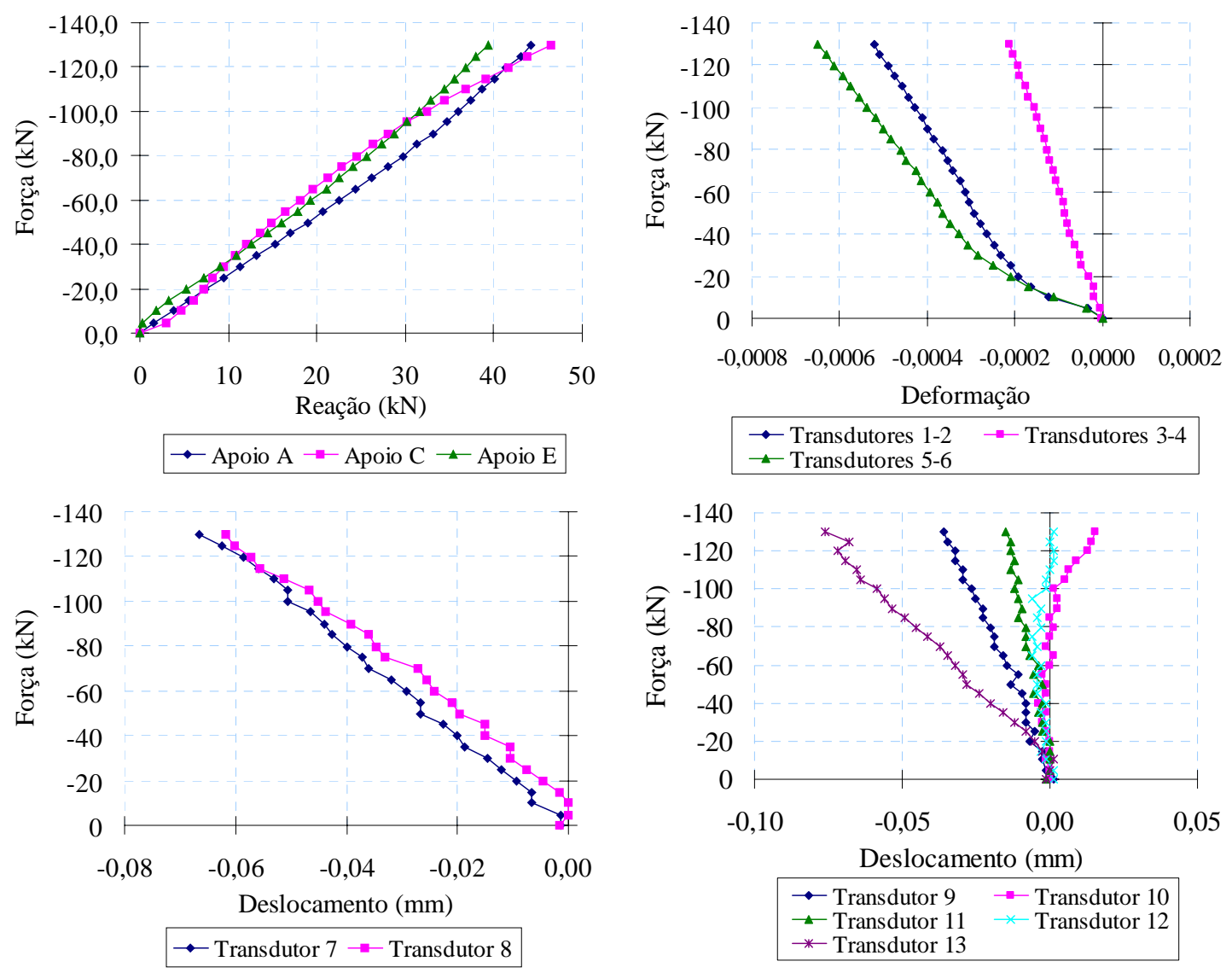

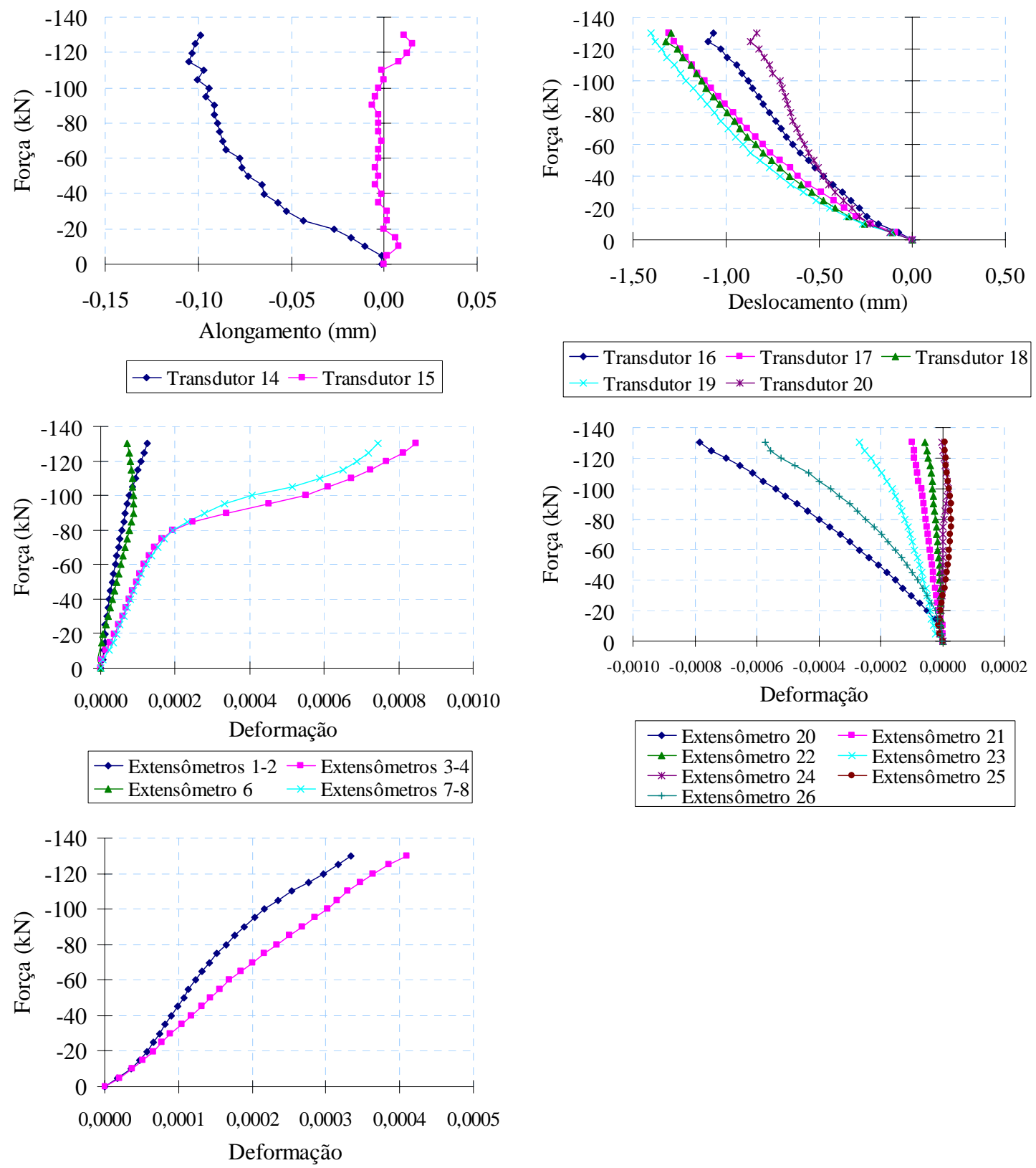

$\begin{array}{ll}\rightarrow-\text { Extensômetro 20 } & \rightarrow \text { - Extensômetro 21 } \\ \rightarrow \text { Extensômetro 22 } & \rightarrow \text { Extensômetro 23 } \\ \rightarrow \text { Extensômetro 24 } & \rightarrow \text { Extensômetro 25 } \\ \rightarrow \text { - Extensômetro 26 } & \end{array}$

Extensômetro $27 \rightarrow-$ Extensômetro 28 


\section{Situação 2}
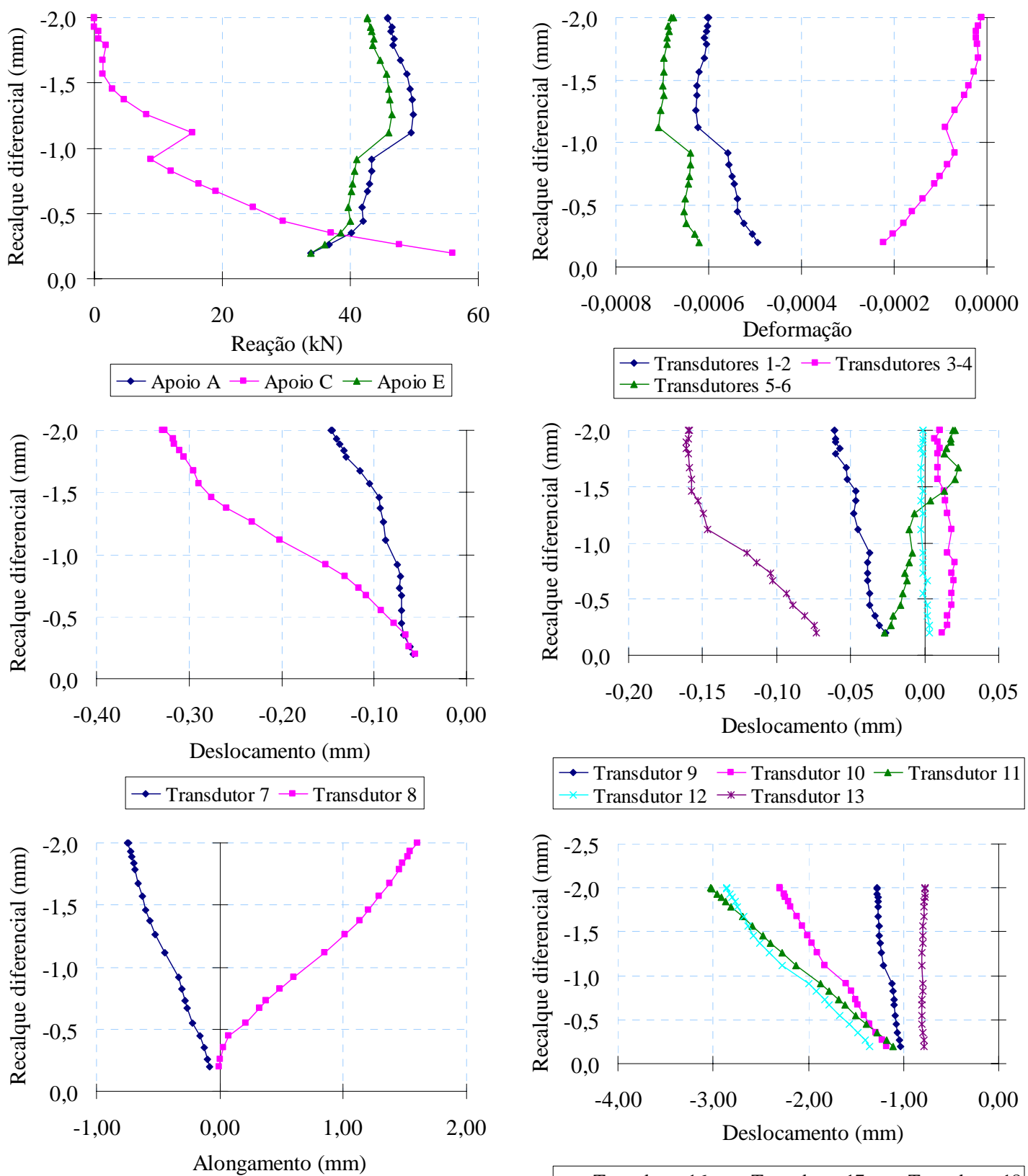

$\rightarrow$ Transdutor $14-$ Transdutor 15

Transdutor $16 \rightarrow$ Transdutor $17 \rightarrow$ Transdutor 18 Transdutor $19 *$ Transdutor 20 

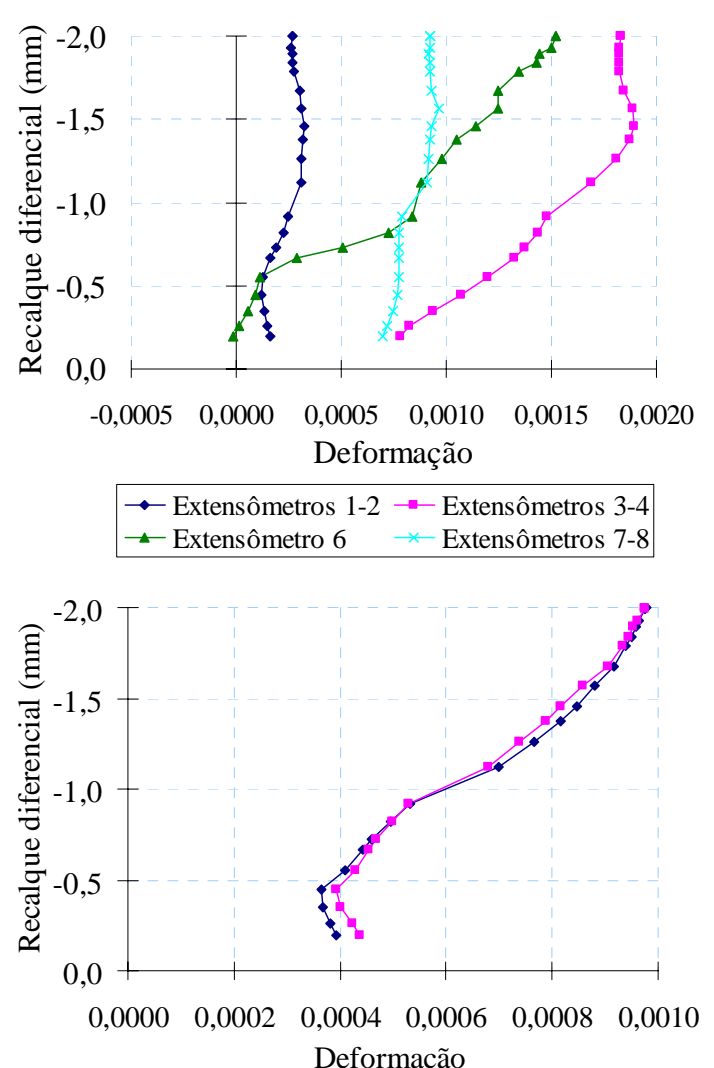

Extensômetro 27 - Extensômetro 28

\section{Situação 3}

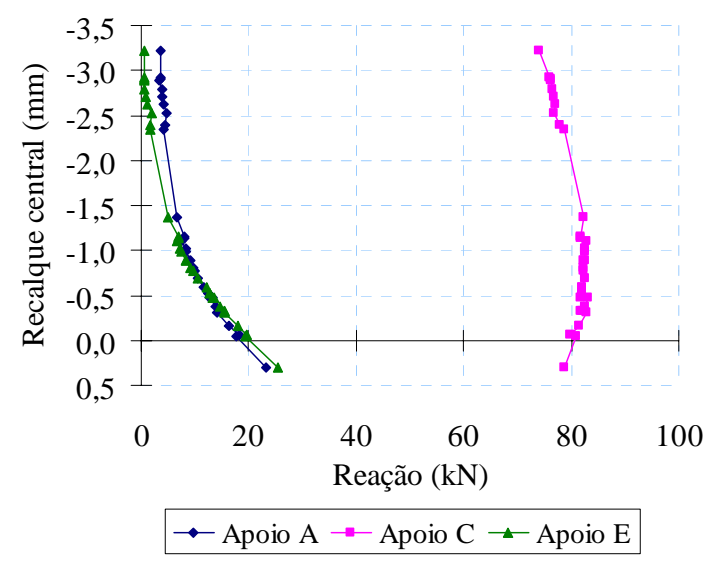

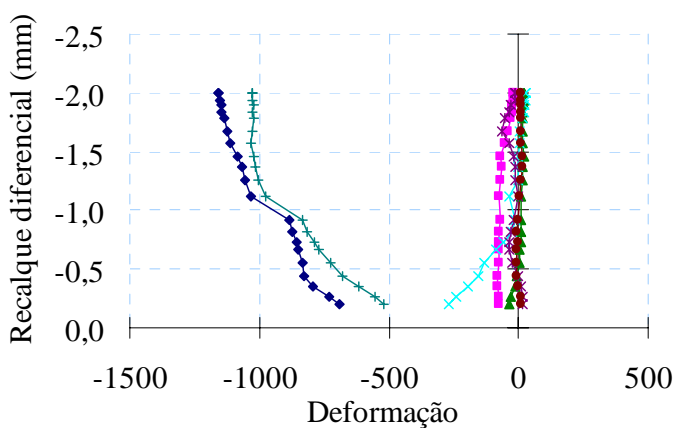

$\rightarrow$ Extensômetro $20 \rightarrow$ Extensômetro 21 - Extensômetro $22 \rightarrow$ Extensômetro 23

* Extensômetro $24 \rightarrow$ Extensômetro 25 Extensômetro 26

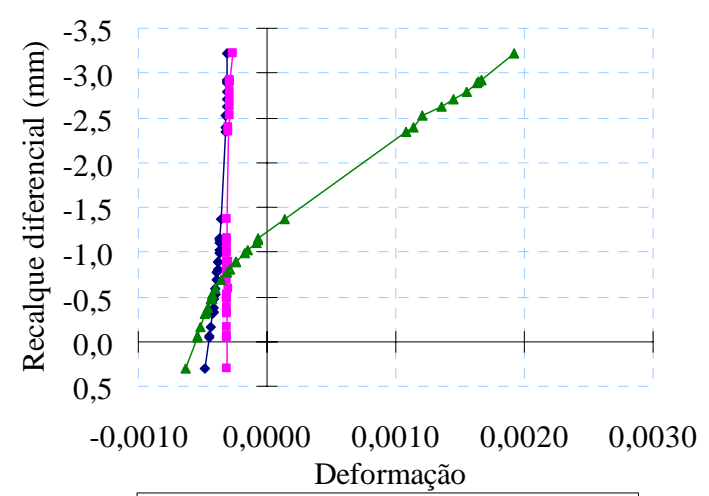

- Transdutores 1-2 - - Transdutores 3-4 $\_$Transdutores 5-6 


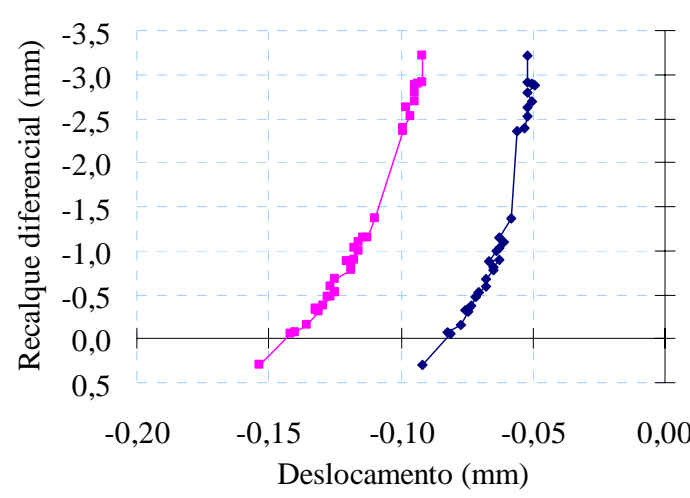

$\rightarrow$ Transdutor $7 \rightarrow-$ Transdutor 8

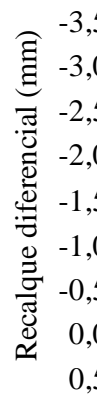

$\begin{array}{llllll}-0,50 & 0,00 & 0,50 & 1,00 & 1,50 & 2,00\end{array}$

Alongamento (mm)

- Transdutor $14 \rightarrow$ Transdutor 15

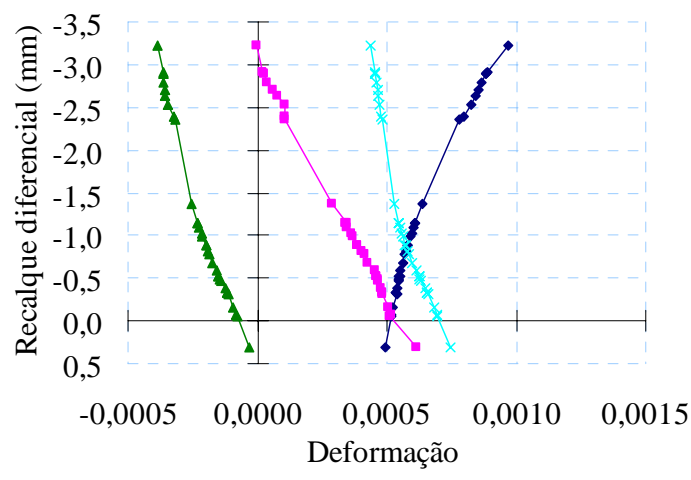

$\rightarrow$ Extensômetros 1-2 $\rightarrow$ - Extensômetros 3-4

$\leftarrow$ Extensômetro $6 \rightarrow$ Extensômetros 7-8

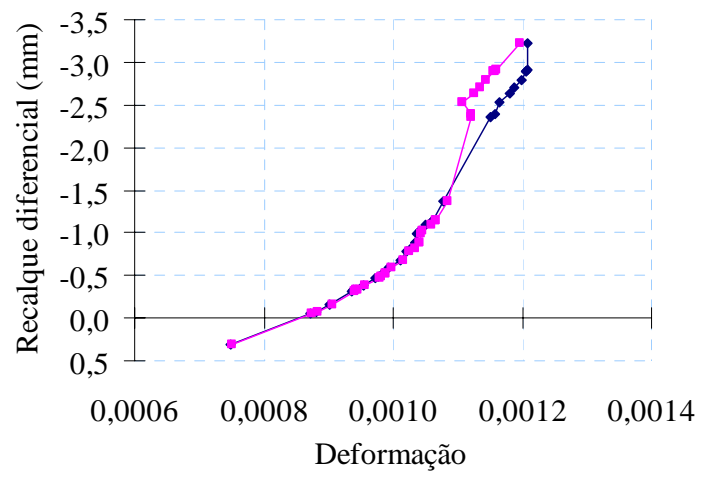

- Extensômetro $27-$ - Extensômetro 28

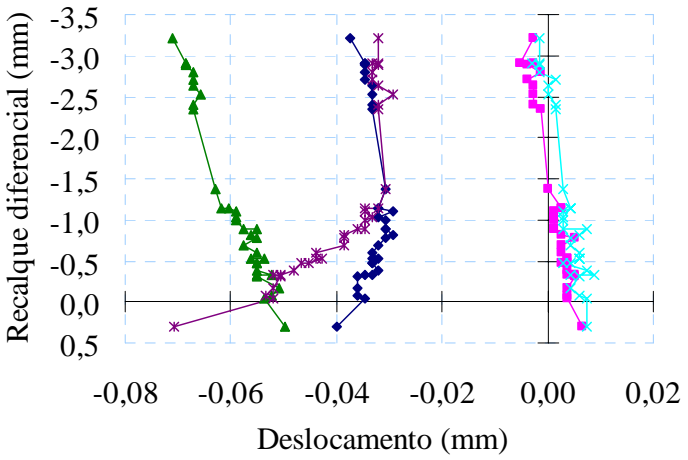

- Transdutor $9 \rightarrow$ Transdutor $10 \backsim$ Transdutor 11 Transdutor $12 *$ Transdutor 13

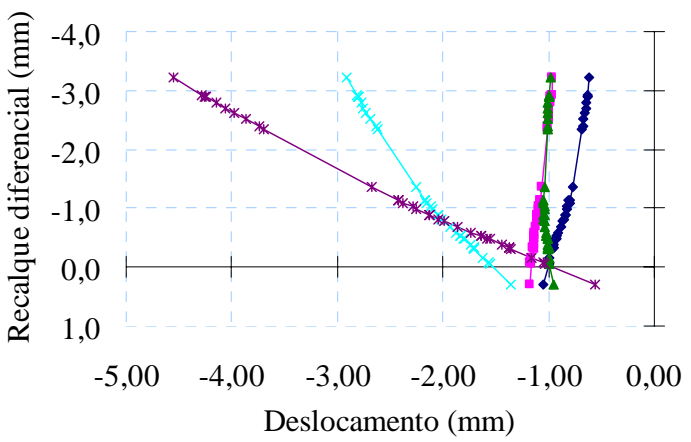

- Transdutor $16-$ Transdutor $17 \multimap$ Transdutor 18 Transdutor $19 *$ Transdutor 20

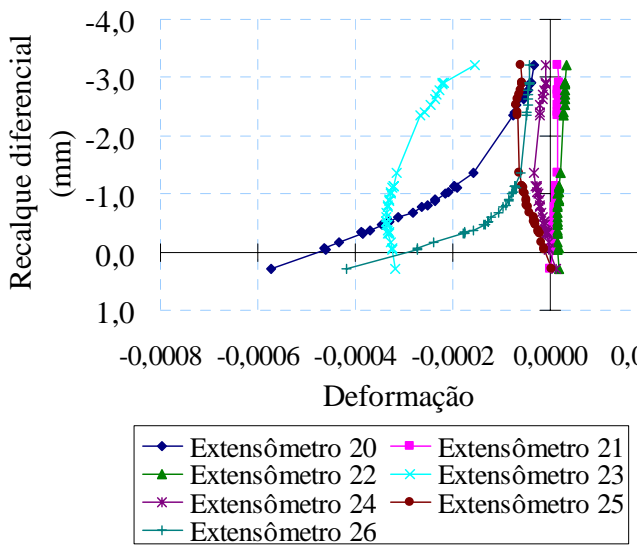




\section{MODELO 3}

\section{Situação 1}
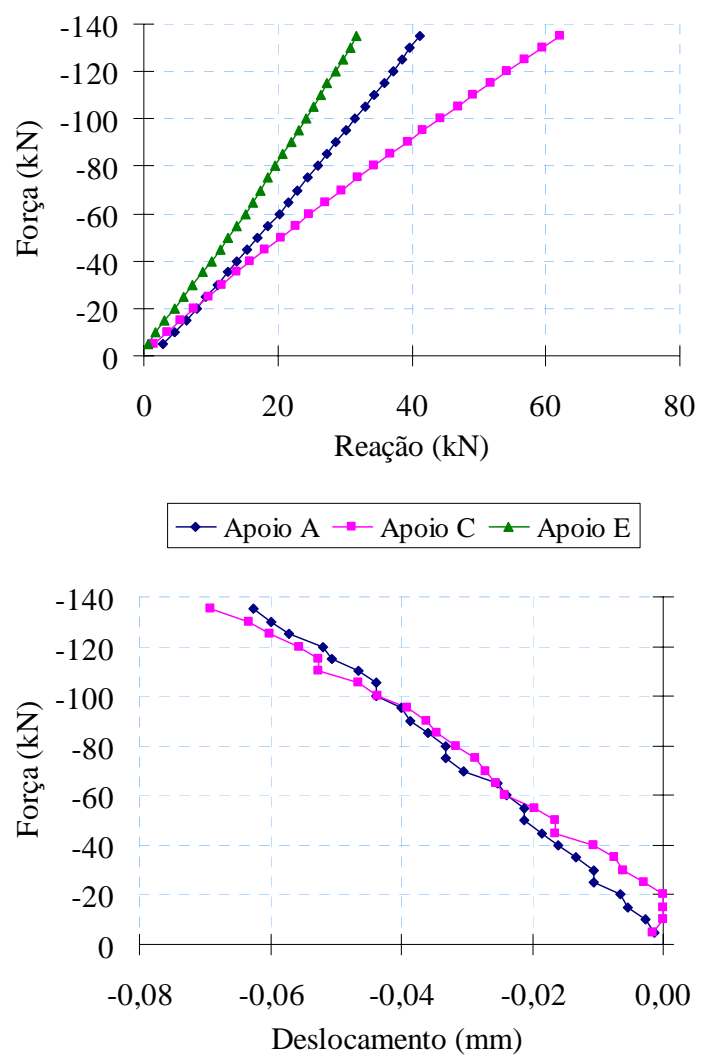

$\rightarrow$ Transdutor $7 \rightarrow-$ Transdutor 8

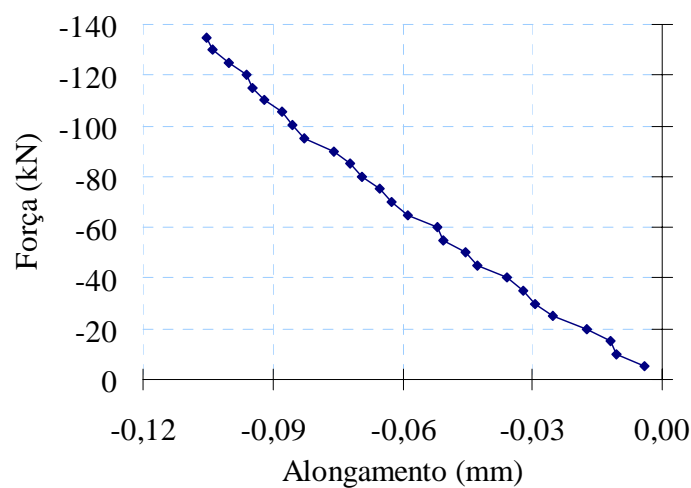

Transdutor 13

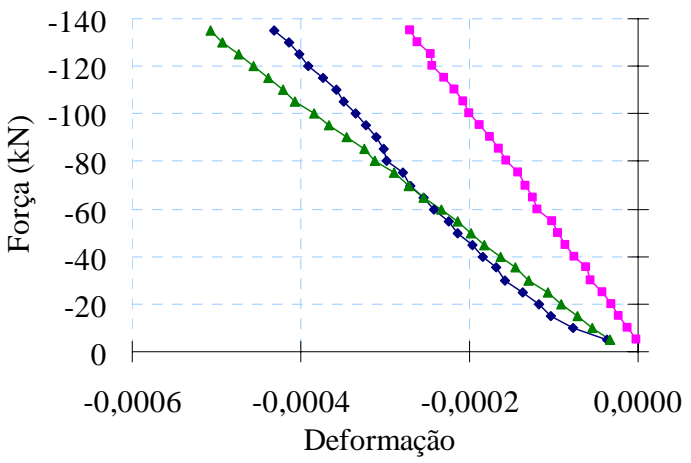

- Transdutores 1-2 - - Transdutores 3-4 Transdutores 5-6

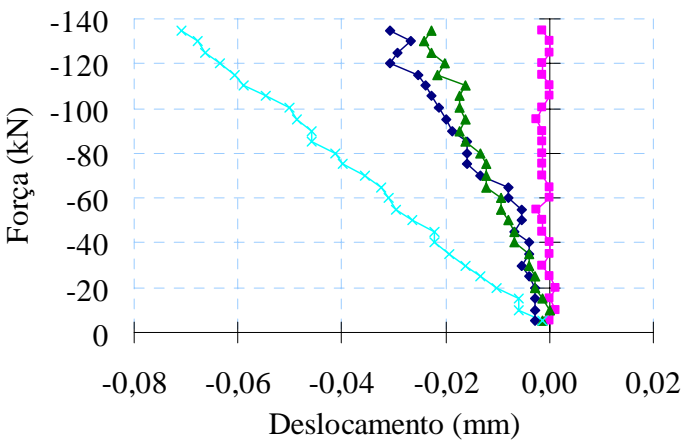

- Transdutor $9 \rightarrow$ Transdutor 10

$\leftarrow$ Transdutor $11 \rightarrow$ Transdutor 12

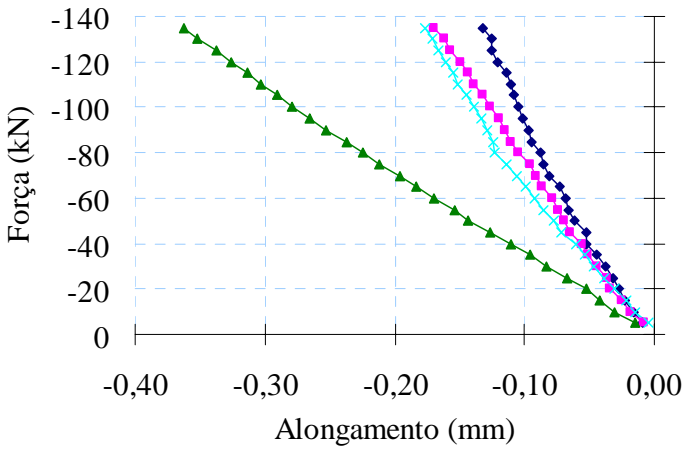

$\rightarrow$ Transdutor $14 \rightarrow-$ Transdutor 15

Transdutor $16 \rightarrow$ Transdutor 17 


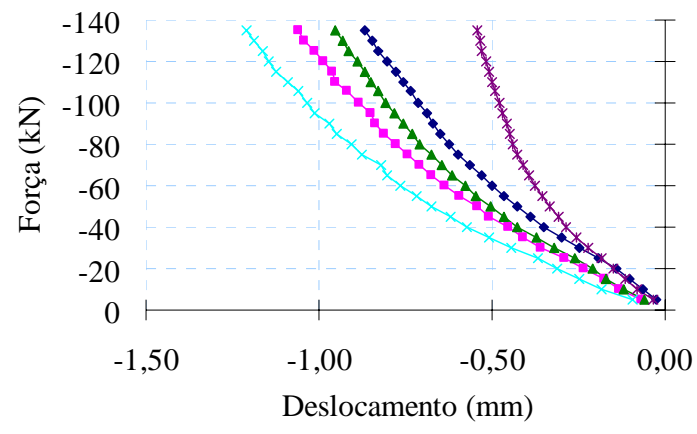

$\rightarrow$ Transdutor $18 \rightarrow$ Transdutor $19 \multimap$ Transdutor 20 Transdutor $21 *$ Transdutor 22

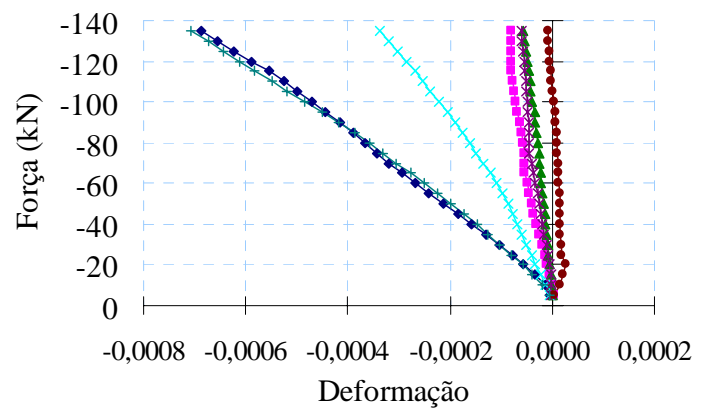

$\begin{array}{ll}\rightarrow-\text { Extensômetro 20 } & \rightarrow \text { Extensômetro 21 } \\ \rightarrow \text { Extensômetro 22 } & \rightarrow \text { Extensômetro 23 } \\ \text { * Extensômetro 24 } & \rightarrow \text { Extensômetro 25 } \\ \rightarrow-\text { Extensômetro 26 } & \end{array}$

\section{Situação 2}

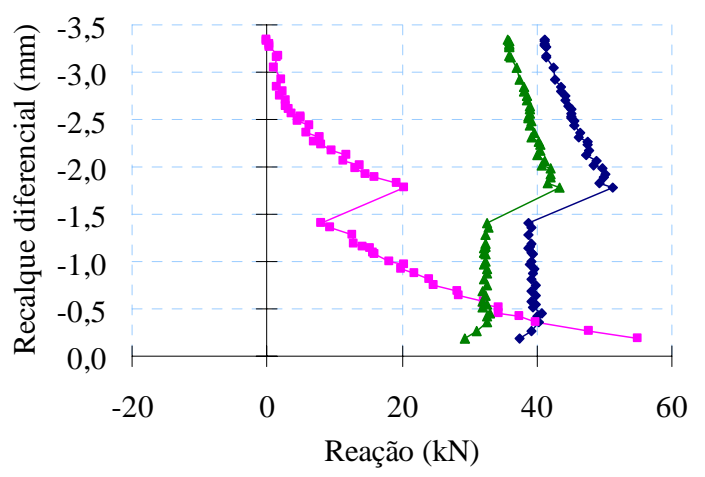

Apoio $\mathrm{A} \rightarrow-$ Apoio $\mathrm{C} \rightarrow$ Apoio $\mathrm{E}$

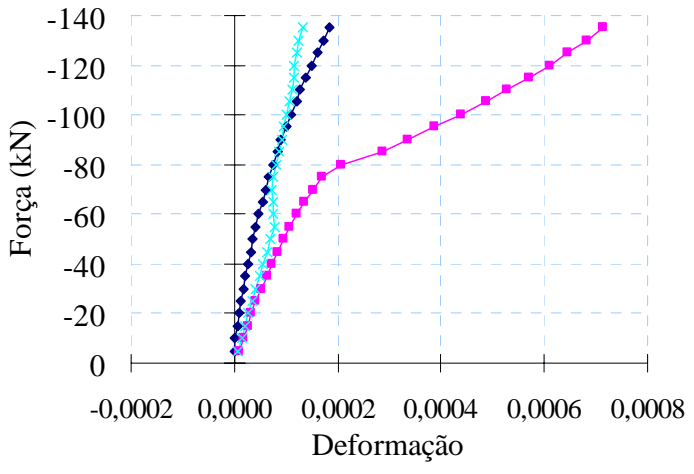

$\rightarrow$ Extensômetros 1-2 - - Extensômetros 3-4 Extensômetros 7-8

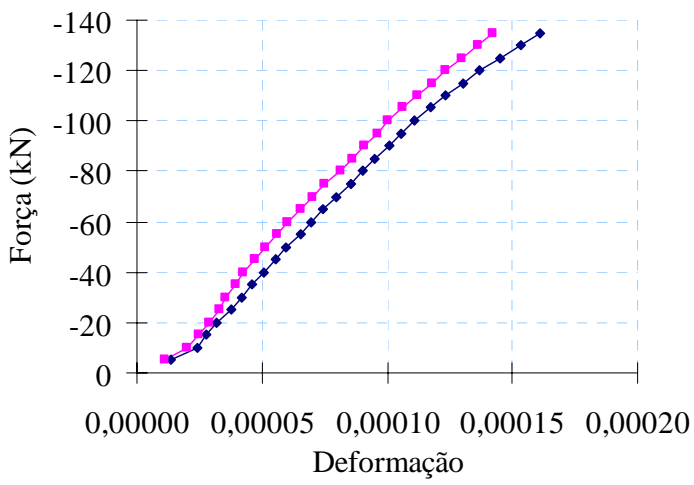

Extensômetro 27 - - Extensômetro 28

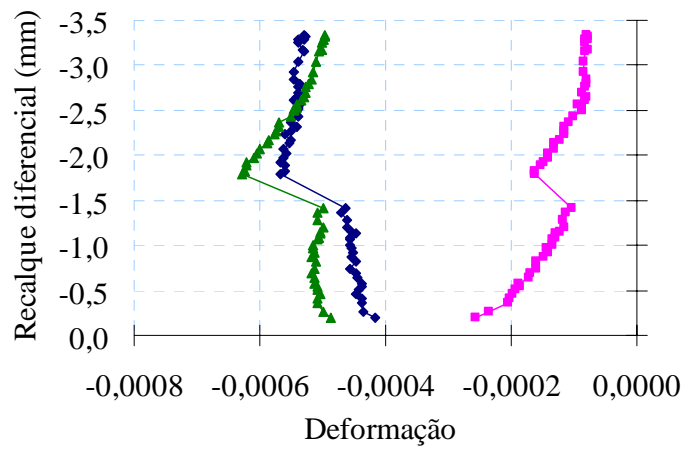

Transdutores 1-2 $\rightarrow$ Transdutores 3-4

- Transdutores 5-6 

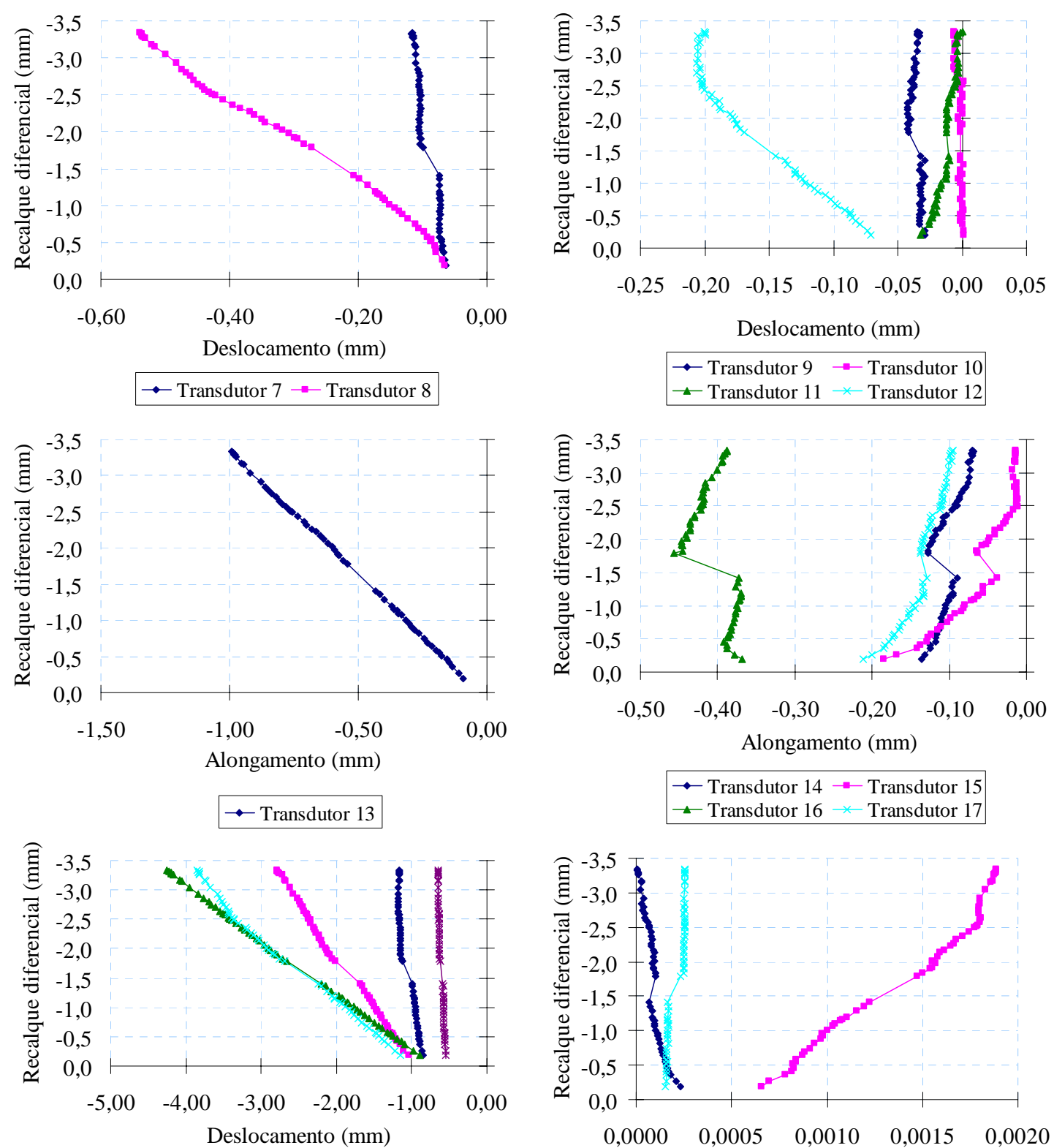

$\rightarrow$ Transdutor $18 \rightarrow$ Transdutor $19 \rightarrow$ Transdutor 20
$\rightarrow$ Transdutor $21 \rightarrow$ Transdutor 22
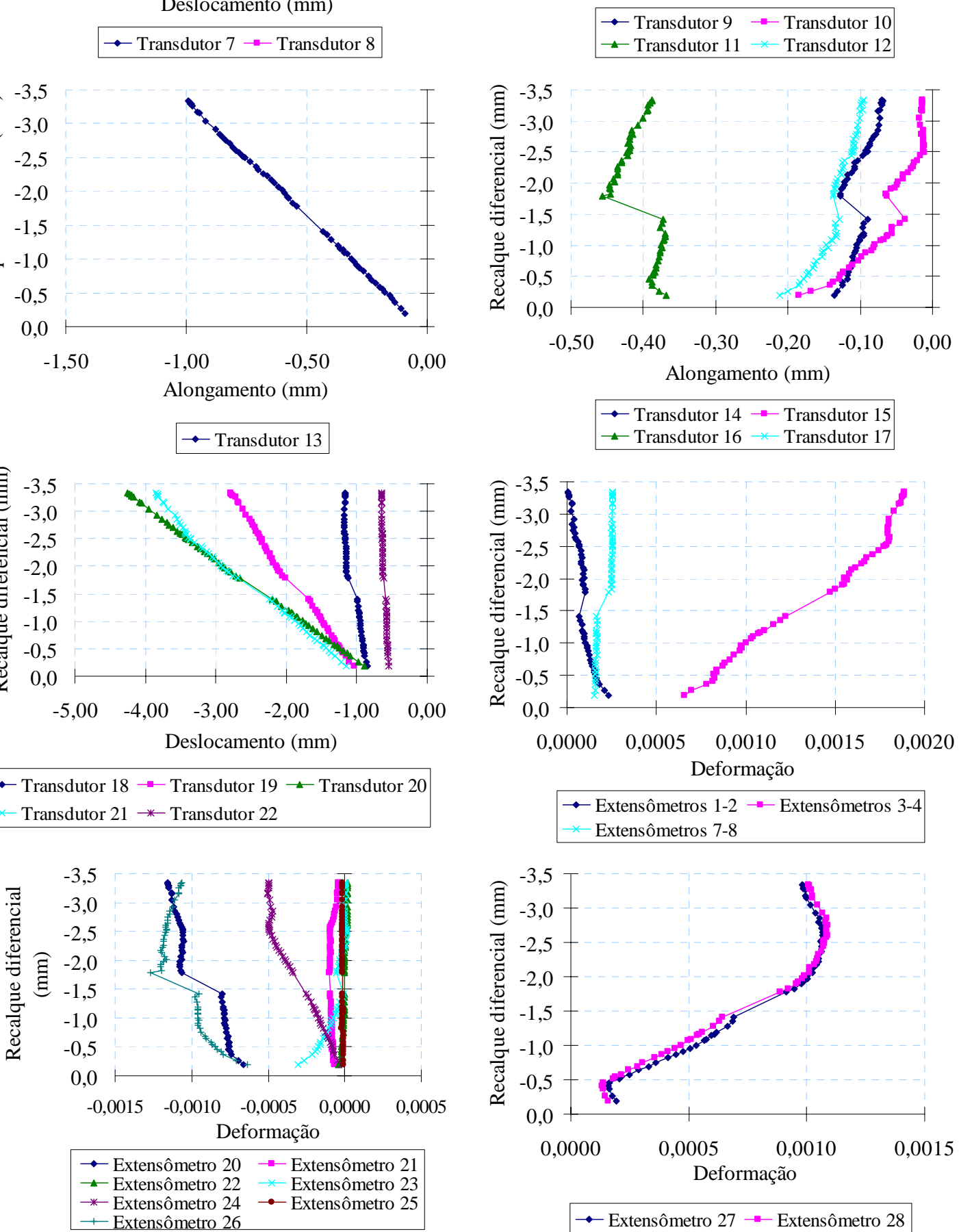

- Extensômetro $27-$ Extensômetro 28 


\section{Situação 3}
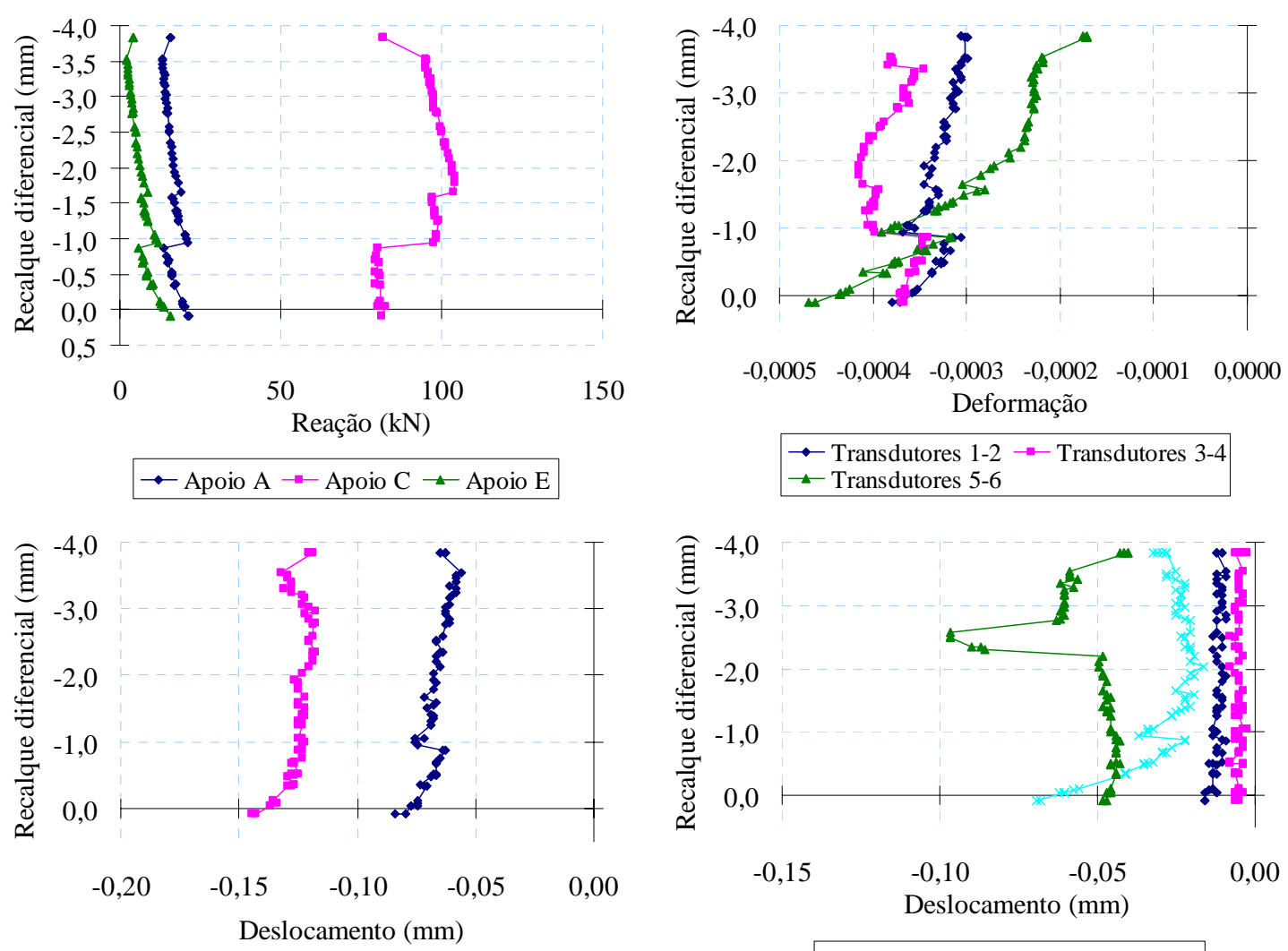

$\rightarrow$ Transdutor $7 \rightarrow$ Transdutor 8
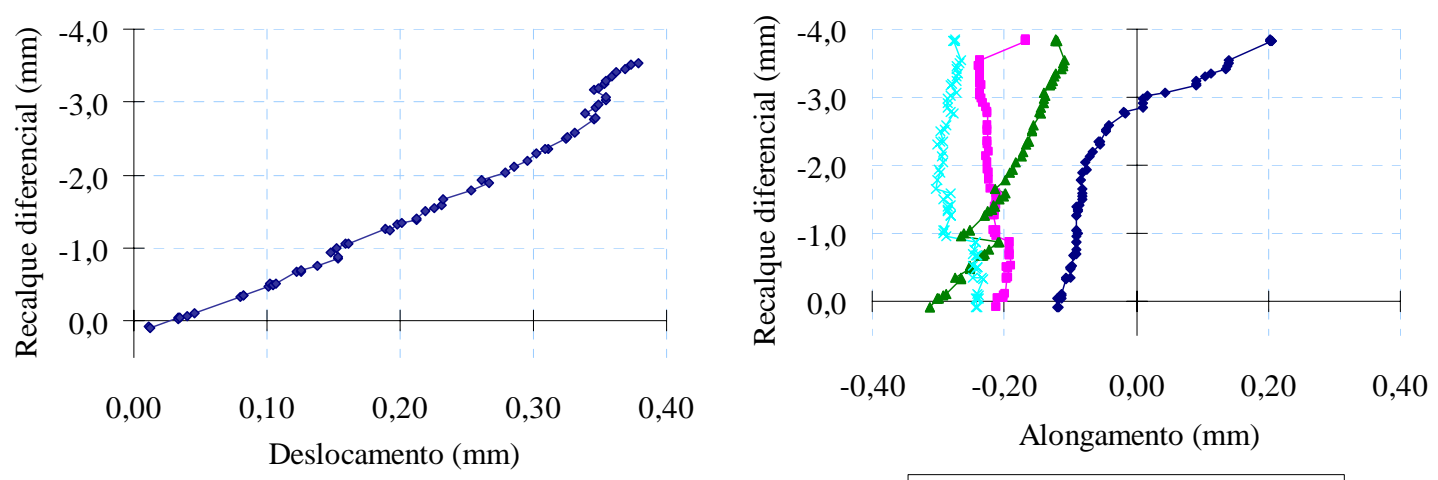

$\rightarrow$ Transdutor 13

$\rightarrow-$ Transdutor $14 \rightarrow-$ Transdutor 15

$\triangle$ Transdutor $16 \rightarrow$ Transdutor 17 

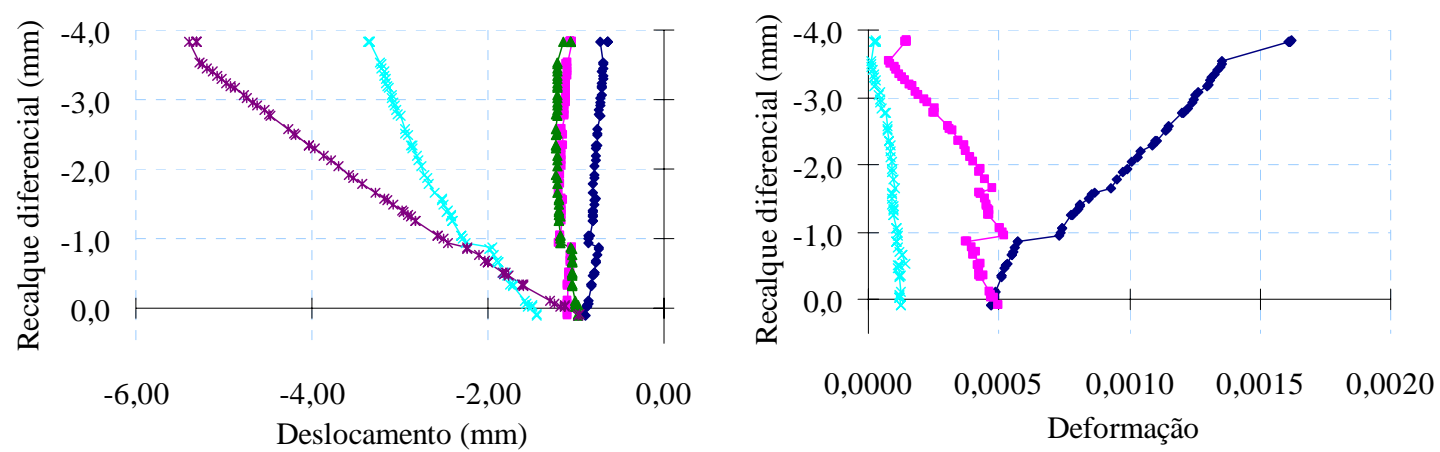

$\rightarrow$ Transdutor $18 \rightarrow$ Transdutor $19 \rightarrow$ Transdutor 20 Transdutor $21 *$ Transdutor 22

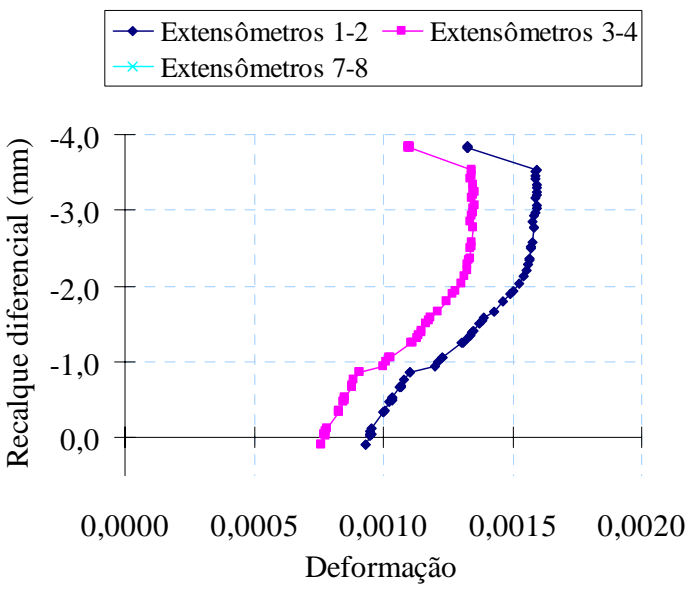

$$
\begin{aligned}
& \rightarrow \text { Extensômetro 20 } \\
& \rightarrow \text { Extensômetro 22 } \\
& \rightarrow \text { Extensômetro 21 } \\
& \text { * Extensômetro 24 } \\
& \rightarrow \text { Extensômetro 23 } \\
& \rightarrow \text { Extensômetro 26 }
\end{aligned}
$$




\section{MODELO 4}

\section{Situação 1}
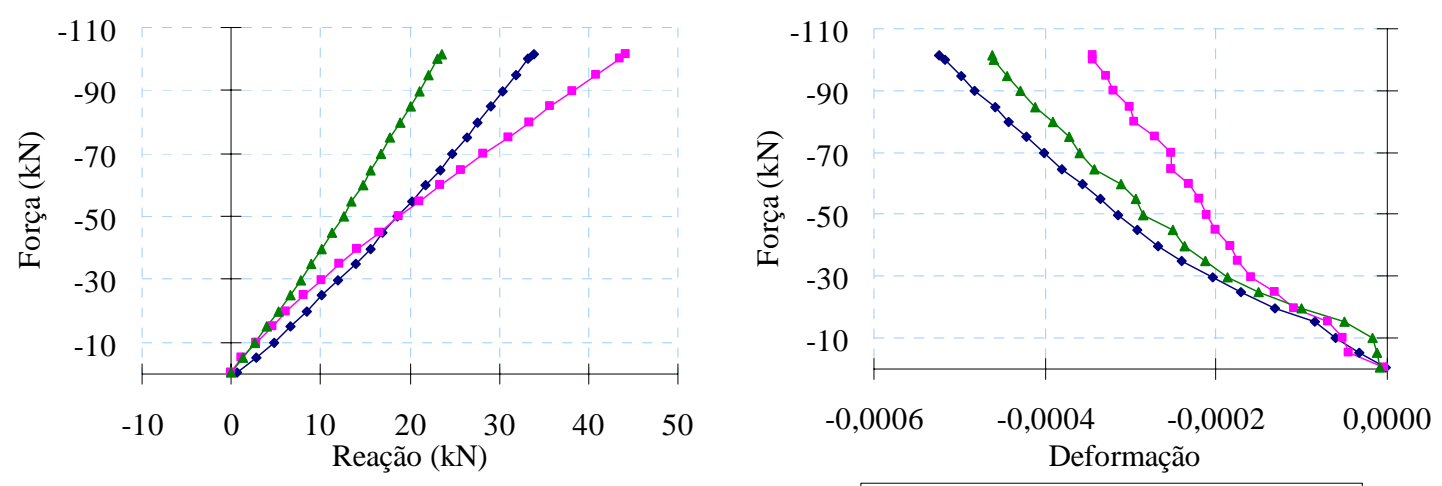

$\rightarrow$ Apoio $\mathrm{A} \rightarrow$ Apoio $\mathrm{C} \rightarrow$ Apoio E
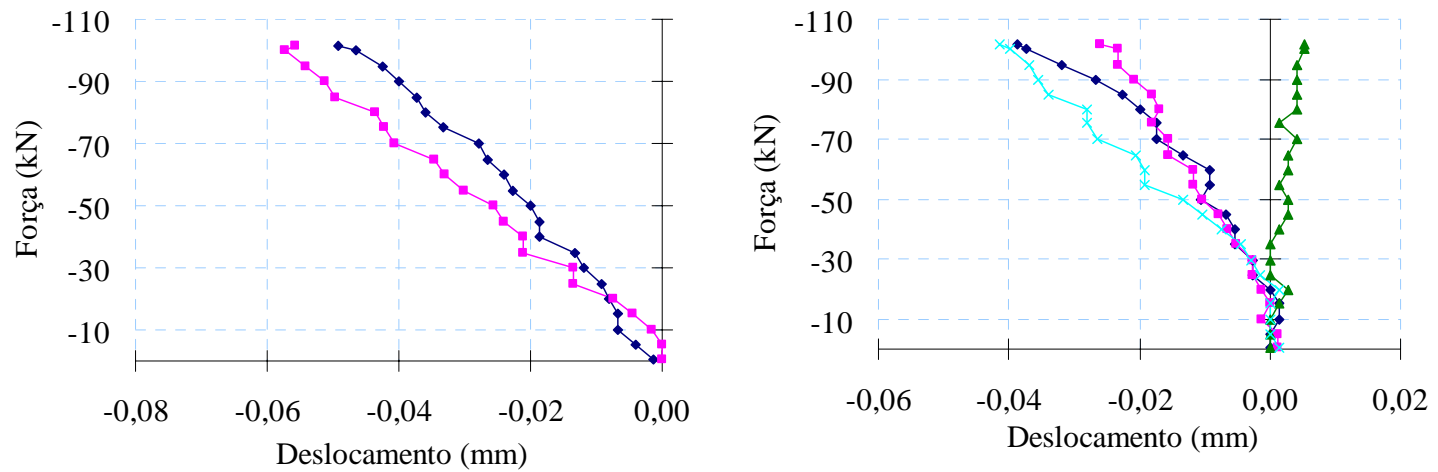

$\rightarrow$ Transdutor $7 \rightarrow-$ Transdutor 8
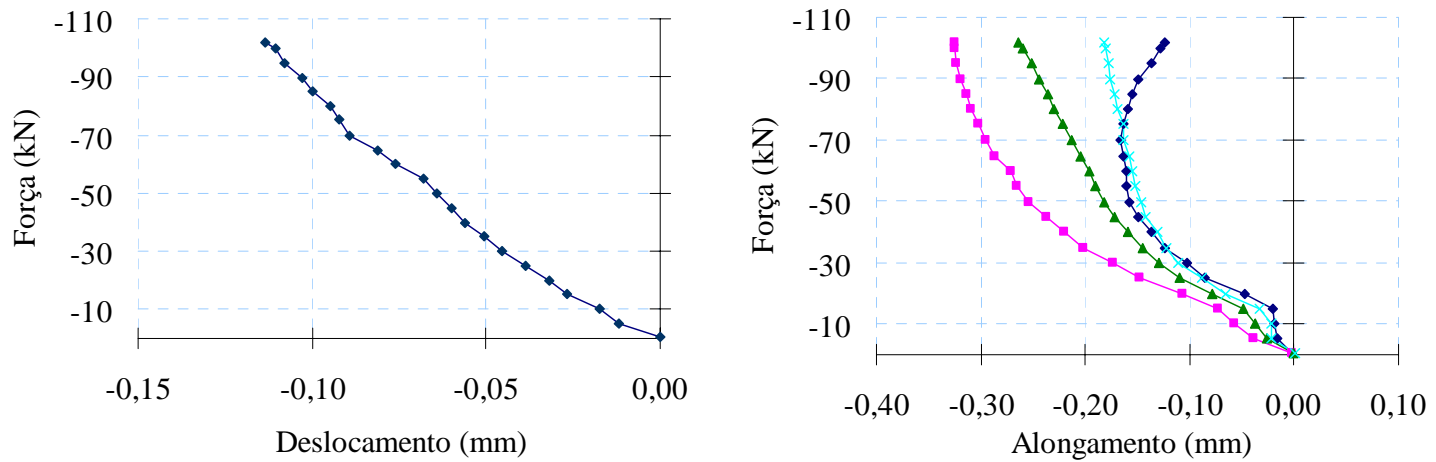

- Transdutor 13

$\rightarrow$ Transdutor $14 \rightarrow-$ Transdutor 15 $\rightarrow$ Transdutor $16 \rightarrow$ Transdutor 17 

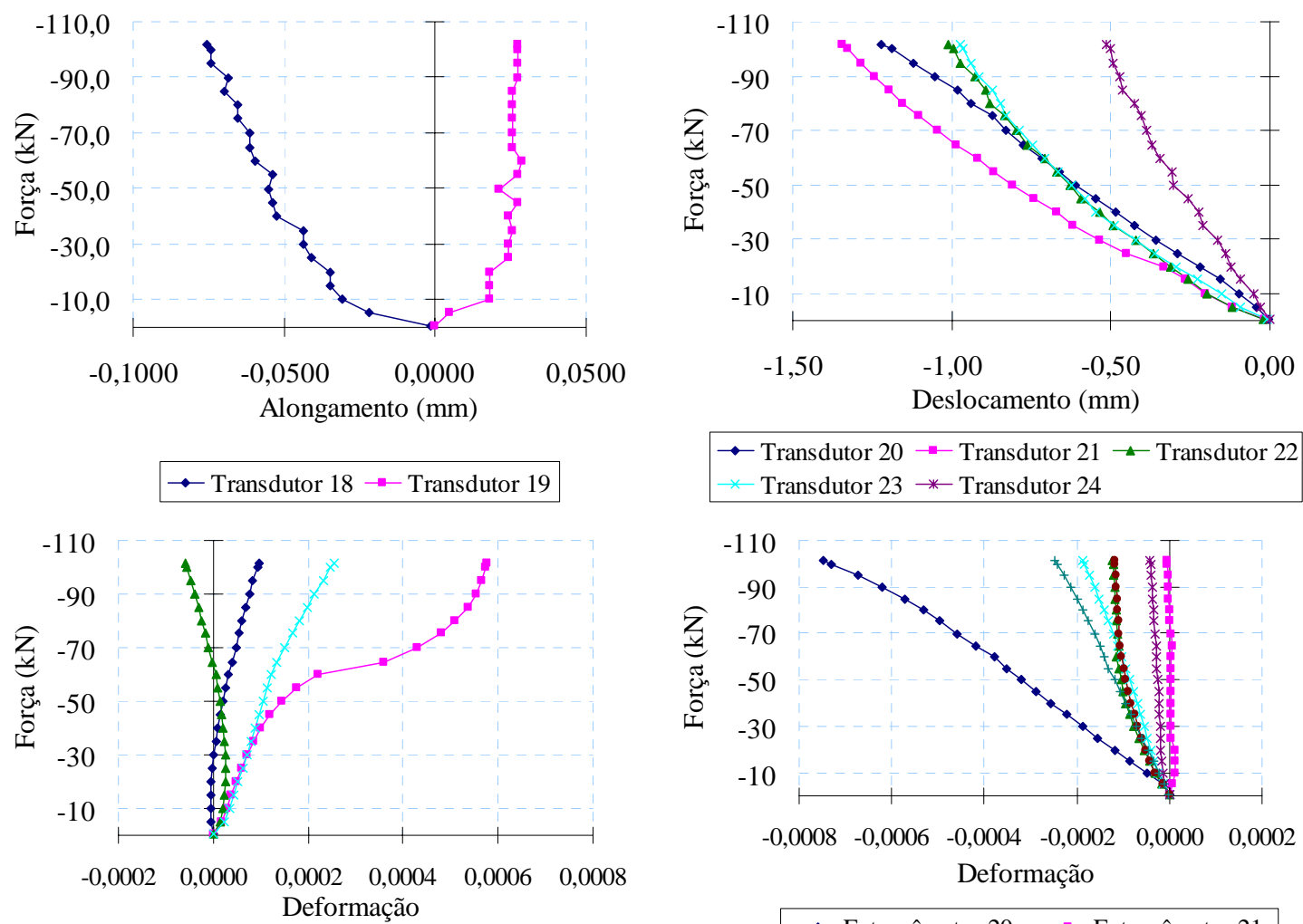

$\rightarrow$ Transdutor $20-$ Transdutor $21 \leadsto$ Transdutor 22 Transdutor $23 \rightarrow$ Transdutor 24

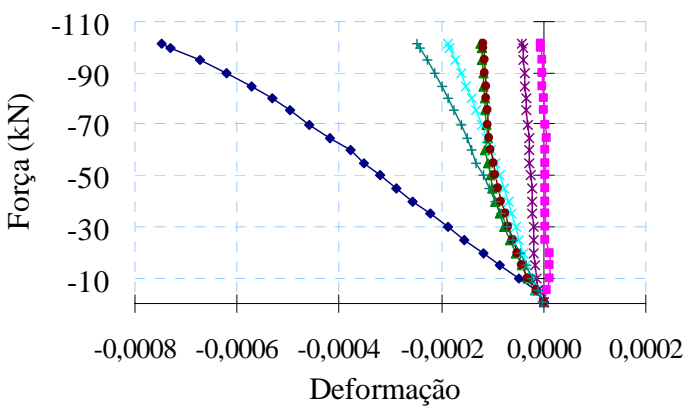

$\rightarrow-$ Extensômetros 1-2 $\rightarrow-$ Extensômetros 3-4 $\rightarrow$ Extensômetros 5-6 $*$ Extensômetros 7-8

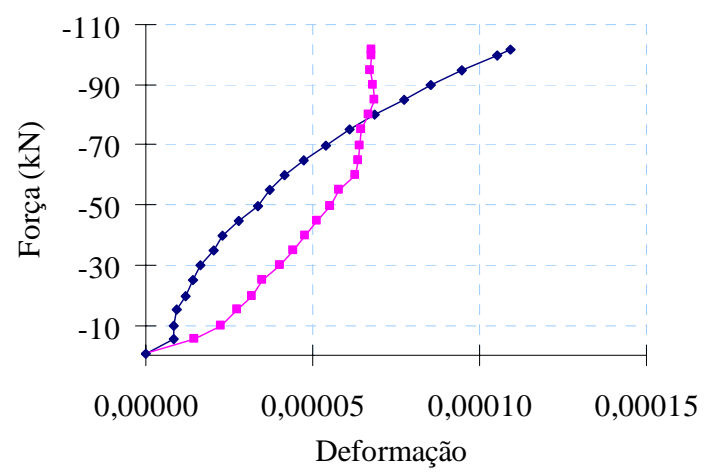

$\rightarrow$ Extensômetro 20
$\rightarrow$ Extensômetro 22
$\rightarrow$ Extensômetro 21
$\rightarrow$ Extensômetro 24
$\rightarrow$ Extensômetro 23
$\rightarrow$ Extensômetro 26




\section{Situação 2}
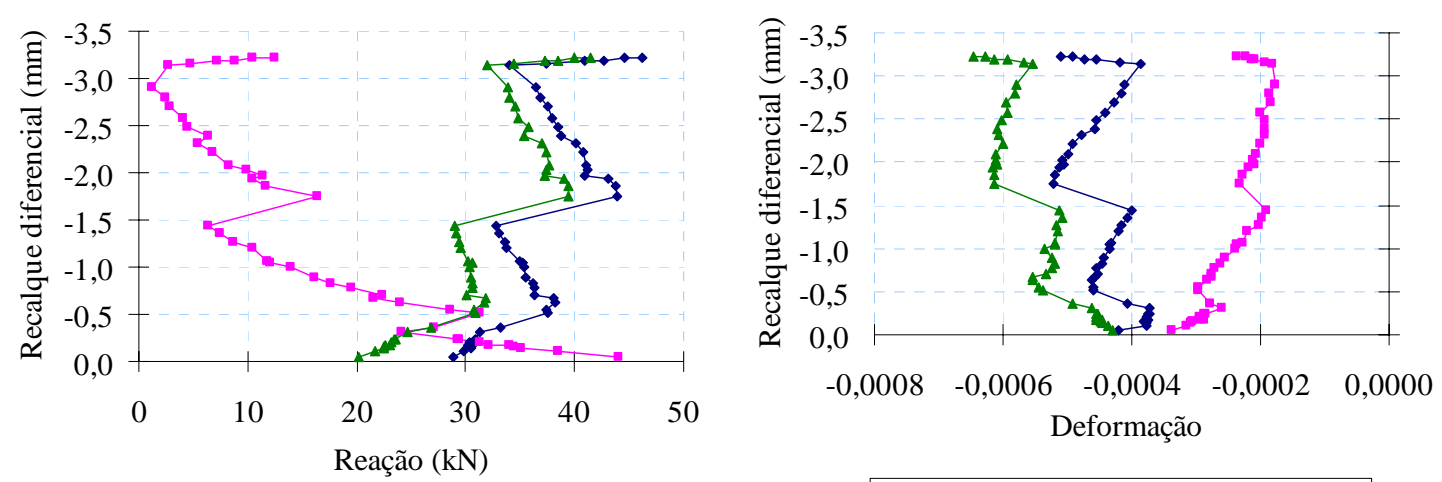

$$
\rightarrow \text { Apoio A } \rightarrow \text { Apoio } C \rightarrow \text { Apoio E }
$$
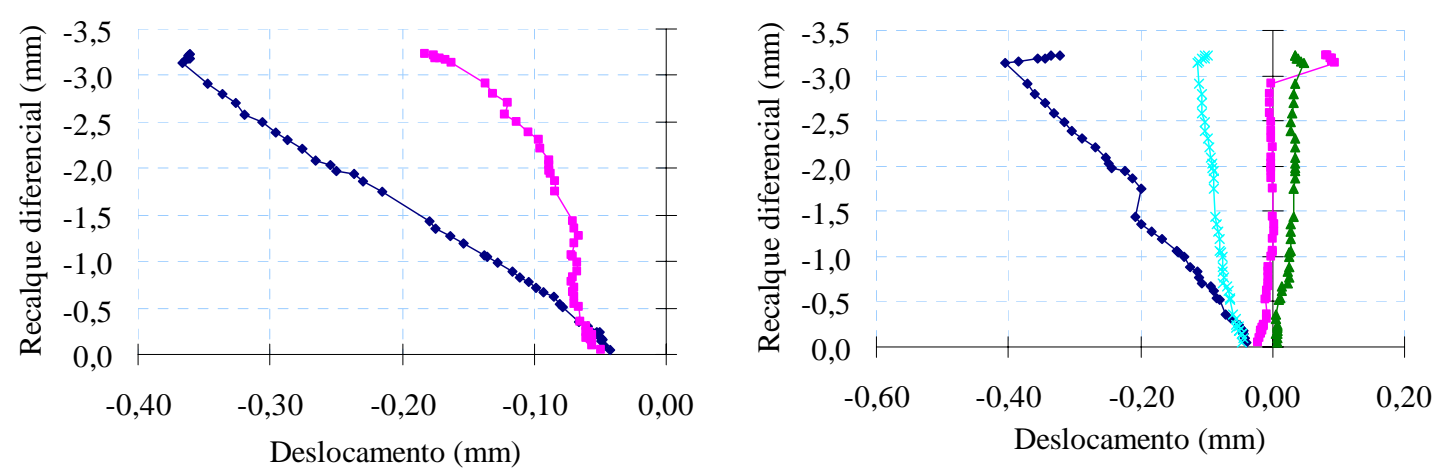

Transdutor $7 \rightarrow$ Transdutor 8
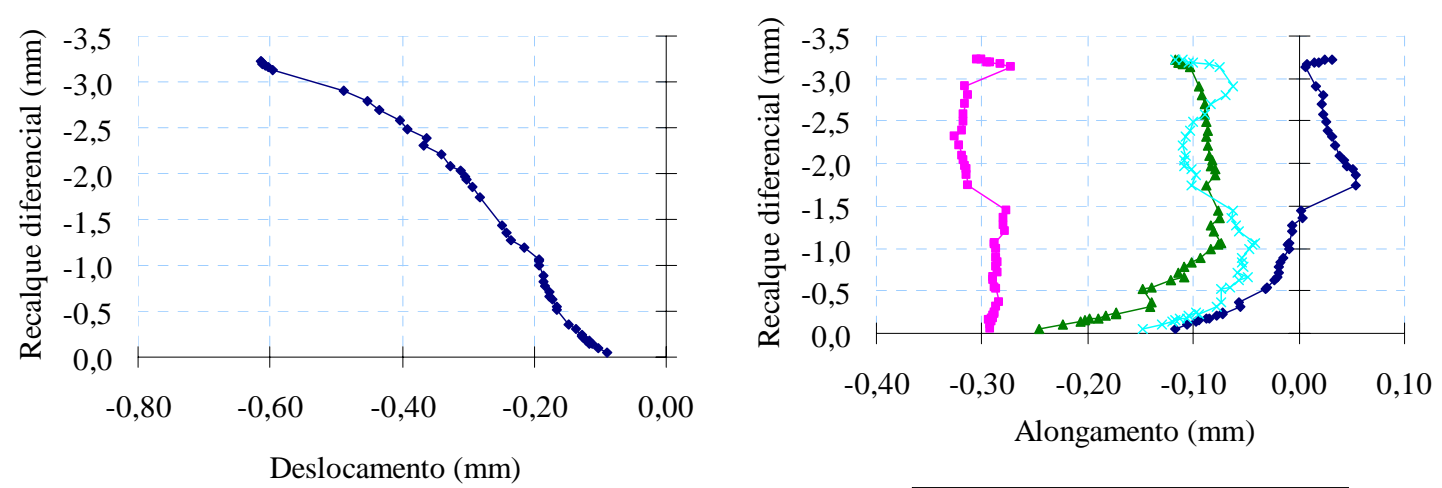

$\rightarrow-$ Transdutor 13 

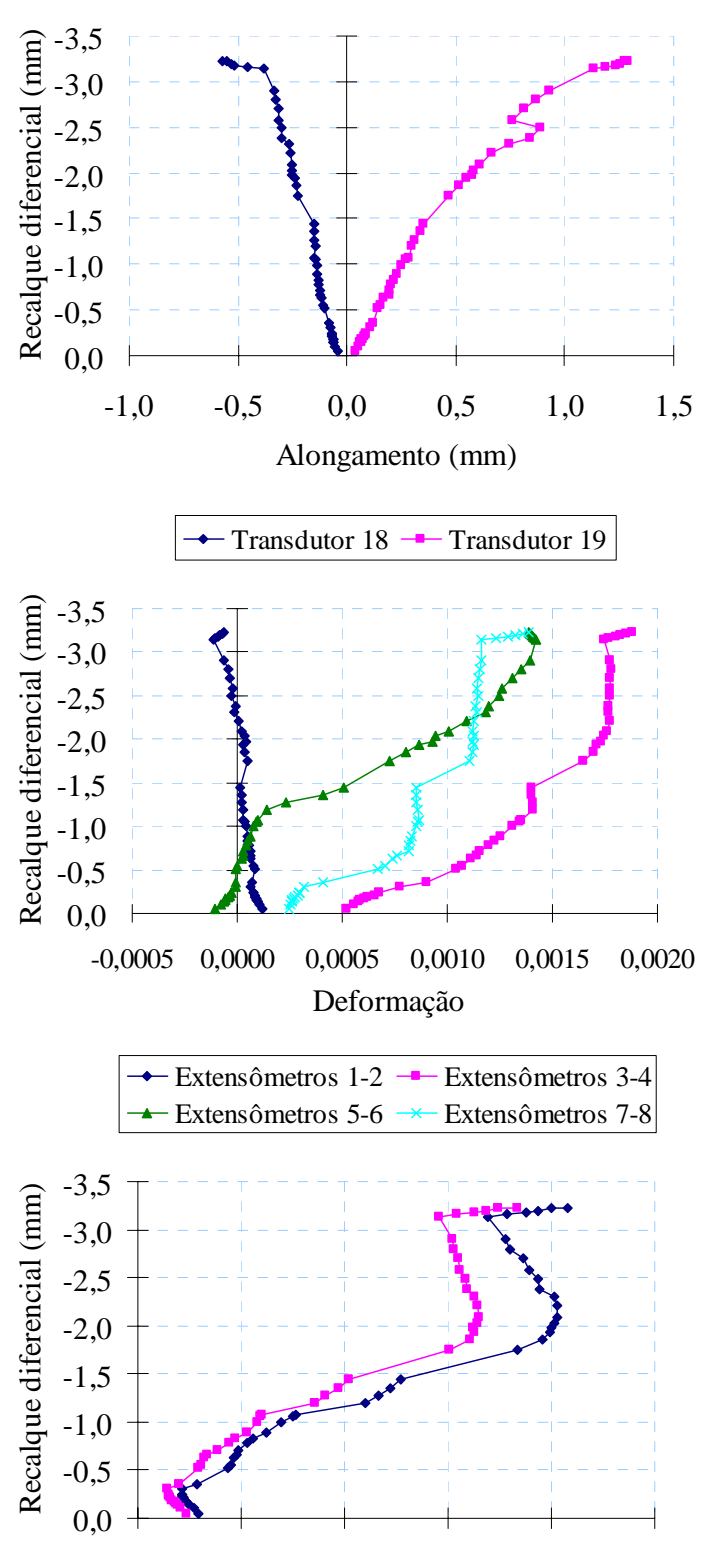

$\begin{array}{llllll}0,0000 & 0,0002 & 0,0004 & 0,0006 & 0,0008 & 0,0010\end{array}$

Deformação

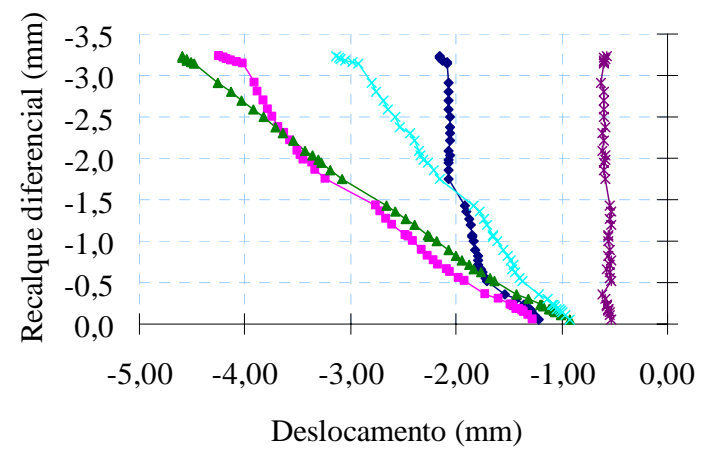

$\rightarrow$ Transdutor $20 \rightarrow$ Transdutor $21 \rightarrow$ Transdutor 22 Transdutor $23 \rightarrow$ Transdutor 24

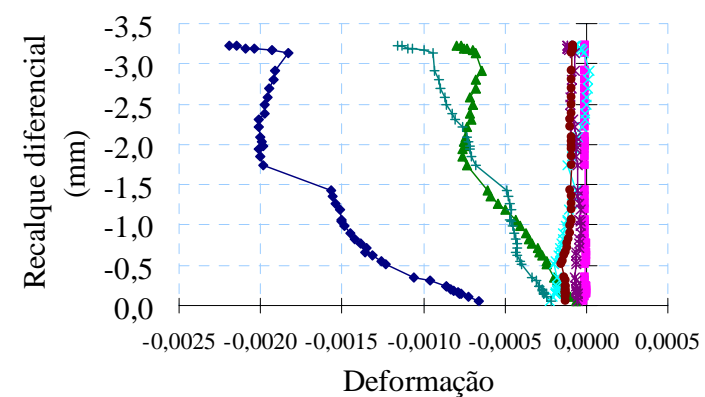

$\rightarrow$ - Extensômetro $20 \rightarrow$ Extensômetro 21 - Extensômetro $22 \rightarrow-$ Extensômetro 23

- Extensômetro $24 \rightarrow$ Extensômetro 25 Extensômetro 26 


\section{Situação 3}
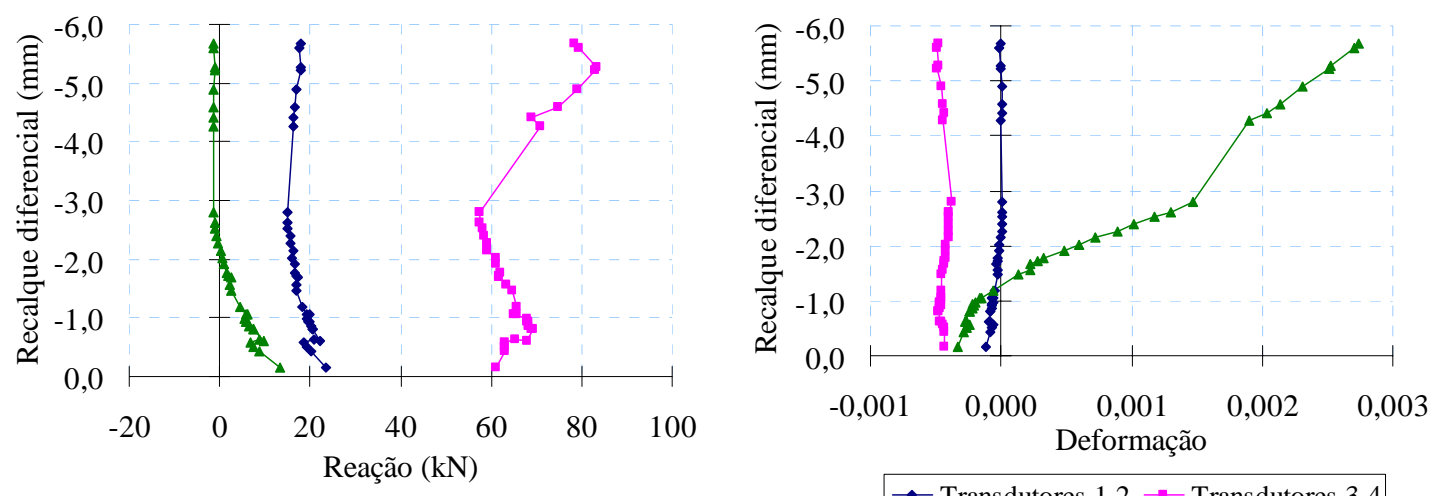

$\rightarrow$ Apoio $\mathrm{A} \rightarrow$ Apoio $\mathrm{C} \backsim$ Apoio $\mathrm{E}$
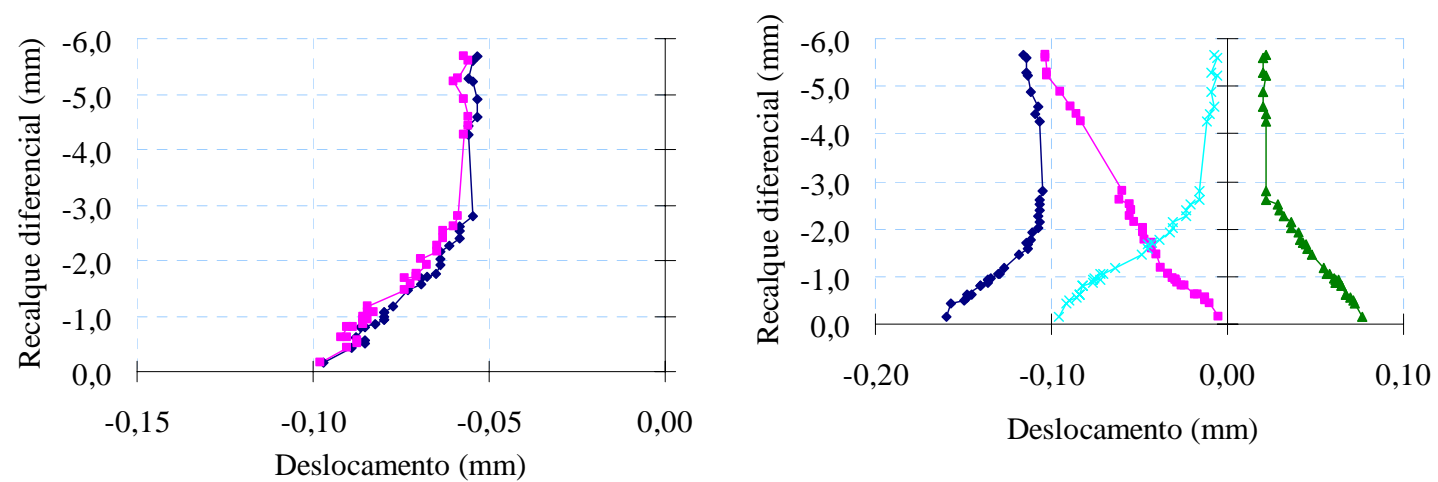

Deslocamento (mm)

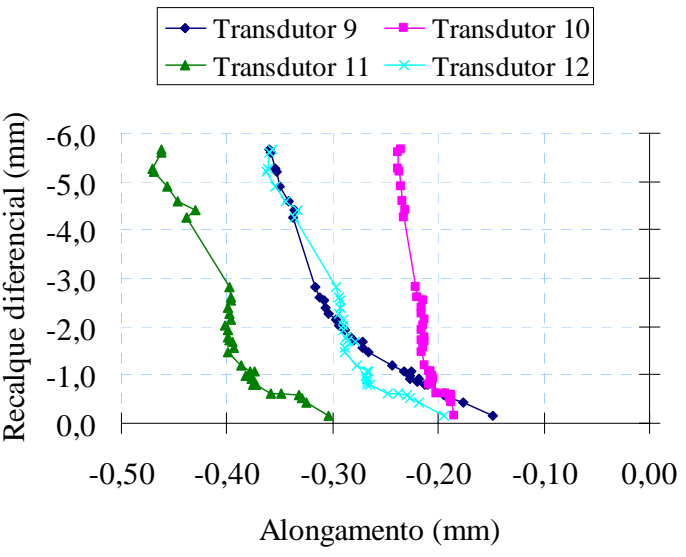

Deslocamento $(\mathrm{mm})$

Transdutor 13 


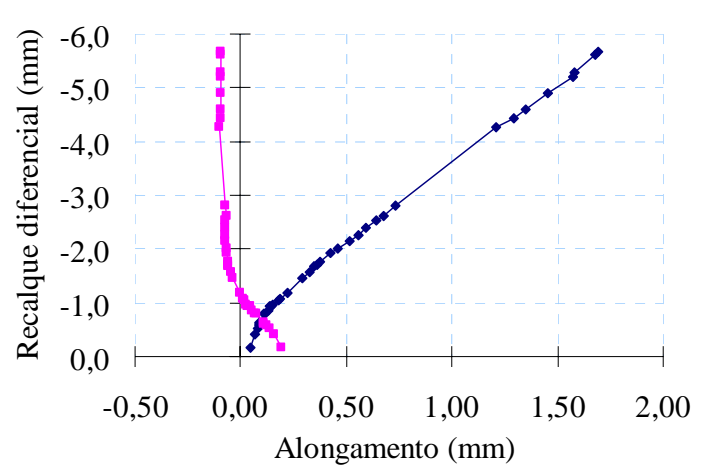

$\rightarrow$ Transdutor $18 \rightarrow$ Transdutor 19

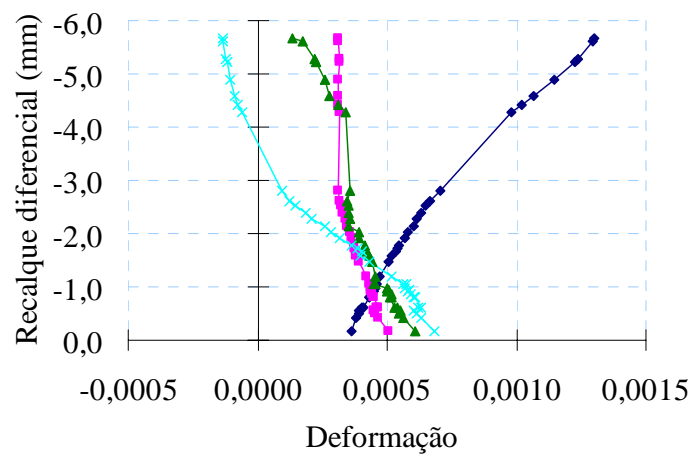

- Extensômetros 1-2 - Extensômetros 3-4

$\rightarrow$ Extensômetros 5-6 $*$ Extensômetros 7-8

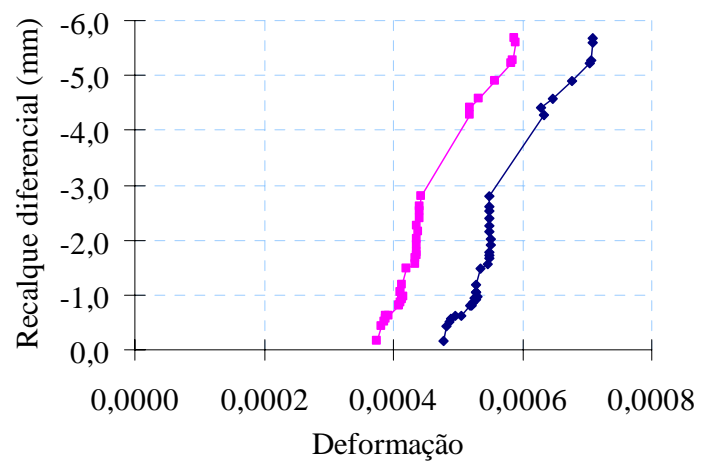

$\rightarrow$ Extensômetro $27 \rightarrow-$ Extensômetro 28

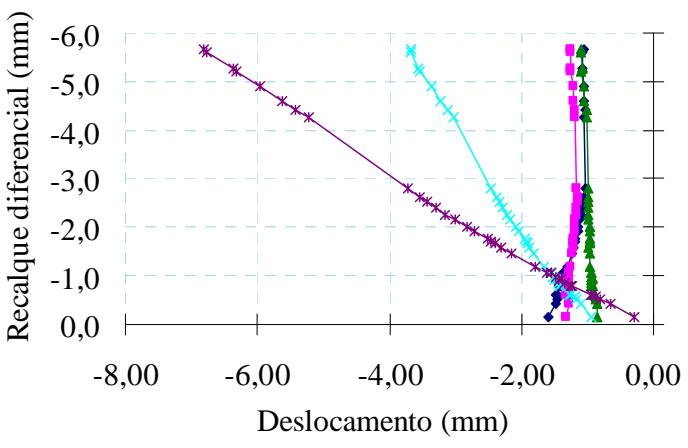

$\rightarrow$ Transdutor $20 \rightarrow$ Transdutor $21 \rightarrow$ Transdutor 22

Transdutor $23 \rightarrow$ Transdutor 24

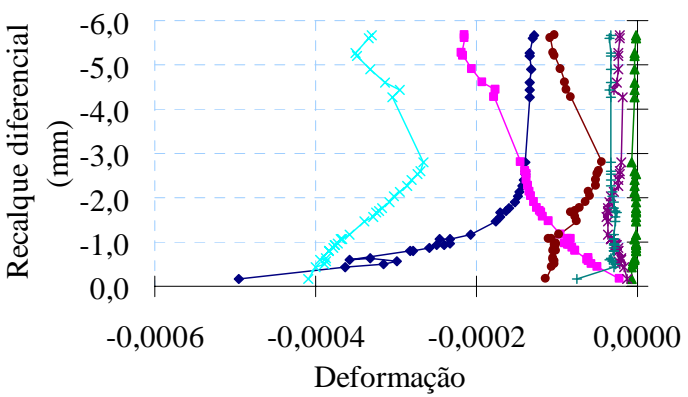

$\rightarrow$ Extensômetro $20 \rightarrow-$ Extensômetro 21

- Extensômetro $22 \rightarrow$ Extensômetro 23

* Extensômetro $24 \rightarrow$ Extensômetro 25 Extensômetro 26 


\section{MODELO 5}

\section{Situação 1}
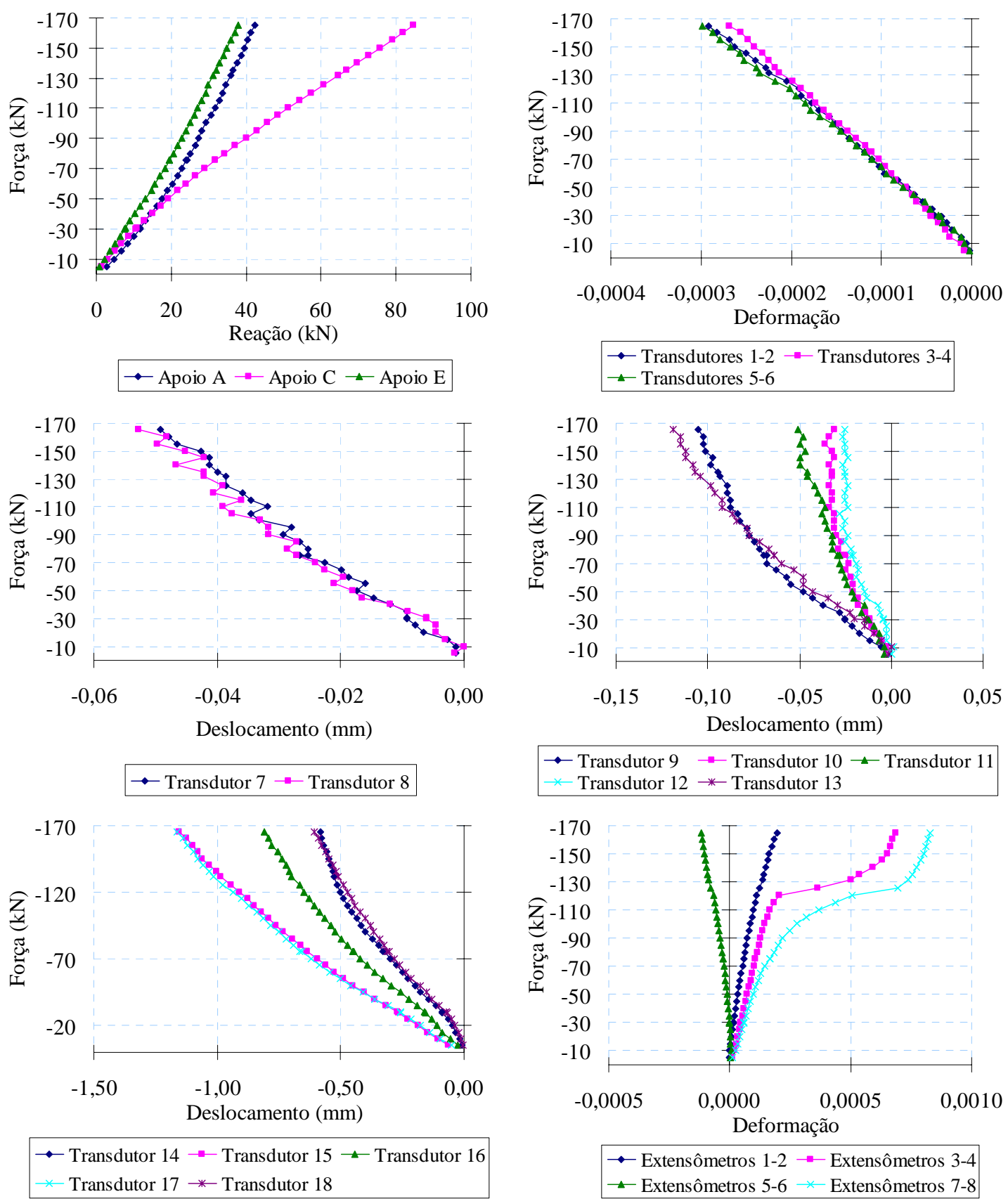

- Transdutor $9 \rightarrow$ Transdutor $10 \leadsto$ Transdutor 11 Transdutor $12 \rightarrow$ Transdutor 13

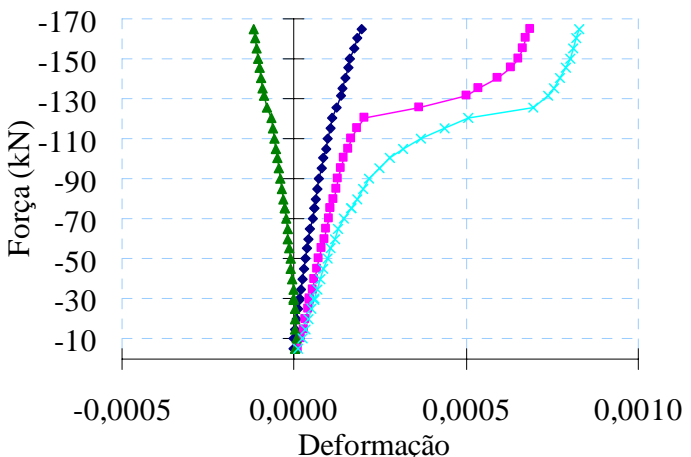

Deformação 


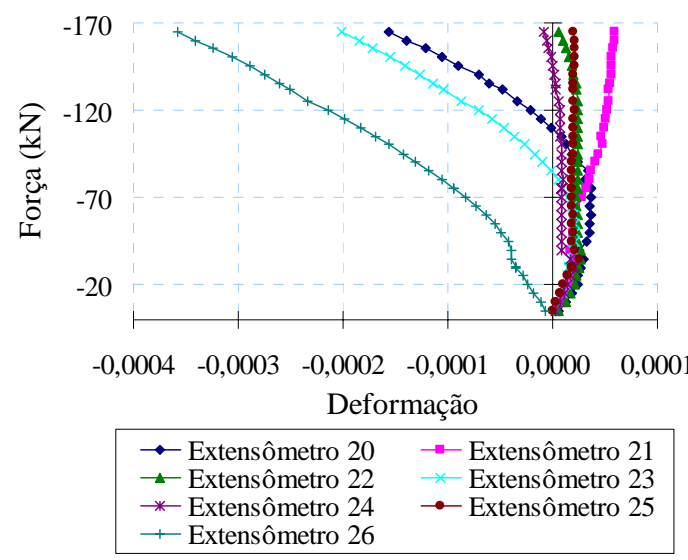

\section{Situação 2}
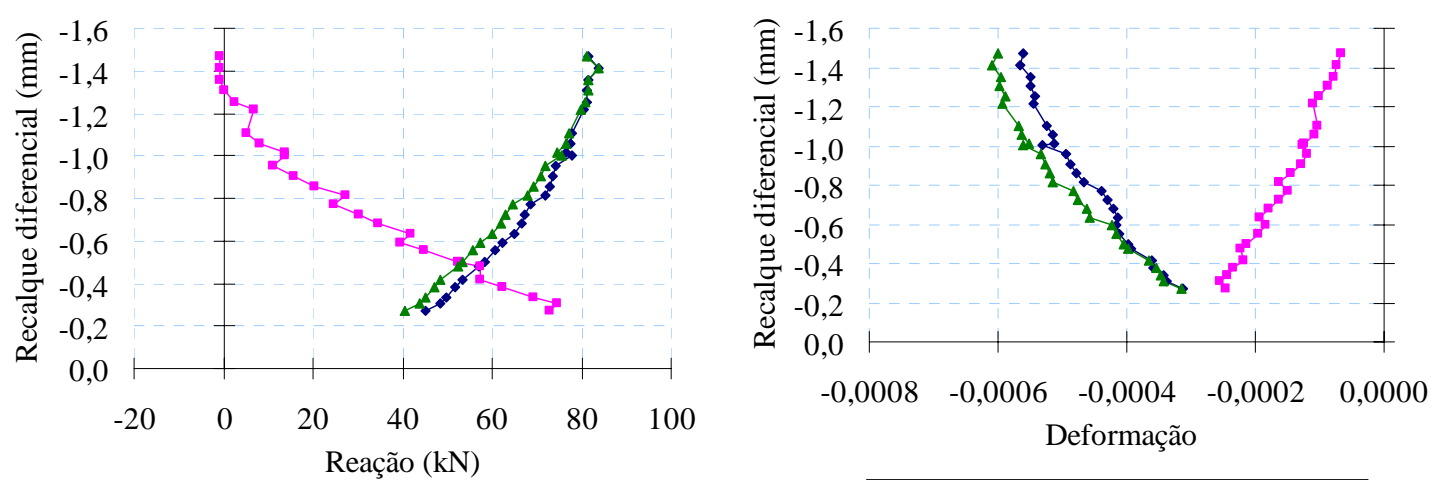

- Apoio A $\rightarrow$ Apoio $\mathrm{C} \backsim$ Apoio E
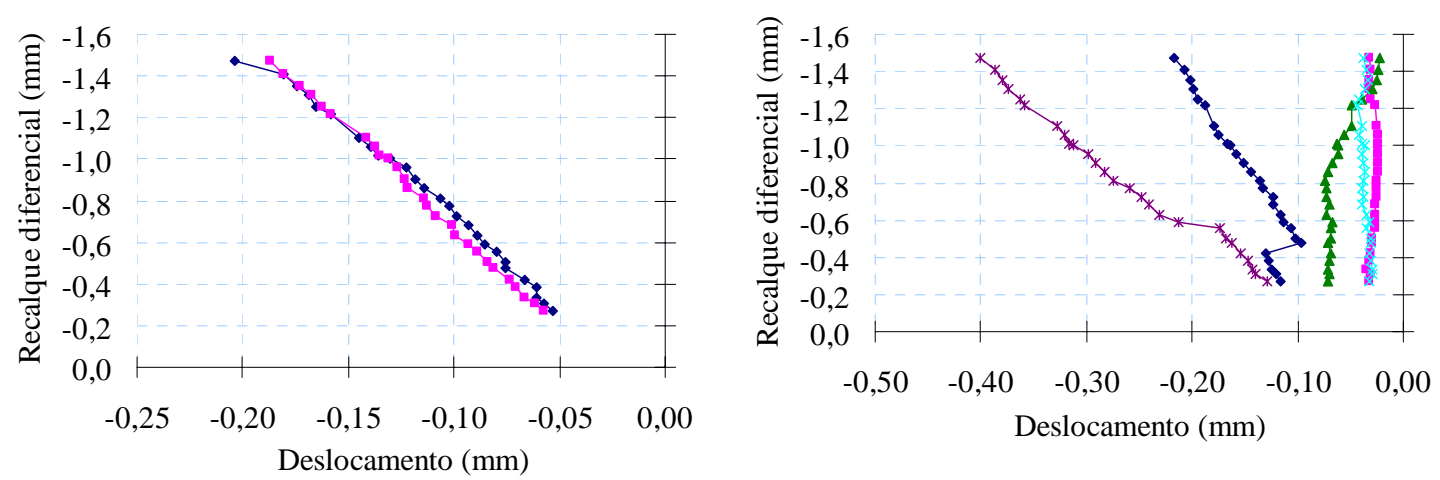

$\rightarrow$ Transdutor $7 \rightarrow-$ Transdutor 8

- Transdutor $9 \rightarrow-$ Transdutor $10 \rightarrow-$ Transdutor 11

Transdutor $12 *$ Transdutor 13 


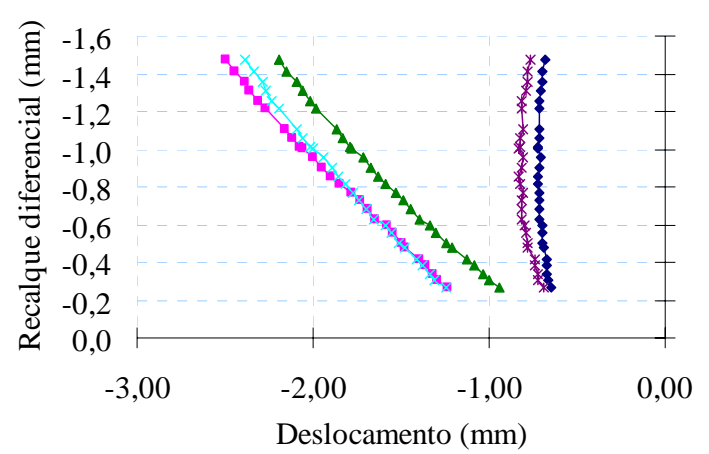

$\rightarrow$ Transdutor $14 \rightarrow$ Transdutor $15 \multimap$ Transdutor 16 Transdutor $17 \rightarrow$ Transdutor 18

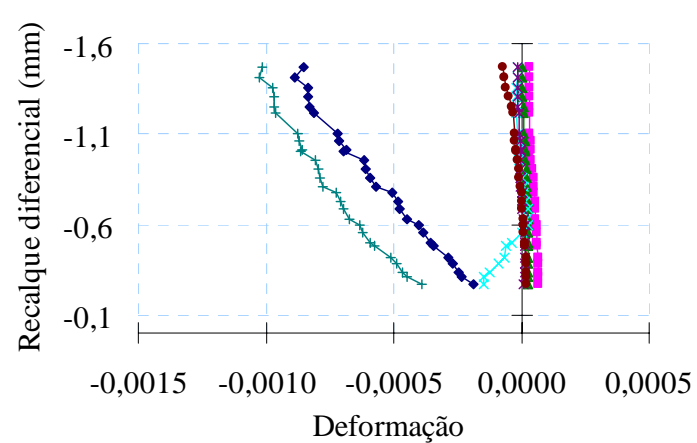

Deformação

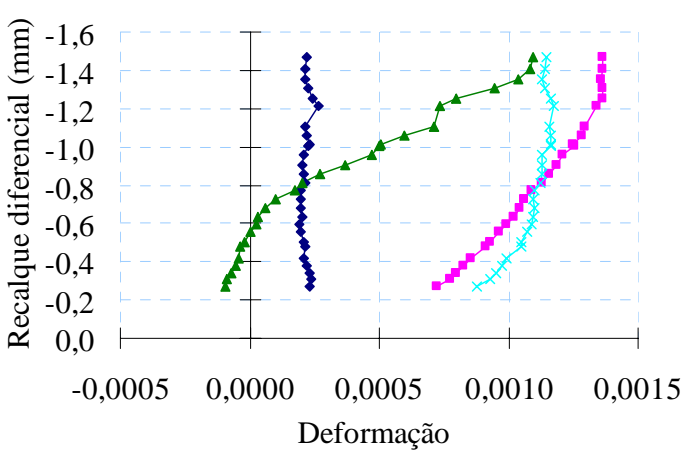

$\multimap-$ Extensômetros 1-2 $\rightarrow-$ Extensômetros 3-4 ^-Extensômetros 5-6 $\rightarrow$ Extensômetros 7-8

\section{Situação 3}

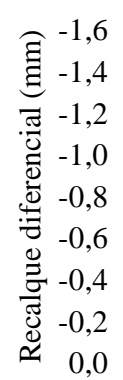

$-50$

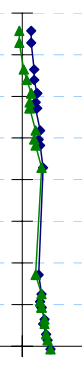

$50 \quad 100$

Reação $(\mathrm{kN})$

Apoio $\mathrm{A} \rightarrow$ Apoio $\mathrm{C} \rightarrow$ Apoio $\mathrm{E}$

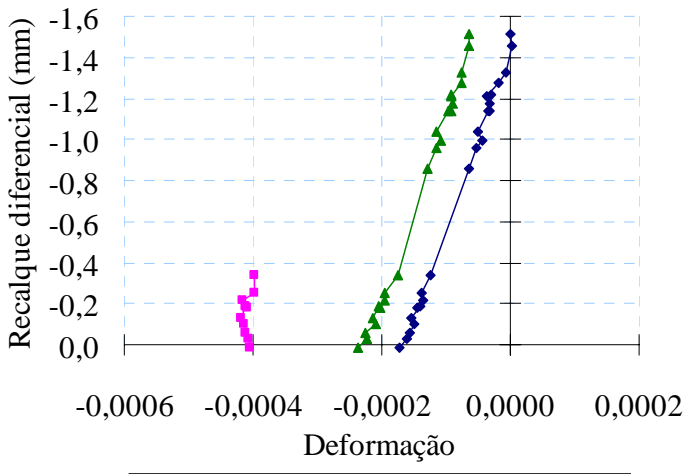

- - Transdutores 1-2 - - Transdutores 3-4 - Transdutores 5-6 


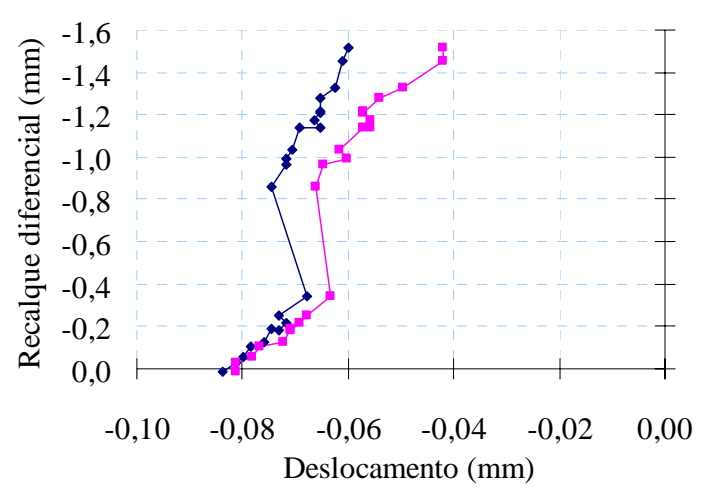

$\multimap$ Transdutor $7 \rightarrow$ Transdutor 8

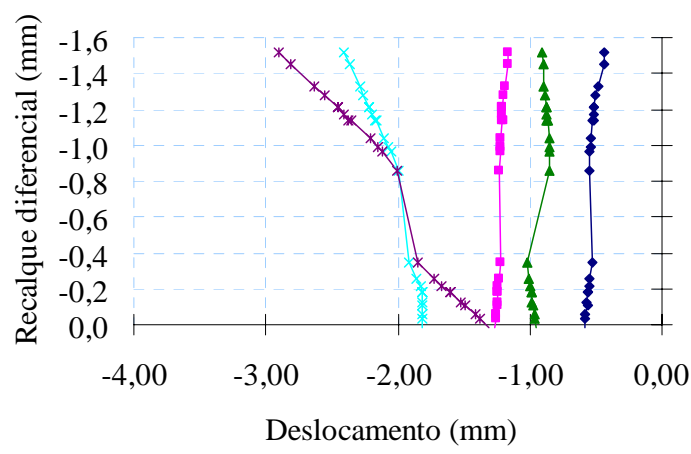

- Transdutor $14 \rightarrow$ Transdutor $15 \multimap$ Transdutor 16 - Transdutor $17 \rightarrow$ Transdutor 18

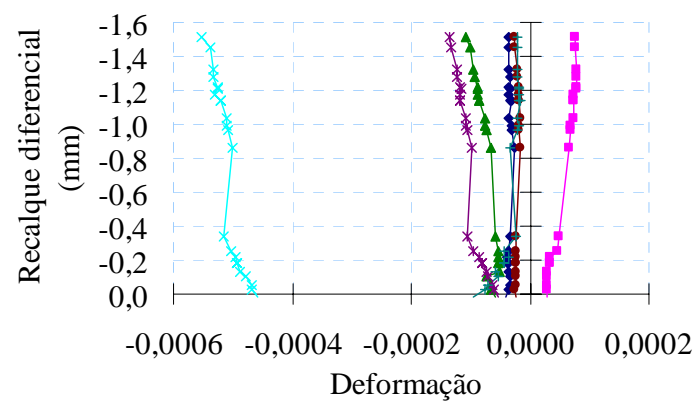

$\rightarrow$ Extensômetro $20 \rightarrow$ Extensômetro 21 Extensômetro $22 \rightarrow-$ Extensômetro 23

*-Extensômetro $24 \rightarrow$ Extensômetro 25 Extensômetro 26

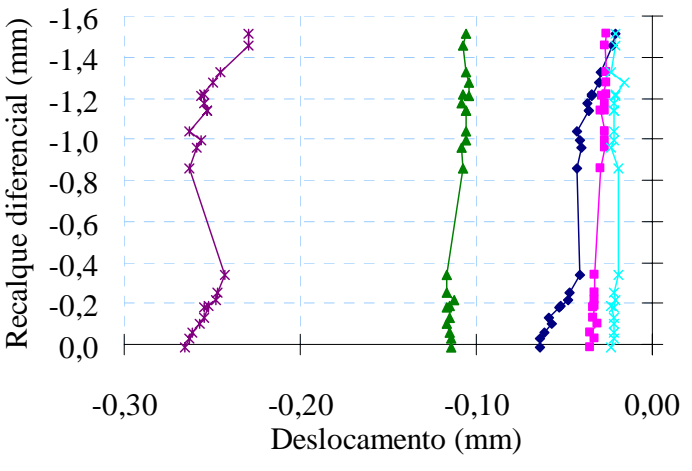

- Transdutor $9 \rightarrow$ Transdutor $10 \rightarrow$ Transdutor 11 Transdutor $12 \rightarrow$ Transdutor 13

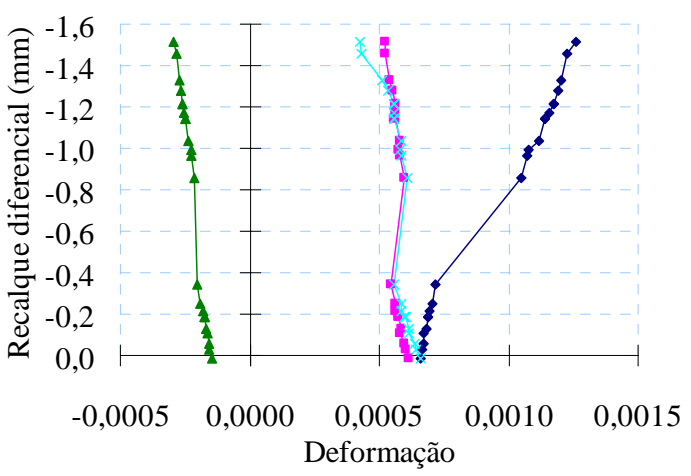

$\rightarrow$ Extensômetros 1-2 - Extensômetros 3-4 $\rightarrow$ Extensômetros 5-6 $\rightarrow$ Extensômetros 7-8 


\section{MODELO 6}

\section{Situação 1}
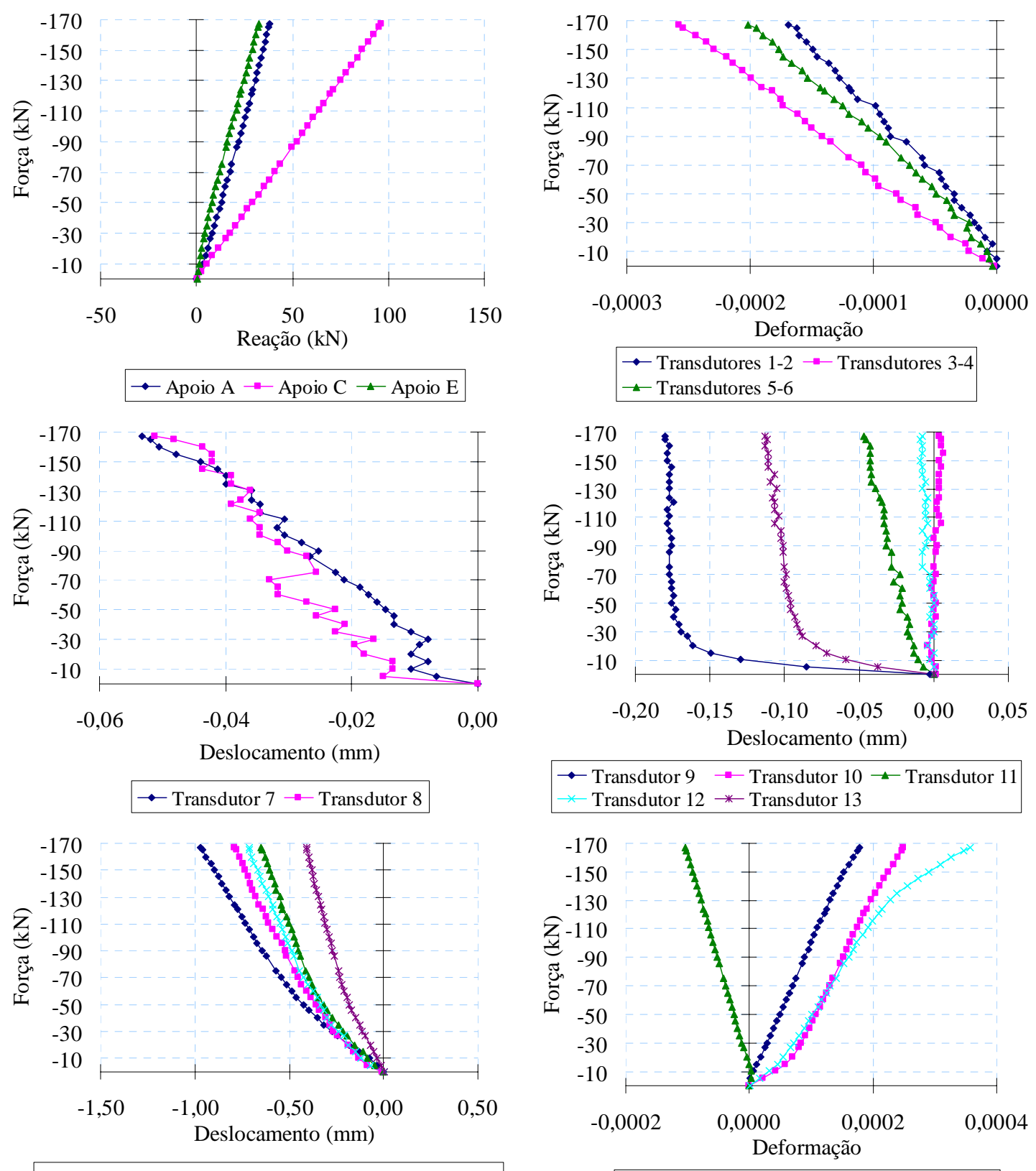

- Transdutor $14 \rightarrow-$ Transdutor $15 \multimap$ Transdutor 16 Transdutor $17 \rightarrow$ Transdutor 18 


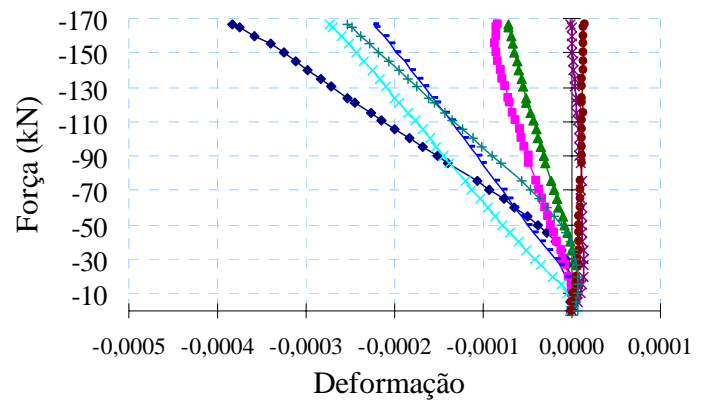

$\begin{array}{ll}\rightarrow \text { - Extensômetro } 9 & \rightarrow-\text { Extensômetro } 10 \\ \rightarrow \text { Extensômetro 11 } & \rightarrow \text { Extensômetro 12 } \\ \rightarrow \text { Extensômetro 13 } & \text { * Extensômetro 14 } \\ \rightarrow \text { - Extensômetro 15 } & \rightarrow \text { Extensômetro 16 }\end{array}$

\section{Situação 2}
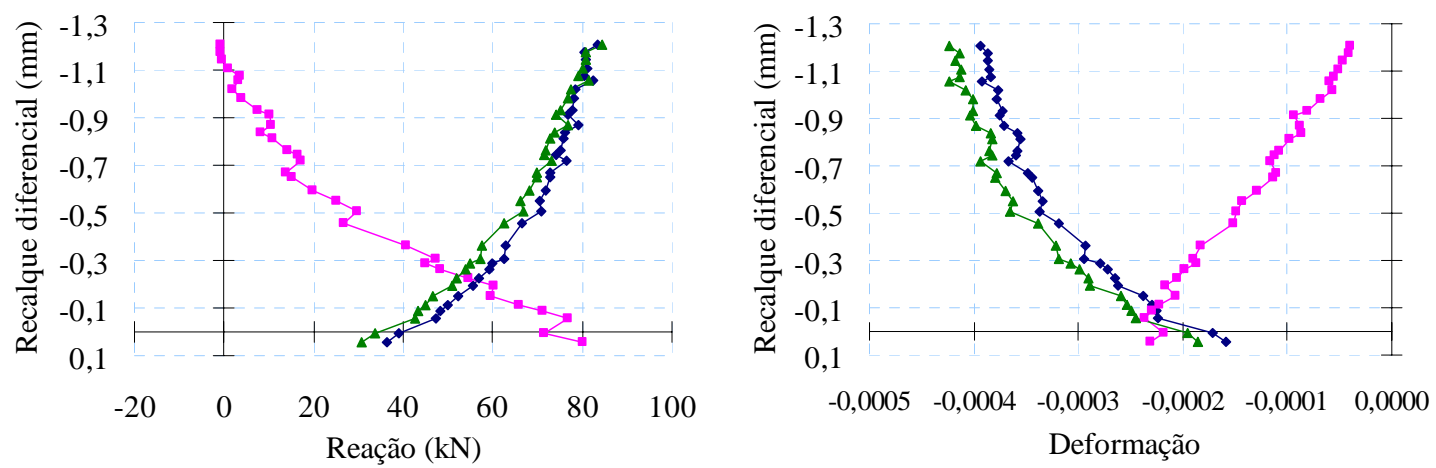

$\rightarrow$ Apoio $\mathrm{A} \rightarrow$ Apoio $\mathrm{C} \multimap$ Apoio E
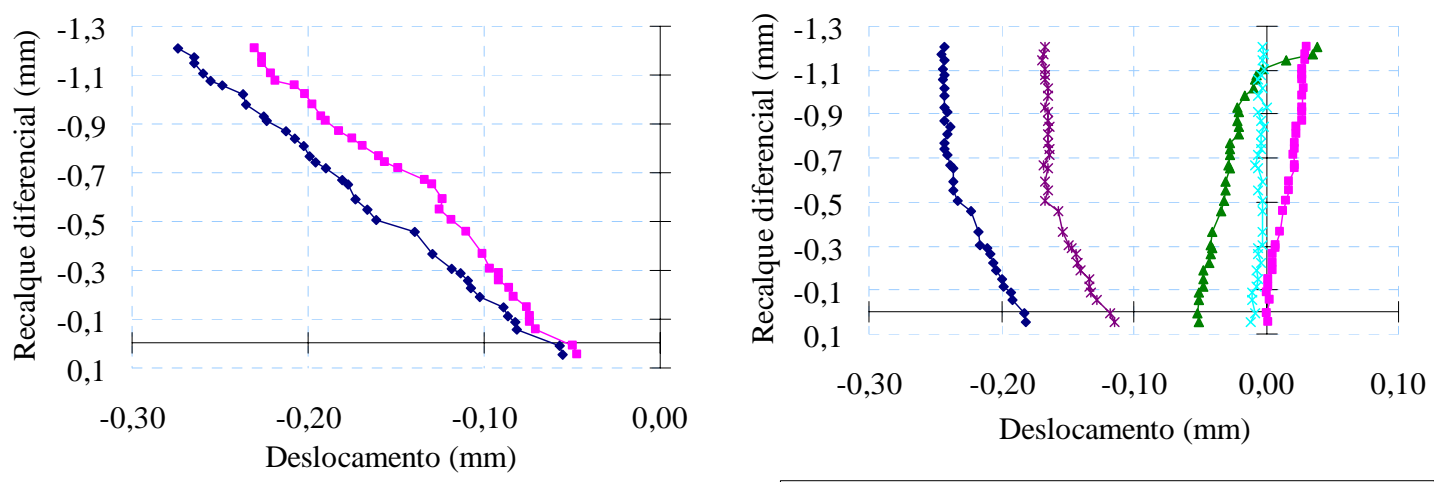

$\rightarrow$ Transdutor $7 \rightarrow-$ Transdutor 8

Transdutor $9 \rightarrow-$ Transdutor $10 \multimap$ Transdutor 11 Transdutor $12 \rightarrow$ Transdutor 13 


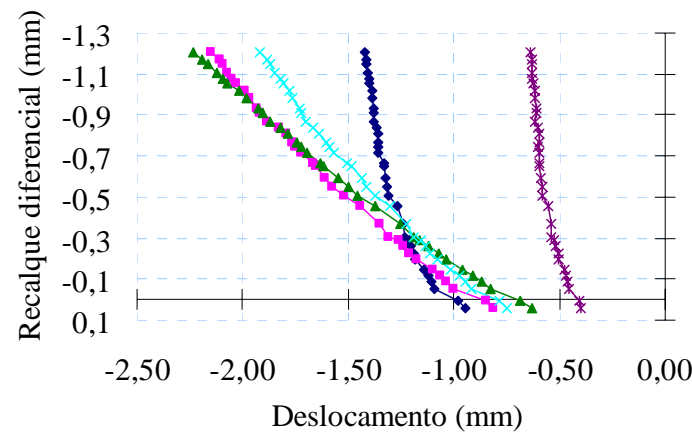

$\rightarrow$ Transdutor $14 \rightarrow$ Transdutor $15 \multimap$ Transdutor 16 Transdutor $17 \rightarrow$ Transdutor 18

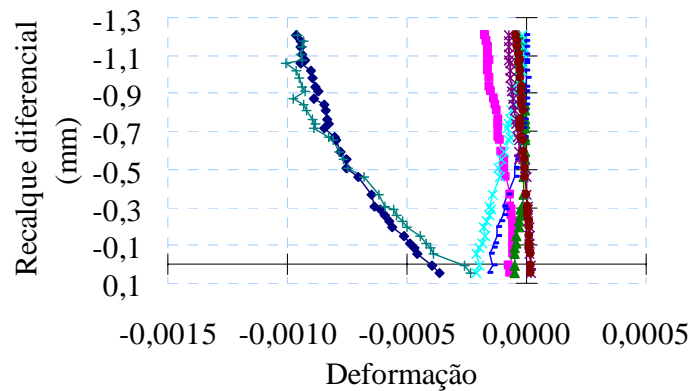

Deformação

\begin{tabular}{|ll|}
$\rightarrow-$ Extensômetro 9 & - Extensômetro 10 \\
$\rightarrow$ Extensômetro 11 & $*$ Extensômetro 12 \\
- Extensômetro 13 & $*$ Extensômetro 14 \\
$\rightarrow$ - Extensômetro 15 & - Extensômetro 16 \\
\hline
\end{tabular}

\section{Situação 3}
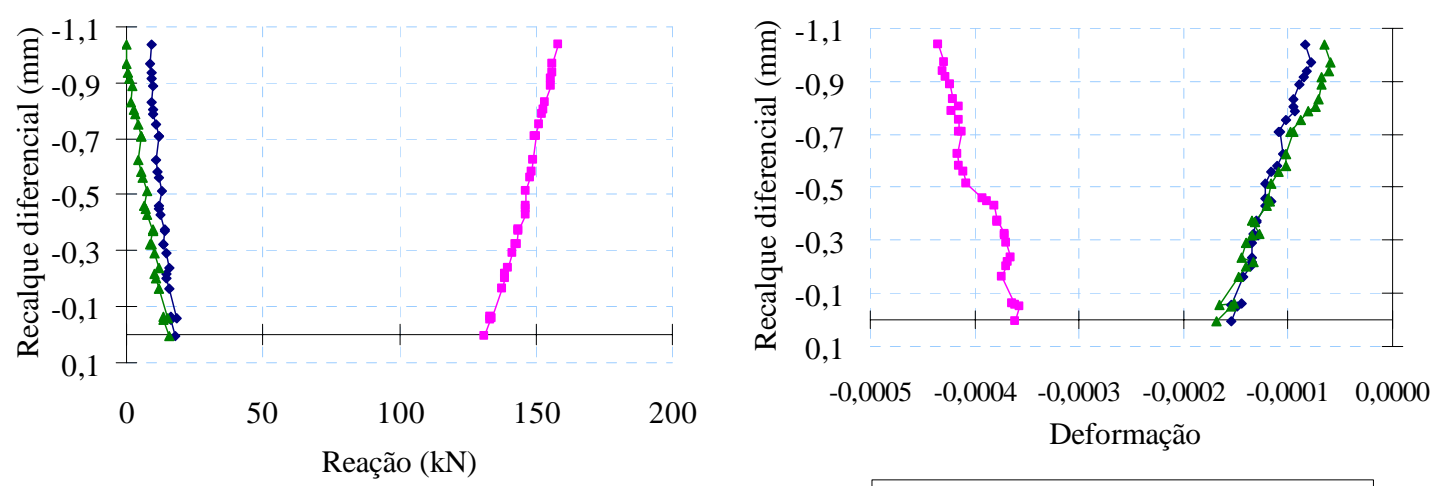

Apoio $\mathrm{A} \rightarrow-$ Apoio $\mathrm{C} \rightarrow$ Apoio $\mathrm{E}$

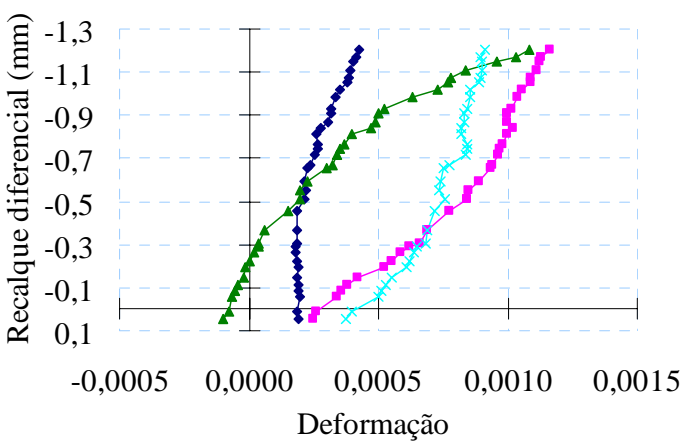

- Extensômetros 1-2 - Extensômetros 3-4

^Extensômetros 5-6 $\rightarrow$ Extensômetros 7-8 


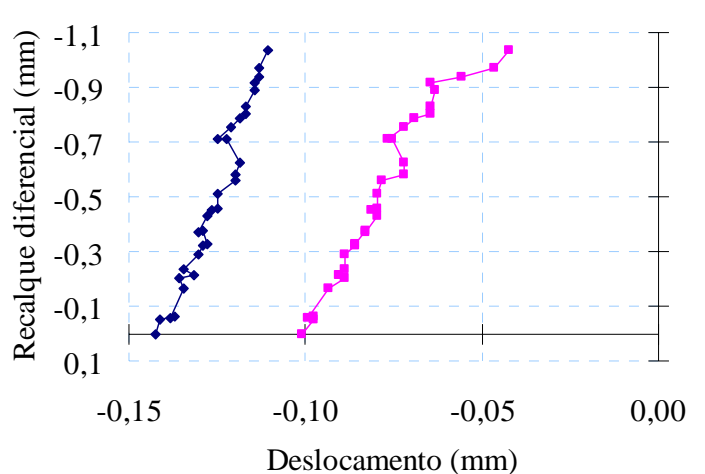

$\rightarrow$ Transdutor $7 \rightarrow$ Transdutor 8

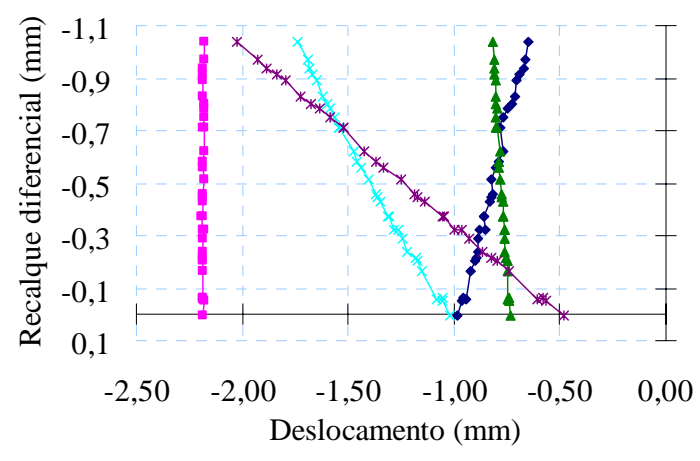

$\rightarrow-$ Transdutor $14 \rightarrow-$ Transdutor $15 \rightarrow$ Transdutor 16 Transdutor $17 \rightarrow$ Transdutor 18

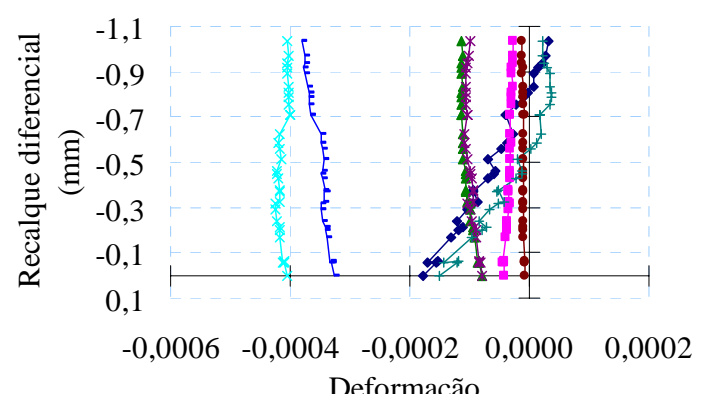

Deformação

- Extensômetro $9 \rightarrow$ Extensômetro 10

^ Extensômetro $11 \rightarrow$ Extensômetro 12

- Extensômetro $13 \rightarrow$ * Extensômetro 14

- Extensômetro 15 —- Extensômetro 16

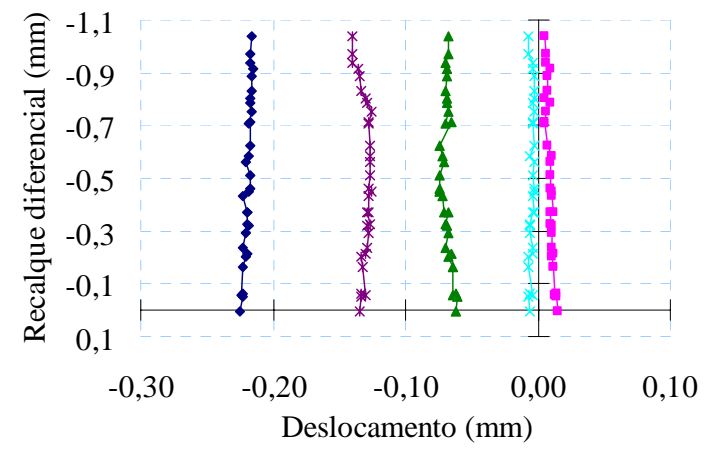

$\rightarrow-$ Transdutor $9 \rightarrow-$ Transdutor $10 \rightarrow$ Transdutor 11
$\rightarrow$ Transdutor $12 \rightarrow$ Transdutor 13

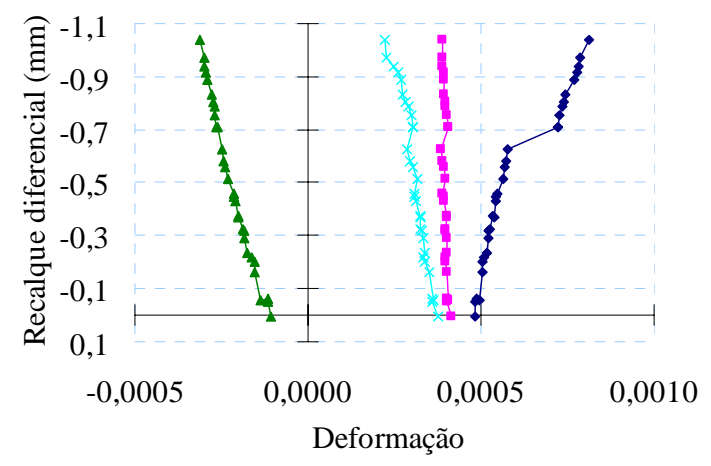

- Extensômetros 1-2 - Extensômetros 3-4

^-Extensômetros 5-6 $\rightarrow$ Extensômetros 7-8 


\section{REFERÊNCIAS BIBLIOGRÁFICAS}

ABBOUD, B. E. et al. (1990). Small-scale modeling of concrete block masonry structures. ACI Structural Journal, v. 87, n. 2, p. 145-55.

AMERICAN CONCRETE INSTITUTE (1994). ACI 530R-92 - Commentary on building code requirements for masonry structures. In: . ACI manual of concrete practice. Detroit. part. 5.

ANSYS RELEASE 5.5.1 (1998). Elements Reference. 10. ed. SAS IP, Inc.

ANTHOINE, A. (1997). Homogenization of periodic masonry: plane stress, generalized plane strain or 3D modelling? Communications in Numerical Methods in Engineering, v. 13, p. 319-26.

ASSOCIAÇÃO BRASILEIRA DE NORMAS TÉCNICAS (2001). Projeto de revisão da NBR 6118 - Projeto de estruturas de concreto. Rio de Janeiro.

ASSOCIAÇÃO BRASILEIRA DE NORMAS TÉCNICAS (1996). NBR 6122 - Projeto e execução de fundações. Rio de Janeiro.

ASSOCIAÇÃO BRASILEIRA DE NORMAS TÉCNICAS (1983). NBR 7211 - Agregado para concreto. Rio de Janeiro.

ASSOCIAÇÃO BRASILEIRA DE NORMAS TÉCNICAS (1987). NBR 7217 - Agregados - Determinação da composição granulométrica. Rio de Janeiro.

ASSOCIAÇÃO BRASILEIRA DE NORMAS TÉCNICAS (1983). NBR 8043 - Bloco cerâmico portante para alvenaria - Determinação da área líquida. Rio de Janeiro.

ASSOCIAÇÃO BRASILEIRA DE NORMAS TÉCNICAS (1985). NBR 8798 - Execução e controle de obras em alvenaria estrutural de blocos vazados de concreto. Rio de Janeiro.

ASSOCIAÇÃO BRASILEIRA DE NORMAS TÉCNICAS (1985). NBR 8949 - Paredes de alvenaria estrutural - Ensaio à compressão simples. Rio de Janeiro.

ASSOCIAÇÃO BRASILEIRA DE NORMAS TÉCNICAS (1989). NBR 10837 - Cálculo de alvenaria estrutural de blocos vazados de concreto. Rio de Janeiro. 
ASSOCIAÇÃO BRASILEIRA DE NORMAS TÉCNICAS (1995). NBR 13279 - Argamassa para assentamento de paredes e revestimento de paredes e tetos - Determinação da resistência à compressão. Rio de Janeiro.

ASSOCIAÇÃO BRASILEIRA DE NORMAS TÉCNICAS (1999). NBR 14321 - Paredes de alvenaria estrutural - Determinação da resistência ao cisalhamento. Rio de Janeiro.

BARBOSA, P. C. (2000). Estudo da interação de paredes de alvenaria estrutural com vigas de concreto armado. São Carlos. 110 p. Dissertação (Mestrado) - Escola de Engenharia de São Carlos, Universidade de São Paulo.

BATI, S. B. et al. (1999). Suitability of micromechanical model for elastic analysis of masonry. Journal of Engineering Mechanics, v. 125, n. 8, p. 922-9.

BERANEK, W. J. (1987). The prediction of damage to masonry buildings caused by subsoil settlements. Heron, v. 32, n. 4, p. 55-93.

BRITISH STANDARDS INSTITUTION (1992). BS 5628 - Code of practice for use of masonry. Part 1 - Structural use of unreinforced masonry. London.

BURHOUSE, P. (1969). Composite action between brick panel walls and their supporting beams. Proceedings of the Institution of Civil Engineers, v. 43, p. 175-94.

BURLAND, J. B. et al. (1977). Behaviour of foundations and structures. In: INTERNATIONAL CONFERENCE ON SOIL MECHANICS AND FOUNDATION ENGINEERING, 9., Tokyo, 1977. Proceedings. Tokyo, Japanese Society of Soil Mechanics and Foundation Engineering. v. 2, p. 495-546.

CAMACHO, J. S. (1995). Contribuição ao estudo de modelos físicos reduzidos de alvenaria estrutural cerâmica. São Paulo. 157 p. Tese (Doutorado) - Escola Politécnica, Universidade de São Paulo.

CHEN, H.-L.; SHAH, S. P. (1988). Test of model masonry songle pier under dynamic shaking and quasistatic cyclic loading. In: HARRIS, H. A., ed. Masonry: materials, design, construction and maintenance. Philadelphia, ASTM. p. 145-65. (ASTM STP 992.)

CRAWFORD, C. B. (1976). Deformation due to foundation settlement. In: DBR BUILDING SCIENCE SEMINAR - CRACKS, MOVEMENTS AND JOINTS IN BUILDINGS, 1972. National Research Council of Canada, Division of Building Research.

DRYSDALE, R. G. et al. (1979). Shear strength of brick masonry joints. In: INTERNATIONAL BRICK MASONRY CONFERENCE, 5., Washington DC, 1979. Proceedings. Reston, VA, Estados Unidos, Brick Industry Association. p. 106-13. 
DRYSDALE, R. G. et al. (1994). Masonry structures: behavior and design. Englewood Cliffs, Prentice Hall.

GALlEGOS, H. (1989). Albañilería estructural. 2. ed. Lima, Pontificia Universidad Católica del Peru.

GHAZALI, M. Z.; RIDDINGTON, J. R. (1988). Simple test method for masonry shear strength. Proceedings of the Institution of Civil Engineers, Part 2, v. 85, p. 567-74.

GRANT, R. et al. (1974). Differential settlement of buildings. Journal of the Geotechnical Engineering Division, v. 100, n. GT9, p. 973-91.

GRIMM, C. T. (1982). Masonry failure investigations. In: BORCHELT, J. G., ed. Masonry: materials, properties and performance. Philadelphia, ASTM. p. 245-60. (ASTM STP 778.)

GRIMM, C. T. (1988). Masonry cracks: a review of the literature. In: HARRIS, H. A., ed. Masonry: materials, design, construction and maintenance. Philadelphia, ASTM. p. 257-80. (ASTM STP 992.)

GRIMM, C. T. (1997). Masonry cracks: cause, prevention and repair. Masonry International, v. 10, n. 3, p. 66-76.

HARDY, S. J. (2000). Design of steel lintels supporting masonry walls. Engineering Structures, v. 22, p. 597-604.

HENDRY, A. W. et al. (1981). An introduction to load bearing brickwork design. Chichester, Ellis Horwood.

HOGG, V.; CHOO, B. S. (2000). A study of scale effects in masonry arch bridges: is testing of large-scale structures still necessary? The Structural Engineer, v. 78, n. 5, p. 24-9.

HUGHES, T. G.; KITCHING, N. (2000). Small scale testing of masonry. In: INTERNATIONAL BRICK/BLOCK MASONRY CONFERENCE, 12., Madrid, 2000. Proceedings. Madrid, Universidad Politecnica de Madrid. v. 2, p. 893-902.

JUKES, P.; RIDDINGTON, J. R. (1997). A review of masonry joint shear strength test methods. Masonry International, v. 11, n. 2, p. 37-43.

KOMORNIK, A.; MAZURIK, A. (1977). Restrained settlements of masonry buildings. In: INTERNATIONAL CONFERENCE ON SOIL MECHANICS AND FOUNDATION ENGINEERING, 9., Tokyo, 1977. Proceedings. Tokyo, Japanese Society of Soil Mechanics and Foundation Engineering. v. 1, p. 613-8.

LOURENÇO, P. B. (1996). Computational strategies for masonry structures. Delft. 210 p. Thesis - Delft University of Technology.

MacLEOD, I. A. (1987). Use of bed-joint reinforcement in brick buildings to resist settlement. The Structural Engineer, v. 65A, n. 10, p. 369-76. 
MAMAGHANI, I. H. P. et al. (1999). Analysis of masonry structures under static and dynamic loading by discrete finite element method. Journal of Structural Mechanics and Earthquake Engineering, v. 16, n. 2, p. 75-86.

MASIA, M. J. et al. (1998). Serviceability design for masonry structures subjected to foundation movements. In: AUSTRALASIAN MASONRY CONFERENCE, 5., Gladstone, Australia, 1998. Proceedings. Gladstone, Central Queensland University. p. $255-64$.

MASIA, M. J. et al. (2000). A probabilistic model for the prediction of cracking in masonry structures. In: INTERNATIONAL BRICK/BLOCK MASONRY CONFERENCE, 12., Madrid, Spain, 2000. Proceedings. Madrid, Universidad Politecnica de Madrid. v. 2, p. 1209-19.

MEYERHOF, G. G. (1953). Some recent foundation research and its application to design. The Structural Engineer, v. 31, p. 151-67.

NOVAIS-FERREIRA, H. (1977). Assentamentos admissíveis. Geotecnia, v. 18, p. 53-86.

OLIARI, G. F.; DUARTE, R. B. (2000). Uma investigação da resistência ao cisalhamento de prismas de tijolos cerâmicos maciços [CD-ROM]. In: JORNADAS SUDAMERICANAS DE INGENIERÍA ESTRUCTURAL, 29., Punta del Este, Uruguay, 2000. Memorias. Montevideo, Universidade de la República/ASAIE. 12 p.

PAGE, A. W. (1978). Finite element model for masonry. Journal of the Structural Division, v. 104, n. ST8, p. 1267-85.

PAGE, A. W. (1979). A non-linear analysis of the composite action of masonry walls on beams. Proceedings of the Institution of Civil Engineers, Part 2, v. 67, p. 93-110.

PAGE, A. W. (1993). Cracking in masonry housing. Newcastle, Australia, The University of Newcastle. (Research Report n. 085.05.1993.)

PANDE, G. N. et al. (1989). Equivalent elastic moduli for brick masonry. Computers and Geotechnics, n. 8, p. 243-65.

POLSHIN, D. E.; TOKAR, R. A. (1957). Maximum allowable non-uniform settlement of structures. In: INTERNATIONAL CONFERENCE ON SOIL MECHANICS AND FOUNDATION ENGINEERING, 4., London, 1957. Proceedings. London, Butterworths Scientific Publications. v. 1, p. 402-5.

RIDDINGTON, J. R. et al. (1997). Numerical study of failure initiation in different joint shear tests. Masonry International, v. 11, n. 2, p. 44-50.

RIDDINGTON, J. R.; GHAZALI, M.Z. (1990). Hypothesis for shear failure in masonry joints. Proceedings of the Institution of Civil Engineers, Part 2, v. 89, p. 89-102. 
RIDDINGTON, J. R.; JUKES, P. (1994). A masonry joint shear strength test method. Proceedings of the Institution of Civil Engineers: Structures and Buildings, v. 104, p. 267-74.

RIDDINGTON, J. R.; STAFFORD SMITH, B. (1978). Composite method of design for heavily loaded wall-beam structures. Proceedings of the Institution of Civil Engineers, Part 1, v. 64, p. 137-51.

ROMAN, H. R. (1991). Resistência ao cisalhamento vertical ao plano de juntas de argamassa submetidas a tensões não uniformes. In: JORNADAS SUL-AMERICANAS DE ENGENHARIA ESTRUTURAL, 25., Porto Alegre, 1991. Anais. Porto Alegre, UFRGS. v. 4, p. 343-54.

ROSENHAUPT, S. (1962). Experimental study of masonry walls on beams. Journal of the Structural Division, v. 88, n. ST3, p. 137-65.

ROTS, J. G. (1991). Numerical simulation of cracking in structural masonry. Heron, v. 36, n. 2, p. 49-63.

ROYLES, R.; HENDRY, A. W. (1991). Model tests on masonry arches. Proceedings of the Institution of Civil Engineers, Part 2, v. 91, p. 299-321.

SAW, C. B. (1974). Linear elastic finite element analysis of masonry walls on beams. Building Science, v. 9, p. 299-307.

SCHUBERT, P. (1979). E-Modul-Werte von Mauerwerk. In: INTERNATIONAL BRICK MASONRY CONFERENCE, 5., Washington DC, 1979. Proceedings. Reston, VA, Estados Unidos, Brick Industry Association. p. 139-44.

SHRIVE, N. G. (1983). A fundamental approach to the fracture of masonry. In: CANADIAN MASONRY SYMPOSIUM, 3., Edmonton, Canada, 1983. Proceedings. p. 4-1-4-16.

SKEMPTON, A. W.; MacDONALD, D. H. (1956). The allowable settlement of buildings. Proceedings of the Institution of Civil Engineers, Part 3, v. 5, p. 727-68.

THOMAZ, E. (1998a). As causas de fissuras. Téchne, n. 36, p. 44-9.

THOMAZ, E. (1998b). Prevenção e recuperação de fissuras em alvenaria. Téchne, n. 37, p. $48-52$.

TOMAZEVIC, M.; VELECHOVSKY, T. (1992). Some aspects of testing small-scale masonry building models on simple earthquake simulators. Earthquake Engineering and Structural Dynamics,v. 21, p. 945-63.

TRIKHA, D. N.; BHANDARI, N. M. (1977). Distress in masonry structures due to foundation settlement. In: INTERNATIONAL SYMPOSIUM ON SOIL-STRUCTURE 
INTERACTION, 3., Roorkee, India, 1977. Proceedings. Roorkee, University of Roorkee. v. 1, p. 245-50.

WOOD, R. H. (1952). Studies in composite construction. Part 1: the composite action of brick panel walls supported on reinforced concrete beams. London, Her Majesty's Stationery Office. 25 p. (National Building Studies, Research Paper n. 13.) 


\section{BIBLIOGRAFIA COMPLEMENTAR}

ACCETTI, K. M. (1998). Contribuições ao projeto estrutural de edifícios em alvenaria. São Carlos. 247p. Dissertação (Mestrado) - Escola de Engenharia de São Carlos, Universidade de São Paulo.

ASSOCIAÇÃO BRASILEIRA DE NORMAS TÉCNICAS (1994). NBR 6136 - Bloco vazado de concreto simples para alvenaria estrutural. Rio de Janeiro.

ASSOCIAÇÃO BRASILEIRA DE NORMAS TÉCNICAS (1983). NBR 6461 - Bloco cerâmico para alvenaria - Verificação da resistência à compressão. Rio de Janeiro.

ASSOCIAÇÃO BRASILEIRA DE NORMAS TÉCNICAS (1992). NBR 7171 - Bloco cerâmico para alvenaria. Rio de Janeiro.

ASSOCIAÇÃO BRASILEIRA DE NORMAS TÉCNICAS (1992). NBR 8042 - Bloco cerâmico para alvenaria - Formas e dimensões. Rio de Janeiro.

ASSOCIAÇÃO BRASILEIRA DE NORMAS TÉCNICAS (1983). NBR 8215 - Prismas de blocos vazados de concreto simples para alvenaria estrutural - Preparo e ensaio à compressão. Rio de Janeiro.

ASSOCIAÇÃO BRASILEIRA DE NORMAS TÉCNICAS (1991). NBR 12118 - Blocos vazados de concreto simples para alvenaria - Determinação da absorção de água, do teor de umidade e da área líquida. Rio de Janeiro.

CAMACHO, J. S. (1986). Alvenaria estrutural não-armada: parâmetros básicos a serem considerados no projeto dos elementos resistentes. Porto Alegre. 161 p. Dissertação (Mestrado) - Escola de Engenharia, Universidade Federal do Rio Grande do Sul.

CAPUZZO NETO, V. (2000). Estudo teórico e experimental da interação de paredes de alvenaria estrutural submetidas a ações verticais. São Carlos. 111 p. Dissertação (Mestrado) - Escola de Engenharia de São Carlos, Universidade de São Paulo.

DULÁCSKA, E., ed. (1992). Soil settlement effects on buildings. Amsterdam, Elsevier. (Developments in geotechnical engineering, 69.)

FRANCO, L. S. (1987). Desempenho estrutural do elemento parede de alvenaria empregado na alvenaria estrutural não armada, quando submetido a esforços de 
compressão. São Paulo. 136 p. Dissertação (Mestrado) - Escola Politécnica, Universidade de São Paulo.

HACHICH, W. et al., ed. (1996). Fundações: teoria e prática. São Paulo, PINI.

ORTON, A. (1992). Structural design of masonry. 2. ed. London, Longman.

PINHEIRO, L. M. (1996). Concreto armado: tabelas e ábacos. São Carlos, EESC.

SELVADURAI, A. P. S. (1979). Elastic analysis of soil-foundation interaction. Amsterdam,

Elsevier. (Developments in geotechnical engineering, 17.)

TAYLOR, D. W. (1960). Fundamentals of soil mechanics. New York, John Wiley \& Sons.

VELLOSO, D. A.; LOPES, F. R. (1996). Fundações. Rio de Janeiro, COPPE/UFRJ. v. 1. 